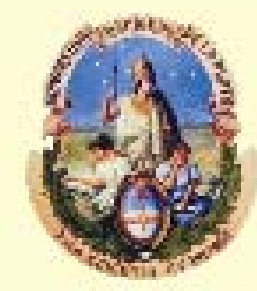

Universidad Nacional de La Plata Facultad de Ciencias Exactas Departamento de Química

\title{
CARACTERIZACIÓN DE LA SEMILLA Y EL ACEITE DE CHÍA (Salvia hispanica L.) OBTENIDO MEDIANTE DISTINTOS PROCESOS. APLICACIÓN EN TECNOLOGÍA DE ALIMENTOS
}

\section{Tesis Doctoral \\ Vanesa Y. Ixtaina}

\author{
Director
}

Dra. Mabel C. Tomás

Codirector

Ms.Sc. Susana M. Nolasco 
El presente trabajo de Tesis para optar al título de Doctor de la Facultad de Ciencias Exactas de la Universidad Nacional de La Plata fue realizado en el Centro de Investigación y Desarrollo en Criotecnología de Alimentos (CIDCA-UNLP-CONICET) y en la Facultad de Ingeniería de la Universidad Nacional del Centro de la Provincia de Buenos Aires (UNCPBA) bajo la dirección de la Dra. Mabel Cristina Tomás y la codirección de la Ms. Sc. Susana M. Nolasco. 
Arrancaron nuestros frutos, cortaron nuestras ramas, quemaron nuestro tronco, pero no pudieron nunca matar nuestras raíces.

¡jJallalla, jallalla!!

Pensamiento Indígena

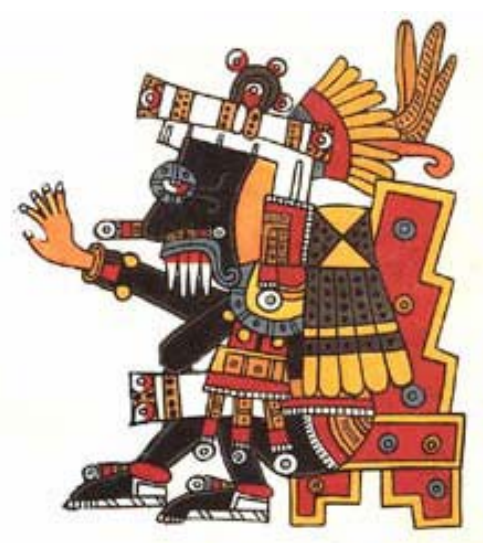


Dedicada a mis padres Graciela y Néstor, a mi compañero de la vida Guillermo, a mi hermana Marisa y a mis sobrinos Pedro y Pilar por ser lo más importante que me dio la vida y el soporte fundamental que me ha permitido llegar hasta donde ahora me encuentro 
Agradecimientos 
Son muchas las personas que han contribuido y han hecho posible el desarrollo y concreción del presente trabajo. Como no sé si podré recordar a cada uno, les doy gracias a todos de corazón.

\section{Quisiera agradecer especialmente:}

A mis directoras de Tesis, Dra. Mabel C. Tomás y Ms. Sc. Susana M. Nolasco, quienes confiaron en mí y me dieron la oportunidad de poder transitar este camino. Gracias por guiarme, acompañarme, por darme fuerzas en los momentos más difíciles y por brindarme todos sus conocimientos y experiencia. Gracias también porque en ellas no sólo encontré a excelentes profesionales, sino principalmente a dos personas con valores intachables y de una calidad humana excepcional. Muchas gracias por todo su cariño.

A los Dres. Miguel Mattea y Damián Cardarelli, excelentes personas y reconocidos profesionales de la Universidad Nacional de Río Cuarto, desde donde estén reciban mi más profundo agradecimiento y sincero homenaje.

A los Dres. Alberto Tecante y Miquel Gimeno, por haber confiado en mí y haberme guiado en el trabajo realizado durante mi estancia de investigación en la Universidad Nacional Autónoma de México.

A la Prof. Carmen Mateo (UNCPBA), a los Dres. Damián Maestri (UNC), Facundo Mattea (Universidad de Valladolid) y Bernd Diehl (Spectral Service), a la Ing. Mariana Ramirez-Gilly (UNAM), a las Dras. Viviana Spotorno (INTA), Marcela Martínez (UNC), Margarita García (INIBIOLP), Adriana Descalzo (INTA) y Viviana Sorrivas (CRIBABB), al Ing. Javier Lecot (CIDCA) y Daniel Russo (CIDCA), y a Arturo Colavita (CIDCA) por su valioso aporte técnico a este trabajo de Tesis.

A Norma "Picky" Tedesco por su contribución en las traducciones al idioma inglés de los trabajos presentados en Revistas Cientificas y Congresos.

A la Bibl. Diana Velasco por su predisposición y eficiencia en el apoyo bibliográfico, el cual es un pilar básico de las tareas de investigación.

A mi amigo y "hermanito" de grupo, Darío M. Cabezas, por tantas horas compartidas, por su ayuda intelectual, su lucha constante y todo su cariño.

A mi amigo y compañero de mates del Anexo, Sandro Goñi, gracias por ayudarme a encontrar la salida en los laberintos que muchas veces se presentaron en 
el camino, por su tiempo y dedicación. A Emmanuel Purlis por sacarme de los apuros con el inglés.

A mis amigos y compañeros del Laboratorio de Aceites, Nicolás Guerello y Claudio Reyes, por el constante acompañamiento tanto en lo laboral como en lo personal.

A mis amigos del CIDCA Jime, Ana, Ruth, Ceci, Martín, Sandra, Vicky, Fabricio y Oli con quienes compartimos día a día, gracias a por estar siempre.

A mis amigas y compañeras de la Facultad de Ingeniería de la UNCPBA, Ethel Pérez, Belén Fernández y Karina de Figueiredo por el apoyo tanto intelectual como emocional, principalmente durante el primer año de trabajo.

A mis compañeras de grupo Marianela Capitani y Estefanía Guiotto por sumarse al "tren" del desafío de la chía y a Pablo Sobral por las horas de trabajo compartidas.

A cada uno de los integrantes del CIDCA y de la Facultad de Ingeniería (UNCPBA) con quienes hemos compartido mates, charlas de pasillo, intercambios de ideas y todo lo que contribuye a crear un entorno agradable para desarrollar el trabajo diario.

A mis amigos y compañeros de los Laboratorios 313 y 314 del Departamento de Alimentos y Biotecnología de la Facultad de Química (UNAM), muy especialmente a Alberto López Luna y a Andrea Vega por su disponibilidad y ayuda permanente en el trabajo y a Carolina Castillo Ruz y Perla Campillo por todo el cariño y alegría. A Ángela López, Carolina Caicedo Cano, Fernando Cuenú y Bellis López por haberme hecho sentir "como en casa" estando muy lejos. Gracias a todos porque haber encontrado un apoyo fundamental que hicieron que mi estadía en México fuera inolvidable.

A la Ing. Agr. María de la Merced Mujica, profesora del Curso de Introducción al Mejoramiento Genético de la Facultad de Ciencias Agrarias y Forestales (UNLP), por iniciarme en la investigación científica y darme el aliento necesario para seguir en este camino a pesar de las dificultades.

A mis amigos y compañeros de cátedra, Yanina Yalungo, Lisandro Entío, María Laura Bravo, Marta Galván y Hernán Casalla por entenderme y ayudarme en todos estos años a poder destinar más tiempo y esfuerzo en desarrollar mi tesis doctoral. 
Al Centro de Investigación y Desarrollo en Criotecnología de Alimentos (CIDCA) (CONICET La Plata-UNLP) y al Núcleo de Investigación y Desarrollo en Tecnología de Semillas y Alimentos (TECSE) (Facultad de Ingeniería-UNCPBA), muy especialmente a los Dres Noemí Zaritzky, Rodolfo Mascheroni y a la Ing. Isabel Riccobene, por haberme abierto sus puertas para desarrollar el presente trabajo de Tesis.

A la Universidad Nacional de La Plata, por haberme brindado una formación gratuita de excelencia desde la escuela secundaria.

A la Universidad Nacional Autónoma de México (UNAM) y a la Universidad Nacional de Río Cuarto (UNRC) por haberme permitido realizar parte del trabajo en sus instituciones.

A las instituciones y entidades que mediante diversos tipos de financiamiento posibilitaron la realización del presente trabajo. Al Consejo Nacional de Investigaciones Científicas y Técnicas (CONICET), Universidad Nacional de La Plata (UNLP), Universidad Nacional del Centro de la Provincia de Buenos Aires (UNCPBA), Agencia Nacional de Promoción Científica y Tecnológica (ANPCyT), Secretaría de Relaciones Exteriores del Gobierno de México (SRE).

A los Sres. V. García, F. Galli y Nutracéutica Sturla por el aprovisionamiento de las semillas y del aceite de chía, a Danisco y Productos Harmony S.A. por la provisión de los antioxidantes y a Spectral Service por su aporte a este trabajo.

Ahora quisiera agradecer a aquéllos, que desde lo personal, de una u otra manera estuvieron a mi lado con su cariño, su aliento, su apoyo, sus fuerzas y su estímulo:

A Silvana, Jorge, Rocío y Marianela, mi "familia adoptiva" de Bolívar.

A mis amigos del alma María Helena, Natalia R., Natalia F., Silvina, Máximo, Nieves, Damián, Vale, Andrés, Maru y Pablo.

A mis ahijados Abril, Serena y Tomás por toda su ternura.

A Román, por la compañía en las largas noches de escritura.

A toda mi familia por estar siempre, principalmente a mis padrinos Ricardo y Tati, a mi cuñado Martín, a mis tíos y primos y a mi suegro Oscar.

A quienes por esas "cosas de la vida", hoy ya no están conmigo en lo físico pero sí en lo más profundo de mi corazón: a mi Noni y abuelos, quienes con su sabiduría y amor fueron las raíces de mi ser; a mi suegra Betty, hermosa persona a quien me 
hubiese gustado tener a mi lado por muchos años más; a mi "cuñatai" Mariana, por ser el ejemplo de fidelidad a uno mismo, esa "loca linda" que emprendió su vuelo de repente...

Finalmente, me detendré en los seres más importantes de mi vida, a quienes tengo que agradecerles todo:

A mis papás, Graciela y Néstor, por el amor que día a día me han brindado, por todo su apoyo y comprensión, su constante aliento y por haberme transmitido los valores que me han formado como persona.

A mi hermana Marisa por haber sido mi "primera maestra" desde muy pequeña, por su ayuda incondicional siempre y por haberme dado dos solcitos hermosos, Pedro y Pilar, que han llenado nuestra vida de luz.

A Guillermo, mi esposo, gracias por su amor, su comprensión, su paciencia, por compartir los buenos y malos momentos que nos ha tocado vivir y principalmente por estar a mi lado siempre y ayudarme a poder realizarme tanto en lo profesional como en lo personal. Espero que la vida nos regale lo que tanto deseamos...

Gracias a todos de corazón 
Resumen 
En los últimos años existe una búsqueda y revalorización de sustratos provenientes de fuentes naturales que presenten constituyentes y/o productos derivados aplicables al desarrollo de alimentos, los cuales incidan en la nutrición mediante el aporte simultáneo de efectos benéficos para la salud. En ese contexto se encuentra la chía (Salvia hispanica L.), especie vegetal originaria del sudeste de EEUU y noroeste de América Central (México, Guatemala). Los pueblos asentados en esas regiones han consumido las semillas de este cultivo desde épocas precolombinas habiendo constituido un elemento básico de la dieta de los pueblos azteca y del oeste norteamericano. En nuestro país, su creciente expansión en las provincias del noroeste puede representar un aporte tendiente a la diversificación de la producción agrícola, con el consecuente impacto socioeconómico en dicha región. Así, las cualidades nutricionales de la semilla de chía y de los productos derivados de la misma han comenzado a ser revalorizados dado su elevado contenido de ácidos grasos $\omega-3$, fibra dietaria, proteínas y antioxidantes, ofreciendo una nueva oportunidad para mejorar la nutrición humana.

Los aceites vegetales comestibles constituyen un componente importante en nuestra alimentación, cuya variedad y consumo depende de la disponibilidad de la materia prima en cada país y región. No obstante la variedad de especies oleaginosas, el mayor consumo está representado por los aceites de palma, soja, colza y girasol. Actualmente, es reconocido el aporte de los lípidos a la salud y bienestar, lo cual está determinado fundamentalmente por su composición. Así, se ha demostrado que tanto el perfil de ácidos grasos, especialmente los niveles relativos de ácidos grasos $\omega-9, \omega-6$ y $\omega-3$ así como la presencia de algunos componentes minoritarios, pueden ejercer una influencia positiva en las funciones fisiológicas de nuestro organismo. En los últimos años, se ha registrado un incremento en la búsqueda de fuentes vegetales subutilizadas, a partir de las cuales puedan obtenerse aceites con una elevada proporción de ácidos grasos de alto valor nutricional. En este sentido, las semillas de chía son una fuente interesante ya que su aceite presenta un elevado tenor de ácidos grasos esenciales, cuya incorporación en la dieta permitiría disminuir la incidencia de enfermedades coronarias, así como de otras enfermedades (diabetes, síndrome metabólico, enfermedades de la piel, procesos inflamatorios, desórdenes del sistema inmunológico, cáncer, depresión). 
En función de las consideraciones realizadas, en este trabajo de Tesis se propuso desarrollar el estudio de la caracterización de la semilla y de la obtención del aceite de chía mediante procesos convencionales (prensa, extracción por solventes) y a partir de nuevas tecnologías (extracción por fluidos supercríticos), evaluando los distintos aspectos que inciden en su calidad global así como investigar un mayor y mejor aprovechamiento y aplicación de sus componentes para la obtención de alimentos funcionales, benéficos para la salud del consumidor.

En el Capítulo I, se presenta una introducción sobre Salvia hispanica L., describiendo el origen y los antecedentes históricos de esta especie, las principales características botánicas y el manejo agronómico del cultivo, así como la composición química y nutricional de la semilla de chía, los aspectos legislativos y los usos actuales. Además, se describen las propiedades físicas y la composición química de las semillas (núculas) analizándose los aspectos más relevantes relacionados con los aceites vegetales comestibles, en cuanto a su importancia en la alimentación, composición, estructura así como los procesos convencionales y alternativos de extracción.

En el Capítulo II, se realiza una caracterización de las semillas de chía oscuras y blancas provenientes de dos orígenes geográficos diferentes (Argentina y Guatemala) en lo referido a sus aspectos morfológicos mediante el estudio de su forma y tamaño (largo, ancho y espesor, diámetro geométrico, área superficial específica, relación de aspecto), propiedades gravimétricas (peso de mil semillas, densidad real, densidad aparente, porosidad, diámetro equivalente, esfericidad) así como en sus propiedades friccionales (ángulo de reposo y coeficiente estático de fricción). Por otra parte, se analiza la microestructura a través de observaciones de las semillas enteras y de cortes longitudinales de las mismas mediante microscopía electrónica de barrido (SEM), realizándose además su caracterización fisicoquímica.

En el Capítulo III, se analizan los procesos convencionales de obtención de aceite de chía (extracción por solventes y prensado), estudiando la influencia de los mismos sobre los componentes mayoritarios (composición acídica y triacilglicerídica) y minoritarios (tocoferoles, antioxidantes fenólicos, fosfolípidos, ceras, metales) del mismo, sus índices de calidad y genuinidad así como sus propiedades térmicas (curvas de fusión) mediante calorimetría diferencial de barrido (DSC). 
En el Capítulo IV, se describe el estudio del proceso de extracción de aceite de chía mediante $\mathrm{SC}-\mathrm{CO}_{2}$ realizado -como una alternativa a los métodos convencionales- a partir de semillas provenientes de Argentina y de México y se evalúan las principales características fisicoquímicas de los aceites obtenidos. Además, se analiza la incidencia de las diferentes variables operativas (temperatura, presión y tiempo de extracción) sobre dicho proceso aplicando la Metodología de Superficies de Respuesta (MSR).

En el Capítulo V se investiga la estabilidad oxidativa y las condiciones de conservación más adecuadas de este sustrato con alto contenido de ácidos grasos poliinsaturados, analizando la eficiencia de la adición de ciertos antioxidantes naturales (extractos de romero y de té verde, tocoferoles) y de palmitato de ascorbilo, solos o en diferentes combinaciones con respecto al deterioro oxidativo del aceite de chía.

Finalmente, se exponen las Conclusiones generales obtenidas a partir de este trabajo de Tesis y en base a ellas, las Perspectivas futuras. 
Capítulo 1. Introducción general 1

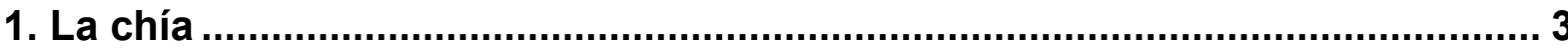

1.1. Origen y antecedentes históricos............................................................. 3

1.2. Ubicación sistemática y características botánicas.................................. 7

1.3. Distribución geográfica y producción......................................................... 9

1.4. Composición química y aspectos nutricionales de la semilla de chía.... 13

1.4.1. Contenido de aceite y composición de ácidos grasos................................................ 14

1.4.2. Contenido de proteínas y composición de aminoácidos ............................................. 15

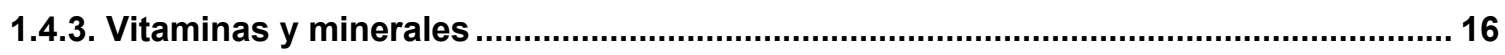

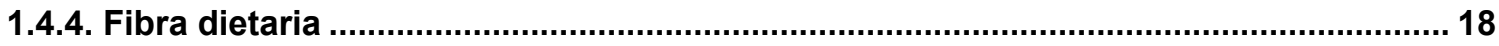

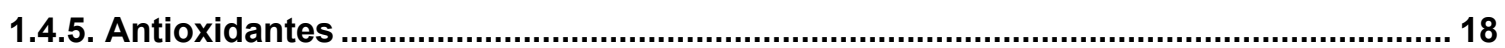

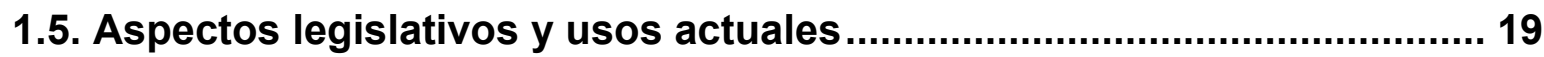

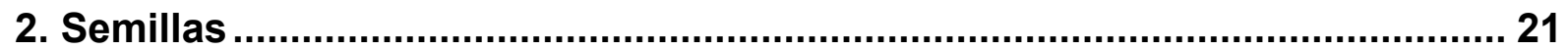

2.1. Importancia de las semillas en la nutrición humana ................................ 21

2.2. Propiedades físicas de las semillas ..................................................... 21

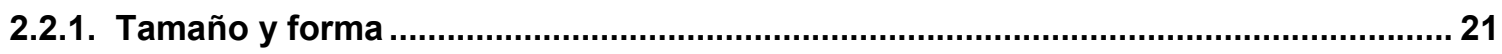

2.2.2. Propiedades gravimétricas

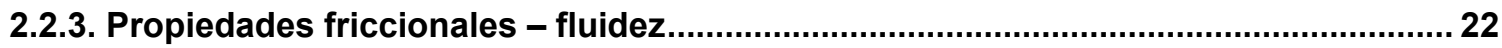

3. Aceites vegetales comestibles ....................................................................... 23

3.1. La importancia de las grasas y aceites.................................................. 23

3.2. Composición y estructura de las grasas y aceites y sus derivados ....... 24

3.2.1. Ácidos grasos ........................................................................................................ 27

3.2.1.1 Ácidos grasos saturados no ramificados ……............................................................. 27

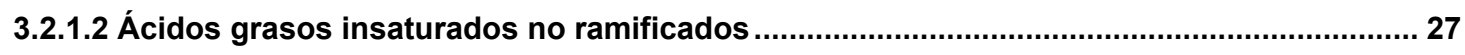

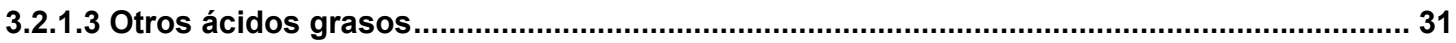

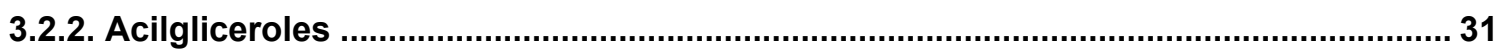

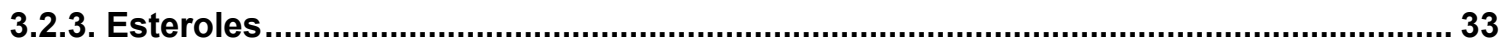

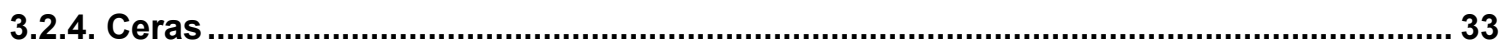

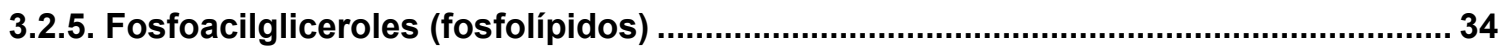

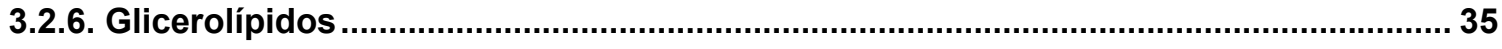

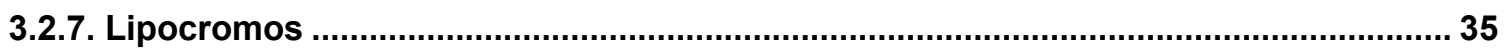

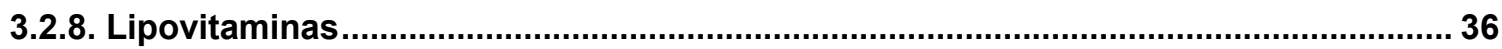

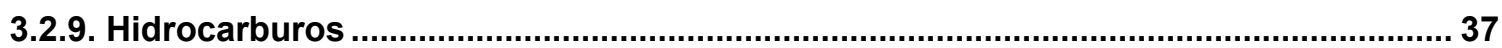

3.3 Aceites especiales "gourmet" .................................................................. 37 
3.4. Procesamiento de aceites vegetales mediante procesos convencionales

3.4.1 Etapas incluidas en el proceso de preparación de las semillas oleaginosas.............. 43

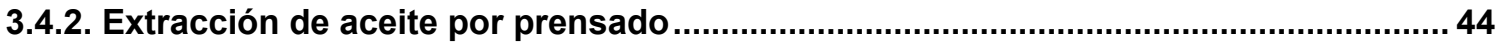

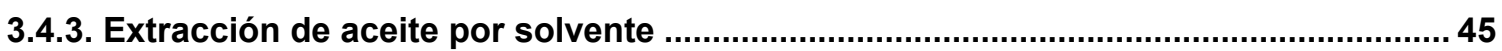

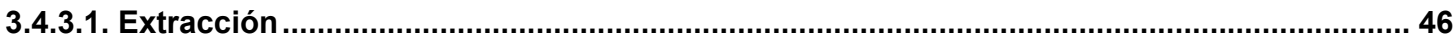

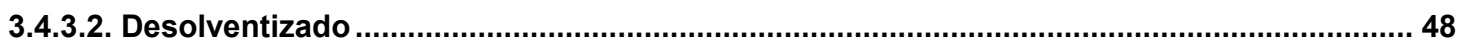

3.5. Extracción mediante fluidos supercrítícos (EFSC) ................................. 49

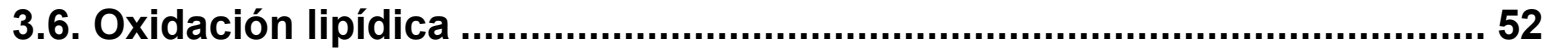

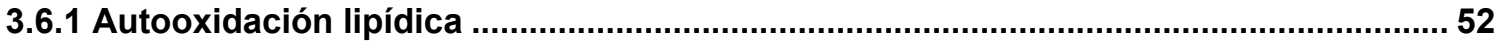

3.6.2. Factores que afectan la velocidad de autooxidación lipídica....................................56

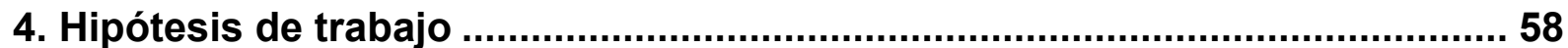

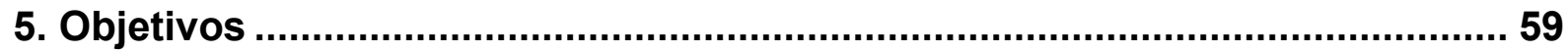

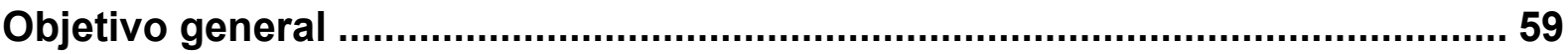

Objetivos específicos............................................................................... 59

Capítulo 2. Caracterización de las semillas de chía .............................60

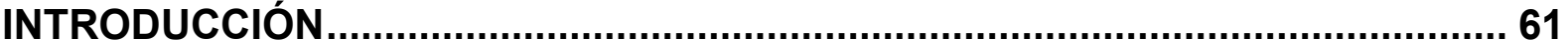

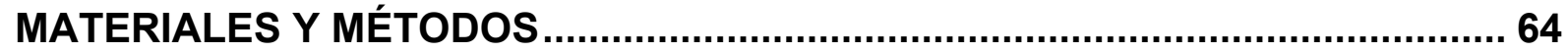

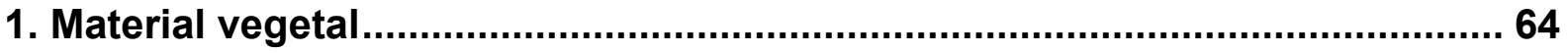

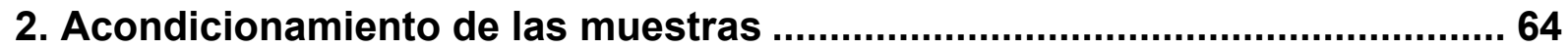

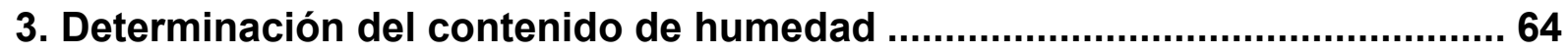

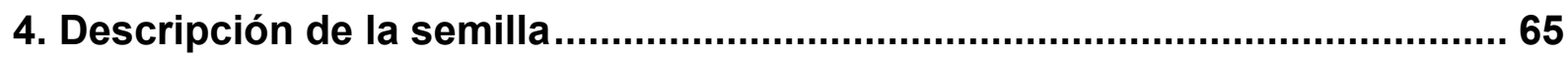

4.1. Composición de la mezcla comercial de las semillas según el color del

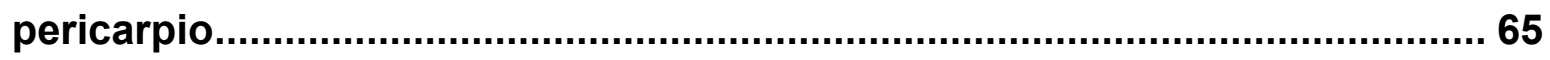

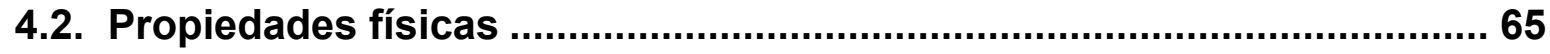

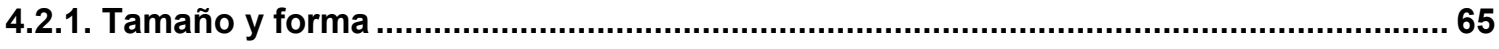

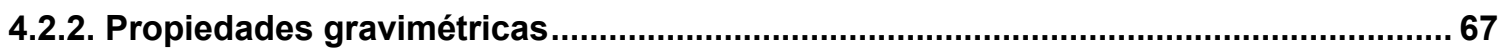

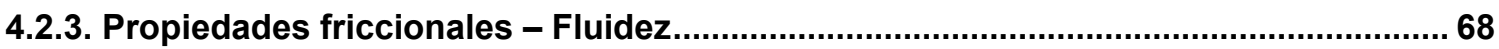

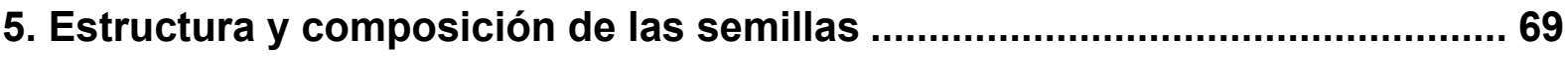

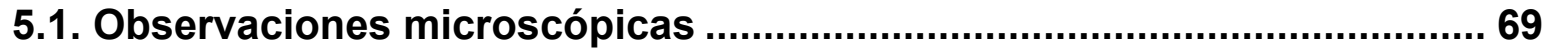


5.2. Determinación del contenido de proteínas................................................69

5.3. Determinación de materia grasa.............................................................. 71

5.4. Determinación del contenido de cenizas ............................................... 71

5.5. Determinación de fibra cruda ................................................................. 71

5.6. Esquema de análisis de Van Soest ....................................................... 72

5.7. Compuestos antioxidantes ................................................................... 75

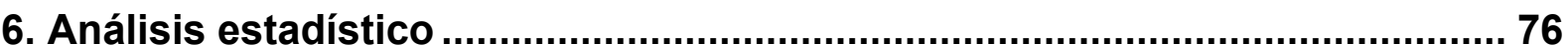

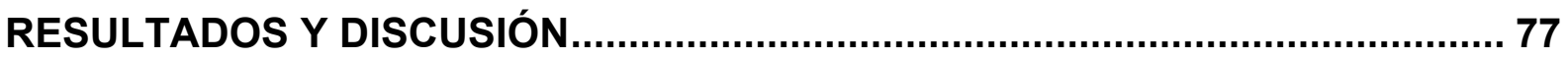

1. Semillas de chía provenientes de Salta (Argentina) ...................................... 77

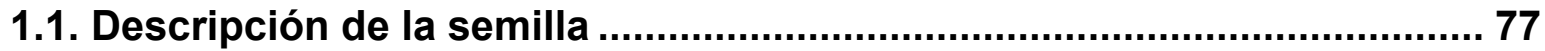

1.1.1 Composición y contenido de humedad de la mezcla comercial de las semillas según

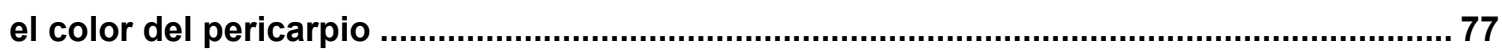

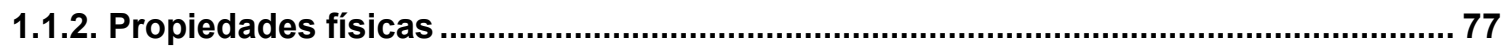

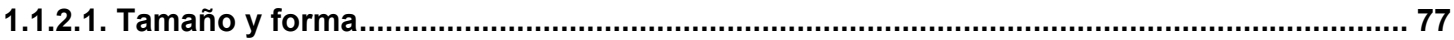

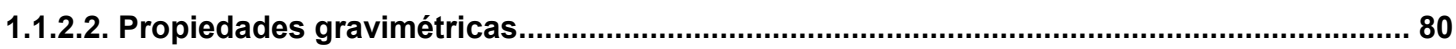

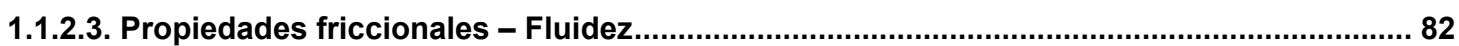

1.2. Estructura y composición de las semillas .............................................. 82

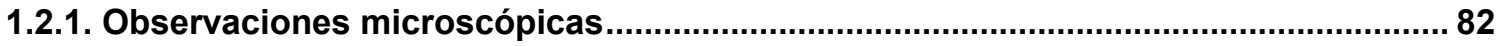

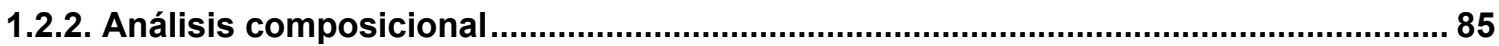

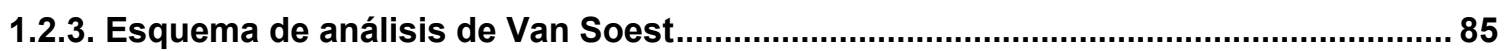

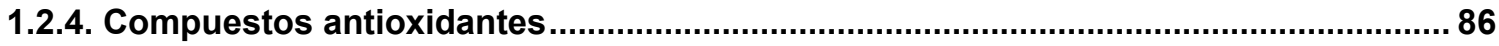

2. Semillas de chía provenientes de Quetzaltenango (Guatemala)................... 88

2.1. Descripción de la semilla ......................................................................... 88

2.1.1 Composición y contenido de humedad de la mezcla comercial de las semillas según

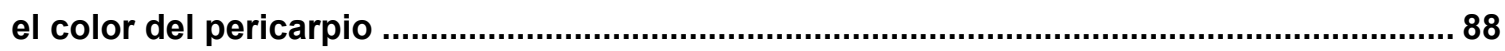

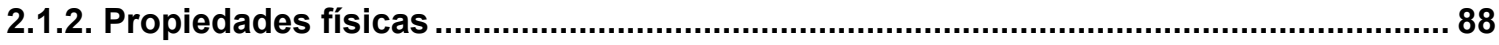

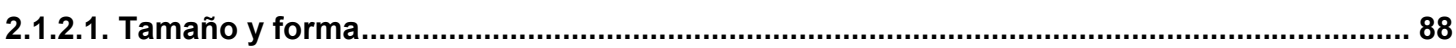

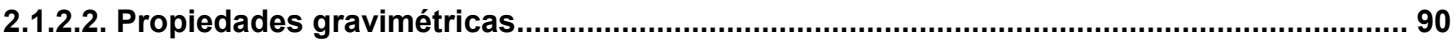

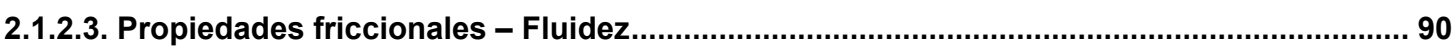

2.2. Estructura y composición de las semillas .............................................. 91

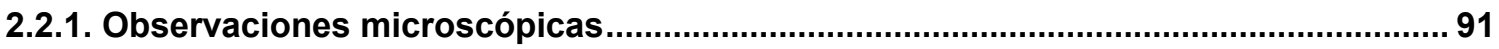

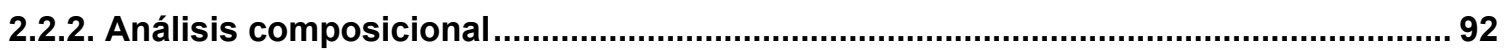

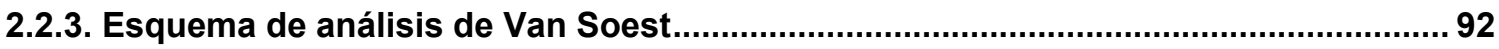

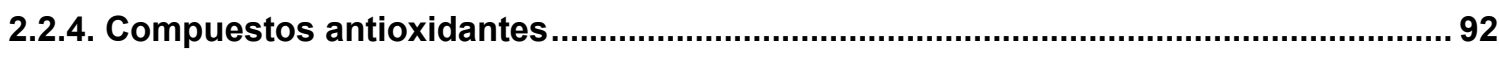

3. Estudio comparativo de las semillas de Argentina y Guatemala .................. 94 
3.1. Descripción de la semilla 94

3.1.1 Composición y contenido de humedad de la mezcla comercial de las semillas según el color del pericarpio 94

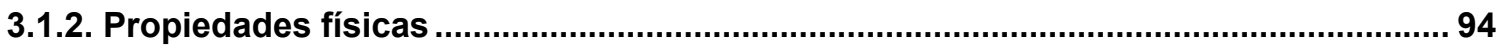

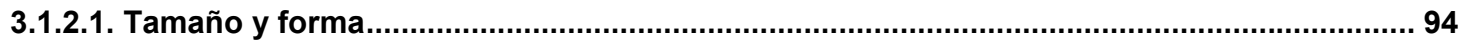

3.1.2.2. Propiedades gravimétricas................................................................................................ 95

3.1.2.3. Propiedades friccionales - Fluidez............................................................................. 96

3.2. Estructura y composición de las semillas ............................................... 96

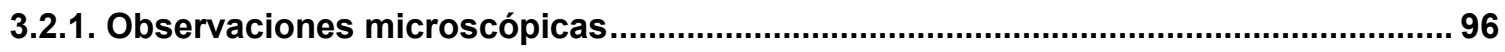

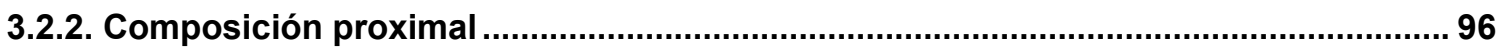

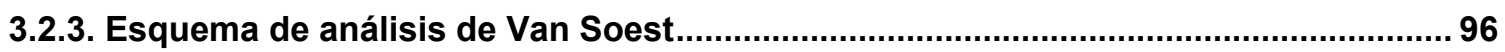

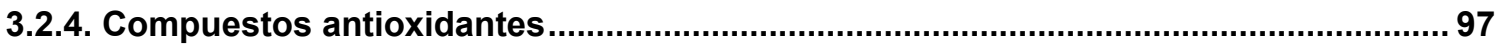

CONCLUSIONES PARCIALES ..................................................................... 99

DIFUSIÓN DE RESULTADOS ....................................................................... 101

Capítulo 3 Obtención y caracterización de aceite de chía mediante procesos convencionales ................................................................... 102

INTRODUCCIÓN.......................................................................................... 103

MATERIALES Y MÉTODOS ......................................................................... 106

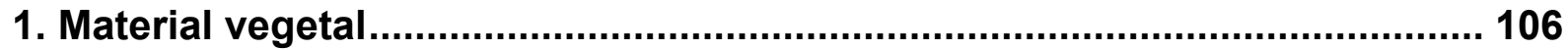

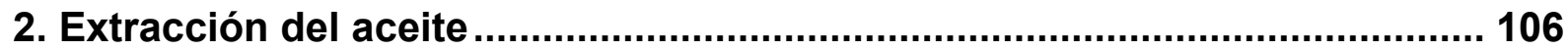

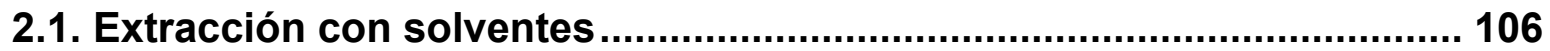

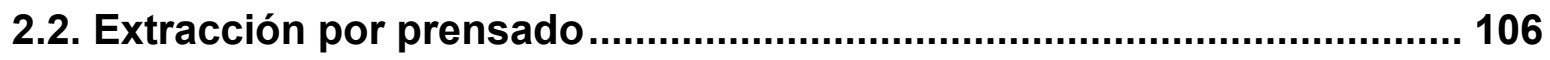

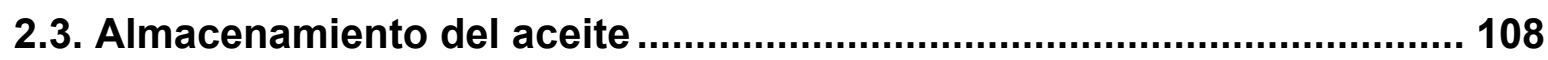

3. Análisis fisicoquímico de los aceites …….................................................. 108

3.1. Composición de ácidos grasos mediante cromatografía gaseosa (CG)108

3.2. Composición y distribución de la posición acílica de los ácidos grasos en la molécula de glicerol mediante espectroscopía de ${ }^{13} \mathrm{C}$ NMR ................ 108

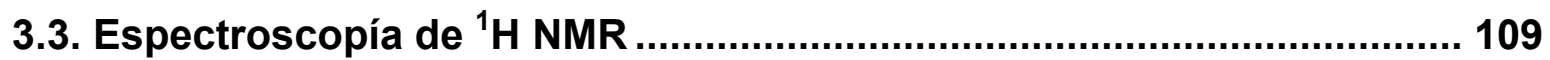

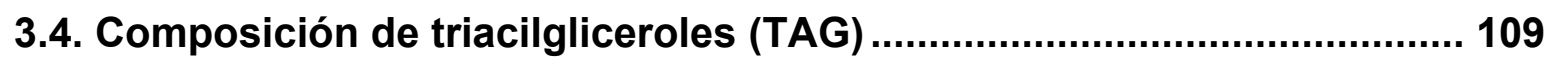

3.5. Índices de iodo y de saponificación (II, IS) ........................................... 110

3.6. Índice de refracción ............................................................................. 111 
3.7. Ácidos grasos libres (FFA) ................................................................ 111

3.8. Índice de peróxido (PV) ......................................................................... 112

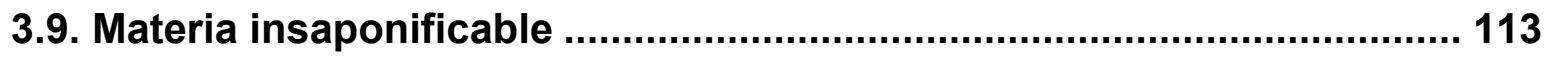

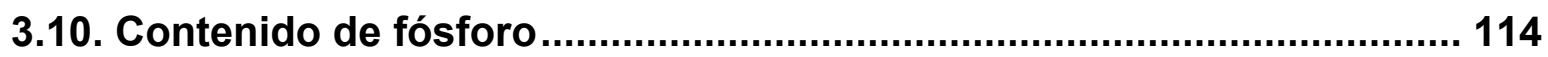

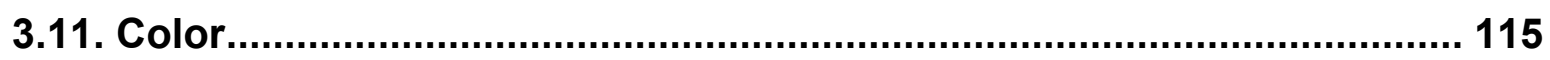

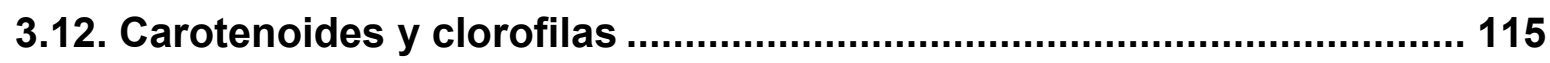

3.13. Determinación del contenido de ceras ................................................ 116

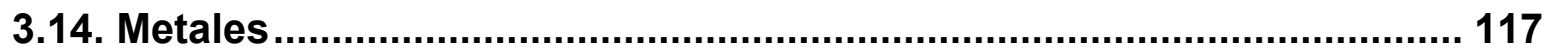

3.15. Tocoferoles

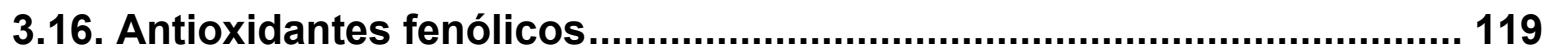

3.17. Ensayo acelerado de estabilidad oxidativa (Rancimat) ....................... 120

3.18. Calorimetría diferencial de barrido (DSC) ........................................... 121

4. Análisis estadístico …................................................................................... 122

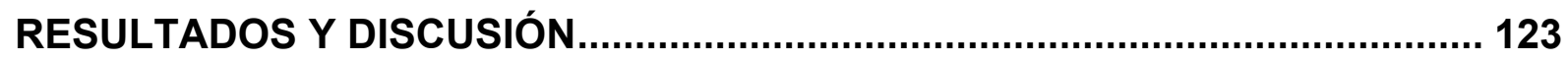

1. Caracterización comparativa de los aceites de chía obtenidos mediante extracción con solvente y por prensado......................................................... 123

2. Caracterización comparativa de los aceites de chía obtenidos mediante extracción con solvente a partir de las semillas oscuras y blancas provenientes de Salta (Argentina) ................................................................... 143

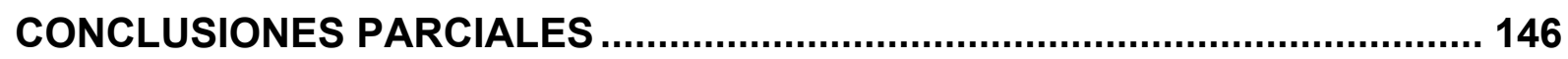

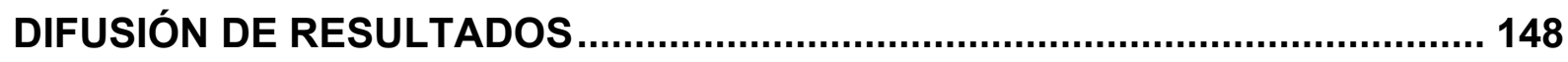

Capítulo 4 Obtención y caracterización de aceite de chía mediante extracción por fluidos supercríticos (EFSC) ..................................150

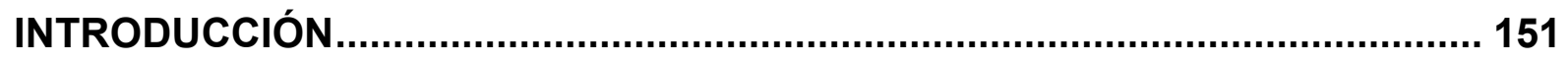

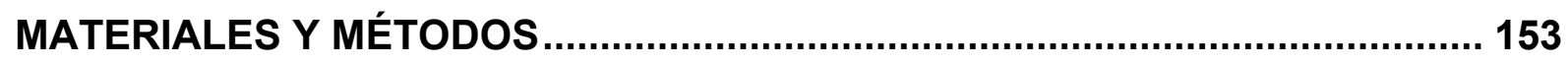

1. Extracción a partir de semillas de chía provenientes de Salta (Argentina). 153

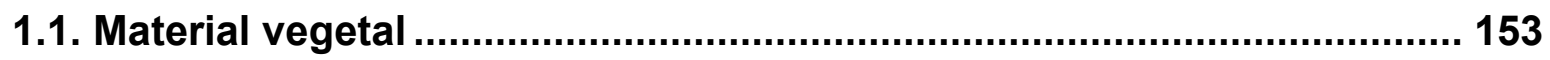

1.2. Acondicionamiento y caracterización de la muestra............................. 153

1.3. Extracción de aceite mediante $\mathrm{SC}-\mathrm{CO}_{2}$. Cinética de extracción ............ 153 
1.4. Caracterización de los aceites obtenidos 155

1.5. Análisis estadístico 155

2. Análisis conjunto de los aceites de chía obtenidos a partir de las semillas de Argentina mediante los diferentes procesos de extracción a través de un análisis multivariado 156

3. Extracción a partir de semillas de chía provenientes de Jalisco (México). 156

3.1. Material vegetal 156

3.2. Acondicionamiento y caracterización de la muestra. 156

3.3. Extracción mediante $\mathrm{SC}-\mathrm{CO}_{2}$ 156

3.4. Cinética de extracción 158

3.5. Diseño experimental 158

3.6. Determinación de la composición de ácidos grasos 160

3.7. Determinación de los índices de iodo y de saponificación 161

3.8. Determinación de los ácidos grasos libres y del índice de peróxido.... 161

3.9. Determinación de las propiedades termo-reológicas 161

3.10. Análisis estadístico 162

RESULTADOS Y DISCUSIÓN 162

1. Extracción supercrítica de aceite de chía obtenido a partir de semillas provenientes de Salta (Argentina) 162

2. Análisis conjunto de los aceites de chía obtenidos a partir de las semillas provenientes de Argentina mediante los diferentes procesos de extracción a través de un análisis multivariado

3. Extracción supercrítica de aceite de chía obtenido a partir de semillas provenientes de Jalisco (México)

3.1. Proceso de extracción, modelo de regresión y análisis de resultados mediante la metodología de superficie de respuesta (MSR). 181

3.2. Análisis fisicoquímico de los aceites extraídos 189

CONCLUSIONES PARCIALES 196

DIFUSIÓN DE RESULTADOS 198 
Capítulo 5. Conservación del aceite de chía. Efecto de las condiciones de almacenamiento y de la aplicación de antioxidantes

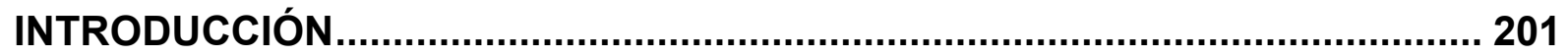

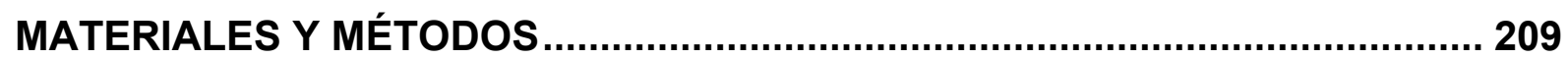

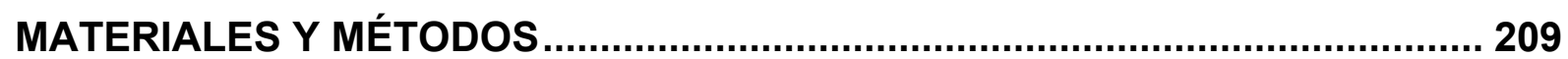

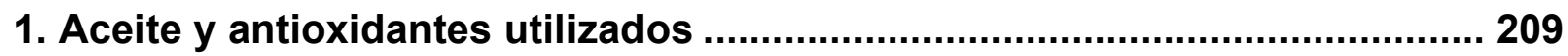

2. Ensayo de estabilidad oxidativa acelerada mediante Rancimat .................. 209

3. Estudio de la oxidación de aceite de chía mediante calorimetría diferencial

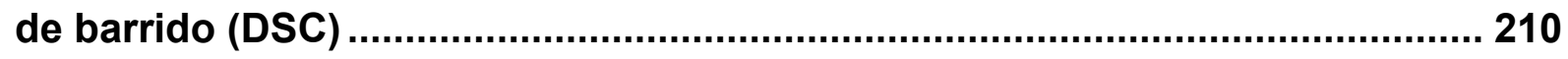

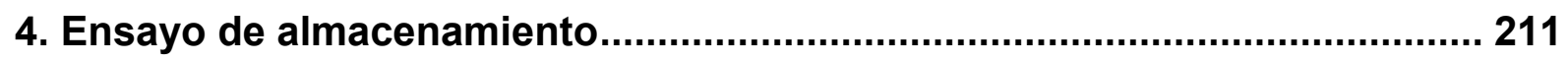

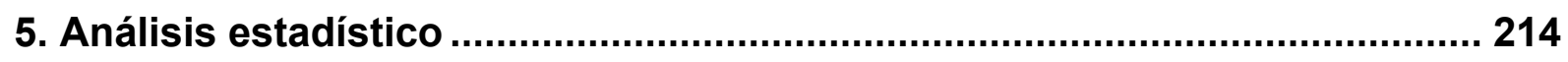

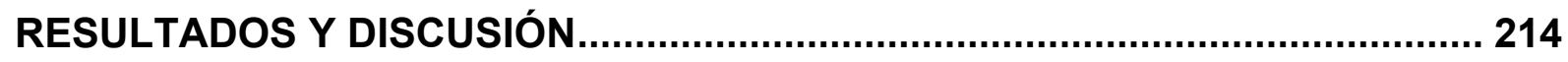

1. Ensayo de estabilidad oxidativa acelerada mediante RANCIMAT ............... 215

2. Estudio de la oxidación de aceite de chía mediante calorimetría diferencial

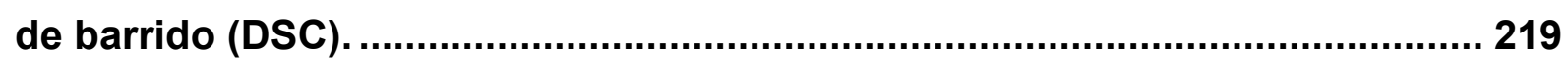

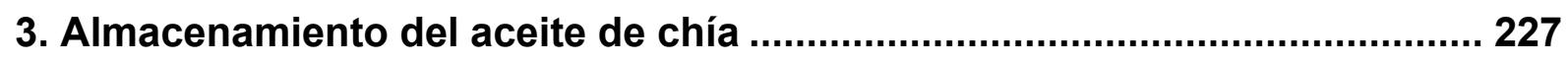

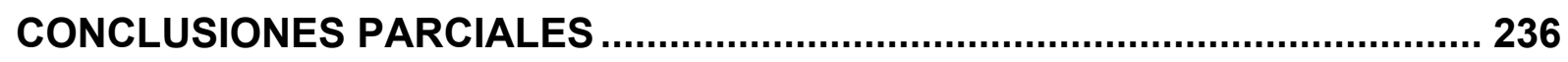

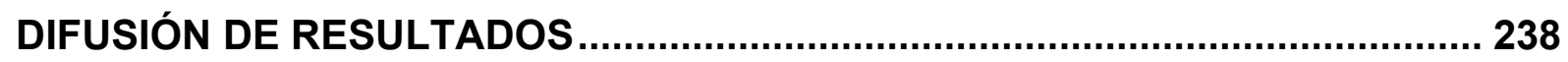

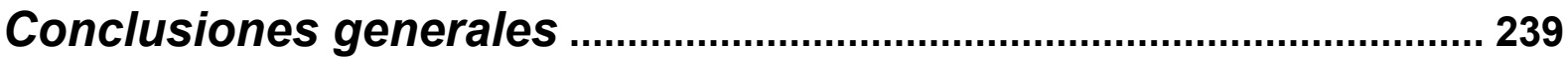

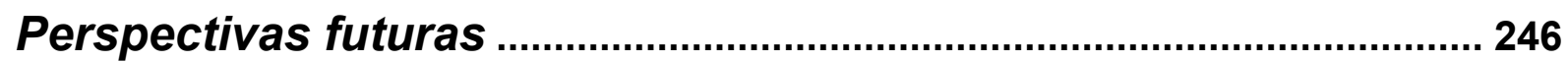

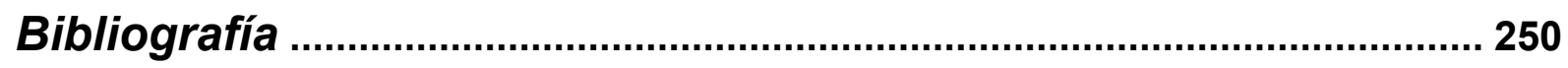




\section{Listado de abreviaturas}




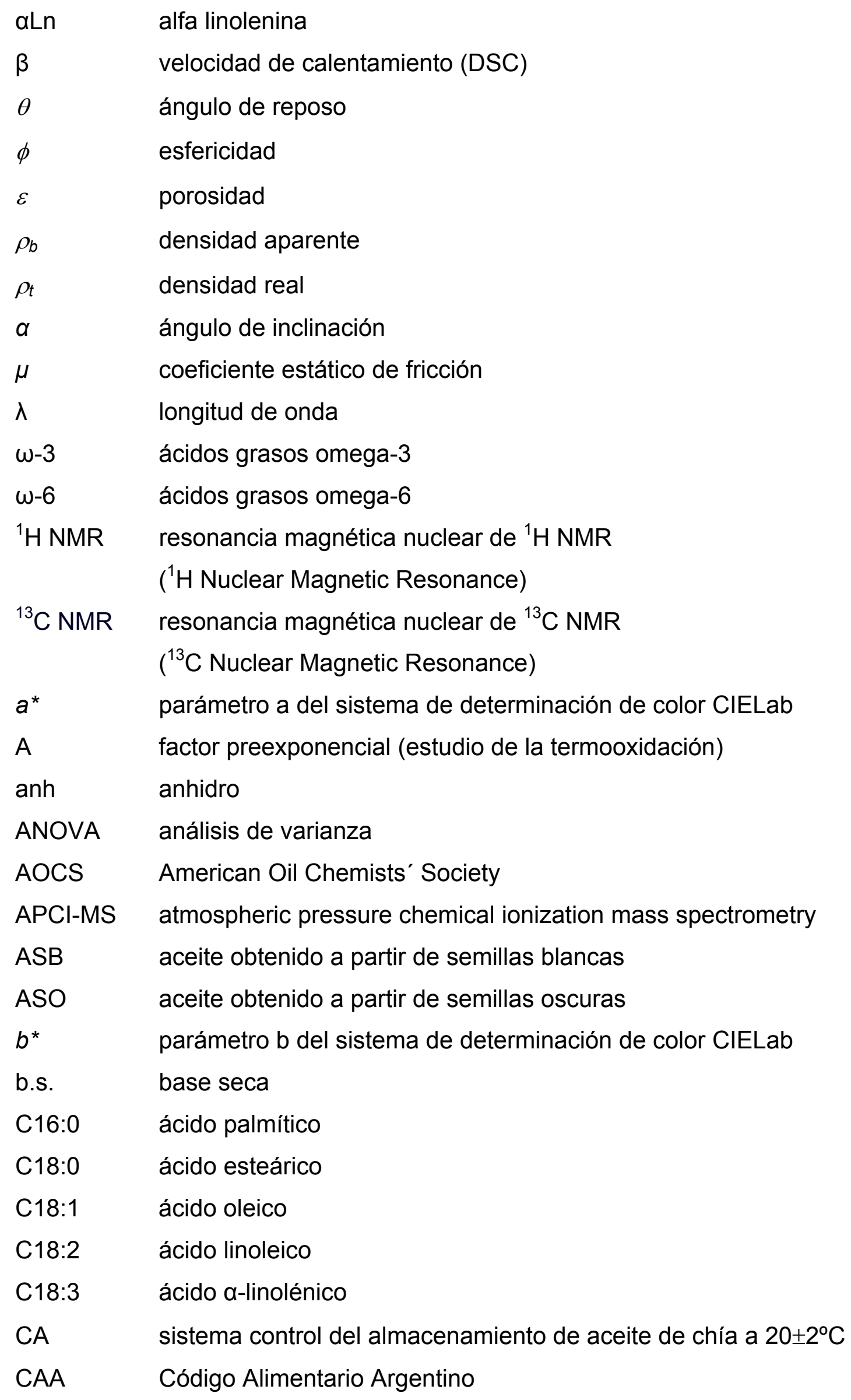




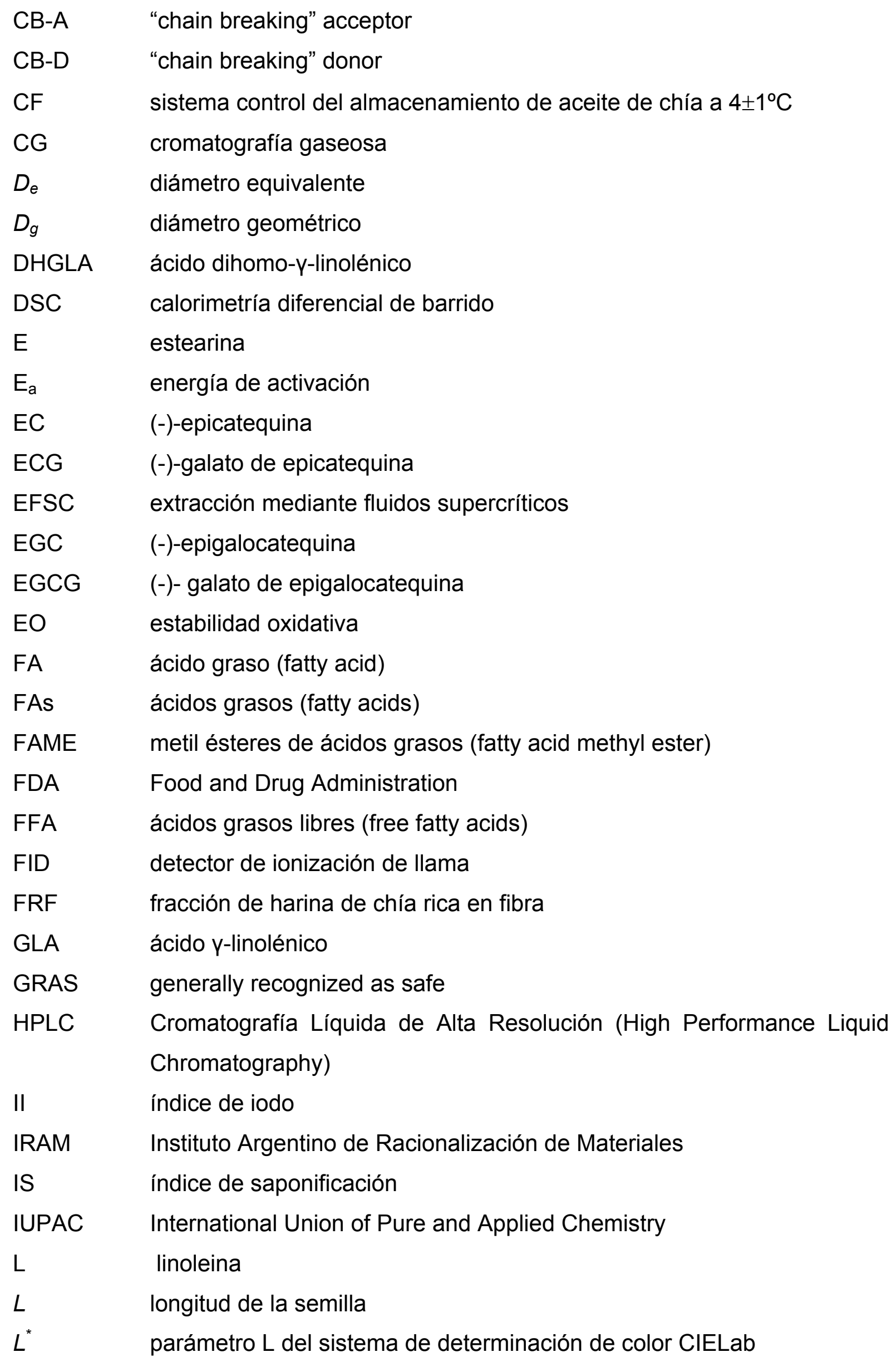


$\mathrm{L}^{\bullet} \quad$ radical libre lipídico

LH lípido

$\mathrm{LOO}^{\bullet} \quad$ radical peroxilo

$\mathrm{LOOH} \quad$ hidroperóxido

$m$

masa unitaria

$\mathrm{m} / \mathrm{z}$

relación masa/carga

$\mathrm{n}$

número de repeticiones

nd

no detectado

NS

number of scans (número de corridas)

$\mathrm{O}$

oleina

OFW método de Ozawa-Flynn-Wall

P palmitina

p nivel de significación

$\mathrm{P}_{\mathrm{c}} \quad$ Presión crítica del fluido supercrítico

P2500F aceite de chía con 2500 ppm de palmitato de ascorbilo almacenado a $4 \pm 1^{\circ} \mathrm{C}$

P2500A aceite de chía con 2500 ppm de palmitato de ascorbilo almacenado $20 \pm 2^{\circ} \mathrm{C}$

$p$-AV valor de $p$-ansidina

pe punto de ebullición

psi libra/pulgada ${ }^{2}$ (rounds per square inch)

PRE periodo rápido de extracción mediante fluidos supercríticos

PLE $\quad$ periodo lento de extracción mediante fluidos supercríticos

PUFAs ácidos grasos poliinsaturados (polyunsaturated fatty acids)

PV índice de peróxido (peroxide value)

$r \quad$ coeficiente de correlación

$R \quad$ relación de aspecto de una semilla

R500F aceite de chía con 500 ppm extracto de romero almacenado a $4 \pm 1^{\circ} \mathrm{C}$

R500A aceite de chía con 500 ppm extracto de romero almacenado a $20 \pm 2^{\circ} \mathrm{C}$

R2500F aceite de chía con 2500 ppm extracto de romero almacenado a $4 \pm 1^{\circ} \mathrm{C}$

R2500A aceite de chía con 2500 ppm extracto de romero almacenado a $20 \pm 2^{\circ} \mathrm{C}$

sn-1/3 posiciones $1 / 3$ del ácido graso en la molécula del glicerol

sn-2 posición 2 del ácido graso en la molécula del glicerol 


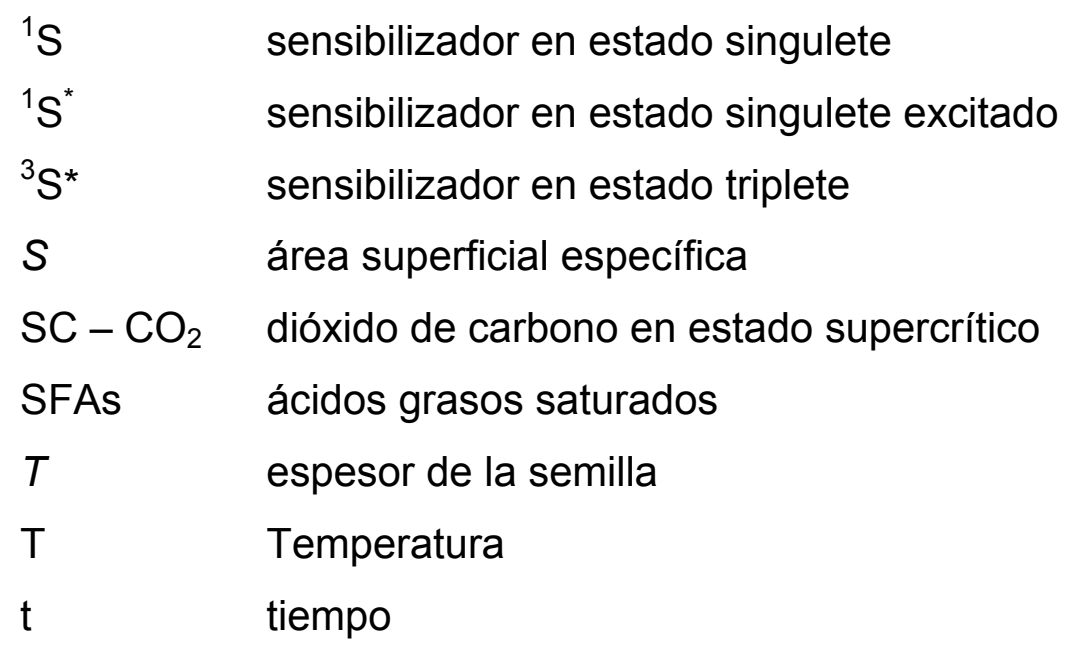

T500F aceite de chía con $500 \mathrm{ppm}$ extracto de té verde almacenado a $4 \pm 1^{\circ} \mathrm{C}$

T500A aceite de chía con $500 \mathrm{ppm}$ extracto de té verde almacenado a $20 \pm 2^{\circ} \mathrm{C}$

T2500F aceite de chía con 2500 ppm extracto de té verde almacenado a $4 \pm 1^{\circ} \mathrm{C}$

T2500A aceite de chía con 2500 ppm extracto de té verde almacenado a $20 \pm 2^{\circ} \mathrm{C}$

TAG triacilglicerol

$\mathrm{T}_{\mathrm{C}} \quad$ Temperatura crítica del fluido supercrítico

$\mathrm{T}_{\mathrm{e}} \quad$ Temperatura extrapolada de inicio de la oxidación (DSC)

$T_{\text {end }} \quad$ Temperatura de finalización del proceso de fusión (DSC)

ti tiempo de inducción (Rancimat)

tia tiempo de inducción del aceite de chía con el agregado de antioxidantes (Rancimat)

$t_{\text {ic }} \quad$ tiempo de inducción del aceite de chía sin el agregado de antioxidantes (Rancimat)

Totox valor total de oxidación

To $\quad$ Temperatura onset del inicio del proceso de fusión (DSC)

$\mathrm{T}_{\mathrm{p} 1} \quad$ Temperatura máxima del primer pico (DSC)

$\mathrm{T}_{\mathrm{p} 2} \quad$ Temperatura máxima del segundo pico (DSC)

$\mathrm{t}_{\mathrm{r}} \quad$ tiempo de retención

$\operatorname{Tr} \quad$ valores traza

UV ultravioleta

$V \quad$ volumen de la semilla

W ancho de la semilla

$W_{1000} \quad$ peso de mil semillas 
Introducción general 
En la historia de la civilización, las modificaciones del modo de vida fueron acompañadas por cambios en los hábitos alimenticios. La alimentación actual es muy diferente a la típica dieta del periodo Paleolítico (2.000.000 - 10.000 a.C.), la cual se basaba en alimentos de origen vegetal y animal en proporciones similares, conteniendo altas concentraciones de proteínas y fibra así como bajos o moderados tenores de carbohidratos y de grasas. Los cambios más importantes tuvieron lugar con el inicio de la actividad agrícola y posteriormente durante la Revolución Industrial (Simopoulos, 1998). En la actualidad, las modernas dietas occidentales se caracterizan por un elevado consumo de grasas saturadas, ácidos grasos trans y $\omega-6$, así como por una deficiencia en ácidos grasos $\omega-3$. La relación $\omega-6: \omega-3$, que actualmente es de 10:1 a 20:1, en el periodo Paleolítico se ubicaba en valores cercanos a 1:1 (Eaton y col., 1998). Por otra parte, la agricultura moderna ha logrado aumentar la producción de los granos tradicionales de cereales y oleaginosas (trigo, cebada, girasol, maíz, soja, entre otros), siendo elevada la dependencia de relativamente pocas especies vegetales y animales, lo que nos ubica en una situación muy precaria (Cordain, 1999).

Los aceites vegetales comestibles constituyen un componente importante en nuestra alimentación, cuya variedad y consumo depende de la disponibilidad de la materia prima en cada país y región. Ahora bien, no obstante la variedad de especies oleaginosas, el mayor consumo está representado por los aceites de palma, soja, colza y girasol con 40,2; 37,5; 18,4 y 9,0 millones de toneladas al año, respectivamente, lo que representa aproximadamente el $83 \%$ del total de aceites consumidos mundialmente (American Soybean Association, 2009). Por otra parte, es reconocido el aporte de los lípidos en nuestra salud y bienestar, el cual está determinado fundamentalmente por su composición. Así, se ha demostrado que tanto el perfil de ácidos grasos -especialmente los niveles relativos de ácidos grasos $\omega-9$, $\omega-6$ y $\omega-3-$ como algunos componentes minoritarios ejercen una influencia positiva a nivel fisiológico en el organismo humano (Moreau y Kamal-Eldin, 2009). En los últimos años se ha registrado un mayor incremento en la búsqueda de fuentes vegetales subutilizadas, a partir de las cuales puedan obtenerse aceites con una elevada proporción de ácidos grasos de alto valor nutricional.

En este sentido, las semillas de chía (Salvia hispanica L) son el recurso natural de origen vegetal con mayor contenido de ácidos grasos $\omega-3$ (60\% de ácidos grasos totales del aceite) conocido hasta el momento, además de ser una buena fuente de 
proteínas, fibra, minerales, vitaminas y antioxidantes (Ayerza y Coates, 2005). Estas características nutricionales han conducido a un creciente interés por este cultivo y por los productos obtenidos a partir del mismo, así como sobre su potencial aplicación en la industria alimentaria.

\section{La chía}

\subsection{Origen y antecedentes históricos}

Salvia hispanica L. es una especie originaria de Mesoamérica cuya mayor diversidad genética se presenta en la vertiente del Océano Pacífico (Miranda, 1978; Cahill, 2004). Beltrán-Orozco y Romero (2003), específicamente indican que la misma es originaria de las áreas montañosas del oeste y centro de México. Las fuentes indígenas disponibles previas a 1519, fecha de la llegada de los españoles a territorio mexicano, muestran una fuerte relación etnobotánica entre la chía y varias culturas mesoamericanas. Si bien ninguna fuente afirma de manera categórica que la chía sea originaria de un lugar específico, existe una alta probabilidad que la semilla sea originaria de los territorios que actualmente ocupan la República Mexicana y Guatemala (Tecante 2010, comunicación personal).

S. hispanica L. es comúnmente conocida como chía, siendo esta palabra una adaptación española al término nahua chian o chien (plural), término que en náhuatl significa "semilla de la que se obtiene aceite" (Watson, 1938). La chía cultivada por los Nahuas a la llegada de los españoles a América así como la que actualmente se siembra en Argentina, Bolivia y México, corresponde a S. hispanica L. Sin embargo, también se aplica el término chía a un cierto número de otras plantas nativas de México y de los Estados Unidos pertenecientes a otras especies del género Salvia, así como al género Hyptis y Amaranthus. Esta confusión pudo haber ocurrido en el periodo postcolombino cuando el sistema botánico de clasificación Nahua fue abandonado (Ayerza y Coates, 2005).

Existes evidencias que demuestran que la semilla de chía fue utilizada como alimento hacia el año 3500 (a.C.) siendo cultivada en el Valle de México entre los años 2600 y 900 (a.C.) por las civilizaciones teotihuacanas y toltecas. Asimismo, fue uno de los principales componentes de la dieta de los Aztecas junto con la quinoa, el amaranto, el maíz y alguna variedad de porotos (Rodríguez Vallejo, 1992). La importancia de estos cuatro cultivos en la dieta azteca está bien fundamentada en el Codex Florentino escrito en tiempos de la conquista de América entre 1548 y 1585 
por Fray Bernardino de Sahagún, titulado Historia general de las cosas de Nueva España, en el cual se describen algunos aspectos relacionados con la producción, comercialización y usos de la chía (Figura 1.1). La chía era utilizada como materia prima para la elaboración de medicinas, alimentos y pinturas, así como en ofrendas a los dioses durante las ceremonias religiosas (Sahagún, 1579). Tenochtitlán, la capital del Imperio Azteca, recibía entre 5000 y 15000 t de chía anualmente como tributo de los pueblos conquistados (Codex Mendoza, 1542). Con respecto a los Mayas, no existe evidencia que la chía fuera cultivada en el apogeo de su civilización (800 a.C. a 900 d.C), aunque la existencia de un intenso comercio entre los centros Teotihuacanos y Mayas durante varios siglos hacen suponer que la chía también era conocida por este pueblo precolombino, el cual ocupó una gran parte de México, Guatemala, Honduras y El Salvador (Ayerza y Coates, 2005).

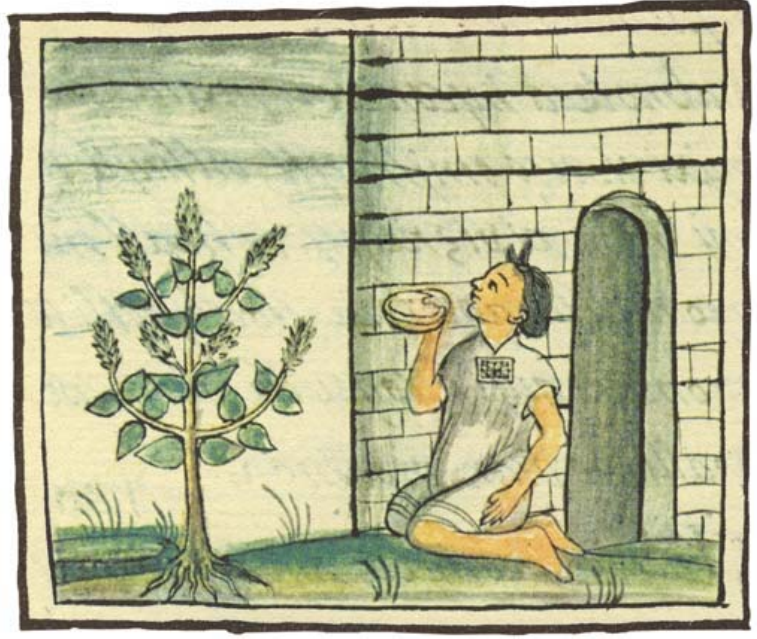

Figura 1.1. Imagen tomada del

Codex Florentino ilustrando la planta chía (Sahagún, 1579)

Con la llegada de los españoles, las tradiciones de los nativos fueron suprimidas y la mayor parte de su agricultura intensiva y de su sistema de comercialización destruidos. Muchos cultivos que habían tenido la mayor preponderancia en las dietas precolombinas fueron prohibidos por los españoles debido a su estrecha asociación con los cultos religiosos y reemplazados por especies exóticas (trigo, cebada, arroz, entre otras) demandadas por los conquistadores (Soustelle, 1955; Engel, 1987). Así, de los cuatro cultivos básicos de la dieta azteca, la chía y el amaranto perdieron sus lugares privilegiados y casi 
desaparecieron, siendo los efectos de la persecución española mayores sobre la chía que sobre el amaranto. Este último, conocido como kiwicha en quechua y qmasa en aymara, fue también uno de los principales cultivos del Imperio Inca, contemporáneo de los Aztecas. Así, el desarrollo paralelo del cultivo en las dos civilizaciones indudablemente aumentó la supervivencia del amaranto comparado con el de la chía (National Research Council, 1989). Otro factor que contribuyó a la persistencia del maíz, el poroto y el amaranto -a diferencia de la chía- se relaciona con los requerimientos fotoperiódicos correspondientes a cada uno de estos cultivos. Las tres primeras especies son insensibles o poco sensibles a un fotoperiodo en particular pudiendo florecer y completar su ciclo de cultivo tanto en España como en otros países europeos. En cambio, la chía es una planta de día corto, cuya floración sólo puede ser lograda en los países europeos durante el periodo de heladas o cercano a ellas, a las cuales no es tolerante. Así, este requerimiento fisiológico impidió que la chía fuera cultivada en el Viejo Mundo (Ayerza y Coates, 2005).

Sin embargo, esta especie logró sobrevivir a la persecución de los conquistadores españoles debido a la conservación de algunas tradiciones precolombinas por parte de pequeños grupos de descendientes de las naciones Nahua. Así, estos pueblos lograron vencer a los conquistadores y las presiones de la cultura impuesta permaneciendo aislados en el sudoeste de México y las zonas montañosas de Guatemala. Actualmente, los descendientes de los Nahua y de los Mayas utilizan este grano ancestral en una popular bebida denominada chía fresca, aunque su preparación difiere de la realizada por los antiguos Mexicans (Ayerza y Coates, 2005).

Con respecto al periodo postcolombino, existen algunas referencias tales como datos censales de 1780, así como la Nueva farmacopea de México (1874) y las estadísticas del Departamento de Agricultura publicadas por la Secretaría Mexicana de Agricultura y Promoción desde 1932 a 1935 que citan a la chía entre los cultivos realizados en México (Cortéz y Larraz, 1958; American Journal of Pharmacy, 1885; Rulfo, 1937). Durante muchos años las semillas de chía fueron comercializadas solamente en los mercados mexicanos y utilizada como materia prima para la elaboración de la bebida denominada "chía fresca", la cual era consumida por razones étnicas o religiosas. En 1965 la chía comenzó a estar disponible en comercios dietéticos del sudeste de California y Arizona (Hicks, 1966) y hacia finales de los años 1980s se comenzó a comercializar en los Estados Unidos un alimento 
para mascotas (Chia Pets), incrementándose la demanda de las semillas y posibilitando la venta mayoritaria de su producción.

En 1991 se inició el Proyecto Regional del Noroeste de Argentina con el fin de identificar y llevar a producción comercial nuevos cultivos industriales que pudieran ayudar a diversificar la producción agrícola e incrementar las ganancias de los agricultores de dicha región. Desde su comienzo, organizaciones privadas y gubernamentales tanto de los Estados Unidos como de Argentina han trabajado en este proyecto en forma cooperativa. En virtud de ello se identificaron seis especies con un potencial significativo para la región: chía, lesquerella (Lesquerella fendleri (Gray) S. Wats), vernonia (Vernonia galamensis (Cass.) Less), y chan (Hyptis suaveolens L.), todas fuentes de aceites industriales; guayule (Parthenium argentatum Gray), fuente de caucho, resinas y látex; y kenaf (Hibiscus cannabinus L.), materia prima para papeles y diarios. Durante el curso del proyecto, la chía fue identificada como la especie más promisoria, siendo sólo esta útlima y la lesquerella cultivadas comercialmente (Ayerza y Coates, 2005).

Paralelamente, los resultados de las investigaciones científicas acerca de los efectos negativos de las grasas saturadas, los ácidos grasos trans y el desbalance entre los ácidos grasos $\omega-6$ y $\omega-3$ en la dieta occidental así como los beneficios del consumo de $\omega$-3 para prevenir enfermedades cardiovasculares, depresión, cáncer y otras patologías, comenzó a ser cada vez de mayor interés. Asimismo, la información sobre la chía describiéndola como una fuente natural de este tipo de ácidos grasos, antioxidantes y fibra dietaria acrecentó las expectativas en torno a su cultivo. En virtud de ello, su uso como alimento comenzó a expandirse fuera de México (Ayerza y Coates, 2005).

La ciencia actual permite explicar por qué las antiguas civilizaciones consideraban a la chía un componente básico de su dieta. La composición química y el valor nutricional asociado, le confieren un gran potencial para incorporarla a los mercados alimenticios e industriales. A su vez, la información tecnológica ha dado una excelente oportunidad para desarrollar una industria agrícola capaz de ofrecer al mundo un "cultivo nuevo y antiguo a la vez" (Ayerza y Coates, 2005). 


\subsection{Ubicación sistemática y características botánicas}

Según la clasificación taxonómica propuesta por Linneo, la posición sistemática de la chía (Salvia hispanica L.) es la siguiente:

Reino: Vegetal o Plantae

División: Magnoliophyta o Angiospermae

Clase: Magnoliopsida o Dicotyledoneae

Orden: Lamiales

Familia: Lamiaceae

Subfamilia: Nepetoideae

Tribu: Mentheae

Género: Salvia

Especie: hispanica

La familia Lamiaceae cuenta con 170 géneros y más de 3000 especies de amplia distribución en regiones tropicales y templadas, de las cuales en Argentina existen alrededor de 26 géneros (Burkart, 1979). Son hierbas anuales o arbustos perennes, que contienen aceites esenciales en los pelos glandulares de sus hojas y tallos, motivo por el cual han sido domesticadas para ser utilizadas como condimentos y en la elaboración de perfumes. Según León (1987), la mayoría de las especies cultivadas se originan en la región mediterránea: Rosmarinus officinalis, Lavandula angustifolia, L. latifolia, Salvia sp., Mentha sp., Origanum vulgare, O. majorana, Ocimum basilicum, Thymus vulgaris y otros. Muchas labiadas se cultivan por su follaje ornamental, como Coleus spp., o por sus flores, como es el caso de Salvia sp. En Mesoamérica, las semillas de ciertos Hyptis y Salvia se usan en la preparación de refrescos (León, 1987).

El género Salvia incluye unas 900 especies y se distribuye extensamente en varias regiones del mundo, tales como Sudáfrica, América Central, América del Norte, Sudamérica y Asia Sur-Oriental. Las plantas pueden ser herbáceas o leñosas, y sus flores muy atractivas y de varios colores.

S. hispanica es una planta herbácea anual de 1 a $1,5 \mathrm{~m}$ de altura, con tallos ramificados de sección cuadrangular con pubescencias cortas y blancas. Las hojas opuestas con bordes aserrados miden $8-10 \mathrm{~cm}$ de longitud y 4-6 $\mathrm{cm}$ de ancho (Figura 1.2). 


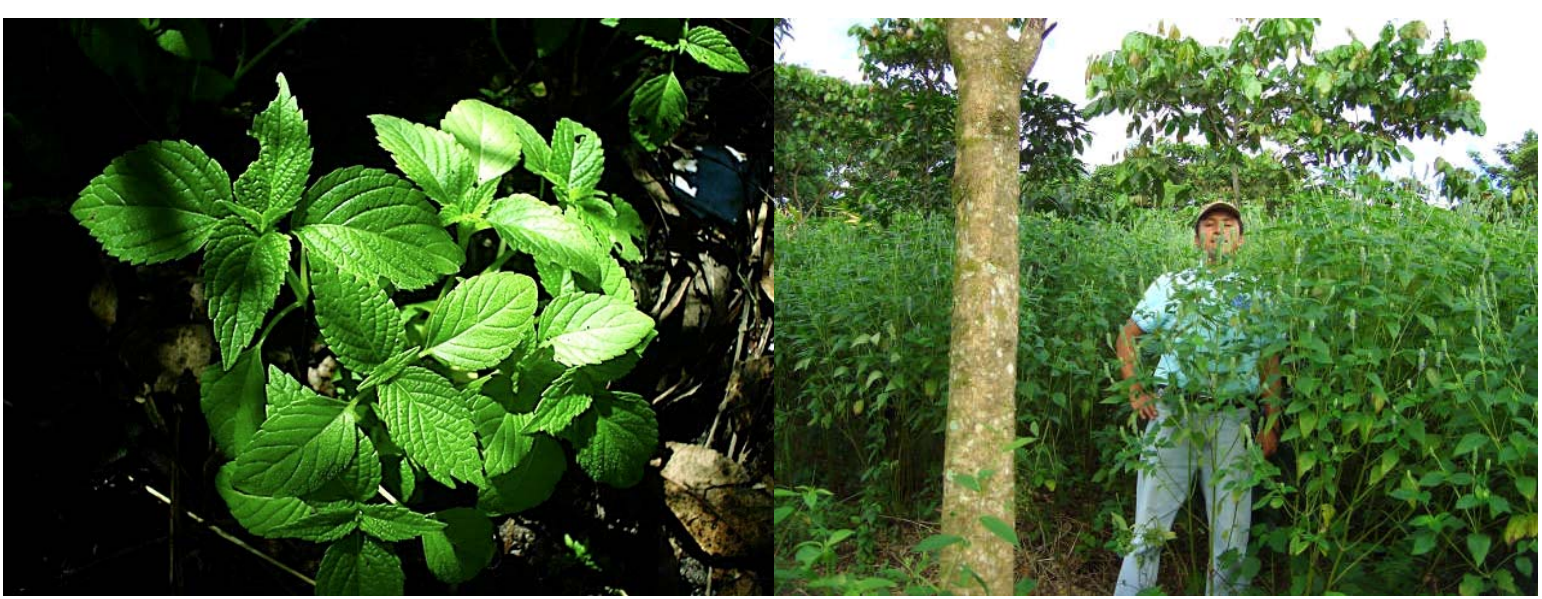

La descripción de la morfología floral de $S$. hispanica fue abordada por Martínez (1959) y Ramamoorthy (1985). Las flores son hermafroditas, púrpuras o blancas, pedunculadas y se encuentran reunidas en grupos de seis o más, en verticilos sobre el raquis de la inflorescencia (Figura 1.3).

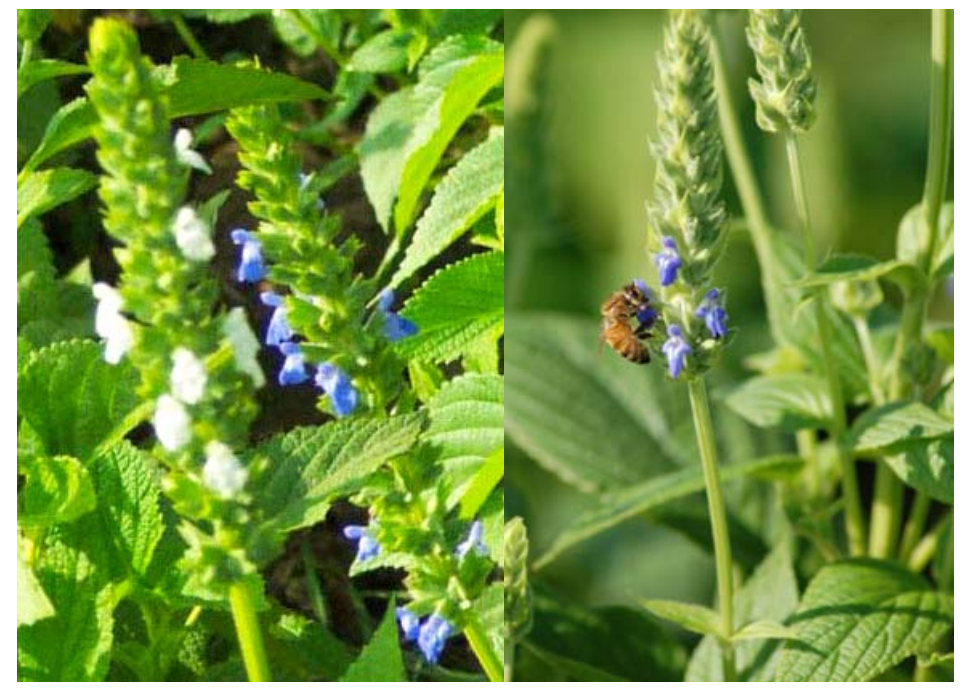

Figura 1.3. Inflorescencias de Salvia hispanica L. (Studio Balance, 2010)

Si bien no se conoce con precisión el mecanismo de polinización en $S$. hispanica, algunos autores indican que es una especie alógama de polinización entomófila, lo cual se ve favorecido por el color de los pétalos, la morfología floral y la presencia de néctar en la base del ovario, así como por la existencia de mecanismos que promueven la fecundación cruzada tales como la protandria y la 
androesterilidad (Mann, 1959; Martínez, 1959; Ramamoorthy, 1985). Por otra parte, Haque y Goshal (1981) indican que S. hispanica sería una especie autógama y autocompatible. Hernández-Gómez y col. (2008) informaron que los genotipos de S. hispanica de Acatic presentan un sistema de apareamiento intermedio o mixto, con un promedio de cruzamiento natural de $22,17 \%$, mientras que señalan que en poblaciones silvestres de esta especie el sistema de fecundación es principalmente autógamo con un promedio de fecundación cruzada del $1,5 \%$.

El fruto, al igual que otras especies de la familia Lamiaceae, es típicamente un esquizocarpo consistente en lóculos indehiscentes que se separan para formar 4 mericarpios parciales denominados núculas, comúnmente conocidos como "semillas", los cuales son monospérmicos, ovales, suaves y brillantes, de color pardo grisáceo con manchas irregulares marrones en su mayoría y algunos blancos (Ayerza y Coates, 2005).

Las características morfológicas y fenológicas que diferencian a las variedades domesticadas de las silvestres de S. hispanica son: cálices cerrados, semillas de mayor tamaño, inflorescencias más compactas, flores más largas, presencia de dominancia apical y uniformidad en los periodos de floración y maduración (Cahill, 2005). Como en la mayoría de las plantas cultivadas, en la chía ha existido una ligera pérdida de variabilidad genética en el proceso de domesticación. En la actualidad, los esfuerzos se han dirigido hacia la selección de plantas domesticadas, a partir de una porción pequeña del total de la diversidad genética (Cahill, 2004). S. hispanica presenta un número somático de $2 n=12$, el cual representa el número de cromosomas más bajo del género (Ramamoorthy y Elliot, 1993).

\subsection{Distribución geográfica y producción}

S. hispanica se encuentra naturalmente en áreas de bosque de encino o de pinoencino y se distribuye en ambientes semicálidos y templados del Eje Neovolcánico Transversal de las Sierras Madre Occidental, del Sur y de Chiapas, en altitudes entre 1400 y 2200m. Históricamente, esta especie ha sido cultivada tanto en ambientes tropicales como subtropicales, en áreas libres de heladas y en regiones con heladas anuales, desde el nivel del mar hasta los $2500 \mathrm{msnm}$. La Tabla 1.1 muestra las características de algunas localidades donde la chía ha sido y es aún cultivada. 
Tabla 1.1. Características de la localización de los sitios de cultivo de la chía (Ayerza y Coates, 2005)

\begin{tabular}{|c|c|c|c|c|c|c|}
\hline País & Localidad & Latitud & $\begin{array}{c}\text { Elevación } \\
\text { (msnm) }\end{array}$ & $\begin{array}{c}\mathrm{T}^{\mathrm{o}} \\
\text { anual/estación }{ }^{2} \\
\left({ }^{\circ} \mathrm{C}\right)\end{array}$ & $\begin{array}{c}\text { Precipitaciones } \\
\text { anuales/estación } \\
(\mathrm{mm})\end{array}$ & $\begin{array}{l}\text { Ciclo } \\
\text { de } \\
\text { cultivo } \\
\text { (días) }\end{array}$ \\
\hline Argentina & El Carril & $25^{\circ} 05^{\prime} \mathrm{S}$ & 1170 & $17,3 / 16,6$ & $560 / 390$ & 150 \\
\hline Bolivia & Santa Cruz & $17^{\circ} 43^{\prime} \mathrm{S}$ & 437 & $24,6 / 22,8$ & $1141 / 566$ & 150 \\
\hline Colombia $^{1}$ & La Unión & $4^{\circ} 32^{\prime} \mathrm{N}$ & 920 & $24 / 23,8$ & $1118 / 341$ & 90 \\
\hline México ${ }^{1}$ & México & $19^{\circ} 00^{\prime} \mathrm{N}$ & 2259 & $15,5 / 16,3$ & $579 / 470$ & 150 \\
\hline México & Acatic & $20^{\circ} 55^{\prime} \mathrm{N}$ & 1680 & 18,5/- & $700 / 553$ & 150 \\
\hline Perú1 & Ica & $14^{\circ} 05^{\prime} \mathrm{S}$ & 396 & $21,1 / 20,4$ & $3 / 1$ & 150 \\
\hline
\end{tabular}

${ }^{1}$ Discontinuo

${ }^{2}$ Promedio de la estación de cultivo de la chía

Actualmente, a nivel comercial la chía se cultiva en Argentina, México, Bolivia, Guatemala, Ecuador y Australia (Figura 1.4). En el año 2008, "The Ord Valley”, en el extremo noroccidental de Australia, fue el principal productor de semillas de chía del mundo, con un área sembrada de 750 ha y una perspectiva de cultivo para 2009 de 1700 ha, lo que representa dos tercios de su producción mundial (Matt, 2008).

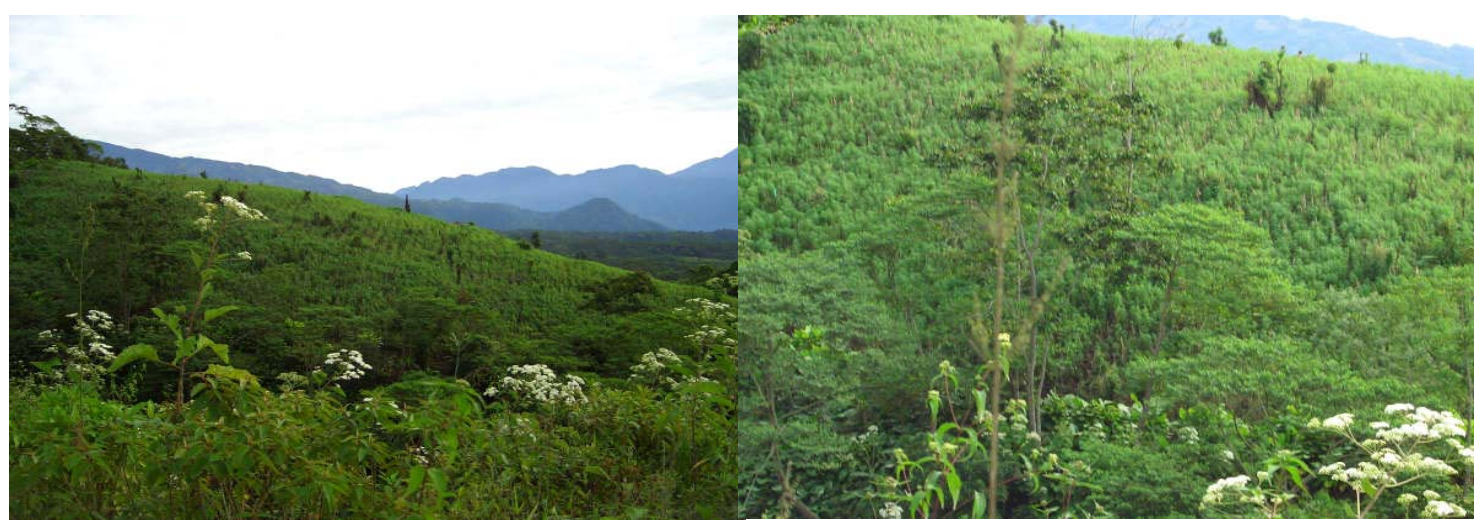

Figura 1.4. Cultivos de chía en Quetzaltenango (Guatemala) (cortesía de Víctor García, productor de Guatemala)

En países donde las condiciones climáticas no permiten la realización del cultivo a campo (Gran Bretaña), las semillas se siembran en un invernadero durante los meses de marzo y abril. La germinación usualmente tarda un lapso de dos semanas y las plántulas se trasplantan cuando tienen la altura suficiente para ser 
colocadas en macetas individuales y luego a tierra firme desde finales de la primavera hasta principios del verano (Plants for a Future, 2002).

Debido a que es una planta sensible al fotoperiodo (longitud del día), la estación de crecimiento depende de la latitud a la cual se realice el cultivo. Por ejemplo, un cultivar sembrado en La Unión (Valle del Cauca, Colombia) presenta un ciclo de cultivo de 90 días, mientras que la duración del ciclo del mismo cultivar sembrado en El Carril (Salta, Argentina) es de 150 días (Tabla 1.1). A mayores latitudes, como Choele-Choel (39 $11^{\circ} \mathrm{S}$, Argentina) y Tucson $\left(32^{\circ} 14^{\prime} \mathrm{N}\right.$, Estados Unidos) la chía no produce semillas ya que la planta muere por la ocurrencia de heladas antes del fin de la floración (Coates y Ayerza 1996, 1997, 1998). En Argentina es un cultivo estival, cuya zona de cultivo se circunscribe a las provincias del noroeste (NOA).

Los suelos areno-limosos favorecen su crecimiento aunque también puede desarrollarse en suelos arcillo-limosos con buen drenaje. Las observaciones de campo indican un buen crecimiento de este cultivo en suelos con un amplio nivel de variación de nutrientes. Sin embargo, un bajo contenido de nitrógeno puede ser un factor limitante para obtener buenos rendimientos (Ayerza y Coates, 2005). La densidad de siembra es de 6-8 kg/ha, con un espaciamiento entre surcos de 70 a 80 $\mathrm{cm}$. Es necesario que la cama de siembra esté bien preparada, con buen drenaje y nivelada a fin de evitar que las lluvias arrastren las pequeñas semillas que deben sembrarse a una profundidad de siembra menor a $1 \mathrm{~cm}$. Si bien la semilla de chía necesita suelos húmedos para germinar, una vez que se han establecido las plántulas, se comporta bien con cantidades limitadas de agua siendo capaz de crecer bajo un amplio rango de precipitaciones (Ayerza y Coates, 2005).

Los primeros 45 días del cultivo son críticos debido al lento crecimiento inicial, lo que dificulta la competencia con las malezas por la luz, los nutrientes y el agua. Debido a que no ha sido aprobado hasta el momento ningún herbicida para la chía, el control de malezas previo a la siembra es de vital importancia. Una vez que las plantas se han establecido, se puede realizar un control mecánico de las mismas hasta el cierre del canopeo, lo cual se ve favorecido por las hojas anchas y el hábito erecto de las plantas (Figura 1.5). En cuanto a lo que se refiere a la presencia de enfermedades y de insectos no se dispone de documentación, siendo necesaria la realización de mayores investigaciones al respecto, si bien no parece constituir un problema para el cultivo (Ayerza y Coates, 2005). 


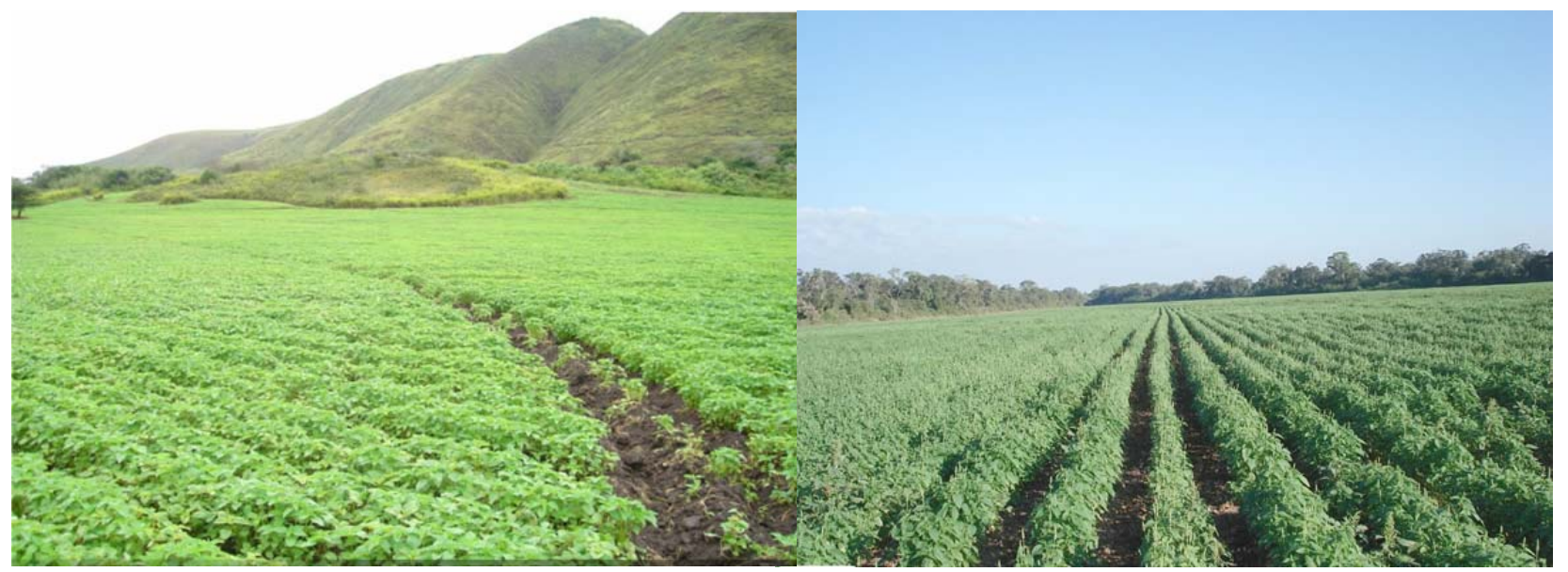

Figura 1.5. Cultivo de chía a los 45 días de sembrado (izq.); cultivo en inicio de floración (der) (CICH S.A., Argentina)

El material genético utilizado en Argentina y en Bolivia es lo suficientemente uniforme para permitir el uso de cosechadoras mecánicas. Para ello, se utiliza una cosechadora estándar con algunas modificaciones necesarias para mejorar el rendimiento (Ayerza y Coates, 2005) (Figura 1.6).

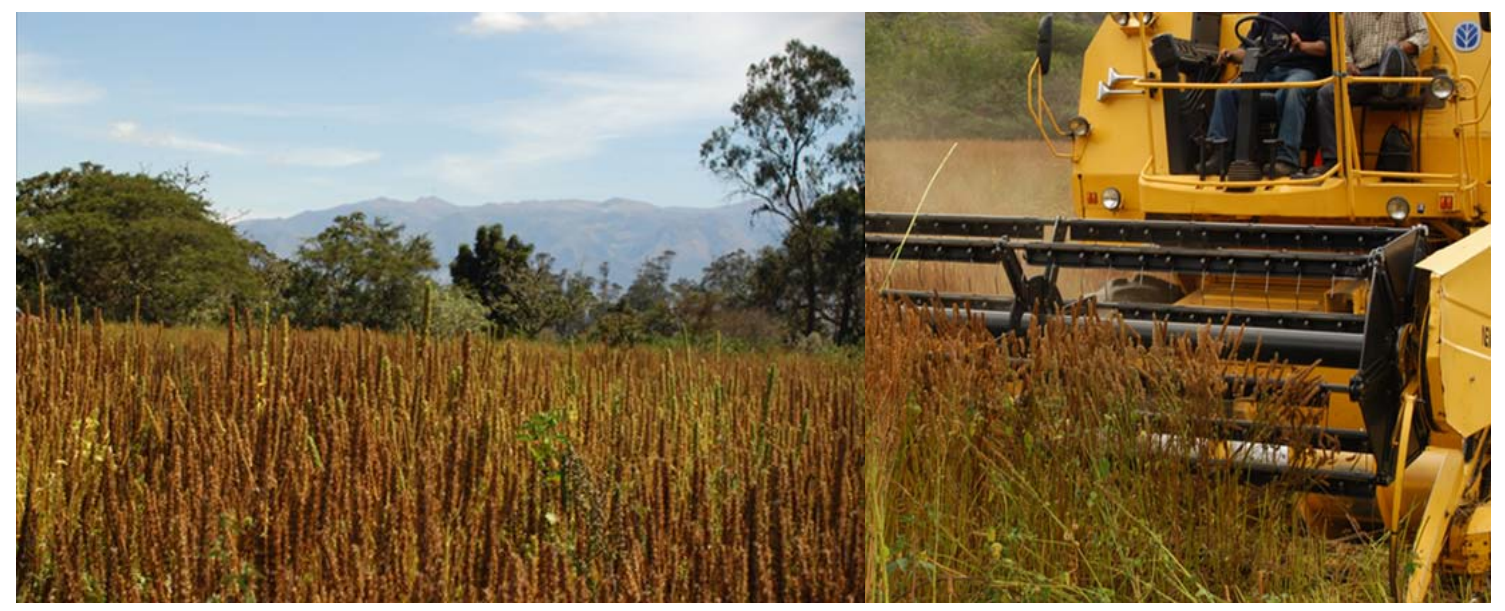

Figura 1.6. Cultivo de chía maduro (izq); cosecha de chía (der.) (CICH S.A., Argentina)

El rendimiento promedio de esta especie en plantaciones comerciales es de alrededor de $500-600 \mathrm{~kg} / \mathrm{ha}$, aunque se han logrado obtener hasta $1260 \mathrm{~kg} / \mathrm{ha}$ (Coates y Ayerza, 1998). En parcelas experimentales de la provincia de Salta, con la 
implementación de riego y fertilización nitrogenada se han registrado rendimientos de $2500 \mathrm{~kg} / \mathrm{ha}$.

La fecha de siembra ha influenciado la producción en el noroeste argentino. La época de siembra comprende desde mediados de enero hasta principios de marzo, siendo óptima la primera quincena de febrero. La temperatura, la luz, el tipo de suelo y la nutrición de las plantas afectan tanto la cantidad como la calidad del aceite contenido en la semilla de chía. Se ha encontrado una correlación negativa entre las temperaturas medias y el contenido del ácido graso a-linolénico de la semilla de chía formada a principios de abril y a fines de mayo (Ayerza, 1995). Es probable que las altas temperaturas reduzcan la formación del ácido graso a-linolénico, tal como ocurre en otras oleaginosas, según lo informado por Howell y Collins (1957).

La Tabla 1.2 muestra el contenido y la composición acídica del aceite de semilla de chía obtenido a partir de cultivos comerciales realizados en Argentina, Bolivia, Colombia, México y Perú, utilizando la misma fuente de material genético. Como puede observarse, existen diferencias debido a la influencia de los factores ambientales previamente comentados (Ayerza y Coates, 2005).

Tabla 1.2. Contenido y composición de ácidos grasos de aceite de semilla de chía cultivada en diversos países de América (Ayerza y Coates, 2005)

\begin{tabular}{lcccccc}
\hline \multirow{2}{*}{ País } & Aceite & \multicolumn{5}{c}{ Ácido graso (\%) } \\
& (g/100 g semilla) & Palmítico & Esteárico & Oleico & Linoleico & a-linolénico \\
\hline Argentina & 34,0 & 7,0 & 3,0 & 6,7 & 19,5 & 63,1 \\
Bolivia & 32,7 & 7,4 & 2,7 & 7,1 & 18,7 & 63,6 \\
Colombia & 29,9 & 7,5 & 3,5 & 7,6 & 19,2 & 57,9 \\
México & 31,0 & 6,7 & 3,3 & 7,5 & 19,6 & 61,6 \\
Perú & 32,4 & 7,2 & 3,0 & 6,9 & 18,4 & 64,2 \\
\hline
\end{tabular}

\subsection{Composición química y aspectos nutricionales de la semilla de chía}

La Tabla 1.3 muestra la composición de las semillas de chía y la correspondiente a los cinco cereales de mayor importancia a nivel mundial (arroz, cebada, avena, trigo, maíz). Puede verse que el contenido de proteínas, lípidos, fibra y energía de la semilla de chía es mayor que los presentes en los demás cultivos. Asimismo, si bien la chía es conocida principalmente como una importante fuente de 
ácidos grasos $\omega-3$, también contiene otros compuestos de importancia a nivel nutricional.

Tabla 1.3. Energía y composición centesimal correspondiente a diversos granos

\begin{tabular}{lcccccc}
\hline \multirow{2}{*}{ Grano } & $\begin{array}{c}\text { Energía } \\
\text { kcal/100g }\end{array}$ & Proteínas & Lípidos & Carbohidratos & Fibra & Cenizas \\
\cline { 3 - 7 } & 358 & 6,5 & 0,5 & 79,1 & 2,8 & 0,5 \\
\hline Arroz $^{1}$ & 354 & 12,5 & 2,3 & 73,5 & 17,3 & 2,3 \\
Cebada $^{1}$ & 389 & 16,9 & 6,9 & 66,3 & 10,6 & 1,7 \\
Avena $^{1}$ & 339 & 13,7 & 2,5 & 71,1 & 12,2 & 1,8 \\
Trigo $^{1}$ & 365 & 9,4 & 4,7 & 74,3 & 3,3 & 1,2 \\
Maíz $^{1}$ & 550 & $19-23$ & $30-35$ & $9-41$ & $18-30$ & $4-6$ \\
Chía $^{2,3}$ & & &
\end{tabular}

${ }^{1}$ United States Department of Agriculture (2002); ${ }^{2}$ Ayerza y Coates (2004); ${ }^{3}$ Diario oficial de la Unión Europea (2009)

\subsubsection{Contenido de aceite y composición de ácidos grasos}

El contenido de aceite presente en la semilla de chía es de alrededor de $33 \%$, el cual presenta el mayor porcentaje de ácido $\alpha$-linolénico conocido hasta el momento (62 - 64\%) (Ayerza, 1995) así como el tenor más elevado $(82,3 \%)$ de ácidos grasos esenciales (ácidos a-linolénico y linoleico), seguido por el cártamo, el lino y el girasol con 75,72 y $67 \%$, respectivamente. Los aceites de colza y de oliva son altamente insaturados (67 y $82 \%$, respectivamente) debido al gran contenido de ácido oleico pero con un bajo tenor de ácidos grasos poliinsaturados (27 y 11\%, respectivamente).

Actualmente, se disponen en el mercado de cuatro fuentes de ácidos grasos $\omega$-3. Las dos más importantes en volumen de producción son las asociadas al pez menhaden (Brevoortia tyrannus) y la semilla de lino, mientras que la fuentes minoritarias son la semilla de chía y las algas marinas. La Tabla 1.4 muestra una caracterización comparativa del perfil de ácidos grasos de dichas fuentes.

De estas cuatro materias primas, el lino (Linnum usitatissimum L.) y la chía son los cultivos agrícolas que presentan la mayor concentración conocida de ácido a-linolénico (Ayerza, 1995; Ayerza y Coates, 1996; Oomah y Kenasehuk, 1995). Las otras dos fuentes son de origen marino y contienen DHA y EPA, ambos ácidos grasos $\omega-3$ de cadena larga. Las fuentes de origen vegetal a nivel terrestre presentan un contenido de estos compuestos mucho mayor, así como un menor tenor de ácidos grasos saturados con respecto a las fuentes marinas. 
Tabla 1.4. Caracterización comparativa de diversas fuentes de ácidos grasos ricos en $\omega$-3 (Adaptada de Ayerza y Coates, 2005)

\begin{tabular}{|c|c|c|c|c|c|c|c|c|c|c|c|}
\hline \multirow{2}{*}{ Aceite } & \multicolumn{11}{|c|}{ Ácido graso (\% del total de ácidos grasos) } \\
\hline & $14: 0$ & $16: 0$ & 16:1 & 18:0 & $18: 1^{2}$ & $18: 2^{3}$ & $18: 3^{4}$ & $20: 4^{3}$ & $20: 5^{4}$ & $22: 5^{4}$ & $22: 6^{4}$ \\
\hline Menhaden & 8,0 & 15,2 & 10,5 & 7,8 & 14,5 & 2,1 & 1,5 & 1,2 & 13,2 & 4,9 & 8,6 \\
\hline Algas & 4,2 & 14,5 & 27,6 & 0,8 & 5,4 & 2,3 & 1,7 & 4,7 & 27,7 & - & - \\
\hline Chía & - & 6,9 & - & 2,8 & 6,6 & 19,0 & 63,8 & - & - & - & - \\
\hline Lino & - & 5,5 & - & 1,4 & 19,5 & 15,0 & 57,5 & - & - & - & - \\
\hline
\end{tabular}

14:0: ácido mirístico; 16:0: ácido palmítico; 16:1: ácido palmitoleico; 18:0: ácido esteárico; 18:1: ácido oleico; 18:2: ácido linoleico; 18:3: ácido $\alpha$-linolénico; 20:4: araquidónico; 20:5: ácido eicosapentanoico (EPA); 22:5: docosapentanoico (DPA); 22:6: ácido docosahexanoico (DHA); ${ }^{1} \omega-7 ;{ }^{2} \omega-9 ;{ }^{3} \omega-6 ;{ }^{4} \omega-3$

Cabe señalar que los aceites de chía, lino y algas marinas -al ser especies vegetales- se diferencian principalmente del obtenido a partir del pez menhaden, ya que este último -al ser un recurso de origen animal- contiene cantidades apreciables de colesterol (521 mg/100g) (United States Department of Agriculture, 2002).

Los efectos benéficos del pescado han recibido mucha atención; sin embargo, los ácidos grasos EPA y DHA son fácilmente peroxidados formando hidroperóxidos, cuyos productos de degradación secundaria son dañinos para las células (Sugihara y col., 1994). El EPA y DHA se oxidan más rápidamente que los ácidos linoleico, $\alpha-$ linolénico y araquidónico, originando productos de oxidación con implicancias desde el punto de vista toxicológico (Freese y Mutanen, 1997). La evidencia científica muestra que tanto EPA como DHA pueden ejercer efectos benéficos en cuanto a reducir el riesgo de enfermedades cardiovasculares, sólo si la protección contra el estrés oxidativo es suficiente para minimizar el daño a nivel tisular (Song y col., 2000).

Por otra parte, en lo que respecta al enriquecimiento de alimentos con $\omega-3$, la chía presenta la ventaja de no transmitir el característico "olor a pescado", lo que la diferencia de las otras fuentes previamente mencionadas, con un menor contenido de sodio (Ayerza y Coates, 2005).

\subsubsection{Contenido de proteínas y composición de aminoácidos}

La chía posee un contenido de proteínas que oscila entre 19 y 23\% (ver Tabla 1.3), el cual es mayor que el asociado a los cereales tradicionales, presentando como ventaja adicional el no contener gluten, motivo por el cual ha sido aprobada por la Asociación Celíaca Argentina como apta para su uso en pacientes celíacos. 
Los aminoácidos de las proteínas de la chía se muestran en la Tabla 1.5. Como puede observarse, las proteínas de chía presentan un buen balance de aminoácidos esenciales. Entre ellos, puede destacarse el contenido de lisina, así como porcentajes de metionina y cistina mayores que los presentes en las proteínas de otras semillas oleaginosas (Ting y col., 1990).

Tabla 1.5. Contenido de aminoácidos correspondientes a hidrolizados de proteínas de semillas de chía (Ayerza y Coates, 2005)

\begin{tabular}{llll}
\hline \multicolumn{1}{c}{ Aminoácido } & $\mathbf{g / 1 6} \mathbf{~ g ~ N}$ & Aminoácido & $\mathbf{g} / \mathbf{1 6} \mathbf{~ g ~ N}$ \\
\hline Ácido aspártico & 7,64 & Isoleucina & 3,21 \\
Treonina & 3,43 & Leucina & 5,89 \\
Serina & 4,86 & Triptófano & - \\
Ácido glutámico & 12,40 & Tirosina & 2,75 \\
Glicina & 4,22 & Fenilalanina & 4,73 \\
Alanina & 4,31 & Lisina & 4,44 \\
Valina & 5,10 & Histidina & 2,57 \\
Cistina & 1,47 & Arginina & 8,90 \\
Metionina & 0,36 & Prolina & 4,40 \\
\hline Total & & & $\mathbf{8 0 , 6 4}$ \\
\hline
\end{tabular}

\subsubsection{Vitaminas y minerales}

La semilla de chía es una buena fuente de vitaminas B (Tabla 1.6). Investigaciones recientes muestran que el bajo nivel de vitamina B en la sangre está asociado a un aumento en el riesgo de sufrir una enfermedad cardiocoronaria fatal y apoplejía (American Heart Association, 1999). La comparación del contenido de vitaminas de la chía con respecto a la de otros cultivos tradicionales muestra que el nivel de niacina es mayor que el presente en maíz, soja, arroz y cártamo, mientras que su tenor de vitamina A es inferior al de maíz. Las concentraciones de tiamina y riboflavina son similares a las del arroz y el maíz, aunque menores que las de soja y de cártamo (Ayerza y Coates, 2005). 
Tabla 1.6. Contenido de vitaminas y minerales presentes en semillas de chía y en harina residual desgrasada

\begin{tabular}{|c|c|c|}
\hline \multirow{2}{*}{ Nutriente } & \multicolumn{2}{|c|}{ Semilla de chía } \\
\hline & Entera $^{1}$ & Harina desgrasada ${ }^{2}$ \\
\hline \multicolumn{3}{|c|}{ Macroelementos $(\mathrm{mg} / 100 \mathrm{~g})$} \\
\hline Calcio & 714 & 1180 \\
\hline Potasio & 700 & 1100 \\
\hline Magnesio & 390 & 500 \\
\hline Fósforo & 1067 & 1170 \\
\hline \multicolumn{3}{|c|}{ Microelementos (mg/100g) } \\
\hline Aluminio & 2 & 4,3 \\
\hline Boro & - & 1,4 \\
\hline Cobre & 0,2 & 2,6 \\
\hline Hierro & 16,4 & 20,4 \\
\hline Manganeso & 2,3 & 6,8 \\
\hline Molibdeno & 0,2 & - \\
\hline Sodio & - & 2,9 \\
\hline Zinc & 3,7 & 8,5 \\
\hline \multicolumn{3}{|c|}{ Vitaminas $(\mathrm{mg} / 100 \mathrm{~g})$} \\
\hline Niacina & 6,13 & 11,30 \\
\hline Tiamina & 0,18 & 0,79 \\
\hline Riboflavina & 0,04 & 0,46 \\
\hline Vitamina A & $44 \mathrm{IU}$ & - \\
\hline
\end{tabular}

Con respecto al contenido de minerales, las semillas de chía son una excelente fuente de calcio, fósforo, magnesio, potasio hierro, zinc y cobre (Tabla 1.6). Además, contienen entre 13-354, 2-12 y 1,6-9 veces más calcio, fósforo y potasio, respectivamente que el trigo, arroz, cebada, avena y maíz. Asimismo, en comparación con la leche, las semillas de chía presentan un contenido 6 veces mayor de calcio, el doble de fósforo y 4,6 veces más de potasio (United States Department of Agriculture (USDA), 2002; Instituto Nacional de Alimentos, 2003).

Los niveles de hierro en las semillas de chía y en la harina desgrasada son muy elevados, representado valores poco frecuentes en semillas (Bushway y col., 1981). 


\subsubsection{Fibra dietaria}

El análisis comparativo del contenido de fibra de las semillas de chía (18$30 \%$ ) respecto al de otros cereales, permite apreciar que la chía tiene 1,6; 2,3; 2,6; 8,3 y 9,8 veces más contenido de fibra dietaria que la cebada, trigo, avena, maíz y arroz, respectivamente (ver Tabla 1.3). El contenido de fibra en la harina residual (luego de la extracción de aceite) de chía representa alrededor de un 40\%, de la cual un $5 \%$ corresponde a fibra soluble, denominada mucílago. Las semillas de chía al ser sumergidas en agua, quedan envueltas por un material de aspecto gelatinoso conocido como mucílago, el cual es de interés no sólo desde el punto de vista nutricional sino de importancia como agente espesante en la industria alimentaria. Dicho mucílago es un tetrapolisacárido lineal compuesto por D-xilosa, D- glucosa, 4o-metil-D-ácido glucurónico en proporciones de 2:1:1, cuyo peso molecular varía entre 0,8 a $2 \times 10^{6} \mathrm{Da}$, presentando una elevada viscosidad en agua con posibles y benéficos efectos metabólicos con respecto a fuentes de fibra dietaria de menor viscosidad tales como la goma guar o $\beta$ - glucano (Lin y col., 1994).

\subsubsection{Antioxidantes}

La Tabla 1.7 muestra los compuestos polifenólicos presentes en extractos hidrolizados y no hidrolizados obtenidos a partir de la semilla de chía (Taga y col, 1984).

Vázquez-Ovando y col. (2009) obtuvieron una fracción de harina de chía rica en fibra (FRF) y evaluaron su actividad antioxidante, la cual fue de 488,8 mmol equivalentes Trolox (TE)/g, valor similar al informado para el salvado de sorgo con alto contenido de taninos (Awika y col., 2003), mayor que el de algunos granos de trigo (lqbal y col., 2005) y la mitad que el informado para el vino tinto, el que presenta uno de los niveles más altos de actividad antioxidante (Saura-Calixto y Goñi, 2006). La elevada actividad antioxidante de la FRF es atribuible a la presencia de los compuestos polifenólicos citados en la Tabla 1.7, principalmente los ácidos cafeico y clorogénico (Taga y col., 1984) y la quercetina, la cual es uno de los compuestos más potentes y estables para los cuales se ha evaluado la actividad antioxidante (Huang y col., 2005). 
Tabla 1.7. Concentración de antioxidantes fenólicos presentes en extractos de semilla de chía (Taga y col., 1984)

\begin{tabular}{lc}
\hline \multicolumn{1}{c}{ Compuesto } & g/kg de semilla de chía \\
\hline $\begin{array}{l}\text { Extracto no hidrolizado } \\
\text { Flavonoles }\end{array}$ & nd \\
Ácidos cinámicos & $6,6 \times 10^{-3}$ \\
$\quad$ Ácido cafeico & $7,1 \times 10^{-3}$ \\
$\quad$ Ácido clorogénico & \\
Extracto hidrolizado & \\
Flavonoles & \\
$\quad$ Mircetina & $3,1 \times 10^{-3}$ \\
$\quad$ Quercetina & $0,2 \times 10^{-3}$ \\
Kaempferol & $1,1 \times 10^{-3}$ \\
Ácidos cinámicos & \\
Ácido cafeico & $13,5 \times 10^{-3}$ \\
\hline
\end{tabular}

\subsection{Aspectos legislativos y usos actuales}

Mediante la Resolución Conjunta 201/2008 y 567/2008 se realizó una modificación del Artículo 896 bis, a fin de incorporar la semilla de chía en el Código Alimentario Argentino (CAA). En dicho artículo, se denomina semillas de chía a las semillas sanas, limpias y bien conservadas de Salvia hispanica L., de color marrón oscuro, tamaño muy pequeño y de buena fluidez, con aroma suave, agradable y propio de la semilla. El máximo contenido de agua permitido (determinado a 100$105^{\circ} \mathrm{C}$ ) es de $7 \%$, con un mínimo de $33 \%$ de materia grasa, menos de $0,5 \%$ de semillas dañadas y libres de insectos vivos. Las semillas no deben contener más de $1 \%$ de materias extrañas, de las cuales el material mineral debe ser inferior a $0,25 \%$, mientras que los insectos muertos, fragmentos o restos de insectos $\mathrm{y} / \mathrm{u}$ otras impurezas de origen animal no deben superar el $0,1 \%$ (Código Alimentario Argentino, 2008).

En el año 2009, se incorporó al CAA el Artículo 1407 bis, en el cual se incluyó con la denominación de harina de chía al producto proveniente de la molienda de la semilla de chía (Salvia hispana L.), debiendo presentar esta última características de semillas sanas, limpias y bien conservadas, que han sido sometidas a prensado para la remoción parcial o prácticamente total del aceite que contienen. En el mismo, 
se tienen en cuenta dos tipos de harina de chía, según lo especificado en la Tabla 1.8 .

Tabla 1.8. Composición de diversos tipos de harina de chía autorizadas en el Código Alimentario Argentino (Art. 1407 bis, CAA)

\begin{tabular}{lcc}
\hline & Harina de chía & \\
\hline & Parcialmente desgrasada & Desgrasada \\
\hline Humedad $\left(100-105^{\circ} \mathrm{C}\right)(\%)$ & 9 & 5 \\
Proteína $(\mathrm{N} \times 6,25)$ mín $(\%)$ & 20 & 29 \\
Grasa (Extracto etéreo) máx $(\%)$ & 18 & 7 \\
Fibra total máx $(\%)$ & 35 & 52 \\
Cenizas $\left(500-550^{\circ} \mathrm{C}\right)$ máx & 5 & 6 \\
\hline
\end{tabular}

En el mismo año, mediante Resolución Conjunta 76/2009 y 391/2009 Modificación (06/2009), se autorizó el uso de aceite de chía exclusivamente en suplementos dietarios, en los términos del Artículo 1381 del Código Alimentario Argentino (CAA).

A nivel internacional, la semilla de chía es considerada como un suplemento dietario por la FDA (Food and Drug Administration). Por otra parte, en el año 2009, quedó autorizada en el mercado comunitario (Unión Europea) la comercialización de semillas de chía (S. hispanica) y semillas de chía trituradas, para ser utilizadas como un nuevo ingrediente alimentario en productos de panadería con un contenido máximo de semillas de chía del 5\% (Comisión de las Comunidades Europeas, 2009).

Las ventajas nutricionales de la chía descriptas en los diversos trabajos científicos previamente citados así como la comercialización de productos que la incluyen como ingrediente alimentario están en creciente avance a nivel mundial. Actualmente, es posible encontrar semillas de chía en alimentos destinados al consumo humano y animal, utilizándola en la elaboración de panes, galletitas, barras energéticas, suplementos dietarios, bebidas energéticas y aceite. Además, se han logrado obtener productos de origen animal enriquecidos con $\omega-3$, tales como huevos, pollo, carne bovina, jamón, leche y quesos, los cuales presentan atributos sensoriales aceptables por parte del consumidor. 


\section{Semillas}

\subsection{Importancia de las semillas en la nutrición humana}

La semilla es, de acuerdo a la botánica, la parte del fruto que contiene el embrión de una futura planta. Esta parte se encuentra protegida por una testa y deriva de los tegumentos del primordio seminal. Las plantas con semillas se conocen como espermatófitas. La semilla es producida mediante la maduración de un óvulo de una gimnosperma o de una angiosperma y además de contener al embrión de una futura planta, la semilla es una fuente de alimento (Vázquez Yanes y col., 1997).

Las semillas y sus funciones tienen una gran importancia para la alimentación humana. Por eso, más allá de la acción de la naturaleza, el hombre ha desarrollado un proceso productivo que incluye la siembra, la cosecha, el secado, la clasificación, la selección, el lavado, el tratamiento, el almacenaje y el embalaje de las semillas.

\subsection{Propiedades físicas de las semillas}

El conocimiento de las propiedades físicas de los materiales agrícolas resulta de importancia para la realización adecuada de las operaciones de post-cosecha, así como para el diseño y selección del equipamiento para el procesamiento de las mismas (Mohsenin, 1986).

Las propiedades físicas podemos agruparlas en aquéllas que caracterizan el tamaño y la forma (longitudes características, diámetro geométrico, área superficial específica), gravimétricas (densidad aparente y real, porosidad) y friccionales (ángulo de reposo y coeficiente de fricción).

\subsubsection{Tamaño y forma}

El tamaño y la forma de un objeto físico son inseparables y el conocimiento de las dimensiones axiales es necesario para que el mismo sea descripto satisfactoriamente. Así, la dimensión de la semilla se obtiene midiendo sus longitudes características (largo, ancho y espesor). El diámetro geométrico se define como la media geométrica de las tres longitudes características, mientras que el área superficial específica se refiere al área superficial de la semilla por unidad de volumen de granos que intercambia energía y humedad con el aire durante el secado. De este modo, el conocimiento de la morfología y distribución del tamaño de 
la semilla de chía es esencial para una adecuada selección del equipo de limpieza, nivelación y separación, así como para el proceso de secado (Mohsenin, 1986).

\subsubsection{Propiedades gravimétricas}

La densidad aparente es la relación de la masa de las semillas con respecto al volumen total que ocupa. Esta propiedad es importante para determinar el volumen del silo requerido para el almacenamiento de una cierta masa de granos.

La densidad real es la relación de masa de las semillas con el volumen "sólido" ocupado por la muestra, es decir, no tiene en cuenta el aire intergranario.

La porosidad del lecho es el espacio de aire intergranario presente en una masa de granos, expresado en relación al porcentaje del volumen total de los granos. La resistencia al flujo del aire, que depende entre otros factores de la porosidad del lecho y del tamaño del grano, es importante para la determinación del espesor de las capas de granos que pueden ser secadas, así como para la elección del tipo de ventilador.

A partir del conocimiento de estas propiedades se puede calcular el volumen de una semilla (como la relación de la masa de una semilla con la densidad real); el diámetro equivalente (teniendo en cuenta el volumen de la semilla) y la esfericidad referida a la forma de la semilla comparándola con una esfera.

Las propiedades gravimétricas son importantes para diseñar los equipamientos relacionados con la aireación, secado, almacenamiento y transporte; la densidad aparente determina la capacidad de los sistemas de almacenamiento y transporte, mientras que la densidad real es útil para equipos de separación; la porosidad de la masa de las semillas determina la resistencia al aire durante la aireación y el secado (Mohsenin, 1986).

\subsubsection{Propiedades friccionales - fluidez}

A fin de lograr el deslizamiento de los granos por una rampa y su posterior descarga en un depósito a granel, deben vencerse las fuerzas estáticas de fricción, debidas a la acción interpartículas y a la fricción partícula-pared. Cuando el producto comienza a fluir, para que el flujo continúe, tiene que sobrepasarse el coeficiente de fricción dinámica. Las propiedades friccionales de los alimentos juegan por lo tanto, un papel importante en el transporte gravitacional o neumático, en la carga y 
descarga de recipientes o espacios para el almacenamiento a granel y en las operaciones de mezcla (Mohsenin, 1986).

Las diferencias en las propiedades friccionales pueden ser útiles para la separación de los contaminantes, en las operaciones de limpieza y para la separación de las unidades dañadas o defectuosas de las que están sanas. (Brennan y col., 1998).

La fluidez se refiere a la calidad de movimiento de los granos. Esta característica resulta de gran importancia en el diseño de conductos por gravedad ya que afecta a la velocidad a la que puede llegar el grano y por lo tanto, la fuerza de choque. La fluidez depende de las fricciones entre los granos en movimiento y está directamente relacionada con el ángulo de reposo, el cual determina el ángulo máximo de una pila de granos con el plano horizontal. El ángulo de reposo se define como el ángulo de inclinación entre la base de apoyo y el talud natural del material al caer a velocidad cero.

\section{Aceites vegetales comestibles}

\subsection{La importancia de las grasas y aceites}

Las grasas y los aceites alimentarios constituyen una fuente muy importante para la alimentación de los seres humanos y su demanda se ha incrementado en función del tiempo lo cual no es un hecho menor ya que el crecimiento de la población mundial trae aparejado este tipo de necesidades y depara un desafío permanente (Autino, 2009a). La importancia de los aceites vegetales comestibles radica en su alto valor energético, el cual permite el máximo almacenamiento en la menor cantidad posible de sustancia alimenticia. Además, las grasas pueden ser vehículo de las vitaminas liposolubles y fuente de ácidos grasos esenciales, los cuales son indispensables para el organismo. Además, son excelentes portadores de sabor incidiendo en la palatabilidad de los alimentos (Bockisch, 1998).

Las grasas también proporcionan una consistencia suave y cremosa, la cual se traduce en una agradable sensación bucal. El mejoramiento del sabor es el motivo principal por el cual las grasas y los aceites han sido apreciados durante largo tiempo. Sin embargo, sólo desde el comienzo del siglo $\mathrm{XX}$ ha sido posible proveer a la población de cantidades de grasas suficientes a precios razonables.

La importancia de las grasas y aceites en la economía global puede observarse claramente al considerar la cantidad de semillas y frutos oleaginosos 
producidos a nivel mundial. En 2009 la producción de granos fue de 395,2 millones de $t$, ocupando la soja el primer lugar (Figura 1.7). Con respecto al consumo de aceites vegetales, el mismo fue de 129,5 millones de $t$, siendo los aceites de palma y de soja los más relevantes en este sentido (Figura 1.8).

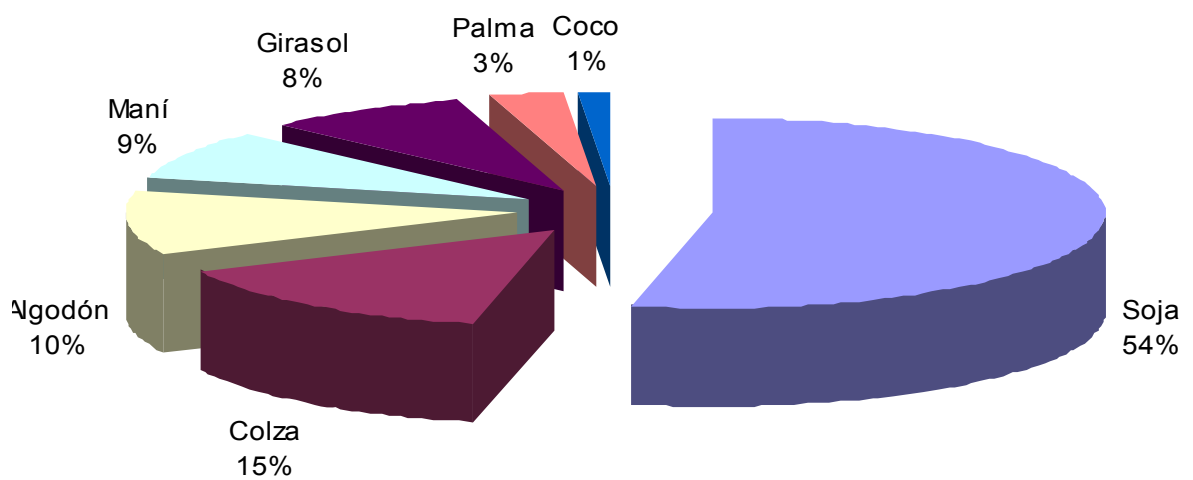

Figura 1.7. Producción mundial de semillas oleaginosas 2009 (Fuente: USDA, 2010)

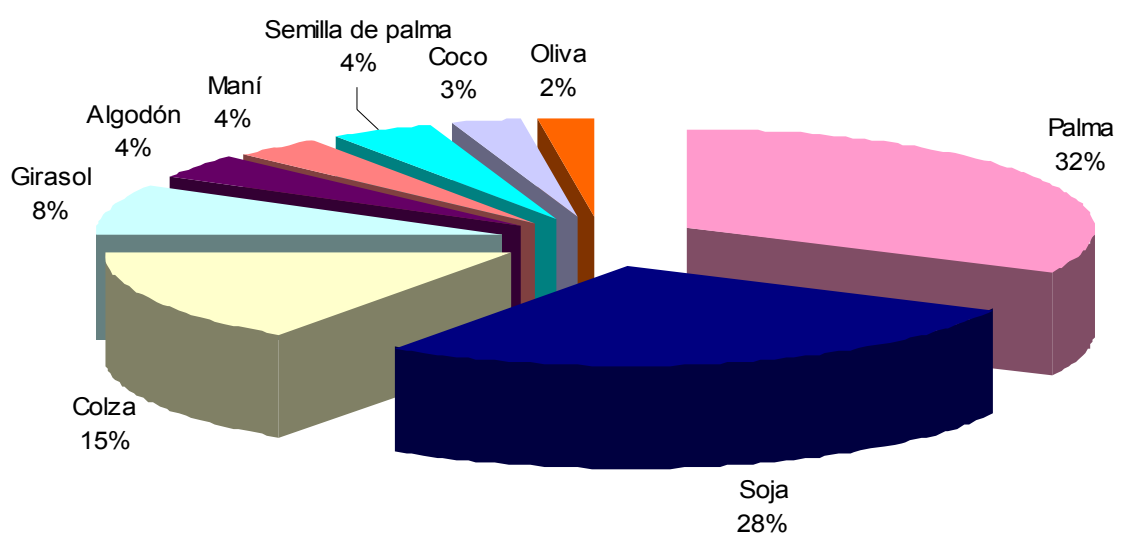

Figura 1.8. Consumo de aceites vegetales 2009 (Fuente: USDA, 2010)

\subsection{Composición y estructura de las grasas y aceites y sus derivados}

A fin de comprender las reacciones que involucran a las grasas y aceites y las tecnologías aplicadas, así como para poder influir sobre sus características y comportamiento durante el procesamiento, es importante conocer las propiedades de los mismos. Los aceites y grasas más comunes están compuestos por un número pequeño de unidades constitutivas principales, motivo por el cual la mayoría de las diferentes características puede atribuirse a la presencia de componentes menores y 
a la inmensa cantidad de posibles combinaciones de estas unidades de construcción (Bockisch, 1998).

Las grasas son ésteres de ácidos grasos con el glicerol. Debido a la estructura simétrica de la molécula de glicerol, existen dos posiciones idénticas exteriores (1-, 3-) y una posición central (2-), en las cuales se esterifican los ácidos grasos. El tipo de ácido graso, así como su distribución en estas posiciones, determina las características del triacilglicerol. Así, no sólo es de gran importancia la composición acídica sino también la estructura de los triacilgliceroles la cual da origen a la respectiva composición triacilglicerídica (Bockisch, 1998).

Es interesante conocer el aporte de los diferentes ácidos grasos en la producción mundial de los aceites y grasas comestibles (Tabla 1.9). El cálculo de Boekenoogen (1941) registra más de 50 años de antigüedad. Actualmente, la distribución ha sufrido modificaciones, principalmente como resultado de un desplazamiento de las principales áreas de cultivo desde las regiones tropicales hacia aquéllas con climas moderados y también debido a la incorporación de nuevos cultivos.

La Tabla 1.9 muestra la distribución de 1941 - 1990 calculada a partir de la composición acídica media por especies. Como puede observarse, en dicho periodo la composición acídica de las principales oleaginosas ha presentado una escasa variación a través del tiempo. Sin embargo, puede destacarse que en las nuevas variedades de colza, el ácido erúcico ha sido casi completamente reemplazado por el ácido oleico y que existe una tendencia hacia oleaginosas con un alto contenido de ácidos grasos esenciales tales como el ácido linoleico y a-linolénico; el aceite de coco ha disminuido drásticamente en relación a los otros aceites, resultando en una paralela disminución del ácido láurico. En los últimos años, los avances en el conocimiento de la genética vegetal así como el desarrollo de la ingeniería genética han ampliado la posibilidad de modificar la composición de ácidos grasos de los aceites de manera más rápida y precisa que las técnicas de mejoramiento tradicionales. En general, por una parte, se ha tendido a obtener aceites más estables, con mayor contenido de ácidos grasos monoinsaturados y menor proporción de ácidos grasos poliinsaturados, mientras que otros proyectos tienen como objetivo la obtención de cultivos oleaginosos con mayor contenido de ácidos grasos de la serie de los $\omega-6$ y $\omega-3$ (Bockisch, 1998). 
Tabla 1.9. Distribución de los ácidos grasos presentes en las principales grasas y aceites vegetales durante el periodo 1941-1990

\begin{tabular}{llllllll}
\hline \multirow{2}{*}{ Ácido graso } & \multicolumn{7}{c}{ Aporte (\%) } \\
\cline { 3 - 8 } \multicolumn{1}{c}{} & $\mathbf{1 9 4 1}$ & $\mathbf{1 9 5 0}$ & $\mathbf{1 9 6 0}$ & $\mathbf{1 9 7 0}$ & $\mathbf{1 9 8 0}$ & $\mathbf{1 9 9 0}$ \\
\hline C 12:0 & Láurico & 7 & 8 & 7 & 4 & 4 & 3 \\
C 14:0 & Mirístico & 3 & 3 & 2 & 2 & 2 & 1 \\
C 16:0 & Palmítico & 11 & 14 & 14 & 13 & 14 & 16 \\
C 18:0 & Esteárico & 3 & 3 & 3 & 3 & 4 & 4 \\
C 18:1 & Oleico & 34 & 30 & 29 & 30 & 31 & 31 \\
C 18:2 & Linoleico & 29 & 24 & 32 & 36 & 38 & 37 \\
C 18:3 & Linolénico & 6 & 6 & 5 & 6 & 5 & 5 \\
C 22:1 & Erúcico & 3 & 8 & 5 & 2 & 0 & 0 \\
otros & & 4 & 4 & 3 & 4 & 2 & 3 \\
\hline
\end{tabular}

Fuente: Boekenoogen (1941) y Bockisch (1998)

Las composiciones de ácidos grasos de los aceites individuales se presentan en la Tabla 1.10. Así, el espectro de ácidos grasos de los principales aceites vegetales está constituido por alrededor de 10-12 compuestos, los cuales representan más del $98 \%$ de todos los ácidos grasos presentes en los alimentos. Estadísticamente, estos 10 tipos de ácidos grasos permiten la formación de más de 650 triacilgliceroles diferentes si bien no es posible encontrar en la naturaleza todas las combinaciones posibles.

Tabla 1. 10. Composición acídica de los principales aceites vegetales

\begin{tabular}{lccccc}
\hline \multirow{2}{*}{ Aceite vegetal } & \multicolumn{5}{c}{ Cantidades relativas de ácidos grasos (\%) } \\
& Saturados & Oleico & Linoleico & $\boldsymbol{\alpha}$-linolénico & Otros \\
\hline Girasol & 12,3 & 18,6 & 68,2 & 0,5 & 0,4 \\
Girasol alto oleico & 8 & 87 & 5 & 0 & 0 \\
Oliva & 17,4 & 71,1 & 10 & 0,6 & 0,9 \\
Soja & 15,2 & 23,4 & 53,2 & 7,8 & 0,4 \\
Maíz & 14,5 & 27,5 & 57 & 0,9 & 0,1 \\
Canola ${ }^{2}$ & 6 & 64,1 & 18,7 & 9,2 & 2 \\
Lino & 9,4 & 19,9 & 15,9 & 52,7 & 2 \\
\hline
\end{tabular}

Las diferentes características físicas y químicas de las grasas y aceites sólo pueden ser atribuidas parcialmente a las características propias de los ácidos grasos. Uno de los principales parámetros que influencian dichas características es el grado de insaturación de los ácidos grasos y la distribución de los 10-12 
principales ácidos grasos en las tres diferentes posiciones de la molécula del glicerol. Por tal motivo, distintas investigaciones orientan sus esfuerzos para lograr la separación de ciertos triacilgliceroles o bien cambiar su distribución en la molécula de glicerol (Bockisch, 1998).

\subsection{1. Ácidos grasos}

Actualmente, si bien se conocen más de 200 ácidos grasos, son pocos los que participan con un porcentaje $>3 \%$ en la conformación de los triacilgliceroles de los aceites y grasas alimenticias. El resto, generalmente se presentan a nivel de trazas o en mayores cantidades en ciertas especies.

Todos los ácidos grasos que predominan en las grasas y aceites alimenticios pertenecen a las familias de los ácidos grasos derivados de los alcanos y alquenos. Su estructura y nomenclatura siguen las reglas comunes de la química. Sin embargo, la terminología de los ácidos grasos es complicada debido a la existencia de varios sistemas diferentes de nomenclatura (Bockisch, 1998).

\subsubsection{1 Ácidos grasos saturados no ramificados}

Los ácidos grasos saturados hasta $\mathrm{C}_{8}$ son líquidos a temperatura ambiente y se encuentran presentes principalmente en la grasa de la leche. Los ácidos cáprico, mirístico y láurico son característicos del aceite de coco y la semilla de palma, mientras que los ácidos palmítico y esteárico son los ácidos grasos saturados más comunes.

\subsubsection{2 Ácidos grasos insaturados no ramificados}

Estos ácidos grasos son muy especiales debido a que algunos de ellos son esenciales para los mamíferos y en especial para el hombre. Esto significa que el organismo no puede sintetizarlos y por lo tanto depende de su incorporación a través de la dieta.

Con respecto a los ácidos grasos monoinsaturados, la cadena más corta que ha sido detectada hasta el momento en las grasas naturales es la del ácido caproleico $\left(\mathrm{C}_{10: 1}\right)$, del cual se han encontrado trazas en la grasa de la leche. El único ácido graso monoinsaturado presente en cantidades significativas es el ácido oleico, mientras que los demás existen en cantidades promedio mucho menores. Sin embargo, esto no significa que su contribución dentro del espectro de los ácidos 
grasos de fuentes específicas sea baja. Las crucíferas, por ejemplo contienen altas cantidades de ácido erúcico (las variedades antiguas de colza contenían hasta $70 \%)$. Generalmente, los ácidos monoenoicos se encuentran distribuidos tal como se detalla a continuación: $\mathrm{C}_{10: 1}-\mathrm{C}_{18: 1}$, en la grasa de la leche; $<\mathrm{C}_{30: 1}$, en aceites de semillas; $\mathrm{C}_{16: 1}-\mathrm{C}_{24: 1}$, en aceites marinos.

Los ácidos grasos poliinsaturados (PUFAs) (Figura 1.9) poseen dos o más pares de átomos de carbono con dobles enlaces. Los PUFAs de mayor importancia son los ácidos linoleico y a-linolénico, los cuales son esenciales ya que no pueden ser sintetizados en el organismo y deben por lo tanto, ser obtenidos a partir de la dieta. Los PUFAs constituyen un sustrato fácilmente oxidable, presentando una mayor susceptibilidad al deterioro oxidativo a medida que aumenta el número de dobles enlaces. Debido a la importancia de los PUFAs en el aceite de chía, en la Tabla 1.11 se presentan las principales propiedades físicas y químicas de los mismos.

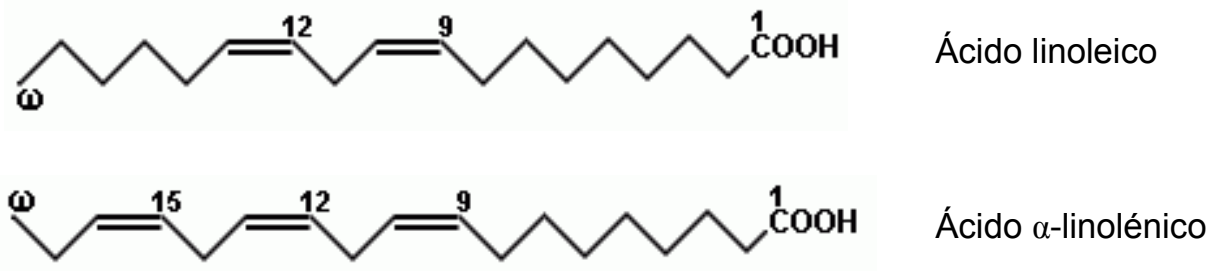

Figura 1.9. Estructura de los ácidos grasos poliinsaturados más importantes en aceites vegetales (ácidos linoleico y a-linolénico) 
Tabla 1.11. Propiedades físicas y químicas de los principales ácidos grasos poliinsaturados $\left(\mathrm{C}_{n} \mathrm{H}_{2 \mathrm{n}-2} \mathrm{O}_{2}\right)(\mathrm{Bockisch}$, 1998).

\begin{tabular}{|c|c|c|c|c|c|c|c|c|c|c|}
\hline $\mathbf{n}$ & $\begin{array}{l}\text { Nombre } \\
\text { común }\end{array}$ & Denominación química & $\begin{array}{c}\text { Desde } \\
\mathrm{CH}_{3}\end{array}$ & $\boldsymbol{\omega}$ & $\begin{array}{c}\text { Peso } \\
\text { molecular }\end{array}$ & $\begin{array}{c}\text { Punto } \\
\text { de } \\
\text { fusión } \\
\left({ }^{\circ} \mathrm{C}\right)\end{array}$ & $\begin{array}{c}\text { Densidad } \\
(\mathrm{g} / \mathrm{mL} \text { a } \\
\left.{ }^{\circ} \mathrm{C}\right)\end{array}$ & $\begin{array}{l}\text { Índice de } \\
\text { refracción } \\
\text { (unidad } /{ }^{\circ} \mathrm{C} \text { ) }\end{array}$ & $\begin{array}{c}\text { Índice } \\
\text { de } \\
\text { iodo }\end{array}$ & $\begin{array}{c}\text { Número } \\
\text { ácido }\end{array}$ \\
\hline 12 & Linoleico & 9,12-octadecadienoico (LA) & $n-6$ & 6 & 280,44 & $-5,2$ & $0,9020 / 20$ & $1,4699 / 20$ & 181 & 200 \\
\hline 18 & $\alpha$-linolénico & $9,12,15$-octadecatrienoico (ALA) & $n-3$ & 3 & 278,42 & -11 & $0,9046 / 20$ & $1,4780 / 20$ & 274 & 202 \\
\hline 18 & $\gamma$-linolénico & $6,9,12$-octadecatrienoico (GLA) & $n-6$ & 6 & 278,42 & -6 & - & - & 274 & 202 \\
\hline 18 & Elaeosteárico & $9 c, 11 t, 13 t$-octadecatrienoico & $n-5$ & 5 & 278,42 & -49 & $0,9028 / 50$ & $1,5112 / 50$ & 274 & 202 \\
\hline 20 & Araquidónico & 5,8,11,14-eicosatetraenoico (AA) & $n-6$ & 6 & 304,46 & $-49,5$ & $0,9219 / 20$ & $1,4824 / 20$ & 304 & 184 \\
\hline 20 & Timnodonoico & 5,8,11,14, 17-eicosapentaenoico (EPA) & $n-3$ & 3 & 302,45 & - & - & $1,4977 / 23$ & - & 186 \\
\hline 22 & Clupadonoico & $4,8,12,15,19$-docosapentaenoico (DPA) & $n-3$ & 3 & 330,50 & $<-78$ & $0,9290 / 20$ & $1,5014 / 20$ & 464 & 170 \\
\hline 22 & Cervónico & $4,7,10,13,16,19-$ docosahexaenoico (DHA) & $n-3$ & 3 & 328,49 & $<<-75$ & - & $1,5017 / 20$ & - & 172 \\
\hline
\end{tabular}


Los ácidos grasos poliinsaturados pueden ser mejor descriptos en términos de familias debido a que su metabolismo permite la interconversión dentro pero no entre familias de PUFAs. La esencialidad de los $\omega-6$ se conoce desde los años 1920s. Los signos de deficiencia de $\omega-6$ incluyen la disminución en el crecimiento, el incremento en la pérdida de agua epidérmica, deterioro en la cicatrización de las heridas, alteraciones en la reproducción (Mead y col., 1986; Chapkin, 1992). Si bien los primeros estudios no aportaban información clara acerca de la esencialidad de los ácidos grasos $\omega-3$, desde 1970s se han acumulado evidencias en ese sentido. Ahora bien, no todos los PUFAs son ácidos grasos esenciales. Las plantas son capaces de sintetizar "de novo" e interconvertir las familias de $\omega-3$ y $\omega-6$ via desaturasas con especificidad en las posiciones $\Delta 12$ y $\Delta 15$. Los animales tienen enzimas desaturasas $\Delta 5, \Delta 6$ y $\Delta 9$ y por lo tanto, son incapaces de sintetizar $\omega$-3 y $\omega-6$ "de novo". Sin embargo, ocurren elongaciones y desaturaciones de los ácidos grasos esenciales, primariamente a nivel hepático. La elongación y desaturación de los ácidos grasos insaturados se muestran en la Figura 1.10. El ácido graso $\omega-6$ más común de nuestra dieta es el linoleico (18:2 $\omega-6)$, conocido como el padre de dicha familia, el cual es el primero en ser desaturado a 18:3 $\omega-6$. Se estima que la velocidad de esta primera desaturación se encuentra limitada en los bebés prematuros, ancianos y bajo ciertos estados de enfermedad. Por este motivo, ha habido un gran interés por los escasos aceites que contienen 18:3 $\omega$-6, ácido $\gamma$ linolénico (GLA). Algunas fuentes ricas en este ácido graso incluyen grosella negra (Ribes nigrum L), la onagra o prímula (Oenothera biennis L.) y la borraja (Borago officinalis L.). GLA es elongado a 20:3 $\omega$-6, ácido dihomo- $\gamma$-linolénico (DHGLA), el cual es una molécula precursora de las prostaglandinas serie 1. DHGLA es posteriormente desaturado a 20:4 $\omega-6$, precursor de las prostaglandinas serie 2 . Luego pueden ocurrir la elongación y desaturación a 22:4 $\omega-6$ y 22:5 $\omega-6$, aunque la función de estos ácidos grasos aún no se conoce con exactitud.

La Figura 1.10 también muestra la elongación y desaturación del 18:3 w-3 en la cual la conversión desde 20:5 $\omega-3$ al 22:6 $\omega-3$ se realiza mediante una doble elongación, desaturación y $\beta$-oxidación.

Una de las funciones de los ácidos grasos esenciales es su conversión a prostaglandinas y leucotrienos, compuestos metabólicamente activos (Granstrom y KumLin, 1987; Slater y McDonald-Gibson, 1987). 


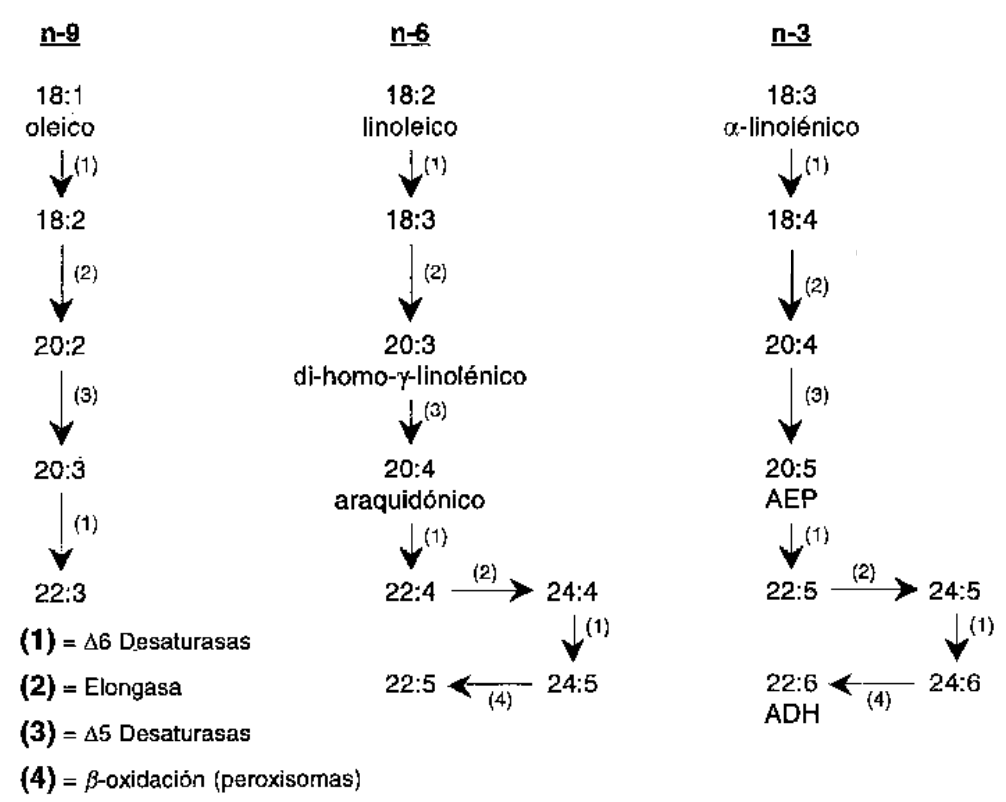

Figura 1.10. Secuencia de conversiones de ácidos grasos insaturados

\subsubsection{Otros ácidos grasos}

Además de los ácidos grasos insaturados mencionados, se conoce la presencia de ácidos grasos con triples enlaces, ácidos grasos ramificados, alicíclicos y sustituidos. Estos subgrupos son de menor importancia ya que no se encuentran presentes en la mayoría de las grasas alimenticias. Los ácidos grasos con triples enlaces son especialmente raros, mientras que los ramificados se encuentran a nivel de trazas en muchas grasas, predominantemente de origen animal. Los ácidos grasos sustituidos son poco frecuentes si bien son igualmente importantes. Los hidroxilados existen en un $53 \%$ en los cerebrósidos (Chibnall y col., 1953) y son muy importantes en la función cerebral.

\subsubsection{Acilgliceroles}

Los acilgliceroles son los constituyentes principales de los aceites y grasas de importancia comercial. La molécula de glicerol puede ser esterificada con uno, dos o tres ácidos grasos, los cuales pueden estar localizados en los diferentes carbonos del glicerol. Se prefieren los términos monoacilglicerol, diacilglicerol y triacilglicerol a los términos mono-, di- y tri-glicéridos (IUPAC, 1979).

Los ácidos grasos pueden ser esterificados sobre los grupos hidroxilos primarios o secundarios del glicerol (Figura 1.11). Si bien el glicerol por sí solo no 
tiene un centro quiral, se convierte en quiral si se esterifican diferentes ácidos grasos a los hidroxilos primarios o si uno de los hidroxilos primarios es esterificado. Así, la terminología debe diferenciar entre las dos posibles configuraciones. La convención más común para diferenciar estos estereoisómeros es la convención sn de Hirshmann (1960). En la numeración que describe los grupos hidroxilos sobre la molécula de glicerol en la proyección Fisher, las designaciones sn-1, sn-2, sn-3 son utilizadas para los grupos $\mathrm{OH}$ superior (C1), medio (C2) e inferior (C3).

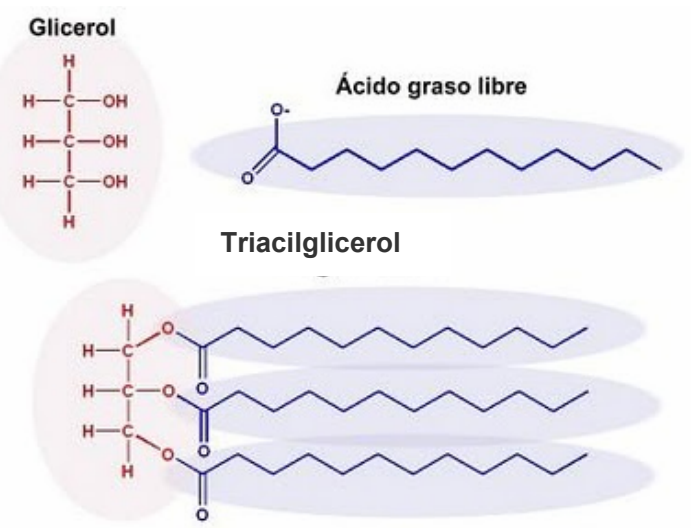

Figura 1.11. Estructura de la molécula de un glicerol, de un ácido graso libre y de un triacilglicerol

La nomenclatura estándar permite el empleo de varios nombres diferentes para cada TAG (IUPAC, 1979). Un TAG con tres ésteres de ácido esteárico puede ser llamado como gilcerol triestearato, triestearil glicerol, o tri-O-estearoil glicerol. Más comúnmente, la nomenclatura TAG emplea la designación -ina para indicar la molécula en un TAG, por ejemplo, triestearina. Así, si diferentes ácidos grasos son esterificados al TAG, por ejemplo, el TAG con sn-1 ácido palmítico, sn-2 ácido oleico y sn-3 ácido esteárico, se reemplaza -ico del nombre del ácido con -oil, y los ácidos grasos se nombran en el orden sn-1, sn-2, sn-3 (1-palmitoil-2-oleoil-3estearoil-snglicerol). Si dos de los ácidos grasos son idénticos, el nombre incorpora la designación di-, por ejemplo, 1,2-dipalmitoil-3-oleil-sn-glicerol.

Mattson (1963) ha descripto que los ácidos grasos saturados son esterificados predominantemente en las posiciones 1- ó 3-, mientras que la posición 2- es ocupada principalmente por los ácidos grasos insaturados. 


\subsubsection{Esteroles}

Los esteroles son alcoholes policíclicos derivados del esteareno (ciclopentanoperhidrofenantreno) como base de su estructura. Los esteroles se encuentran principalmente en la fracción insaponificable de las grasas y aceites. Según su origen, se pueden distinguir los zooesteroles de origen animal, fitoesteroles provenientes de las plantas y micoesteroles a partir de organismos menores como los hongos.

El colesterol es el esterol más importante cuya fuente principal se relaciona con alimentos de origen animal, especialmente en la grasa animal. Los aceites y grasas vegetales están libres de colesterol, teniendo en cuenta el acuerdo general que todas las sustancias libres de colesterol contienen menos de 50 ppm (Guo y col., 1995).

Los fitoesteroles y los fitoestanoles (formas reducidas de los fitoesteroles) son esteroles de origen vegetal cuya estructura química es muy similar a la del colesterol, encontrándose en pequeñas cantidades en los frutos, semillas, hojas y tallos de la mayoría de los vegetales conocidos (Ling y Jones, 1995). Si bien se han descripto más de 200 tipos diferentes de esteroles vegetales en diferentes especies de plantas, el $\beta$.sitosterol (C29), el campesterol (C28) y el estigmasterol (C29) son los que se encuentran en mayor proporción; en su conjunto constituyen el 95 - 98\% de los fitoesteroles identificables en extractos vegetales (Ling y Jones, 1995). Se ha propuesto que la diferencia estructural en la cadena lateral de los fitoesteroles y de los fitoestanoles con respecto al colesterol es responsable de los particulares efectos hipocolesterolémicos atribuidos a ambos esteroles vegetales y también de la baja absorción a nivel del tracto intestinal observada para estos esteroles (lkeda y col., 1988).

\subsubsection{Ceras}

Las ceras son compuestos complejos que actúan como barrera a la pérdida de agua producida por la evaporación y transpiración de los tejidos vegetales. El análisis de este parámetro se utiliza para detectar la presencia de adulteración de aceites obtenidos por prensado con aquéllos extraídos con disolventes orgánicos.

Químicamente, las ceras son ésteres formados a partir de la unión de ácidos grasos (C20-C28) y alcoholes de alto peso molecular (PM) (C27-32) (Pérez-Camino y col., 2003). Las ceras pueden tener hasta 58 átomos de carbono, lo que influye en 
sus propiedades físicas tales como un elevado peso molecular, punto de fusión superior a $70^{\circ} \mathrm{C}$ y precipitación a temperaturas de $40^{\circ} \mathrm{C}$, siendo las más frecuentes las de C40, C42, C44 y C46.

Dado que las ceras se producen mediante la esterificación entre los alcoholes alifáticos presentes en el aceite y los ácidos grasos libres, cuando se registra la hidrólisis de los triacilgliceroles aumenta el contenido de ácidos grasos libres y la velocidad de la reacción de esterificación. Varios autores han demostrado que se producen cambios en la concentración de ceras en los aceites de forma natural. Así, se ha observado un incremento en el contenido de ceras durante el almacenamiento de aceite de oliva virgen. Este incremento depende de la concentración de las especies reactivas y de las condiciones de almacenamiento (Mariani y Venturini, 1996). De esta manera, una elevada concentración de alcoholes alifáticos también puede provocar un aumento del contenido inicial de ceras en función del tiempo.

\subsubsection{Fosfoacilgliceroles (fosfolípidos)}

Los fosfolípidos poseen un rol esencial en el metabolismo de los diferentes organismos vivos. Estas macromoléculas son un componente estructural de las membranas celulares y actúan como agentes activos en diversos procesos metabólicos (activación de enzimas, surfactantes a nivel pulmonar, componentes detergente de la bilis, intervienen en la síntesis de sustancias de señalización celular) (Devlin, 2004). Los glicerofosfolípidos o fosfolípidos son anfipáticos, es decir, contienen a la vez una región polar o grupo de la cabeza, constituido por el fosfato cargado y las sustituciones del mismo y una cola no polar, constituida por las cadenas hidrocarbonadas hidrofóbicas. Los ácidos grasos esterifican al glicerol en las posiciones $s n-1$ y sn-2 y el grupo fosfato, en la posición sn-3. Por lo general, el C-1 del glicerol se encuentra esterificado por un ácido graso saturado y el C-2 por un ácido graso insaturado (Berg y col., 2002).

El 1,2-diacilglicerol 3-fosfato o ácido fosfatídico, es el compuesto que da origen a una serie de glicerofosfolípidos en los que los diferentes sustituyentes que contienen hidroxilos están esterificados con el grupo fosfato. Dichos sustituyentes pueden diferenciarse en amino alcoholes (colina, etanolamina, serina) y compuestos polihidroxilados (glicerol, inositol) (Devlin, 2004). En las lecitinas de origen vegetal, los principales compuestos unidos por el enlace fosfodiester al glicerol son colina, etanolamina e inositol. Durante la extracción del aceite, parte de los fosfolípidos se 
dispersa en el mismo y usualmente son removidos mediante el proceso de degomado obteniendo como subproducto las gomas crudas. Dichas gomas, acondicionadas adecuadamente, dan lugar a las lecitinas.

\subsubsection{Glicerolípidos}

Los glicerolípidos o glicolípidos se forman cuando un 1,2-diacil-sn-3-glicerol se une vía sn-3 a una molécula de carbohidrato, el cual generalmente es un mono o disacárido.

\subsubsection{Lipocromos}

Los carotenoides son derivados de una molécula base que consiste en una cadena C40, la cual está compuesta por 8 unidades isoprénicas. Debido a los dobles enlaces conjugados y a la dependencia de las clases de sustituyentes, son coloreados desde el amarillo oscuro al rojo. Su máxima absorción varía entre 425 y $525 \mathrm{~nm}$. Los carotenoides son sensibles al oxígeno y a la luz constituyendo los colorantes naturales de los alimentos. Así, se puede distinguir entre $\alpha-, \beta-$ y $\gamma^{-}$ caroteno (Figura 1.12) siendo la principal fuente de $\alpha$-caroteno el aceite de palma. Los carotenos funcionan como provitamina A (Bockisch, 1998).

La clorofila es otro colorante presente principalmente en aquellos aceites producidos a partir de porotos, colza, oliva y palta. Generalmente el color verde es removido mediante el proceso de refinación, excepto en el caso del aceite de oliva.

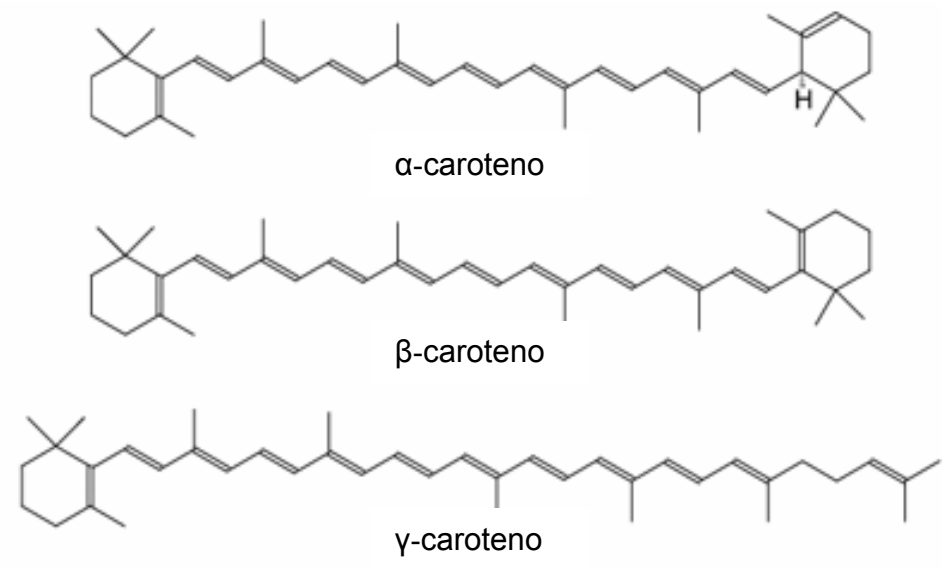

Figura 1.12. Estructura de carotenos (Bockisch, 1998) 


\subsubsection{Lipovitaminas}

Tal como se describió previamente, los carotenoides pueden ser transformados en vitamina A. La vitamina A se encuentra en las especies marinas a nivel del hígado. La deficiencia de vitamina A puede producir ceguera nocturna o permanente, crecimiento anormal de los huesos, aumento de la presión cerebroespinal y disminución del crecimiento, mientras que la hipervitaminosis $A$ puede causar dolor de cabeza y vómitos.

La vitamina D pertenece a la familia de los esteroles. Los aceites y grasas vegetales así como las grasas animales no contienen cantidades importantes de esta vitamina, por lo que muchos productos grasos como la margarina son enriquecidos con la misma (Bockisch, 1998).

La vitamina $\mathbf{E}$ incluye a los tocoferoles y tocotrienoles. Existen cuatro tocoferoles y cuatro tocotrienoles en las formas $\alpha, \beta, \delta$ y $\gamma$ para ambos isómeros y se distinguen entre sí por el número de grupos metílicos en el anillo aromático (Figura 1.13) (Ramírez y Quiles, 2005). Estos compuestos presentan una elevada inestabilidad frente a los tratamientos térmicos y en el proceso de refinado son removidos parcialmente (Szydlowska-Czerniak y col., 2008).

Los tocoferoles son compuestos poco polares y se localizan en la fase lipídica de los alimentos. Su actividad biológica depende de la proporción de los distintos isómeros. El a-tocoferol constituye un importante elemento estabilizador en los procesos de oxidación, ya que protege a los ácidos grasos constituyentes de las membranas celulares frente a los daños causados por los radicales libres (Elliot, 1999). En cuanto a las formas $\beta, y$ y $\delta$ de los tocoferoles, se ha descripto que su poder antioxidante en el aceite presenta el siguiente orden decreciente $\delta>\gamma \sim \beta>\alpha$ (Valavanidis y col., 2004). Las actividades biológicas del $\beta, y$ y $\delta$ en relación a la correspondiente al $\alpha$-tocoferol son del 30, 15 y 1\%, respectivamente.

Los tocoferoles se encuentran principalmente en las semillas oleaginosas, aunque también en hojas y otras partes verdes de las plantas. Como fuentes alimentarias pueden citarse los aceites vegetales comestibles (soja, maíz, girasol, oliva, semilla de algodón y cártamo), los productos derivados de estos aceites (margarinas y mayonesas), el germen de trigo, las nueces, frutos secos y los cereales integrales, ya que esta vitamina se concentra principalmente en el germen de la semilla. Existe una correlación positiva importante entre el contenido de vitamina $\mathrm{E}$ de los aceites vegetales y su grado de insaturación (Bockisch, 1998). 


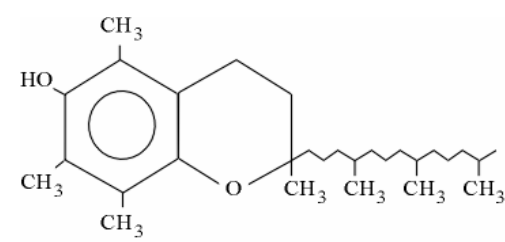

Alfa tocoferol

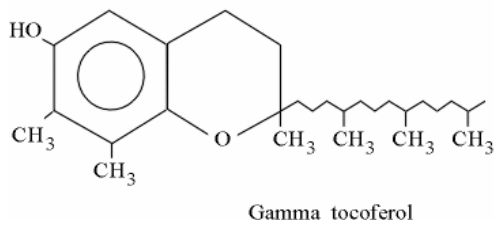

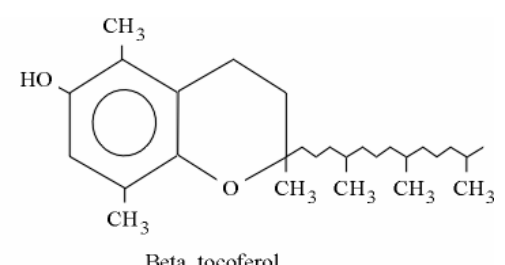

Beta tocoferol

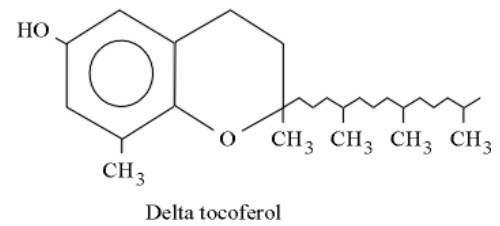

Figura 1.13. Estructura química de los tocoferoles (Bockisch, 1998)

\subsubsection{Hidrocarburos}

Los hidrocarburos alifáticos y terpenoides se encuentran distribuidos en grasas y aceites, los cuales pueden ser removidos durante el proceso de refinación (Bockisch, 1998). De la familia de los terpenoides, el escualeno se encuentra presente en el aceite de oliva en cantidades relativamente elevadas comparado con otros aceites vegetales, constituyendo una sustancia utilizada para la detección de adulteraciones en dicho aceite (Bockisch, 1998).

\subsection{Aceites especiales "gourmet"}

Un "alimento gourmet" es un alimento de muy buena calidad, perfectamente preparado e ingeniosamente presentado. Los aceites "gourmet" son así caracterizados por su aroma y sabor, principalmente resultantes del hecho que estos aceites no son refinados. El aceite gourmet más popular es el aceite de oliva. Otros aceites usados actualmente como aceites gourmet en restaurantes de distintas partes del mundo incluyen el aceite de palta y algunos obtenidos a partir de frutos secos. Sin embargo, muchos de ellos retienen su aroma y sabor debido a que son producidos en pequeña escala y no son sometidos a métodos convencionales de refinación, blanqueado y desodorización, habitualmente empleados para lograr la remoción de impurezas y prolongar la vida útil de los aceites vegetales comodities consumidos por los seres humanos (Moreau y Kamal-Eldin, 2009).

La distinción entre aceites especiales y comodities requiere una definición precisa de dichos términos. Una revisión reciente sobre los "aceites especiales 
menores" ha sugerido que aquel aceite con una producción anual inferior a 1 millón de toneladas por año podrían ser considerado un aceite "menor" (Gunstone, 2006). Los aceites gourmet son alternativamente descriptos como aceites vírgenes o prensados en frío. Los aceites vírgenes son definidos como aquéllos obtenidos sin la participación de agentes químicos que puedan alterar la naturaleza del aceite es decir, mediante prensado bajo calentamiento suave y sucesiva purificación mediante lavado con agua, asentamiento, filtración y centrifugación (FAO/WHO, 1993). Cabe señalar que la aplicación de calor excesivo puede conducir a la destrucción de vitaminas y clorofilas $\mathrm{u}$ otros pigmentos comprometidos en la designación de "virgen". Los aceites prensados en frío, aceites virgen de grado máximo, son comercializados en el mercado a precios muy superiores a los asociados a los aceites comodities y se consideran la mejor opción para la cocción y utilización como aderezo de ensaladas en restaurantes. Estos aceites son reconocidos por su elevada calidad y particularmente apreciados por su aroma, color, flujo viscoso y connotaciones benéficas para la salud. Los aceites vírgenes y prensados en frío se obtienen a partir de varias partes de las plantas que incluyen a las semillas, nueces y mesocarpios. Muchos de los aceites gourmet y "health-promoting" son producidos por prensado en frío, pero también son utilizadas otras tecnologías de extracción (Tabla 1.12) (Moreau y Kamal-Eldin, 2009). 
Tabla 1.12. Procesos de extracción de aceites especiales y comodities (Moreau y Kamal-Eldin, 2009)

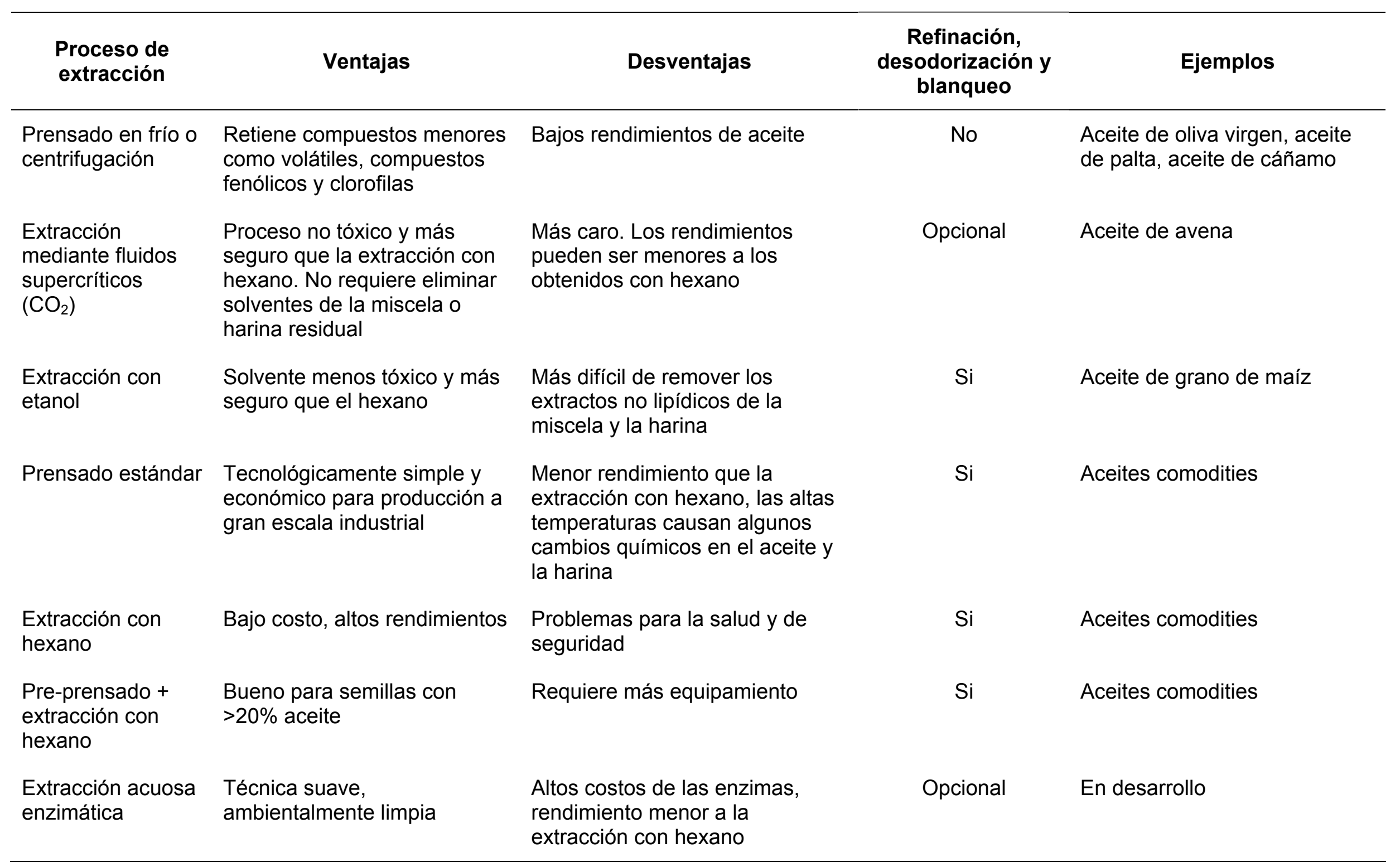


La composición de ácidos grasos de los aceites vegetales es generalmente la propiedad que recibe la mayor atención aunque tal como se vio anteriormente, existe una serie de compuestos minoritarios que contribuyen significativamente a las propiedades nutricionales de los aceites. Los aceites vegetales son buenas fuentes de ácidos grasos esenciales (ácidos linoleico y a-linolénico) y otros ácidos grasos derivados de éstos. Se sabe que se requiere un adecuado balance de los ácidos grasos esenciales como precursores de las prostaglandinas y leucotrienos, con el objeto de proveer al organismo humano un estatus óptimo pro-inflamatorio y antiinflamatorio. Luego de la revolución agrícola, el consumo de ácido linoleico aumentó y consecuentemente los productos inflamatorios dinoprostona (o prostaglandina E2) y cierto número de leucotrienos. Se aconseja mejorar el balance de consumo de las grasas ricas en $\omega-6$ mediante la ingesta relativa de otros ácidos grasos incluyendo los ácidos oleico, a-linolénico, y-linolénico, EPA y DHA (Simopoulos, 2004).

\subsection{Procesamiento de aceites vegetales mediante procesos convencionales}

Para la extracción de aceites vegetales a nivel industrial se utilizan básicamente dos métodos: prensado mecánico y extracción con solvente.

El prensado mecánico se realiza a través del uso de las denominadas prensas continuas, las cuales comprimen la masa de la semilla preparada a presión elevada, logrando de esta manera liberar el aceite contenido en la masa, el cual escurre a través del barril de la prensa. El material que sale de las prensas con un bajo contenido de aceite residual (6-7\%) se denomina "torta o expeller", mientras que el aceite separado, el cual arrastra impurezas, deberá ser clarificado a través del uso de decantadoras y separadoras centrífugas antes de ser derivado a los tanques de almacenamiento (Autino, 2009b).

Por su parte, la extracción por solvente se basa en la separación del aceite de la masa previamente preparada y acondicionada, utilizando un solvente orgánico (generalmente hexano) el cual se hace pasar a través del material en proceso en cantidad y temperatura adecuadas para asegurar una correcta extracción del aceite. A fin de que el proceso de extracción se lleve a cabo de manera correcta, el material a extraer debe ser convenientemente preparado, mientras que el disolvente debe ser puro, sin contaminantes y calentado hasta la temperatura adecuada de modo tal que el proceso extractivo se lleve a cabo con la mayor eficiencia posible (Autino, 2009b). Todas las semillas oleaginosas tienen que ser preparadas para la extracción. Los 
pasos individuales requeridos dependen de la clase de semilla y de la tecnología elegida. La preparación consiste en una serie de tratamientos mecánicos y físicos, aplicados a las semillas con el objetivo de optimizar la extracción, ya sea a través del prensado mecánico o utilizando en forma directa la extracción por solvente.

En muchas semillas durante el proceso de preparación se realiza un acondicionado, cuya finalidad es la de calentar el grano para darle plasticidad o bien romper los tejidos que envuelven al glóbulo graso, con el propósito de optimizar el laminado o prensado de la semilla (Autino, 2009b).

Todos los pasos realizados en la preparación tienen el fin de "liberar" el aceite del tejido que lo recubre y además, acondicionar el grano para lograr una óptima extracción del mismo.

El proceso de extracción de aceite de semillas oleaginosas consta de cuatro pasos básicos:

- limpieza de la semilla y pretratamiento

- extracción de aceite (prensado o extracción con solventes)

- tratamiento de la miscela o del aceite extraído

- tratamiento de la harina de extracción

En la Figura 1.14 se muestran los pasos de las etapas del proceso de extracción de aceite de semilla mediante un diagrama de flujo (Bockisch, 1998). 


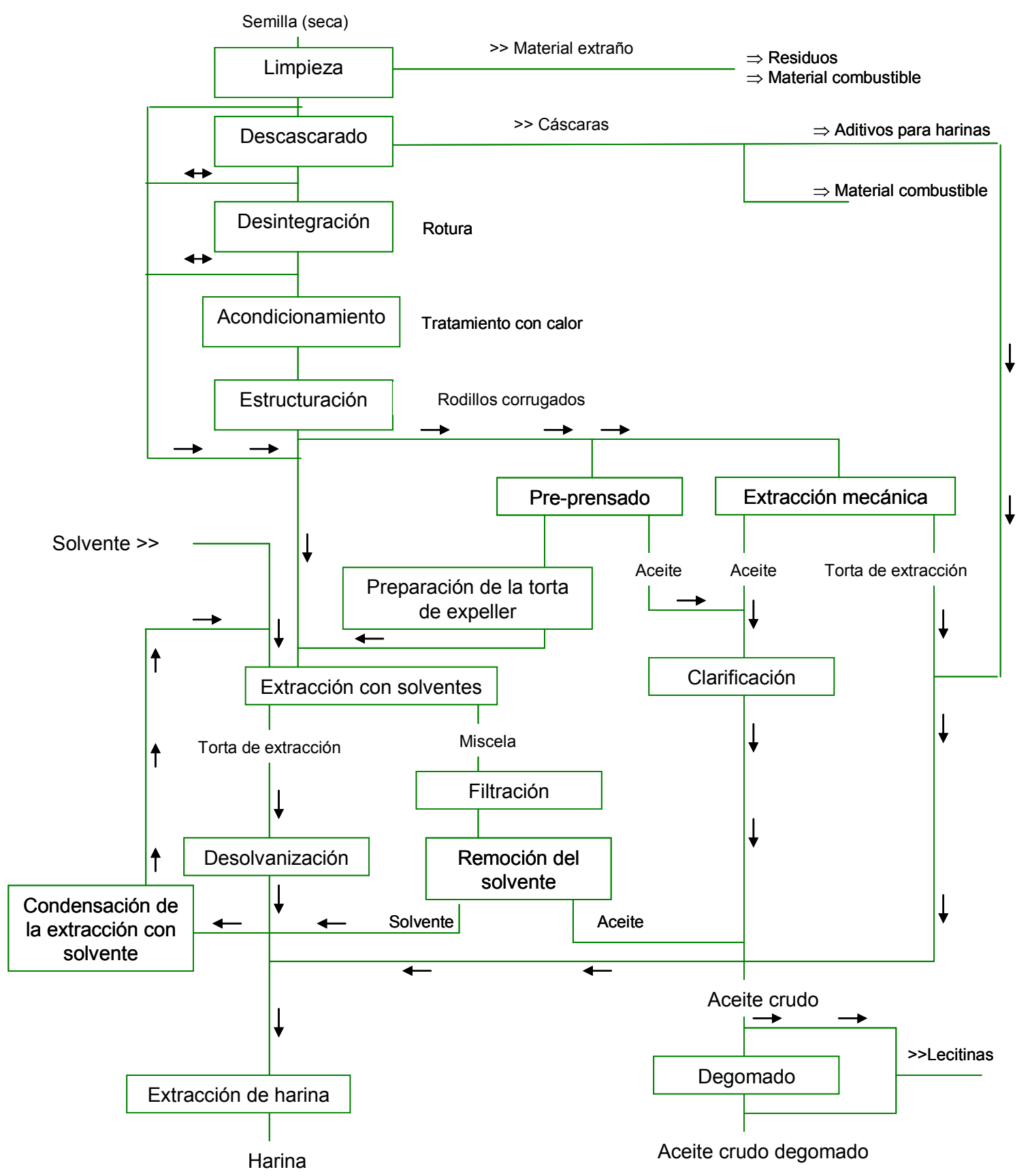

Figura 1.14. Diagrama de flujo de la extracción de aceite de semilla (Bockisch, 1998) 


\subsubsection{Etapas incluidas en el proceso de preparación de las semillas oleaginosas}

El primer paso es la limpieza, cuya función es despojar a los granos de partículas indeseables que aún permanezcan en los mismos, entre los cuales se incluyen metales, hojas, pequeñas ramas y otros materiales extraños. Los equipos utilizados en esta etapa son zarandas, cernidores rotativos, separadores magnéticos y sistemas de aspiración.

Luego, el pesaje de los granos nos permitirá conocer la cantidad que vamos a procesar.

El triturado es la reducción del tamaño a través del uso de los molinos quebradores o trituradores.

La mayoría de las oleaginosas son descascaradas. La extracción sin descascarado es posible; sin embargo, las cáscaras usualmente no contienen aceite y así reducen la capacidad de la planta de extracción. También pueden contener componentes que disminuyen la calidad del aceite. La conveniencia económica del descascarado depende de la proporción de cáscara en el total de peso de las semillas (Bockisch, 1998).

El acondicionamiento del grano partido a través del uso del calor previo al laminado tiene como propósito otorgarle condiciones de plasticidad, facilitando a consecuencia de ello, su procesamiento (Autino, 2009b).

El laminado consiste en someter las partículas a la acción del molino laminador, con la finalidad de producir la rotura fibrilar y facilitar la liberación del aceite contenido en las celdillas, durante el proceso de extracción por solventes o bien por prensado (Autino, 2009b).

La cocción es utilizada en el caso de los granos con elevado contenido de aceite, cuyo propósito puede sintetizarse en los siguientes aspectos: disminuir el tenor de humedad del grano, incrementar su plasticidad por incremento de la fluidez del aceite, producir la ruptura de las células grasas complementarias, coagular las proteínas del grano, esterilizar los granos destruyendo bacterias y otros microorganismos, desactivar enzimas termosensibles, destruir sustancias tóxicas.

En algunas semillas (soja y algodón) se realiza el expandido cuya finalidad es mejorar el manejo y la extractabilidad del material, llevándose a cabo el posterior secado y enfriado. 


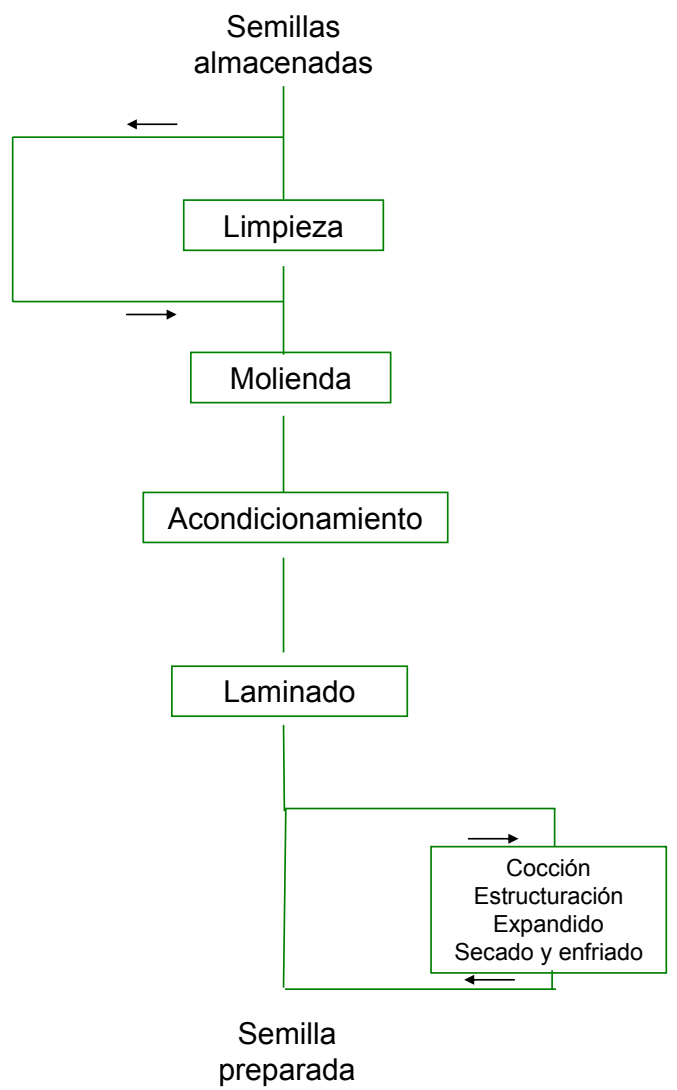

Figura 1.15. Preparación de las semillas para el proceso de extracción de aceite (Bockisch, 1998)

\subsubsection{Extracción de aceite por prensado}

En la mayoría de los molinos aceiteros la extracción se realiza con prensas de tornillo, como paso previo a la extracción con solventes o directamente como proceso en sí. Si bien hasta los años 1990s la extracción directa mediante prensado era raramente llevada a cabo debido a sus bajos rendimientos, actualmente, bajo consideraciones de protección ambiental, este proceso está cobrando nuevamente interés (Bockisch, 1998).

Las prensas abiertas son comúnmente utilizadas en la actualidad para la extracción de aceite de oliva; para las semillas oleaginosas, se usan casi exclusivamente las prensas de tornillo sinfín (Bockisch, 1998).

Una prensa consta de una jaula que posee un diámetro constante desde el comienzo al final, la cual aloja al tornillo sinfín cuyo eje aumenta en esta dirección, con el fin de mantener la presión como compensación de la reducción de volumen causada por la pérdida del aceite extraído. El diámetro de la salida de la torta, y el diseño del tornillo determina la presión dentro de la prensa. Se pueden alcanzar 
presiones de hasta 3000 bar provocando temperaturas de hasta $170^{\circ} \mathrm{C}$ dependiendo del tipo de prensa. En condiciones normales, para pre-prensado se alcanzan 30-40 bar en combinación con una temperatura de aproximadamente $95^{\circ} \mathrm{C}$; para prensado directo el objetivo es alcanzar 400 bar en combinación con $115-125^{\circ} \mathrm{C}$ y por lo tanto, no puede ser denominado "prensado en frío". El proceso de extracción por prensado es influenciado por varios parámetros tales como el contenido de humedad de la semilla, la capacidad de la prensa y la potencia aplicada. El aceite obtenido por prensado debe ser posteriormente purificado mediante el uso de separadores, filtros y decantadores (Bockisch, 1998).

Por otra parte, la torta o expeller debe ser desintegrada mediante trituradores para la posterior utilización de la harina ya sea en la extracción con solventes o para procesarla como tal.

Una alternativa al prensado convencional es el proceso de prensado en frío, en el cual la materia prima no se somete a calentamiento previo o durante la extracción, lo cual permite la retención de una mayor cantidad de compuestos fitoquímicos de interés como algunos antioxidantes naturales. La prensa utilizada comúnmente es la de tornillo helicoidal, aplicando una presión de molienda a las semillas. Otro tipo de prensa es la que aplica presión directamente sobre las semillas ubicadas en un barril con orificios a los costados lo cual permite el escurrimiento del aceite (Parker y col., 2003).

\subsubsection{Extracción de aceite por solvente}

La extracción por solvente es la etapa de obtención del aceite crudo a partir de semillas oleaginosas previamente tratadas mediante una preparación adecuada. Varias operaciones unitarias se utilizan en cada una de las secciones de la extracción siendo la de transferencia de masa, la más trascendente. La parte más importante de una extracción por solvente es el extractor ya que es allí donde se produce el desaceitado del material entrante previamente preparado. El otro equipamiento u operación inseparable -en los métodos utilizados industrialmente- de la extracción es la desolventización. En ambos casos, la operación de transferencia de masa es fundamental, aunque no es la única. 


\subsubsection{Extracción}

En la transferencia del aceite desde el sólido hasta el solvente/miscela se presentan distintos mecanismos: el material a extraer se pone en contacto con el solvente, el cual inunda los poros intra-partícula y disuelve el aceite formando la miscela, cuya composición queda establecida por el equilibrio logrado con el aceite contenido en el sólido. A través de esta miscela, el aceite difunde hacia el exterior de la partícula y posteriormente, es transportado hacia la salida del lecho por la corriente global. Cabe señalar que el lavado o arrastre del aceite desde su superficie es tan importante como la difusión del aceite dentro del sólido. El tipo de contacto es un factor de relevante importancia en la eficiencia de esta operación (Demarco, 2009).

Los extractores comerciales disponibles operan mediante dos métodos básicos de contacto para disolver el aceite en el solvente. El primero es el método de inmersión, donde el solvente es bombeado a través de la semilla preparada, de forma de asegurar que ésta quede totalmente sumergida en el mismo. El segundo es el método de percolación, en el cual el solvente se esparce desde la parte superior del lecho de semillas, a una velocidad determinada por la resistencia del lecho al flujo por gravedad del solvente. En general, siempre se encuentran los dos métodos combinados si bien alguno de ellos prevalece (Demarco, 2009).

El proceso de percolación se basa en el principio de humedecimiento permanente de la superficie por percolación del solvente. Esto significa que hay un intercambio permanente entre solvente/miscela libre y el solvente que se encuentra “absorbido" por la harina. La percolación asegura que el solvente saturado sea permanentemente reemplazado por solvente/miscela no saturado. Un prerrequisito para el éxito de este proceso es que el solvente pase libremente (percole) a través de las partículas de semilla. El proceso también necesita "aceite libre", es decir, un pretratamiento de la semilla que logre la mayor cantidad de células abiertas posible. La ventaja comparada con la inmersión es que no hay necesidad de agitar las partículas de semillas, evitando así la reducción no deseada de su tamaño. Sin embargo, la formación de partículas finas de harina no puede ser totalmente evitada (Bockisch, 1998).

A diferencia del proceso de percolación, en el proceso de inmersión la semilla se encuentra completamente sumergida en el solvente. El principio implica que la miscela altamente concentrada sea reemplazada por solvente fresco si no hay 
desplazamiento forzado del disolvente. Así, el sistema estático necesita agitación para asegurar que el solvente concentrado sea reemplazado. Este hecho conduce al incremento en la formación de partículas de semillas muy pequeñas las que luego deben ser removidas de la miscela. Generalmente, el proceso de inmersión es más apropiado que el de percolación si el aceite tiene que ser extraído a partir de matrices dificultosas, como aquéllas con alto contenido de fibra o baja concentración de aceite (Bockisch, 1998).

El proceso de extracción se lleva a cabo en una serie de etapas que generalmente responden a un flujo neto en contracorriente. Para lograr una buena eficiencia de la operación, no deben producirse mezclas entre las miscelas de las distintas etapas.

En las células, hay una zona de aceite la cual es fácil de extraer ya que está cerca de la pared celular. Esta parte de la extracción ocurrirá en muy poco tiempo de contacto entre el solvente y el material a extraer. Sin embargo, hay otra parte del aceite que tendrá que recorrer una mayor distancia para alcanzar la pared celular y poder ser arrastrada por el solvente hasta la corriente de la miscela. En cada uno de los movimientos del aceite se encontrará con diferentes "obstáculos" (carbohidratos, paredes celulares, etc.) a los que le tomará tiempo poder superar. Es por ello que el tiempo de contacto durante esta operación de extracción (transferencia de masa) es importante, independientemente del tipo de extractor utilizado (Demarco, 2009).

El tiempo de extracción influye sobre la velocidad de extracción debido a que los procesos de disolución y difusión requieren de un cierto tiempo operativo. El tiempo requerido depende de la clase de semilla, su pretratamiento y el equipo utilizado. Por otra parte, siempre existe un factor económico que limita el tiempo de extracción. En líneas generales, a mayor tiempo de extracción será mejor el desempeño de la planta en su conjunto (Figura 1.16). 


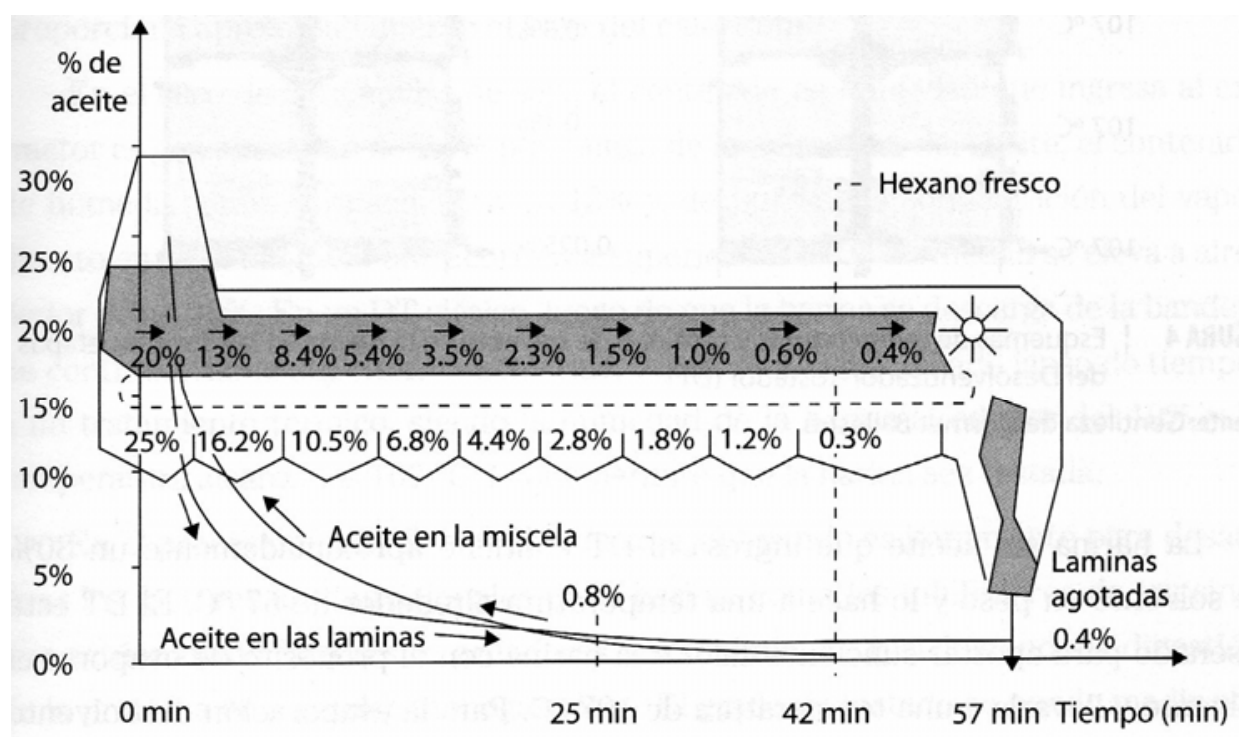

Figura 1.16. Curva de extracción típica (Demarco, 2009)

La temperatura de extracción también es importante ya que disminuye la viscosidad e incrementa la solubilidad del extracto. Menores viscosidades y mayores solubilidades resultan en mayores velocidades de extracción. La temperatura no sólo afecta este último parámetro, sino también la proporción entre los componentes lipídicos y no-lipídicos del aceite crudo (Bockisch, 1998; Demarco, 2009).

\subsubsection{Desolventizado}

El disolvente asociado a la fracción de aceite se puede eliminar a niveles residuales muy bajos utilizando una evaporación de efecto múltiple y tecnología de recuperación de capa fina con vapor bajo vacío. Por otra parte, el disolvente presente en la fracción harina es mucho más difícil de remover. Generalmente, se retira mediante un equipo desolventizador-tostador en contracorriente, normalmente denominado DT.

La miscela proveniente de la percolación tiene un contenido de solvente de $70-80 \%$, mientras que la procedente de la inmersión $87-93 \%$. Por ende, puede observarse que las cantidades de disolvente a ser destilado son elevadas. Así, con el aumento en el contenido de aceite, la presión de vapor del sistema aumenta y también el punto de ebullición, lo cual se traduce en incrementos en la cantidad de energía (Bockisch, 1998).

La remoción del aceite debería ser realizada a bajas temperaturas a fin de proteger al mismo y propender al ahorro energético. La calidad del aceite también puede verse influenciada por un excesivo tiempo de contacto con los 
intercambiadores de calor. Así, es necesario encontrar una solución de compromiso entre los parámetros tiempo de contacto y temperatura (Bockisch, 1998).

\subsection{Extracción mediante fluidos supercrítícos (EFSC)}

Desde mediados de los años 1950s se han investigado muchas aplicaciones de la utilización de fluidos supercríticos para la extracción y refinación de aceites y grasas a partir de sustancias naturales.

La producción mundial de grasas vegetales y animales se ha incrementado durante las últimas décadas, mientras que al mismo tiempo, el precio de los agentes clásicos de extracción, como el hexano. La preocupación por los residuos tóxicos en los productos derivados de los aceites también ha promovido la búsqueda de procesos alternativos, tales como la EFSC. En un número creciente de países, la mayoría de los solventes orgánicos están prohibidos para la extracción de productos alimenticios, o bien autorizados a extremadamente bajas concentraciones residuales (< 5 ppm para hexano) (US Food and Drug Administration (FDA), 2009). Además, los consumidores tienden a exigir productos obtenidos a partir de tecnologías limpias, evitando el uso de solventes orgánicos.

Por otra parte, los productos extraídos con fluidos supercríticos son de calidad superior a los obtenidos por extracción con solventes orgánicos, fundamentalmente porque no hay residuos de solvente en los mismos, pero también porque los materiales son procesados a temperaturas moderadas, de modo que sus propiedades son poco alteradas.

No obstante lo expuesto anteriormente, existen otros factores, fundamentalmente económicos, que se oponen a la rápida difusión de la tecnología supercrítica. El empleo de altas presiones requiere altos costos de inversión y de operación. En la actualidad, los procesos supercríticos compiten con los procesos de extracción tradicionales cuando se aplican en la obtención de productos de alto valor agregado (ácidos grasos poliinsaturados, aceites cítricos esenciales, etc.) o cuando se procesan grandes volúmenes de materiales, como en el caso del procesamiento del café y del té, entre otros. Sin embargo, las regulaciones cada vez más estrictas en relación con los efectos sobre la capa de ozono, la descarga de compuestos orgánicos volátiles y concentraciones residuales en el producto final para la protección de los consumidores y el ambiente, facilitarán el desarrollo de procesos 
de extracción y fraccionamiento supercrítico, haciéndolos más competitivos que en la actualidad (Espinosa, 2001).

Darr y Poliakoff (1999) definen a un fluido supercrítico como cualquier sustancia cuya temperatura y presión son más altas que sus valores críticos y su densidad aproximada o mayor que su densidad crítica. En la Figura 1.17 se representa el diagrama de fases para un componente puro. La temperatura y presión del punto crítico (C) al final de la curva de presión de vapor limitan inferiormente la zona supercrítica. Por encima del punto crítico de una sustancia pura, no puede existir equilibrio líquido-vapor. Los fluidos supercríticos exhiben propiedades intermedias entre aquéllas correspondientes a gases y líquidos. Densidades similares a las de los líquidos y propiedades de transporte que se aproximan más a aquéllas de los gases, son algunas de las características que los hacen aptos para la extracción (Espinosa, 2001).

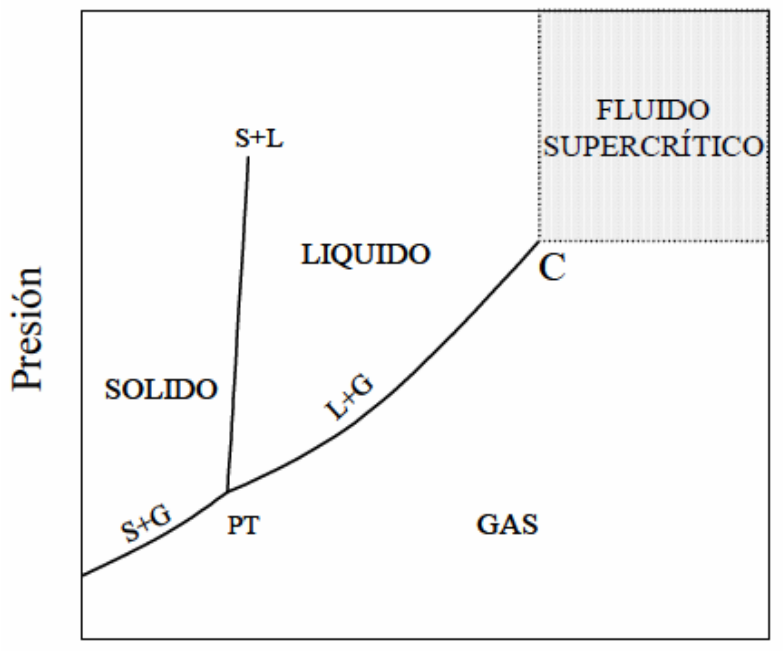

Temperatura

Figura 1.17. Diagrama de fases para un componente puro

En particular, la densidad y la viscosidad cambian drásticamente en condiciones cercanas al punto crítico. La tensión superficial despreciable sumada a valores de coeficientes de difusión de un orden de magnitud superior y viscosidades cien veces menores a las de los solventes líquidos, resultan en una gran penetración del fluido en matrices sólidas con altas velocidades de transferencia del soluto en el fluido supercrítico. Adicionalmente, en regiones donde un fluido supercrítico es altamente compresible, su densidad (y por lo tanto su poder solvente) puede ser 
ajustada sobre un amplio rango, con pequeñas variaciones de temperatura y/o presión. La habilidad de los fluidos supercríticos de modificar su poder solvente constituye una característica clave, la cual puede ser usada para controlar su comportamiento de fase, procesos de separación (extracción supercrítica, desolventización), velocidades y selectividades en reacciones químicas y morfologías en el procesado de materiales (ej. en la industria farmacéutica) (Espinosa, 2001).

Otras propiedades relacionadas con la utilización de fluidos supercríticos en procesos de extracción son:

- Baja temperatura de extracción: muchos de los fluidos comúnmente utilizados presentan temperaturas críticas inferiores a $100^{\circ} \mathrm{C}$ y otros como el $\mathrm{CO}_{2}$, el etano y etileno aún menores de $50^{\circ} \mathrm{C}$. Esta propiedad hace que los fluidos supercríticos sean adecuados para procesar materiales térmicamente inestables, como lo son la mayoría de los productos naturales, pudiendo reemplazarse operaciones por extracción supercrítica a temperaturas moderadas (Espinosa, 2001).

- Selectividad: la posibilidad de ajustar el poder solvente de un fluido supercrítico modificando levemente la temperatura y presión, hace que los fluidos supercríticos tengan el potencial para disolver y extraer en forma preferencial clases seleccionadas de compuestos. Por otro lado, los fluidos supercríticos ofrecen las ventajas de la destilación y de la extracción, puesto que separan compuestos no sólo por diferencias de presiones de vapor, sino también por interacciones específicas entre soluto y solvente (Espinosa, 2001).

- Productos finales libres de solventes: después que un fluido supercrítico ha extraído los componentes deseados de una mezcla, el mismo puede separarse totalmente del producto con sólo modificar la temperatura y/o presión de operación, lo que permite su reutilización en unidades de procesos continuos y semicontinuos. En las extracciones líquidas que utilizan solventes orgánicos, la separación del solvente del producto final se realiza a través de un tren de destilación, involucrando grandes consumos energéticos (Espinosa, 2001). 
La posibilidad de utilizar los fluidos supercríticos como sustitutos, se debe no sólo a las propiedades físicas favorables ya descriptas, sino también a la imposición de regulaciones cada vez más severas respecto al uso de solventes orgánicos ambientalmente peligrosos y más aún, en cuanto a solventes utilizados para el procesado de productos consumidos por el hombre, como el hexano.

Los tres fluidos más populares en la tecnología de fluidos supercríticos son: dióxido de carbono, agua y propano. El dióxido de carbono no es tóxico, ni inflamable, es ambientalmente benigno, ampliamente disponible con alto nivel de pureza y bajo costo, presentando una temperatura crítica de $31^{\circ} \mathrm{C}$. Es el fluido supercrítico por excelencia adoptado para el procesado de productos naturales con aplicaciones en la industria de alimentos, nutracéutica, farmacéutica y cosmética. A pesar de sus ventajas, el $\mathrm{CO}_{2}$ no es un buen solvente para compuestos de muy baja volatilidad. Sin embargo, la baja solubilidad de los compuestos poco volátiles deja de ser una desventaja cuando se trata de la refinación, fraccionamiento y purificación de aceites. En tales casos, compuestos de mayor presión de vapor que los triacilgliceroles (ácidos, ésteres, hidrocarburos livianos, etc.) pueden ser fácilmente separados del aceite.

Una de las aplicaciones de los fluidos supercríticos al procesamiento de productos naturales es la extracción, refinación y fraccionamiento de aceites comestibles, grasas y ceras. La extracción se refiere a la separación de algunos solutos presentes en materiales naturales sólidos, tales como semillas o frutos.

\subsection{Oxidación lipídica}

\subsubsection{Autooxidación lipídica}

Los lípidos insaturados pueden sufrir procesos de deterioro durante el procesamiento, almacenamiento y/o manipulación de alimentos. Estos procesos pueden dar origen a compuestos tóxicos o indeseables desde el punto de vista de la calidad organoléptica del producto y afectar tanto las propiedades funcionales de sus componentes, como su valor nutricional (Tironi, 2005).

La autooxidación de lípidos se produce a través de un mecanismo de radicales libres, el cual puede describirse mediante una serie de etapas que se detallan a continuación (Nawar, 1996; Frankel, 2005) (Figura 1.18). 


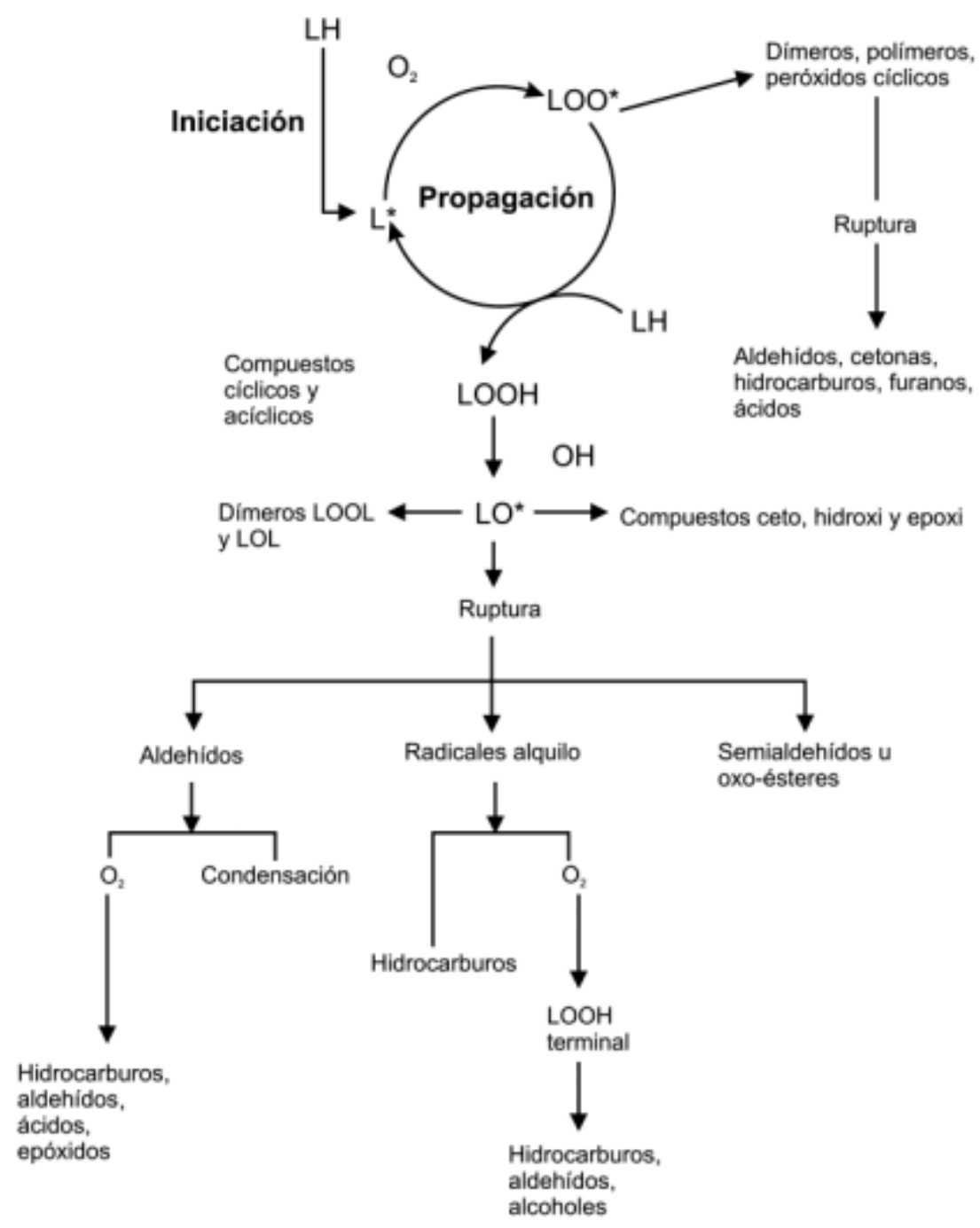

Figura 1.18. Esquema general del proceso de autooxidación lipídica (Nawar, 1996)

\section{Iniciación}

La oxidación directa de los lípidos insaturados por el oxígeno triplete (la forma más estable del oxígeno) es termodinámicamente desfavorable, dado que los dobles enlaces de los ácidos grasos se encuentran en estado singulete y tal reacción no cumpliría con la regla de la conservación del spin. En función de ello, la producción de los primeros radicales debe estar catalizada. En presencia de factores de iniciación o iniciadores (I), los lípidos insaturados (LH) pierden un radical hidrógeno $\left(\mathrm{H}^{*}\right)$ de la posición a con respecto a los dobles enlaces del ácido graso para formar un radical libre lipídico $\left(L^{*}\right)$ según la reacción: 


\section{$\mathrm{LH} \underset{\mathrm{R}}{\stackrel{\mathrm{l}}{\longrightarrow}} \mathrm{IH}+\mathrm{L}^{*}$}

Ec. 1.1

Los iniciadores pueden producir radicales por disociación térmica de hidroperóxidos presentes como impurezas o por descomposición de hidroperóxidos catalizada por metales o exposición a la luz.

Por otra parte, el oxígeno singulete puede reaccionar con los ácidos grasos insaturados con mucha mayor velocidad que el oxígeno triplete generando hidroperóxidos, los cuales pueden servir como iniciadores en las reacciones anteriores. La vía más común de generación del oxígeno singulete es la fotosensibilización de los pigmentos naturales presentes en los alimentos, tales como clorofila, hemoglobina y mioglobina (Frankel, 2005).

\section{Propagación}

El radical libre lipídico $\left(\mathrm{L}^{*}\right)$ reacciona muy rápidamente con el oxígeno molecular para formar radicales peroxilos (LOO*) (Ec. 1.2). Esta reacción es mucho más rápida que la siguiente, en la cual se transfiere un hidrógeno de otra molécula lipídica LH para dar un hidroperóxido LOOH y otro radical L* (Ec. 1.3).

$\mathrm{L}^{*}+\mathrm{O}_{2} \stackrel{\mathrm{K}_{0}}{\longrightarrow} \mathrm{LOO}^{*}$

$\mathrm{LOO}^{*}+\mathrm{LH} \stackrel{\mathrm{K}_{\mathrm{p}}}{\longrightarrow} \mathrm{LOOH}+\mathrm{L}^{*}$

La susceptibilidad de los lípidos a la autooxidación depende de la disponibilidad y de la relativa facilidad de los hidrógenos alílicos para reaccionar con los radicales peroxilos. Debido a la estabilización por resonancia de las especies $L^{*}$, pueden formarse hidroperóxidos isoméricos. Los hidroperóxidos son los productos primarios fundamentales de la oxidación lipídica. Son relativamente inestables y por ello participan en numerosas reacciones posteriores. En los primeros estadíos de la autooxidación, su velocidad de formación excede a la velocidad de descomposición; mientras que en los últimos estadíos se registra la relación inversa (Frankel, 2005). 


\section{Terminación}

En las últimas etapas de la oxidación lipídica, luego de alcanzar un máximo, la velocidad disminuye, los radicales peroxilos reaccionan unos con otros formando productos no radicalarios (Ec. 1.4).

$$
\mathrm{LOO}^{*}+\mathrm{LOO}^{*} \stackrel{\mathrm{K}_{\mathrm{i}}}{\longrightarrow} \text { Productos no radicalarios }
$$

Los hidroperóxidos pueden sufrir reacciones tales como la homólisis catalizada por metales o calor, generando radicales peroxilos y alcoxilos que pueden continuar la cadena amplificando el proceso de oxidación, o bien formar productos finales no radicalarios (Tironi, 2005).

Otras reacciones de terminación involucran la condensación de radicales peroxilos $\left(\mathrm{LOO}^{*}\right)$, alcoxilos $\left(\mathrm{LO}^{*}\right)$ o alquilos $\left(\mathrm{L}^{*}\right)$, siendo dependientes de la presión de oxígeno y de la temperatura. Algunas de estas reacciones se muestran a continuación:

$2 \mathrm{LOO}^{*} \longrightarrow \mathrm{LOOL}+\mathrm{O}_{2}$

$\mathrm{LO}^{*}+\mathrm{L}^{*} \longrightarrow \mathrm{LOL}$

$\mathrm{L}^{*} \longrightarrow \mathrm{L}-\mathrm{L}$

Ec. 1.7

\section{Descomposición de los hidroperóxidos}

Los hidroperóxidos generados por el mecanismo de radicales libres sufren una posterior descomposición mediante complejas rutas de reacción que conducen a la formación de una mezcla de sustancias monoméricas, poliméricas y volátiles de bajo peso molecular (productos secundarios) (Nawar, 1996). Cada hidroperóxido produce un conjunto de productos de degradación típicos y específicos, dependiendo de la posición del grupo peróxido en la molécula. Estos productos pueden a su vez, sufrir posteriores oxidaciones y descomposiciones, contribuyendo a un gran "pool" de radicales libres (Frankel, 2005). 


\subsubsection{Factores que afectan la velocidad de autooxidación lipídica}

Diversos factores relacionados con los ácidos grasos presentes, las características físicas y químicas del alimento así como también con la presencia de otros componentes, tienen efecto sobre el proceso de oxidación lipídica. A continuación se enumeran y describen los principales factores involucrados.

\section{Composición de los ácidos grasos}

El número, posición y geometría de los dobles enlaces afecta la velocidad de oxidación. Las menores energías de disociación para hidrógenos unidos a carbonos se encuentran entre dobles enlaces adyacentes (Nawar, 1996). Por lo tanto, éstos son los sitios más favorecidos termodinámicamente para ser atacados por los radicales peroxilos, por ello a mayor grado de insaturación la velocidad de oxidación es mayor. Por otra parte, los isómeros cis se oxidan más rápidamente que los trans, la longitud de la cadena del ácido graso no tiene efecto aparente en la velocidad o extensión de la formación de radicales y los ácidos grasos libres se oxidan a mayor velocidad que los esterificados.

\section{Concentración de oxígeno}

En condiciones de alta concentración de oxígeno (condiciones atmosféricas), la velocidad de oxidación es independiente de la misma; pero a muy bajas concentraciones, la velocidad es aproximadamente proporcional a esta variable (Davidovich y col, 1980).

\section{Temperatura}

La velocidad de las reacciones asociadas con la oxidación lipídica aumenta en función del aumento de la temperatura. La temperatura ejerce un efecto sobre la presión parcial de oxígeno así como también actúa disminuyendo la solubilidad del oxígeno (Tironi, 2005).

\section{Área superficial}

La velocidad de oxidación se incrementa proporcionalmente al área superficial expuesta de los lípidos (Tironi, 2005).

\section{Humedad}

En alimentos con muy baja actividad acuosa $\left(a_{w}<0,1\right)$ la oxidación ocurre a alta velocidad. A medida que la $a_{w}$ aumenta, hasta aproximadamente 0,3 , la velocidad disminuye alcanzando un mínimo, para incrementarse nuevamente a mayores valores de $a_{w}$ (Labuza y col, 1972). 


\section{Agentes prooxidantes}

La presencia de trazas de metales de transición, como el cobre y el hierro, producen un efecto de catálisis sobre el proceso de oxidación lipídica favoreciendo la formación de radicales libres (Frankel, 2005).

\section{Energía radiante}

Tanto la radiación visible, ultravioleta como gamma son promotoras de la oxidación lipídica (Frankel, 2005).

\section{Agentes antioxidantes}

Los antioxidantes son un extenso grupo de compuestos químicos que tienen la capacidad de inhibir o retrasar los procesos de oxidación. Estos compuestos pueden clasificarse en dos grandes grupos: sintéticos y naturales.

Los antioxidantes sintéticos han sido empleados durante muchos años por la industria de alimentos aunque en la actualidad son cuestionados por razones de índole toxicológica. Este hecho ha originado una tendencia de sustitución progresiva de los mismos por antioxidantes naturales (Frankel, 2005).

Los antioxidantes pueden actuar a distintos niveles de la secuencia de reacciones del proceso de oxidación lipídica: 1) disminuyendo la concentración de oxígeno, 2) interceptando al oxígeno singulete, 3) atrapando ("scavenging") radicales libres tales como los radicales hidroxilo $\left(\mathrm{OH}^{\circ}\right)$, 4) uniéndose a metales que actúan como agentes prooxidantes, 5) favoreciendo la descomposición de productos primarios a compuestos no radicalarios y 6) por interrupción de la cadena de iniciación o propagación transfiriendo átomos de hidrógeno a los radicales lipídicos $\left(\mathrm{L}^{\bullet}\right)$ y peroxilos (LOO`) (Shahidi, 1997; Frankel, 2005). 


\section{Hipótesis de trabajo}

I. Las propiedades físicas, la microestructura y las características fisicoquímicas de las semillas (núculas) de Salvia hispanica L. presentan diferencias tanto dentro de las mezclas comerciales (semillas oscuras y blancas) como entre las mismas (mezclas de distinta procedencia).

II. La composición acídica y triacilglicerídica así como la presencia de compuestos minoritarios le confieren al aceite de chía cualidades benéficas desde el punto de vista nutricional, siendo de interés su aplicación potencial en la industria alimentaria.

III. El proceso de obtención tiene efecto sobre el rendimiento de aceite de chía así como sobre sus características fisicoquímicas (composición acídica, triacilglicerídica, índices de calidad y genuinidad, compuestos bioactivos, estabilidad oxidativa).

IV. La temperatura y el tiempo de almacenamiento del aceite de chía así como la adición de antioxidantes influyen sobre la estabilidad oxidativa y por consiguiente sobre su conservación. 


\section{Objetivos}

En virtud de lo expuesto, los objetivos del presente trabajo de Tesis Doctoral se detallan a continuación.

\section{Objetivo general}

- Estudiar las características fisicoquímicas de las semillas y del aceite de chía (Salvia hispanica L.) obtenido mediante distintos procesos y evaluar su potencial aplicación en la industria alimentaria

\section{Objetivos específicos}

- Estudiar las propiedades físicas, la microestructura y las características fisicoquímicas de las semillas de chía

- Estudiar el efecto del proceso de obtención (prensado, extracción con hexano, extracción supercrítica mediante dióxido de carbono) sobre la calidad del aceite de chía

- Evaluar la influencia de diferentes parámetros sobre la conservación del aceite de chía (temperatura y tiempo de almacenamiento, adición de antioxidantes)

- Evaluar la aplicación potencial de las semillas y del aceite de chía en la industria alimentaria 
Capítulo 2

Caracterización de las semillas de chía 


\section{INTRODUCCIÓN}

La búsqueda de nuevas fuentes de alimentos que además de proporcionar los nutrientes necesarios para el organismo tengan propiedades funcionales, es cada vez más importante. Dentro de esta tendencia de alimentos saludables, los frutos y las semillas ocupan un lugar clave.

La semilla, además de constituir la estructura mediante la cual las plantas se propagan sexualmente, tiene una gran importancia en la alimentación humana. Los granos y semillas, utilizados directamente o transformados en proteína animal, representan la fuente alimenticia más importante para el hombre (Multon, 1982). La composición química de la chía y su valor nutricional le confieren un gran potencial para la alimentación. Estas semillas ofrecen una nueva oportunidad para mejorar la nutrición humana, siendo una fuente natural de ácidos grasos $\omega-3$, antioxidantes, proteínas, vitaminas, minerales y fibra dietética (Coates y Ayerza, 1996).

En el estudio de las propiedades físicas de los granos y semillas es esencial tener una estimación precisa de la forma, el tamaño, el volumen, el área superficial y de otras características físicas que son consideradas como parámetros ingenieriles para este tipo de productos. El conocimiento de las propiedades físicas de los materiales agrícolas resulta de gran importancia para la realización adecuada de las operaciones de post-cosecha, así como para el diseño y selección de equipamiento para el procesamiento de las semillas. Además, el estudio de las propiedades físicas es importante para minimizar el efecto de un inadecuado uso del equipamiento, lo que podría afectar la calidad de las semillas y sus subproductos y/o elevar los costos de operación (Mohsenin, 1986).

Las propiedades físicas se pueden agrupar en:

1) tamaño y forma de la semilla (longitudes características, diámetro geométrico, área superficial específica, relación de aspecto)

2) propiedades gravimétricas (densidad aparente y real, porosidad)

3) propiedades friccionales (ángulo de reposo y coeficiente de fricción)

El conocimiento de la morfología y de la distribución del tamaño de la semilla de chía es esencial para una adecuada selección del equipo de limpieza, nivelación y separación, así como para el proceso de secado. La forma y tamaño son inseparables en un objeto físico y ambos son generalmente necesarios para lograr 
su descripción. Además, es preciso determinar algunos parámetros dimensionales para definir la forma del objeto, en este caso de la semilla (Mohsenin, 1986).

Las propiedades gravimétricas son importantes para diseñar los equipos relacionados con la aireación, secado, almacenamiento y transporte (Kachru y col., 1994). La densidad aparente determina la capacidad de los sistemas de almacenamiento y transporte, mientras que la densidad real es útil para el diseño de los equipos de separación y limpieza. Además, la porosidad de la masa de las semillas está relacionada con la resistencia al aire durante la aireación y secado, la cual es importante en la determinación del espesor de las capas de granos que pueden ser secadas, así como en la elección del tipo de ventilador.

Las propiedades friccionales de los alimentos cumplen un papel importante en el transporte gravitacional o neumático, en la carga y descarga de recipientes o espacios para el almacenamiento a granel y en las operaciones de mezcla. Las diferencias en las propiedades friccionales pueden ser útiles para la separación de los contaminantes, en las operaciones de limpieza y para la separación de las unidades dañadas o defectuosas de las sanas (Brennan y col., 1998). Para que los granos puedan deslizarse por una rampa y ser descargados desde un depósito a granel, deben vencer las fuerzas estáticas de fricción, debidas a la acción de interpartículas y a la fricción partícula-pared. Cuando el producto comienza a fluir, para que el flujo continúe, tiene que sobrepasarse el coeficiente de fricción dinámica. La fluidez depende de las fricciones entre los granos en movimiento y está directamente relacionada con el ángulo de reposo, el cual determina el ángulo máximo de una pila de granos con el plano horizontal.

El estudio de la composición química de un alimento contribuye al conocimiento del aporte energético que el mismo puede brindar a la dieta e indica los tipos de procesos a los cuales puede ser sometido sin sufrir alteraciones importantes en sus componentes, características sensoriales y funcionales (Robinson, 1991).

El cultivo y la domesticación de la chía han tenido como consecuencias cambios en sus caracteres cualitativos, tales como el color de la cubierta seminal y la pigmentación de los tallos. La coloración blanca del pericarpio está determinada por un gen cualitativo, designado como scc (Cahill y Provance, 2002). Las semillas con pericarpio blanco, que originalmente provienen de mezclas de semillas provenientes del este de Jalisco (México), fueron propagadas en Argentina durante los años 90. Estas semillas son producidas solamente por plantas que tienen flores 
blancas. Asimismo, se han encontrado diferencias en el contenido de proteínas y la composición de ácidos grasos entre las semillas blancas y oscuras. Las semillas oscuras presentan un mayor contenido de proteínas, mientras que las blancas tienen un mayor tenor de ácido a-linolénico (Ayerza y Coates, 1997). La proporción de semillas blancas en la mezcla de semillas ha ido disminuyendo durante el proceso de domesticación de la especie, posiblemente debido a un proceso de selección a favor de las semillas oscuras, ya que las comunidades aztecas apreciaban los mayores rendimientos que las mismas poseían así como la mejor calidad del aceite utilizado para pinturas.

En virtud de lo expuesto, se realizó un estudio descriptivo relacionado con la estructura y la morfología de las distintas semillas de chía, así como la determinación de sus respectivas propiedades físicas y químicas. 


\section{MATERIALES Y MÉTODOS}

\section{Material vegetal}

Las semillas de chía utilizadas se obtuvieron de dos fuentes comerciales: Functional Products S.A., Argentina $(20 \mathrm{~kg})$ y Apsaxela, Guatemala $(20 \mathrm{~kg})$. Las semillas de Argentina provinieron de cultivos realizados en la provincia de Salta $\left(25^{\circ}\right.$ $S$ y $\left.65,5^{\circ} \mathrm{O}\right)$, mientras que las de Guatemala procedieron de Quetzaltenango $\left(15^{\circ} \mathrm{N}\right.$ y $91,5^{\circ}$ O). Las mismas se conservaron en envases plásticos cerrados herméticamente a $5 \pm 1^{\circ} \mathrm{C}$ hasta el momento de la realización de las experiencias.

\section{Acondicionamiento de las muestras}

A partir de cada uno de los $20 \mathrm{~kg}$ de semillas provenientes de diferente origen, se seleccionaron al azar $1 \mathrm{~kg}$ mediante un cuarteador (CPASA, Centro Proveedor Agropecuario, Buenos Aires, Argentina).

Se realizó una limpieza manual de las semillas, descartándose aquéllas peladas, con pericarpio dañado, quebradas, vanas y materias extrañas. Las mismas fueron almacenadas a $5 \pm 1^{\circ} \mathrm{C}$ hasta su posterior utilización.

\section{Determinación del contenido de humedad}

El contenido de humedad se evaluó según la técnica de la AOAC (1990). Para ello se distribuyó uniformemente $1 \mathrm{~g}$ de semillas en cápsulas de aluminio, las cuales fueron secadas en una estufa de vacío durante $4 \mathrm{~h}$ a $100^{\circ} \mathrm{C}$. El procedimiento se realizó por triplicado. El porcentaje de humedad en base seca se calculó según la ecuación:

$H^{\circ}($ b.s. $)=\frac{P h-P s}{P s} \times 100$

donde:

$P_{h}$ : peso de la muestra antes del calentamiento $(\mathrm{g})$

$P_{s:}$ peso de la muestra después del calentamiento $(\mathrm{g})$ 


\section{Descripción de la semilla}

4.1. Composición de la mezcla comercial de las semillas según el color del pericarpio

A fin de determinar el porcentaje de semillas blancas y oscuras, se seleccionaron al azar 8 grupos de $20 \mathrm{~g}$ de semillas cada uno y se realizó la separación manual de las mismas, según el color del pericarpio en blancas y oscuras. Se determinó el porcentaje en peso de cada tipo de semillas presente en la muestra, utilizando una balanza electrónica $(0,001 \mathrm{~g}$ de precisión). Ambos tipos de semillas fueron almacenadas separadamente.

\subsection{Propiedades físicas}

Las propiedades físicas fueron determinadas tanto en las semillas blancas como en las oscuras por separado, excepto el ángulo de reposo y el coeficiente estático de fricción, los cuales fueron evaluados para el conjunto de semillas (mezcla comercial).

\subsubsection{Tamaño y forma}

El tamaño de la semilla se determinó a través de la medición de sus dimensiones características: largo $(L)$, ancho $(W)$ y espesor $(T)$, a partir de 90 semillas de cada tipo de color de pericarpio, seleccionadas al azar a partir de la mezcla comercial. Para ello, se utilizó un micrómetro de exteriores, con calibre digital (0,01 mm de precisión), según se indica en la Figura 2.1 . 
a)

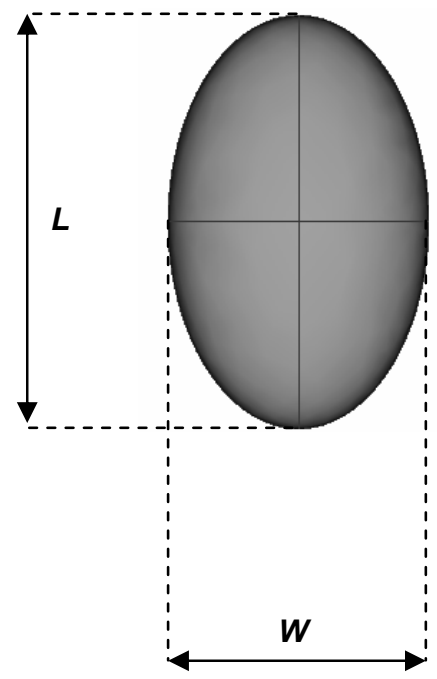

b)

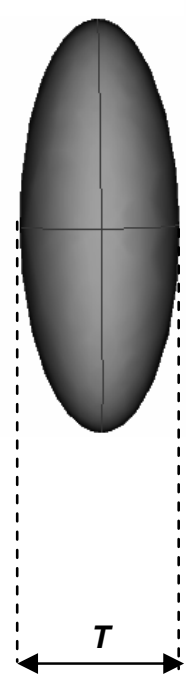

c)

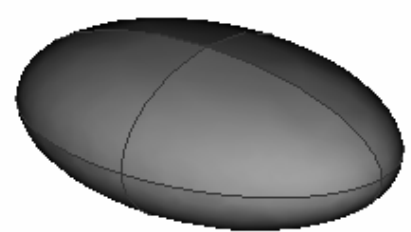

Figura 2.1. Dimensiones características (a) vista frontal, (b) vista del perfil y (c) geometría tridimensional de la semilla de chía

Debido a que el tamaño de la semilla se considera un parámetro importante en el procesamiento (Aviara y Haque, 2000), las mismas se clasificaron en 3 categorías según el largo: grandes $(L>2,25 \mathrm{~mm})$, medianas $(2,00 \mathrm{~mm}<L \leq 2,25 \mathrm{~mm})$ y pequeñas $(L \leq 2,00 \mathrm{~mm})$.

El diámetro geométrico $\left(D_{g}\right)$ de una semilla individual fue calculado a partir de las tres dimensiones características de acuerdo a la siguiente expresión (Mohsenin, 1986):

$D_{g}=(L W T)^{1 / 3}$

El área superficial específica $(S)$ fue calculada asumiendo la forma elipsoidal de la semilla, según la siguiente ecuación (McCabe y col., 1986):

$S=\pi D_{g}^{2}$

Para completar la información sobre la forma de la semilla de chía, se calculó la relación de aspecto $(R)$ (Maduako y Faborode, 1990):

$R=\frac{W}{L} \times 100$ 


\subsubsection{Propiedades gravimétricas}

La densidad aparente de las semillas de chía se determinó empleando el método de Singh y Goswami (1996), utilizando una balanza de peso hectolítrico normalizada, la cual consta de una medida de capacidad $\left(90 \mathrm{~cm}^{3}\right)$, tubo volcador, tubo receptor, cuchilla y émbolo o extractor de aire.

Para ello se llenó el tubo volcador con las semillas y se traspasó su contenido al tubo receptor, procurando que las semillas cayeran en el centro del tubo a una velocidad uniforme. Posteriormente, se retiró la cuchilla provocando la caída del émbolo junto con las semillas dentro de la medida de capacidad y se colocó nuevamente la cuchilla para enrasar la superficie del grano. Finalmente, se pesaron los granos contenidos en la unidad de medida (medida de capacidad + émbolo + cuchilla + granos) y se calculó el peso de los mismos por diferencia con respecto a la balanza de peso hectolítrico vacía (medida de capacidad + émbolo + cuchilla).

La densidad aparente $\left(\rho_{b}\right)$, se calculó mediante la relación entre la masa de las semillas $(\mathrm{g})$ y el volumen de la medida de capacidad $\left(90 \mathrm{~cm}^{3}\right)$. Las mediciones se realizaron por triplicado.

La densidad real $\left(\rho_{t}\right)$, definida como la relación entre la masa sólida de las semillas y el volumen de sólido ocupado por las mismas, fue determinada mediante el método de picnometría líquida (Mohsenin, 1986) utilizando xileno $\left(\mathrm{C}_{6} \mathrm{H}_{4}\left(\mathrm{CH}_{3}\right)_{2 ;} \delta=\right.$ $0,862 \pm 0,001 \mathrm{~g} \mathrm{~cm}^{-3}$ ) como solvente para evitar la absorción de líquido en las semillas durante el experimento. Se pesó el picnómetro lleno con xileno (enrasado y seco) midiéndose la temperatura $\left(\mathrm{T}^{\circ}\right)$ del mismo. Se pesaron aproximadamente 300 semillas de cada muestra utilizando una balanza de precisión $( \pm 0,0001 \mathrm{~g})$ y se colocaron en el picnómetro $(50 \pm 0,1 \mathrm{~mL})$ lleno de xileno. Posteriormente, se enrasó y secó el picnómetro, pesándolo nuevamente. El volumen de los granos fue equivalente al volumen de xileno desplazado, el cual se calculó a partir de la densidad del solvente a la temperatura medida. La densidad real de los granos se calculó dividiendo el peso de las 300 semillas por el volumen de las mismas.

La porosidad $(\varepsilon)$ del empaque se define como la fracción del espacio en el conjunto de granos que no es ocupado por los mismos (Thompson e Isaacs, 1967). El porcentaje de porosidad se calculó a partir de la siguiente relación (Mohsenin, 1986): 
$\varepsilon=\left(\frac{\left(\rho_{t}-\rho_{b}\right)}{\rho_{t}}\right) \times 100$

El volumen de una semilla $(V)\left(\mathrm{mm}^{3}\right)$ se determinó a partir de la siguiente relación (Özarslan, 2002):

$V=\left(\frac{m}{\rho_{t}}\right) 10^{3}$

$m$ es la masa de una semilla (g) calculada a partir de la muestra utilizada en la determinación de la densidad real.

El diámetro equivalente $(D e)$ de la esfera que tiene el mismo volumen que una semilla individual, fue calculado utilizando la siguiente expresión (Gupta y Das, 1997):

$D_{e}=\left(\frac{6 V}{\pi}\right)^{1 / 3}$

La esfericidad se calculó a partir de la Ec. 8 (McCabe y col., 1986):

$\phi=\left(\frac{D_{e}}{L}\right) \times 100$

Para la determinación del peso de mil semillas, se seleccionaron al azar 24 sub-muestras de 100 semillas cada una y se pesaron en una balanza analítica con una precisión de 0,0001 g. Luego se extrapoló el resultado a 1000 semillas (Vilche y col., 2003).

\subsubsection{Propiedades friccionales - Fluidez}

Debido a la cantidad de muestra necesaria para la determinación de las propiedades friccionales, las mismas se determinaron sólo para la mezcla comercial de semillas.

El ángulo de reposo $(\theta)$ se determinó utilizando una caja de madera contrachapada $(0,3 \mathrm{~m} \times 0,3 \mathrm{~m} \times 0,3 \mathrm{~m})$ con panel frontal removible, la cual fue llenada con las semillas. Luego se quitó el panel frontal permitiendo a las semillas conseguir su inclinación natural. El ángulo de reposo fue calculado midiendo la distancia del desplazamiento horizontal de las semillas y la altura de la masa de semillas (Dutta y col., 1988), mediante la realización de 10 repeticiones. 
Se determinó el coeficiente estático de fricción con respecto a dos superficies diferentes: chapa galvanizada y acero inoxidable. Estos materiales son habitualmente utilizados para el transporte, almacenamiento y manipulación de los granos, legumbres y semillas.

Para ello se colocó un cilindro hueco $(50 \mathrm{~mm}$ de diámetro y $50 \mathrm{~mm}$ de alto, abierto en ambos lados) lleno con la muestra de semillas sobre un plano inclinado ajustable, de manera tal que el cilindro no toque la superficie de la mesa. La inclinación de la superficie estructural con el cilindro en reposo se fue aumentando gradualmente mediante un tornillo hasta que el cilindro conteniendo las semillas comenzó a deslizarse (Singh y Goswami, 1996). El ángulo de inclinación ( $\alpha$ ) fue medido $(n=10)$ en una escala graduada, calculándose el coeficiente estático de fricción, según la siguiente relación:

$\mu=\tan \alpha$

Ec. 2.9

\section{Estructura y composición de las semillas}

\subsection{Observaciones microscópicas}

Las semillas enteras fueron fijadas a un cubreobjeto con esmalte traslúcido, mientras que aquéllas a ser observadas en su estructura interna fueron sometidas a cortes longitudinales y sumergidas en nitrógeno líquido a fin de conservar las estructuras al practicar el corte. Para ello, las mismas fueron colocadas bajo una lupa y las disecciones fueron realizadas con una hoja de bisturí. Luego, tanto las semillas enteras como partidas, se metalizaron con una capa delgada de oro (600 $⿱$ ) en un sputter coater marca Pelco (91000), a fin de permitir un flujo de carga electrónico producido por un evaporador catódico. Las observaciones se realizaron en un microscopio electrónico de barrido (LEO model EVO 40) operando a $5 \mathrm{kV}$. Se utilizaron aumentos de 113 a 4700x.

\subsection{Determinación del contenido de proteínas}

El contenido de proteína bruta se determinó utilizando el método de Kjeldahl (AOAC, 1990), empleando un digestor y destilador Büchi (Suiza).

Este método se basa en el pasaje del $\mathrm{N}$ orgánico a ion $\mathrm{NH}_{4}{ }^{+}$mediante una digestión de la muestra en caliente en medio sulfúrico concentrado. El ion $\mathrm{NH}_{4}{ }^{+}$es 
neutralizado y el $\mathrm{NH}_{3}$ liberado se destila y cuantifica mediante una titulación. EI N cuantificado se convierte a contenido de proteínas por medio de un factor.

Las etapas del proceso consistieron en:

\section{Digestión}

En esta etapa se produjo la conversión del nitrógeno en ion amonio $\left(\mathrm{NH}_{4}^{+}\right)$.

La muestra se colocó en un balón de Kjeldahl de $500 \mathrm{~mL}$ junto con una mezcla de una sal conteniendo una pequeña proporción de un catalizador (10 g de $\mathrm{K}_{2} \mathrm{SO}_{4}, 1 \mathrm{~g}$ de $\mathrm{CuSO}_{4} .5 \mathrm{H}_{2} \mathrm{O}$ ), perlas de vidrio y $25 \mathrm{~mL}$ de $\mathrm{H}_{2} \mathrm{SO}_{4}$ concentrado. Se calentó suavemente hasta el cese del desprendimiento de espuma, y posteriormente se continuó realizando el calentamiento enérgicamente hasta completar la digestión de la materia orgánica (no visualización de partículas carbonosas sin oxidar y líquido translúcido de color débilmente verdoso o azul-verdoso). Se retiró y se dejó enfriar. Se preparó en forma paralela un blanco.

\section{Destilación}

Esta etapa se basa en la separación del amoníaco por una destilación con arrastre con vapor y posterior solubilización en una solución ácida de concentración conocida.

Para ello, luego del enfriamiento del balón salido de la digestión, se realizó una dilución con $100 \mathrm{~mL}$ de agua y se añadió una solución de $\mathrm{NaOH} 40 \%$ con el propósito de liberar el ion amonio presente, convirtiéndolo en amoníaco. Dicho balón se conectó al equipo destilador y el $\mathrm{NH}_{3}$ fue recogido en una solución ácida de concentración conocida. El medio ácido receptor consistió en $50 \mathrm{~mL}$ de una solución de $\mathrm{H}_{3} \mathrm{BO}_{3} 4 \%$ y gotas de indicador Mortimer $(0,02 \mathrm{~g}$ de rojo de metilo y $0,04 \mathrm{~g}$ de verde de bromocresol disueltos en $19 \mathrm{~mL}$ de alcohol etílico y $1 \mathrm{~mL}$ de agua destilada), el cual forma con el $\mathrm{NH}_{4}{ }^{+}$un compuesto de adición. La destilación se realizó hasta llegar aproximadamente a $200 \mathrm{~mL}$ en el erlenmeyer colector.

\section{Valoración}

Esta etapa permite la medición de la cantidad de ácido neutralizado por el amoníaco disuelto lo cual indica la cantidad de nitrógeno presente en la muestra inicial.

El destilado recogido se tituló en forma directa, con una solución de $\mathrm{HCl} 0,1 \mathrm{~N}$.

$\%$ Nitrógeno $=\frac{\left[\left(\mathrm{V}_{1}-\mathrm{V}_{\mathrm{B}}\right) \times \mathrm{N}_{\mathrm{HCl}}\right] \times 0,014}{\mathrm{w}_{1}} \times 100$ 
donde:

$V_{1}$ : volumen de $\mathrm{HCl}$ consumidos en la titulación de la muestra $(\mathrm{mL})$

$V_{B}$ : volumen de $\mathrm{HCl}$ consumidos en la titulación del blanco $(\mathrm{mL})$

0,014: peso miliequivalente del $\mathrm{N}(\mathrm{g})$

$w_{1}$ : peso de la muestra, expresado en base seca $(\mathrm{g})$

$N_{H C l}$ Normalidad del ácido clorhídrico utilizado en la titulación

A fin de estimar el porcentaje de proteínas se multiplicó el \% Nitrógeno por un factor $F=6,25$.

\subsection{Determinación de materia grasa}

La materia grasa se estimó utilizando $n$-hexano (punto de ebullición $68-72^{\circ} \mathrm{C}$ ) como solvente en un equipo Soxhlet con ciclos térmicos a $80^{\circ} \mathrm{C}, 8 \mathrm{~h}$ siguiendo el método standard propuesto por IUPAC (1992). Las semillas fueron molidas utilizando un molinillo de café (Braun, Type 4041, México) por 60 s. Luego de esta primera extracción, la harina residual fue nuevamente molida y se extrajo el aceite remanente durante un periodo adicional de $8 \mathrm{~h}$, de igual manera que la previamente comentada. El solvente fue removido del aceite utilizando un rotavapor R-114 (Büchi, Flawil, Suiza) a $40^{\circ} \mathrm{C}$ a presión reducida bajo una corriente de nitrógeno. El contenido de aceite fue determinado gravimétricamente y expresado como porcentaje en peso sobre base seca (\%, b.s.).

\subsection{Determinación del contenido de cenizas}

La determinación de cenizas se basó en la técnica AOCS Ba-49 (1998). Se llevó a cabo la combustión de la materia orgánica en una mufla a $550^{\circ} \mathrm{C}$ hasta obtener un residuo blanquecino (aprox. 2 h). El contenido de cenizas se expresó como porcentaje en peso de harina seca.

$\%$ cenizas $=\frac{\text { peso de la muestra calcinada }}{\text { peso de la muestra seca }} \times 100$

\subsection{Determinación de fibra cruda}

La fibra cruda (FC) permite estimar el contenido de los carbohidratos estructurales. Una porción de la celulosa y hemiceulosa se disuelve así como la 
mayor parte de la lignina, mientras que algunos compuestos nitrogenados pueden quedar retenidos en el residuo. Este método indica que a valores mayores de FC menos digestible es una muestra.

La muestra, exenta de grasa, se sometió a dos procesos sucesivos de hidrólisis con ácido sulfúrico $0,255 \mathrm{~N}$ e hidróxido de sodio $0,313 \mathrm{~N}$, ambas en caliente durante $30 \mathrm{~min}$. El residuo menos el contenido de cenizas se considera fibra (AOCS Ba 6-84, 1998).

\subsection{Esquema de análisis de Van Soest}

Este método divide a la célula vegetal en dos partes (Guiragossian y col., 1977; AOAC, 1990):

- contenido celular, altamente digestible

- pared celular, parcialmente digestible y dependiente del grado de lignificación

El método de análisis separa la pared celular del contenido celular y sus componentes: celulosa, hemicelulosa y lignina. Para tal fin, la técnica hace uso de detergentes ácidos y neutros. En la Figura 2.2 se muestra la separación de las diferentes fracciones.

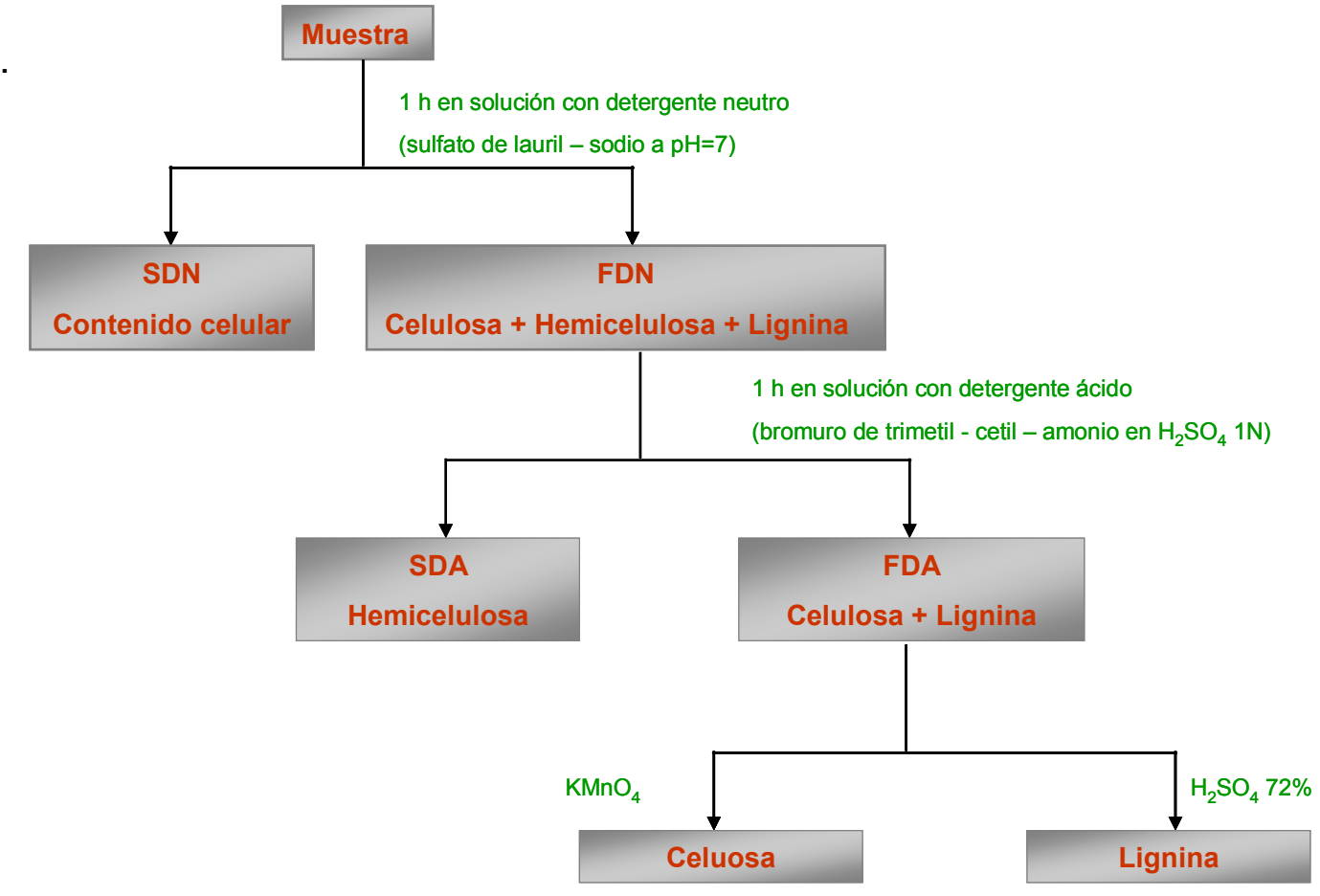

Figura 2.2. Esquema del método de análisis de Van Soest. SDN, soluble en detergente neutro; FDN, fibra detergente neutro; SDA, soluble en detergente ácido; FDA, fibra detergente ácido 
De esta manera, se tiene el siguiente balance:

Materia seca $(\mathrm{MS})=$ SDN (contenido celular) + FDN (pared celular)

Pared celular $($ FDN $)=$ SDA $($ hemicelulosa $)+$ FDA $($ celulosa + lignina $)$

\section{Determinación de Fibra Detergente Neutro}

Este análisis permite evaluar de modo rápido el contenido de fibra total en alimentos fibrosos (Guiragossian y col., 1977).

\section{Solución de detergente neutro}

A cada litro de agua destilada se agregó $30 \mathrm{~g}$ de laurilsulfato de sodio; 18,61 g de EDTA; 4,56 $\mathrm{g}$ de fosfato de hidrógeno disódico; 6,81 $\mathrm{g}$ de borato de sodio decahidratado y $10 \mathrm{~mL}$ de etilenglicol (2-etoxietanol). Se ajustó el pH en el rango 6,9-7,0.

\section{Procedimiento}

La muestra se colocó en un erlenmeyer de $500 \mathrm{~mL}$ con boca esmerilada. Se añadieron $100 \mathrm{~mL}$ de solución de detergente neutro. Se conectó el refrigerante y se colocó sobre la placa calefactora. Se hirvió uniformemente bajo reflujo durante $1 \mathrm{~h}$.

El contenido del erlenmeyer se filtró a través de un crisol Gooch de porosidad $\mathrm{N}^{0} 1$, previamente tarado, empleando vacío. El residuo se enjuagó con aproximadamente $300 \mathrm{~mL}$ de agua caliente $\left(80^{\circ} \mathrm{C}\right)$ y finalmente con $10-15 \mathrm{~mL}$ de acetona.

El crisol con su contenido se colocó en estufa a $105^{\circ} \mathrm{C}$ durante toda la noche. Se dejó enfriar en un desecador y se pesó.

$\% F D N=\frac{\left(w_{2}-w_{1}\right)}{w_{3}} \times 100$

donde:

$W_{1}$ : peso del crisol $(\mathrm{g})$

$w_{2}$ : peso del crisol y el residuo $(\mathrm{g})$

$w_{3}:$ peso de la muestra en base seca $(g)$ 


\section{Determinación de Fibra Detergente Ácido}

Solución de detergente ácido

Se añadieron $20 \mathrm{~g}$ de bromuro de etiltrimetilamonio a $1 \mathrm{~L}$ de $\mathrm{H}_{2} \mathrm{SO}_{4} 1 \mathrm{~N}$

Procedimiento

La muestra se colocó en un erlenmeyer de boca esmerilada junto con $100 \mathrm{~mL}$ de solución detergente ácido. Se conectó el refrigerante y se colocó en la placa calefactora. La temperatura se ajustó de manera tal de lograr la ebullición de $3-5$ min. Luego, se redujo el calentamiento y la ebullición se prosiguió por $1 \mathrm{~h}$.

Los sólidos del erlenmeyer se filtraron en un crisol Gooch de porosidad №1, previamente tarado, a presión reducida bajo vacío. Se lavó varias veces con agua caliente $\left(80-90^{\circ} \mathrm{C}\right)$, posteriormente, con acetona hasta que el líquido de lavado fuera incoloro. El último enjuague se realizó con hexano. El crisol con el residuo se colocó en una estufa a $105^{\circ} \mathrm{C}$ durante toda la noche, se enfrió en desecador y se pesó.

El residuo se reservó para determinar el contenido de lignina.

$\% F D A=\frac{\left(w_{2}-w_{1}\right)}{w_{3}} \times 100$

donde:

$W_{1}$ : peso del crisol $(\mathrm{g})$

$w_{2}$ : peso del crisol y el residuo $(\mathrm{g})$

$w_{3}$ : peso de la muestra en base seca $(\mathrm{g})$

\section{Determinación de Lignina}

En la determinación de la lignina se utiliza a la fibra detergente ácido como paso previo al procedimiento. El detergente remueve la proteína y otros materiales solubles en ácido, los que pueden interferir con la determinación de lignina. El principio del procedimiento está basado en que la fibra detergente ácido está constituida principalmente por lignocelulosa, a partir de la cual se disuelve la celulosa con la solución de $\mathrm{H}_{2} \mathrm{SO}_{4} 72 \%$. El residuo remanente está constituido por lignina y materiales insolubles en ácido.

Por ello, el residuo proveniente de la determinación de la fibra detergente ácido se colocó en un crisol dentro de un cristalizador con la solución de $\mathrm{H}_{2} \mathrm{SO}_{4} 72 \%$ fría a 
una temperatura de $20-23^{\circ} \mathrm{C}$. Luego de $3 \mathrm{~h}$, se procedió al filtrado bajo vacío y enjuague del residuo con agua caliente $\left(80-90^{\circ} \mathrm{C}\right)$ hasta que el líquido de lavado estuviese libre de ácido. Se llevó el crisol con el residuo a una estufa a $105^{\circ} \mathrm{C}$ durante toda la noche. Luego, se lo calcinó en una mufla a $500^{\circ} \mathrm{C}$ por tres horas, se enfrío y pesó.

$\%$ Lignina $=\frac{\left(w_{2}-w_{1}\right)}{w_{3}} \times 100$

donde:

$W_{1}$ : peso del crisol $(\mathrm{g})$

$w_{2}$ : peso del crisol y el residuo $(\mathrm{g})$

$w_{3}$ : peso de la muestra en base seca $(\mathrm{g})$

\subsection{Compuestos antioxidantes}

\section{Tocoferoles}

El contenido de tocoferoles en las semillas de chía fue determinado mediante una técnica cromatográfica basada en las normas IUPAC 2.432 (1992) y AOCS Ce 8-89 (1998). Se extrajo el aceite de las semillas molidas de chía en un equipo Soxhlet utilizando $n$-hexano como solvente durante $4 \mathrm{~h}$ a temperatura ambiente y $4 \mathrm{~h}$ a $80^{\circ} \mathrm{C}$. El solvente fue removido del aceite utilizando un rotavapor R-114 (Büchi, Flawil, Suiza) con vacío a $40^{\circ} \mathrm{C}$ bajo una corriente de nitrógeno. Posteriormente, el aceite obtenido fue disuelto en hexano para su cuantificación por HPLC con detector de fluorescencia ( $\lambda$ excitación: $290 \mathrm{~nm}, \lambda$ emisión: $330 \mathrm{~nm}$ ). Se utilizó un cromatógrafo HPLC Hewlett Packard Serie 1050, columna fase normal Lichrosob Si60 (25 x 0,4 cm; $5 \mu \mathrm{m}$ de tamaño de partícula), fase móvil isopropanol:hexano $(0,5: 99,5 \mathrm{v} / \mathrm{v}$, filtrado y desgasificado) a una velocidad de flujo de $1,5 \mathrm{~mL} / \mathrm{min}$ y $20 \mu \mathrm{L}$ de volumen de inyección.

\section{Flavonoides y ácidos fenólicos}

Las semillas de chía ( $1 \mathrm{~g}$ ) fueron molidas en un mortero con $1 \mathrm{~mL}$ de hexano, realizando la extracción con $3 \mathrm{~mL}$ de una solución de acetonitrilo:ácido acético al 10\% (50:50), por agitación con mezcladora orbital durante 15 min y posterior centrífugación a $700 \mathrm{~g}$ durante $15 \mathrm{~min}$. La fase acuosa se concentró en evaporador speed-vac y se resuspendió en $200 \mu \mathrm{l}$ de acetonitrilo:ácido acético al 10\% (50:50). El 
extracto fue concentrado bajo atmósfera de nitrógeno y analizado por HPLC-UV. Se utilizó una columna C18, $5 \mu \mathrm{m}$ (Vydac, $25 \times 0,45 \mathrm{~m}$ ), y un gradiente de elución acetonitrilo: acético 10\% según: (90:10 v/v) 0 a 5 min; gradiente lineal hasta (60:40 v/v) a $15 \mathrm{~min} ;$ y (80:20 v/v) de 16 a $18 \mathrm{~min}$. Este gradiente de polaridad de la fase móvil permitió la elución, en primer lugar, de los ácidos fenólicos y luego de los flavonoles. La detección se realizó mediante la absorbancia a $255 \mathrm{~nm}$ hasta los 5 min y luego a $375 \mathrm{~nm}$.

\section{Análisis estadístico}

Para la comparación de las medias entre las semillas blancas y oscuras de cada origen, así como para la comparación de las semillas según su origen geográfico se aplicó el test de Student (prueba de "t") a un nivel de significación del $5 \%$. Los análisis se realizaron empleando el programa informático Statgraphics Plus 4.0 Manugistic Inc., USA (1999). 


\section{RESULTADOS Y DISCUSIÓN}

\section{Semillas de chía provenientes de Salta (Argentina)}

\subsection{Descripción de la semilla}

1.1.1 Composición y contenido de humedad de la mezcla comercial de las semillas según el color del pericarpio

Las muestras provenientes de Argentina estuvieron compuestas por $91,6 \pm 0,3 \%$ en peso de semillas con pericarpio oscuro, mientras que el resto fueron blancas. El contenido de humedad de la mezcla comercial fue de $7,0 \pm 0,4 \%$ (b.s.), mientras que si se consideran ambos tipos de semillas por separado, el nivel de humedad fue de 7,2 y $6,6 \%$ para las semillas oscuras y blancas, respectivamente.

\subsubsection{Propiedades físicas}

\subsubsection{Tamaño y forma}

Las semillas de chía presentaron tres semiejes desiguales, cuya forma se puede describir mediante un elipsoide escaleno. En la Tabla 2.1 se muestra la distribución de tamaño de las mismas.

La dimensión longitudinal $(\boldsymbol{L})$ varió entre 1,73-2,63 mm, encontrándose el mayor número de semillas en el rango de tamaño medio $(2,00 \leq L \leq 2,25 \mathrm{~mm})$, lo cual representa el $59 \%$ de las semillas oscuras y $62 \%$ de las blancas.

El promedio del ancho $(\boldsymbol{W})$ y espesor $(\boldsymbol{T})$ de las semillas oscuras y blancas fue de $1,32-0,81 \mathrm{~mm}$ y $1,40-0,83 \mathrm{~mm}$, respectivamente. Estas medidas se encuentran en el mismo rango que las informadas por Rulfo (1937) para semillas de chía. Las semillas blancas presentaron un ancho y un espesor significativamente mayor ( $p \leq$ 0,05 ) a los correspondientes a las semillas oscuras (Tabla 2.1). Sin embargo, no se encontraron diferencias significativas $(p>0,05)$ en la longitud correspondiente a las mismas. 
Tabla 2.1. Distribución de tamaño de semillas de chía oscuras y blancas provenientes de Salta (Argentina)

\begin{tabular}{|c|c|c|c|c|c|c|c|c|}
\hline $\begin{array}{l}\text { Tipo de } \\
\text { semilla }\end{array}$ & $\begin{array}{c}\text { Rango de } L \\
(\mathrm{~mm})^{1}\end{array}$ & $\begin{array}{c}\% \text { de } \\
\text { semillas }\end{array}$ & $\begin{array}{c}L \\
(\mathrm{~mm})^{1}\end{array}$ & $\begin{array}{c}W \\
(\mathrm{~mm})^{1}\end{array}$ & $\begin{array}{c}T \\
(\mathrm{~mm})^{1}\end{array}$ & $\begin{array}{c}D_{g} \\
(\mathrm{~mm})^{1}\end{array}$ & $\begin{array}{c}S \\
\left(\mathrm{~mm}^{2}\right)^{1}\end{array}$ & $\begin{array}{c}R \\
(\%)^{1}\end{array}$ \\
\hline \multicolumn{9}{|l|}{ Oscuras } \\
\hline Sin clasificar & $1,76-2,42$ & 100 & $2,11^{\mathrm{a}}$ & $1,32^{\mathrm{a}}$ & $0,81^{a}$ & $1,31^{\mathrm{a}}$ & $5,42^{\mathrm{a}}$ & $62,7^{\mathrm{a}}$ \\
\hline Grandes & $>2,25$ & 17 & 2,33 & 1,36 & 0,84 & 1,38 & 6,01 & 64,5 \\
\hline Medianas & $2,00-2,25$ & 59 & 2,13 & 1,35 & 0,82 & 1,33 & 5,41 & 62,4 \\
\hline Pequeñas & $\leq 2,00$ & 24 & 1,90 & 1,22 & 0,77 & 1,21 & 4,64 & 58,2 \\
\hline \multicolumn{9}{|l|}{ Blancas } \\
\hline Sin clasificar & $1,73-2,63$ & 100 & $2,15^{\mathrm{a}}$ & $1,40^{b}$ & $0,83^{b}$ & $1,36^{b}$ & $5,79^{b}$ & $65,3^{b}$ \\
\hline Grandes & $>2,25$ & 20 & 2,37 & 1,45 & 0,85 & 1,43 & 6,41 & 69,4 \\
\hline Medianas & $2,00-2,25$ & 62 & 2,14 & 1,40 & 0,80 & 1,36 & 5,78 & 65,5 \\
\hline Pequeñas & $\leq 2,00$ & 18 & 1,93 & 1,30 & 0,81 & 1,27 & 5,11 & 61,1 \\
\hline
\end{tabular}

\footnotetext{
1 Valores promedio $(n=90)$ determinados a un contenido de humedad de 7,2 y 6,6 \% (b.s.) para las semillas oscuras y blancas,
} respectivamente. Letras dstintas entre semillas oscuras y blancas sin clasificar indican que existen diferencias significativas $(p \leq 0,05)$.

El diámetro geométrico $\left(D_{g}\right)$ varió entre 1,10 - 1,54 mm, con un promedio de $1,31 \mathrm{~mm}$ para las semillas oscuras, el cual fue significativamente menor $(p \leq 0,05)$ que el calculado para las semillas blancas $\left(D_{g}=1,36 \mathrm{~mm}\right)$; estos valores de $D_{g}$ fueron menores que la longitud y el ancho y mayores que el espesor (Tabla 2.1).

El área superficial específica de una semilla $(\boldsymbol{S})$ y la relación de aspecto $(\mathbf{R})$ fueron $5,42 \mathrm{~mm}^{2}-62,7 \%$ y $5,79 \mathrm{~mm}^{2}-65,3 \%$ para las semillas oscuras y blancas, respectivamente, con diferencias significativas $(p \leq 0,05)$ entre ambos tipos de semillas (Tabla 2.1). Los valores de relación de aspecto calculados muestran la tendencia de la forma de la semilla de chía hacia un elipsoide más que hacia una esfera.

El tamaño de las semillas de chía, descripto a través de sus dimensiones características, fue similar al informado para las semillas de quinoa (Chenopodium quinoa Willd.) y colza (Brassica napus oleifera L.) (Vilche y col., 2003; Çahşir y col., 2005) pero mayor que las de amaranto (Amaranthus cruentus L.) (Abalone y col., 2004) y menor que las de comino (Cuminum cyminum L.), mijo perla (Pennisetum 
typhoides S. \& H.), sésamo (Sesamum indicum L.), cártamo (Carthamus tinctorius L.), lino (Linum usitatissimum L.) y coriandro (Coriandrum sativum L.) (Singh y Goswami, 1996; Jain y Bal, 1997; Tunde - Akintunde y Akintunde, 2004; Baümler y col., 2006; Coşkuner y Karababa, 2007a, 2007b). La importancia de estas dimensiones características en la determinación del tamaño de apertura y otros parámetros en el diseño de maquinarias ha sido discutida por Mohsenin (1986).

Los coeficientes de correlación mostraron las relaciones entre las dimensiones características entre sí y con el $D_{g}$ de las semillas (Tabla 2.2). Todas las relaciones establecidas fueron altamente significativas $(p \leq 0,01)$. La relación $L / T$ presentó el mayor valor mientras que las proporciones $L / D_{g}$ y $L / W$ fueron similares. Este hecho indica que la longitud de las semillas está positivamente relacionada con su ancho, espesor y diámetro geométrico. La siguiente expresión general puede ser utilizada para describir la relación entre las tres dimensiones características de las semillas de chía de Argentina:

$L=1,58 W=2,60 T$

Tabla 2.2. Correlación de las dimensiones de la semilla de chía provenientes de Argentina

\begin{tabular}{lcccc}
\hline Relación & Valor del Cociente & $\begin{array}{c}\text { Grados de } \\
\text { libertad }\end{array}$ & $\begin{array}{c}\text { Coeficiente de } \\
\text { correlación }(\mathbf{r})\end{array}$ & $\mathbf{p}$ \\
\hline$L W$ & 1,58 & 178 & 0,341 & $0,0000^{* * \star *}$ \\
$L / T$ & 2,60 & 178 & 0,306 & $0,0000^{* * * *}$ \\
$L / D_{g}$ & 1,60 & 178 & 0,712 & $0,0000^{* * * *}$ \\
$W / T$ & 1,66 & 178 & 0,223 & $0,0026^{* * *}$ \\
$W / D_{g}$ & 1,02 & 178 & 0,790 & $0,0000^{* * * *}$ \\
$T / D_{g}$ & 0,62 & 178 & 0,658 & $0,0000^{* * *}$ \\
\hline
\end{tabular}

${ }^{* * \star}$ Significativo al 0,1 \%; ${ }^{* * *}$ Significativo al 0,01 \% 


\subsubsection{Propiedades gravimétricas}

La Tabla 2.3 muestra los valores promedios de cada una de las propiedades gravimétricas estudiadas. Sólo se encontraron diferencias significativas $(p \leq 0,05)$ entre semillas oscuras y blancas para la densidad aparente $\left(\boldsymbol{p}_{\mathbf{b}}\right)$ y el peso de mil semillas $\left(\boldsymbol{W}_{1000}\right)$, siendo mayores en las primeras. En el resto de las propiedades gravimétricas no se registraron diferencias significativas $(p>0,05)$ entre ambos tipos de semillas (Tabla 2.3).

Tabla 2.3. Propiedades físicas gravimétricas de las semillas de chía oscuras y blancas.

\begin{tabular}{|c|c|c|c|c|c|c|c|}
\hline $\begin{array}{l}\text { Tipo de } \\
\text { semilla }\end{array}$ & $\begin{array}{c}\rho_{\mathrm{b}} \\
\left(\mathrm{g} / \mathrm{cm}^{3}\right)^{1}\end{array}$ & $\begin{array}{c}\rho_{\mathrm{t}} \\
\left(\mathrm{g} / \mathrm{cm}^{3}\right)^{1}\end{array}$ & $\begin{array}{c}\varepsilon \\
(\%)^{1}\end{array}$ & $\begin{array}{c}V \\
\left(\mathrm{~mm}^{3}\right)^{1}\end{array}$ & $\begin{array}{c}D_{e} \\
(\mathrm{~mm})^{1}\end{array}$ & $\begin{array}{c}\phi \\
(\%)^{1}\end{array}$ & $\begin{array}{l}W_{1000} \\
(\mathbf{g})^{2}\end{array}$ \\
\hline Oscuras & $0,722^{b}$ & $1,009^{a}$ & $28,2^{a}$ & $1,30^{\mathrm{a}}$ & $1,35^{a}$ & $64,4^{\mathrm{a}}$ & $1,323^{b}$ \\
\hline Blancas & $0,667^{a}$ & $0,999^{a}$ & $33,1^{\mathrm{a}}$ & $1,27^{\mathrm{a}}$ & $1,34^{a}$ & $63,0^{a}$ & $1,301^{\mathrm{a}}$ \\
\hline
\end{tabular}

La densidad real $\left(\rho_{t}\right)$ de la semilla de chía fue mayor que la de las semillas de girasol (Helianthus annuus L.) (Gupta y Das, 1997), cártamo (Baümler y col., 2006) y coriandro (Coşkuner y Karababa, 2007b); menor que la de soja (Glycine max L.) (Deshpande y col., 1993), mijo perla (Jain y Bal, 1997), amaranto (Abalone y col., 2004) y sésamo (Tunde-Akintunde y Akintunde, 2004) aunque del mismo rango que las de quinoa (Vilche y col., 2003), comino (Singh y Goswami, 1996) y lino (Coşkuner y Karababa, 2007a).

Con respecto a la porosidad $(\varepsilon)$, los valores encontrados fueron similares a los informados para quinoa (Vilche y col., 2003) y coriandro (Coşkuner y Karababa. 2007b). Este parámetro es importante debido a que la porosidad de la masa de semillas determina la resistencia al flujo de aire durante los procesos de aireación y secado de granos.

La esfericidad $(\phi)$ resultó menor que la de soja (Deshpande y col., 1993), mijo perla (Jain y Bal. 1997), quinoa (Vilche y col., 2003), amaranto (Abalone y col., 2004) colza (Çahşir y col., 2005) y coriandro (Coşkuner y Karababa. 2007b) y mayor que la de girasol (Gupta y Das, 1997), sésamo (Tunde-Akintunde y Akintunde, 2004) y 
cártamo (Baümler y col., 2006). Los valores de esfericidad encontrados indican que la semejanza de la semilla de chía con una esfera es baja.

Asimismo, se comparó el diámetro equivalente $\left(D_{e}\right)$ con el diámetro geométrico $\left(D_{g}\right)$, no encontrándose diferencias significativas $(p>0,05)$ entre ambos. Esta similitud entre ambos diámetros confirma la asunción de la forma elipsoide de la semilla y por lo tanto, el diámetro geométrico puede ser utilizado convenientemente para la determinación teórica del volumen de la semilla de chía y su esfericidad.

El volumen de una semilla (V), calculado según la Ec. 2.6, presentó un promedio de 1,30 y $1,27 \mathrm{~mm}^{3}$ para las semillas oscuras y blancas, respectivamente. El volumen y la esfericidad de la semilla también fueron calculados a partir de la fórmula del volumen de una esfera reemplazando $D_{e}$ por $D_{g}$ en la Ec. 2.8, respectivamente. En este caso no se encontraron diferencias significativas $(p>0,05)$ con respecto al volumen real y la esfericidad real de la semilla.

Teniendo en cuenta la baja relación de aspecto determinada previamente y la esfericidad, puede deducirse que las semillas de chía presentarán una mayor tendencia a deslizarse sobre su superficie plana que a rodar. Esta tendencia a rodar o deslizarse es muy importante para el diseño de tolvas debido a que las semillas más planas caen más fácilmente que las que ruedan sobre las superficies estructurales. Además, estos índices de forma, indican que la semilla de chía puede ser considerada como un elipsoide escaleno para la predicción analítica de su comportamiento al secado.

El peso de mil semillas $\left(\boldsymbol{W}_{1000}\right)$ para las semillas oscuras $(1,323 \pm 0,010 \mathrm{~g})$ fue significativamente mayor $(p \leq 0,05)$ que el correspondiente a las semillas blancas $(1,301 \pm 0,010 \mathrm{~g})$ (Tabla 2.3). Estos valores son menores que los registrados para comino (Singh y Goswami, 1996), mijo perla (Jain y Bal, 1997), quinoa (Vilche y col., 2003), sésamo (Tunde-Akintunde y Akintunde, 2004), colza (Çahşir y col., 2005) y lino (Coşkuner y Karababa, 2007a) pero mayores que los de amaranto (Abalone y col., 2004). Este parámetro es necesario para la estimación del volumen de una semilla y el cálculo posterior del diámetro equivalente así como para la realización de la limpieza de las semillas a través del uso de fuerzas aerodinámicas. 


\subsubsection{Propiedades friccionales - Fluidez}

El ángulo de reposo de las semillas de chía de Argentina varió entre 16 - $18^{\circ}$ (promedio $17,1 \pm 0,4^{\circ}$ ). Estos valores son similares a los $17^{\circ}$ informados para semillas de "oilbean seed" (Pentaclethra macrophylla Benth) (Oje y Ugbor, 1991), mayores que los $13^{\circ}$ y $15^{\circ}$ asociados a las semillas de "African locust bean" (Parkia filicoidea Welw. ex Oliv.) y "African star apple" (Chrysophyllum albidum G.), respectivamente (Olajide y Ade - Omowaye, 1999; Oyelade y col., 2005); pero mucho menores que los de girasol, mijo, quinoa, sésamo, lino y coriandro (Gupta y Das, 1997; Jain y Bal, 1997; Vilche y col., 2003; Tunde-Akintunde y Akintunde, 2004; Coşkuner y Karababa. 2007a, 2007b). Los bajos valores registrados en el ángulo de reposo pueden atribuirse a la facilidad de las semillas de deslizarse unas sobre otras debido a la superficie exterior lisa y a la forma de las mismas.

El coeficiente de fricción promedio fue de 0,28 \pm 0,01 sobre acero galvanizado y 0,31 $\pm 0,01$ sobre acero inoxidable. Esta diferencia puede atribuirse a la rugosidad de las superficies estudiadas. La rugosidad de la superficie interior de los silos pueden calificarse según Ravenet (1992) como: pulidas $\left(D_{1}\right)$, lisas $\left(D_{2}\right)$, rugosas $\left(D_{3}\right)$ y perfiles corrugados $\left(D_{4}\right)$. Así, el acero galvanizado se incluye dentro de $D_{1}$, mientras que el acero inoxidable sería una superficie clasificada como $D_{2}$. El coeficiente de fricción sobre acero galvanizado fue menor que los informados para las semillas de comino (Singh y Goswami, 1996), girasol (Gupta y Das. 1997), sésamo (Tunde-Akintunde y Akintunde, 2004), African star apple (Oyelade y col., 2005), lino y coriandro (Coşkuner y Karababa. 2007a. 2007b), mayor que el de mijo y quinoa (Jain y Bal, 1997; Vilche y col., 2003) y similar al de semilla de colza (Çahşir y col., 2005).

\subsection{Estructura y composición de las semillas}

\subsubsection{Observaciones microscópicas}

Tal como se describió previamente en la introducción, el fruto de S. hispanica consiste en cuatro pequeñas núculas, similares a un aquenio indehiscente, cada una de las cuales contiene una única semilla. El gineceo bicarpelar de las especies del género Salvia, tras la fecundación, se convierte en un esquizocarpo tetranuculado. Cada una de estas núculas tiene un pericarpio claramente estratificado: cutícula, 
epicarpio, mesocarpio, capa de esclereidas y endocarpio, el cual está en contacto con la testa de la semilla. La morfología de las núculas es de utilidad taxonómica a distintos niveles jerárquicos dentro de la familia Lamiaceae (Budantsev y Lobova, 1997).

La Figura 2.3 muestra las imágenes obtenidas mediante microscopía electrónica de barrido (SEM) de las núculas de $S$. hispanica. Las mismas son glabras (sin pelos) y están compuestas por la semilla verdadera y el pericarpio que la rodea (Figura 2.3.B). La semilla verdadera consta de una cubierta seminal (testa), el endosperma y el embrión, el cual está compuesto principalmente por los cotiledones.
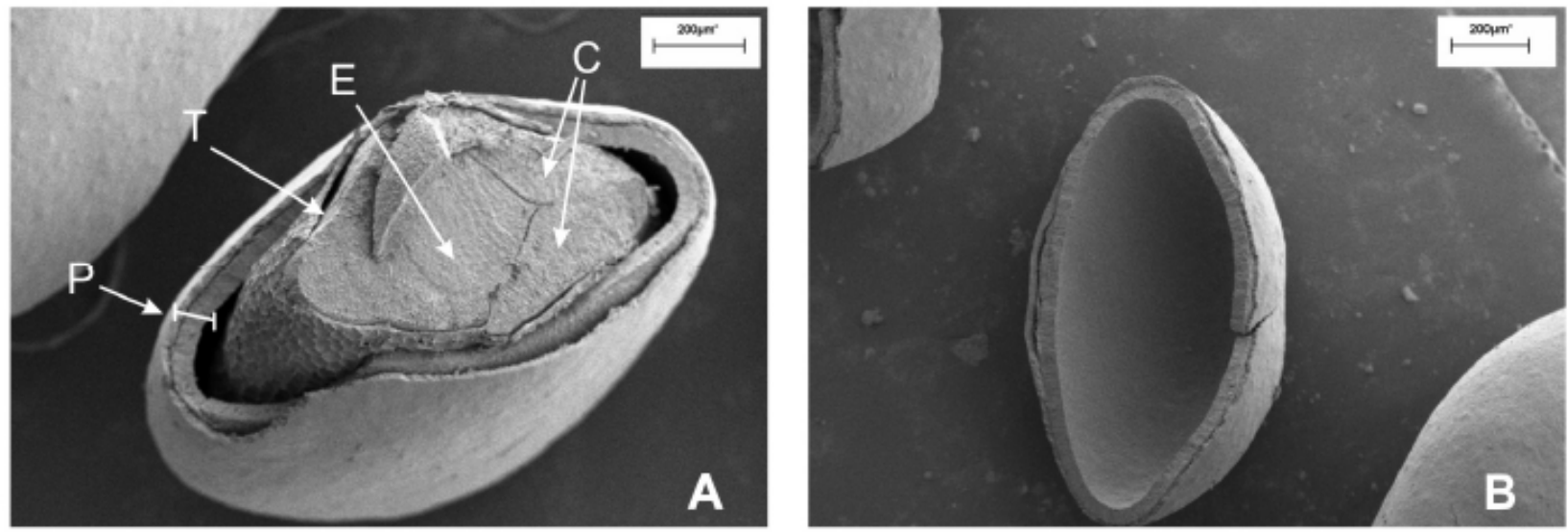

Figura 2.3. Micrografías obtenidas por microscopía electrónica de barrido (SEM) de núculas de Salvia hipsnica L. provenientes de Argentina; (A) Sección longitudinal mostrando la estructura interna (x 187). (B) Pericarpio (x 152). P:pericarpio; T: testa; E: endosperma; C: cotiledones

En la Figura 2.4 se muestran las micrografías correspondientes a las núculas oscuras y blancas, con diferentes grados de magnificación. Como puede observarse, y en concordancia con lo descripto previamente a través de las propiedades físicas de las semillas, las mismas presentan una forma elipsoidal. Las núculas oscuras y blancas son similares en forma y tamaño (Figura 2.4 A-B, E-F), aunque puede apreciarse que las semillas blancas son apenas más grandes que las oscuras, según el análisis de la forma y tamaño presentado en la Sección 1.1.2.1.

El detalle de la superficie de las núculas se muestra en la Figura 2.4 C-G, donde puede observarse que las núculas blancas tienen una superficie más rugosa que las oscuras. La estructura del pericarpio se muestra en la Figura 2.4 D-H. En el epicarpio, generalmente se encuentran células que producen mucílago cuando se 
las humedece. Las paredes anticlinales de las células que forman el epicarpio llevan refuerzos de fibrillas celulósicas espiraladas, acompañadas, frecuentemente, de inclusiones de morfología y composición variada (Ryding 1992). Cuando las núculas entran en contacto con el agua, el epicarpio se hincha, la cutícula se rompe al agotar su elasticidad y el contenido de las células epicárpicas se derrama como mucílago rodeando toda la superficie del fruto. La mixocarpia o condición mucilaginosa del fruto es una propiedad compartida por muchas especies del género Salvia (Hedge 1970).

Las capas inmediatamente por debajo del epicarpio son delgadas (mesocarpio) y hacia el interior hay una capa de células de esclereidas en forma de hueso, las cuales confieren una mayor rigidez al pericarpio.

Hedge (1970) encontró que las núculas del género Salvia tienen una estructura básica similar, mostrando algunas diferencias en el espesor del pericarpio, en las capas individuales y en el color. Sin embargo, la estructura interna de ambos tipos de núculas es muy similar. La principal diferencia entre las núculas blancas y oscuras es el arreglo de las capas de esclereidas, la cual es más compacta en las blancas.
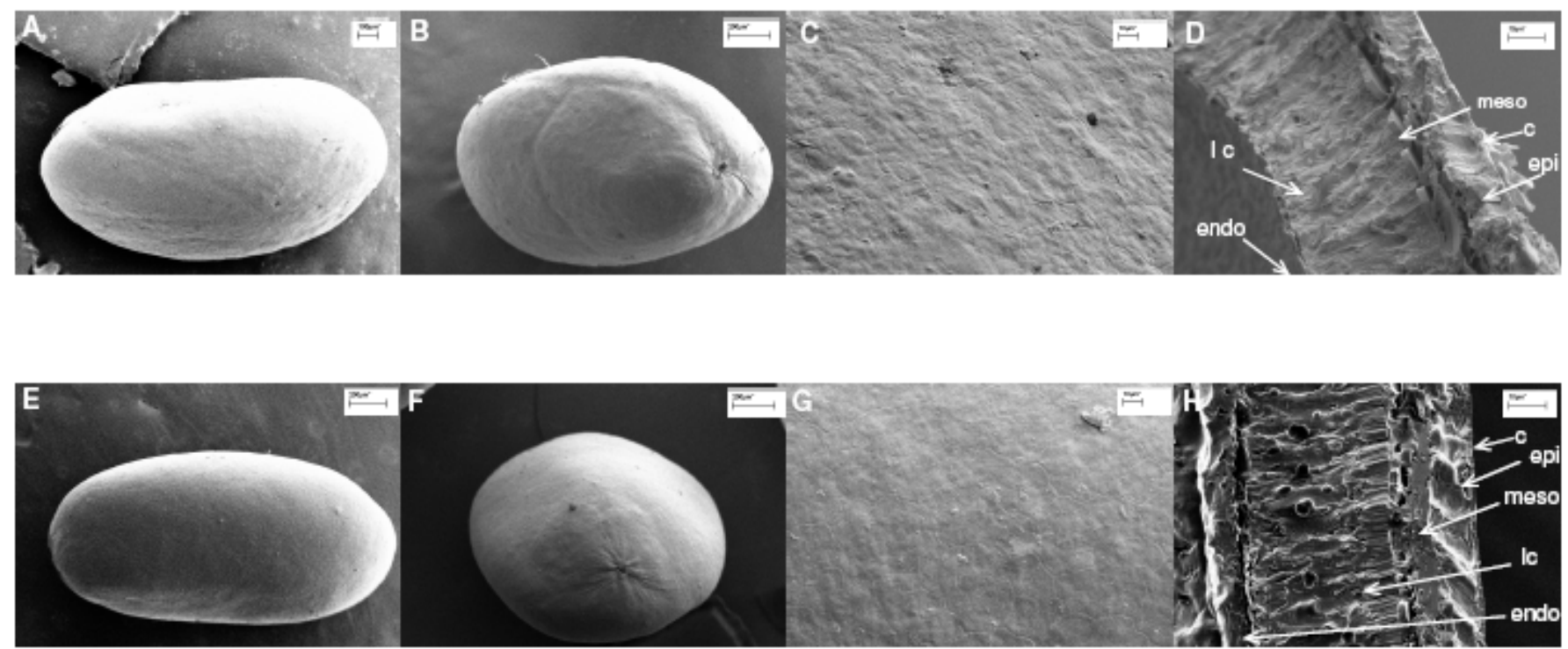

Figura 2.4. Micrografías electrónicas obtenidas por microscopia electrónica de barrido (SEM) de núculas de Salvia hispanica provenientes de Argentina. A - D, Núculas blancas. E - H, Núculas oscuras. Vista lateral: A, E (x 145); vista frontal: B, F (x 170); superficie del pericarpio: C, G (x 1500); sección transversal del pericarpio: D, H (x 3000). C: cutícula; epi: epicarpio; meso: mesocarpio; lc: capa de esclereidas; endo: endocarpio 


\subsubsection{Análisis composicional}

En la Tabla 2.4 se indica la composición centesimal de las semillas de chía provenientes de Salta (Argentina). Como puede observarse, los lípidos representan el componente principal de la semilla, si bien su contenido es menor que el de girasol $(47 \%)$ y el del maní (51\%). Sin embargo, el contenido proteico de la semilla de chía es elevado, siendo superior al promedio informado para trigo (10,6\%), maíz $(11 \%)$ y arroz $(7,4 \%)$ (Hernández y col., 1977). Además, puede destacarse el elevado contenido de fibra, el cual también supera al presente en los principales cereales (ver Capítulo 1.4).

Tabla 2.4 Composición (\%, b.s.) promedio de semillas de chía provenientes de Salta, Argentina

\begin{tabular}{lc}
\hline \multicolumn{1}{c}{ Componente } & $\begin{array}{c}\text { Contenido } \\
\text { (\% b.s.) }\end{array}$ \\
\hline Proteínas & 29 \\
Lípidos & 32 \\
Cenizas & 5 \\
Fibra & 27 \\
Hidratos de carbono* & 7 \\
\hline${ }^{*}$ Calculado por diferencia &
\end{tabular}

\subsubsection{Esquema de análisis de Van Soest}

La Tabla 2.5 muestra los resultados correspondientes al contenido de fibra detergente neutro (FDN) y ácido (FDA) calculados a partir del método propuesto por Van Soest (Guiragossian, 1977). El valor de FDN representa el contenido de pared celular mientras que el de FDA, el de celulosa y lignina. El contenido de FDN se correlaciona negativamente con la digestibilidad. Los mayores valores de FDN en relación a los valores informados para el girasol cultivable (Trimachi y col., 1992; Pinto y col., 1992) indican que la semilla de chía presenta un menor porcentaje de contenido celular. Los mayores niveles de FDA encontrados para las semillas de chía están asociados a un porcentaje más elevado de celulosa y no de lignina. 
Tabla 2.5 Composición de fibra de las semillas de chía provenientes de Argentina analizada según el método de Van Soest, expresados en \% (b.s.)

\begin{tabular}{cccccc}
\hline & FDA & FDN & Lignina & Hemicelulosa & Celulosa \\
\cline { 2 - 6 } & \multicolumn{5}{c}{$\%$ b.s. } \\
\hline Semillas de chía & 42,6 & 60,2 & 6,0 & 17,6 & 36,6 \\
\hline Girasol cultivable $^{1,2}$ & $22-31$ & $34-48$ & $8-11$ & $12-17$ & $14-20$ \\
\hline
\end{tabular}

${ }^{1}$ Trimachi y col., 1992

2 Pinto y col., 1992

\subsubsection{Compuestos antioxidantes}

En la Figura 2.5 se muestra el contenido de tocoferoles presentes en las semillas blancas y oscuras provenientes de Argentina. El contenido total de tocoferoles fue de alrededor de $95 \mathrm{ppm}$, siendo el principal compuesto $\mathrm{\gamma}$-tocoferol ( $\sim 80 \mathrm{ppm})$. Además, fue posible la detección de menores concentraciones de $\delta$ tocoferol, así como trazas de $\alpha$-tocoferol. Puede observarse un tenor similar ( $p>$ $0,05)$ de tocoferoles en ambos tipos de semillas.

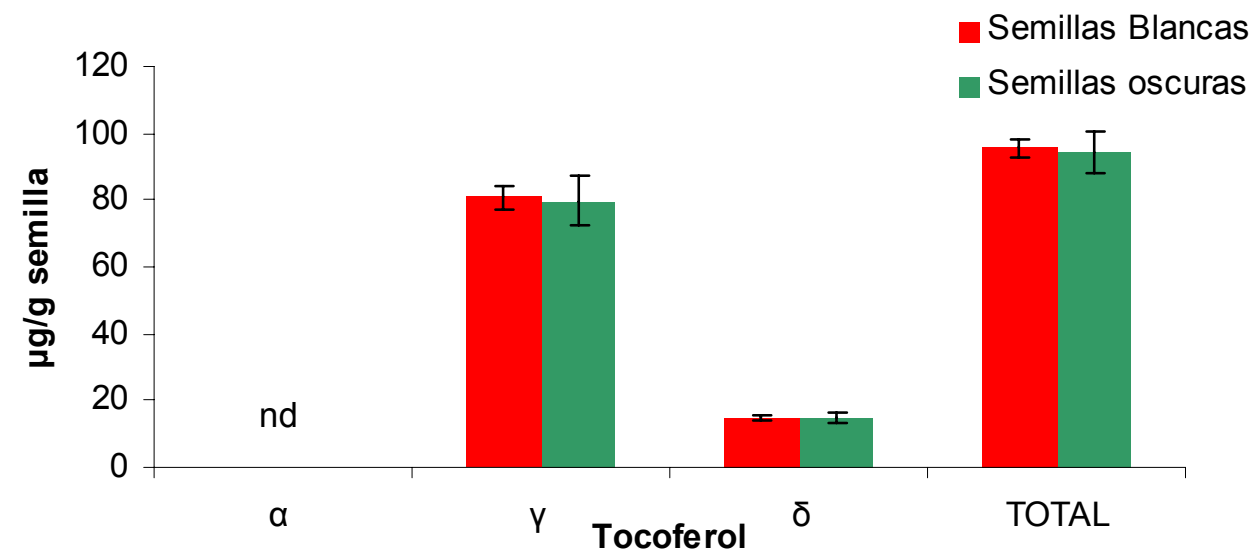

Figura 2.5 Contenido de tocoferoles de las semillas de chía provenientes de Argentina. Las barras verticales indican la desviación estándar.

Por otra parte, los principales antioxidantes polifenólicos presentes en las semillas de chía fueron miricetina, ácidos clorogénico y cafeico, seguidos de trazas de kaempferol y quercetina (Figura 2.6). Esta información es similar a la proporcionada por Taga y col (1984), quienes detectaron la presencia de estos 
mismos antioxidantes en extractos hidrolizados y no hidrolizados de semillas de chía provenientes de México (ver Tabla 1.7). El contenido total de antioxidantes polifenólicos así como los niveles de cada uno de los componentes correspondientes a las semillas blancas y oscuras presentaron diferencias significativas ( $p \leq 0,05)$, siendo mayores los niveles asociados a las primeras.

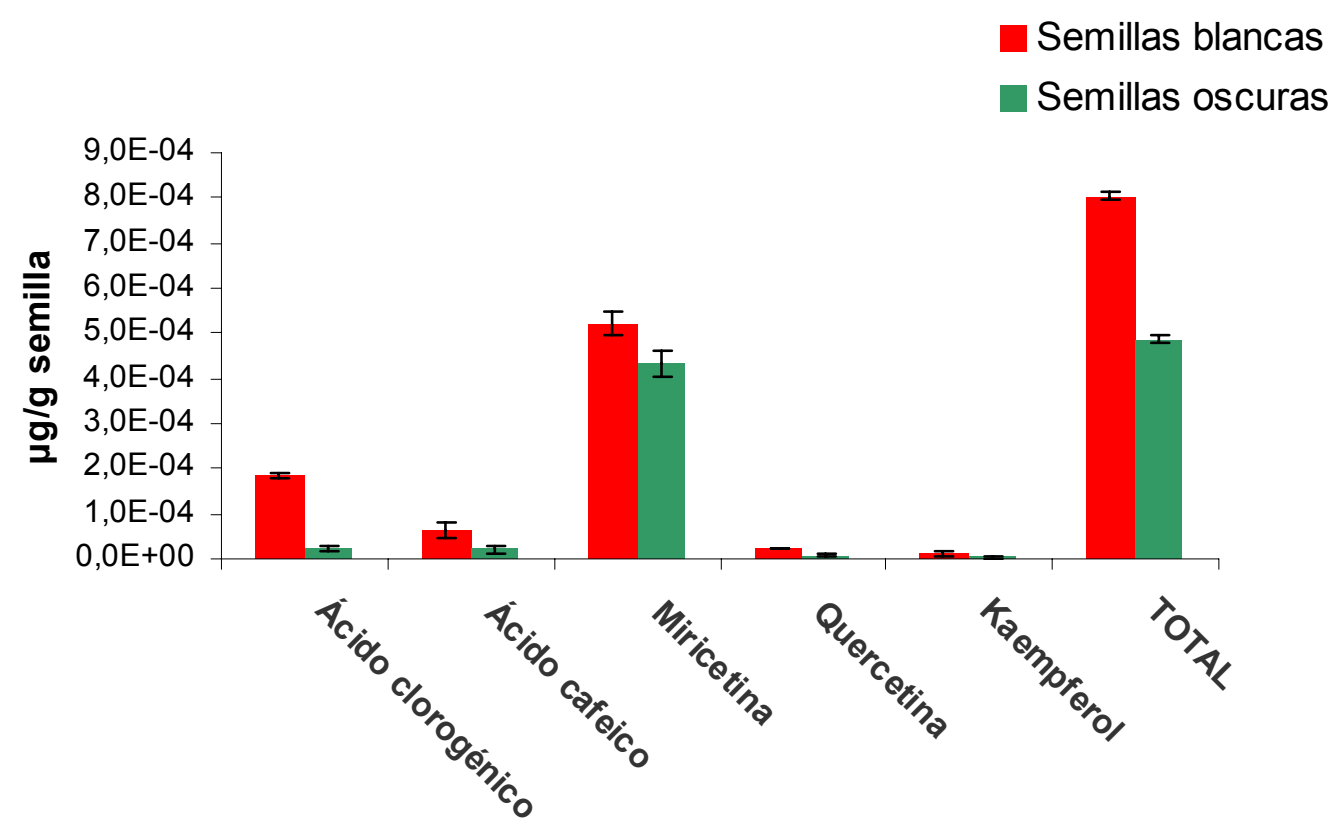

Figura 2.6 Contenido de antioxidantes fenólicos correspondientes a las semillas de chía provenientes de Salta (Argentina). Las barras verticales indican la desviación estándar. 


\section{Semillas de chía provenientes de Quetzaltenango (Guatemala)}

\subsection{Descripción de la semilla}

2.1.1 Composición y contenido de humedad de la mezcla comercial de las semillas según el color del pericarpio

Con respecto a las muestras originarias de Guatemala, la mezcla comercial estuvo integrada por $99,4 \pm 0,3 \%$ en peso de semillas oscuras mientras que sólo 0,6 $\pm 0,3 \%$ de las semillas presentaron el pericarpio blanco. Debido a que las semillas blancas fueron muy escasas, las propiedades gravimétricas y friccionales se determinaron sólo en el caso de las semillas oscuras. El contenido de humedad de la mezcla comercial fue de $10,0 \pm 0,1 \%$ (b.s.).

\subsubsection{Propiedades físicas}

\subsubsection{Tamaño y forma}

La Tabla 2.6 muestra la distribución en tamaño de las semillas de chía provenientes de Guatemala, indicando las dimensiones características de cada clase, así como el $D_{g}$, $S$ y $R$ de las mismas.

La dimensión longitudinal varió entre 1,60 - 2,73 mm, con un mayor porcentaje de semillas pequeñas ( $L \leq 2,00 \mathrm{~mm}$ ), lo cual representa el $47 \%$ de las semillas oscuras y el $57 \%$ de las blancas.

A diferencia de lo observado en las semillas de Argentina, no se registraron diferencias estadísticamente significativas $(p>0,05)$ en las propiedades físicas concernientes al tamaño y a la forma de las semillas oscuras y blancas de Guatemala excepto para el espesor, el cual fue mayor en el caso de las semillas oscuras. 
Tabla 2.6. Distribución en tamaño de semillas de chía oscuras y blancas provenientes de Guatemala determinadas a un contenido de humedad de $10,0 \%$ (b.s.)

\begin{tabular}{|c|c|c|c|c|c|c|c|c|}
\hline $\begin{array}{l}\text { Tipo de } \\
\text { semilla }\end{array}$ & $\begin{array}{l}\text { Rango de } L \\
\left((\mathrm{~mm})^{1}\right.\end{array}$ & $\begin{array}{c}\% \text { de } \\
\text { semillas }\end{array}$ & $\begin{array}{c}L \\
(\mathrm{~mm})^{1}\end{array}$ & $\begin{array}{c}W \\
(\mathrm{~mm})^{1}\end{array}$ & $\begin{array}{c}T \\
(\mathrm{~mm})^{1}\end{array}$ & $\begin{array}{c}D_{g} \\
(\mathrm{~mm})^{1}\end{array}$ & $\begin{array}{c}S \\
\left(\mathrm{~mm}^{2}\right)^{1}\end{array}$ & $\begin{array}{c}R \\
(\%)^{1}\end{array}$ \\
\hline \multicolumn{9}{|l|}{ Oscuras } \\
\hline Sin clasificar & $1,60-2,39$ & 100 & $2,03^{a}$ & $1,27^{\mathrm{a}}$ & $0,76^{b}$ & $1,25^{\mathrm{a}}$ & $4,91^{\mathrm{a}}$ & $63,2^{\mathrm{a}}$ \\
\hline Grandes & $>2,25$ & 10 & 2,33 & 1,27 & 0,79 & 1,32 & 5,53 & 54,5 \\
\hline Medianas & $2,00-2,25$ & 43 & 2,12 & 1,27 & 0,79 & 1,28 & 5,20 & 60,2 \\
\hline Pequeñas & $\leq 2,00$ & 47 & 1,87 & 1,27 & 0,72 & 1,19 & 4,51 & 67,8 \\
\hline \multicolumn{9}{|l|}{ Blancas } \\
\hline Sin clasificar & $1,60-2,73$ & 100 & $1,99^{a}$ & $1,31^{a}$ & $0,67^{a}$ & $1,20^{a}$ & $4,58^{a}$ & $66,2^{a}$ \\
\hline Grandes & $>2,25$ & 10 & 2,44 & 1,50 & 0,76 & 1,41 & 6,24 & 61,7 \\
\hline Medianas & $2,00-2,25$ & 33 & 2,11 & 1,35 & 0,69 & 1,25 & 4,91 & 64,1 \\
\hline Pequeñas & $\leq 2,00$ & 57 & 1,84 & 1,26 & 0,65 & 1,14 & 4,10 & 68,3 \\
\hline
\end{tabular}

${ }^{1}$ Valores promedio $(n=90)$. Letras distintas entre semillas oscuras y blancas sin clasificar indican que existen diferencias significativas $(p \leq 0,05)$.

La Tabla 2.7 muestra las relaciones entre las dimensiones características y $D_{g}$. Las relaciones fueron estadísticamente significativas, en todos los casos registrándose los mayores valores del coeficiente de correlación para las relaciones que involucraron el $D_{g}\left(T / D_{g}, W / D_{g}\right.$ y $\left.L / D_{g}\right)$.

La siguiente expresión general puede ser utilizada para describir la relación entre las tres dimensiones características de las semillas de chía procedentes de Guatemala:

$L=1,57 W=2,83 T$

Ec. 2.16 
Tabla 2.7. Correlación de las dimensiones de la semilla de chía provenientes de Quetzaltenango (Guatemala)

\begin{tabular}{lcccc}
\hline Relación & Valor del Cociente & $\begin{array}{c}\text { Grados } \\
\text { de } \\
\text { libertad }\end{array}$ & $\begin{array}{c}\text { Coeficiente de } \\
\text { correlación }(\mathbf{r})\end{array}$ & $\mathbf{p}$ \\
\hline$L / W$ & 1,57 & 178 & 0,373 & $0,0000^{* \star * *}$ \\
$L / T$ & 2,83 & 178 & 0,421 & $0,0000^{* * *}$ \\
$L / D_{g}$ & 1,64 & 178 & 0,775 & $0,0000^{* \star *}$ \\
$W / T$ & 1,83 & 178 & 0,177 & $0,0032^{* * *}$ \\
$W / D_{g}$ & 1,05 & 178 & 0,727 & $0,0000^{* \star * *}$ \\
$T / D_{g}$ & 0,58 & 178 & 0,716 & $0,0000^{* * *}$ \\
\hline
\end{tabular}

*** Significativo al 0,1\%; **** Significativo al 0,01\%

\subsubsection{Propiedades gravimétricas}

En la Tabla 2.8 se observan los valores promedio de cada una de las propiedades gravimétricas estudiadas. Tal como se mencionó previamente, estas propiedades fueron determinadas sólo para las semillas oscuras, ya que debido al bajo porcentaje de semillas blancas presentes en la muestra fue muy difícil disponer de la cantidad de semillas necesaria para la determinación de las mismas.

Tabla 2.8. Propiedades físicas gravimétricas de las semillas de chía oscuras provenientes de Guatemala

\begin{tabular}{lccccccc}
\hline $\begin{array}{c}\text { Tipo de } \\
\text { semilla }\end{array}$ & $\begin{array}{c}\rho_{\mathrm{b}} \\
\left(\mathbf{g} / \mathbf{c m}^{\mathbf{3}}\right)^{\mathbf{1}}\end{array}$ & $\begin{array}{c}\boldsymbol{\rho}_{\mathrm{t}} \\
\left(\mathbf{g} / \mathbf{c m}^{\mathbf{3}}\right)^{\mathbf{1}}\end{array}$ & $\begin{array}{c}\varepsilon \\
(\mathbf{\%})^{\mathbf{1}}\end{array}$ & $\begin{array}{c}\boldsymbol{V} \\
\left(\mathbf{m m}^{\mathbf{3}}\right)^{\mathbf{1}}\end{array}$ & $\begin{array}{c}D_{\mathrm{e}} \\
(\mathbf{m m})^{\mathbf{1}}\end{array}$ & $\begin{array}{c}\phi \\
\mathbf{( \% )})^{\mathbf{1}}\end{array}$ & $\begin{array}{c}W_{\mathbf{1 0 0 0}} \\
\mathbf{( g )} \mathbf{2}^{\mathbf{2}}\end{array}$ \\
\hline Oscuras & 0,706 & 0,980 & 27,9 & 1,17 & 1,31 & 64,5 & 1,150 \\
\hline
\end{tabular}

${ }^{1}$ Valores promedio $(n=3) ;{ }^{2}$ Valores promedio $(n=24)$

\subsubsection{Propiedades friccionales - Fluidez}

El ángulo de reposo de las semillas de chía de Guatemala fue de $16,0 \pm 0,2^{\circ}$, mientras que el coeficiente de fricción promedio $0,28 \pm 0,01$ y 0,30 $\pm 0,01$ sobre acero galvanizado y acero inoxidable, respectivamente. 


\subsection{Estructura y composición de las semillas}

\subsubsection{Observaciones microscópicas}

La Figura 2.7 muestra las imágenes correspondiente a las núculas blancas y oscuras de Guatemala obtenidas mediante microscopía electrónica de barrido (SEM) con diferentes grados de magnificación. Las mismas presentaron una estructura interna correspondiente a las especies del género Salvia, tal como fue descripta para las semillas de chía procedentes de Argentina.

Puede visualizarse que la rugosidad de la superficie es similar tanto en las núculas blancas como en las oscuras, mientras que en la estructura interna del pericarpio, la capa de esclereidas es más compacta en las núculas oscuras.
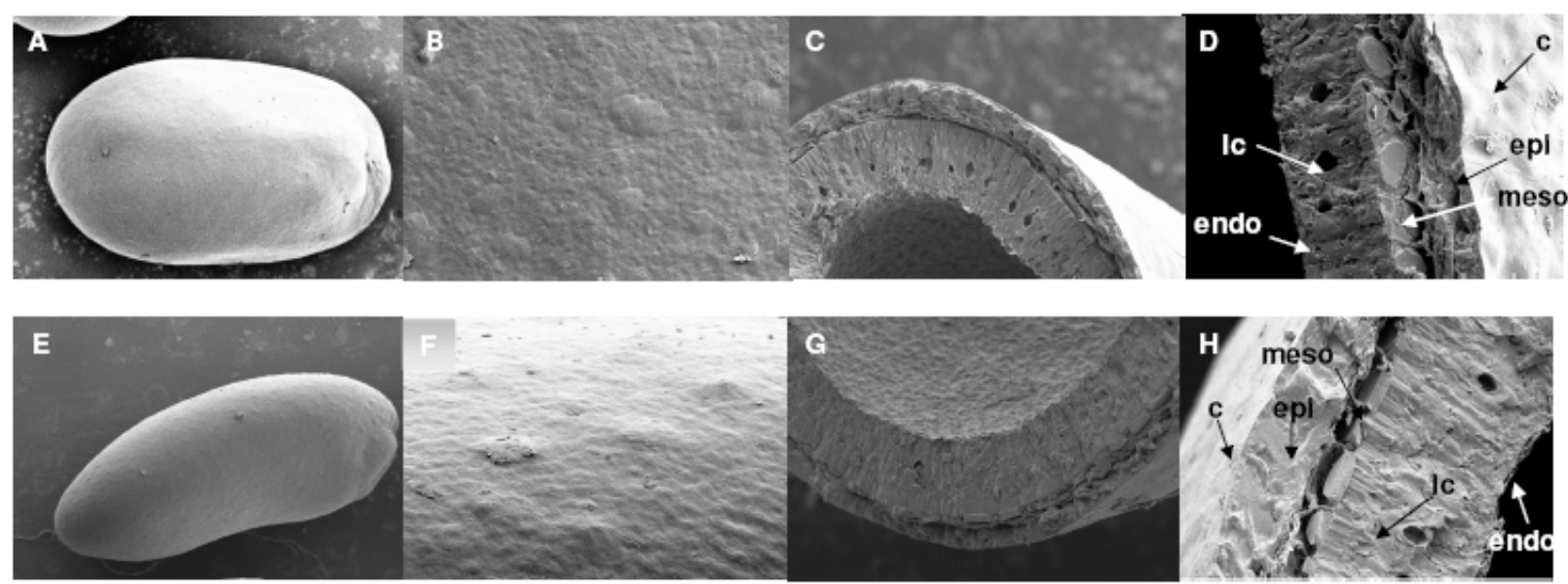

Figura 2.7. Micrografías electrónicas obtenidas por microscopia electrónica de barrido (SEM) de núculas de Salvia hispanica provenientes de Guatemala. A - D, Núculas blancas. E - H, Núculas oscuras. Vista lateral: A, E (x 145); vista frontal: B, F (x 170); superficie del pericarpio: C, G (x 1500); sección transversal del pericarpio: D, H (x 3000). C: cutícula; epi: epicarpio; meso: mesocarpio; lc: capa de esclereidas; endo: endocarpio 


\subsubsection{Análisis composicional}

En la Tabla 2.9 se indica la composición centesimal de las semillas de chía provenientes de Quetzaltenango (Guatemala). Puede observarse que la fibra y la fracción lipídica constituyen los componentes mayoritarios.

Tabla 2.9. Composición (\%, b.s.) promedio de semillas de chía provenientes de Quetzaltenango, Guatemala

\begin{tabular}{|c|c|}
\hline Componente & $\begin{array}{c}\text { Contenido } \\
\text { (\% b.s.) }\end{array}$ \\
\hline Proteínas & 19 \\
\hline Lípidos & 25 \\
\hline Cenizas & 4 \\
\hline Fibra & 29 \\
\hline Extractos libres de nitrógeno* & 23 \\
\hline
\end{tabular}

\subsubsection{Esquema de análisis de Van Soest}

La Tabla 2.10 muestra los resultados de los análisis de FDN y FDA, calculados a partir del método propuesto por Van Soest (Guiragossian, 1977). Como en la mayoría de las semillas oleaginosas, la celulosa representa el mayor polímero estructural de la pared celular, el cual es un homopolímero formado por cadenas lineales $\beta$ 1-4 unidas a unidades de glucopiranosil, formando parte de la fracción insoluble de la fibra.

Tabla 2.10. Valores de la calidad de las semillas de chía provenientes de Guatemala analizados según el método de Van Soest, expresados en \% (b.s.)

\begin{tabular}{cccccc}
\hline & FDA & FDN & Lignina & Hemicelulosa & Celulosa \\
\cline { 2 - 6 } & \multicolumn{5}{c}{$\%$ b.s. } \\
\hline Semillas de chía & 47,4 & 62,8 & 6,2 & 15,4 & 41,2 \\
\hline
\end{tabular}

\subsubsection{Compuestos antioxidantes}

Las Figuras 2.8 y $\mathbf{2 . 9}$ muestran la composición y el contenido de tocoferoles y compuestos fenólicos presentes en las semillas de Guatemala, respectivamente. Los resultados obtenidos no registraron diferencias estadísticamente significativas ( $p>$ 
0,05) entre ambos tipos de semillas, con un contenido total de tocoferoles de alrededor de 110 ppm. El 97\% del contenido total de tocoferoles correspondió a Ytocoferol, detectándose además pequeñas cantidades de $\delta$-tocoferol y trazas de $\alpha$ tocoferol.

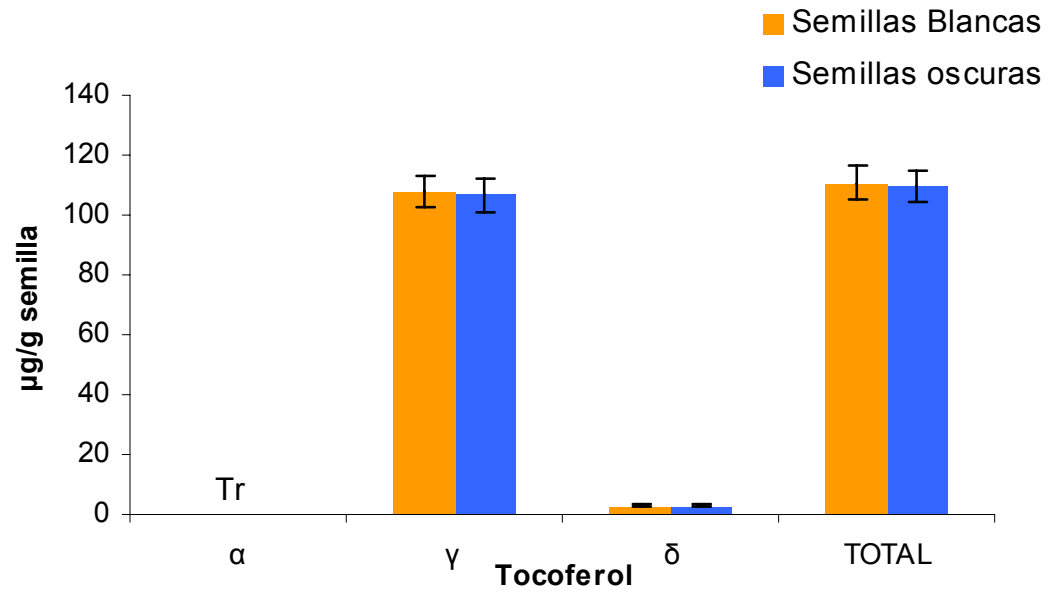

Figura 2.8 Contenido de tocoferoles de las semillas provenientes de Quetzaltenango (Guatemala). Las barras verticales indican la desviación estándar.

Con respecto a los compuestos fenólicos, se encontró que el contenido total fue significativamente mayor $(p \leq 0,05)$ en las semillas blancas que en las oscuras, siendo el tenor correspondiente a los ácidos clorogénico y cafeico, los principales responsables de esta diferencia. El contenido de quercetina y kaempferol fue significativamente $(p \leq 0,05)$ mayor en las semillas blancas, no detectándose diferencias $(p>0,05)$ en el contenido de miricetina.

Semillas blancas

Semillas oscuras

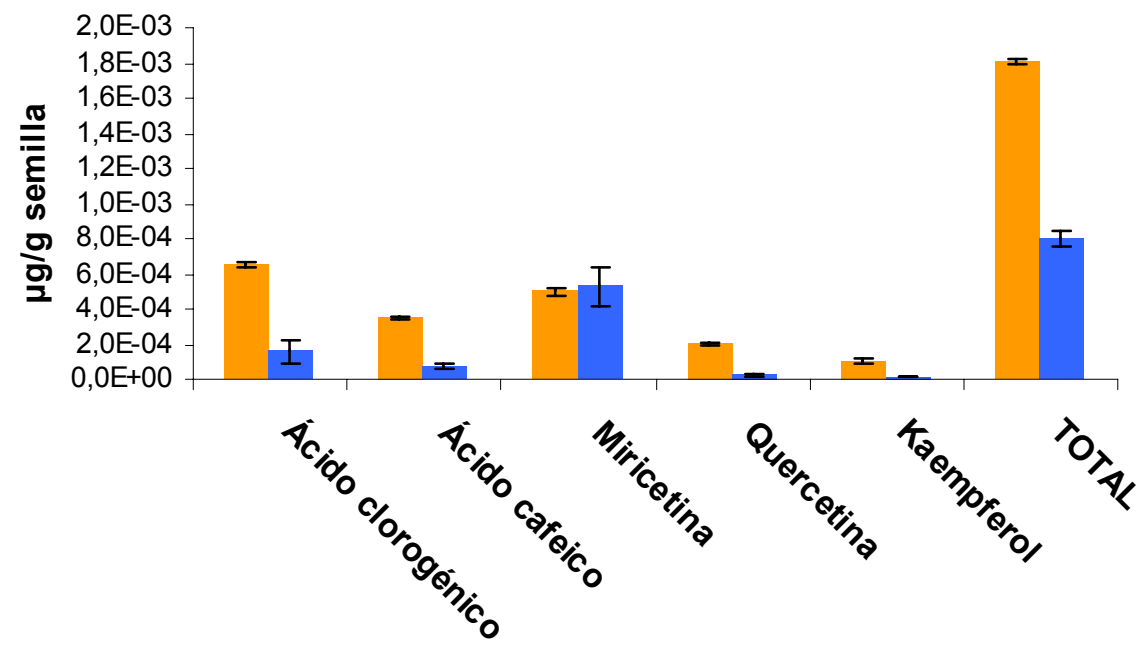

Figura 2.9 Contenido de antioxidantes fenólicos correspondientes a las semillas de chía provenientes de Quetzaltenango (Guatemala). Las barras verticales indican la desviación estándar. 


\section{Estudio comparativo de las semillas de Argentina y Guatemala}

\subsection{Descripción de la semilla}

3.1.1 Composición y contenido de humedad de la mezcla comercial de las semillas según el color del pericarpio

Como puede apreciarse, el porcentaje de semillas blancas en la mezcla comercial de Guatemala fue significativamente menor ( $p \leq 0,05)$ que el correspondiente a las de Argentina. El carácter color del pericarpio de la semilla está codificado por un gen de herencia cualitativa y por lo tanto poco influenciado por el ambiente, por lo que las diferencias encontradas pueden atribuirse a la composición genética de las mezclas comerciales estudiadas. Debido a que las semillas blancas fueron muy escasas en la mezcla comercial proveniente de Guatemala, la determinación de las propiedades gravimétricas sólo fue llevada a cabo en las semillas oscuras, mientras que las propiedades friccionales se determinaron para la mezcla comercial de semillas.

La semillas procedentes de Guatemala presentaron un contenido de humedad $(10,0 \pm 0,1 \%$ b.s. $)$ superior a las semillas cultivadas en Argentina $(7,0 \pm 0,4 \%$ b.s. $)$.

\subsubsection{Propiedades físicas}

\subsubsection{Tamaño y forma}

En la Tablas 2.11 y 2.12 se presentan los valores de $t$ y de probabilidad ( $p$ ) resultantes del análisis del test de Student al comparar las semillas provenientes de orígenes diferentes para cada tipo de semilla (oscuras y blancas).

Las semillas oscuras de Argentina presentaron un largo, espesor y diámetro geométrico significativamente mayor $(p \leq 0,05)$ y una relación de aspecto significativamente menor ( $p \leq 0,05)$ que las de Guatemala, mientras que no se encontraron diferencias $(p>0,05)$ en el ancho ni en el área superficial específica (ver Tablas 2.1 y 2.6).

La comparación de las semillas blancas de ambos orígenes, permitió observar diferencias estadísticamente significativas $(p \leq 0,05)$ en todas las dimensiones características, así como en las demás propiedades que permiten caracterizar la forma y tamaño de las semillas de chía. Las semillas blancas de Argentina presentaron en promedio un mayor tamaño que las de Guatemala (ver Tablas 2.1 y 2.6). 
Tabla 2.11. Comparación de medias de las propiedades físicas relacionadas con el tamaño y la forma de las semillas oscuras provenientes de Argentina y Guatemala

\begin{tabular}{lcccccc}
\hline Propiedad física & $\boldsymbol{L}$ & $\boldsymbol{W}$ & $\boldsymbol{T}$ & $\boldsymbol{D}_{\boldsymbol{g}}$ & $\boldsymbol{S}$ & $\boldsymbol{R}$ \\
\hline Valor de t & 2,37 & 1,47 & 4,05 & 3,30 & 0,74 & 3,24 \\
$\mathbf{p}$ & $0,0193^{*}$ & $0,1450^{\text {ns }}$ & $0,0000^{* * * *}$ & $0,0013^{* *}$ & $0,4605^{\text {ns }}$ & $0,0015^{* *}$ \\
\hline${ }^{\text {ns }}$ no significativo; ${ }^{*}$ Significativo al 5\%; ${ }^{* *}$ Significativo al 1 \%; *** Significativo al 0,01\% & &
\end{tabular}

Tabla 2.12. Comparación de medias de las propiedades físicas relacionadas con el tamaño y la forma de las semillas blancas provenientes de Argentina y Guatemala

\begin{tabular}{lcccccc}
\hline Propiedad física & $\boldsymbol{L}$ & $\boldsymbol{W}$ & $\boldsymbol{T}$ & $\boldsymbol{D}_{\boldsymbol{g}}$ & $\boldsymbol{S}$ & $\boldsymbol{R}$ \\
\hline Valor de $\mathbf{t}$ & 3,49 & 2,49 & 12,00 & 7,27 & 3,51 & 7,23 \\
$\mathbf{p}$ & $0,0012^{* \star}$ & $0,0171^{*}$ & $0,0000^{\star * \star *}$ & $1,22 \times 10^{-8^{* \star \star \star}}$ & $0,00062^{* \star \star}$ & $1,09 \times 10^{-8^{* \star \star *}}$ \\
\hline
\end{tabular}

${ }^{\text {ns }}$ no significativo; * Significativo al $5 \%$; ${ }^{* *}$ Significativo al $1 \% ;{ }^{* * *}$ Significativo al 0,1 \%*** Significativo al 0,01 \%

\subsubsection{Propiedades gravimétricas}

La comparación de medias de las propiedades gravimétricas de las semillas oscuras provenientes de ambos orígenes indicó la existencia de diferencias significativas $(p \leq 0,05)$ en la densidad aparente y en el peso de mil semillas (Tabla 2.13). El mayor valor de $\boldsymbol{W}_{1000}$ asociado a las semillas de Argentina respecto a las de Guatemala puede relacionarse con un tamaño más grande de las primeras. Teniendo en cuenta además que no se encontraron diferencias significativas ( $p$ > $0,05)$ en la porosidad ni en la $\boldsymbol{\rho}_{r}$, el mayor valor de la $\boldsymbol{\rho}_{\boldsymbol{b}}$ podría estar relacionado con las diferencias morfológicas $(\boldsymbol{R})$ y consecuentemente con la disposición de las semillas en el lecho.

Tabla 2.13. Comparación de medias de las propiedades gravimétricas de las semillas oscuras provenientes de Argentina y Guatemala

\begin{tabular}{|c|c|c|c|c|c|c|c|}
\hline $\begin{array}{l}\text { Propiedad } \\
\text { física }\end{array}$ & $\rho_{b}$ & $\rho_{\mathrm{t}}$ & $\varepsilon$ & $V$ & $D_{e}$ & $\phi$ & $W_{1000}$ \\
\hline Valor de $\mathbf{t}$ & 8,28 & 0,70 & 0,12 & 2,67 & 2,74 & 0,07 & 16,49 \\
\hline p & $0,0012^{* *}$ & $0,5240^{\mathrm{ns}}$ & $0,9050^{\mathrm{ns}}$ & $0,0557^{\mathrm{ns}}$ & $0,0598^{n s}$ & $0,9465^{\mathrm{ns}}$ & $0,0000^{* * \star *}$ \\
\hline
\end{tabular}




\subsubsection{Propiedades friccionales - Fluidez}

Las propiedades friccionales de la mezcla comercial de semillas provenientes de ambos orígenes fueron similares, lo cual es atribuible a la semejanza existente entre la superficie de las semillas y su esfericidad.

\subsection{Estructura y composición de las semillas}

\subsubsection{Observaciones microscópicas}

La organización básica del pericarpio resulta similar en las núculas de $S$. hispanica de ambos orígenes estudiados, con un grosor de aproximadamente 76 $\mu \mathrm{m}$, el cual es menor que el correspondiente a Cinopodium vulgare L. aunque apenas mayor que el de Calamintha nepeta subsp. Nepeta Mill., géneros pertenecientes a la familia Lamiaceae (Martín Mosquero y col., 2004). A nivel estructural, la principal diferencia está relacionada con el espesor del epicarpio, el cual fue mayor en las núculas provenientes de Guatemala $(\sim 20 \mu \mathrm{m})$ que en las de Argentina $(\sim 12 \mu \mathrm{m})$ así como en el de la cutícula, que fue $0,4 \mu \mathrm{m}$ más grueso en las semillas de Guatemala $(\sim 1,6 \mu \mathrm{m})$. El resto de las capas que componen el pericarpio presentaron dimensiones similares para ambas núculas. La estructura del pericarpio tiene valor de diferenciación taxonómica entre géneros o especies. Sin embargo, a nivel intraespecie las diferencias son muy pequeñas lo cual puede apreciarse en la semejanza entre las núculas provenientes de ambos orígenes de $S$. hispanica.

\subsubsection{Composición proximal}

Se observaron diferencias a nivel de la composición proximal, habiéndose detectado un mayor contenido de proteínas y de lípidos en las semillas provenientes de Argentina, lo cual podría ser atribuido tanto al genotipo como a las diferentes condiciones ambientales de cultivo. El contenido de fibra y de cenizas fue similar en ambas semillas, mientras que los hidratos de carbono resultaron mayores en las semillas provenientes de Guatemala (ver Tablas 2.4 y 2.9).

\subsubsection{Esquema de análisis de Van Soest}

La composición de la fibra determinada a través de este método presentó diferencias entre las semillas provenientes de ambos orígenes, pudiéndose observar un mayor contenido de celulosa y menor de hemicelulosa en las semillas de Guatemala que en las procedentes de Argentina (ver Tablas 2.5 y 2.10) 


\subsubsection{Compuestos antioxidantes}

La Figura 2.10 presenta la composición y el contenido de tocoferoles correspondientes a la mezcla comercial de semillas provenientes de ambos orígenes estudiados. Las semillas de Guatemala exhibieron un contenido total de tocoferoles significativamente superior $(p \leq 0,05)$ al de las de Argentina. Esta diferencia fue también observada en el contenido de $\gamma$-tocoferol, mientras que el tenor de $\delta$ tocoferol fue significativamente mayor $(p \leq 0,05)$ en las semillas de Argentina. Estos resultados pueden ser atribuidos a las diferentes condiciones climáticas de ambas zonas de producción y/o diferencias entre los genotipos que componen ambos cultivares.

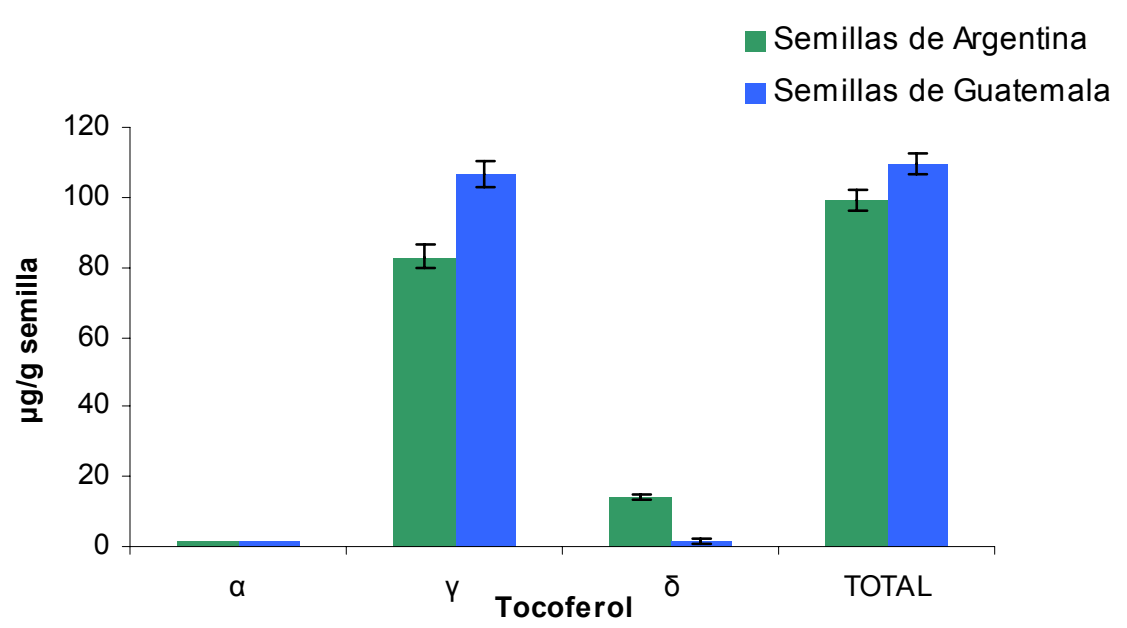

Figura 2.10 Contenido de tocoferoles correspondiente a la mezcla de semillas provenientes de Argentina y de Guatemala. Las barras verticales indican la desviación estándar.

Por otra parte, el contenido de compuestos polifenólicos presentes en la mezcla comercial de las semillas estudiadas se presenta en la Figura 2.11. Puede observarse que al igual que lo registrado en el caso de los tocoferoles, el contenido total de compuestos polifenólicos fue significativamente mayor $(p \leq 0,05)$ en las semillas de Guatemala, registrándose estas diferencias en cada uno de los antioxidantes polifenólicos, principalmente en el ácido clorogénico. 
Semillas de Argentina

Semillas de Guatemala

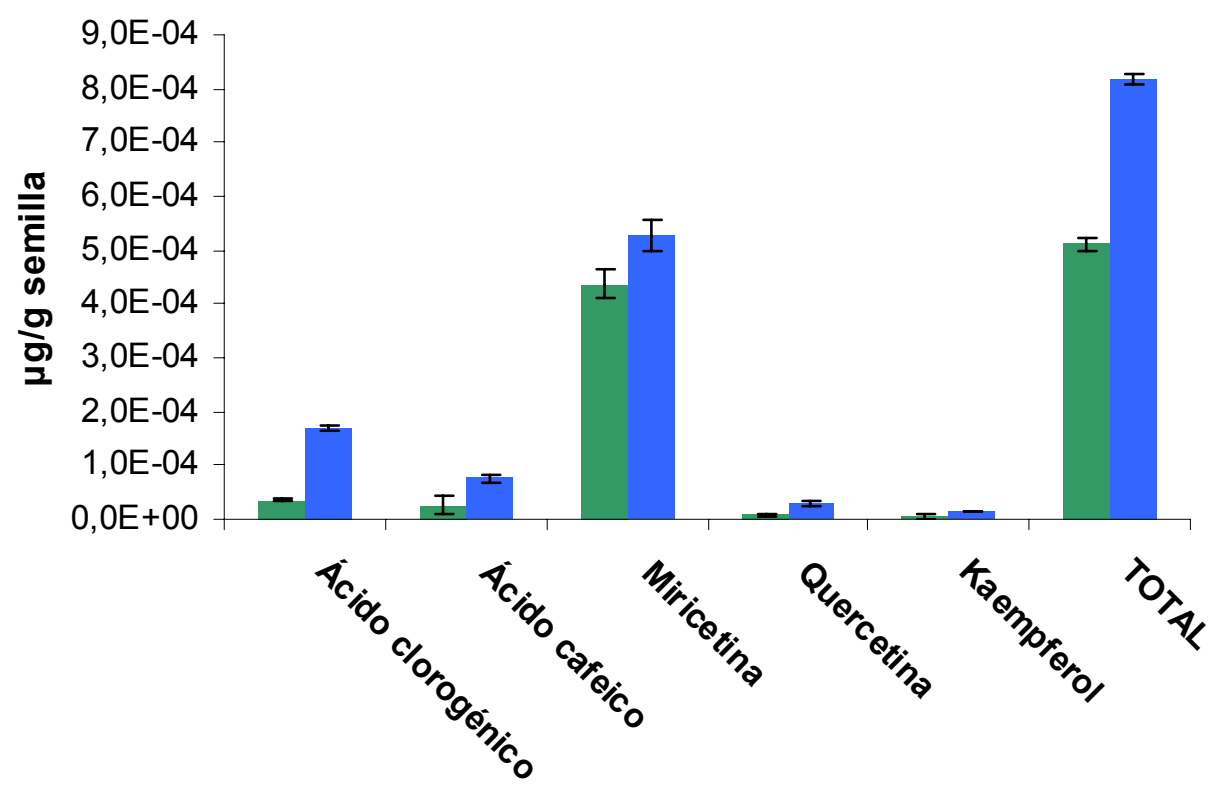

Figura 2.11 Contenido de antioxidantes fenólicos correspondiente a la mezcla de semillas provenientes de Argentina y de Guatemala. Las barras verticales indican la desviación estándar. 


\section{CONCLUSIONES PARCIALES}

El estudio relacionado con la estructura, morfología y propiedades físicas y químicas de las semillas de chía (núculas) provenientes de Salta (Argentina) y Quetzaltenango (Guatemala) permitió alcanzar las siguientes conclusiones:

- Las semillas de chía presentaron tres semiejes desiguales, cuya forma puede describirse mediante un elipsoide escaleno.

- Las dimensiones características de las semillas oscuras y blancas provenientes de Salta (Argentina) fueron 2,11; 1,32 y $0,81 \mathrm{~mm}$ y 2,$15 ; 1,40$ y $0,83 \mathrm{~mm}$ para el largo, ancho y espesor, respectivamente. Las semillas de Guatemala resultaron en promedio de menor tamaño, cuyas dimensiones características fueron 2,$03 ; 1,27$ y $0,76 \mathrm{~mm}$ y 1,$99 ; 1,31$ y $0,67 \mathrm{~mm}$ para el largo, ancho y espesor de las semillas oscuras y blancas, respectivamente.

- Las semillas oscuras provenientes de Argentina presentaron un valor de $\boldsymbol{W}_{1000}$ mayor que el de las semillas blancas correspondientes a la misma procedencia geográfica, registrando valores de 1,323 y $1,301 \mathrm{~g}$, respectivamente, mientras que la comparación entre las semillas oscuras de ambos orígenes mostró que las semillas de Argentina fueron más pesadas que las de Guatemala $(1,150 \mathrm{~g})$.

- Las propiedades $\rho_{t}, \varepsilon, V, D_{e}$ y $\phi$ fueron similares para las semillas de chía oscuras provenientes de ambos orígenes, con valores promedio de 1,009/ $0,980 \mathrm{~g} / \mathrm{cm}^{3} ; 28,2 / 27,9 \% ; 1,30 / 1,17 \mathrm{~mm}^{3} ; 1,35-1,31$ y $64,4-64,5 \%$, para las semillas de Argentina y Guatemala, respectivamente. Por otra parte, la $\rho_{b}$ fue mayor en las semillas oscuras provenientes de Argentina.

- El diámetro geométrico de las semillas de chía puede ser utilizado convenientemente para el cálculo teórico del volumen y la esfericidad de la misma.

- Las propiedades friccionales fueron similares para la mezcla comercial de semillas de chía provenientes de ambos orígenes, con un ángulo de reposo de 16 a $18^{\circ}$ y un coeficiente de fricción sobre chapa galvanizada y acero inoxidable de 0,28 y 0,31 , respectivamente. 
- Las semillas (núculas) de chía son glabras, constituidas por el pericarpio y la semilla verdadera. Las núculas blancas y oscuras presentaron características estructurales similares, observándose sólo pequeñas variaciones a nivel del pericarpio.

- El contenido de proteínas y de lípidos de las semillas fue de $19-29 \%$ y 25 $32 \%$, respectivamente, siendo mayor en aquéllas provenientes de Argentina respecto de las de Guatemala. El tenor de fibra y cenizas presentó un rango de variación menor, con valores de 27-29 y 4-5\%, respectivamente.

- Se registró la presencia de tocoferoles y de compuestos polifenólicos en las semillas de chía estudiadas. El contenido total de tocoferoles varió de 95-110 ppm, siendo el principal compuesto $\mathrm{y}$-tocoferol. Además, fue posible la detección de menores concentraciones de $\delta$-tocoferol, así como trazas de $\alpha$ tocoferol. Por otra parte, los principales antioxidantes polifenólicos fueron miricetina, ácidos clorogénico y cafeico, seguidos de trazas de kaempferol y quercetina.

Por lo expuesto previamente, se acepta la hipótesis I: "Las propiedades físicas, la microestructura y las características fisicoquímicas de las semillas (núculas) de Salvia hispanica L. presentan diferencias tanto dentro de las mezclas comerciales (semillas oscuras y blancas) como entre las mismas (mezclas de distinta procedencia)". 


\section{DIFUSIÓN DE RESULTADOS}

Capítulos de libro

- Characterization of chia (Salvia hispanica L.) white and dark seeds and oils. Ixtaina VY, Nolasco SM, Tomás MC. En Advances in Fats and Oils Research (2010). Editor M.C. Tomás. Ed. Transworld Research Network, Kerala (India), pp 135-147.

Publicaciones Científicas en Revistas Internacionales

- Physical properties of chía (Salvia hispanica L.) seeds. Vanesa Y. Ixtaina, Susana M. Nolasco, Mabel C. Tomás, Industrial Crops and Products 28 (2008), 286-293.

Presentaciones en Congresos

- Caracterización de semillas y aceite de chía (Salvia hispanica L.). V.Y.Ixtaina, S.M. Nolasco y M. C. Tomás, Congreso Internacional de Ciencia y Tecnología de los Alimentos, Córdoba, Argentina, 15 al 17 de noviembre de 2006.

- Caracterización microestructural de la semilla y el mucílago de chía (Salvia hispanica L), Vanesa Y. Ixtaina, Marianela Capitani, Susana M. Nolasco y Mabel C. Tomás, Congreso Argentino de Química, Lanús, septiembre de 2010. 
Capítulo 3

\section{Obtención y caracterización de aceite de chía} mediante procesos convencionales 


\section{INTRODUCCIÓN}

Uno de los principales objetivos de la producción de aceite de chía radica en la adecuada selección del método de extracción. El rendimiento de extracción y la calidad del aceite obtenido son de suma importancia para determinar la viabilidad de su producción comercial.

La extracción con solventes, principalmente hexano, es uno de los procesos más tradicionales empleados en la obtención de aceites de semillas oleaginosas. El principio de extracción con solvente se basa en el hecho que un componente (soluto) se distribuye entre dos fases según la relación de equilibrio determinada por la naturaleza del componente y las dos fases (Bockisch, 1998). A fin de facilitar el proceso de extracción, es necesario reducir el tamaño de la semilla o grano mediante el quebrado e inclusive el laminado (King y col., 1944; Karnofsky, 1949, 1986, 1987; Wingard y Phillips, 1949; Myers, 1977; Prámparo y col., 2003). La aplicación de un tratamiento térmico antes o durante la extracción produce la rotura de la emulsión celular, reduce la viscosidad del aceite facilitando su fluidez y desplazamiento así como disminuye la tensión superficial del aceite. No obstante, dicho tratamiento puede afectar negativamente la calidad química del mismo incrementando los parámetros de oxidación.

Patricelli y col. (1979) realizaron experiencias con girasol parcialmente descascarado en un sistema "batch", estudiando la influencia de la granulometría, el contenido de humedad, la temperatura de extracción y la relación sólido-solvente. Estos autores determinaron que la etapa limitante es la difusiva y que la extracción del aceite aumenta cuando disminuye el tamaño de partícula y se incrementa la temperatura de extracción.

En los últimos años, se ha intensificado el interés por la obtención de aceites a través de tecnologías de prensado. En el caso de la obtención de aceites vegetales no tradicionales, el prensado, mediante prensa hidráulica o de tornillo, provee un método sencillo para obtener aceites a partir de pequeños lotes de semillas (Wiesenborn y col., 2001; Singh y col., 2002; Zheng y col., 2003). Si bien los rendimientos en aceite obtenidos por prensado son menores que los alcanzados mediante la extracción con solventes, esta tecnología resulta apropiada para materiales con alto contenido en aceite, ya que requiere instalaciones menos costosas e implica operaciones más seguras y de menor riesgo para el medio ambiente. El principio de extracción por prensado se basa en que cada partícula 
retiene el aceite en su interior y el objetivo del prensado es lograr que el mismo migre desde el sistema hacia el exterior. En la estructura celular, el aceite se encuentra dentro de pequeños orgánulos de forma esférica (esferosomas), rodeados por una fina membrana. La aplicación de una fuerza externa durante el prensado produce una serie de alteraciones (deformaciones) tanto a nivel microscópico (células) como macroscópico. Así, se comprime cada partícula y cada una de ellas se reacomoda en el conjunto. Las membranas que limitan a cada esferosoma se destruyen, al igual que las paredes celulares, permitiendo al aceite salir de la partícula y luego, a través del sistema macroscópico, hacia el exterior. Estos dos últimos efectos resultan de la deformación producida por la fuerza y la consecuente reducción del espacio físico disponible (Mattea, 1999).

El rendimiento de la extracción por prensa de tornillo depende de varios factores, entre ellos, el acondicionamiento del material, que consiste en una serie de operaciones como la limpieza, molienda, calentamiento, secado o humedecimiento hasta alcanzar el contenido de humedad óptimo (Singh y col., 2002). La aplicación de un tratamiento térmico antes o durante el prensado generalmente mejora la extracción del aceite ya que influye sobre la viscosidad del fluido y la resistencia mecánica de las partículas (Ward, 1976). El efecto del contenido de humedad de la semilla en el momento del prensado ha sido ampliamente estudiado en una gran variedad de materiales (Singh y Bargale, 1990; Singh y Bargale, 2000; Wiesenborn, 2001; Singh y col., 2002). El porcentaje de humedad resulta muy importante ya que no sólo aumenta la plasticidad del material sino que también contribuye al prensado por su acción lubricante. Sin embargo, altos contenidos de humedad pueden afectar negativamente la extracción y/o alterar la calidad química del aceite, a través de la hidrólisis de glicéridos con el consiguiente incremento de la acidez.

Singh y Bargale (2000) desarrollaron un expeller de dos etapas, en el cual analizaron la influencia de la humedad del material y de la temperatura de prensado sobre la cantidad de aceite extraído, relacionando estos parámetros con el tiempo de prensado y la energía consumida. En concordancia con Singh y col. (2002) y Zheng y col. (2003), concluyeron que existe un porcentaje de humedad óptimo para lograr la máxima extracción de aceite. Asimismo, observaron que la energía consumida disminuye al aumentar el contenido de humedad, lo cual fue atribuido a una reducción del coeficiente de fricción por efecto de una mayor plasticidad del material. 
Teniendo en cuenta lo expuesto previamente, en este capítulo se propone estudiar las características fisicoquímicas de los aceites de chía obtenidos mediante solvente y prensado con el propósito de contribuir a su conocimiento y establecer las bases sólidas para la obtención de aceite de chía a nivel industrial. 


\section{MATERIALES Y MÉTODOS}

\section{Material vegetal}

El material vegetal utilizado para la extracción del aceite por procesos convencionales fue el mismo empleado para la caracterización de las semillas previamente descripto. Se tomaron muestras al azar de cada una de las dos fuentes de semillas (Argentina y Guatemala) con un cuarteador (CPASA, Centro Proveedor Agropecuario, Buenos Aires, Argentina), a partir de las cuales se obtuvo el respectivo aceite por prensado o solvente. Cada uno de los aceites obtenidos fue analizado en forma independiente.

\section{Extracción del aceite}

\subsection{Extracción con solventes}

Las semillas de ambos lotes se trituraron en un molinillo de cuchillas (Braun, Type 4041, México) durante 60 s. La extracción del aceite se llevó a cabo en un equipo Soxhlet, empleando como disolvente $n$-hexano (grado analítico, CAS $\mathrm{N}^{0}$ : 110-54-3, valoración: mínimo $96 \%$, punto de ebullición: $\left.69^{\circ} \mathrm{C}\right)$, siguiendo la norma IUPAC 1.122 (IUPAC, 1992). Se dispusieron aproximadamente $40 \mathrm{~g}$ de las muestras trituradas en cartuchos de papel Whatman $\mathrm{N}^{\circ} 3$. El proceso se efectuó durante $8 \mathrm{~h}$ a una temperatura de $80^{\circ} \mathrm{C}$ a presión atmosférica. La evaporación del solvente se llevó a cabo en un evaporador rotatorio (Büchi, Flawil, Suiza) bajo vacío a $40^{\circ} \mathrm{C}$. El residuo de $n$-hexano fue removido mediante una corriente de nitrógeno hasta peso constante El contenido de aceite se determinó gravimétricamente y se expresó como porcentaje en masa de la semilla triturada libre de humedad (g aceite/100 g semilla, b.s.).

Para las semillas provenientes de Argentina, la extracción de aceite con solvente además de realizarse a partir de la mezcla comercial de semillas, se llevó a cabo sobre las semillas blancas y oscuras en forma separada, determinando las principales características fisicoquímicas de los aceites obtenidos en cada caso.

\subsection{Extracción por prensado}

El contenido de humedad de las semillas fue ajustado a $10 \%$ con el objetivo de aumentar el rendimiento de aceite y evitar problemas de atoramiento durante el proceso de prensado. Este contenido de humedad fue seleccionado debido a que se obtuvo la máxima capacidad de prensado, definiéndose la misma como el peso 
de aceite extraído en un tiempo determinado. La humidificación se llevó a cabo según la metodología propuesta por Singh y Bargale (2000). El agua se agregó a la muestra mediante aspersión. Luego se colocó en un recipiente metálico con cierre hermético y se almacenó durante $48 \mathrm{~h}$ hasta alcanzar el equilibrio. El recipiente fue sometido a agitación, a intervalos regulares de tiempo, para asegurar una distribución uniforme de la humedad en el material. Previo a su ingreso a la prensa, se determinó el contenido de humedad de cada muestra según la metodología descripta en el Capítulo 2.

La extracción del aceite se llevó a cabo en una sola etapa a $25-30^{\circ} \mathrm{C}$ en una prensa de tornillo helicoidal a escala piloto marca Komet (Modelo CA 59 G IBG Monforts, Mönchengladbach, Alemania) (Figura 3.1). Las muestras fueron suministradas a la prensa desde la tolva por gravedad, según la demanda. La longitud total y efectiva, así como el diámetro interno del barral de la prensa fueron de 7,3 y $3,5 \mathrm{~cm}$, respectivamente. La longitud y el diámetro del tornillo fueron de 15 $\mathrm{cm}$ y $3 \mathrm{~cm}$, respectivamente. Se utilizó una restricción de $5 \mathrm{~mm}$ y la velocidad de prensado fue de $20 \mathrm{rpm}$, habiendo sido establecida mediante ensayos preliminares. La temperatura de salida de la torta o residuo de extracción fue controlada con un termómetro digital colocado en el orificio de salida (reducción) de la prensa. La cantidad de aceite obtenido fue determinada gravimétricamente y expresada como porcentaje en peso ( $g$ aceite/100 g semilla, b.s.).

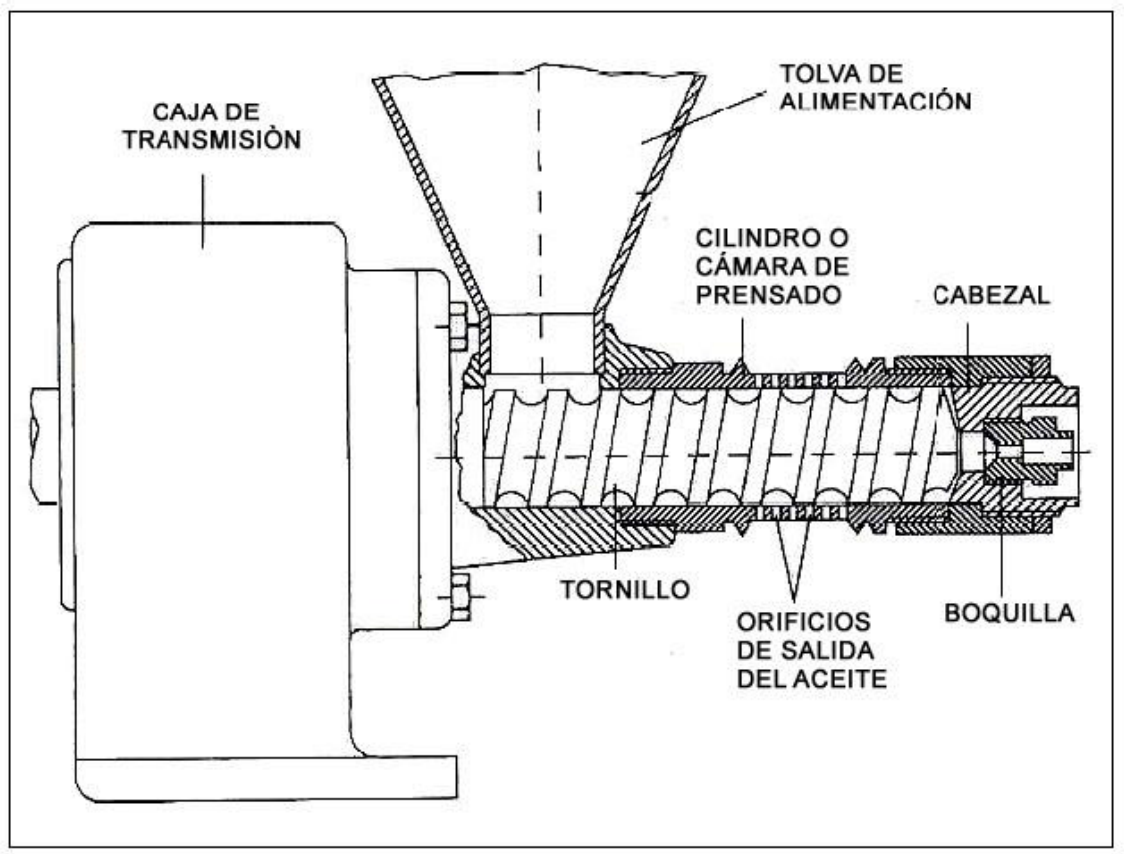

Figura 3.1. Esquema de la prensa de tornillo helicoidal utilizada para la extracción del aceite (Martínez, 2010) 


\subsection{Almacenamiento del aceite}

El aceite de chía obtenido a través de ambos sistemas de extracción fue almacenado en recipientes de vidrio color caramelo, bajo atmósfera de nitrógeno a $4 \pm 1^{\circ} \mathrm{C}$ hasta su posterior utilización.

\section{Análisis fisicoquímico de los aceites}

\subsection{Composición de ácidos grasos mediante cromatografía gaseosa (CG)}

La identificación y cuantificación de ácidos grasos (FAs) de los aceites se llevó a cabo por cromatografía gaseosa, de acuerdo a los métodos IUPAC 2.301 y 2.302 (1992). Los aceites crudos (100 $\mu \mathrm{L}$ ) fueron saponificados con $1 \mathrm{~mL}$ de solución de $\mathrm{KOH} 10 \%$ en metanol mediante reflujo a $85^{\circ} \mathrm{C}$ durante $45 \mathrm{~min}$. El material insaponificable se extrajo con éter de petróleo (p.e. $30-40^{\circ} \mathrm{C}$ ). Luego de la acidificación con $\mathrm{HCl}$, los ácidos grasos hidrolizados fueron extraidos de la fase metanólica con éter de petróleo y se metilaron con $1 \mathrm{~mL}$ de trifluoruro de boro (solución al $20 \%$ en metanol) (Merck) en $1 \mathrm{~mL}$ metanol a $60^{\circ} \mathrm{C}$ durante 45 min. Los ésteres metílicos de los ácidos grasos (FAME) se obtuvieron a partir de la fase metanólica con éter de petróleo.

Análisis por CG: la mezcla de FAME se analizó en un cromatógrafo de gases (Hewlett Packard 6890) equipado con detector de ionización de llama. La separación se realizó en una columna capilar Supelco 11090-02A Omegawax (30 m x 0.250 $\mathrm{mm}$, diámetro interno $25 \mu \mathrm{m})$ a $175-220^{\circ} \mathrm{C}\left(3^{\circ} \mathrm{C} / \mathrm{min}\right)$ empleando helio como gas portador $(25,1 \mathrm{psi})$ y detector de llama a $260^{\circ} \mathrm{C}$ (Christie, 2003). El contenido de cada uno de los ácidos grasos identificados se expresó como valor porcentual en relación al contenido total de los mismos.

\subsection{Composición y distribución de la posición acílica de los ácidos grasos en la molécula de glicerol mediante espectroscopía de ${ }^{13} \mathrm{C}$ NMR}

El análisis de la distribución de los FAs en la molécula de glicerol se realizó mediante espectroscopía de resonancia magnética nuclear de ${ }^{13} \mathrm{C}\left({ }^{13} \mathrm{C} N \mathrm{NM}\right)$. Las determinaciones se llevaron a cabo en colaboración con investigadores de Spectral Service (Cologne, Alemania). Las muestras fueron analizadas en un espectrómetro Avance III 600 (Bruker, Karlsruhe, G), con una densidad de flujo magnético 14,1 Tesla equipado con un cabezal criogénico QNP y un inyector automático Bruker BACS 120. Para la adquisición de datos se utilizó un procesador Intel Core2 Duo 2.4 
GHz bajo el sistema MS Windows XP; el procesamiento de los mismos fue llevado a cabo mediante el software Bruker TopSpin 2.1, siguiendo el procedimiento operativo standard SAA-GMR028-01. Las muestras fueron preparadas diluyendo $200 \mathrm{mg}$ de aceite en $1 \mathrm{~mL}$ de cloroformo deuterado $\left(\mathrm{CDCl}_{3}\right)$ y $200 \mu \mathrm{LMSO}-\mathrm{d}_{6}$. Posteriormente, las muestras fueron secadas con $200 \mathrm{mg}$ de sulfato de sodio anhidro. El número de corridas (NS) fue 1024.

\subsection{Espectroscopía de ${ }^{1} \mathrm{H}$ NMR}

Análogamente, la composición de ácidos grasos también fue determinada por espectroscopía de NMR. La ${ }^{1} \mathrm{H}$ NMR permite el análisis de los dobles enlaces determinando un parámetro comparable al índice de iodo, lo cual es útil para un análisis más detallado de los aceites. La preparación de las muestras y el equipo utilizado fueron similares a los indicados en el ítem 3.2. El número de corridas NS fue 16.

\subsection{Composición de triacilgliceroles (TAG)}

Las muestras de aceite $(10 \mathrm{mg})$ fueron disueltas en $2 \mathrm{~mL}$ de $\mathrm{CHCl}_{3} / \mathrm{CH}_{3} \mathrm{OH} / \mathrm{HCOOH} \quad(50: 50: 0,1)$ determinándose la composición de triacilgliceroles por HPLC/APCI-MS. El cromatógrafo consistió en una bomba de gradiente Rheos 2000 (Flux Instruments, Basel, CH), un degasificador on-line Degasser ERC-3415 a (ERC GmbH, Riemerling, G), un detector UV con arreglo de diodo 6000LP (Thermo Finnigan, San José, CA), un muestreador automático HTC PAL (CTC Analytics AG, Zwingen, CH), y un compartimento termostatizado para la columna (L-5025, Merck, Darmstadt, G). Las condiciones de HPLC se detallan en la Tabla 3.1.

Tabla 3.1. Condiciones de trabajo empleadas en la determinación de triacilgliceroles por HPLC/APCI-MS

\begin{tabular}{ll}
\hline Columna cromatográfica & Nucleosil $120 \mathrm{C} 18(125 \mathrm{~m} \times 4 \mathrm{~mm} \times 5 \mu \mathrm{m})$ \\
Velocidad de flujo & $0,4 \mathrm{~mL} / \mathrm{min}$ \\
Volumen de inyección & $10 \mu \mathrm{L}$ \\
Temperatura de la columna & $40^{\circ} \mathrm{C}$ \\
Fase móvil & $\mathrm{A}:$ acetonitrilo; B: acetato de amonio en 2-propanol $(0,1 \% \mathrm{p} / \mathrm{v})$ \\
Detector & UV acoplado en serie con un APCl-MS ion-positivo \\
Longitud de onda & $200 \mathrm{~nm}$ \\
\hline
\end{tabular}


Se aplicó el siguiente gradiente de elución: el porcentaje de solvente A disminuyó de 60 a 35\% en los primeros 31 min, luego aumentó de 35 a $60 \%$ hasta el $\min 35$ y se mantuvo constante hasta el min 45. La aguja de inyección se lavó con la fase móvil previamente a cada inyección. Se utilizó un espectrómetro de masas Finnigan LTQ (Termo Electron Corp., San José, CA) en un rango m/z de 500 - 1000, fijando los siguientes parámetros de ajuste: temperatura capilar $250^{\circ} \mathrm{C}$, flujo de gas de revestimiento 20 psi, flujo de gas secante $20 \mathrm{~L} / \mathrm{min}$, temperatura del vaporizador $\mathrm{APCl} 450^{\circ} \mathrm{C}$. Se realizó la integración de los picos de los cromatogramas en la región m/z 800 - 1000. Los datos fueron analizados en una computadora PIV 2.8 $\mathrm{GHz}$ bajo sistema Windows XP y utilizando el Software Xcalibur 2.0.

\section{5. Índices de iodo y de saponificación (II, IS)}

El índice de iodo es una medida de los dobles enlaces correspondientes a los ácidos grasos presentes en el aceite expresado en función del porcentaje de iodo absorbido, mientras que el valor de saponificación es la cantidad de álcali necesaria para saponificar cuantitativamente la muestra presente expresándose como el número de $\mathrm{mg}$ de hidróxido de potasio requeridos para saponificar un gramo de aceite. Debido a que todos los ácidos grasos se unen a una molécula de $\mathrm{KOH}$, el valor de saponificación también es una medida indirecta del peso molecular medio de los triacilgliceroles de un aceite y por lo tanto, un número característico.

Debido a las dificultades operativas en las determinaciones analíticas de estos índices, los mismos pueden también calcularse a partir de la composición porcentual de los ésteres metílicos de los ácidos grasos obtenidos por cromatografía gaseosa (AOCS Cd 1c-85 y Cd 3a-94, 1998).

Los índices de iodo (II) y saponificación (IS) teóricos fueron calculados de acuerdo a las siguientes ecuaciones:

$$
\begin{array}{lr}
I I=\left(C_{16: 1} \times 0,950\right)+\left(C_{18: 1} \times 0,86\right)+\left(C_{18: 2} \times 1,732\right)+\left(C_{18: 3} \times 2,616\right)+\left(C_{20: 1} \times 0,785\right)+\left(C_{22: 1} \times 0,723\right) & \text { Ec. } 3.1 \\
I S=\left[\frac{3 \times 56,1 \times 1000}{[\overline{P M} \times 3)+92,09-(3 \times 18)}\right] & \text { Ec. } 3.2
\end{array}
$$

donde:

\section{6,1: peso molecular de $\mathrm{KOH}$}

92,09: peso molecular del glicerol

18: peso molecular del agua 
$\overline{P M}$ : peso molecular promedio

donde:

$$
\overline{P M}=\sum P M_{i} \times X_{i}
$$

siendo,

$P M_{i}$ : peso molecular del ácido graso $i$

$X_{i}$ : fracción molar del ácido graso $i$

\section{6. Índice de refracción}

El índice de refracción (IR) se determinó de acuerdo a la norma AOCS Cc 725 (1998). El método se basa en la relación de las velocidades de la luz en el vacío y en la sustancia, la cual depende del grado de saturación, longitud de cadena, contenido de ácidos grasos libres y oxidación entre otros factores. La medición fue realizada en un refractómetro Abbe que consta de un medidor de temperatura digital. Se empleó luz monocromática de una lámpara de vapor de sodio. En la práctica, las lecturas se refirieron respecto al aire con una exactitud de 0,0002. La ecuación utilizada para ajustar las lecturas a la temperatura estándar $\left(20^{\circ} \mathrm{C}\right)$ fue:

$I R=I R^{\prime}+0,000385 \times\left(T-T^{\prime}\right)$

donde:

$\mathrm{T}$ : temperatura de referencia $\left(20^{\circ} \mathrm{C}\right)$

$\mathrm{T}^{\prime}$ : temperatura a la que se realiza la lectura $\left({ }^{\circ} \mathrm{C}\right)$

IR': lectura del índice de refracción realizada a la temperatura T'

IR: índice de refracción corregido

\section{7. Ácidos grasos libres (FFA)}

Se determinaron los ácidos grasos libres según la norma Ca 5a-40 AOCS (1998). Para ello se pesaron $6 \mathrm{~g}$ de aceite con una aproximación de $0,01 \mathrm{~g}$ y se colocaron en un erlenmeyer de $250 \mathrm{~mL}$. El aceite se disolvió en una mezcla de 75 $\mathrm{mL}$ de alcohol etílico $(95 \% \mathrm{v} / \mathrm{v})$ caliente y se neutralizó con $\mathrm{NaOH}$ y $0,3 \mathrm{~mL}$ de solución de fenolftaleína $(1 \% \mathrm{p} / \mathrm{v})$. La concentración de ácidos grasos libres del aceite se obtuvo mediante titulación de esta mezcla con una solución de $\mathrm{NaOH} 0,1$ $\mathrm{N}$ y se expresó como porcentaje $(\mathrm{p} / \mathrm{p})$ de ácido oleico. 
$F F A=\frac{V \times N \times 28,2}{P M}$

donde:

V: volumen de $\mathrm{NaOH}$ utilizados en la titulación $(\mathrm{mL})$

$\mathrm{N}$ : normalidad del $\mathrm{NaOH}$

PM: peso de la muestra $(\mathrm{g})$

\section{8. Índice de peróxido (PV)}

El índice de peróxido (PV) se determinó según la norma Cd 8-53 AOCS (1998). Este método permite determinar todas aquellas sustancias que oxidan el ioduro de potasio en las condiciones del ensayo, en términos de miliequivalentes de peróxido por $\mathrm{kg}$ de grasa, las cuales son peróxidos o bien otros productos similares originados por la oxidación del aceite. La técnica consiste en una titulación iodométrica y se basa en la capacidad oxidante de los peróxidos para liberar iodo a partir del ioduro de potasio.

Se pesaron $5 \mathrm{~g}$ de aceite con una aproximación de $0,05 \mathrm{~g}$ y se colocaron en un erlenmeyer de $250 \mathrm{~mL}$. Se agregaron $30 \mathrm{~mL}$ de solución de ácido acético: cloroformo (3:2 v/v) agitando vigorosamente hasta lograr su disolución. Se adicionaron $0,5 \mathrm{~mL}$ de solución saturada de ioduro de potasio, se agitó y luego se dejó en reposo en oscuridad durante $1 \mathrm{~min}$. Posteriormente, se agregaron $30 \mathrm{~mL}$ de agua destilada y el iodo liberado se tituló, agitando continuamente con solución 0,01 $\mathrm{N}$ de tiosulfato de sodio hasta la desaparición del color amarillo. Se adicionaron 0,5 $\mathrm{mL}$ de solución de almidón ( $1 \% \mathrm{p} / \mathrm{v}$ ) y se continuó titulando hasta la desaparición del color azul. El índice de peróxido (expresado como miliequivalentes de peróxido/kg de aceite) se calculó en base a la siguiente ecuación:

$$
P V=\frac{(S-B) \times N \times 1000}{P M}
$$

donde:

S: volumen de la solución de tiosulfato de sodio consumidos en la titulación de la muestra $(\mathrm{mL})$

B: volumen de la solución de tiosulfato de sodio consumidos en el blanco $(\mathrm{mL})$

$\mathrm{N}$ : normalidad de la solución de tiosulfato de sodio

PM: peso de la muestra $(\mathrm{g})$ 


\subsection{Materia insaponificable}

El residuo de materia insaponificable se determinó según la norma AOCS Ca 6b-53 (1998). El residuo insaponificable incluye todos los compuestos no saponificables por álcalis, insolubles en agua y solubles en solventes comunes de grasa, como por ejemplo hidrocarburos saturados y no saturados, alcoholes de alto peso molecular, esteroles, entre otros. Generalmente, el mismo representa un tenor inferior al $2 \%$ de la muestra. Como solventes de extracción se emplean éter etílico o éter de petróleo y debido a que los procesos de extracción continua no brindan resultados precisos, la separación se realiza utilizando ampollas de decantación.

Se pesaron $5 \mathrm{~g}$ de aceite en un balón y se agregaron $30 \mathrm{~mL}$ de una solución de alcohol etílico $95 \%$ y $5 \mathrm{~mL}$ de $\mathrm{KOH}$ al $5 \%$, calentándolo bajo reflujo a Baño de María durante $60 \mathrm{~min}$. Posteriormente se transfirió el contenido a una ampolla de decantación, completando hasta la marca de $40 \mathrm{~mL}$ con alcohol etílico $95 \%$ y agua destilada hasta los $80 \mathrm{~mL}$. Una vez enfriado a temperatura ambiente se agregaron $50 \mathrm{~mL}$ de éter agitando la ampolla fuertemente durante $1 \mathrm{~min}$. Se dejó reposar hasta separación total de fases y se transfirió la capa inferior a una ampolla similar. Se agregaron $5 \mathrm{~mL}$ de agua a la primera ampolla y el líquido acuoso se transfirió a la segunda. Se añadieron a ésta última $50 \mathrm{~mL}$ de éter etílico, agitando fuertemente, dejando posteriormente separar las capas. La capa inferior fue descartada (ácidos). Los líquidos etéreos se reunieron en la primera ampolla, a la cual se agregaron 30 $\mathrm{mL}$ de agua. Se decantó la capa inferior, realizando otro lavado similar, descartando nuevamente la fase acuosa. Se añadieron 1 a $2 \mathrm{~mL}$ de solución de $\mathrm{KOH}(0,1 \%)$ en etanol y $20 \mathrm{~mL}$ de agua (para destruir los jabones ácidos), agitando, decantando y desechando la capa inferior. Se siguió con los lavados con agua (50-100 mL) agitando fuertemente, hasta reacción neutra al tornasol de los líquidos acuosos. La capa etérea final fue tratada con $\mathrm{Na}_{2} \mathrm{SO}_{4}$ (anh.) y se filtró por papel embebido en éter etílico (por retención de restos de agua). Se lavaron la ampolla y embudo 2 ó 3 veces con pequeñas porciones de éter. Se evaporó el solvente por destilación a Baño de María hasta alcanzar aproximadamente $5 \mathrm{~mL}$ de solución. Se trasvasó a un erlenmeyer de $50 \mathrm{~mL}$ seco y previamente tarado, con la ayuda de pequeñas porciones de éter, evaporándose nuevamente y se terminó de secar en estufa a 75$80^{\circ} \mathrm{C}$ y $200 \mathrm{~mm}$ de $\mathrm{Hg}$. Una vez enfriado en desecador se pesó (valor A).

Después de pesar se retomó el residuo con $50 \mathrm{~mL}$ de etanol $95 \%$ a $50^{\circ} \mathrm{C}$ conteniendo indicador fenolftaleína, previamente neutralizado. Se tituló con una 
solución de $\mathrm{NaOH}$ 0,02 N. Se corrigió el peso del residuo debido a los ácidos grasos libres, utilizando la siguiente relación $1 \mathrm{~mL}$ de $\mathrm{NaOH} 0,02 \mathrm{~N}$ es equivalente a 0,0056 $\mathrm{g}$ de ácido oleico.

El peso de los ácidos grasos determinados por la titulación constituyó el valor B en el cálculo para determinar el porcentaje de insaponificable. Además, se llevó a cabo la corrección por el blanco. Los cálculos se realizaron según la siguiente ecuación:

$\%$ insaponificable $=\frac{A-(B+C)}{P M} \times 100$

donde:
A: masa de residuos de la muestra $(\mathrm{g})$
$\mathrm{B}$ : masa de ácidos grasos $(\mathrm{g})$
C: masa de residuos del blanco $(\mathrm{g})$
PM: peso de la muestra $(\mathrm{g})$

\subsection{Contenido de fósforo}

El contenido de fósforo total fue determinado mediante el método colorimétrico según las normas IRAM 5597 (IRAM, 1970).

Para ello se pesaron aproximadamente $70 \mathrm{mg}$ de muestra, la cual fue calcinada a $650^{\circ} \mathrm{C}$ en presencia de óxido de magnesio, habiéndose retomado las cenizas con agua bidestilada y $1,25 \mathrm{~mL}$ de ácido sulfúrico $10 \mathrm{~N}$. La solución fue transferida a una ampolla de $125 \mathrm{~mL}$ conteniendo $3 \mathrm{~mL}$ de solución de molibdato de amonio $5 \% \mathrm{p} / \mathrm{v}$. Los iones ortofosfatos presentes reaccionaron con el molibdato de amonio para formar un compuesto de fosfomolibdato. Se agregaron $10 \mathrm{~mL}$ de alcohol isobutílico, se agitó vigorosamente durante 2 min y se permitió la separación de las dos fases. La fase inferior (acuosa) fue separada y luego de sucesivos lavados de la fase superior (alcohólica) con porciones de $5 \mathrm{~mL}$ de $\mathrm{H}_{2} \mathrm{SO}_{4}$ se agregaron $10 \mathrm{~mL}$ de solución de $\mathrm{SnCl}_{2}$ a fin de reducir el fosfomolibdato a azul de molibdeno (color turquesa azulado). Se agitó vigorosamente la ampolla durante $15 \mathrm{~s}$, decantándose la fase acuosa. El contenido de la ampolla se colocó en una probeta graduada de $10 \mathrm{~mL}$. Se lavó la ampolla con pequeñas porciones de alcohol isobutílico las cuales se incorporaron a la probeta hasta completar $10 \mathrm{~mL}$. Se mezcló por inversión de la probeta 3 veces. Se dejó en reposo $30 \mathrm{~min}$, realizándose al cabo 
de dicho tiempo la medición espectrofotométrica del complejo de color azul formado a $650 \mathrm{~nm}$.

Por otra parte, previamente se obtuvo una curva de calibración a partir de una solución diluida de fósforo a distintas concentraciones $(0-2,5 \mu \mathrm{g} / \mathrm{mL})$. La cantidad de fósforo en la muestra (ppm) se calculó a partir del valor hallado mediante la curva de calibración $(A)$.

$$
P=\frac{A}{P M}
$$

donde:

A: cantidad de P determinado de la curva de calibración $(\mu g)$

PM: peso de la muestra $(\mathrm{g})$

\subsection{Color}

El color de los aceites de chía se determinó mediante el sistema CIELab. Las muestras se colocaron en un recipiente circular de aproximadamente $4 \mathrm{~cm}$ de diámetro x $1 \mathrm{~cm}$ de altura. Se midieron los valores $L^{*}, a^{*}$, y $b^{*}$ con un colorímetro Minolta (CR-400, Konica Minolta Sensing Inc., Japan). El parámetro a* representa las tonalidades que van desde el verde (valores negativos) al rojo (positivos), mientras que el valor de $b^{*}$ indica los tonos azules para los valores negativos y amarillos para los positivos. Para ambos parámetros, el cero equivale al gris. A través de la coordenada $L^{*}$ se representa la luminosidad, correspondiendo 100 al blanco, 50 al gris y 0 al negro. Se realizaron 10 repeticiones por muestra.

\subsection{Carotenoides y clorofilas}

La extracción y cuantificación de los carotenoides fue realizada según Messina y col. (2009). Las muestras de aceite $(0,5 \mathrm{~g})$ fueron llevadas a un volumen total de $3 \mathrm{~mL}$ con solución al $0,9 \%$ de $\mathrm{NaCl}$, y mezcladas con pirogalol en etanol $1 \%$ (v/v). La saponificación se realizó durante $30 \mathrm{~min}$ a $70^{\circ} \mathrm{C}$ con $0,9 \mathrm{~mL}$ de solución de $\mathrm{KOH} 12 \mathrm{~N}$. Luego, las muestras fueron extraídas dos veces con $n$-hexano (3 volúmenes por extracción), después de la adición de agua destilada, se evaporó bajo flujo de nitrógeno, se resuspendió en $n$-hexano, se diluyó en etanol absoluto y se filtró a través de una membrana de nylon antes de la inyección. La cuantificación de carotenoides se efectuó mediante HPLC. Se utilizó una bomba modelo P4000, con un degasificador de vacío de membrana y un inyector de bucle de $20 \mu$ l, todos 
adquiridos en TSP (Thermo Separation Products Inc.,USA), conectado a una columna Alltima C18 $(250 \mathrm{~mm} \times 4.6 \mathrm{~mm} ; 5 \mu \mathrm{m}$ de tamaño de partícula). El detector electroquímico (Decade, Antec Leyden, The Netherlands) fue equipado con una célula de flujo con $\mathrm{Ag} / \mathrm{AgCl}$ y electrodo de referencia de carbón vítreo y de trabajo, respectivamente. La fase móvil utilizada para la detección electroquímica fue modificada de acuerdo a la técnica descripta por de Rijke y col. (1997). La velocidad de flujo fue de $1 \mathrm{~mL} / \mathrm{min}$ y la celda de referencia fue seleccionada a $+700 \mathrm{mV}$. La recuperación de $\beta$-caroteno fue $98 \%$. Las curvas de calibración fueron obtenidas utilizando como estándar $\beta$-caroteno diluido en etanol absoluto (Sigma-Aldrich, St. Louis, USA).

El contenido de clorofilas fue determinado por análisis espectrofotométrico a $670 \mathrm{~nm}$, en ciclohexano utilizando los valores de extinción específicas (MinguezMosquera y col., 1991).

\subsection{Determinación del contenido de ceras}

La determinación del contenido de ceras en aceites de chía se basó en el método del Diario Oficial de las Comunidades Europeas $N^{\circ}$ L 22/61-65 Anexo IV (30.01.93), el que fue adaptado para aceites de girasol (Carelli y col., 2002). El mismo consiste en:

a) fraccionamiento del aceite, al que se le ha añadido un patrón interno adecuado, mediante cromatografía en columna de gel de sílice hidratado y recuperación de la fracción eluída en las condiciones de ensayo;

b) análisis directo mediante cromatografía de gases, con columna capilar y detector FID.

\section{Fraccionamiento}

Se pesaron con exactitud aproximadamente $0,5 \mathrm{~g}$ de aceite, previamente calentado a $80^{\circ} \mathrm{C}$ para disolver posibles ceras precipitadas y luego fue enfriado a temperatura ambiente. Se añadieron $500 \mu \mathrm{l}$ de la solución empleada como estándar interno ( $5 \mathrm{mg}$ de laurato de araquidilo en $25 \mathrm{~mL}$ de $n$-hexano) y una gota de colorante Sudán I ( $1 \%$ en hexano). La muestra así preparada fue transferida a la columna cromatográfica. El disolvente se eluyó hasta que se situó al nivel de la fase sólida del absorbente. Luego se inició la elución cromatográfica con $n$-hexano:éter etílico libre de peróxidos $(98,5: 1,5)$ a una velocidad de elución de $3 \mathrm{~mL} / \mathrm{min}$. Cuando 
la banda coloreada llegó al fondo de la columna, el proceso se consideró finalizado. El colorante Sudán I posee un frente de avance comprendido entre las ceras y los triacilgliceroles, lo que permitió visualizar la completa elución de las ceras. Se eliminó el solvente de la fracción resultante en un evaporador rotatorio hasta un volumen 2-3 $\mathrm{mL}$. Se llevó a sequedad con una corriente de $\mathrm{N}_{2}$ y se añadieron $500 \mu \mathrm{l}$ de $n$-heptano, inyectando posteriormente la muestra en el cromatógrafo gaseoso.

\section{Análisis cromatográfico}

La composición de ceras fue determinada mediante cromatografía de gases con columna capilar, según las condiciones operativas que se muestran en la Tabla 3.2 .

Tabla 3.2. Condiciones de trabajo empleadas en la determinación de ceras presentes en aceite de chía

Cromatógrafo

Columna

Detector

Gas Carrier

Inyector

Volumen de inyección $3 \mu \mathrm{l}$

Procesador de datos Millenium 2010 (Millipore Corporation, Milford, MA)
Gas-líquido, Varian 3700

Capilar de sílice fundida, fase estacionaria HP5, $11 \mathrm{~m} \times 0,32$ $\mathrm{mm}$, espesor:0,52 $\mu \mathrm{m}$ (Hewlett Packard)

FID

$\mathrm{H}_{2}, 3 \mathrm{~mL} / \mathrm{min}$, presión en la cabeza de la columna: $8 \mathrm{psi}$

"on column" Varian Associates Inc $\left(80-40^{\circ} \mathrm{C} / \mathrm{min}-320\right)$

\subsection{Metales}

La cuantificación del contenido de los metales calcio, magnesio, hierro y cobre fue realizada mediante espectroscopía de absorción atómica utilizando un espectrómetro GBC $902 \mathrm{AA}$. Las muestras fueron mineralizadas $\left(550^{\circ} \mathrm{C}, 16 \mathrm{~h}\right)$ hasta obtener cenizas blancas. Las cenizas fueron diluidas en $\mathrm{HCl}$ concentrado y filtradas para llevarlas a medio líquido. Las muestras se analizaron por triplicado y los resultados fueron expresados en $\mathrm{mg} / \mathrm{kg}$ aceite. 


\subsection{Tocoferoles}

El contenido de tocoferoles se determinó mediante una técnica cromatográfica basada en las normas IUPAC 2.432 (1992) y AOCS Ce8-89 (1998). La muestra de aceite se disolvió en hexano grado HPLC para su posterior separación por cromatografía líquida de alta resolución (HPLC) con detector de fluorescencia. La concentración de tocoferoles se determinó por el método de estándar externo, utilizando el $\alpha$-tocoferol como referencia y se expresó en $\mu \mathrm{g}$ de tocoferol/g aceite.

La descripción del equipo y condiciones de trabajo se especifican en la Tabla 3.3. Los parámetros de trabajo se ajustaron con una solución de aceite de soja y de germen de trigo ( $1 \mathrm{~g}$ de cada uno de los aceites diluidos en $25 \mathrm{~mL}$ de fase móvil). Se identificaron los picos correspondientes a los tocoferoles en función de los tiempos de retención relativos y de patrones ( $\alpha$-tocoferol, $\beta$-tocoferol, $y$-tocoferol y $\delta$-tocoferol).

Tabla 3.3. Condiciones operativas empleadas en la determinación de tocoferoles por cromatografía líquida de alta resolución

Cromatógrafo

Columna

Detector

Fase móvil

Velocidad de flujo

Volumen de inyección
HPLC Hewlett Packard Serie 1050

Lichrosorb Si 60; 25 x 0,4 cm, $5 \mu \mathrm{m}$ de tamaño de partícula

Fluorescencia Agilent 1100 Series; $\lambda$ exitación: $290 \mathrm{~nm} ; \lambda$ de emisión: $330 \mathrm{~nm}$

Isopropanol:hexano, 0,5:99,5 (v/v), filtrado y desgasificado

$1,5 \mathrm{~mL} / \mathrm{min}$

$20 \mu \mathrm{l}$

\section{Curva de calibración}

Para la determinación de la curva de calibración se utilizó un estándar de $\alpha$ tocoferol (Sigma T\#3251, 95\% de pureza), preparándose una solución de $10 \mathrm{mg}$ de este compuesto diluidos en $100 \mathrm{~mL}$ de $n$-hexano. Para determinar la concentración real de esta solución, se tomó una alícuota de $10 \mathrm{~mL}$ y se colocó en un frasco color ámbar. El hexano se evaporó con una corriente de nitrógeno y al residuo resultante se le añadió $10 \mathrm{~mL}$ de metanol. Se midió la absorbancia a $292 \mathrm{~nm}$ en un espectrofotómetro UV. El valor obtenido se dividió por 0,0076, obteniendo como resultado la concentración de tocoferoles en $\mu \mathrm{g} / \mathrm{mL}$. A partir de la solución estándar 
de a-tocoferol se prepararon disoluciones de diferentes concentraciones para realizar la curva de calibración.

Preparación y análisis de las muestras

Las muestras fueron preparadas en el momento de ser utilizadas para su análisis. Se pesaron aproximadamente $0,25 \mathrm{~g}$ de aceite en un matraz aforado de 5 $\mathrm{mL}$ y se llevó a volumen con hexano de calidad HPLC, previa homogeneización de la solución utilizando un baño ultrasónico. Los recipientes fueron envueltos con papel aluminio a fin de proteger las muestras de la luz.

Los resultados del análisis permitieron cuantificar el contenido de los tocoferoles presentes en el aceite. Este valor se expresó como $\mu \mathrm{g}$ de tocoferol/g de aceite, siendo calculado a partir de la siguiente ecuación:

Concentración de tocoferol $(\mu \mathrm{g} / \mathrm{g})=[\mathrm{Toc}] \times \frac{\mathrm{V}}{\mathrm{m}}$ donde:

[Toc]: concentración de tocoferol calculado a partir de la curva de calibración $(\mu \mathrm{g} / \mathrm{mL})$

$\mathrm{V}$ : volumen de la muestra $(\mathrm{mL})$

$\mathrm{M}$ : peso del aceite $(\mathrm{g})$

\subsection{Antioxidantes fenólicos}

Las muestras de aceite $(2 \mathrm{~g})$ fueron disueltas con $5 \mathrm{~mL}$ de hexano. Los compuestos polifenólicos se extrajeron con $2 \mathrm{~mL}$ de una mezcla de acetonitrilo: ácido acético 10\% cada vez, en una proporción de 60:40, 50:50 y 40:60 agitando con un vortex. Se centrifugaron las muestras y se colectó la fase polar. Se evaporó hasta sequedad utilizando un evaporador centrífugo (tipo speed-vac) Heto VR-1. El residuo se disolvió en acetonitrilo: ácido acético 10\% (50:50) y se analizó por HPLCMS.

Los análisis fueron llevados a cabo en un cromatógrafo Surveyor Plus, provisto de bomba cuaternaria y autocargador, acoplado a una trampa lineal de iones LTQ XL (Thermo Fisher Scientific). Las separaciones cromatográficas se realizaron utilizando una columna $C_{18}(150 \mathrm{~mm} \times 2 \mathrm{~m} \times 1 \mathrm{~mm} ; 335 \mu \mathrm{m})$ XTerra (Waters) y una columna de guardia $\mathrm{C}_{18}(4 \mathrm{~mm} \times 2 \mathrm{~mm}$ ) (Phenomenex); la fase móvil consistió en $0,1 \%$ de ácido acético en acetonitrilo:agua (95:5) (solvente A) y 0,1\% ácido acético en agua (solvente B), a $300 \mu \mathrm{L} / \mathrm{min}$ y $20^{\circ} \mathrm{C}$. Se aplicó el siguiente 
gradiente: el porcentaje de solvente A se aumentó de 10 a $50 \%$ en los primeros 5 min, luego fue mantenido hasta $t=12$ min, posteriormente se disminuyó a $10 \%$ en t=13 min, manteniéndose constante durante los últimos 4 min próximos a la inyección. El volumen de inyección fue de $10 \mu \mathrm{L}$. Todos los ensayos fueron realizados por duplicado.

La detección fue realizada en un detector de masas utilizando una sonda de ionización química a presión atmosférica (APCI) operando en modo ion positivo. Los polifenoles formaron $[\mathrm{M}+\mathrm{H}]^{+}$, los cuales fueron detectados de acuerdo a las relaciones masa/carga que se indican en la Tabla 3.4.

Tabla 3.4. Relación masa/carga $(\mathrm{m} / \mathrm{z})$ para la detección de los compuestos polifenólicos presentes en aceites de chía

\begin{tabular}{ll}
\hline \multicolumn{1}{c}{ Compuesto polifenólico } & Relación $\mathbf{~ m / z}$ \\
\hline Ácido cafeico & 181 \\
Kaempferol & 287 \\
Quercetina & 303 \\
Mircetina & 319 \\
Ácido clorogénico & 355 \\
\hline
\end{tabular}

La miricetina fue utilizada para crear el archivo de ajuste para el método instrumental. La cuantificación de las muestras fue realizada mediante el método de estándar externo para polifenoles en el rango de 100-3 $\mu \mathrm{M}$ (Taga y col., 1984; de Rijke y col., 2006).

\subsection{Ensayo acelerado de estabilidad oxidativa (Rancimat)}

La estabilidad oxidativa de los aceites fue evaluada mediante un ensayo acelerado de estabilidad oxidativa determinando como parámetro el tiempo de inducción ( $\mathrm{t}_{\mathrm{i}}$ ) en un equipo Rancimat 679 (Suiza) (Metrohm lonenanalytik, 2001). Así, se colocaron $5 \mathrm{~g}$ de aceite en el recipiente de reacción y se sometieron a una temperatura de $98^{\circ} \mathrm{C}$ con burbujeo continuo de una corriente de aire a una velocidad de 20 L/h. Los productos de oxidación de naturaleza volátil fueron transportados por dicha corriente de aire a la celda de medición donde se dispersaron en una solución de muy baja conductividad (agua bidestilada) (Figura 3.2). De esta manera, mediante el registro de la conductividad de esta solución en función del tiempo, se 
obtuvieron las curvas de oxidación, cuyo punto de inflexión se designa $t_{i}$ y representa una magnitud característica que permite evaluar la correspondiente estabilidad oxidativa de la muestra en cuestión (Metrohm lonenanalytik, 2001).

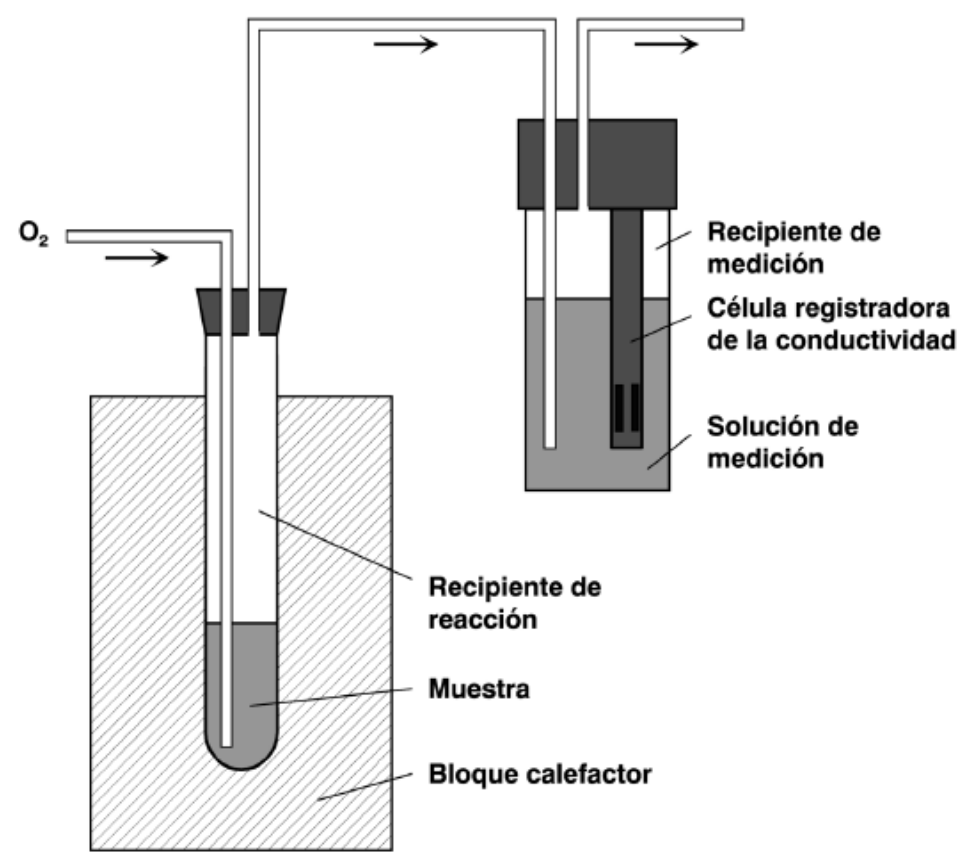

Figura 3.2 Esquema del equipo Rancimat (Metrohm lonenanalytik, 2001)

\subsection{Calorimetría diferencial de barrido (DSC)}

La calorimetría diferencial de barrido es una técnica de análisis térmico, empleada en la determinación de temperaturas y flujos de calor asociados tanto a las transiciones de fase de la materia (cristalización, fusión y evaporación) como a las reacciones químicas de hidrólisis y oxidación, cuya evolución puede seguirse en función del tiempo y la temperatura. El perfil térmico de los aceites obtenidos mediante DSC está relacionado con diversas propiedades físicas y químicas de estos productos (Jiménez Márquez y col., 2007).

Para el análisis térmico de las muestras se utilizó un calorímetro diferencial de barrido Q 100 V9.8 Build 296 (TA Instruments, USA) controlado por el software TA Instruments Universal Analysis 2000/XP v. 4.2 E.

Las muestras de aceite de chía $(5-11 \mathrm{mg})$ se pesaron con una precisión de $0,1 \mathrm{mg}$ en cápsulas de aluminio, las cuales fueron selladas mediante una prensa de manera tal de lograr el cierre hermético de las mismas. Cada cápsula se colocó en el calorímetro, utilizando como referencia una cápsula vacía de la misma capacidad, realizándose este ensayo por duplicado. 
Las muestras fueron sometidas a procesos de enfriamiento $y$ de calentamiento mediante el siguiente programa de temperatura consistente en: calentamiento de las muestras desde la temperatura ambiente hasta los $70^{\circ} \mathrm{C}$ bajo una corriente de nitrógeno a $50 \mathrm{~mL} / \mathrm{min}$; isoterma a $70^{\circ} \mathrm{C}$ durante 3 min e inicio de las rampas de enfriamiento desde $\operatorname{los} 70^{\circ} \mathrm{C}$ a $-80^{\circ} \mathrm{C}$ a una velocidad $\beta=1^{\circ} \mathrm{C} / \mathrm{min}$ y un periodo de modulado de $60 \mathrm{~s}$, amplitud de temperatura de $\pm 0,16^{\circ} \mathrm{C}$; isoterma a $-80^{\circ} \mathrm{C}$ durante 3 min e inicio de las rampas de calentamiento a $10^{\circ} \mathrm{C} / \mathrm{min}$ hasta los $80^{\circ} \mathrm{C}$.

Se obtuvieron los datos de flujo de calor (en $\mathrm{mW}$ ) en función del tiempo y de la temperatura durante la etapa de calentamiento, a partir de los cuales se determinaron los valores de las temperaturas de los picos de transición $\left(T_{p}\right)$, de la temperatura de inicio ( $\left.T_{0}\right)$ y de la temperatura de finalización ( $T_{\text {end }}$ ) de las transiciones durante la evolución del proceso de fusión. Durante cada uno de estos procesos se definió el inicio y el fin de la transición como el punto de temperatura en el cual se cortan la extrapolación de la línea base y la de la pendiente en el estado de transición.

\section{Análisis estadístico}

Los aceites provenientes de ambos lotes de semillas comerciales (Argentina y Guatemala) fueron analizados en forma independiente mediante un análisis de varianza (ANOVA) unifactorial, considerando el proceso de extracción del aceite como la fuente de variabilidad. Esta metodología de análisis fue seleccionada debido a la escasa disponibilidad de información acerca de los cultivares correspondientes a cada uno de los lotes de semillas y de las condiciones agroclimáticas bajo las cuales se realizaron los respectivos cultivos. La distribución normal de las variables fue comprobada mediante el test de Kolmogorov - Smirnov $(p \leq 0,05)$ y la homogeneidad de las varianzas por el test de Cochran's. Cuando fue necesario, los datos fueron transformados a fin de no violar los supuestos en los que se basa este análisis. En aquellos casos en los cuales se observaron diferencias estadísticamente significativas ( $p \leq 0,05$ ), se utilizó a posteriori un test de comparaciones múltiples (test de Tukey's). Para estimar las correlaciones entre los parámetros evaluados se utilizó el test de correlación de Pearson. Los datos fueron procesados utilizando el software Statgraphics Plus (Version 4.0 for Window, Manugistics Inc., USA). 


\section{RESULTADOS Y DISCUSIÓN}

\section{Caracterización comparativa de los aceites de chía obtenidos mediante extracción con solvente y por prensado}

La Tabla 3.5 muestra los valores promedio correspondientes al rendimiento y a la composición de ácidos grasos de los aceites de chía extraídos por solvente y prensado a partir de las semillas provenientes de Salta (Argentina) y Quetzaltenango (Guatemala).

Tabla 3.5. Rendimiento (\% b.s.) y composición de ácidos grasos (\% del total de ácidos grasos) correspondiente a los aceites extraídos por solvente y prensado a partir de las semillas provenientes de Salta (Argentina) y Quetzaltenango (Guatemala)

\begin{tabular}{|c|c|c|c|c|}
\hline & \multicolumn{2}{|c|}{ Argentina } & \multicolumn{2}{|c|}{ Guatemala } \\
\hline & $\begin{array}{l}\text { Extracción } \\
\text { con solvente }\end{array}$ & Prensado & $\begin{array}{l}\text { Extracción } \\
\text { con solvente }\end{array}$ & Prensado \\
\hline Rendimiento & $33,6 \pm 0,4^{b}$ & $24,8 \pm 0,5^{a}$ & $26,7 \pm 1,9^{B}$ & $20,3 \pm 0,5^{\mathrm{A},}$ \\
\hline \multicolumn{5}{|l|}{ Ácido graso } \\
\hline Palmítico (16:0) & $6,2 \pm 0,4^{a}$ & $6,6 \pm 0,3^{a}$ & $5,5 \pm 0,1^{A}$ & $5,9 \pm 0,1^{A}$ \\
\hline Esteárico (18:0) & $3,0 \pm 0,7^{a}$ & $3,1 \pm 0,1^{\mathrm{a}}$ & $2,7 \pm 0,2^{A}$ & $3,9 \pm 0,9^{A}$ \\
\hline Oleico (18:1) & $5,3 \pm 1,1^{a}$ & $5,4 \pm 0,4^{a}$ & $5,8 \pm 0,3^{A}$ & $5,5 \pm 0,4^{A}$ \\
\hline Vaccénico (18:1) & $0,5 \pm 0,01^{a}$ & $0,5 \pm 0,02^{a}$ & $0,4 \pm 0,02^{A}$ & $0,5 \pm 0,02^{\mathrm{A}}$ \\
\hline Linoleico (18:2) & $19,7 \pm 0,0^{a}$ & $20,3 \pm 0,2^{a}$ & $16,6 \pm 1,2^{A}$ & $17,5 \pm 0,2^{A}$ \\
\hline a-Linolénico (18:3) & $65,6 \pm 0,8^{a}$ & $64,5 \pm 0,2^{a}$ & $69,3 \pm 1,0^{A}$ & $67,7 \pm 0,4^{A}$ \\
\hline SFAs & $9,3 \pm 0,3^{a}$ & $9,8 \pm 0,4^{a}$ & $8,3 \pm 0,1^{A}$ & $9,9 \pm 1,1^{A}$ \\
\hline PUFAs & $85,4 \pm 0,8^{a}$ & $84,9 \pm 0,0^{a}$ & $85,9 \pm 0,2^{A}$ & $85,1 \pm 0,6^{A}$ \\
\hline PUFAs/SFAs & $8,7 \pm 0,2^{a}$ & $9,2 \pm 0,4^{a}$ & $10,4 \pm 0,1^{A}$ & $8,8 \pm 0,9^{A}$ \\
\hline$\omega-3 / \omega-6$ & $3,32 \pm 0,03^{a}$ & $3,18 \pm 0,03^{a}$ & $4,18 \pm 0,4^{A}$ & $3,87 \pm 0,0^{A}$ \\
\hline
\end{tabular}

Valores medios \pm desviación estándar $(n=3)$. Letras minúsculas distintas indican diferencias significativas $(p \leq 0,05)$ entre procesos de extracción para las semillas de Argentina; letras mayúsculas distintas indican diferencias significativas $(p \leq 0,05)$ entre procesos de extracción para las semillas de Guatemala; SFAs, ácidos grasos saturados; PUFAs, ácidos grasos poliinsaturados; $\omega$ 6/w-3, relación ácido linoleico/ácido a-linolénico

El rendimiento del aceite se encontró en un rango de variación de 20,3 a $33,6 \%$ (b.s.), valores que resultaron menores que los publicados por Ayerza (1995) y 
en el mismo rango que Velasco Vargas y col. (2004) mediante extracción con solventes. Los principales ácidos grasos presentes en los aceites estudiados fueron: a-linolénico $(\mathrm{C} 18: 3)>$ linoleico $(\mathrm{C} 18: 2)>$ oleico $(\mathrm{C} 18: 1) \approx$ palmítico $(\mathrm{C} 16: 0)>$ esteárico $(C 16: 0)>$ vaccénico $(\Delta 11)(18: 1)$. Estos resultados concuerdan con estudios realizados previamente (Ayerza, 1995; AOCS, 1998), en los cuales el principal ácido graso fue el a-linolénico en un rango de $64,5-69,3 \%$. La relación $\omega$ $3 / \omega-6$ varió de 3,18 a 4,18, siendo estos valores marcadamente superiores a los de la mayoría de los aceites vegetales entre los que podemos mencionar a los aceites de canola $(0,45)$, oliva $(0,13)$, soja $(0,15)$ y germen de trigo $(0,20)$ (Belitz y Grosch, 1999). Así, la incorporación del aceite de chía a la dieta sería relevante debido a que existen evidencias científicas que demuestran que los aceites con un elevado contenido de ácidos grasos poliinsaturados (PUFAs) brindan numerosos beneficios para la salud (Bowen y Clandinin, 2005).

La comparación entre ambos sistemas de extracción estudiados mostró diferencias significativas $(p \leq 0,05)$ en el rendimiento en aceite y una composición acídica similar $(p>0,05)$. El máximo rendimiento se obtuvo para la extracción con solvente, el cual resultó en promedio aproximadamente un 30\% mayor que el alcanzado mediante prensado (Tabla 3.5). Este hecho puede ser atribuido a la mayor capacidad de los solventes orgánicos para extraer la mayoría de los componentes lipídicos presentes en la semilla de chía. La similitud encontrada en la composición acídica correspondiente a los aceites obtenidos por diferentes procesos de extracción concuerda con lo informado por Brevedan y col. (2000) y Concha y col. (2006) para los aceites de girasol y rosa mosqueta, respectivamente. Se encontró una correlación negativa significativa $(r=-0,91 ; p=0,0015)$ entre los ácidos grasos poliinsaturados y saturados, lo cual concuerda con la información relacionada con la síntesis de ambos tipos de ácidos grasos (Belitz y Grosch, 1999).

Con respecto a la composición triacilglicerídica, la ${ }^{13} \mathrm{C}$ NMR es una técnica analítica que permite obtener información sobre la composición de ácidos grasos y su ubicación en la molécula de glicerol presentes en el aceite. La región de los carbonilos es sensible al análisis de la posición de los diferentes tipos de ácidos grasos; de esta forma es posible hacer una distinción entre las posiciones $s n-1,3$ y sn-2. (Diehl, 2008). La región olefínica, la cual presenta una mayor dispersión de los desplazamientos químicos, puede ser utilizada para cuantificar aquellos grupos acilos que se superponen en la región de los carbonilos. Así, una combinación de los 
espectros obtenidos de ambas regiones puede proveer la información necesaria para cuantificar en forma completa la distribución posicional de los ácidos grasos presentes en el aceite de chía. En la Figura $\mathbf{3 . 3}$ se presenta un espectro típico obtenido por ${ }^{13} \mathrm{C}$ NMR. Este espectro muestra las resonancias de cuatro grupos de señales: carbonilos (172-174 ppm), carbonos insaturados (125 - 135 ppm), carbonos correspondientes a la estructura del glicerol (60-80 ppm) y carbonos alifáticos (15-35 ppm). La región espectral de los carbonilos (172,8-173,3 ppm) se encuentra amplificada en la Figura 3.3a, en la cual las resonancias registradas para altas y bajas frecuencias pueden atribuirse a las esterificaciones en las posiciones $s n-1,3$ y sn-2, respectivamente. Estas dos regiones de resonancia de los carbonilos están separadas por aproximadamente $0,4 \mathrm{ppm}$. La diferencia en sus desplazamientos puede atribuirse al hecho que los grupos $\mathrm{C}=\mathrm{O}$ de la posición 2 experimentan dos interacciones con carbonilos vecinos, mientras que los de la posición 1 y 3 , sólo una (Mannina y col., 1999).

Las resonancias 1,3- y 2-linoleil y linolenil se superponen en la región de los carbonilos. Por ello, para poder discriminar la posición que ocupan cada uno de estos dos ácidos grasos, es necesario analizar el espectro de la región de los dobles enlaces. En este sentido, la Figura 3.3 b muestra una imagen amplificada de la región olefínica del espectro de ${ }^{13} \mathrm{C}$ NMR. Los grupos acilos insaturados no resueltos en la región de los carbonilos, como el linoleil y linolenil, tienen cuatro y seis carbonos olefínicos, respectivamente, lo que nos permite seleccionar varias zonas. Además, es posible realizar una diferenciación entre los ácidos linoleico y linolénico en forma de $\omega-3$ vs. $\omega-6$ mediante la suma de los átomos de carbono situados en la porción terminal de las cadenas de ácidos grasos (metil y sn-2). De esta manera, es posible mediante una serie de diversas combinaciones cuantificar el contenido de los ácidos linoleico y linolénico, así como su distribución posicional.

En la Tabla 3.6, se observa el contenido porcentual correspondiente a los ácidos grasos saturados e insaturados en posiciones $s n-1,3$ y sn-2 en la estructura del glicerol. 


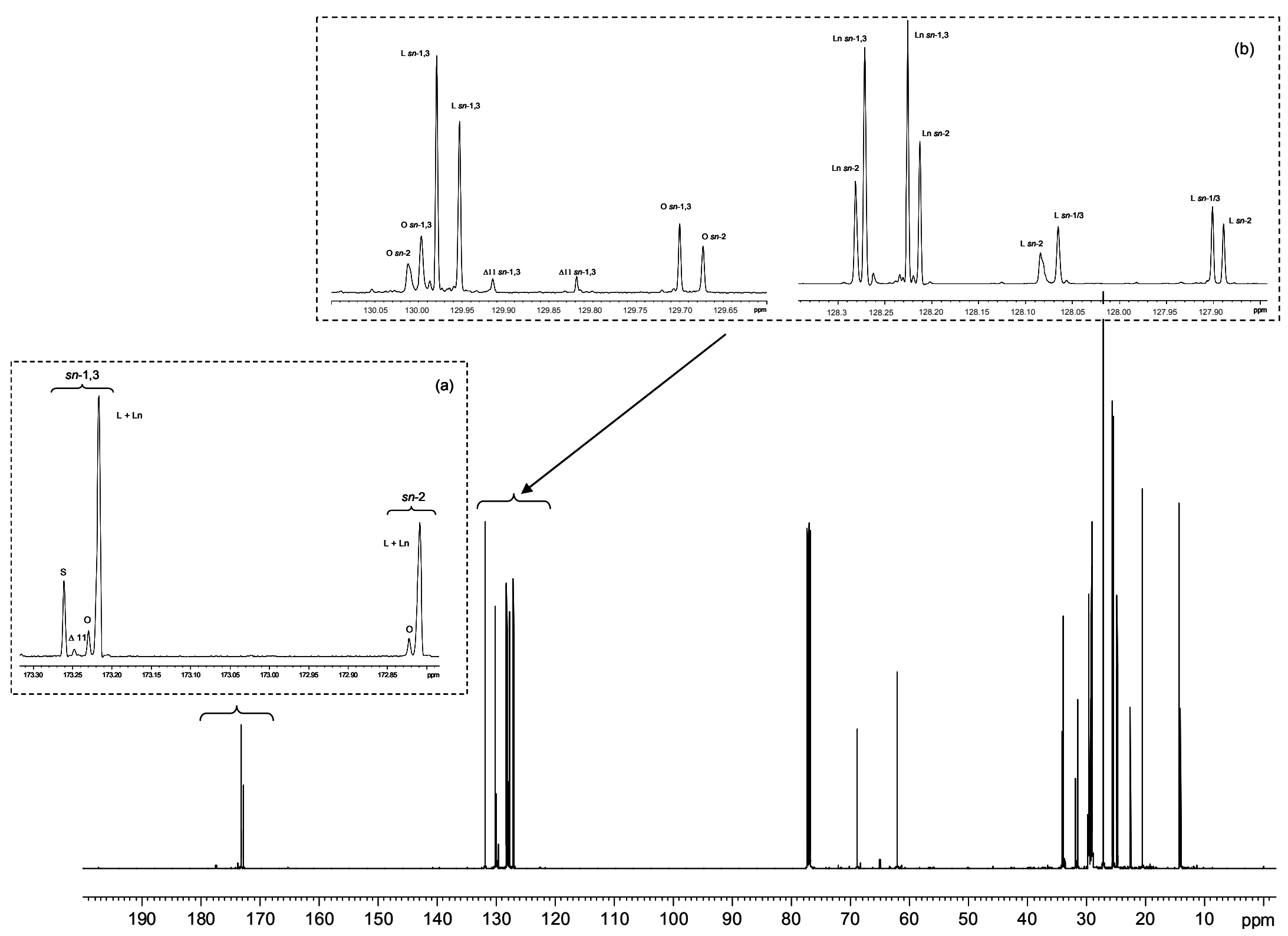

Figura 3.3. Espectro de ${ }^{13} \mathrm{C}$ NMR de aceite de Salvia hispanica L. Los recuadros (a) y (b) son vistas ampliadas de la región carbonílica y olefínica respectivamente. $\mathrm{S}=$ ácidos grasos saturados; $\mathrm{O}=$ ácido oleico; $\mathrm{L}=$ ácido linoleico; Ln= ácido $\alpha$-linolénico 
Tabla 3.6 Distribución de los ácidos grasos saturados e insaturados presentes en los aceites de Salvia hispanica L. extraídos por solvente y prensado determinados por ${ }^{13} \mathrm{C}$ NMR

\begin{tabular}{|c|c|c|c|c|}
\hline & \multicolumn{2}{|c|}{ Argentina } & \multicolumn{2}{|c|}{ Guatemala } \\
\hline & $\begin{array}{c}\text { Extracción } \\
\text { con } \\
\text { solvente }\end{array}$ & Prensado & $\begin{array}{c}\text { Extracción } \\
\text { con } \\
\text { solvente }\end{array}$ & Prensado \\
\hline \multicolumn{5}{|l|}{$\% s n-1,3$} \\
\hline Ácidos grasos saturados & 12,3 & 12,5 & 9,8 & 9,8 \\
\hline Ácido vaccénico & 1,1 & 1,1 & 0,8 & 1,0 \\
\hline Ácido oleico & 6,1 & 6,1 & 4,4 & 4,4 \\
\hline Ácido linoleico & 12,3 & 12,1 & 8,9 & 9,0 \\
\hline Ácido a-linolénico & 33,5 & 33,8 & 41,7 & 41,4 \\
\hline \multicolumn{5}{|l|}{$\%$ sn-2 } \\
\hline Ácido oleico & 4,4 & 4,5 & 2,8 & 2,9 \\
\hline Ácido linoleico & 9,9 & 9,9 & 7,4 & 7,7 \\
\hline Ácido a-linolénico & 18,7 & 19,0 & 23,8 & 23,4 \\
\hline \multicolumn{5}{|l|}{ Total $(s n-1,3+s n-2)$} \\
\hline Ácidos grasos saturados $(1,3: 2)$ & $12,3(100: 0)$ & $12,5(100: 0)$ & $9,8(100: 0)$ & $9,8(100: 0)$ \\
\hline Ácido vaccénico $(1,3: 2)$ & $1,1(100: 0)$ & $1,1(100: 0)$ & $0,8(100: 0)$ & $1,0(100: 0)$ \\
\hline Ácido oleico $(1,3: 2)$ & $10,5(58: 42)$ & $10,6(58: 42)$ & $7,2(61: 39)$ & $7,3(60: 40)$ \\
\hline Ácido linoleico $(1,3: 2)$ & $22,2(55: 45)$ & $22,0(55: 45)$ & $16,3(55: 45)$ & $16,7(54: 46)$ \\
\hline Ácido a-linolénico $(1,3: 2)$ & $52,2(64: 36)$ & $52,8(64: 36)$ & $65,5(64: 36)$ & $64,8(64: 36)$ \\
\hline
\end{tabular}


Puede observarse que los ácidos grasos saturados (ácidos palmítico y esteárico) y el vaccénico se encuentran mayormente distribuidos en las posiciones $s n-1,3$, no siendo detectables en la posición sn-2. La relación sn-1,3:2 correspondiente al ácido oleico fue de alrededor 60:40. Con respecto a los ácidos grasos poliinsaturados, $8,9-12,3 \%$ de ácido linoleico y 33,5 - 41,7\% de a-linolénico se distribuyeron en la posición 1,3, lo cual representa aproximadamente el 55 y $64 \%$ del contenido total de ácidos linoleico y a-linolénico presente en el aceite de chía, respectivamente. Además, cabe señalar que la distribución de los ácidos grasos en el glicerol no fue afectada por el sistema de extracción del aceite. Paralelamente, los resultados de la composición acídica determinados mediante ${ }^{13} \mathrm{C}$ NMR concuerdan con los obtenidos mediante CG (Tabla 3.5).

La Tabla 3.7 muestra los principales resultados del análisis de los aceites de chía obtenidos mediante ${ }^{1} \mathrm{H}$ NMR. Un espectro típico de este aceite puede observarse en la Figura 3.4. En coincidencia con los valores obtenidos para la composición acídica de los aceites de chía analizados por CG, se observa que el contenido total de ácidos grasos insaturados, especialmente en el caso de los ácidos grasos de la serie $\omega-3$ es elevado. Este alto grado de insaturación se ve también reflejado en el índice de iodo. Con respecto a los porcentajes de ácidos grasos libres, los mismos representan niveles bajos de acidez es decir, un bajo grado de hidrólisis de los triacilgliceroles presentes en el aceite de chía.

Tabla 3.7 Composición de ácidos grasos según grupos, índice de iodo y ácidos grasos libres presentes en aceites de Salvia hispanica L. extraídos por solvente y prensado, determinados por ${ }^{1} \mathrm{H}$ NMR

\begin{tabular}{lccccc}
\hline & \multicolumn{2}{c}{ Argentina } & & \multicolumn{2}{c}{ Guatemala } \\
\cline { 2 - 3 } \cline { 5 - 6 } & $\begin{array}{c}\text { Extracción } \\
\text { con } \\
\text { solvente }\end{array}$ & Prensado & $\begin{array}{c}\text { Extracción } \\
\text { con } \\
\text { solvente }\end{array}$ & Prensado \\
\hline Índice de iodo & 190,6 & 193,5 & & 211,0 & 209,1 \\
Ácidos grasos libres & 2,0 & 1,3 & & 1,0 & 1,0 \\
Total de ácidos grasos insaturados (\%) & 84,7 & 85,8 & & 88,9 & 87,5 \\
Total de ácidos grasos saturados (\%) & 15,3 & 14,2 & & 11,1 & 12,5 \\
Suma de ácidos grasos $\omega-3(\%)$ & 53,5 & 53,9 & & 65,2 & 65,4 \\
\hline
\end{tabular}




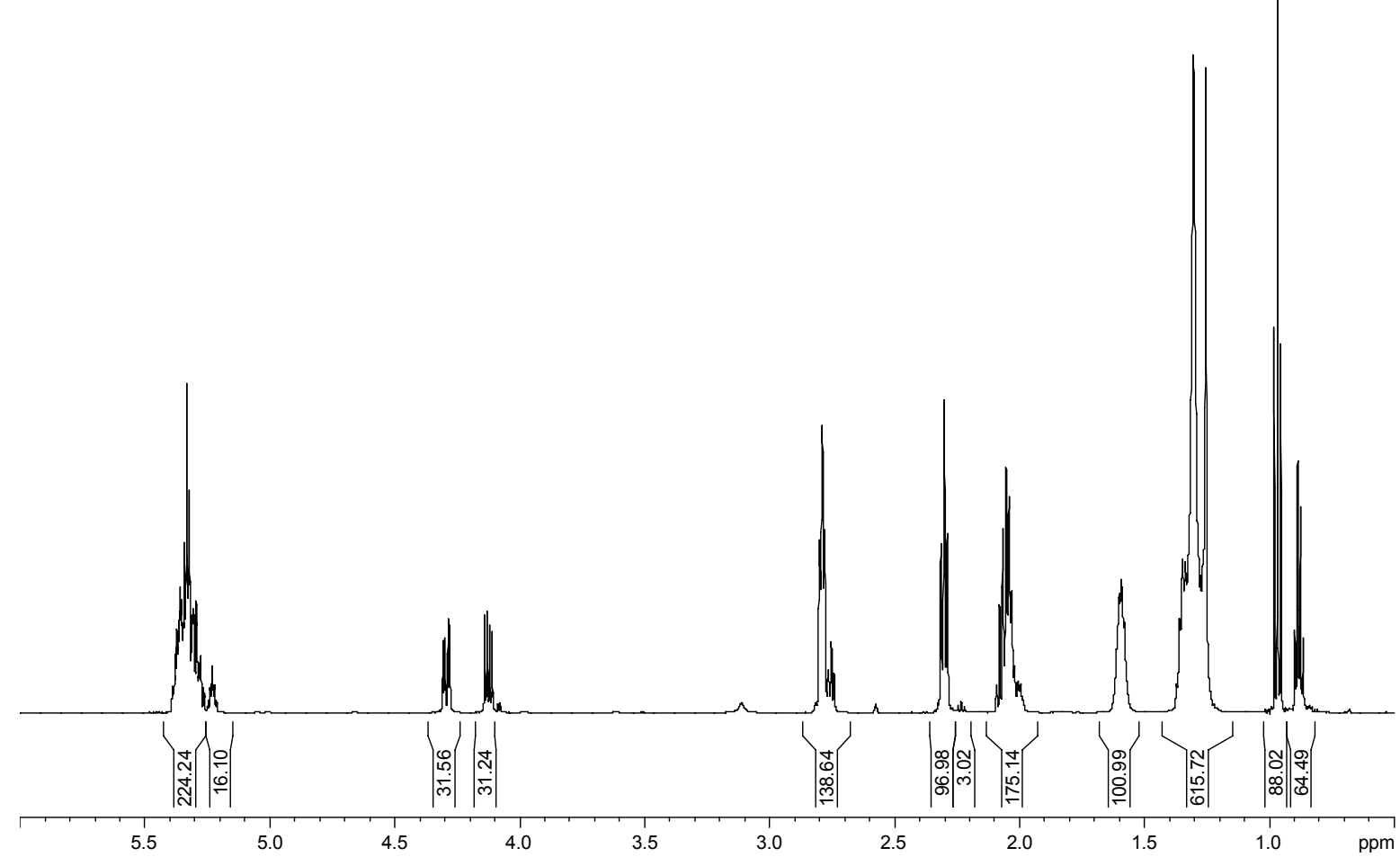

Figura 3.4. Espectro de ${ }^{1} \mathrm{H}$ NMR del aceite de chía proveniente de Argentina obtenido mediante extracción con solventes

La composición de triacilgliceroles fue determinada por HPLC/APCI-MS para los aceites de chía obtenidos mediante extracción con solvente a partir de las semillas de Argentina y de Guatemala debido a que el sistema de extracción no afectó la composición acídica, tal como fuera descripto previamente (Tabla 3.8). Los aceites de chía procedentes de semillas de Guatemala presentaron un mayor contenido de ácido a-linolénico que los de Argentina (ver Tabla 3.5). Las especies de triacilgliceroles (TAG) identificados estuvieron compuestas por los ácidos grasos principales detectados mediante CG. Se encontraron 12 especies de TAG diferentes, siendo los más importantes aLnaLnaLn, aLnaLnL, aLnLL, aLnaLnP, aLnLO y aLnLP, los cuales representan aproximadamente el $87-95 \%$ del total de TAG. Es interesante destacar que la mayoría de los TAG presentan al menos un resto del ácido a-linolénico y que las principales diferencias entre los aceites con mayor y menor tenor de este ácido graso difieren en el contenido de aLnaLnaLn, con un mayor nivel presente en los aceites obtenidos a partir de semillas de chía de Guatemala que en los de Argentina. Por otra parte, los restos de ácidos grasos saturados se ubican principalmente en las posiciones 1,3 de la molécula del glicerol, 
mientras que los TAG con un resto de ácido graso saturado en la posición 2, representan menos del $2 \%$ ( $\alpha$ LnPP, $\alpha$ LnEP) con respecto al \% total (Tabla 3.8).

Tabla 3.8. Composición de los triacilgliceroles presentes en aceites de chía obtenidos mediante extracción con solventes

\begin{tabular}{|c|c|c|c|c|}
\hline \multirow{2}{*}{ Triacilglicerol } & \multicolumn{2}{|c|}{ Argentina } & \multicolumn{2}{|c|}{ Guatemala } \\
\hline & $t_{r}(\min )$ & $\%$ & $t_{r}(\min )$ & $\%$ \\
\hline aLn aLn aLn & 5,55 & 32,8 & 5,56 & 47,0 \\
\hline$\alpha \operatorname{Ln} \alpha \operatorname{Ln} L$ & 6,23 & 20,3 & 6,21 & 20,8 \\
\hline aLnLL & 7,11 & 13,8 & 7,08 & 11,7 \\
\hline aLnaLn P & 7,35 & 7,7 & 7,35 & 6,7 \\
\hline aLnLO & 8,05 & 7,0 & 8,07 & 3,9 \\
\hline aLnLP & 8,35 & 5,3 & 8,40 & 4,7 \\
\hline$\alpha \operatorname{LnOO}+\alpha \operatorname{LnOP}$ & 9,46 & 8,3 & 9,40 & 4,1 \\
\hline aLnPP & 9,93 & 0,8 & 9,94 & 0,2 \\
\hline LLE & 10,71 & 1,1 & 10,75 & 0,2 \\
\hline aLnOE & 11,10 & 2,1 & 11,04 & 0,6 \\
\hline$\alpha \operatorname{LnEP}$ & 11,39 & 1,0 & 11,37 & 0,1 \\
\hline
\end{tabular}

$\alpha \mathrm{Ln}=\alpha$ linolenina; $\mathrm{L}=$ linoleína; $\mathrm{O}=$ oleína; $\mathrm{P}=$ palmitina; $\mathrm{E}=$ estearina

La Tabla 3.9 muestra las principales propiedades fisicoquímicas e índices de calidad de los aceites de chía estudiados. 
Tabla 3.9 Características fisicoquímicas correspondientes a los aceites de semilla de Salvia hispanica L. obtenidos mediante extracción con solvente y prensado

\begin{tabular}{|c|c|c|c|c|}
\hline \multirow[b]{2}{*}{ Propiedad fisicoquímica } & \multicolumn{2}{|c|}{ Argentina } & \multicolumn{2}{|c|}{ Guatemala } \\
\hline & $\begin{array}{l}\text { Extracción con } \\
\text { solvente }\end{array}$ & Prensado & $\begin{array}{l}\text { Extracción con } \\
\text { solvente }\end{array}$ & Prensado \\
\hline Índice de iodo ( $\mathrm{g} \mathrm{I}_{2} / 100 \mathrm{~g}$ aceite $)$ & $210,5 \pm 1,1^{a}$ & $208,5 \pm 0,6^{a}$ & $215,0 \pm 0,9^{A}$ & $212,0 \pm 1,2^{A}$ \\
\hline Índice de saponificación (mg KOH/g aceite) & $193,09 \pm 0,07^{a}$ & $193,12 \pm 0,04^{a}$ & $193,01 \pm 0,03^{A}$ & $192,99 \pm 0,01^{\mathrm{A}}$ \\
\hline Índice de refracción $\left(40^{\circ} \mathrm{C}\right)$ & $1,4709 \pm 0,0006^{a}$ & $1,4736 \pm 0,0001^{b}$ & $1,4704 \pm 0,0006^{A}$ & $1,4741 \pm 0,0000^{B}$ \\
\hline \multicolumn{5}{|l|}{ Color (CIELAB) } \\
\hline$L^{*}$ & $43,177 \pm 0,081^{b}$ & $42,855 \pm 0,031^{a}$ & $43,032 \pm 0,003^{B}$ & $39,720 \pm 1,371^{A}$ \\
\hline$a^{*}$ & $-4,545 \pm 0,191^{b}$ & $-3,757 \pm 0,060^{a}$ & $-4,850 \pm 0,056^{B}$ & $-2,087 \pm 0,067^{A}$ \\
\hline \multicolumn{5}{|l|}{ Metales (mg/kg) } \\
\hline $\mathrm{Cu}$ & $0,2 \pm 0,01^{a}$ & $0,1 \pm 0,05^{a}$ & $0,3 \pm 0,01^{A}$ & $0,3 \pm 0,01^{A}$ \\
\hline $\mathrm{Fe}$ & $1,8 \pm 0,04^{b}$ & $0,3 \pm 0,03^{a}$ & $3,9 \pm 0,04^{B}$ & $3,4 \pm 0,03^{A}$ \\
\hline Fósforo (mg/kg) & $54 \pm 11^{\text {a }}$ & $225 \pm 1^{b}$ & $100 \pm 20^{A}$ & $146 \pm 25^{\mathrm{B}}$ \\
\hline tiempo de inducción (h) & $2,4 \pm 0,1^{a}$ & $2,8 \pm 0,1^{a}$ & $2,4 \pm 0,1^{\mathrm{A}}$ & $2,4 \pm 0,1^{\mathrm{A}}$ \\
\hline
\end{tabular}


El contenido de ácidos grasos libres de los aceites fue bajo, coincidente con los datos obtenidos mediante el análisis por ${ }^{1} \mathrm{H}$ NMR, con valores medios que variaron entre 0,70 y $2,05 \%$ oleico, los cuales resultaron menores que el límite establecido para otros aceites obtenidos por prensado, tales como el aceite de oliva (Codex Alimentarius Commission, 1999). Este hecho indicó que los aceites obtenidos no sufrieron procesos de degradación hidrolítica y/o microbiológica lo que podría producir la hidrólisis de los glicéridos con el consiguiente incremento de los ácidos grasos libres. Se encontró que el contenido de ácidos grasos libres de los aceites obtenidos por extracción con solvente fue significativamente mayor ( $p \leq$ $0,05)$ que los de prensado, resultados que coinciden con los informados por otros autores en aceite de girasol (Brevedan y col., 2000).

El alto contenido de ácidos grasos poliinsaturados se refleja en los elevados índices de iodo $(208,5-215,0)$, los cuales fueron mayores que los hallados previamente por otros autores (AOCS, 1998; Velasco Vargas y col., 2004). En consecuencia y teniendo en cuenta este parámetro, el aceite de chía puede clasificarse dentro de los aceites secantes. Por otra parte, los índices de saponificación (193,0-193,1) fueron similares a los informados en la literatura (AOCS, 1998; Velasco Vargas y col., 2004), no habiéndose detectado diferencias significativas $(p>0,05)$ entre ambos procesos de extracción analizados.

El material insaponificable varió entre 0,68 - 1,27\%, incluyendo este rango el valor publicado por la AOCS (1998) (1,2\%) como característico del aceite de chía, no encontrándose diferencias significativas $(p>0,05)$ entre los sistemas de extracción (Tabla 3.9).

Los aceites y grasas pueden ser caracterizados a través de su índice de refracción. Así, el valor de este parámetro calculado a $20^{\circ} \mathrm{C}$ varió entre 1,4781 1,4818 , presentando diferencias significativas $(p \leq 0,05)$ entre los aceites obtenidos por ambos sistemas de extracción (Tabla 3.9). El índice de refracción del aceite de chía se encuentra cercano al correspondiente al de la trilinolenina $\left(1,4800\right.$ a $\left.20^{\circ} \mathrm{C}\right)$ (Wheeler y col., 1940), principal triacilglicerol encontrado en este aceite. Además, los valores calculados a $40^{\circ} \mathrm{C}$ fueron similares a los del aceite de lino $(1,472-1,475$ a $40^{\circ} \mathrm{C}$ ) (Codex Alimentarius, 1999) de similar composición acídica que el aceite de chía.

Con respecto al color, se detectaron diferencias $(p \leq 0,05)$ en los valores de $L^{*}$ y $a^{*}$ entre los distintos procesos de extracción. Si bien no existen hasta el momento 
estándares de color para el aceite de chía, la medición de los parámetros $L^{*} a^{*}$ y $b^{*}$ podrían ser utilizados para su caracterización. Los menores valores de $L^{*}$ se encontraron en los aceites obtenidos por prensado, lo cual indica que los mismos resultaron más oscuros que los extraídos con hexano. En todos los casos, el parámetro $a^{*}$ presentó un valor negativo, con un estrecho rango de variación, coincidente con los valores informados para el $\beta$-caroteno por Meléndez - Martínez y col. (2006). Además, se encontró una correlación negativa $(r=-0,92 ; p=0,0014)$ entre los parámetros $L^{*}$ y $a^{*}$. Todos los aceites de chía mostraron valores positivos para $b^{*}$, lo cual indica una tendencia hacia el color amarillo, no habiéndose encontrado diferencias estadísticamente significativas $(p>0,05)$ entre ambos sistemas de extracción.

El color de los aceites vegetales está asociado con el contenido total de pigmentos. En este sentido, se detectó la presencia de compuestos carotenoides en el aceite de chía mientras que la presencia de clorofilas no fue detectada. El contenido total de carotenoides varió de $0,53 \mathrm{mg} / \mathrm{kg}$ a $1,21 \mathrm{mg} / \mathrm{kg}$, siendo el $\beta$ caroteno el principal compuesto. Estos valores son mayores que los informados en aceites de soja $(0,3 \mathrm{mg} / \mathrm{kg})$ y girasol $(0,1 \mathrm{mg} / \mathrm{kg})$, similares a los de lino $(0,7 \mathrm{mg} / \mathrm{kg})$ y maíz $(0,9 \mathrm{mg} / \mathrm{kg})$ y menores que los correspondientes al aceite de colza $(1,7 \mathrm{mg} / \mathrm{kg})$ (Tuberoso y col., 2007), no encontrándose diferencias significativas $(p>0,05)$ entre los aceites extraídos a través de distintos procesos.

La estabilidad oxidativa de los alimentos depende de su composición así como de la concentración y actividad de los sustratos reactivos, prooxidantes y antioxidantes. A fin de minimizar el uso de aditivos alimentarios, la estabilidad oxidativa puede ser potencialmente mejorada mediante la preservación o el aumento de los sistemas endógenos de control de la oxidación de los alimentos (Decker, 1998).

Pequeñas cantidades de metales, particularmente cobre y hierro, tienen un efecto prooxidante en los procesos de deterioro tales como la oxidación lipídica, motivo por el cual su presencia no es deseable en los aceites vegetales. El contenido de ambos metales en el aceite de chía (Tabla 3.9) fue menor que el máximo nivel permitido para los aceites vegetales vírgenes (Codex Alimentarius Commission, 1999) y que los informados en la literatura para los aceites de girasol crudos y degomados (Brevedan y col., 2000). Así, no se detectaron diferencias significativas $(p>0,05)$ en el contenido de cobre de los aceites obtenidos mediante 
ambos procesos de extracción. Sin embargo el contenido de hierro resultó ser significativamente $(p \leq 0,05)$ diferente; el tenor de este elemento resultó ser mayor en los aceites extraídos con hexano que en aquéllos obtenidos por prensado.

El contenido de fósforo presentó un rango de 54-225 ppm, siendo estos valores menores que los hallados en la literatura para aceites crudos de girasol (441932 ppm) (Brevedan y col., 2000) y soja (600-800 ppm) (List y col., 1978). Si bien no está establecido un factor para la conversión del contenido de fósforo a fosfolípidos específico para aceite de chía, en los últimos años se ha generalizado el uso de un factor 30, calculado originalmente para aceite crudo de soja (AOCS, 1998). Sin embargo, teniendo en cuenta la composición de ácidos grasos de los fosfolípidos individuales, Chapman (1980) ha determinado un valor de 25 para aceites de soja y girasol. A su vez, Carelli y col. (2002) han estimado un factor teórico de conversión de 24,7 para aceite crudo de girasol. En base a estos antecedentes, la aplicación de un factor de 25 a los aceites de chía analizados en este trabajo de Tesis, da lugar a un contenido de fosfolípidos totales en un rango de $0,1-0,6 \%$, valor que resulta inferior al encontrado en algunos aceites vegetales crudos (Gunstone, 2002). En base a la información disponible en la literatura relacionada, la facilidad de extracción de estos compuestos depende del método de extracción (Kamal-Eldin y Appelqvist, 1995). En este sentido, el contenido total de fósforo de los aceites obtenidos por prensado fue significativamente mayor $(p \leq 0,05)$ que en los extraídos con solvente, lo cual podría atribuirse a la baja solubilidad de los fosfolípidos en el hexano.

La Tabla 3.10 muestra el perfil de ceras correspondientes a los aceites estudiados. El contenido total de ceras varió de 92 a $180 \mathrm{mg} / \mathrm{kg}$, el cual es menor al informado para los aceites de girasol cultivado $(400-1100 \mathrm{mg} / \mathrm{kg})$ y silvestre (678$1128 \mathrm{mg} / \mathrm{kg}$ ) (Pérez y col., 2004). Los principales componentes fueron ésteres de 34 a 48 átomos de carbono, con una alta concentración de la fracción de C48, seguidos por las fracciones C38 y C36. Los aceites obtenidos mediante extracción con solvente presentaron mayores concentraciones de ceras que los de prensado, lo cual puede atribuirse a la alta solubilidad de estos compuestos en hexano en caliente. Estas diferencias registradas entre los procesos de extracción también han sido informadas por Carelli y col. (2002) en aceites obtenidos a partir de las semillas de Helianthus annuus L. 
Tabla 3.10. Perfil de ceras correspondientes a los aceites de semilla de Salvia hispanica L. obtenidos mediante extracción con solvente y prensado

\begin{tabular}{|c|c|c|c|c|c|c|c|c|}
\hline \multirow{3}{*}{ Cera } & \multicolumn{4}{|c|}{ Argentina } & \multicolumn{4}{|c|}{ Guatemala } \\
\hline & \multicolumn{2}{|c|}{$\begin{array}{l}\text { Extracción con } \\
\text { solvente }\end{array}$} & \multicolumn{2}{|c|}{ Prensado } & \multicolumn{2}{|c|}{$\begin{array}{l}\text { Extracción con } \\
\text { solvente }\end{array}$} & \multicolumn{2}{|c|}{ Prensado } \\
\hline & ppm & $\%$ & ppm & $\%$ & ppm & $\%$ & ppm & $\%$ \\
\hline C34 & 2 & 1,7 & 2 & 2,3 & 2 & 1,2 & 2 & 2,3 \\
\hline C36 & 18 & 12,5 & 19 & 18,0 & 11 & 6,3 & 13 & 13,8 \\
\hline C37 & 2 & 1,1 & 2 & 2,3 & 1 & 0,7 & 3 & 2,8 \\
\hline C38 & 24 & 16,8 & 26 & 24,0 & 17 & 9,2 & 14 & 15,3 \\
\hline C39 & 13 & 9,3 & 15 & 14,1 & 13 & 7,1 & 12 & 12,9 \\
\hline $\mathrm{C} 40$ & 6 & 4,0 & 5 & 5,1 & 8 & 4,3 & 3 & 3,1 \\
\hline C41 & 4 & 2,6 & 3 & 3,1 & 9 & 4,8 & 3 & 3,5 \\
\hline $\mathrm{C} 42$ & 3 & 2,1 & 3 & 2,8 & 11 & 6,4 & 2 & 2,1 \\
\hline C43 & 4 & 2,6 & 8 & 7,8 & 1 & 0,5 & 5 & 4,9 \\
\hline C44 & nd & nd & nd & nd & nd & nd & nd & nd \\
\hline C45 & 5 & 3,2 & 5 & 4,8 & 12 & 6,6 & 6 & 6,1 \\
\hline C46 & nd & nd & nd & nd & nd & nd & nd & nd \\
\hline C47 & nd & nd & nd & nd & 23 & 12,8 & nd & nd \\
\hline C48 & 65 & 45,8 & 19 & 18,1 & 75 & 41,3 & 33 & 35,5 \\
\hline Total & 142 & 100,0 & 108 & 100,0 & 180 & 100,0 & 92 & 100,0 \\
\hline
\end{tabular}

Las Figuras 3.5 y 3.6 muestran los perfiles de tocoferoles de los aceites obtenidos mediante extracción con solvente y prensado a partir de ambos lotes de 
semillas. El contenido total de tocoferoles varió entre 238 y $427 \mathrm{mg} / \mathrm{kg}$, siendo el $\mathrm{Y}^{-}$ tocoferol el componente más abundante de esta fracción (226 - $420 \mathrm{mg} / \mathrm{kg})$, seguido y el $\delta$-tocoferol $(2-49 \mathrm{mg} / \mathrm{kg}$ ) y pequeñas cantidades de $\alpha$-tocoferol $(0,4-9,9 \mathrm{mg} /$ $\mathrm{kg})$. La concentración total de tocoferoles correspondiente a los aceites de chía fue similar a la informada en aceite de maní $(398,6 \mathrm{mg} / \mathrm{kg})$ e inferior a la de lino $(588,5$ $\mathrm{mg} / \mathrm{kg}$ ), girasol $(634,4 \mathrm{mg} / \mathrm{kg}$ ) y soja $(1797,6 \mathrm{mg} / \mathrm{kg}$ ) (Tuberoso y col., 2007). Los aceites extraídos con solvente presentaron un contenido de tocoferoles significativamente mayor $(p \leq 0,05)$ que los obtenidos mediante prensado. Por otra parte, se ha encontrado la existencia de una correlación positiva significativa entre el contenido de ácido $\alpha$ - linolénico y el contenido total de tocoferoles $(r=0,95 ; p=$ $0,0034)$ así como entre este ácido graso y el $y$-tocoferol $(r=0,94 ; p=0,0055)$. En este sentido, se ha citado en la literatura que las altas concentraciones de tocoferoles están asociadas a elevados contenidos de PUFAs (Tuberoso y col., 2007).

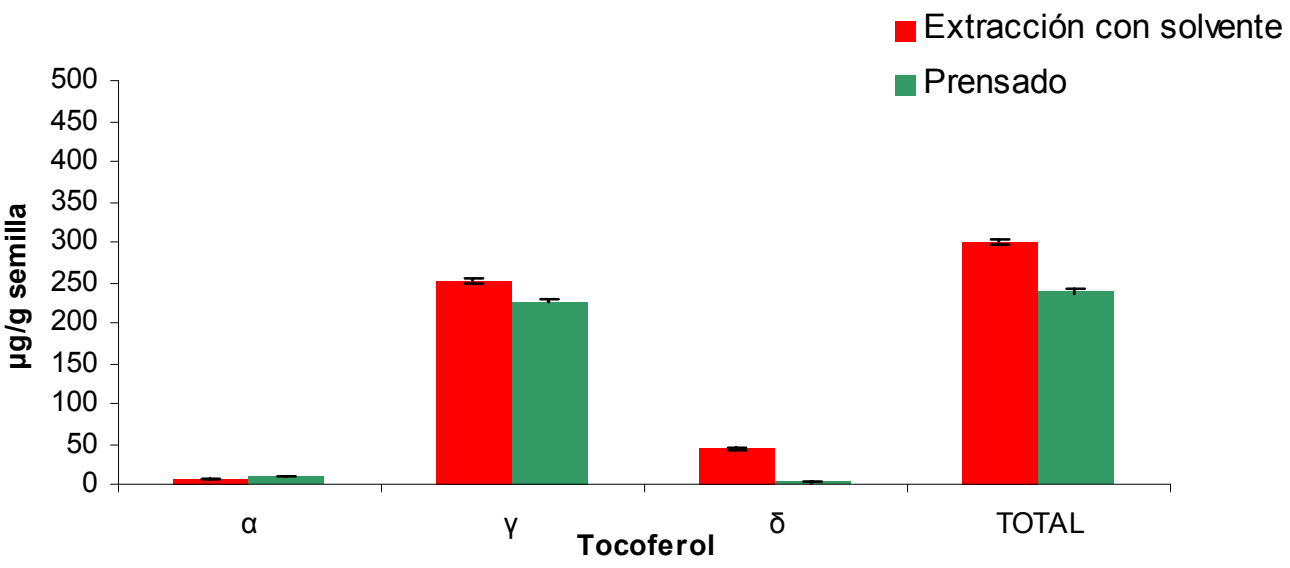

Figura 3.5. Perfil de tocoferoles presentes en aceites de chía obtenidos mediante extracción con solvente y prensado a partir de semillas provenientes de Argentina. Las barras verticales indican la desviación estándar 


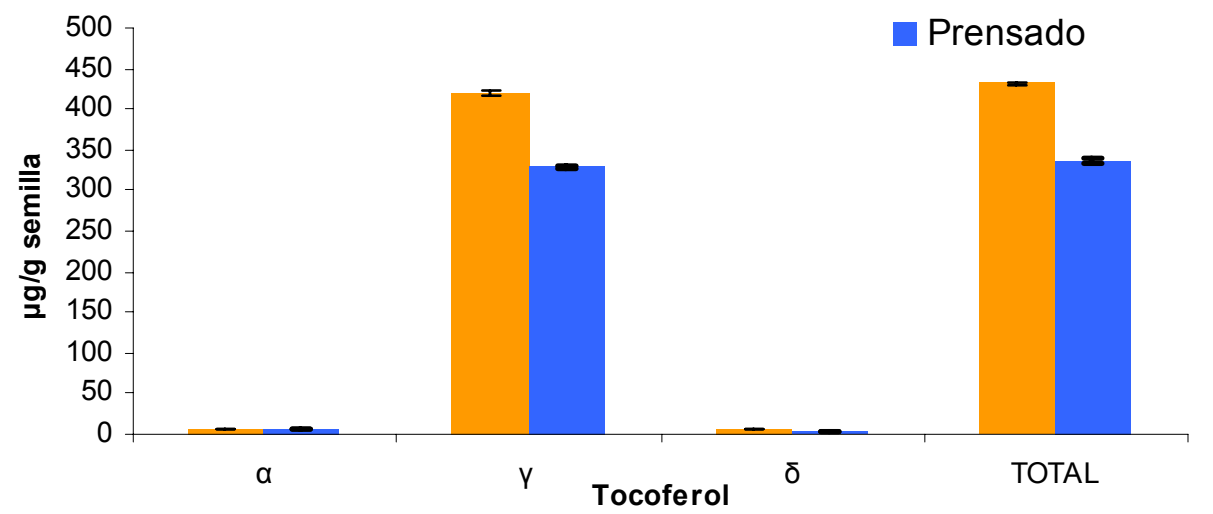

Figura 3.6. Perfil de tocoferoles presentes en aceites de chía obtenidos mediante extracción con solvente y prensado a partir de semillas provenientes de Guatemala. Las barras verticales indican la desviación estándar.

Con respecto a la determinación de antioxidantes fenólicos en los aceites de chía, la Figura 3.7 muestra un cromatograma típico correspondiente a una solución estándar de $100 \mu \mathrm{M}$ de cada compuesto, pudiéndose observar que los tiempos de retención variaron de 4 a 9 min.

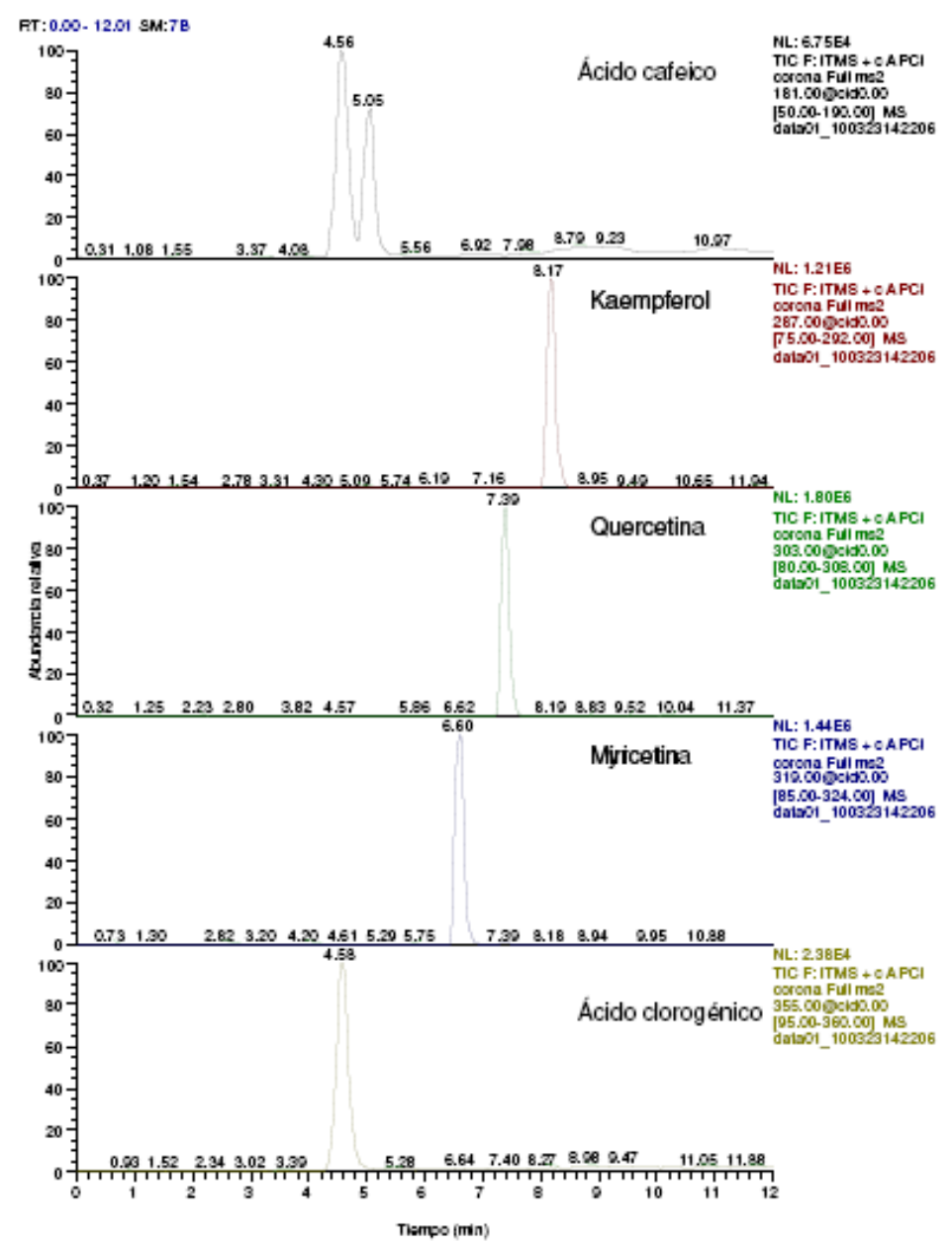

Figura 3.7. Cromatograma típico para una solución estándar de $100 \mu \mathrm{M}$ de cada compuesto polifenólico 
El contenido total de antioxidantes polifenólicos en los aceites de chía varió de $6 \times 10^{-6}$ a $2,1 \times 10^{-5} \mathrm{~mol} / \mathrm{kg}$, siendo los principales componentes los ácidos clorogénico y cafeico, seguidos por la miricetina, quercetina y kaempferol (Figuras 3.8 y 3.9). La composición de esta fracción fue similar a la encontrada en las semillas de chía, tal como se mencionó en el Capítulo 2, aunque con una menor concentración de cada uno de los compuestos polifenólicos, lo cual puede atribuirse a la baja solubilidad de los mismos en el aceite debido a su naturaleza de tipo hidrofílica. Es importante destacar que estos compuestos no son habitualmente encontrados en otros aceites vegetales (Tuberoso y col., 2007). Se registraron diferencias significativas $(p \leq 0,05)$ en los aceites obtenidos mediante los diferentes procesos de extracción. Así, tanto el contenido de ácido clorogénico como la concentración total de los compuestos polifenólicos fueron significativamente mayores $(p \leq 0,05)$ en los aceites obtenidos por prensado que en los extraídos con solvente (Figuras 3.8 y 3.9).

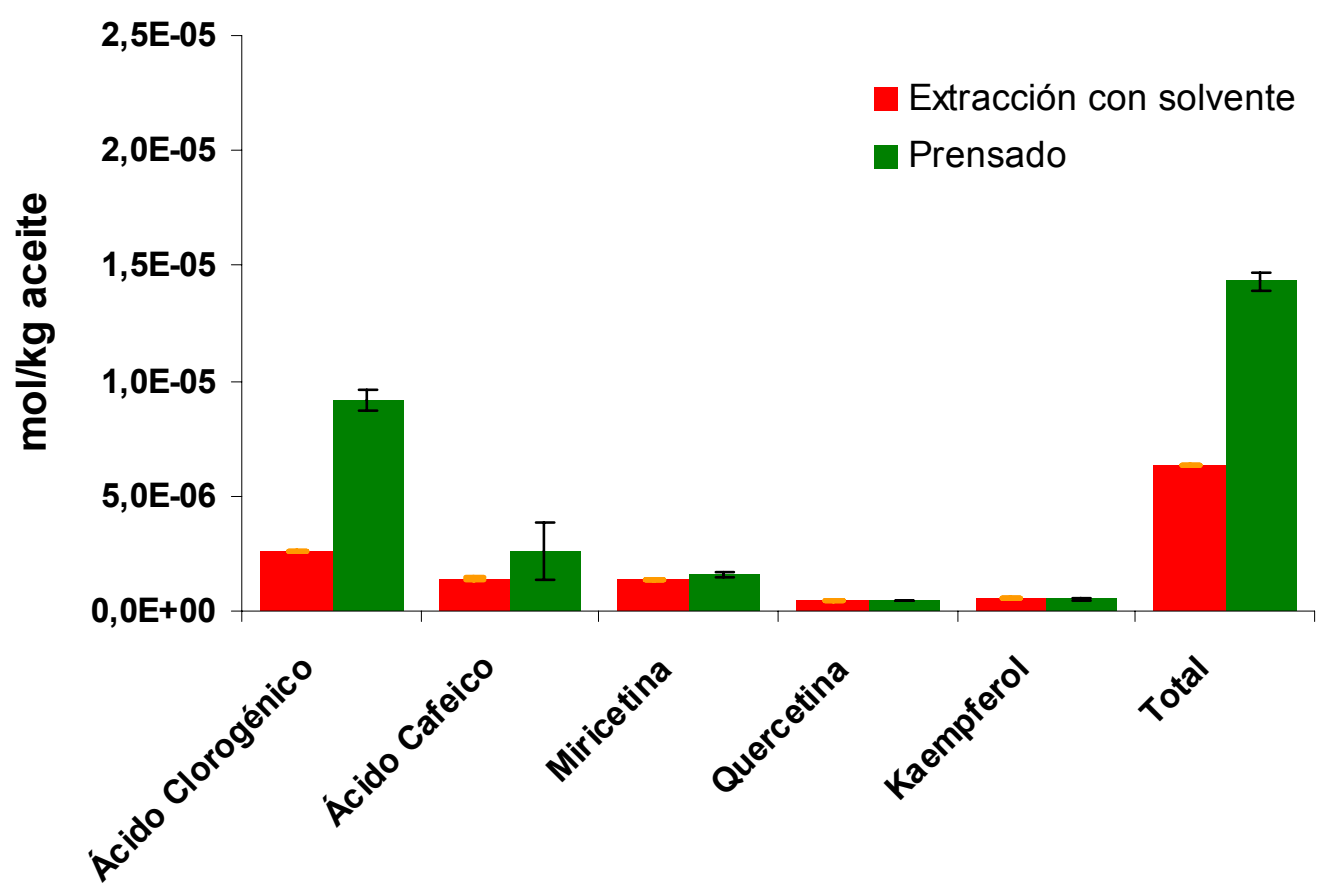

Figura 3.8. Perfil de compuestos polifenólicos de los aceites de chía obtenidos mediante extracción con solvente y prensado a partir de las semillas provenientes de Argentina. Las barras verticales indican la desviación estándar 


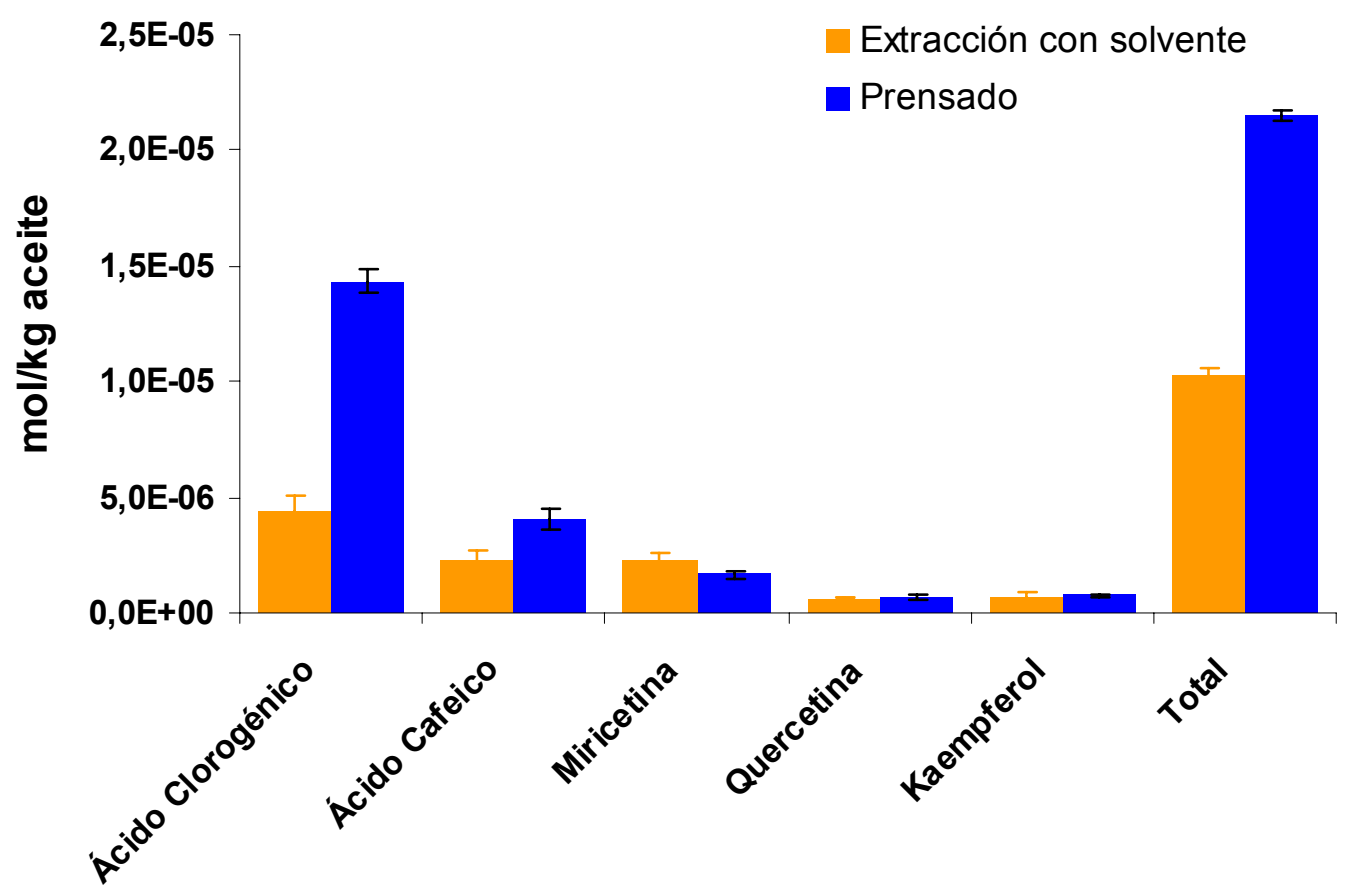

Figura 3.9. Perfil de compuestos polifenólicos de los aceites de chía obtenidos mediante extracción con solvente y prensado a partir de las semillas provenientes de Guatemala. Las barras verticales indican la desviación estándar

Con respecto a la estabilidad oxidativa determinada mediante el ensayo acelerado (Rancimat), la misma se caracterizó por los bajos tiempos de inducción obtenidos (2,4 - 2,8 h, ver Tabla 3.9) indicando que los aceites de chía son inestables en relación a los procesos de termo-oxidación, en comparación con otros aceites vegetales (Arranz y col., 2008). Asimismo, no se registraron diferencias significativas $(p>0,05)$ entre los distintos aceites de chía estudiados (Tabla 3.9). Se obtuvo una correlación positiva estadísticamente significativa entre la estabilidad oxidativa y el contenido de fósforo $(r=0,76 ; p=0,0268)$. En relación a este hecho, algunos autores han informado que los fosfolípidos pueden incidir en la estabilidad oxidativa de los aceites vegetales debido a sus propiedades antioxidantes y al sinergismo con otros antioxidantes naturales presentes en los aceites vegetales tales como los tocoferoles (Gordon y Rahman, 1991). Sin embargo, el alto tenor de PUFAs determina que los tiempos de inducción registrados para este tipo de aceite sean muy bajos, aún en presencia de un interesante contenido de tocoferoles, flavonoides y ácidos fenólicos. 
La calorimetría diferencial de barrido (DSC) puede aplicarse para lograr la caracterización de diferentes aceites y grasas mediante la obtención de sus perfiles térmicos (Nassu y Goçalves, 1999; Tan y Che Man, 2000; Tan y Che Man, 2002), el estudio de la cinética de oxidación y la determinación de la estabilidad oxidativa (Gupta y Jaworski, 1991; Simon y col., 2000), el estudio de adulteraciones (Marikkar y col., 2002) y la identificación de la procedencia de las semillas (Dyszel y Pettit, 1990). En virtud de ello, esta técnica ha sido implementada en el presente trabajo de Tesis para obtener información acerca de las propiedades térmicas del aceite de chía. Así, los termogramas obtenidos mediante DSC para los aceites de chía analizados se presentan en la Figura 3.10. En todos los casos puede visualizarse el proceso característico de fusión, de naturaleza endotérmica. A su vez, los aceites de chía provenientes de semillas de Guatemala presentan dos picos endotérmicos importantes, mientras que los aceites obtenidos a partir de semillas de chía de Argentina registran un pico principal con un pequeño hombro. En la Tabla 3.11 se detallan los valores de temperatura máxima de dichos picos $\left(T_{p 1}\right.$ y $\left.T_{p 2}\right)$, así como la temperatura del inicio $\left(T_{0}\right)$ y finalización ( $T_{\text {end }}$ ) de la transición. Se observa que tanto el primero como el segundo pico correspondientes a los aceites obtenidos a partir de las semillas de Guatemala aparecen a una temperatura menor que los aceites de Argentina. Esta diferencia podría estar relacionada principalmente con el contenido de acido $\alpha$-linolénico así como con la composición triacilglicerídica de los respectivos aceites estudiados. Tal como se mencionó con anterioridad, los aceites obtenidos a partir de las semillas de Guatemala presentaron un mayor tenor de ácido a-linolénico y de trilinolenina que los de Argentina (ver Tablas 3.5 y 3.8). Así, la presencia de un mayor contenido de ácidos grasos poliinsaturados se tradujo en un descenso del punto de congelación de los mismos (Tan y Che Man, 2000). Por otra parte, la temperatura del inicio de la fusión ( $\mathrm{T}_{\mathrm{o}}$ ), aumentó conforme a la disminución del contenido de ácido a-linolénico. Así, el aceite extraído por solvente a partir de las semillas de Guatemala, de mayor contenido en C18:3, fue el que comenzó a fundir antes con valores de $\mathrm{T}_{0}$ en torno a los $-54^{\circ} \mathrm{C}$, mientras que el obtenido por prensa a partir de las semillas de Argentina registró el inicio de este proceso alrededor de los $-50^{\circ} \mathrm{C}$. Con respecto a los aceites obtenidos por diferentes procesos a partir de las semillas provenientes de Guatemala, no se observaron diferencias significativas ( $p>$ $0,05)$ en los parámetros estudiados. Sin embargo, el proceso de extracción afectó significativamente $(p \leq 0,05)$ los valores de $T_{0}$ y $T_{\text {end }}$ de los aceites obtenidos a partir 
de las semillas de Argentina, habiéndose registrado que aquéllos extraídos con hexano iniciaron y finalizaron el proceso de fusión a temperaturas más bajas que los obtenidos por prensado.

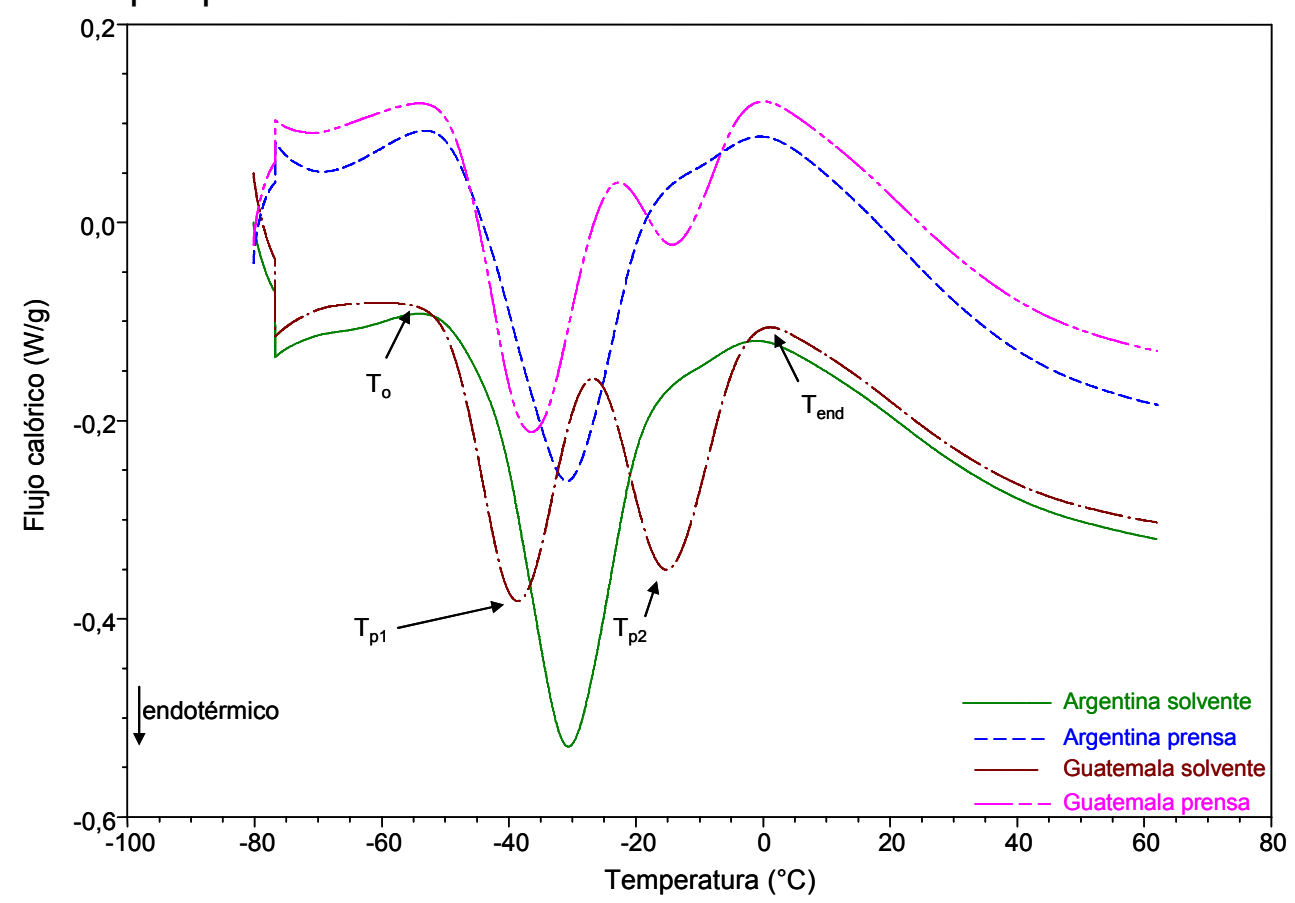

Figura 3.10. Termogramas (DSC) de aceites de chía obtenidos mediante extracción con solvente y prensa a partir de semillas procedentes de Argentina y Guatemala

Una de las características que pueden presentar las grasas y aceites, como consecuencia de las diferencias en la composición de ácidos grasos y su distribución en la molécula de glicerol, es la posibilidad de registrar polimorfismo o coexistencia de más de una forma cristalina cuando solidifican (Bailey, 1950), caracterizándose cada tipo de estructura cristalina por tener asociadas propiedades físicas bien diferenciadas. En general, los triacilgliceroles exhiben tres formas polimórficas principales $\alpha, \beta^{\prime}$ y $\beta$, ordenadas en función del aumento de su punto de fusión, es decir de su estabilidad térmica. Generalmente, los aceites que presentan relativamente pocas especies de triacilgliceroles con estructura relacionada tienden a transformarse rápidamente hacia la forma más estable $\beta$. Por el contrario, aquéllos cuya composición triacilglicerídica es más heterogénea tienden a registrar transiciones polimórficas más lentas (Nawar, 1996). Che Man y col. (1999) han indicado la posibilidad de obtener información acerca de la presencia de estas formas polimórficas a partir de los termogramas de calentamiento de DSC. En este sentido, Garti y col. (1989) han informado que el primer pico de un termograma de 
calentamiento de una mezcla de triacilgliceroles correspondería a la forma $\alpha$, mientras que el último pico a la forma $\beta$, más estable. El perfil de DSC del aceite de chía sugiere la presencia de dos tipos de estructuras cristalinas, asociándose a la segunda una contribución mayor en los aceites obtenidos a partir de las semillas de Gutemala. Futuros estudios a llevarse a cabo mediante difracción de rayos $X$ permitirán complementar la caracterización de las posibles estructuras cristalinas previamente mencionadas.

Tabla 3.11. Temperaturas máximas de pico $\left({ }^{\circ} \mathrm{C}\right)\left(T_{p 1}\right.$ y $\left.T_{p 2}\right)$, del inicio $\left(T_{0}\right)$ y del final de la transición ( $\mathrm{T}_{\text {end }}$ ) correspondientes a las curvas de fusión de los aceites de chía obtenidos mediante extracción con solvente y prensado a partir de las semillas provenientes de Argentina y Guatemala

\begin{tabular}{|c|c|c|c|c|}
\hline & \multicolumn{2}{|c|}{ Argentina } & \multicolumn{2}{|c|}{ Guatemala } \\
\hline & $\begin{array}{l}\text { Extracción con } \\
\text { solvente }\end{array}$ & Prensado & $\begin{array}{l}\text { Extracción } \\
\text { con solvente }\end{array}$ & Prensado \\
\hline Onset $\left(T_{0}\right)$ & $-51,4 \pm 0,1^{a}$ & $-50,3 \pm 0,0^{b}$ & $-52,9 \pm 0,3^{A}$ & $-52,8 \pm 0,4^{A}$ \\
\hline Pico $1\left(T_{p 1}\right)$ & $-31,3 \pm 0,9^{a}$ & $-31,4 \pm 0,7^{a}$ & $-38,3 \pm 0,6^{A}$ & $-38,0 \pm 2,1^{\mathrm{A}}$ \\
\hline Pico $2\left(T_{p 2}\right)$ & $-10,05 \pm 0,3^{a}$ & $-10,3 \pm 0,4^{a}$ & $-15,1 \pm 0,1^{A}$ & $-14,7 \pm 0,4^{A}$ \\
\hline Endset $\left(T_{\text {end }}\right)$ & $-1,42 \pm 0,1^{b}$ & $-1,0 \pm 0,0^{a}$ & $-0,2 \pm 0,1^{\mathrm{A}}$ & $-0,3 \pm 0,0^{A}$ \\
\hline Calor de fusión $(\mathrm{J} / \mathrm{g})$ & $43,9 \pm 1,2^{\mathrm{a}}$ & $42,3 \pm 2,5^{\mathrm{a}}$ & $42,6 \pm 3,1^{\mathrm{A}}$ & $42,1 \pm 0,2^{\mathrm{A}}$ \\
\hline
\end{tabular}

Los calores de fusión obtenidos se encontraron en un rango de 42,1 - 43,9 $\mathrm{J} / \mathrm{g}$, no habiéndose registrado diferencias significativas $(p>0,05)$ entre los aceites estudiados. 


\section{Caracterización comparativa de los aceites de chía obtenidos mediante} extracción con solvente a partir de las semillas oscuras y blancas provenientes de Salta (Argentina)

Tal como fue descripto en el Capítulo 2 de este trabajo de Tesis, se han observado diferencias en las propiedades físicas así como en la composición química de las semillas blancas y oscuras de chía. La existencia de cultivares conformados por semillas blancas únicamente (Salba ${ }^{\circledR}$ ) obtenidos a través de sucesivos ciclos de selección artificial a favor de este carácter, nos conduce a la necesidad de estudiar si estas diferencias pueden estar presentes en los aceites obtenidos a partir de ambos tipos de semillas. Para ello, se estudiaron las principales características fisicoquímicas de los aceites obtenidos mediante extracción con solventes a partir de las semillas oscuras y blancas provenientes de Salta (Argentina).

En la Tabla 3.12 se presenta el rendimiento de aceite obtenido para las semillas blancas y oscuras provenientes de Argentina así como la composición acídica de los aceites obtenidos. El contenido total de aceite fue de 33,8 y 32,7\% para las semillas blancas y oscuras, respectivamente, no habiéndose detectado diferencias significativas $(p>0,05)$ entre las mismas. Estos valores fueron menores que los publicados por Ayerza (1995), aunque del mismo rango que los informados por Velasco Vargas y col. (2004). La composición de ácidos grasos fue significativamente diferente $(p \leq 0,05)$ entre los aceites obtenidos a partir de las semillas oscuras (ASO) y las blancas (ASB). El tenor de los ácidos grasos oleico y a-linolénico fue mayor en el ASO que en el ASB, mientras que pudo observarse una tendencia inversa para los ácidos palmítico y esteárico. Cuando se consideraron los grupos de FA según su nivel de insaturación, se observaron variaciones significativas $(p \leq 0,05)$ para los SFAs, siendo mayor su nivel en el ASB, mientras que la relación entre PUFAs/SFAs así como $\omega-3 / \omega-6$ fueron mayores en el ASO (Tabla 3.12). Teniendo en cuenta que las semillas fueron cultivadas bajo las mismas condiciones ambientales, estas diferencias podrían ser atribuidas a variaciones genéticas entre ambos tipos de semillas. Existe abundante literatura relacionada con los beneficios para la salud asociados con el contenido de PUFAs así como de la necesidad de un correcto balance entre los ácidos grasos $\omega-3$ y $\omega-6$ (Simon y col., 1995; Bourre, 2003; Zhao y col., 2004; Bowen y Clandinin, 2005; Galli y Marangoni, 2006). En este sentido, las semillas de chía podrían ser una fuente alternativa para 
la obtención de aceites con una interesante composición acídica a ser empleados en la industria alimentaria.

Tabla 3.12. Rendimiento (\% b.s.) y composición de ácidos grasos (\% del total de ácidos grasos) correspondiente a los aceites extraídos por solvente a partir de las semillas blancas y oscuras provenientes de Salta (Argentina)

\begin{tabular}{lcc}
\hline & \multicolumn{2}{c}{ Tipo de semilla } \\
\cline { 2 - 3 } & Blanca & Oscura \\
\hline Rendimiento & $33,8^{\mathrm{a}}$ & $32,7^{\mathrm{a}}$ \\
Ácido graso & & \\
Palmítico (16:0) & $6,2^{\mathrm{b}}$ & $5,9^{\mathrm{a}}$ \\
Esteárico (18:0) & $3,0^{\mathrm{b}}$ & $2,5^{\mathrm{a}}$ \\
Oleico (18:1) & $5,6^{\mathrm{a}}$ & $5,8^{\mathrm{b}}$ \\
$\Delta 11(18: 1)$ & $\mathrm{nd}^{\mathrm{a}}$ & $\mathrm{nd}^{\mathrm{a}}$ \\
Linoleico (18:2) & $20,1^{\mathrm{a}}$ & $20,0^{\mathrm{a}}$ \\
a-Linolénico (18:3) & $64,8^{\mathrm{a}}$ & $65,6^{\mathrm{b}}$ \\
SFAs & $9,2^{\mathrm{b}}$ & $8,4^{\mathrm{a}}$ \\
PUFAs & $84,9^{\mathrm{a}}$ & $85,6^{\mathrm{a}}$ \\
PUFAs/SFAs & $9,2^{\mathrm{a}}$ & $10,2^{\mathrm{b}}$ \\
W-3/w-6 & $3,2^{\mathrm{a}}$ & $3,3^{\mathrm{b}}$
\end{tabular}

Valores medios $(n=3)$. Letras minúsculas distintas indican diferencias significativas $(p \leq 0,05)$ entre las semillas blancas y oscuras; SFAs, ácidos grasos saturados; PUFAs, ácidos grasos poliinsaturados; $\omega-6 / \omega-3$, ácido linoleico/ácido $\alpha$-linolénico; nd: no detectado

Las principales propiedades fisicoquímicas de los ASB y ASO se muestran en la Tabla 3.13. Se encontraron diferencias significativas $(p \leq 0,05)$ para los índices de iodo y acidez. El índice de iodo fue inferior en el ASB que en el correspondiente al ASO, lo cual puede asociarse al menor tenor de ácido a-linolénico encontrado en las semillas blancas. El ASB presentó un mayor contenido de ácidos grasos libres que el ASO, mientras que los valores de IS variaron entre 193,07 y 194,23, resultando similares a los hallados previamente en la literatura (AOCS, 1998; Velasco Vargas y Col., 2004). Con respecto al PV, los resultados obtenidos mostraron que los aceites provenientes de ambos tipos de semillas se encontraron por debajo del máximo nivel 
permitido aún para los aceites refinados (10 meq peróxido/kg aceite; Codex Alimentarius Commission, 1999; Código Alimentario Argentino, 2008). Además, no se encontraron diferencias significativas $(p>0,05)$ entre los aceites obtenidos a partir de ambos tipos de semillas para el IS, IR ni para PV.

Tabla 3.13. Características fisicoquímicas correspondientes a los aceites obtenidos mediante extracción con solvente a partir de las semillas blancas y oscuras de chía provenientes de Salta (Argentina)

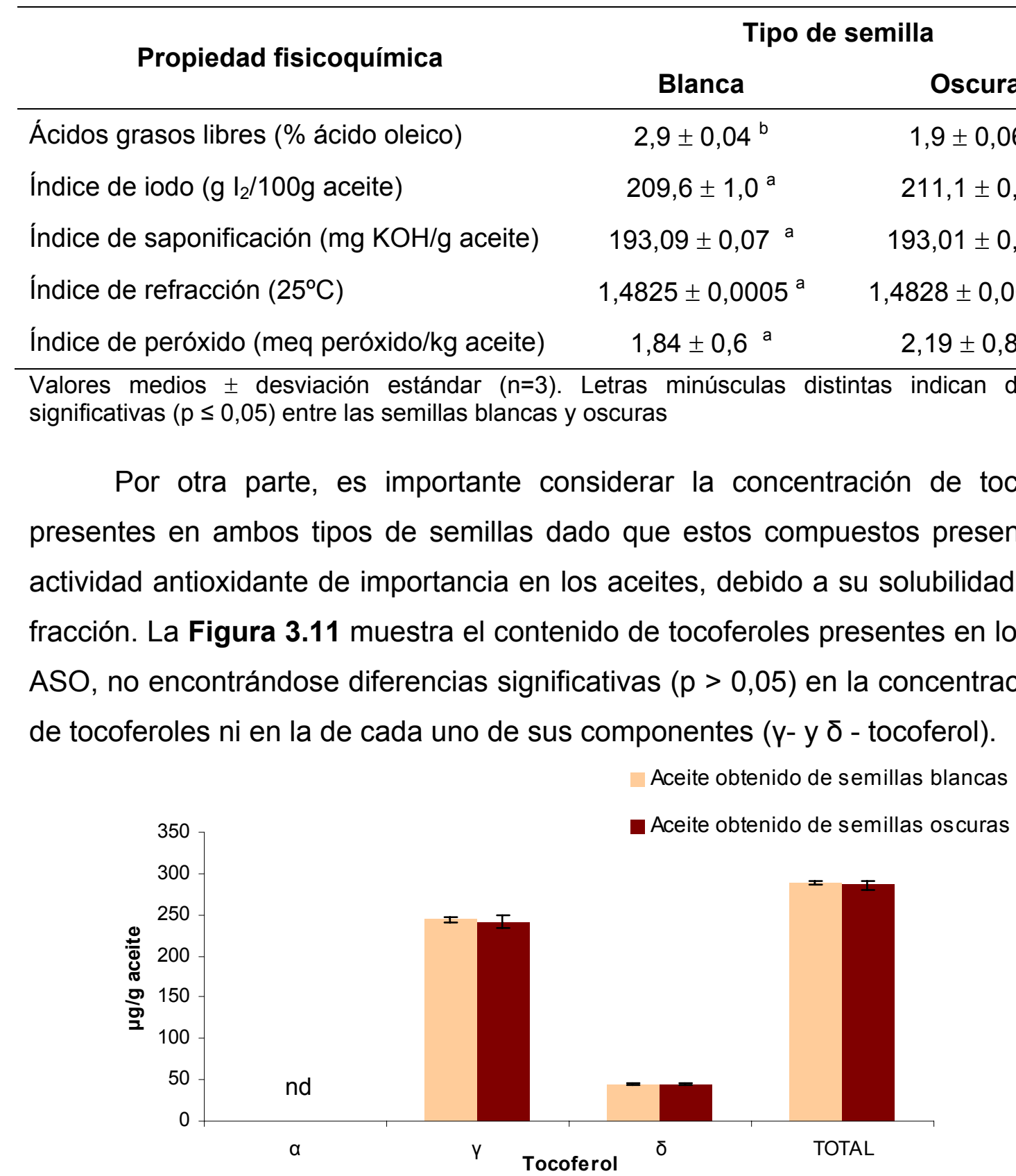

Figura 3.11. Perfil de tocoferoles de los aceites de chía obtenidos mediante extracción con solvente a partir de las semillas blancas y oscuras provenientes de Argentina. Las barras verticales indican la desviación estándar 


\section{CONCLUSIONES PARCIALES}

- El rendimiento de aceite obtenido mediante extracción con solvente fue aproximadamente un $30 \%$ mayor que el correspondiente al prensado.

- La genuinidad de los aceites de chía obtenidos se vio reflejada en los índices de iodo, saponificación, refracción y material insaponificable, los cuales se encontraron dentro de los valores establecidos por las normativas internacionales vigentes (AOCS, 1998).

- Los principales ácidos grasos detectados en los aceites de chía obtenidos por ambos procesos fueron los siguientes según el orden de abundancia: ácido alinolénico $(\alpha \mathrm{Ln})>$ ácido linoleico $(\mathrm{L})>$ ácido oleico $(\mathrm{O}) \approx$ ácido palmítico $(P)>$ ácido esteárico $(E)>$ ácido vaccénico $(\Delta 11)$; la composición acídica fue similar para ambos procesos de extracción.

- La relación $\omega-3 / \omega-6$ presentada por los aceites de chía fue 3,18-4,18, siendo la misma marcadamente superior que la correspondiente a otros aceites vegetales tales como girasol, canola, oliva, soja.

- El aceite proveniente de las semillas de chía oscuras (ASO) cultivadas en Argentina presentó un mayor tenor de ácidos oleico y a-linolénico así como una mayor relación PUFAs/SFAs y $\omega-3 / \omega-6$ que el obtenido a partir de las semillas blancas (ASB) del mismo origen.

- Los principales triacilgliceroles determinados mediante HPLC/APCI-MS fueron: $\alpha \operatorname{Ln} \alpha \operatorname{Ln} \alpha \ln >\alpha \operatorname{LiLnL}>\alpha \operatorname{LLL}>\alpha \operatorname{LiLnP}>\alpha \operatorname{LLO} \sim \alpha \operatorname{LnLP}$, los cuales representan aproximadamente el $87-95 \%$ del contenido total de estos compuestos, siendo el tenor de aLnaLnaLn mayor en los aceites provenientes de las semillas de Guatemala.

- Los aceites de chía registraron un moderado contenido de compuestos bioactivos, tales como tocoferoles, polifenoles, carotenoides y fosfolípidos. La composición cuantitativa de algunos de estos compuestos minoritarios fue influenciada por el proceso de extracción, habiéndose registrado un mayor tenor de tocoferoles en los aceites extraídos con solvente, mientras que los aceites obtenidos por prensado presentaron un mayor contenido de fosfolípidos y compuestos polifenólicos. 
- El contenido total de ceras varió de 92 a 180 ppm, siendo los principales componentes los ésteres de 34 a 48 átomos de carbono, con una alta concentración de la fracción C48.

- El aceite de chía fue caracterizado térmicamente mediante DSC a través de la determinación de la temperatura del inicio del proceso de fusión así como de las temperaturas máximas de pico y el calor de fusión. Se registró el inicio del proceso de fusión a una temperatura promedio de $-52,1^{\circ} \mathrm{C}$, la cual varió en función del contenido de ácido $\alpha$-linolénico.

- Los aceites de chía obtenidos exhibieron una baja estabilidad oxidativa debido principalmente al elevado nivel de PUFAs presentes en los mismos.

En virtud de lo expuesto, se aceptan la hipótesis II: "La composición acídica y triacilglicerídica así como la presencia de compuestos minoritarios le confieren al aceite de chía cualidades benéficas desde el punto de vista nutricional, siendo de interés su aplicación potencial en la industria alimentaria"; y la hipótesis III: "El proceso de obtención tiene efecto sobre el rendimiento de aceite de chía así como sobre sus características fisicoquímicas". 


\section{DIFUSIÓN DE RESULTADOS}

Capítulos de libro

- Characterization of chía (Salvia hispanica L.) white and dark seeds and oils. Ixtaina VY, Nolasco SM, Tomás MC (2010). En: Advances in Fats and Oils Research. Editor M.C. Tomás. Ed. Transword Research Network, Kerala (India), pp 135-147.

\section{Publicaciones Científicas en Revistas Internacionales}

- Characterization of chia (Salvia hispanica L.) crude seed oils obtained by pressing and solvent extraction. Vanesa Y. Ixtaina, Marcela L. Martínez, Viviana Spotorno, Damián M. Maestri, Bernd W. Diehl, Susana M. Nolasco, Mabel C. Tomás. Journal of Food Composition and Analysis 2010 (en prensa).

\section{Presentaciones en Congresos con trabajo extendido}

- Antioxidantes en aceite de chía (Salvia hispanica L.) obtenido mediante prensado Ixtaina, Vanesa Y.; Martínez, Marcela; Maestri Damián; Spotorno, Viviana; Mateo, Carmen; Nolasco, Susana M.; Tomás Mabel C., Actas del VI Congreso Iberoamericano de Ingeniería de Alimentos, Ambato (Ecuador) 5 al 8 de noviembre de 2007. ISSN 1390-2180.

- Influencia del método de obtención de aceite de chía (Salvia hispanica L.) sobre su rendimiento y calidad. Vanesa Y. Ixtaina, Susana M. Nolasco Y Mabel C. Tomás. Encuentro de Jóvenes Investigadores de AUGM, Asunción (Paraguay), octubre de 2007.

- Obtención y caracterización de aceite de chía (Salvia hispanica L.) mediante diversas metodologías. Vanesa Ixtaina, Marcela Martínez, Damián Maestri, Susana M. Nolasco y Mabel C. Tomás. XI Congreso Argentino de Ciencia y Tecnología de los Alimentos. $2^{\circ}$ Simposio Internacional de Nuevas Tecnologías "Hacia una mejora continua en la calidad". Buenos Aires, 12 al 14 de septiembre de 2007. Trabajo 3.11. pp. 54-55. ISBN 978-987-22165-2-8. 


\section{Presentaciones en Congresos}

- Oxidative stability and characterization of antioxidants in chia (Salvia hispanica L.) seed oils. Ixtaina V., Spotorno V, Mateo C., Nolasco S. y Tomás M. $98^{\text {th }}$ AOCS Annual Meeting \& Expo. Québec, Canadá, 13 al 16 de mayo de 2007.

- Caracterización de la semilla y aceite de chía. Ixtaina V, SM Nolasco y MC Tomás, Proceedings del Congreso Internacional de Ciencia y Tecnología de los Alimentos, Córdoba, noviembre de 2006. ISBN 987-22457-9-7. 
Capítulo 4

Obtención y caracterización de aceite de chía mediante extracción por fluidos supercríticos (EFSC) 


\section{INTRODUCCIÓN}

En los últimos años, la extracción de aceites vegetales con solventes bajo condiciones supercríticas se ha propuesto como una alternativa para reemplazar los procesos convencionales (prensado, extracción con solvente). Este proceso asegura la ausencia de trazas de solvente en el aceite extraído y permite preservar de manera más eficiente las características químicas y organolépticas del mismo (Herrero y col., 2006; Norulaini y col., 2009).

El principio de extracción se basa en que el fluido es llevado a un estado supercrítico específico a fin de extraer un soluto determinado. Así, el material a ser sometido al proceso es expuesto al fluido bajo condiciones de tiempo, temperatura y presión controladas, lo que permite la disolución de los solutos de interés en el fluido supercrítico. El soluto disuelto es separado posteriormente del fluido supercrítico mediante la disminución de la presión de la solución (Nielsen, 1998).

La manipulación de la temperatura y presión por encima del punto crítico modifica las propiedades del fluido y mejora su habilidad para penetrar en las estructuras y extraer determinadas moléculas de diferentes tipos de materiales (Dunford y col., 2003; Boutin y Badens, 2009).

Dentro de los solventes utilizados en este método se pueden mencionar al etileno, dióxido de carbono, etano, propano, $n$-hexano, acetona, metanol, etanol, acetato de etilo, agua, entre otros. El dióxido de carbono es el fluido supercrítico más comúnmente utilizado para la extracción de productos alimenticios ya que presenta una serie de ventajas: es de bajo costo, se comercializa en un grado de alta pureza, no contamina el ambiente, no es tóxico ni inflamable, es fácilmente removible del producto de interés -a través de una simple despresurización una vez finalizada la extracción- y resulta ideal para extraer compuestos termosensibles $\left(T_{c} 31,1^{\circ} \mathrm{C}, P_{c}\right.$ 73,8 bar). Además, el dióxido de carbono en estado supercrítico $\left(\mathrm{SC}-\mathrm{CO}_{2}\right)$ presenta una alta densidad y baja viscosidad, lo cual aumenta su capacidad para solubilizar compuestos y permite una mejor penetración hacia el interior de los sólidos (Brunner, 2005).

En las últimas cuatro décadas, el $\mathrm{SC}-\mathrm{CO}_{2}$ ha sido empleado en la extracción de PUFAs del aceite de pescado (Rubio Rodríguez y col, 2008) así como para la obtención de aceites a partir de las semillas de la vid (Gómez y col., 1996), el amaranto (Westerman y col., 2006), la avellana (Özkal y col., 2005a), el Sacha Inchi 
(Follegatti-Romero y col., 2009), el lino (Bozan y Temelli, 2002; Özkal, 2009), la soja, el cártamo, el algodón, la canola, el mijo y el arroz (Stahl y col., 1980; Friedrich y Pryde, 1984), entre otras.

Los parámetros que influyen en la extracción mediante fluidos supercríticos (EFSC) incluyen tanto aspectos específicos del material como parámetros intrínsecos del proceso de extracción. Así, con el objetivo de mejorar la transferencia de masa, generalmente se provoca la ruptura de la estructura celular que contiene el aceite antes de comenzar el proceso de extracción.

La solubilidad del aceite en el fluido supercrítico es una función de la temperatura, la presión y de su peso molecular medio. Catchpole y col. (2009) han descripto la existencia de una correlación lineal negativa entre la solubilidad de los aceites en el $\mathrm{SC}-\mathrm{CO}_{2}$ y su peso molecular. Las curvas de extracción de los aceites de semillas de zapallo, amapola, colza, cártamo, níger y cáñamo, entre otras, presentan un periodo de extracción caracterizado por una velocidad constante, el cual es seguido por una etapa de extracción en la cual dicha velocidad disminuye. La explicación de este comportamiento se basa en que durante el primer periodo el "aceite libre" es extraído de la superficie de las partículas. Así, la relación entre el rendimiento acumulado y el $\mathrm{CO}_{2}$ utilizado puede ser representada mediante una línea recta cuya pendiente corresponde a la solubilidad aparente del aceite en el SC$\mathrm{CO}_{2}$. En la segunda etapa, cuando el aceite depositado sobre las partículas ya ha sido removido, la velocidad de extracción se ve limitada por los mecanismos internos de transferencia de masa del "aceite ligado", mostrando una disminución y aproximación asintótica al valor de rendimiento final del aceite (Machmudah y col., 2007). Eggers y col. (2000) han informado que los pretratamientos realizados a la semilla, así como temperaturas de extracción comprendidas entre $40-80^{\circ} \mathrm{C}$, presiones operativas superiores a 500 bar y una relación solvente/sustrato 8,6 - 28,6 $\mathrm{g} \mathrm{CO}_{2} / \mathrm{g}$ sustrato $\mathrm{h}$ no afectaron la solubilidad aparente del aceite de semilla de rosa mosqueta, mientras que la misma fue afectada positivamente por la presión de extracción desde 300 a 500 bar.

En virtud de lo expuesto, se estudió el proceso de extracción de aceite de chía mediante $\mathrm{SC}-\mathrm{CO}_{2}$ como una alternativa a los procesos convencionales de extracción, así como también se evaluaron las principales características fisicoquímicas de los aceites obtenidos. 


\section{MATERIALES Y MÉTODOS}

\section{Extracción a partir de semillas de chía provenientes de Salta (Argentina)}

\subsection{Material vegetal}

Se utilizaron semillas de chía provenientes de Argentina, las cuales fueron similares a las empleadas en la extracción de aceite a través de los procesos convencionales comentados en el Capítulo 3.

\subsection{Acondicionamiento y caracterización de la muestra}

Se realizó la limpieza de las semillas tal como fue descripto en el Capítulo 2, almacenándolas a $5 \pm 1^{\circ} \mathrm{C}$ en recipientes de plástico herméticamente cerrados hasta su posterior utilización. La humedad inicial de las muestras fue determinada de acuerdo al método de la AOAC (1990).

Inmediatamente previo a la extracción, las semillas fueron molidas mediante un molinillo de café (Braun, Type 4041, México) durante 60s, unificándose el tamaño de las partículas a través del pasaje de las mismas por un tamiz $N^{\circ} 18$ (ASTM; 1mm).

\subsection{Extracción de aceite mediante $\mathrm{SC}-\mathrm{CO}_{2}$. Cinética de extracción}

Se realizaron extracciones con $\mathrm{CO}_{2}$ (grado alimenticio) en estado supercrítico empleando una planta a escala piloto (volumen de la cámara 2,3 L; volumen de la canasta o dispositivo de extracción 1,5 L), con un sistema de separación en una sola etapa (volumen del separador 0,5 L) y recirculación del solvente (Figuras 4.1 y 4.2).

Diagrama del proceso: El $\mathrm{CO}_{2}$ localizado en el cilindro contenedor que posee un sistema de sifón adjunto, pasa a través de un intercambiador de calor (IC1) y se almacena en un buffer termostatizado. Luego, el $\mathrm{CO}_{2}$ subenfriado es comprimido mediante una bomba de membrana hasta alcanzar la presión de trabajo. Posteriormente, el $\mathrm{CO}_{2}$ comprimido pasa a través de un intercambiador de calor (IC2) donde alcanza la temperatura de trabajo. En este punto, el $\mathrm{CO}_{2}$ en estado supercrítico ( $\mathrm{SC}-\mathrm{CO}_{2}$ ) entra al extractor. Una camisa termostatizada que cubre al extractor permite controlar la temperatura de extracción. La presión con la que salen del extractor el SC - $\mathrm{CO}_{2}$ con la masa extraída disuelta, es reducida a través de una válvula controladora de la presión (VCP). En esta etapa, el $\mathrm{CO}_{2}$ pasa a estado gaseoso y el extracto precipita. Luego de la VCP, un intercambiador de calor (IC3) provee la energía necesaria para compensar el enfriamiento producido por el efecto 
Joule-Thompson. Los extractos son recogidos en la parte inferior del separador (60 bar, $40^{\circ} \mathrm{C}$ ) y el solvente regresa al buffer pasando a través de un medidor de flujo de masa (MF).

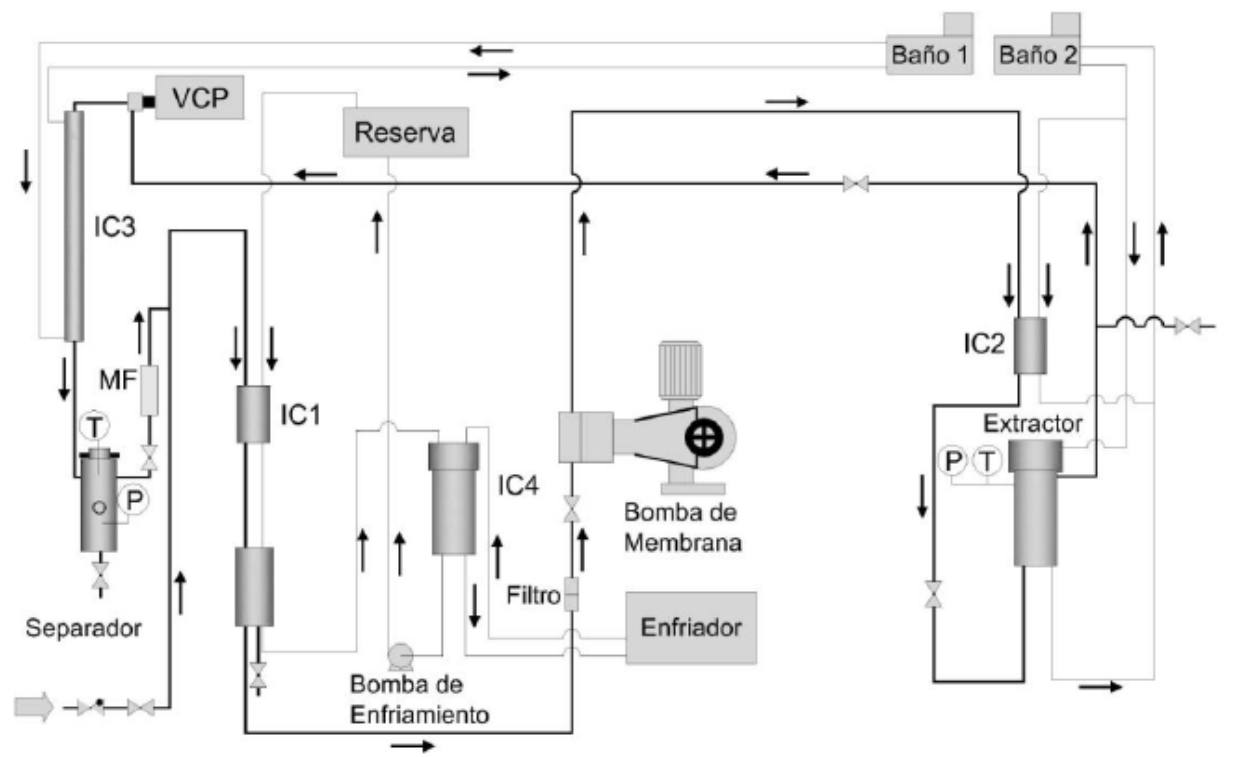

$\begin{array}{lll}\text { IC : Intercambiador de Calor } & \text { T : Sensor de Temperatura } & \text { MF : Medidor de Flujo de masa } \\ \text { VCP : Válvula de Control de Presión } & \text { P : Indicador de Presión }\end{array}$

Figura 4.1. Diagrama esquemático de la planta de extracción supercrítica (Ruetsch y col., 2003).

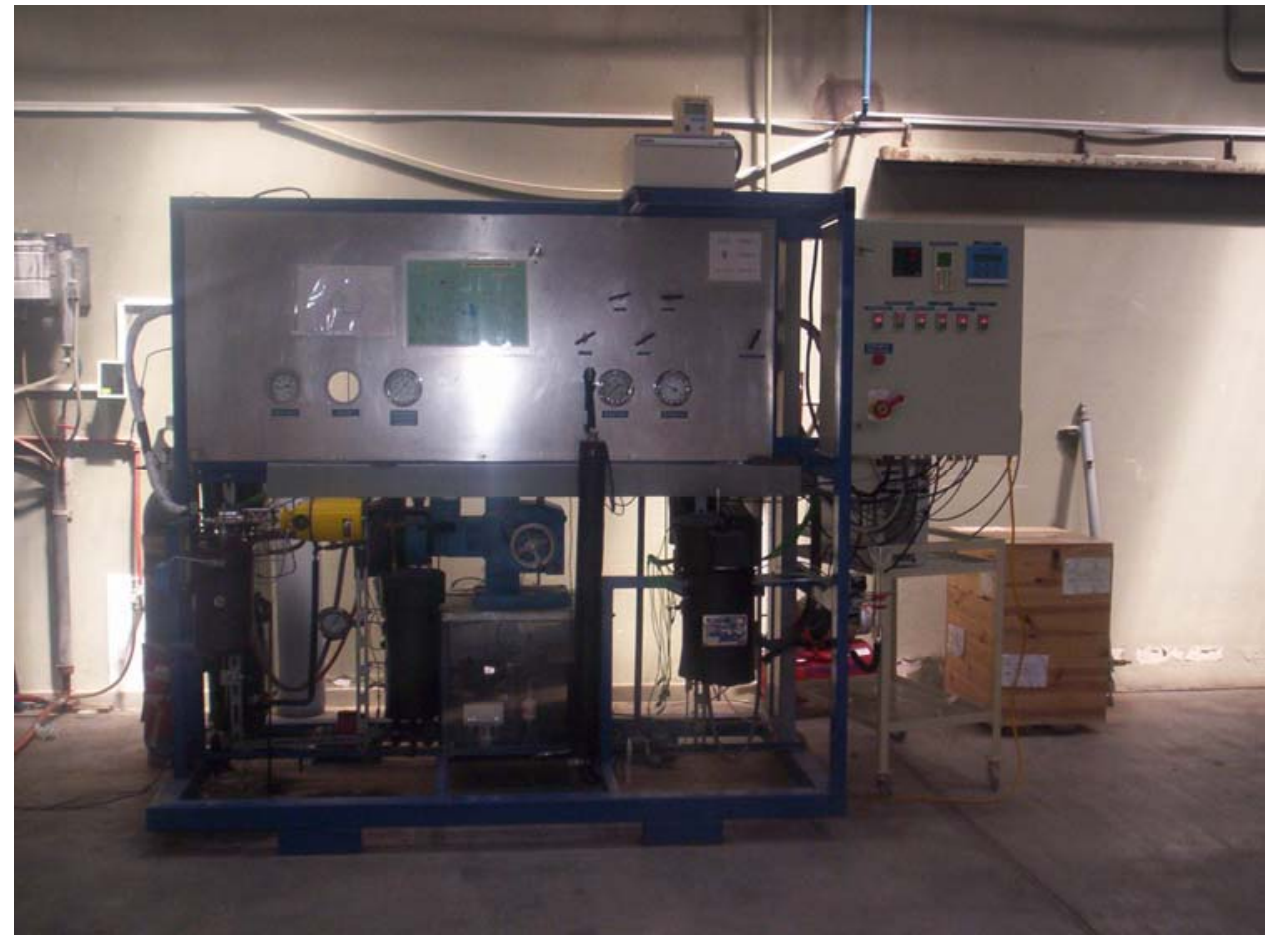

Figura 4.2. Planta piloto de extracción supercrítica a escala piloto, Universidad Nacional de Río Cuarto, Córdoba 
Las extracciones se llevaron a cabo a dos niveles de presión (250 y 450 bar) y de temperatura $\left(40\right.$ y $60^{\circ} \mathrm{C}$ ) con un flujo másico de $\mathrm{CO}_{2}$ de $8,0 \mathrm{~kg} / \mathrm{h}$. Para cada tratamiento (presión/temperatura) se utilizaron $500 \mathrm{~g}$ de semilla de chía molida, previamente deshidratada a $40^{\circ} \mathrm{C}$ hasta peso constante, realizándose cada ensayo por duplicado. Se colectaron los extractos a intervalos de aproximadamente 5 min, determinándose gravimétricamente la cantidad de aceite mediante el registro de la correspondiente masa de $\mathrm{CO}_{2}$ utilizada. La extracción finalizó cuando la diferencias entre dos puntos de la curva de cinética de extracción fue $\leq 0,001 \mathrm{~g}$ aceite/g semilla molida (b.s.).

El rendimiento se definió como la relación entre la cantidad de aceite obtenido durante la extracción y la cantidad inicial de aceite en la semilla (determinada por Soxhlet).

Inicialmente, para cada condición de temperatura/presión estudiadas se obtuvieron 4 fracciones de aceite de aproximadamente 40-50 g cada una correspondientes a distintos periodos de la extracción, las cuales luego de ser analizadas en forma independiente en cuanto a su composición de ácidos grasos, fueron combinadas en una única muestra para obtener el extracto final. En todos los casos los aceites fueron almacenados a $4 \pm 1^{\circ} \mathrm{C}$ en frascos color ámbar bajo atmósfera de $\mathrm{N}_{2}$.

\subsection{Caracterización de los aceites obtenidos}

Se determinó la composición de los ácidos grasos, los índices de iodo y de saponificación, el contenido de antioxidantes polifenólicos y de tocoferoles así como la estabilidad oxidativa por Rancimat, según las técnicas descriptas en el Capítulo 3.

\subsection{Análisis estadístico}

Las extracciones de aceite de chía mediante $\mathrm{SC}-\mathrm{CO}_{2}$ fueron realizadas por duplicado para cada combinación de temperatura/presión. Las determinaciones analíticas de cada extracto fueron realizadas por duplicado, informándose los valores medios. Se realizó un ANOVA unifactorial utilizando el programa informático Statgraphics Plus (Version 4.0 for Windows, Manugistics Inc., USA). Las comparaciones múltiples fueron llevadas a cabo mediante el test de Tukey a un nivel de significancia $(p \leq 0,05)$. 


\section{Análisis conjunto de los aceites de chía obtenidos a partir de las semillas de} Argentina mediante los diferentes procesos de extracción a través de un análisis multivariado

A fin de establecer las relaciones entre los aceites extraídos mediante las diversos procesos estudiados (Capítulos 3 y 4) y los parámetros analizados, se realizó un análisis multivariado (análisis de componentes principales) de los aceites obtenidos a partir de las semillas de Argentina, de manera tal que las diferentes asociaciones pudieran atribuirse a las metodologías de extracción y no a otros factores, tales como el genotipo y/o las condiciones agroclimáticas en las que los cultivos fueron realizados.

\section{Extracción a partir de semillas de chía provenientes de Jalisco (México)}

\subsection{Material vegetal}

Se utilizaron semillas de chía (Salvia hispanica L.) provenientes del estado de Jalisco (México) como materia prima para el proceso de extracción.

\subsection{Acondicionamiento y caracterización de la muestra}

Se procedió a la limpieza manual de las semillas para eliminar el material extraño, tales como semillas de malezas y semillas vanas.

Las semillas fueron trituradas en un molino MF (10 basic microfine grinder drive, IKA 5250) con cabezal de molienda de impacto. Posteriormente, se uniformó el tamaño de partícula a través del pasaje de la misma por un tamiz $N^{\circ} 20$ (USA Standard Testing Sieve $850 \mu \mathrm{m}$ ).

El contenido de humedad y de aceite de las semillas se determinó de acuerdo a las normas AOAC (1990) y IUPAC (1992), respectivamente, tal como se describió en el Capítulo 2. El aceite obtenido por el método Soxhlet se almacenó en frascos color ámbar a $5 \pm 1^{\circ} \mathrm{C}$ bajo atmósfera de nitrógeno hasta su posterior utilización.

\subsection{Extracción mediante $\mathrm{SC}-\mathrm{CO}_{2}$}

Los experimentos de extracción supercrítica con $\mathrm{CO}_{2}$ se realizaron en un extractor de alta presión SFT-250 SFE/SFR (Supercritical Fluid Technology, Inc., Newark, DE, USA) cuya máxima presión operativa es de 550 bar, provisto de un vaso de extracción de 0,5 L, el cual presenta una camisa calefactora (Figuras 4.3 y 4.4). La temperatura fue monitoreada mediante dos termocuplas localizadas en la 
camisa y en el interior del vaso. Tanto la temperatura como la presión operativas fueron fijadas a través del panel de control de la unidad de extracción.

La harina de semilla de chía (aproximadamente 110 - $120 \mathrm{~g}$ ) fue colocada en el vaso de extracción. Luego de una purga de aire inicial, se estableció en el equipo el valor requerido de temperatura y presión de acuerdo al diseño experimental. Cuando la temperatura alcanzó el valor deseado, el $\mathrm{CO}_{2}$ líquido fue bombeado hacia el vaso de extracción mediante una bomba de pistones (Haskel) hasta el valor requerido de presión. Una vez alcanzado dicho valor, se abrió la válvula restrictora, momento a partir del cual se comenzó a registrar el tiempo del experimento. La duración total de cada experimento fue establecida de acuerdo al diseño experimental.

El aceite fue recogido en el vaso colector y pesado en una balanza de precisión (Sartorius BL 610, Alemania).

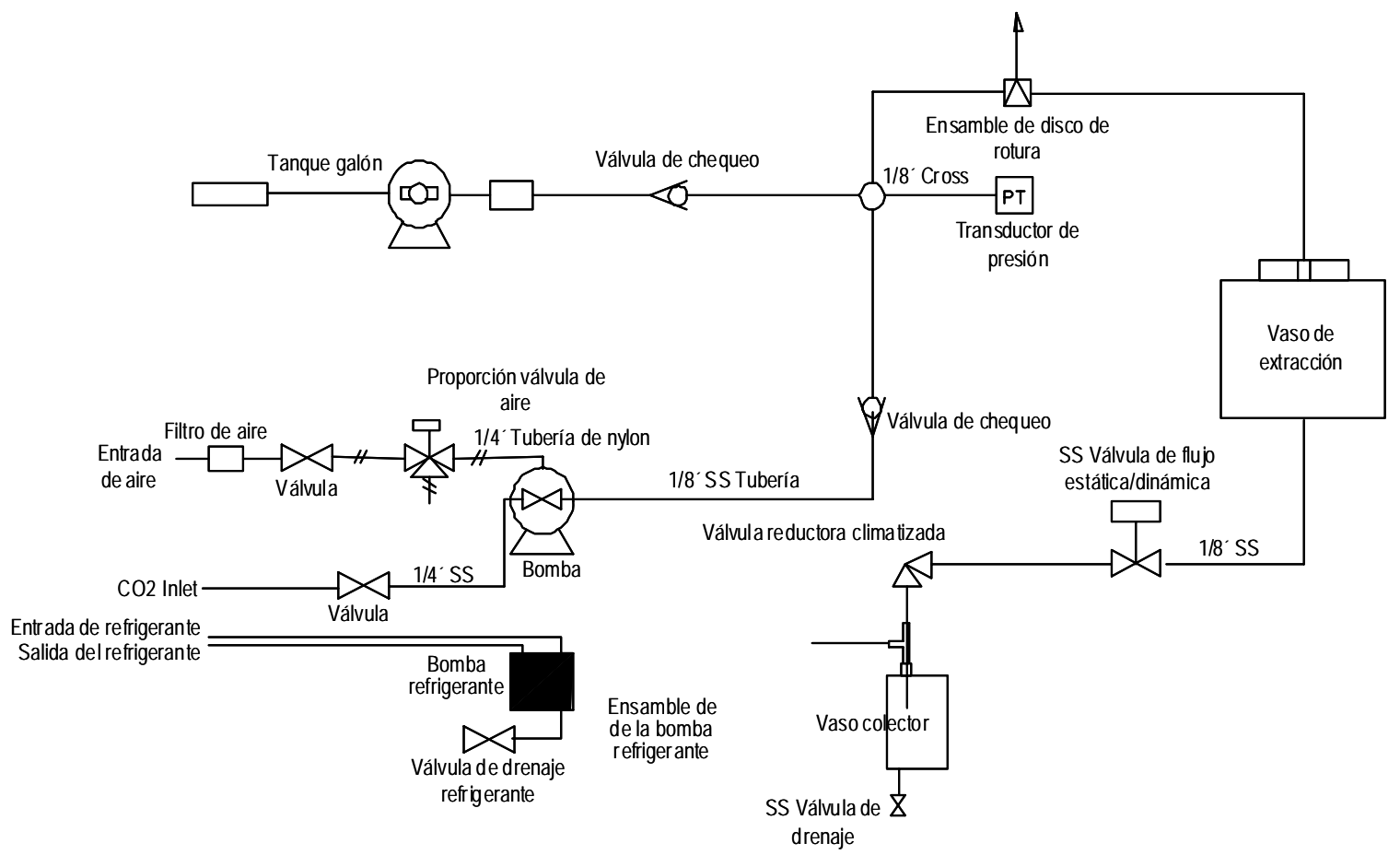

Figura 4.3 Diagrama esquemático del equipo de extracción supercrítica (Supercritical Fluid Technology, Inc., Newark, Del., USA) 

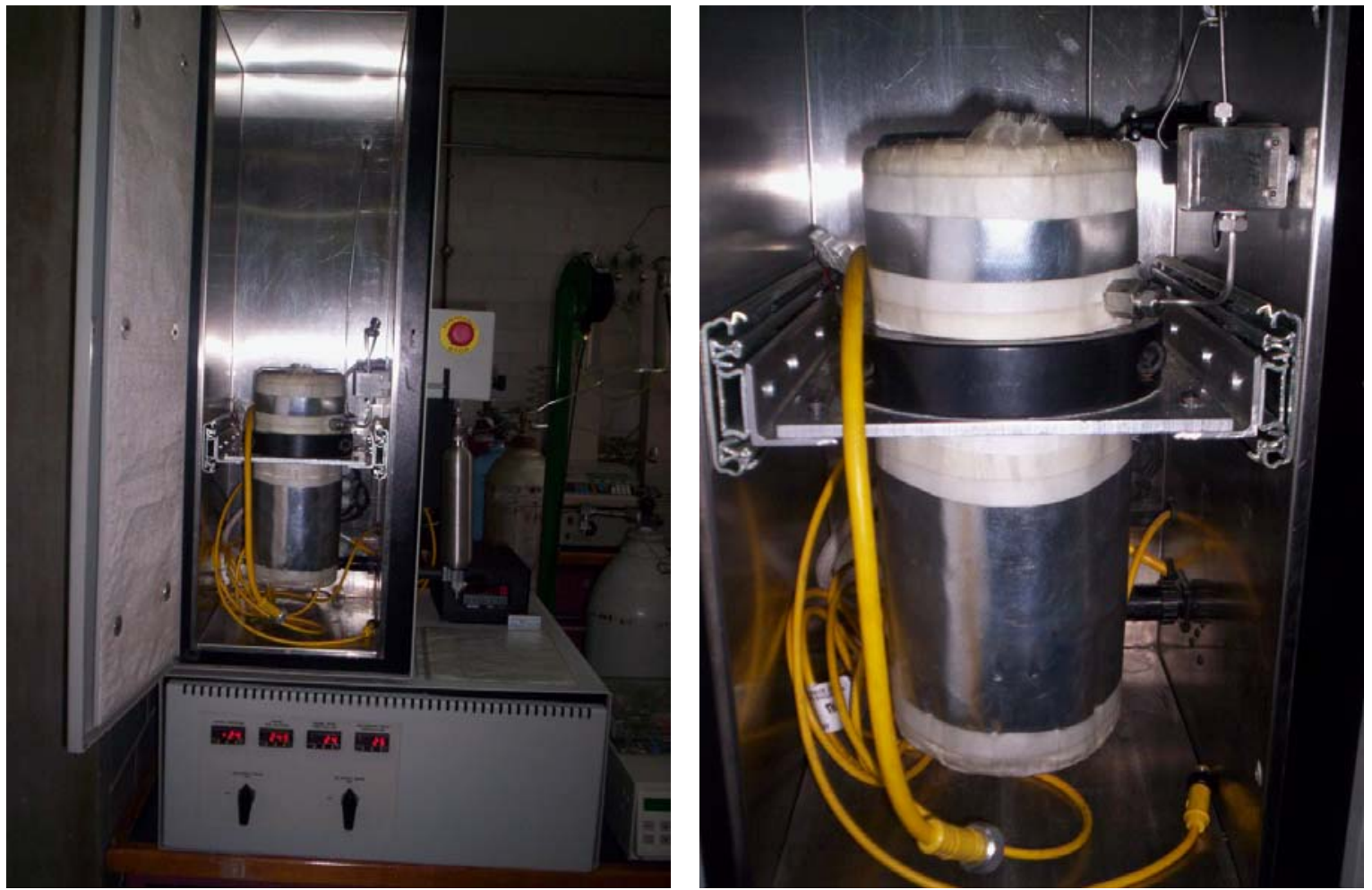

Figura 4.4. Equipo de extracción de alta presión SFT-250 SFE/SFR (Supercritical Fluid Technology, Inc., Newark, Del., USA)

\subsection{Cinética de extracción}

Una vez determinadas la presión y temperatura óptimas del proceso se obtuvo, para dichas condiciones, la curva de cinética de extracción. Para ello, el aceite fue colectado a intervalos de $15 \mathrm{~min}$, determinándose su rendimiento gravimétricamente hasta que la pendiente de la curva se aproximó a 0.

\subsection{Diseño experimental}

En los procesos de extracción supercrítica, las variables independientes que pueden ejercer un efecto significativo sobre el rendimiento son la presión y temperatura de extracción, el flujo de $\mathrm{CO}_{2}$, el tiempo de extracción y el tamaño de partícula. En este experimento, el tamaño de partícula de harina de chía se mantuvo constante $(\phi \leq 850 \mu \mathrm{m})$, debido a que los ensayos preliminares llevados a cabo mostraron que dicho tamaño era apropiado para una efectiva extracción del aceite. El flujo de $\mathrm{CO}_{2}$ también fue constante a $1,8 \mathrm{~kg} / \mathrm{h}$. El efecto de los tratamientos (variables independientes) sobre el rendimiento del aceite de semilla de chía 
mediante $\mathrm{SC}-\mathrm{CO}_{2}$ fue estudiado mediante el método de superficie de respuesta (RSM). El RSM, método utilizado para lograr la optimización de un proceso, incluye un grupo de técnicas empíricas que permiten encontrar la relación entre los factores experimentales controlados y la variable de respuesta (variable dependiente) (Bas y Boyaci, 2007; Pericin y col., 2008). Se aplicó un diseño experimental central compuesto rotable $(\mathrm{CCRD})$ con 3 factores $\left(\mathrm{X}_{1}=\right.$ temperatura, $\mathrm{X}_{2}=$ presión, $\mathrm{X}_{3}=$ tiempo de extracción) y tres niveles por cada factor, los cuales se muestran en la Tabla 4.1. La variable de respuesta fue el rendimiento de aceite de chía, definiéndose al mismo como la relación entre el aceite obtenido mediante la extracción y el contenido de aceite total determinado por Soxhlet.

El diseño experimental incluyó 18 extracciones con ocho puntos factoriales, seis axiales y cuatro replicados del punto central $\left(n=2^{k}+2 k+m\right.$, donde, $n=$ total de experimentos; $k=$ variables independientes, 3 ; y $m=$ número de repeticiones del punto central, 4) (Mason y col., 2003).

Se utilizó una ecuación polinomial de segundo orden para expresar el rendimiento de aceite de chía $(Y$ ) en función de las variables independientes:

$Y=\beta_{0}+\sum_{i=1}^{3} \beta_{i} x_{i}+\sum_{i=1}^{3} \beta_{i i} x_{i}^{2}+\sum_{i=1}^{2} \sum_{j=i+1}^{3} \beta_{i j} x_{i} x_{j}$

donde:

$Y$ : variable de respuesta

$\beta_{0}$ : coeficiente constante

$\beta_{i s}$ : coeficientes lineares

$\beta_{\text {iis: }}$ : coeficientes cuadráticos

$\beta_{i j s}$ : coeficientes de interacción del modelo

$X_{i}, X_{j}$ : valores codificados de las variables independientes.

El análisis estadístico se realizó mediante el programa informático Statgraphics Plus (Version 4.0 para Windows, Manugistics Inc., USA). 
Tabla 4.1. Tratamientos y codificación de las variables independientes utilizadas en el desarrollo experimental de optimización de la extracción de aceite de semilla de chía mediante $\mathrm{CO}_{2}$ supercrítico

\begin{tabular}{lcccc}
\hline \multirow{2}{*}{ Variable independiente } & \multicolumn{2}{c}{ Símbolos } & \multicolumn{2}{c}{ Niveles } \\
\cline { 2 - 5 } & \multicolumn{1}{c}{ Sin codificar } & Codificado & Sin codificar & Codificado \\
\hline Temperatura $\left({ }^{\circ} \mathrm{C}\right)$ & $T$ & $\mathrm{X}_{1}$ & 80 & 1 \\
& & & 60 & 0 \\
Presión $(\mathrm{bar})$ & & & 40 & -1 \\
& & $\mathrm{X}_{2}$ & 450 & 1 \\
tiempo $(\mathrm{min})$ & & 350 & 0 \\
& $H$ & & 250 & -1 \\
& & & 240 & 1 \\
\hline $\mathrm{X}_{1}=(\mathrm{T}-60) / 20, \mathrm{X}_{2}=(\mathrm{P}-350) / 100, \mathrm{X}_{3}=(\mathrm{H}-150) / 90$ & & 150 & 0 \\
\hline
\end{tabular}

\subsection{Determinación de la composición de ácidos grasos}

La determinación de la composición de ácidos grasos por cromatografía gaseosa se realizó siguiendo la Norma mexicana 490 (1999), la cual concuerda con la norma oficial 963.22 AOAC (1990).

Se pesaron $500 \mathrm{mg}$ de aceite de chía en un balón de $50 \mathrm{~mL}$ y se agregaron 6 $\mathrm{mL}$ de solución metanólica de $\mathrm{NaOH} 0,5 \mathrm{~N}$, calentando a reflujo a $40^{\circ} \mathrm{C}$ durante 5 min para lograr la saponificación de la muestra.

Posteriormente, se agregaron $7 \mathrm{~mL}$ de solución metanólica de trifluoruro de boro, calentando a reflujo. Luego de transcurridos $5 \mathrm{~min}$, se agregaron $4 \mathrm{~mL}$ de hexano, se dejó enfriar añadiendo aproximadamente $10 \mathrm{~mL}$ de solución saturada de $\mathrm{NaCl}$, agitando suavemente. Se continuó agregando solución de $\mathrm{NaCl}$ hasta llevar a la fase orgánica al cuello del balón.

Mediante una pipeta se recogieron de $1-1,5 \mathrm{~mL}$ de fase orgánica en un tubo con $0,5 \mathrm{~g}$ de $\mathrm{Na}_{2} \mathrm{SO}_{4}$ anh. Los ésteres metílicos de los ácidos grasos fueron 
transferidos a un vial cerrado bajo atmósfera de nitrógeno, protegido de la luz y almacenado a $-20 \pm 2^{\circ} \mathrm{C}$.

Dichas muestras fueron inyectadas en un cromatógrafo de gases (HP 5890 Serie II Plus) equipado con una torre autoinyectora (HP 7673) y un detector de ionización de llama. La identificación de los ácidos grasos fue llevada a cabo mediante la utilización de patrones de referencia de ácidos grasos (Sigma- Aldrichy Matreya, USA), los cuales fueron saponificados y metilados, tal como se indicó anteriormente. Los metil ésteres de los ácidos grasos (FAME) fueron separados en una columna de GC (Chrompack Wcot fused silica $30 \mathrm{~m} \times 0,25 \mathrm{~mm}$; coating: CP WAX 52CB DF=0,25 $\mu \mathrm{m})$. La temperatura de inyección fue de $260^{\circ} \mathrm{C}$ mientras que la temperatura inicial de la columna fue de $170^{\circ} \mathrm{C}$ y el programa de calentamiento incluyó una rampa de $2,5^{\circ} \mathrm{C} / \mathrm{min}$ hasta $190^{\circ} \mathrm{C}, 1 \mathrm{~min}$ y un subsiguiente incremento a $1^{\circ} \mathrm{C} / \mathrm{min}$ hasta $205^{\circ} \mathrm{C}$.

\subsection{Determinación de los índices de iodo y de saponificación}

Se calcularon los índices de iodo y de saponificación a partir de la composición acídica de los aceites extraídos, tal como se indicó en el Capítulo 3 (AOCS, 1998).

\subsection{Determinación de los ácidos grasos libres y del índice de peróxido}

Para los aceites de chía extraídos en las mejores condiciones (máximo rendimiento del aceite) se determinaron el contenido de ácidos grasos libres (IUPAC 1992) e índice de peróxido (AOCS, 1998), según se ha descripto en el Capítulo 3.

\subsection{Determinación de las propiedades termo-reológicas}

Se determinó la viscosidad del aceite crudo a las siguientes temperaturas: 1, $5,15,25,35,45,55,65,75,85^{\circ} \mathrm{C}$; a 15 velocidades de deformación, que variaron desde 10 a $251 \mathrm{~s}^{-1}$. Las determinaciones se llevaron a cabo en un reómetro ARES RFS III (TA Instruments, USA) mediante una geometría de placas paralelas.

Se utilizó la Ley de la Potencia para analizar el índice de comportamiento de flujo del aceite crudo de chía, la cual se expresa mediante la siguiente ecuación:

$$
\sigma=K \gamma^{n}
$$

donde: 
$\sigma$ : esfuerzo $(\mathrm{Pa})$

$\gamma$ : velocidad de deformación $\left(\mathrm{s}^{-1}\right)$

$K$ : índice de consistencia $\left(\mathrm{Pa} \mathrm{s}^{n}\right)$

$n$ : índice de comportamiento de flujo

Se construyeron las gráficas de $\log \sigma$ versus $\log \gamma$. La recta resultante permitió calcular la magnitud de $n$ (pendiente), a partir de lo cual pudo obtenerse información acerca del tipo de comportamiento de los aceites.

El efecto de la temperatura sobre la viscosidad aparente puede describirse mediante la relación de Arrhenius, la cual se expresa en la siguiente ecuación:

$\eta=k e^{\frac{-E_{a}}{R T}}$

donde:

$\eta$ : viscosidad (Pa s)

$\mathrm{k}$ : factor pre-exponencial

$E_{a}$ : energía de activación (cal/mol)

$\mathrm{R}$ : constante de los gases $\left(1,987 \mathrm{cal} / \mathrm{mol}{ }^{\circ} \mathrm{K}\right)$

$\mathrm{T}$ : temperatura $\left({ }^{\circ} \mathrm{K}\right)$

\subsection{Análisis estadístico}

Para cada variable analizada se llevó a cabo un ANOVA unifactorial y la posterior comparación de medias a través del test de Tukey $(p \leq 0,05)$.

\section{RESULTADOS Y DISCUSIÓN}

1. Extracción supercrítica de aceite de chía obtenido a partir de semillas provenientes de Salta (Argentina)

El contenido de humedad y de aceite de las semillas utilizadas fue de 7,0 \pm $0,4 \%$ (b.s.) y $0,34 \mathrm{~g}$ aceite/g semilla (b.s.), respectivamente.

La Figura 4.5 muestra las curvas correspondientes a la cinética de la extracción de aceite de chía mediante $\mathrm{SC}-\mathrm{CO}_{2}$ para las cuatro condiciones operativas estudiadas: $40^{\circ} \mathrm{C}-250$ bar, $60^{\circ} \mathrm{C}-250$ bar, $40^{\circ} \mathrm{C}-450$ bar y $60^{\circ} \mathrm{C}-$ 450 bar, a una velocidad de flujo de $8,0 \mathrm{~kg} \mathrm{CO}_{2} / \mathrm{h}$. La extracción del aceite de la semilla de chía, de forma similar que para otras semillas oleaginosas, puede ser 
dividida en dos periodos: rápido ( $\mathrm{PRE}$ ) (periodo lineal inicial más periodo de transición) y periodo de extracción lenta (PLE) (segundo periodo lineal con pendiente menor). Como puede observarse en la figura, la mayor extracción de aceite de chía ocurre principalmente en el PRE. La solubilidad aparente del aceite de chía en el $\mathrm{SC}-\mathrm{CO}_{2}$ puede ser calculada a partir de la porción lineal del periodo inicial para cada combinación de las variables operativas presión y temperatura. Los resultados obtenidos, así como el tiempo correspondiente a cada periodo y el rendimiento de aceite pueden verse en la Tabla 4.2.

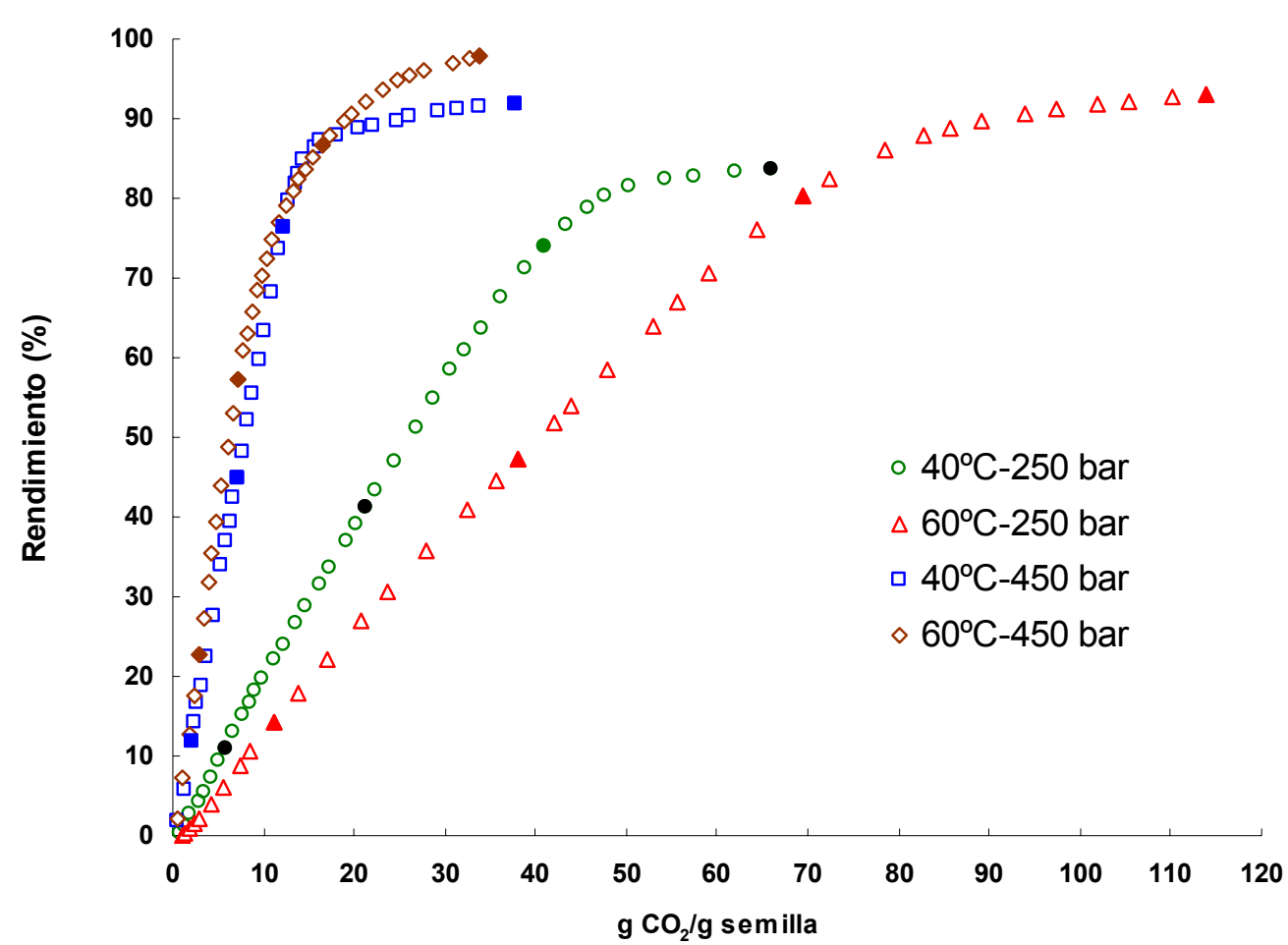

Figura 4.5. Rendimiento de extracción (\%) en función de la masa de $\mathrm{CO}_{2}$ ( $\mathrm{g} \mathrm{CO}_{2} / \mathrm{g}$ semilla) durante la extracción de aceite de chía mediante $\mathrm{SC}-\mathrm{CO}_{2}$

Teniendo en cuenta la longitud del PRE y del PLE así como sus respectivos rendimientos, es posible observar que durante el periodo lento la cantidad de aceite extraído es baja (Tabla 4.2 y Figura 4.5). Así, a $40^{\circ} \mathrm{C}-250$ bar, sólo se obtuvo 0,01 g aceite/g semilla ( $3 \%$ del contenido total de aceite en la semilla) durante los últimos 88 min de extracción. Esta tendencia fue análoga en el resto de las condiciones de extracción estudiadas. Resultados similares se han registrado en la obtención de 
aceite de lino mediante SC-CO (Özkal, 2009). De acuerdo a estos autores, en el PRE el aceite liberado de las células es extraído de la superficie de las partículas, mientras que en el PLE se remueve el aceite que permanece retenido en el interior de las células intactas. De esta manera, la transferencia de masa del aceite en el PRE está determinada por la solubilidad del mismo en el $\mathrm{SC}-\mathrm{CO}_{2}$, mientras que en el PLE, está controlada por la difusión del aceite desde el interior de las partículas. Özkal y col. (2005b) informaron que la velocidad de transferencia de masa fue baja y que el rendimiento de aceite obtenido en el PLE fue insignificante con respecto al correspondiente al PRE para el aceite obtenido a partir de carozos de damasco. Así, la prolongación del proceso de extracción durante el PLE no sería factible, teniendo en cuenta la rentabilidad del proceso. Durante el PRE, la relación entre el tiempo de extracción y el rendimiento fue lineal. Los valores de $r^{2}$ obtenidos para el PRE a $40^{\circ} \mathrm{C}-250$ bar, $60^{\circ} \mathrm{C}-250$ bar, $40^{\circ} \mathrm{C}-450$ bar y $60^{\circ} \mathrm{C}-450$ bar fueron $0,995,0,995,0,996$ y 0,963 , respectivamente $(p \leq 0,0001)$ (Figura 4.5).

El rendimiento total de aceite varió entre $82-97 \%$, no detectándose diferencias significativas $(p>0,05)$ entre las distintas condiciones operativas estudiadas. Similares resultados han sido encontrados en otros aceites vegetales. Por ejemplo, Follegatti-Romero y col. (2009) han informado un rendimiento de $92,3 \%$ de aceite obtenido a partir de semillas de Sacha Inchi a $60^{\circ} \mathrm{C}-400$ bar. Sin embargo, se registraron diferencias significativas $(p \leq 0,05)$ entre las distintas combinaciones de temperatura/presión en la duración del PRE, en el tiempo total de extracción así como en la solubilidad del aceite. Además, en condiciones isotérmicas, un incremento de presión desde 250 a 450 bar produjo una disminución en el tiempo de extracción de aproximadamente $53 \%\left(40^{\circ} \mathrm{C}\right)$ y $67 \%\left(60^{\circ} \mathrm{C}\right)$ (Tabla 4.2 y Figura 4.5). 
Tabla 4.2. Rendimiento de extracción, tiempo y solubilidad del aceite de chía obtenido mediante $\mathrm{SC}-\mathrm{CO}_{2}$ a diferentes condiciones operativas

Condiciones de presión y temperatura de extracción mediante $\mathrm{SC}-\mathrm{CO}_{2}$

$40^{\circ} \mathrm{C}-250$ bar $\quad 60^{\circ} \mathrm{C}-250$ bar $\quad 40^{\circ} \mathrm{C}-450$ bar $\quad 60^{\circ} \mathrm{C}-450$ bar

Cantidad de aceite extraído al final del periodo rápido de extracción

(g aceite/g semilla)

$$
0,27 \pm 0,01^{\text {a }}
$$

$$
0,30 \pm 0,03^{a}
$$

$0,29 \pm 0,07^{a}$

$0,29 \pm 0,07^{\mathrm{a}}$

Cantidad de aceite extraído al final de la extracción

$$
\text { (g aceite/g semilla) }
$$

$$
0,28 \pm 0,01^{\text {a }}
$$$$
0,31 \pm 0,03^{\text {a }}
$$$$
0,31 \pm 0,07^{a}
$$$$
0,33 \pm 0,07^{a}
$$

Rendimiento de aceite al final del periodo rápido de extracción (\%)

$\begin{array}{cccc}79 \pm 3^{a} & 88 \pm 5^{a} & 85 \pm 2^{a} & 85 \pm 2^{a} \\ 82 \pm 3^{a} & 91 \pm 5^{a} & 91 \pm 2^{a} & 97 \pm 2^{a} \\ 197 \pm 2^{b} & 317 \pm 3^{c} & 56 \pm 3^{a} & 70 \pm 2^{a} \\ 88 \pm 2^{b} & 106 \pm 3^{c} & 79 \pm 2^{a b} & 68 \pm 2^{a} \\ 285 \pm 2^{b} & 423 \pm 3^{c} & 135 \pm 2^{a} & 138 \pm 2^{a} \\ 879,6 & 786,8 & 974,6 & 913,4 \\ 0,9897 & 0,8869 & 1,159 & 1,053 \\ 7,0 \pm 0,1^{a} & 4,8 \pm 0,1^{a} & 22,3 \pm 0,9^{b} & 28,8 \pm 3,6^{b}\end{array}$

Rendimiento de aceite extraído al final de la extracción (\%)

Duración del periodo rápido de extracción (min)

Duración del periodo lento de extracción (min)

Duración total de la extracción (min)

Densidad del $\mathrm{CO}_{2}\left(\mathrm{~kg} / \mathrm{m}^{3}\right)$

Viscosidad cinemática del $\mathrm{CO}_{2}\left(\times 10^{-7} \mathrm{~m}^{2} / \mathrm{s}\right)$

Solubilidad (g aceite / $\mathrm{kg} \mathrm{CO}$ )

$7,0 \pm 0,1^{\text {a }}$

$4,8 \pm 0,1$

$22,3 \pm 0,9$

$28,8 \pm 3,6^{b}$

Valores medios \pm desviación estándar $(n=2)$. Letras distintas indican diferencias significativas $(p \leq 0,05)$ entre los tratamientos 
Por otra parte, con respecto a la temperatura operativa, se observó un efecto diferencial sobre el tiempo total de extracción según la presión a la que se llevó a cabo el proceso. Así, a 250 bar un aumento en la temperatura incrementó la duración del PRE y del tiempo total de extracción mientras que a 450 bar no se encontró un efecto significativo debido a la temperatura (Tabla 4.2). Similares tendencias fueron informadas por Salgin y Salgin (2006) en aceite de nuez.

Con respecto a la solubilidad, los resultados mostraron que la misma varió de $4,8 \mathrm{~g}$ aceite/kg $\mathrm{CO}_{2}$ a $60^{\circ} \mathrm{C}-250$ bar a $28,8 \mathrm{~g}$ aceite $/ \mathrm{kg} \mathrm{CO}_{2}$ a $60^{\circ} \mathrm{C}-450$ bar. Las variaciones en la solubilidad del aceite de chía en el $\mathrm{SC}-\mathrm{CO}_{2}$ dependen de la capacidad solvente del $\mathrm{CO}_{2}$, la cual está relacionada principalmente con la densidad y la viscosidad del solvente (Tabla 4.2). A una temperatura constante, la densidad del $\mathrm{CO}_{2}$ es mayor a 450 que a 250 bar y como consecuencia de ello, la solubilidad del aceite es más elevada. Un aumento de la temperatura a presión constante reduce la densidad del $\mathrm{CO}_{2}$ pero paralelamente incrementa la presión de vapor del soluto. Como consecuencia de estos efectos inversos se produce el fenómeno de "crossover" (Stahl y col., 1980), el cual puede ser explicado por el efecto competitivo entre la reducción en la densidad del SC- $\mathrm{CO}_{2}$ y el aumento en la volatilidad del soluto producto del incremento de la temperatura (King, 1993). En nuestras experiencias, un incremento en la temperatura a 250 bar condujo a una disminución de la solubilidad aparente, mientras que el mismo aumento a 450 bar, causó un incremento en la solubilidad del aceite en el $\mathrm{CO}_{2}$. La solubilidad del aceite de chía en las condiciones operativas estudiadas (Tabla 4.2) fue mayor que la informada para aceite de Sacha Inchi (Follegatti-Romero y col., 2009) (4,4; 1,7; 14,7 y 16,7 g aceite/ kg CO 2 a $40{ }^{\circ} \mathrm{C}-200$ bar, $60{ }^{\circ} \mathrm{C}-200$ bar, $40{ }^{\circ} \mathrm{C}-400$ bar y $60{ }^{\circ} \mathrm{C}-400$ bar, respectivamente). Estos resultados pueden ser atribuidos a la diferencia en la presión operativa utilizada así como a la composición acídica de ambos aceites, ya que la solubilidad de los triacilgliceroles en el $\mathrm{SC}-\mathrm{CO}_{2}$ puede verse afectada por los tipos de ácidos grasos presentes en la molécula de glicerol. Así, tanto la existencia de diversos grupos funcionales como la distinta estructura de los triacilgliceroles presentes en los aceites vegetales pueden afectar la presión de vapor del soluto y por lo tanto, la solubilidad. En este caso, el aceite de chía contiene mayores cantidades de ácido $\alpha$-linolénico $(\sim 65 \%)$ que el de Sacha Inchi $(\sim 45 \%)$, lo cual podría ser una de las causas que explicarían las diferencias de solubilidad encontradas. 
Para calcular la difusividad efectiva del aceite en la matriz de chía, se utilizó un modelo de extracción presentado por Catchpole y col. (1996). A través del procedimiento propuesto por estos autores, cuando la velocidad de extracción es controlada por la difusión intrapartícula y la solubilidad del extracto es muy alta comparada con la concentración inicial del mismo en el material vegetal, se puede obtener una solución simple utilizando como parámetro la difusividad efectiva (Ec. 4.4).

$E=1-\exp \left[-\frac{15 D_{e}(t-z \varepsilon / U)}{R^{2}}\right]$

donde:

$E$ : rendimiento del extracto $(\%)$

$D_{e}$ : coeficiente de difusividad intrapartícula $\left(\mathrm{m}^{2} / \mathrm{s}\right)$

$t$ : tiempo de extracción (s)

$z$ : altura del lecho de extracción (m)

$\varepsilon$ : porosidad del lecho

$U:$ velocidad intersticial $(\mathrm{m} / \mathrm{s})$

$R$ : radio de la particula $(\mathrm{m})$

La difusividad ha sido correlacionada con los datos experimentales de extracción mediante la minimización de la diferencia entre los rendimientos experimentales y los calculados, de acuerdo a la función objetivo presentada en la Ec. 4.5 .

$A A R D \%=\frac{100}{n} \sum_{i=1}^{n} \frac{\left|y_{i_{\text {exp }}}-y_{i_{\text {calc }}}\right|}{y_{i \exp }}$

donde:

$n$ : número de pares de datos

$y_{\text {iexp: }}$ rendimientos de extracción experimentales

$y_{\text {icalc: }}$ : rendimientos de extracción calculados

Debido a que la Ec. 4.4 es válida sólo para el periodo de la extracción controlado por la difusión intrapartícula (PLE), se utilizaron los datos correspondientes a un rendimiento de extracción superior a 90\%. En esta región, el 
modelo logró un buen ajuste obteniendo desviaciones medias absolutas relativas $(\mathrm{AARD} \%)<1 \%$ para cada combinación de temperatura y presión operativas.

La difusividad intrapartícula obtenida con esta metodología y la correspondiente AARD\% se presentan en la Tabla 4.3. Los valores obtenidos para la difusividad son similares a los informados por varios autores para la extracción de aceite a partir de matrices similares con $\mathrm{SC}-\mathrm{CO}_{2}$, tales como la semilla de coriandro $\left(2,57 \times 10^{-11} \mathrm{~m}^{2} / \mathrm{s}\right.$ a $40^{\circ} \mathrm{C} / 250$ bar) (Catchpole y col., 1996$)$ y de girasol $\left(9,18 \times 10^{-10}\right.$ $\mathrm{m}^{2} / \mathrm{s}$ a $40^{\circ} \mathrm{C} / 400$ bar) (Salgin y col., 2006). En condiciones isotérmicas, el $D_{e}$ aumentó con la presión, mientras que a una presión dada el mismo disminuyó con la temperatura. Un comportamiento similar fue observado por Salgin y col (2006) en la extracción de aceite de girasol mediante $\mathrm{SC}-\mathrm{CO}_{2}$.

Tabla 4.3. Difusividad intrapartícula calculada según Catchpole y col., 1996.

\begin{tabular}{cccc}
\hline $\begin{array}{c}\text { Temperatura } \\
\left({ }^{\circ} \mathbf{C}\right)\end{array}$ & $\begin{array}{c}\text { Presión } \\
(\text { bar })\end{array}$ & $\begin{array}{c}\text { Difusividad } \\
\left(\mathbf{m} / \mathbf{s}^{2}\right)\end{array}$ & AARD\% \\
\hline 40 & 250 & $5,81 \times 10^{-12}$ & 0,21 \\
60 & 250 & $3,04 \times 10^{-12}$ & 0,53 \\
40 & 450 & $1,19 \times 10^{-11}$ & 0,09 \\
60 & 450 & $9,25 \times 10^{-12}$ & 0,52 \\
\hline
\end{tabular}

La Tabla 4.4 resume la composición acídica correspondiente al extracto final de los aceites obtenidos mediante $\mathrm{SC}-\mathrm{CO}_{2}$ así como los extraídos con hexano. Análogamente a lo registrado para los aceites obtenidos por prensa y por solvente, (ver Capítulo 3), se encontraron elevadas concentraciones de ácido $\alpha$-linolénico $(64,9-65,6 \%)$ y linoleico $(19,8-20,3 \%)$, así como la presencia de los ácidos palmítico $(6,2-6,7 \%)$, oleico $(5,0-5,5 \%)$ y esteárico $(2,7-3,0 \%)$. En general, la composición acídica de los aceites obtenidos mediante los diferentes procesos de extracción no presentó diferencias significativas $(p>0,05)$. El contenido de ácido linoleico sólo fue significativamente mayor $(\mathrm{p} \leq 0,05)$ en los aceites obtenidos mediante $\mathrm{SC}-\mathrm{CO}_{2}$ que en aquéllos extraídos con hexano. También, se encontraron diferencias significativas $(p \leq 0,05)$ entre los aceites obtenidos bajo las diferentes condiciones operativas ensayadas. En este sentido se dispone de variada información en la literatura sobre las diferencias en la composición de ácidos grasos de los aceites obtenidos por diversos procesos. Así, Bozan y Temelli (2002) informaron que la composición de 
ácidos grasos de los aceites de lino obtenidos con $\mathrm{SC}-\mathrm{CO}_{2}$ fue diferente a la de los extraídos por Soxhlet utilizando éter de petróleo como solvente, observando una mayor presencia de PUFAs en los primeros. Martínez y col. (2008) registraron pequeñas diferencias en el contenido individual de los ácidos grasos presentes en el aceite de nuez mediante $\mathrm{SC}-\mathrm{CO}_{2}$ bajo condiciones de extracción similares a las analizadas en el presente trabajo. 
Tabla 4.4. Composición de ácidos grasos, índices de iodo y saponificación y tiempo de inducción correspondientes al extracto final de aceites de chía obtenidos mediante $\mathrm{SC}-\mathrm{CO}_{2}$ y extracción con solvente

\begin{tabular}{|c|c|c|c|c|c|}
\hline \multirow{2}{*}{$\begin{array}{c}\text { Ácido graso } \\
\text { (\%) }\end{array}$} & \multicolumn{4}{|c|}{ Condiciones de presión y temperatura de extracción mediante $\mathrm{SC}-\mathrm{CO}_{2}$} & \multirow{2}{*}{$\begin{array}{l}\text { Extracción con } \\
\text { solvente }\end{array}$} \\
\hline & $40^{\circ} \mathrm{C}-250$ bar & $60^{\circ} \mathrm{C}-250$ bar & $40^{\circ} \mathrm{C}-450$ bar & $60^{\circ} \mathrm{C}-450 \mathrm{bar}$ & \\
\hline Palmítico (16:0) & $6,6 \pm 0,4^{a}$ & $6,6 \pm 0,2^{a}$ & $6,7 \pm 0,4^{a}$ & $6,7 \pm 0,4^{a}$ & $6,2 \pm 0,4^{a}$ \\
\hline Esteárico (18:0) & $2,7 \pm 0,1^{a}$ & $2,8 \pm 0,1^{a}$ & $3,0 \pm 0,3^{a}$ & $3,0 \pm 0,2^{a}$ & $3,0 \pm 0,7^{a}$ \\
\hline Oleico $(18: 1)$ & $5,2 \pm 0,1^{a}$ & $5,5 \pm 0,3^{a}$ & $5,2 \pm 0,6^{a}$ & $5,0 \pm 0,1^{a}$ & $5,3 \pm 1,1^{a}$ \\
\hline Linoleico $(18: 2)$ & $20,0 \pm 0,0^{b}$ & $20,2 \pm 0,0^{c}$ & $20,1 \pm 0,1^{b, c}$ & $20,3 \pm 0,1^{c}$ & $19,8 \pm 0,0^{a}$ \\
\hline a-Linolénico (18:3) & $65,5 \pm 0,3^{a}$ & $64,9 \pm 0,4^{a}$ & $64,9 \pm 0,7^{a}$ & $65,0 \pm 0,4^{a}$ & $65,6 \pm 0,8^{a}$ \\
\hline SFAs & $9,3 \pm 0,5^{a}$ & $9,4 \pm 0,1^{a}$ & $9,8 \pm 0,1^{a}$ & $9,7 \pm 0,2^{a}$ & $9,3 \pm 0,3^{a}$ \\
\hline PUFAs & $85,4 \pm 0,4^{a}$ & $85,1 \pm 0,4^{a}$ & $85,0 \pm 0,7^{a}$ & $85,3 \pm 0,3^{a}$ & $85,4 \pm 0,8^{a}$ \\
\hline PUFAs/SFAs & $9,2 \pm 0,5^{a}$ & $9,0 \pm 0,1^{\text {a }}$ & $8,7 \pm 0,2^{a}$ & $8,8 \pm 0,2^{a}$ & $9,2 \pm 0,2^{a}$ \\
\hline Relación $\omega-6 / \omega-3$ & $0,3 \pm 0,0^{a}$ & $0,3 \pm 0,0^{a}$ & $0,3 \pm 0,0^{a}$ & $0,3 \pm 0,0^{a}$ & $0,3 \pm 0,0^{a}$ \\
\hline Índice de iodo ( $\mathrm{g} \mathrm{I}_{2} / 100 \mathrm{~g}$ aceite $)$ & $210,4 \pm 1,0^{a}$ & $209,5 \pm 0,7^{a}$ & $209,1 \pm 1,3^{a}$ & $209,4 \pm 0,8^{a}$ & $210,5 \pm 1,1^{\mathrm{a}}$ \\
\hline Índice de saponificación (mg KOH/g aceite) & $194,14 \pm 0,05^{a}$ & $193,14 \pm 0,04^{a}$ & $193,14 \pm 0,03^{a}$ & $193,16 \pm 0,05^{a}$ & $193,1 \pm 0,07^{a}$ \\
\hline tiempo de inducción $(\mathrm{h})$ & $1,12 \pm 0,29{ }^{a}$ & $1,22 \pm 0,08^{a}$ & $1,60 \pm 0,22{ }^{a}$ & $1,53 \pm 0,10^{a}$ & $2,37 \pm 0,06^{b}$ \\
\hline
\end{tabular}

Valores medios \pm desviación estándar $(n=2)$ seguidos de letras diferentes indican que existen diferencias significativas $(p \leq 0,05)$. SFAs ácidos grasos saturados; PUFAs ácidos grasos poliinsaturados; $\omega 6 / \omega 3$ FA (ácido linoleico/ ácido $\alpha$-linolénico) 
Las propiedades del aceite de chía obtenido mediante $\mathrm{SC}-\mathrm{CO}_{2}$ no presentaron diferencias significativas $(p>0,05)$ con respecto a los extraídos con hexano en términos de sus parámetros fisicoquímicos, tales como los índices de saponificación y de iodo (Tabla 4.4). Similares resultados fueron hallados por Follegatti-Romero y col. (2009) para aceite obtenido a partir de Sacha Inchi.

La Figura 4.6 muestra la composición acídica de cada una de las cuatro fracciones en las que se subdividieron las muestras de aceite de chía. Pueden observarse diferencias significativas $(p \leq 0,05)$ entre dichas fracciones, habiéndose detectado a $40^{\circ} \mathrm{C}$ - 250 bar un tenor más elevado de ácido esteárico y un menor contenido de ácido $\alpha$-linolénico en la fracción 1 ( 0 - $5 \mathrm{~g} \mathrm{CO}_{2} / \mathrm{g}$ semilla) que en la fracción 3 (21 - $39 \mathrm{~g} \mathrm{CO}_{2} / \mathrm{g}$ semilla). En las condiciones de procesamiento a las cuales se alcanzó el máximo rendimiento en aceite $\left(60^{\circ} \mathrm{C}-450\right.$ bar) también se evidenciaron diferencias significativas $(p \leq 0,05)$ entre las fracciones, registrándose un menor contenido de ácido esteárico y un mayor tenor de ácido oleico asociados a la fracción 3 (8 - $16 \mathrm{~g} \mathrm{CO}_{2} / \mathrm{g}$ semilla) que a la fracción 4 (17-34 g CO $2 / g$ semilla). Además, es interesante destacar que bajo todas las condiciones operativas ensayadas, el ácido a-linolénico mostró una tendencia de concentración creciente desde la fracción 1 a la 3 (correspondiente al 85\% del total del aceite extraído) con una posterior disminución en la fracción 4 , mientras que un comportamiento inverso fue observado para el ácido linoleico (Figura 4.4). Sin embargo, sólo se encontraron diferencias significativas $(p \leq 0,05)$ a $40^{\circ} \mathrm{C}-250$ bar entre las fracciones 1 y 3 para el contenido de ácido a-linolénico, así como a $40^{\circ} \mathrm{C}-450$ bar y $60^{\circ} \mathrm{C}-250$ bar para ambos PUFAs entre las fracciones $3-4$ y 1-3, respectivamente. Por otra parte, a la menor presión operativa ensayada independientemente de la temperatura de extracción, la fracción 1 registró un contenido significativamente mayor $(p \leq 0,05)$ de ácidos esteárico y/o palmítico así como un menor porcentaje de ácido a-linolénico que la fracción 3. No obstante, estas diferencias no fueron detectadas a la mayor presión de trabajo. Hassan y col. (2000) informaron que los triacilgliceroles compuestos por ácidos grasos de cadena corta son más solubles en el $\mathrm{SC}-\mathrm{CO}_{2}$ y pueden ser más fácilmente extraídos de la matriz de extracción. Estos autores encontraron una disminución de los ácidos grasos saturados y un incremento del tenor de insaturados con el aumento del tiempo de extracción de aceite de palma. Sin embargo, estas diferencias no fueron registradas en condiciones de altas 
presiones, en las cuales la composición de los ácidos grasos de cada fracción no mostró cambios significativos, lo cual indicaría una baja selectividad del $\mathrm{SC}-\mathrm{CO}_{2}$.

Ácido palmítico

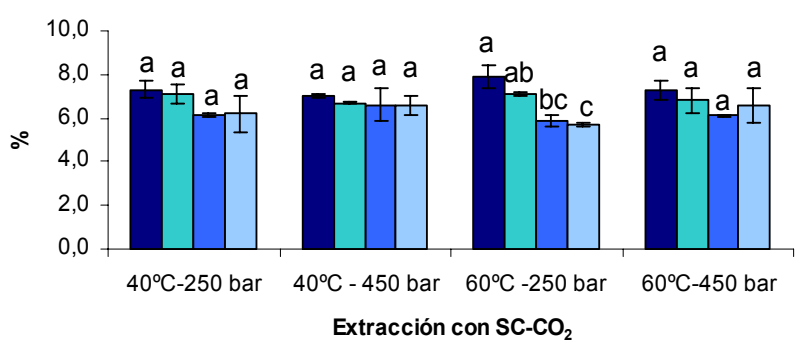

Ácido oleico

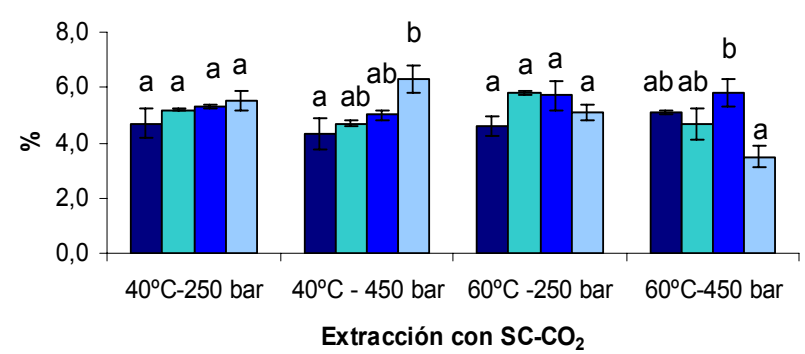

Ácido esteárico

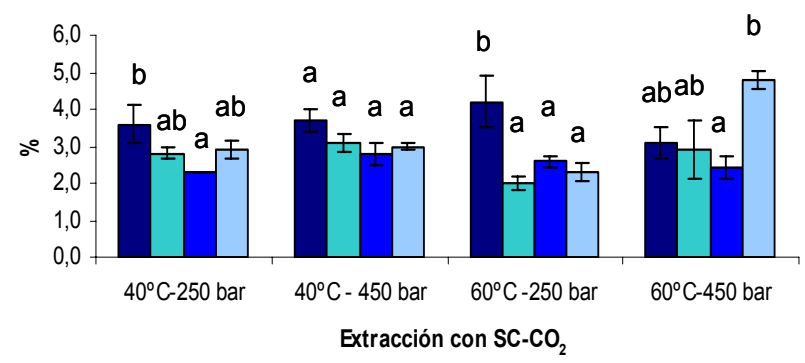

Ácido linoleico

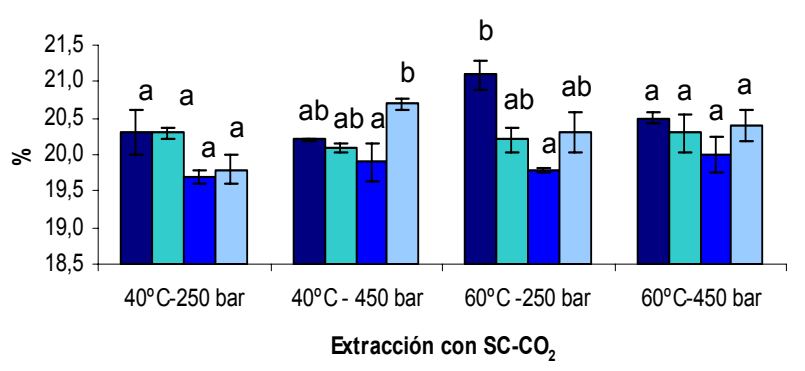

Ácido $\alpha$-linolénico

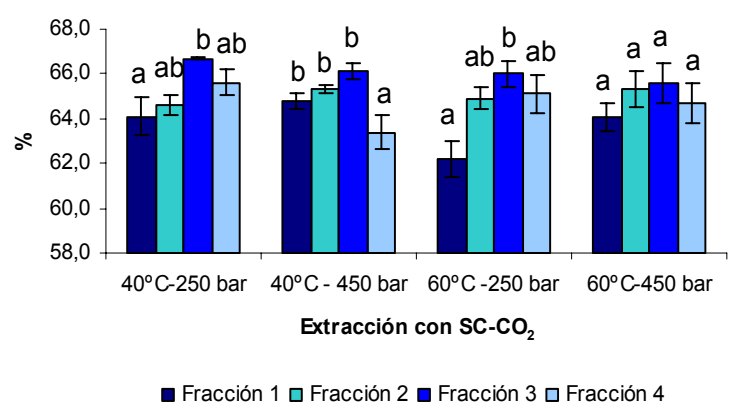

Figura 4.6. Composición acídica de cada una de las fracciones de aceite de chía obtenido a diferentes condiciones operativas de extracción mediante $\mathrm{SC}^{-} \mathrm{CO}_{2}$. Las barras verticales indican la desviación estándar. Letras diferentes indican que existen diferencias significativas $(p \leq 0,05)$ 
A fin de explicar las diferencias previamente enunciadas, se graficó la cantidad no extraída de cada uno de los ácidos grasos (\%) en función de la cantidad de solvente ( $\mathrm{g} \mathrm{CO}_{2} / \mathrm{g}$ semilla) (Figura 4.7) durante el proceso de extracción con SC$\mathrm{CO}_{2}$ para cada condición operativa. A tal efecto, se han considerado dos aproximaciones fenomenológicas. La primera está relacionada con los mecanismos involucrados en la extracción de aceites con fluidos supercríticos a partir de la matriz herbácea, previamente comentados. Así, el proceso de extracción consta de tres etapas características: la primera, durante la cual se extrae el aceite disponible sobre la superficie de las partículas y la velocidad de extracción está determinada por la solubilidad de los compuestos en el fluido supercrítico; la última etapa, donde se extrae el aceite menos accesible y en la cual la interacción entre el soluto, el solvente y las partículas controla la velocidad de extracción y una región de transición, donde ambos mecanismos están involucrados (Eggers, 1996). Así, de las cuatro fracciones colectadas a lo largo del proceso, las dos primeras corresponden a la primera etapa de extracción, mientras que la tercera y la cuarta pertenecen a la zona de transición y a la etapa final, respectivamente, las cuales son delimitadas por símbolos llenos en las correspondientes curvas de extracción (ver Figura 4.5). La segunda consideración se relaciona con los diversos triacilgliceroles (TAG) que constituyen las principales fuentes de ácidos grasos presentes en el aceite de chía (ver Tabla 3.8, Capítulo 3). El aceite de chía contiene principalmente tres TAG LnLnLn, LnLnL y LnLL, con similar peso molecular y estructura química relacionada, las cuales están asociadas a su solubilidad en el $\mathrm{SC}-\mathrm{CO}_{2}$. Estos tres compuestos serían los principales responsables de la velocidad observada durante el proceso de extracción. Varios autores (Nilsson, 1996; Hassan y col., 2000; Zaidul y col., 2006) informaron que la solubilidad de algunos tipos de ácidos grasos presentes en ciertos aceites aumenta con la presión a una determinada temperatura y disminuye con el aumento de la temperatura a presión constante. Este comportamiento fue observado en la primera etapa de las curvas de extracción presentadas en la Figura 4.7. La evolución de las curvas de extracción correspondientes a los diferentes ácidos grasos brinda una información útil para comprender los mecanismos de extracción y proponer las condiciones de extracción a fin de posibilitar el fraccionamiento de los diferentes ácidos grasos. 
a)
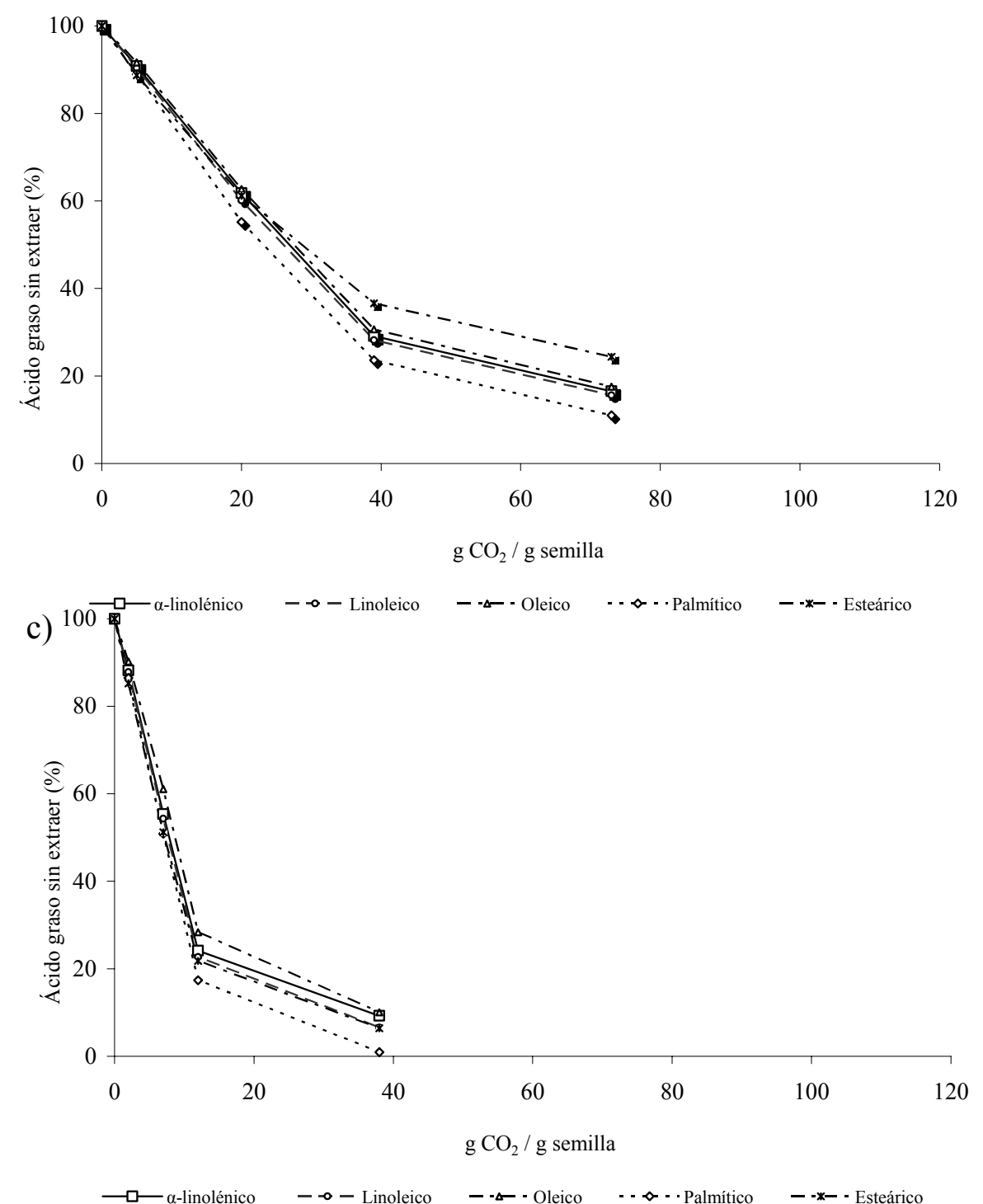

b)
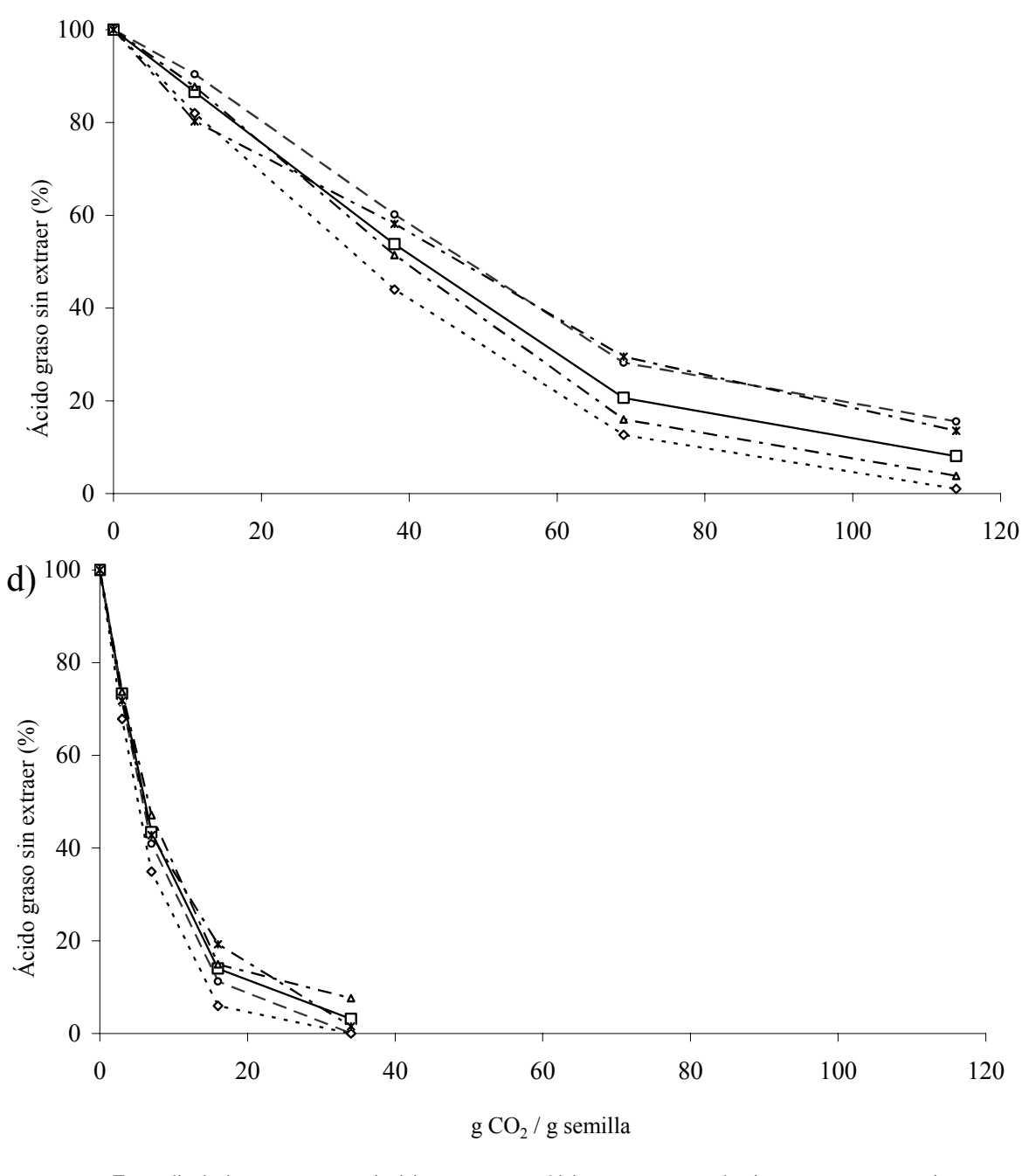

Figura 4.7 . Contenido (\%) no extraído correspondiente a los distintos ácidos grasos (AG) $)^{1}$ durante la extracción de aceite de chía con SC-CO 2 : a) $40^{\circ} \mathrm{C} 250$ bar, b) $60^{\circ} \mathrm{C} 250$ bar, c) $40^{\circ} \mathrm{C} 450$ bar, d) $60^{\circ} \mathrm{C} 450$ bar

${ }^{1} A G$ no extraido $(\%)=\left(\left(\right.\right.$ Total $A G_{x}-A G_{x}$ extraído $) /$ Total $\left.A G_{x}\right) \times 100$ 
En virtud de los resultados obtenidos, pudo evidenciarse que la velocidad de extracción de los ácidos grasos insaturados está estrechamente relacionada con la correspondiente a la de la extracción global del aceite y el fraccionamiento de estos compuestos sería complejo en las condiciones ensayadas. Por otra parte, se observó un comportamiento diferente para los ácidos grasos saturados (palmítico y esteárico). El ácido palmítico, presente en los TAG de menor peso molecular (ver Tabla 3.8 Capítulo 3), exhibió una rápida velocidad de extracción durante la primera etapa (fracciones 1 y 2 ) debido a su solubilidad en el $\mathrm{SC}-\mathrm{CO}_{2}$, la cual depende principalmente de dicha característica. El ácido esteárico en cambio, registró un comportamiento más complejo, presentando una tendencia diferente según la presión operativa ensayada. Así, a 250 bar puede visualizarse una velocidad de extracción diferente entre la primera y la segunda fracción (primera etapa de la curva). Este comportamiento estaría relacionado con las diferencias en la solubilidad de los TAG que poseen ácido esteárico en su estructura tales como LLE, LnOE y LnEP, siendo el último de ellos el más soluble en el $\mathrm{SC}_{-}-\mathrm{CO}_{2}$. La elevada velocidad de extracción inicial correspondiente al ácido esteárico estaría relacionada con la remoción del LnEP al comienzo del proceso, mientras que una vez que dicho TAG fue removido, se registró una disminución en la velocidad de extracción. Esta tendencia fue observada para ambas temperaturas, siendo más pronunciada a $60^{\circ} \mathrm{C}$. Además, el ácido esteárico es el ácido graso menos extraído a bajas presiones siendo posible -en estas condiciones- el fraccionamiento entre dicho compuesto y el ácido palmítico, especialmente a $60^{\circ} \mathrm{C}$.

La Figura 4.8 muestra los niveles de concentración de tocoferoles correspondientes a los aceites de chía obtenidos mediante extracción con hexano y $\mathrm{SC}-\mathrm{CO}_{2}$ a diferentes condiciones de temperatura y presión. Puede verse que el contenido total de tocoferoles del aceite de chía extraído por $\mathrm{SC}-\mathrm{CO}_{2}$ varía entre 36 y $95 \mathrm{mg} / \mathrm{kg}$ aceite, registrando diferencias significativas $(p \leq 0,05)$ en función de las condiciones operativas estudiadas. El contenido total de tocoferoles en los aceites obtenidos a 450 bar fue mayor que el correspondiente a $60^{\circ} \mathrm{C}-250$ bar, el cual presentó el menor tenor de estos compuestos. El perfil de tocoferoles estuvo constituido principalmente por $\gamma$-tocoferol, presente en todos los aceites obtenidos mediante $\mathrm{SC}-\mathrm{CO}_{2}$, mientras que el $\delta$-tocoferol sólo fue detectado a muy bajas concentraciones $\left(4,17 \mathrm{mg} / \mathrm{kg}\right.$ aceite) en el aceite extraído a $40^{\circ} \mathrm{C}$ y $250 \mathrm{bar}$, condiciones operativas asociadas al menor rendimiento de extracción. En este 
sentido, la menor dilución de los tocoferoles en el aceite podría haber permitido la detección del $\delta$-tocoferol.

Leo y col. (2005) manifestaron que como consecuencia de la gran selectividad del $\mathrm{CO}_{2}$ en estado supercrítico por los tocoferoles, estos compuestos se recuperarían principalmente al principio de la extracción, pudiéndose detectar una mayor concentración durante la fase inicial del proceso de obtención del aceite. Sin embargo, otros factores podrían afectar la concentración de tocoferoles, tales como el efecto co-solvente del aceite (Jachmanián y col., 2006) y la degradación térmica (Bostyn y col., 2008). Por otra parte, la concentración de tocoferoles presentes en los aceites obtenidos mediante $\mathrm{SC}-\mathrm{CO}_{2}$ resultó significativamente menor $(\mathrm{p} \leq 0,05)$ que aquélla detectada en los aceites extraídos con hexano. Resultados similares fueron encontrados por Bozan y Temelli (2002) en aceites de algodón y de lino.

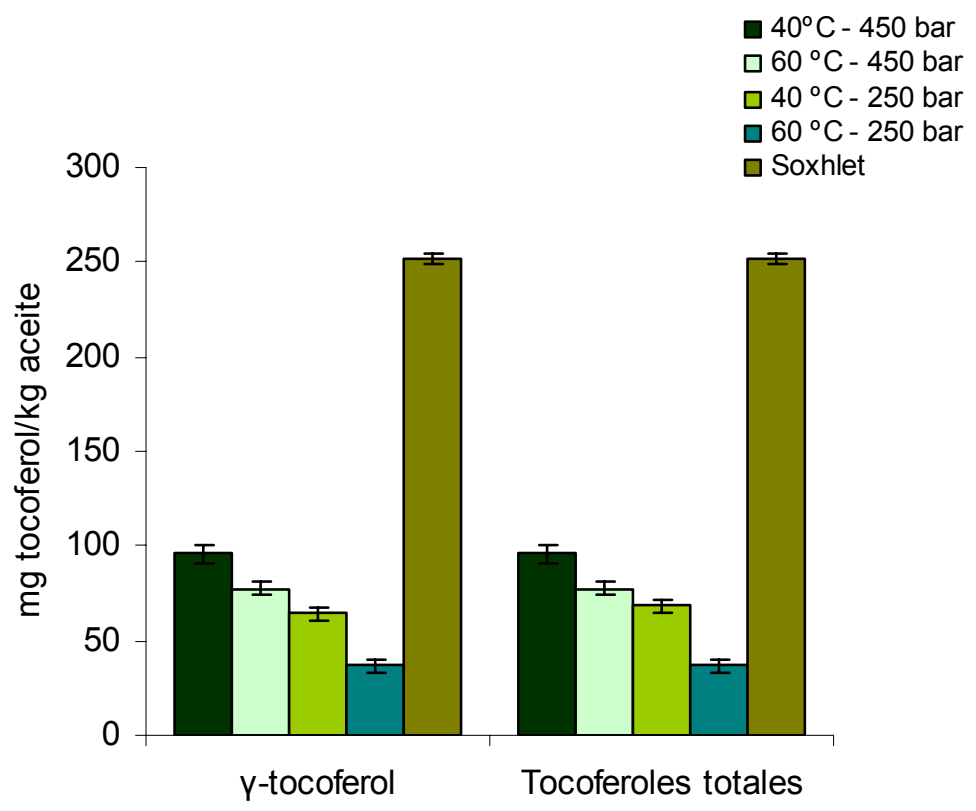

Figura 4.8. Contenido de tocoferoles presentes en el aceite de chía obtenido mediante $\mathrm{SC}-\mathrm{CO}_{2}$ y extracción con solventes (Soxhlet). Las barras verticales indican la desviación estándar. Letras diferentes indican que existen diferencias significativas $(p \leq 0,05)$

Tal como fue expuesto para los aceites obtenidos mediante los procesos convencionales descriptos en el Capítulo 3, los principales compuestos polifenólicos detectados fueron los ácidos cafeico y clorogénico, la miricetina, quercetina y kaempferol, no habiéndose registrado diferencias significativas $(p>0,05)$ para aquéllos obtenidos bajo las diferentes condiciones operativas estudiadas (Tabla 4.5). 
Tabla 4.5. Compuestos polifenólicos de aceites de chía obtenidos mediante $\mathrm{SC}-\mathrm{CO}_{2}$

\begin{tabular}{|c|c|c|c|c|}
\hline \multirow{2}{*}{$\begin{array}{c}\text { Compuesto } \\
\text { polifenólico } \\
(\mathrm{mol} / \mathrm{kg})\end{array}$} & \multicolumn{4}{|c|}{ Extracción mediante $\mathrm{SC}-\mathrm{CO}_{2}$} \\
\hline & $40^{\circ} \mathrm{C}-250 \mathrm{bar}$ & $60^{\circ} \mathrm{C}-250 \mathrm{bar}$ & $40^{\circ} \mathrm{C}-450 \mathrm{bar}$ & $60^{\circ} \mathrm{C}-450 \mathrm{bar}$ \\
\hline Ácido clorogénico & $1,31 \times 10^{-5} \pm 2,17 \times 10^{-6} \mathrm{a}$ & $1,05 \times 10^{-5} \pm 5,95 \times 10^{-8} \mathrm{a}$ & $9,55 \times 10^{-6} \pm 1,42 \times 10^{-9} \mathrm{a}$ & $2,58 \times 10^{-5} \pm 2,00 \times 10^{-5}$ \\
\hline Ácido cafeico & $3,01 \times 10^{-5} \pm 4,61 \times 10^{-6} \mathrm{a}$ & $2,44 \times 10^{-5} \pm 2,57 \times 10^{-7} \mathrm{a}$ & $2,15 \times 10^{-5} \pm 4,47 \times 10^{-7} \mathrm{a}$ & $5,92 \times 10^{-5} \pm 4,59 \times 10^{-5}$ \\
\hline Miricetina & $1,35 \times 10^{-5} \pm 6,33 \times 10^{-7}$ a & $1,75 \times 10^{-5} \pm 2,31 \times 10^{-6}$ a & $1,00 \times 10^{-5} \pm 6,97 \times 10^{-8}$ a & $2,57 \times 10^{-5} \pm 2,32 \times 10^{-6}$ \\
\hline Quercetina & $1,23 \times 10^{-5} \pm 1,76 \times 10^{-6} \mathrm{a}$ & $9,73 \times 10^{-6} \pm 3,48 \times 10^{-7 a}$ & $9,38 \times 10^{-6} \pm 2,02 \times 10^{-7}$ a & $2,34 \times 10^{-5} \pm 1,83 \times 10^{-5}$ \\
\hline Kaempferol & $3,48 \times 10^{-6} \pm 5,35 \times 10^{-7}$ a & $2,89 \times 10^{-6} \pm 1,85 \times 10^{-8} a$ & $2,63 \times 10^{-6} \pm 1,56 \times 10^{-8} a$ & $7,16 \times 10^{-6} \pm 5,77 \times 10^{-6}$ \\
\hline Total & $7,25 \times 10^{-5} \pm 1,94 \times 10^{-6}$ a & $6,50 \times 10^{-5} \pm 5,99 \times 10^{-7} a$ & $5,30 \times 10^{-5} \pm 1,47 \times 10^{-7} a$ & $1,41 \times 10^{-4} \pm 1,85 \times 10^{-5}$ \\
\hline
\end{tabular}


Por otra parte, la estabilidad oxidativa determinada mediante Rancimat a través del tiempo de inducción estuvo comprendida entre 1,12 a 2,37 h, siendo los aceites obtenidos a 250 bar los que registraron los menor valores de este parámetro (Tabla 4.4). La estabilidad oxidativa de los aceites obtenidos con $\mathrm{SC}-\mathrm{CO}_{2}$ fue inferior a la correspondiente a los aceites extraídos con hexano en todos los casos, indicando que los mismos se encuentran menos protegidos contra la oxidación. Calvo y col. (1994), Oliveira y col. (2002) y Martínez y col. (2008) han informado resultados similares en aceites de nuez extraídos con $\mathrm{SC}_{-}-\mathrm{CO}_{2}$. Si bien el contenido de tocoferoles fue menor en los aceites obtenidos mediante $\mathrm{SC}-\mathrm{CO}_{2}$, las diferencias en la estabilidad oxidativa no pueden ser atribuidas sólo al tenor de estos antioxidantes naturales. Una posible explicación se relaciona con la menor solubilidad de los fosfolípidos en el SC- $\mathrm{CO}_{2}$ y el efecto sinérgico entre los tocoferoles y los fosfolípidos (Calvo y col., 1994). Así, el menor tenor de ambos compuestos en el aceite extraído mediante $\mathrm{SC}-\mathrm{CO}_{2}$ sería uno de los factores que podrían determinar la baja estabilidad oxidativa del aceite obtenido por este proceso. Por otra parte, Calvo y col. (1994) informaron que también puede deberse a algún fenómeno intrínseco del proceso de extracción supercrítica. Así, estos autores han demostrado que la oxidación del aceite de girasol extraído con $\mathrm{SC}-\mathrm{CO}_{2}$ podría relacionarse con la presencia de trazas de oxígeno en el solvente de extracción. La presencia de oxígeno y la ausencia de limitaciones a la transferencia de masa favorecerían la oxidación de los triacilgliceroles en la fase supercrítica. Martínez y col. (2008), también han vinculado la baja estabilidad oxidativa del aceite de nuez con el contenido de oxígeno presente en el $\mathrm{CO}_{2}$ utilizado para realizar las extracciones, a pesar de la elevada pureza de este fluido. Por ejemplo, la solubilidad del aceite de chía a 250 bar y $40^{\circ} \mathrm{C}$ fue de $7,0 \mathrm{~g} / \mathrm{kg} \mathrm{CO}$ (Tabla 4.2), lo que implica que son necesarios $0,143 \mathrm{~kg}$ de $\mathrm{CO}_{2}$ para obtener $1 \mathrm{~g}$ de aceite. Teniendo en cuenta que la concentración de oxígeno en el $\mathrm{CO}_{2}$ de alta pureza es de $2 \mathrm{ppm}$, puede estimarse una relación de $0,286 \mathrm{mg}$ de $\mathrm{O}_{2} / \mathrm{g}$ de aceite extraído. Además, asumiendo que la masa molecular media de un triacilglicerol de aceite de chía es igual a 896, resulta de las condiciones experimentales mencionadas previamente, una relación molar de $124,45 \mathrm{~mol}$ de aceite/mol de $\mathrm{O}_{2}$. Por lo tanto, una considerable cantidad de oxígeno estaría en contacto con la matriz y el aceite extraído, pudiendo ser una causa importante de la reducción observada en la estabilidad oxidativa. Sin embargo, otros factores como la presencia de ácidos grasos libres, mono y diacilgliceroles, metales 
de transición y pigmentos estarían involucrados en al estabilidad oxidativa de los aceites (Choe y Min, 2006).

\section{Análisis conjunto de los aceites de chía obtenidos a partir de las semillas} provenientes de Argentina mediante los diferentes procesos de extracción a través de un análisis multivariado

A fin de establecer relaciones entre los aceites extraídos mediante las diferentes metodologías y algunos de los parámetros seleccionados, se realizó un análisis multivariado considerando los aceites obtenidos a partir de las semillas provenientes de Argentina. Los resultados se muestran en el gráfico de componentes principales (CP) (Figura 4.9 a y b). Los componentes principales 1, 2 y 3 explican 43,5, 31,6 y 16,6\% de la variabilidad observada, respectivamente, totalizando en conjunto alrededor del 92\%. Como puede observarse, el CP1 permitió separar las metodologías convencionales de las de extracción mediante $\mathrm{SC}-\mathrm{CO}_{2}$, mientras que el CP2 permitió discriminar claramente la extracción con solvente de la de prensado. Así, teniendo en cuenta el CP1, los aceites obtenidos mediante extracción con hexano y por prensado, aparecieron asociados con los contenidos más altos de ácidos oleico y esteárico, mayor contenido de tocoferoles y estabilidad oxidativa. Por otra parte, los aceites extraídos mediante $\mathrm{SC}-\mathrm{CO}_{2}$ se relacionaron con niveles elevados de ácido palmítico y linoleico así como de polifenoles totales. Con respecto al CP2, el aceite extraído con hexano se vinculó con un mayor rendimiento y contenido de ácido $\alpha$-linolénico, mientras que el obtenido por prensado pudo relacionarse con bajos rendimientos y tenores más altos de ácido palmítico, esteárico, oleico, linoleico y mayor estabilidad oxidativa. EI CP3 agrupó a los aceites obtenidos por $\mathrm{SC}-\mathrm{CO}_{2}$ según la presión operativa. En este sentido, los aceites obtenidos a 250 bar $\left(40-60^{\circ} \mathrm{C}\right)$ se relacionaron con un mayor contenido de ácido oleico, mientras que el extraído a $450 \mathrm{bar}$ y $60^{\circ} \mathrm{C}$ con un rendimiento más elevado, mayor tenor de ácido esteárico y de compuestos polifenólicos totales. 
(a)

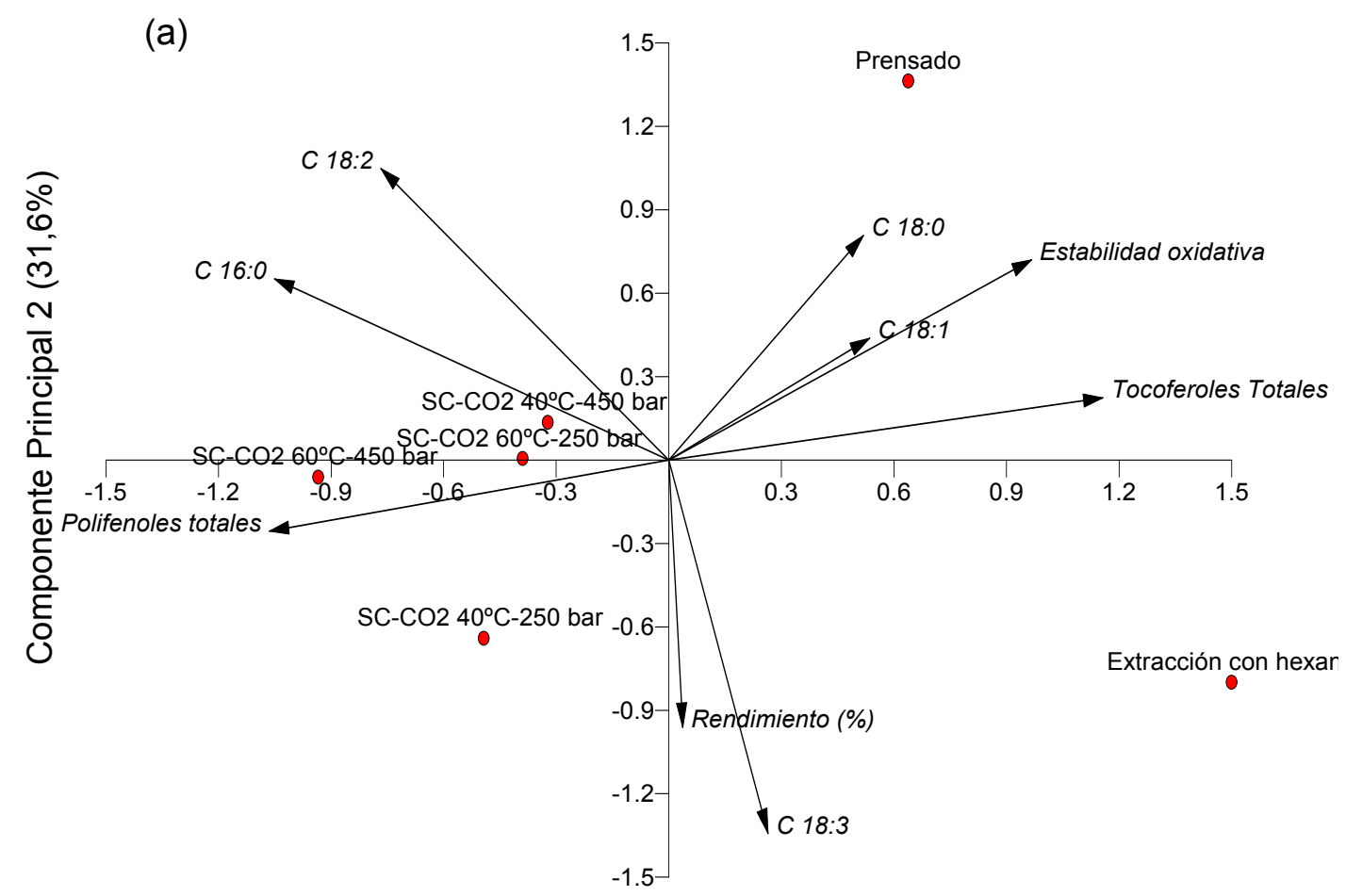

Vector scaling: 2,36

Componente Principal $1(43,5 \%)$

(b)

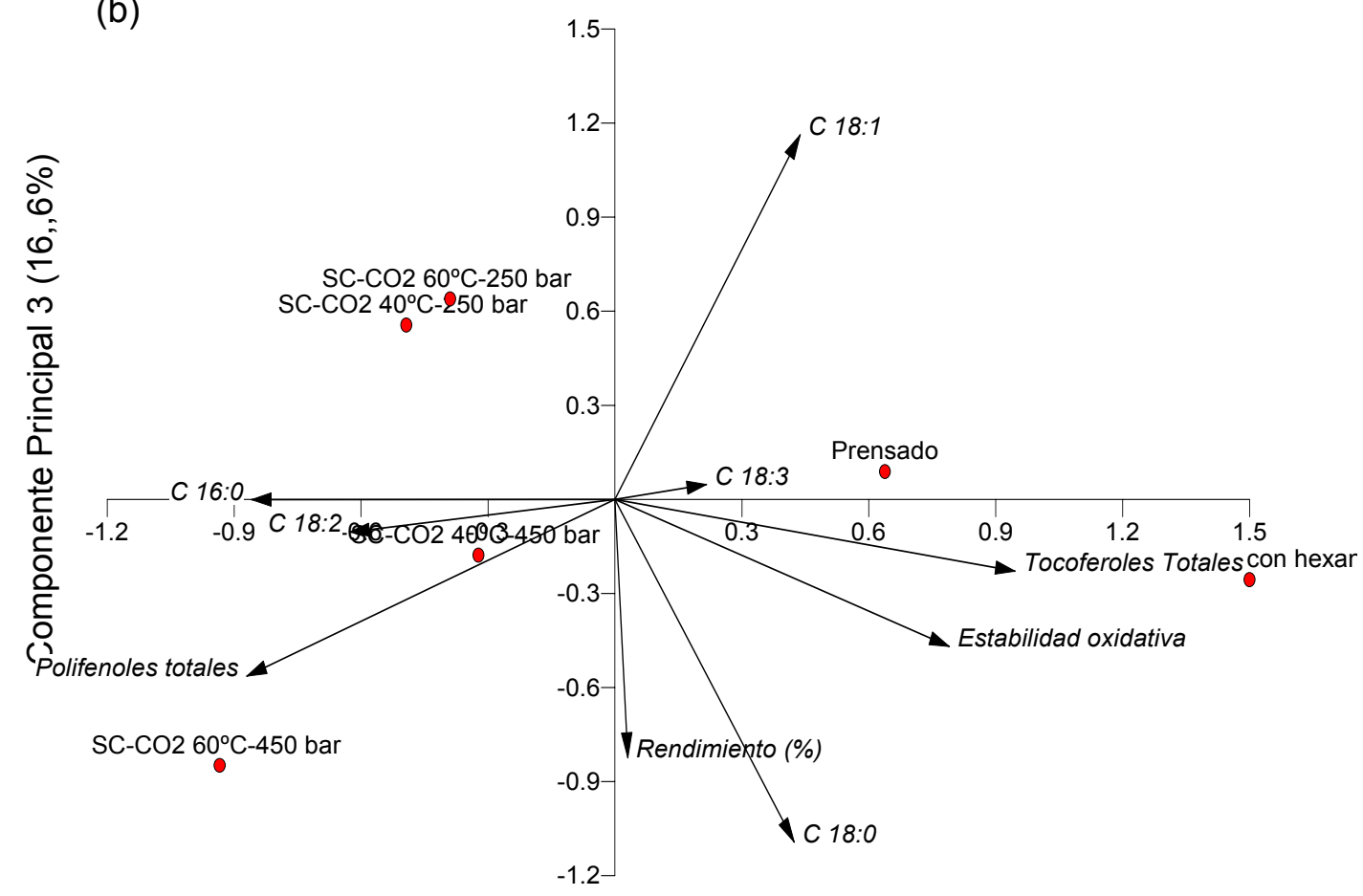

Componente Principal $1(43,5 \%)$

Vector scaling: 1,93

Figura 4.9. Análisis de componentes principales (ACP) de los aceites de chía obtenidos por distitnos procesos a partir de semillas provenientes de Argentina (a) CP1 vs CP2; (b) CP1 vs CP3 
3. Extracción supercrítica de aceite de chía obtenido a partir de semillas provenientes de Jalisco (México)

El contenido de humedad de las semillas fue de $6,9 \pm 0,5 \%$ (b.s.), con un contenido total de aceite estimado mediante extracción con Soxhlet ( $n$-hexano) de $33,0 \%$ (b.s.).

3.1. Proceso de extracción, modelo de regresión y análisis de resultados mediante la metodología de superficie de respuesta (MSR)

Los resultados obtenidos en la extracción de aceite de chía mediante SC- $\mathrm{CO}_{2}$ bajo diferentes condiciones de temperatura y presión y tiempo de extracción se muestran en la Tabla 4.6. El máximo rendimiento de extracción fue de $88,1 \%$ (corrida 8), el cual corresponde a $80^{\circ} \mathrm{C}, 450$ bar y $240 \mathrm{~min}$.

Tabla 4.6. Diseño experimental y rendimiento en aceite de chía obtenido mediante $\mathrm{SC}-\mathrm{CO}_{2}$

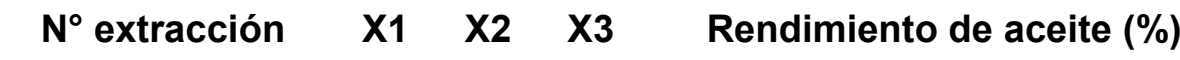

\begin{tabular}{ccccc}
\hline 1 & -1 & -1 & -1 & 6,0 \\
2 & -1 & -1 & +1 & 29,4 \\
3 & -1 & +1 & -1 & 16,8 \\
4 & -1 & +1 & +1 & 46,6 \\
5 & +1 & -1 & -1 & 2,9 \\
6 & +1 & -1 & +1 & 10,8 \\
7 & +1 & +1 & -1 & 23,5 \\
8 & +1 & +1 & +1 & 88,1 \\
9 & -1 & 0 & 0 & 41,8 \\
10 & +1 & 0 & 0 & 34,1 \\
11 & 0 & -1 & 0 & 18,2 \\
12 & 0 & +1 & 0 & 40,3 \\
13 & 0 & 0 & -1 & 12,4 \\
14 & 0 & 0 & +1 & 56,0 \\
15 & 0 & 0 & 0 & 44,7 \\
16 & 0 & 0 & 0 & 43,2 \\
17 & 0 & 0 & 0 & 52,4 \\
18 & 0 & 0 & 0 & 52,2 \\
\hline$X_{1}$ temperatura de extracción; $X_{2}$ presión de extracción; $\mathrm{X}_{3}$ tiempo de extracción
\end{tabular}


Seguidamente, los valores de rendimiento fueron analizados mediante un ANOVA a fin de estudiar el efecto de cada condición operativa sobre los mismos (Tabla 4.7). En la Figura 4.10 se muestra el diagrama de Pareto resultante de dicho análisis, en el que puede observarse las fuentes de variación que presentaron un efecto significativo $(p \leq 0,05)$ sobre el rendimiento de aceite. Así, la cantidad de aceite extraído fue afectada por el tiempo y la presión de extracción, mientras que no se observó un efecto significativo $(p>0,05)$ debido a la temperatura. Además, se registró un efecto significativo de las interacciones temperatura-presión, presióntiempo y presión-presión (Tabla 4.7 y Figura 4.10).

Tabla 4.7. Resultados del ANOVA correspondiente al rendimiento de aceite de semillas de chía provenientes de México, extraído mediante $\mathrm{SC}-\mathrm{CO}_{2}$ bajo diferentes condiciones de temperatura, presión y tiempo de extracción

\begin{tabular}{cccc}
\hline Fuente de variación & Cuadrado Medio & $\mathbf{F}$ & $\mathbf{p}$ \\
\hline $\mathrm{T}$ & 35,34 & 1,5 & 0,3086 \\
$\mathrm{P}$ & 2190,40 & 92,7 & 0,0024 \\
$\mathrm{t}$ & 2866,25 & 121,3 & 0,0016 \\
$\mathrm{TT}$ & 5,82 & 0,25 & 0,6537 \\
$\mathrm{TP}$ & 610,75 & 25,85 & 0,0147 \\
$\mathrm{Tt}$ & 46,56 & 1,97 & 0,2549 \\
$\mathrm{PP}$ & 280,01 & 11,85 & 0,0411 \\
Pt & 497,70 & 21,07 & 0,0194 \\
Tt & 73,71 & 3,12 & 0,1755 \\
Falta de ajuste & 138,38 & 5,86 & 0,0882 \\
Error puro & 23,62 & & \\
\hline T:Temperatura; P: Presión; t: tiempo & &
\end{tabular}




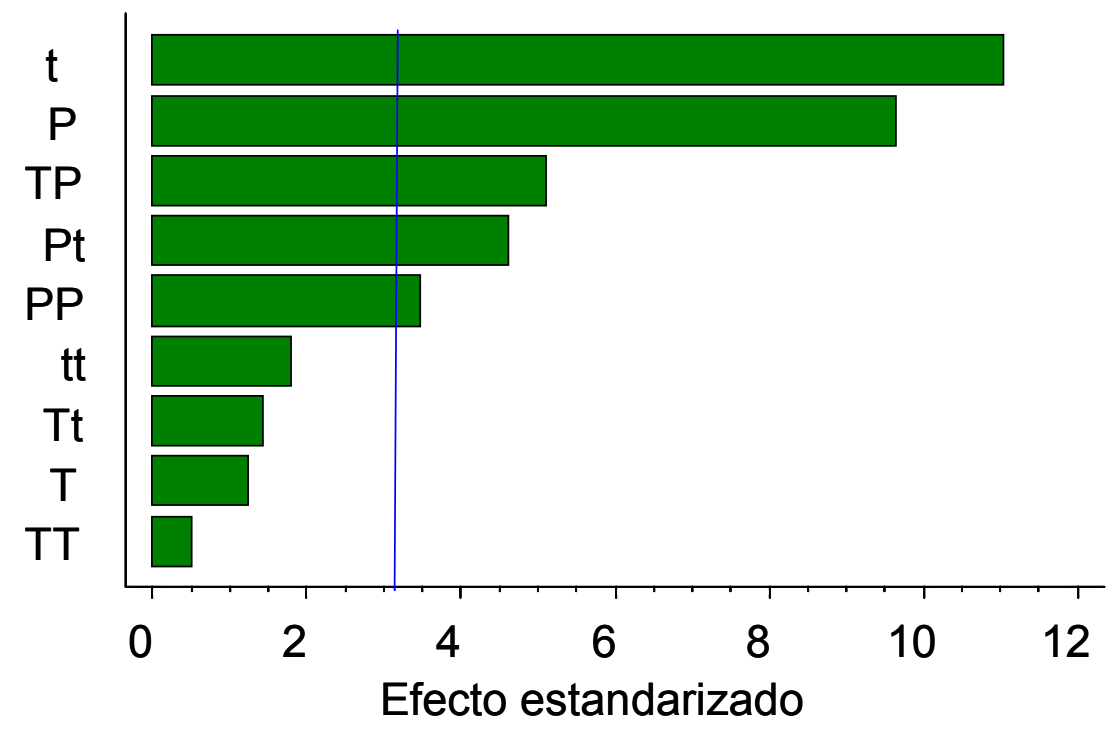

Figura 4.10. Diagrama de Pareto correspondiente al análisis del rendimiento de aceite de chía proveniente de México obtenido mediante $\mathrm{SC}-\mathrm{CO}_{2}$ a distintas condiciones de temperatura, presión y tiempo de extracción. La línea azul indica el nivel crítico a partir del cual las variables presentaron un efecto significativo $(p \leq 0,05)$. T:Temperatura; P: Presión; t: tiempo

El análisis matemático de los datos experimentales se basó en la regresión de un polinomio de segundo grado, desarrollado para establecer la relación entre el rendimiento de aceite $(\mathrm{Y})$ y los valores codificados de las variables independientes de temperatura $\left(X_{1}\right)$, presión $\left(X_{2}\right)$ y tiempo $\left(X_{3}\right)$ así como de sus interacciones. En virtud de ello, se obtuvo el siguiente modelo:

$$
\begin{array}{rlr}
Y= & 43,77+1,88 X_{1}+14,80 X_{2}+16,93 X_{3}-1,47 X_{1}^{2}+8,74 X_{1} X_{2}+2,41 X_{1} X_{3} \quad \text { Ec. } 4.6 \\
& -10,17 X_{2}^{2}+7,89 X_{2} X_{3}-5,22 X_{3}^{2} &
\end{array}
$$

El valor de $r^{2}$ fue de $90,41 \%$, lo que indica que dicho porcentaje de la variabilidad en el rendimiento de aceite de chía extraído por $\mathrm{SC}-\mathrm{CO}_{2}$ es explicado por el modelo planteado, presentando un error absoluto medio (MAE\%) de 5,48\%.

$$
\text { MAE } \%=\frac{100}{n} \times \sum\left|V_{\text {exp }}-V_{\text {pred }}\right|
$$

donde:

$\mathrm{n}$ : número de pares de datos 
$V_{\text {exp }}$ : valores experimentales

$V_{\text {pred: }}$ valores predichos

Por otra parte, el efecto de la falta de ajuste analizado en el ANOVA permitió determinar que el modelo seleccionado fue adecuado para describir los datos observados debido a que el mismo no presentó un efecto significativo $(p>0,05)$.

Con el objeto de simplificar el modelo, el mismo fue replanteado a través de la eliminación de los términos que no tuvieron un efecto significativo $(p>0,05)$ en el modelo polinomial de segundo orden, el cual finalmente se expresa mediante la siguiente ecuación:

$$
Y=42,10+14,80 X_{2}+16,93 X_{3}+8,74 X_{1} X_{2}-13,84 X_{2}^{2}+7,89 X_{2} X_{3}
$$

Así, el modelo simplificado presentó un coeficiente de determinación de $r^{2}=88,04 \%$ y un MAE $=6,09 \%$. En este sentido, el coeficiente de determinación también es una medida del grado de ajuste, habiéndose encontrado en la literatura que dicho valor debe ser al menos de $80 \%$ para considerar que un modelo presenta un buen grado de ajuste (Guan y Yao, 2008). Por consiguiente, puede sugerirse que el modelo simplificado planteado es adecuado para explicar la variabilidad observada en el rendimiento de extracción del aceite de chía mediante $\mathrm{SC}-\mathrm{CO}_{2}$.

En la Figura 4.11 se muestra la comparación entre los valores experimentales vs. los predichos, según el modelo propuesto. La misma muestra un buen ajuste y una distribución uniforme de los valores observados alrededor de los predichos, confirmando que efectivamente podría utilizarse un modelo polinomial de segundo orden para representar la relación entre los parámetros seleccionados.

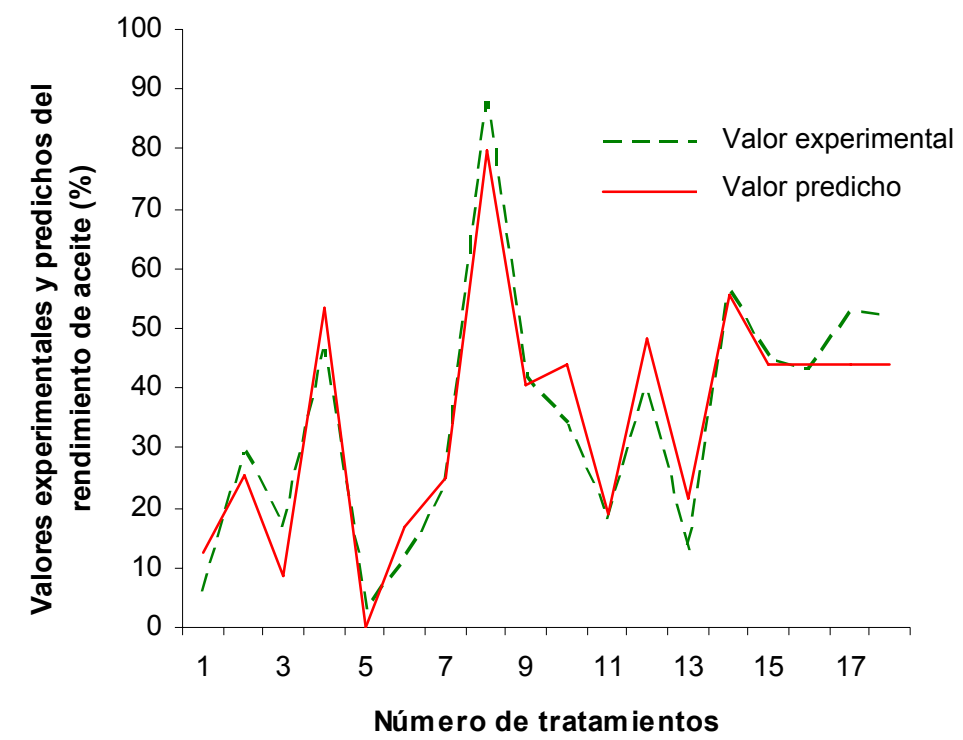

Figura 4.11. Comparación entre los valores experimentales y los predichos mediante el modelo del rendimiento de aceite de chía obtenido por SC-CO 
Una de las mejores maneras de visualizar el efecto de las variables independientes sobre las variables dependientes es a través de los gráficos de superficie de respuesta. Las superficies de respuesta tridimensionales fueron obtenidas modificando dos de las variables estudiadas dentro del rango experimental y manteniendo la otra variable constante en el punto central. Las superficies de respuesta se muestran en la Figura 4.12 (a-c).

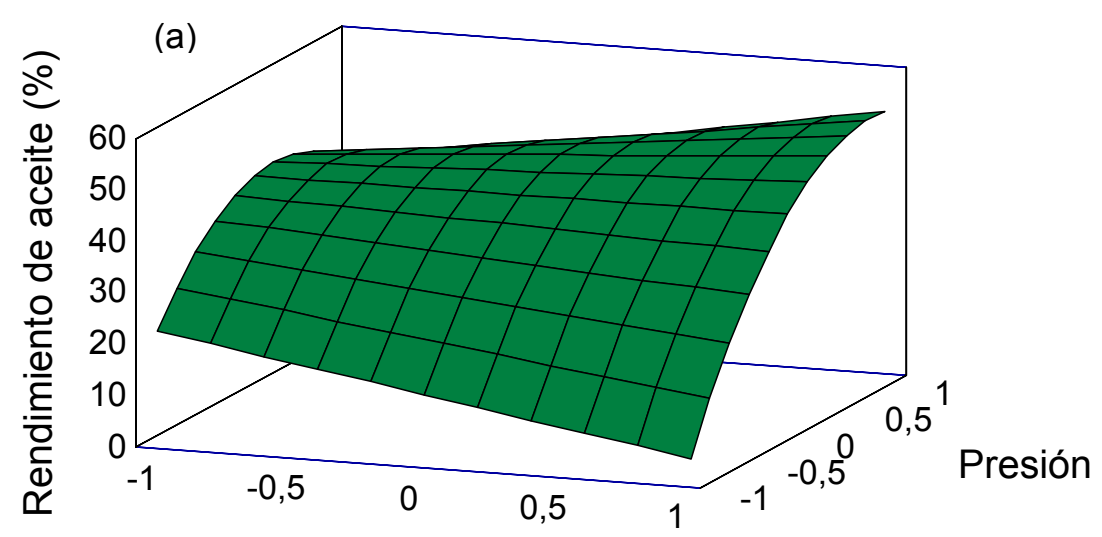

Temperatura

(b)

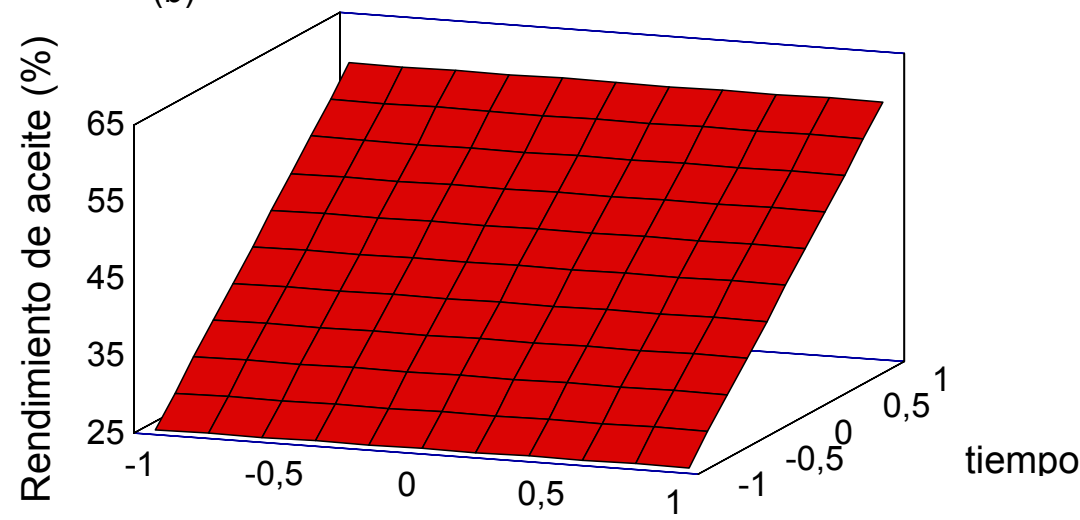

Temperatura

(c)

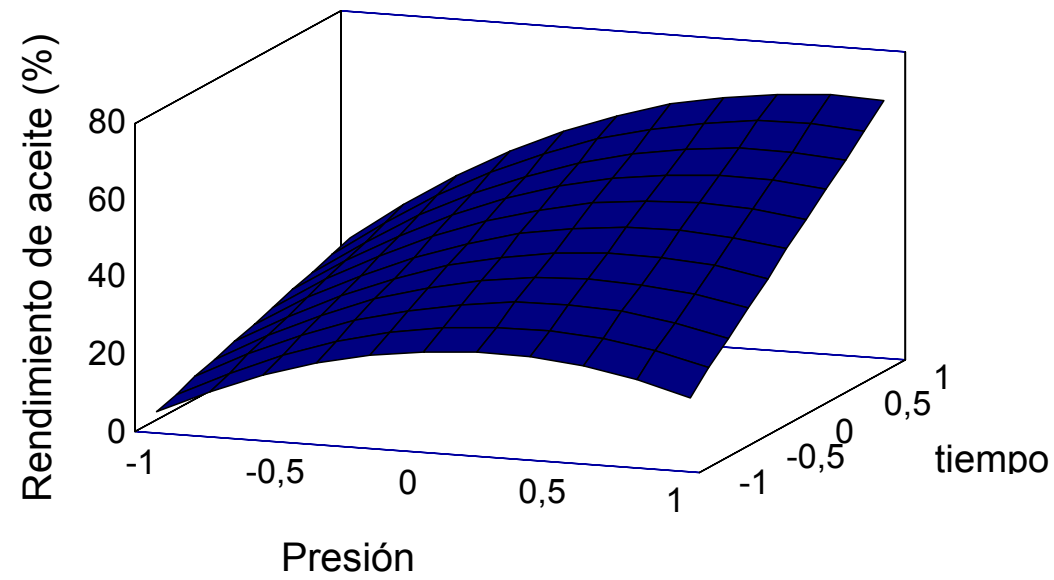

Figura 4.12. Superficies de respuesta correspondientes al rendimiento de aceite de chía obtenido mediante $\mathrm{SC}-\mathrm{CO}_{2}$ a diferentes condiciones operativas 
Tal como fue analizado previamente, puede observarse que el tiempo y la presión asociados al proceso de extracción presentaron los efectos más significativos sobre el rendimiento del aceite de chía. La Figura 4.12a muestra el efecto de la temperatura y de la presión operativas sobre el rendimiento de aceite de chía a tiempo constante $\mathrm{t}=150 \mathrm{~min}\left(\mathrm{X}_{3}=0\right)$. El rendimiento de aceite se incrementó con el aumento de la presión de extracción, efecto que fue más pronunciado a niveles de altas temperaturas. Este resultado es consistente con la interacción significativa detectada entre la presión y la temperatura operativa, tal como fue comprobado a través del ANOVA (Tabla 4.7). Este aumento en el rendimiento en función de la presión operativa, también observado en la extracción a partir de las semillas de chía de Argentina, puede ser atribuido al mejoramiento de la solubilidad del aceite como resultado del incremento de la densidad del $\mathrm{CO}_{2}$ con la presión $(\mathrm{Xu}$ y col., 2008). En forma similar a los resultados experimentales obtenidos para la extracción supercrítica de aceite de chía a partir de las semillas de Argentina a bajas presiones, el rendimiento disminuyó al aumentar la temperatura de extracción debido a la reducción en la densidad del fluido supercrítico. Sin embargo, en los experimentos llevados a cabo a los mayores niveles de presión, este parámetro aumentó en función del incremento en la temperatura. En virtud de lo comentado previamente, la presión a la cual se invierte el efecto de la temperatura sobre el rendimiento se denomina "crossover", lo cual se presenta aproximadamente a los 350 bar $\left(\mathrm{X}_{2}=0\right)$ para la EFSC a partir de las semillas de chía provenientes de México. Este fenómeno también fue encontrado en la extracción de otros aceites vegetales, tales como los de semilla de lino, caracterizada también por su elevado tenor de PUFAs. Se ha informado que el punto crossover en la extracción de dicho aceite fue de 350 bar (Jiao y col., 2008) y 300 bar (Özkal, 2009). Los rendimientos de extracción aumentaron con presiones operativas crecientes hasta cierto nivel, dependiente de la temperatura de extracción, a partir del cual el rendimiento disminuyó al incrementarse la presión. Esta presión a la cual se obtuvo el máximo rendimiento fue mayor a temperaturas más elevadas. Este hecho puede atribuirse al aumento de las interacciones repulsivas soluto/solvente resultantes del $\mathrm{CO}_{2}$ altamente comprimido a elevadas presiones operativas (Clifford, 1999). Resultados similares también fueron encontrados por Machmudah y col. (2007) en la extracción de aceite de semilla de rosa mosqueta. 
La Figura 4.12b muestra los efectos de la temperatura y el tiempo de extracción sobre el rendimiento de aceite de chía a 350 bar. Se encontró una dependencia lineal del rendimiento con respecto al tiempo de extracción independientemente de la temperatura. Sin embargo, los efectos lineal y cuadrático de la temperatura operativa así como la interacción entre la temperatura y el tiempo de extracción no fueron significativos $(p>0,05)$.

Por otra parte, se calculó la solubilidad del aceite de chía a partir de los datos experimentales mediante la relación entre la masa total de aceite extraída y el volumen total de $\mathrm{CO}_{2}$ utilizado en cada corrida. La menor solubilidad fue $0,38 \mathrm{~kg}$ aceite $/ \mathrm{m}^{3} \mathrm{CO}_{2}$ a $80^{\circ} \mathrm{C}$ y 250 bar, mientras que la mayor solubilidad fue $4,11 \mathrm{~kg}$ aceite $/ \mathrm{m}^{3} \mathrm{CO}_{2}$ a $60^{\circ} \mathrm{C}$ y 350 bar. Además, también se estimó la solubilidad utilizando los rendimientos predichos por el modelo planteado, así como mediante los diferentes modelos citados en la literatura (del Valle Aguilera, 1988; Özkal y col., 2005a; Machmudah y col., 2007; Westerman y col., 2006), estimándose los rendimientos mediante el uso de las diferentes solubilidades -calculadas de cada modelo-, a partir de la siguiente relación:

$M=F \times S \times t$

$Y=\frac{M}{M_{0}} \times 100$

donde:

M: masa de aceite extraído (g)

$\mathrm{F}$ : velocidad de flujo de $\mathrm{CO}_{2}\left(\mathrm{~kg} \mathrm{CO}_{2} / \mathrm{min}\right)$

S: solubilidad (g aceite/ $\mathrm{kg} \mathrm{CO}$ ) calculada a partir de los diferentes modelos de la literatura

t: tiempo de extracción (min)

Y: rendimiento (\%)

$\mathrm{M}_{0}$ : masa total de aceite contenida en la semilla determinada por Soxhlet

En este sentido, los modelos que presentaron un mejor ajuste de los datos experimentales y al modelo planteado a través del método de superficie de respuesta, fueron los descriptos en las Ec. 4.11 y 4.12 correspondientes a la aplicación de las ecuaciones planteadas por Chrastill (1982) y del Valle y Aguilera (1988), respectivamente, en la extracción de aceite de semilla de rosa mosqueta 
(Machmudah y col., 2007). El error relativo de estos modelos con respecto a los datos experimentales y los correspondientes al modelo de regresión obtenido fue < $2 \%$. Esta correspondencia podría atribuirse a la composición acídica similar que presenta el aceite de chía y el de rosa mosqueta (Rosa canina L.), el cual se caracteriza también por ser una buena fuente de ácidos grasos insaturados. En los aceites provenientes de ambas especies, los ácidos a-linolénico y linoleico representan alrededor del $85 \%$ del contenido total de ácidos grasos; sin embargo, el aceite de chía contiene un mayor tenor de ácido a-linolénico que linoleico. Esta comparación nos permite también inferir que el máximo tiempo seleccionado para realizar el análisis mediante MSR corresponde al periodo de extracción rápida o fase lineal de la extracción.

$$
\begin{aligned}
& \ln (S)=6,788 \ln (\rho)+\left(\frac{-3254}{T}\right)+(-35,17) \\
& \ln (S)=-35,19+\left(\frac{-3318}{T}\right)+\left(\frac{-19,55}{T^{2}}\right)+6,818 \ln \rho
\end{aligned}
$$

donde:
S: solubilidad $\left(\mathrm{kg} / \mathrm{m}^{3}\right)$
$\rho:$ densidad del $\mathrm{CO}_{2}\left(\mathrm{~kg} / \mathrm{m}^{3}\right)$
$\mathrm{T}$ : Temperatura $\left({ }^{\circ} \mathrm{K}\right)$

La influencia combinada de la presión y el tiempo de extracción se presenta en la Figura 4.12c. Un efecto altamente significativo $(p \leq 0,01)$ de los términos lineales de la presión y el tiempo de extracción ha sido registrado. Además, en dicha figura puede observarse el efecto significativo $(p \leq 0,05)$ del término cuadrático de la presión operativa y de la interacción presión-tiempo de extracción.

Por otra parte, el máximo rendimiento estimado mediante la Ec. 4.8 fue de $76,6 \%$ a $80^{\circ} \mathrm{C}, 450$ bar y 240 min (punto óptimo), valores correspondientes a los niveles máximos de cada una de las variables independientes dentro del rango experimental estudiado.

Ahora bien, una vez establecidas las condiciones óptimas de temperatura y presión operativas $\left(80^{\circ} \mathrm{C}, 450\right.$ bar), se realizó la curva de cinética de extracción hasta lograr un rendimiento aproximado al obtenido mediante Soxhlet, el cual fue 
alcanzado luego de 300 min de extracción (92,8\%) (Figura 4.13). Mediante la utilización de la Ec. 4.8, el rendimiento predicho para $80^{\circ} \mathrm{C}\left(\mathrm{X}_{1}=1\right), 450$ bar $\left(\mathrm{X}_{2}=1\right)$ y $300 \mathrm{~min}\left(X_{3}=1,67\right)$ es de $93,0 \%$. Si bien el tiempo de extracción de $300 \mathrm{~min}$ se encuentra fuera del rango utilizado para construir el modelo, el valor predicho mediante la Ec. 4.8. fue muy cercano al valor experimental.

Tal como fue descripto para la extracción a partir de las semillas de Argentina, y similar a lo informado en otras oleaginosas, la curva de extracción puede dividirse en un periodo de extracción inicial rápida seguido de un periodo lento de extracción. En estas condiciones, aproximadamente el $88 \%$ del aceite total de la semilla de chía se obtuvo durante el periodo rápido de extracción, el cual corresponde a los $240 \mathrm{~min}$.

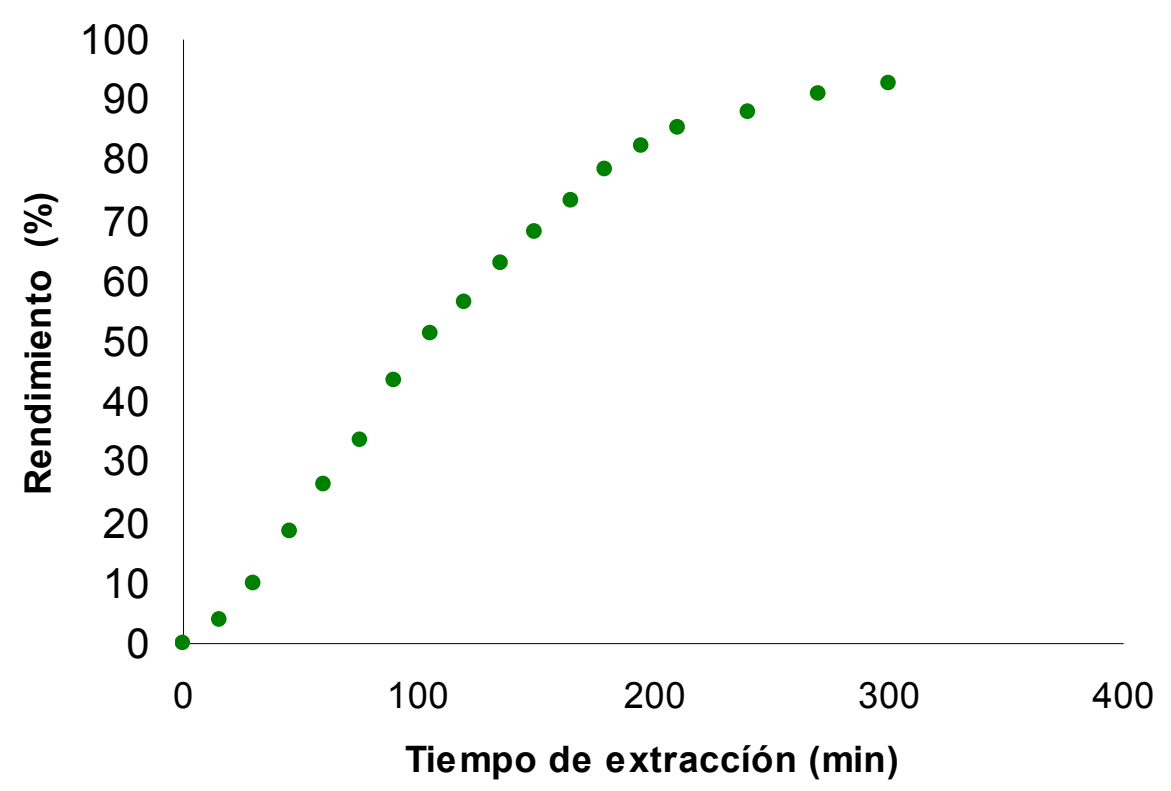

Figura 4.13. Curva de extracción de aceite de chía mediante $\mathrm{SC}-\mathrm{CO}_{2}$ a $80^{\circ} \mathrm{C}$ y $450 \mathrm{bar}$

\subsection{Análisis fisicoquímico de los aceites extraídos}

Los aceites de chía obtenidos mediante $\mathrm{SC}-\mathrm{CO}_{2}$ a diferentes condiciones de presión, temperatura y tiempo de extracción presentaron una composición acídica similar a los obtenidos mediante las otras metodologías de extracción, aunque con un rango de mayor variación según las condiciones operativas utilizadas: ácidos palmítico $(6,8-14,0 \%)$, esteárico $(2,5-13,0 \%)$, oleico $(3,9-11,1 \%)$, linoleico $(19,6-$ 
$35,8 \%$ ) y a-linolénico $(44,4-63,4 \%)$ (Tabla 4.8). En la Tabla 4.9 se presentan los resultados del ANOVA a fin de evaluar la influencia de la presión, temperatura y tiempo de extracción sobre cada uno de los ácidos grasos y las relaciones PUFAs/SFAs y $\omega-6: \omega-3$. Los resultados evidenciaron un efecto significativo ( $p \leq$ $0,05)$ del tiempo de extracción sobre el porcentaje de los ácidos linoleico y a-linolénico, así como su incidencia en la relación $\omega-6 / \omega-3$ (Tabla 4.9). Se observó un incremento en el contenido de ácido a-linolénico a tiempos de extracción prolongados mientras que el tenor de ácido linoleico fue mayor a tiempos intermedios (Figura 4.14). En este sentido, Hassan y col. (2000) encontraron que el tenor de los ácidos grasos de cadena corta disminuye con el tiempo de extracción, mientras que los ácidos grasos de cadena larga y con mayor contenido de insaturaciones presentan un comportamiento inverso en la extracción de aceite de palma. Estos autores describieron que este efecto depende de la presión operativa, ya que a elevadas presiones, la variación en la composición de ácidos grasos no fue significativa, mostrando una baja selectividad del $\mathrm{SC}-\mathrm{CO}_{2}$. Si bien el aceite de palma es rico en ácidos grasos saturados, principalmente C12:0, también contiene ácido linoleico, en un amplio rango de variación (12-30\%). Por otra parte, Özkal y col. (2005a) encontraron un amplio rango de variación en la composición acídica del aceite de avellana sugiriendo que la solubilidad de los triacilgliceroles en el SC- $\mathrm{CO}_{2}$ es el factor responsable de dicha variación. Así, los triacilgliceroles con ácidos grasos de cadena corta y baja polaridad son más solubles en el $\mathrm{SC}_{-} \mathrm{CO}_{2}$ y pueden ser fácilmente removidos de la matriz. La solubilidad de los triacilgliceroles depende de la densidad del $\mathrm{CO}_{2}$ así como del tipo de ácido graso esterificado en el glicerol. Por otra parte, Nilsson y Hudson (1993) mencionan la existencia de interacciones moleculares entre los triacilgliceroles y afirman que la información referente a la solubilidad puede tener un valor limitado para predecir el comportamiento del equilibrio líquido-vapor en sistemas multicomponentes de $\mathrm{SC}-\mathrm{CO}_{2}$ y triacilgliceroles. 
Tabla 4.8. Composición acídica (\% del total de ácidos grasos) para aceites de semilla de chía obtenidos mediante $\mathrm{SC}-\mathrm{CO}_{2}$

\begin{tabular}{|c|c|c|c|c|c|c|c|}
\hline \multirow{2}{*}{$\begin{array}{c}\mathrm{N}^{\circ} \\
\text { extracción }\end{array}$} & \multicolumn{5}{|c|}{ Ácido graso (\%) } & \multirow{2}{*}{ PUFAs/SFAs } & \multirow{2}{*}{$\omega-6 / \omega-3$} \\
\hline & C16:0 & C18:0 & C18:1 & C18:2 & C18:3 & & \\
\hline 1 & 10,1 & 2,8 & 10,3 & 28,0 & 48,8 & 5,9 & 0,57 \\
\hline 2 & 11,5 & 4,1 & 6,6 & 21,0 & 56,8 & 5,0 & 0,37 \\
\hline 3 & 10,7 & 2,5 & 7,5 & 20,0 & 59,2 & 6,0 & 0,34 \\
\hline 4 & 9,6 & 4,0 & 7,8 & 19,8 & 58,8 & 5,8 & 0,34 \\
\hline 5 & 14,0 & 5,2 & 8,9 & 20,8 & 51,1 & 3,7 & 0,40 \\
\hline 6 & 10,4 & 5,3 & 5,5 & 21,8 & 57,0 & 5,0 & 0,38 \\
\hline 7 & 11,9 & 4,1 & 11,1 & 21,5 & 51,4 & 4,6 & 0,42 \\
\hline 8 & 12,5 & 4,9 & 7,5 & 20,8 & 54,3 & 4,3 & 0,38 \\
\hline 9 & 7,5 & 13,0 & 5,3 & 30,0 & 44,4 & 3,6 & 0,67 \\
\hline 10 & 9,2 & 4,3 & 10,0 & 22,3 & 54,2 & 5,7 & 0,41 \\
\hline 11 & 6,8 & 3,1 & 7,1 & 30,5 & 52,5 & 8,4 & 0,58 \\
\hline 12 & 8,0 & 4,9 & 3,9 & 35,8 & 47,5 & 6,5 & 0,75 \\
\hline 13 & 11,4 & 4,4 & 7,6 & 20,6 & 56,1 & 4,9 & 0,37 \\
\hline 14 & 8,7 & 3,4 & 4,9 & 19,6 & 63,4 & 6,9 & 0,31 \\
\hline 15 & 10,5 & 4,5 & 6,8 & 21,8 & 56,4 & 4,2 & 0,41 \\
\hline 16 & 9,5 & 4,2 & 6,2 & 20,6 & 59,5 & 5,9 & 0,35 \\
\hline 17 & 9,8 & 4,3 & 6,4 & 20,9 & 58,6 & 5,6 & 0,36 \\
\hline 18 & 10,1 & 2,8 & 10,3 & 28,0 & 48,8 & 5,9 & 0,57 \\
\hline
\end{tabular}

C 16:0, ácido palmítico; C 18:0, ácido esteárico; C 18:1, ácido oleico; C 18:2, ácido linoleico; C 18:3, a-linolénico; SFAs, ácidos grasos saturados; PUFAs, ácidos grasos poliinsaturados; $\omega-6 / \omega-3$, linoleico/a-linolénico 
Tabla 4.9. Valor de $\mathrm{F}$ y nivel de probabilidad del efecto de la temperatura, presión y tiempo de extracción sobre la composición acídica (\% del total de ácidos grasos) del aceite de chía extraído mediante $\mathrm{SC}-\mathrm{CO}_{2}$.

\begin{tabular}{lccccccc}
\hline & C 16:0 & C 18:0 & C 18:1 & C 18:2 & C 18:3 & PUFAs/SFAs & $\boldsymbol{\omega}-\mathbf{6 / \omega - 3}$ \\
\hline Temperatura & 2,00 & 4,06 & 2,43 & 0,54 & 1,93 & 2,81 & 0,37 \\
Presión & 0,11 & 0,02 & 0,06 & 3,15 & 0,92 & 1,57 & 1,97 \\
tiempo & 4,01 & 0,68 & 3,54 & $4,63^{*}$ & $4,33^{*}$ & 0,24 & $4,32^{*}$ \\
\hline
\end{tabular}

C 16:0, ácido palmítico; C 18:0, ácido esteárico; C 18:1, ácido oleico; C 18:2, ácido linoleico; C 18:3, a-linolénico; SFAs, ácidos grasos saturados; PUFAs, ácidos grasos poliinsaturados; $\omega-6 / \omega-3$, linoleico/a-linolénico; "significativo a $p \leq 0,05$.

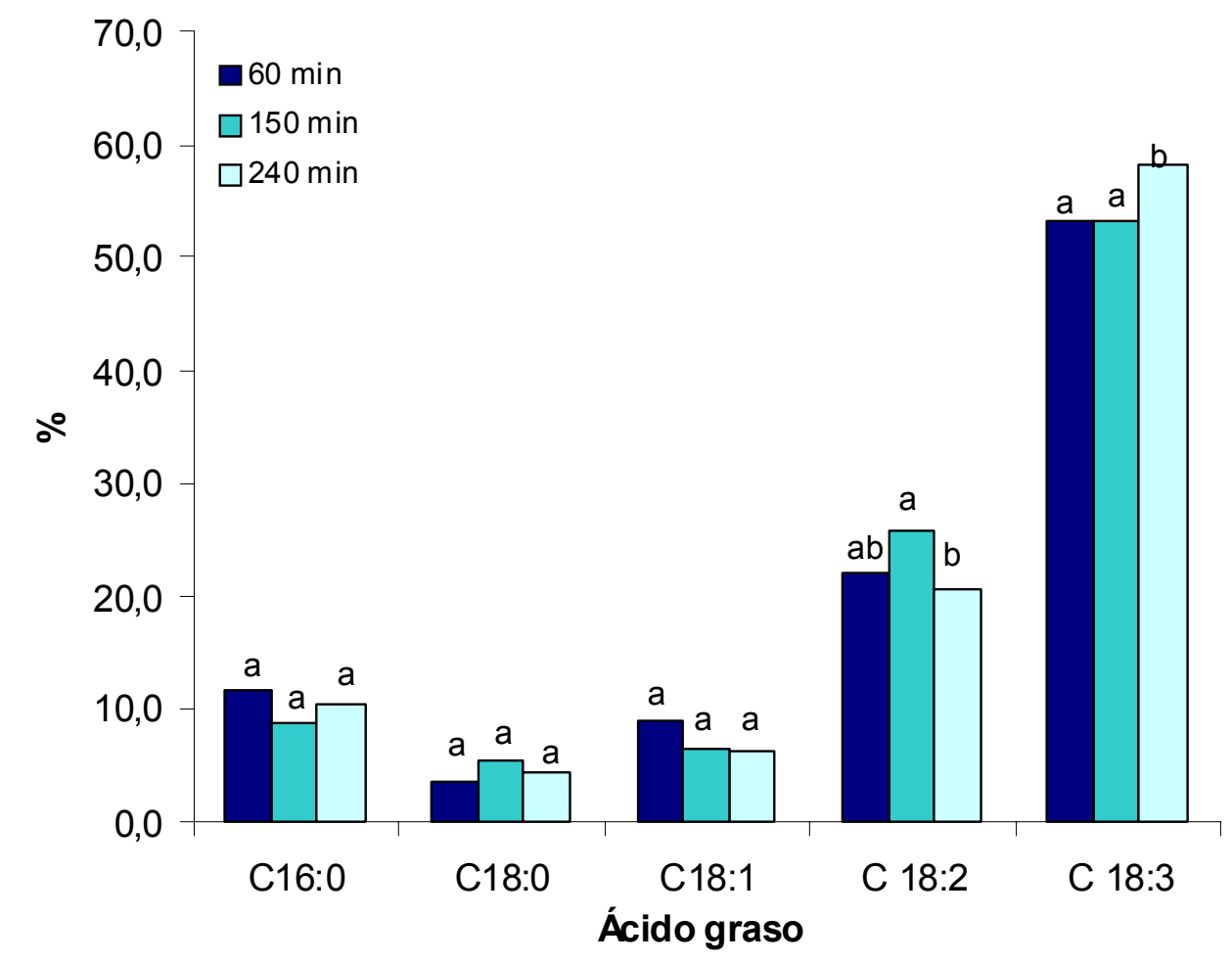

Figura 4.14. Variación de la composición acídica del aceite de chía obtenido mediante $\mathrm{SC}-\mathrm{CO}_{2}$ en función del tiempo de extracción. Letras diferentes indican que existen diferencias significativas $(p \leq 0,05)$ 
La Tabla 4.10 presenta la caracterización comparativa de la composición acídica del aceite obtenido mediante $\mathrm{SC}-\mathrm{CO}_{2}$ a $80^{\circ} \mathrm{C}, 450$ bar y 300 min $(\sim 93 \%$ del contenido total de aceite de la semilla) y el obtenido por extracción con solvente así como de las principales propiedades fisicoquímicas de los mismos. En este sentido, sólo se encontraron diferencias significativas $(p \leq 0,05)$ en el contenido de ácidos grasos libres y en el índice de peróxido, siendo similares la composición de ácidos grasos y los índices de iodo y de saponificación (Tabla 4.10). Así, el contenido de ácidos grasos libres de los aceites de chía extraídos con $\mathrm{SC}-\mathrm{CO}_{2}$ fue menor que el correspondiente a los obtenidos mediante extracción con $n$-hexano. Estos resultados son similares a los informados por Molero Gómez y Martínez de la Ossa (2002) en aceite de borraja. Algunos autores afirman que el contenido de ácidos grasos libres en los aceites extraídos mediante $\mathrm{SC}-\mathrm{CO}_{2}$ depende del tipo de semilla oleaginosa (Eggers, 1996). Panfili y col. (2003) determinaron la cantidad de ácidos grasos libres en función del tiempo de extracción en el aceite de germen de trigo registrando un incremento durante los primeros 50 min, seguidos de una posterior disminución.

Por otra parte, los bajos niveles del índice de peróxido correspondientes a los aceites extraídos por ambos procesos indican que los mismos presentaron un bajo grado de oxidación.

Tabla 4.10. Caracterización comparativa de aceites de chía obtenidos con hexano y mediante $\mathrm{SC}-\mathrm{CO}_{2}$ a $80^{\circ} \mathrm{C}, 450$ bar y $300 \mathrm{~min}$

\begin{tabular}{|c|c|c|c|c|c|c|c|c|c|}
\hline & \multicolumn{5}{|c|}{ Ácido graso } & \multirow{2}{*}{ II } & \multirow{2}{*}{ IS } & \multirow{2}{*}{ FFA } & \multirow{2}{*}{ PV } \\
\hline & C 16:0 & C 18:0 & C 18:1 & C $18: 2$ & C $18: 3$ & & & & \\
\hline Soxhlet & $9,2^{\mathrm{a}}$ & $2,9^{a}$ & $6,8^{a}$ & $19,6^{a}$ & $61,3^{a}$ & $200,3^{a}$ & $193,6^{a}$ & $1,74^{b}$ & $0,82^{b}$ \\
\hline $\mathrm{SC}-\mathrm{CO}_{2}$ & $11,5^{a}$ & $1,9^{a}$ & $4,1^{\mathrm{a}}$ & $20,9^{a}$ & $62,3^{a}$ & $202,9^{a}$ & $192,5^{\mathrm{a}}$ & $0,81^{a}$ & $0,61^{a}$ \\
\hline
\end{tabular}

C 16:0, ácido palmítico; C 18:0, ácido esteárico; C 18:1, ácido oleico; C 18:2, ácido linoleico; C 18:3, a-linolénico; SFAs, ácidos grasos saturados; PUFAs, ácidos grasos poliinsaturados; $\omega-6 / \omega-3$, linoleico/a-linolénico. Valores medios $(n=2)$ en una columna seguidos por letras diferentes indican diferencias significativas $(p \leq 0,05)$. Composición de ácidos grasos (\%); II: índice de iodo $\left(\mathrm{g} \mathrm{I}_{2} / 100 \mathrm{~g}\right.$ aceite); IS: índice de saponificación ( $\mathrm{mg} \mathrm{KOH} / \mathrm{g}$ aceite); FFA: ácidos grasos libres (mg KOH/g aceite); PV: valor de peróxidos (meq peróxido/kg aceite)

Con respecto a las propiedades reológicas, el índice de comportamiento de flujo (n) del aceite de chía calculado según la Ec. 4.2 mostró valores entre 0,9 y 1,0, los cuales permiteron considerar un comportamiento Newtoniano del aceite de chía dentro del rango de velocidad de deformación entre $10-251 \mathrm{~s}^{-1}$. La Figura 4.15 
muestra la influencia de la temperatura sobre la viscosidad del aceite de chía (ver Ec. 4.3). Las viscosidades de todos los aceites de chía extraídos tendieron a un valor de $7 \mathrm{mPa}$ s en función del incremento de la temperatura. Similares resultados fueron encontrados en aceite de girasol, canola, maíz y coco (Nik y col., 2005). El incremento de la temperatura tiende a aumentar el intercambio molecular (movimiento) y reducir las fuerzas atractivas entre las moléculas. Sin embargo, en los líquidos la reducción en las fuerzas atractivas tiene una mayor preponderancia que el aumento de intercambio molecular y así, la viscosidad disminuye con el incremento de temperatura. La Tabla 4.11 muestra la energía de activación $\left(E_{a}\right)$ y la constante A calculada a partir de la relación de tipo Arrhenius para cada uno de los extractos obtenidos. La energía de activación varió entre 5,88-6,60 kcal/mol mientras que A presentó valores comprendidos entre $2,64 \times 10^{-7}-17,4 \times 10^{-7} \mathrm{~Pa} \mathrm{~s}$. La $\mathrm{E}_{\mathrm{a}}$ es un indicador de la estabilidad de la viscosidad con la temperatura, siendo la misma inferior a menores valores de $E_{a}$. Los parámetros correspondientes a los aceites extraídos mediante Soxhlet fueron $5,96 \mathrm{kcal} / \mathrm{mol}$ y $17,0 \times 10^{-7} \mathrm{~Pa} \mathrm{~s}$, mostrando una tendencia similar a la de los obtenidos mediante $\mathrm{SC}-\mathrm{CO}_{2}$.

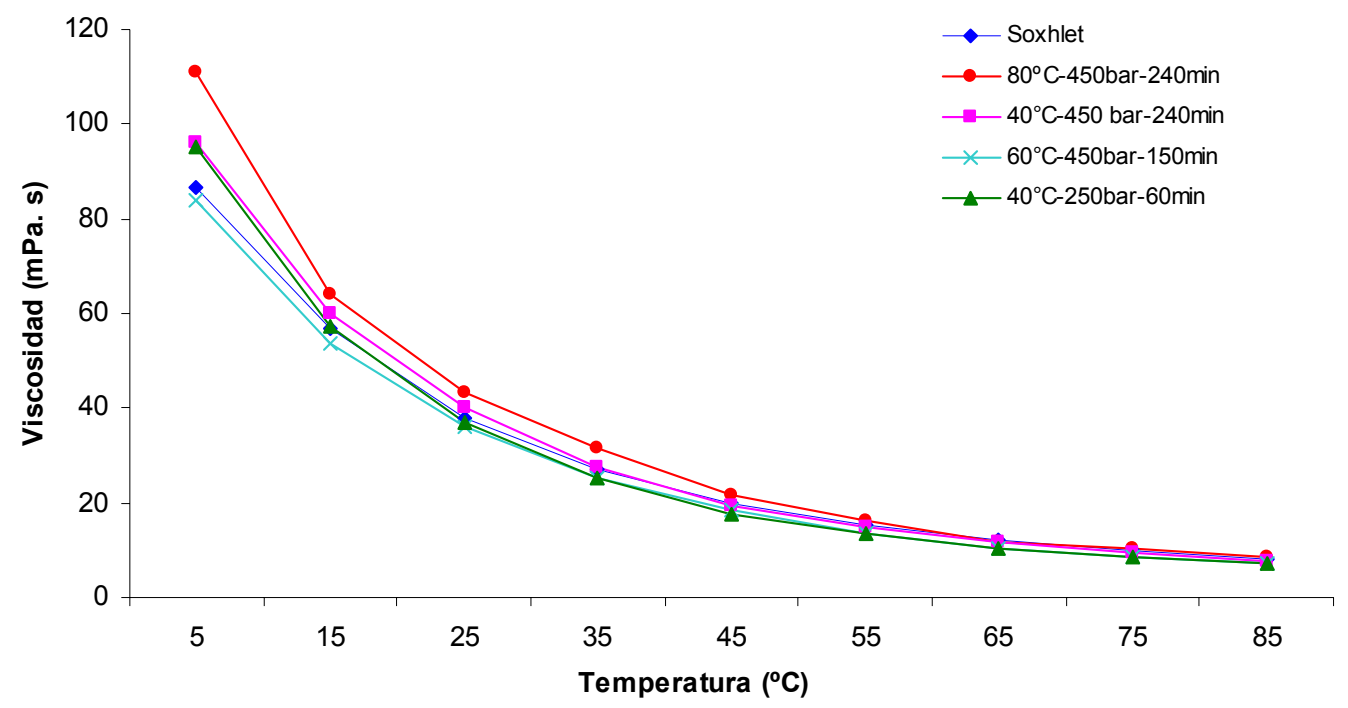

Figura 4.15. Efecto de la temperatura sobre la viscosidad del aceite de chía extraído con $\mathrm{SC}-\mathrm{CO}_{2}$ a diferentes condiciones operativas de temperatura, presión y tiempo de extracción y mediante Soxhlet. 
Tabla 4.11. Energías de activación y constante A (Ec. Arrhenius) relacionadas con la viscosidad correspondiente a los aceites de chía extraídos mediante $\mathrm{SC}-\mathrm{CO}_{2}$ bajo diferentes condiciones de temperatura, presión y tiempo de extracción

\begin{tabular}{|c|c|c|c|c|c|}
\hline $\mathrm{N}^{\circ}$ corrida & $\begin{array}{c}\text { Temperatura } \\
\text { de extracción, } \\
X_{1}\end{array}$ & $\begin{array}{c}\text { Presión de } \\
\text { extracción } \\
\qquad X_{2}\end{array}$ & $\begin{array}{c}\text { tiempo de } \\
\text { extracción } \\
\qquad X_{3}\end{array}$ & $\begin{array}{c}E_{a} \\
\text { (kcal/mol) }\end{array}$ & $\begin{array}{r}\mathrm{A} \times 10^{7} \\
(\mathrm{~Pa} \cdot \mathrm{s})\end{array}$ \\
\hline 1 & -1 & -1 & -1 & 6,60 & 5,75 \\
\hline 2 & -1 & -1 & +1 & 5,88 & 17,4 \\
\hline 3 & -1 & +1 & -1 & 6,30 & 9,61 \\
\hline 4 & -1 & +1 & +1 & 6,37 & 9,07 \\
\hline 5 & +1 & -1 & -1 & 7,04 & 2,64 \\
\hline 6 & +1 & -1 & +1 & 6,51 & 6,95 \\
\hline 7 & +1 & +1 & -1 & 6,29 & 10,3 \\
\hline 8 & +1 & +1 & +1 & 6,48 & 8,33 \\
\hline 9 & -1 & 0 & 0 & 6,28 & 10,4 \\
\hline 10 & +1 & 0 & 0 & 6,41 & 8,16 \\
\hline 11 & 0 & -1 & 0 & 6,31 & 9,26 \\
\hline 12 & 0 & +1 & 0 & 6,26 & 9,74 \\
\hline 13 & 0 & 0 & -1 & 6,32 & 9,76 \\
\hline 14 & 0 & 0 & +1 & 6,13 & 12,3 \\
\hline 15 & 0 & 0 & 0 & 6,46 & 7,75 \\
\hline
\end{tabular}




\section{CONCLUSIONES PARCIALES}

A partir de los ensayos de extracción de aceite de semillas de chía provenientes de Argentina utilizando $\mathrm{SC}-\mathrm{CO}_{2}$ se pueden enunciar las siguientes conclusiones:

- El rendimiento del aceite aumentó con el incremento de la presión operativa, siendo baja la incidencia de la temperatura de extracción sobre el mismo. El máximo rendimiento obtenido con un flujo de $8,0 \mathrm{~kg} \mathrm{CO}_{2} / \mathrm{h}$ fue de $97 \%$, siendo alcanzado a $138 \mathrm{~min}-60^{\circ} \mathrm{C}-450$ bar.

- El proceso de extracción puede ser dividido en dos periodos: rápido y lento, obteniéndose en el primero la mayor parte del aceite. Pudo observarse que la velocidad de extracción de los ácidos grasos insaturados está estrechamente vinculada con la correspondiente a la extracción global del aceite.

- La solubilidad aparente del aceite de chía -propiedad relevante del desarrollo del periodo rápido de extracción- varió entre 4,8 y $28,8 \mathrm{~g}$ aceite/ $\mathrm{kg} \mathrm{CO}_{2}$ a $60^{\circ} \mathrm{C}-250$ bar y $60^{\circ} \mathrm{C}-450$ bar, respectivamente. Por otra parte, la difusividad intrapartícula -la cual controla la velocidad de extracción en el período lento de extracción- presentó valores entre $3,04 \times 10^{-12}$ y $1,19 \times 10^{-11}$ a $60^{\circ} \mathrm{C}-250$ bar y $40^{\circ} \mathrm{C}-450$ bar, respectivamente.

- La composición acídica del aceite de chía extraído mediante la utilización de $\mathrm{SC}-\mathrm{CO}_{2}$ fue similar a la obtenida mediante extracción con Soxhlet.

- La evolución de las curvas de extracción correspondientes a los diferentes ácidos grasos brinda una información útil para entender los mecanismos de extracción y proponer condiciones para el fraccionamiento de los mismos. Así, es posible a 250 bar realizar el fraccionamiento entre los ácidos esteárico y palmítico, especialmente a $60^{\circ} \mathrm{C}$.

- La concentración de tocoferoles de los aceites extraídos mediante $\mathrm{SC}-\mathrm{CO}_{2}$ fue menor a la obtenida por la extracción con hexano, lo que se vio reflejado en una menor estabilidad oxidativa del aceite. Otros factores que podrían influir sobre la misma son el contenido de fosfolípidos, metales, ácidos grasos libres, presencia de oxígeno en el solvente de extracción. 
Con respecto a la extracción mediante $\mathrm{SC}-\mathrm{CO}_{2}$ de aceite de semillas de chía provenientes de México, se detallan a continuación las siguientes conclusiones:

- El modelo polinomial cuadrático propuesto permitió predecir el rendimiento de aceite de chía a partir de una determinada masa de semillas a un caudal constante de $\mathrm{CO}_{2}(1,8 \mathrm{~kg} \mathrm{CO} / \mathrm{h})$.

- El tiempo y la presión de extracción tuvieron una gran influencia sobre el rendimiento de aceite, seguido de las interacciones presión-temperatura, presión-tiempo y el término cuadrático de la presión. Las condiciones operativas óptimas fueron $80^{\circ} \mathrm{C}-450$ bar- $240 \mathrm{~min}$, obteniéndose un rendimiento de aceite de $88,1 \%$.

- En las condiciones óptimas de presión y temperatura $\left(450 \mathrm{bar}-80^{\circ} \mathrm{C}\right)$ y extendiendo el tiempo de extracción hasta $300 \mathrm{~min}$, se logró un rendimiento de aceite equivalente al obtenido con hexano. El aceite de chía obtenido -en dichas condiciones- presentó una composición acídica e índices de iodo y de saponificación similares, así como un menor nivel de índice de peróxido y de ácidos grasos libres.

- El tiempo de extracción tuvo influencia sobre la composición acídica de los aceites obtenidos, afectando principalmente el contenido de ácidos linoleico y $\alpha$-linolénico, así como la relación $\omega-6 / \omega-3$. Se observó un incremento en el contenido de ácido a-linolénico a tiempos de extracción prolongados mientras que el tenor de ácido linoleico fue mayor a tiempos intermedios de extracción.

- El aceite de chía extraído mediante $\mathrm{SC}-\mathrm{CO}_{2}$ presentó un comportamiento Newtoniano. La viscosidad del aceite disminuyó con el aumento de la temperatura siguiendo una relación de tipo Arrhenius.

Las conclusiones previamente expuestas permiten aceptar la hipótesis III: "El proceso de obtención tiene efecto sobre el rendimiento de aceite de chía así como sobre sus características fisicoquímicas". 


\section{DIFUSIÓN DE RESULTADOS}

Publicaciones Científicas en Revistas Internacionales

- Supercritical carbon dioxide extraction of oil from Mexican chia seed (Salvia hispanica L.): characterization and process optimization. V.Y. Ixtaina, A.Vega, S.M. Nolasco, M.C. Tomás, M. Gimeno, E. Bárzana, A. Tecante. The Journal of Supercritical Fluids (2010) 55 (1), 192-199.

- Supercritical Carbon Dioxide Extraction and Characterization of Argentinean Chia Seed Oil. Vanesa Y. Ixtaina, Facundo Mattea, Damián A. Cardarelli †, Miguel A. Mattea $\dagger$, Susana M. Nolasco, Mabel C. Tomás, Journal of the American Oil Chemists' Society (JAOCS) 2010, (en prensa)

\section{Presentaciones en Congresos con trabajo extendido}

- Estabilidad oxidativa y caracterización de antioxidantes en aceite de chía (Salvia hispanica L.) extraído mediante $\mathrm{CO}_{2}$ supercrítico. Ixtaina V, Spotorno V, Cardarelli D, Mattea M, Mateo C, Nolasco S, Tomás MC, Proceedings III Congreso Internacional de Ciencia y Tecnología de los Alimentos Córdoba 2009 (CICyTAC 2009), 15-17 abril de 2009

- Efecto de las condiciones operativas de extracción supercrítica sobre el perfil de olor en aceite de chía. Ixtaina V, Langman L, Grigioni G, Cardarelli D, Mattea M, Nolasco S, Tomás M, Proceedings III Congreso Internacional de Ciencia y Tecnología de los Alimentos Córdoba 2009 (CICyTAC 2009), 15-17 abril de 2009

- Caracterización del aceite de chía (Salvia hispanica L) extraído mediante $\mathrm{CO}_{2}$ supercrítico. Valoración como ingrediente funcional. Vanesa Y. Ixtaina, Susana M. Nolasco; Mabel C. Tomás. XVI Jornadas de Jóvenes Investigadores "La Investigación en la Universidad Latinoamericana, a 90 años de la Reforma de Córdoba", Montevideo (Uruguay), 27-29 de octubre de 2008

- Extracción de aceite de chía (Salvia hispanica L.) mediante $\mathrm{CO}_{2}$ supercrítico. Vanesa Y Ixtaina; Damián A Cardarelli; Miguel A Mattea; Susana M Nolasco; Mabel C Tomás, Proceedings XII Congreso Latinoamericano de Grasas y Aceites, Florianópolis (Brasil), 12-14 de noviembre 2007. LAAOCS 90. ISBN No 978-85-61104-00-9 
- Optimización del proceso extracción y caracterización del aceite de semillas de chía (Salvia hispanica L.) mediante $\mathrm{CO}_{2}$ supercrítico, Vanesa Y. Ixtaina, Andrea Vega, Susana M. Nolasco, Mabel C. Tomás, Miquel Gimeno, Eduardo Bárzana y Alberto Tecante, Congreso Argentino de Ingeniería Química, Mar del Plata, septiembre de 2010 
Capítulo 5

Conservación del aceite de chía.

Efecto de las condiciones de almacenamiento y de la aplicación de antioxidantes 


\section{INTRODUCCIÓN}

La oxidación de lípidos constituye uno de los procesos de deterioro de origen químico más importante de aquéllos que pueden sufrir las grasas, aceites y los alimentos que los contienen. Los sustratos de estas reacciones son fundamentalmente los ácidos grasos insaturados que, cuando están libres, se oxidan por lo general más rápidamente que cuando son parte de las moléculas de triacilgliceroles o fosfolípidos (Martínez, 2010).

Los lípidos pueden oxidarse mediante dos procesos básicos: la autooxidación y la foto-oxidación.

La autooxidación lipídica ocurre en tres etapas (Shahidi y Wanasundara, 1992), las que pueden ser resumidas a través de las siguientes ecuaciones:

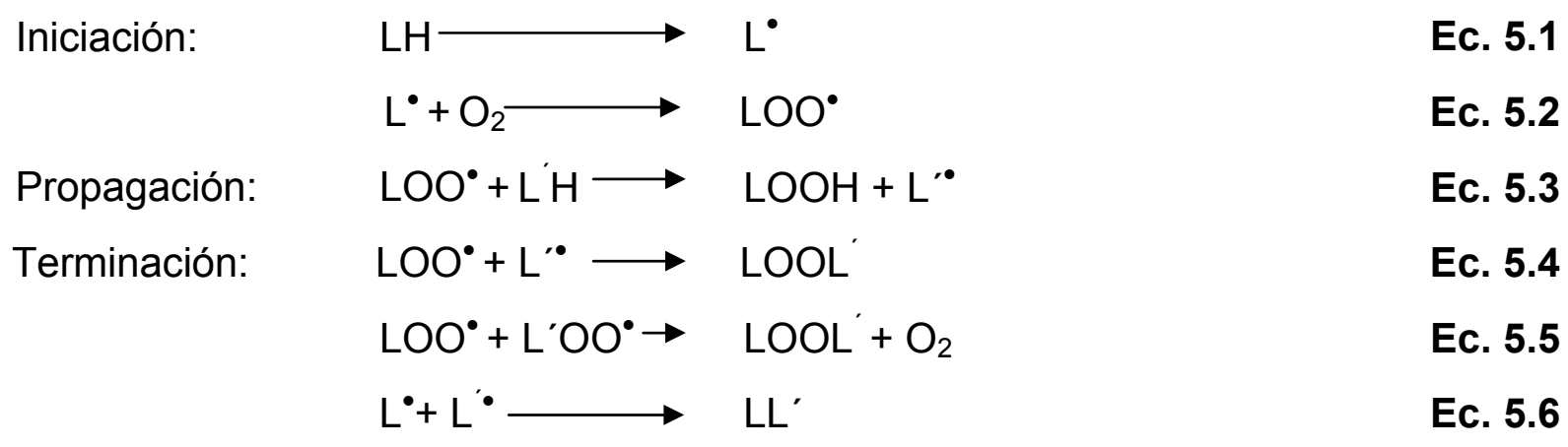

En la etapa de iniciación (Ecs. 5.1 y 5.2) el ácido graso (LH) forma radicales libres $\left(\mathrm{L}^{\circ}\right)$ los cuales reaccionan luego con el oxígeno $\left(\mathrm{O}_{2}\right)$ para formar el radical peroxilo (LOO*). La oxigenación del radical libre $\left(\mathrm{L}^{\circ}\right)$ para formar el radical peroxilo es muy rápida; así, los radicales LOO $^{\circ}$ son los productos primarios de la autooxidación.

Seguidamente, la propagación (Ec. 5.3.) involucra la continuación y aceleración del mecanismo de reacciones en cadena. En esta etapa, el radical peroxilo extrae un átomo de hidrógeno del ácido graso adyacente para originar un radical libre. El radical libre producido $\left(L^{\prime *}\right)$ puede luego oxigenarse formando un radical peroxilo, el cual acelera el ciclo de oxidación.

La terminación es la etapa en la cual los radicales libres comienzan a reaccionar entre sí, formando especies no radicalarias (Ecs. 5.4 - 5.6). Los hidroperóxidos $(\mathrm{LOOH})$ pueden descomponerse en alcoholes, aldehídos, ácidos, cetonas y otras sustancias menos reactivas. A su vez, la etapa de terminación 
completa un ciclo de autooxidación lipídica, el cual puede reiniciarse. Este proceso puede continuar sucesivamente hasta que se consume el sustrato susceptible a la oxidación.

La foto-oxidación u oxidación fotosensibilizada ocurre principalmente en alimentos a través de los siguientes mecanismos (Cuppett y col., 1997):

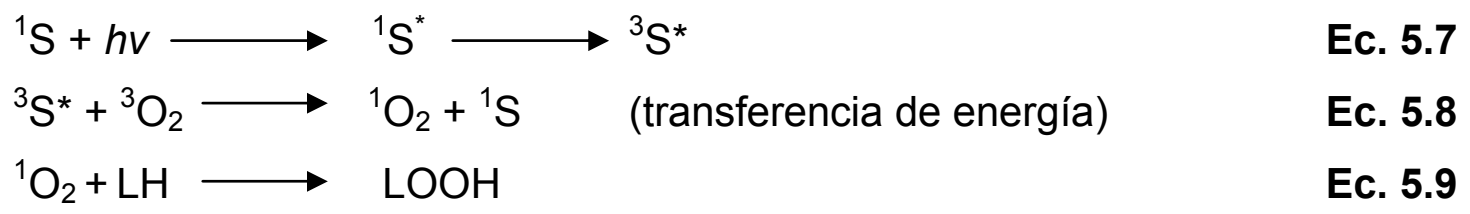

En este mecanismo, ${ }^{1} \mathrm{~S}$, un sensibilizador como la clorofila, absorbe energía ultravioleta $(h v)$ y se excita, pasando a un estado de mayor energía vibracional $\left({ }^{3} S^{*}\right)$. El sensibilizador excitado es capaz de (i) volver al estado singulete $\left({ }^{1} S\right)$ o bien (ii) transferir su energía al menor estado de energía vibracional del oxígeno $\left({ }^{3} \mathrm{O}_{2}\right)$ provocando el pasaje del oxígeno a un estado de energía vibracional mayor definido como oxígeno singulete $\left({ }^{1} \mathrm{O}_{2}\right)$ (Chan, 1977). El oxígeno singulete, siendo extremadamente electrofílico, puede atacar directamente a los ácidos grasos insaturados, debido a la alta densidad electrónica de sus dobles enlaces, resultando en un radical peroxilo y originando finalmente, hidroperóxidos. Así, la foto-oxidación constituye una reacción mucho más rápida que la autooxidación. Rawls y Van Santen (1968) han descripto que el oxígeno singulete reacciona de 1000 a 1500 veces más rápido que el oxígeno triplete.

Ahora bien, aunque existen varios factores que influyen en la oxidación de lípidos, el grado de insaturación de los ácidos grasos presentes es un factor determinante de la velocidad de oxidación; por ej. a $100^{\circ} \mathrm{C}$, las velocidades relativas de oxidación de los ácidos esteárico (C18:0), oleico (C18:1), linoleico (C18:2) y linolénico (C18:3) son 1:100:1000-1500:2000-3500, respectivamente (Frankel, 2005). Los ácidos grasos saturados sólo se oxidan a temperaturas superiores a $60^{\circ} \mathrm{C}$, mientras que los poliinsaturados lo hacen incluso durante el almacenamiento de los alimentos en estado congelado. Además, otros sustratos no saturados tales como algunos hidrocarburos presentes en los aceites (escualeno), las vitaminas A y E y los pigmentos carotenoides, pueden sufrir reacciones de oxidación. Las reacciones de oxidación tienen asociadas como consecuencias negativas una disminución de la calidad nutricional, funcional y organoléptica de los alimentos, debido a las pérdidas de ácidos grasos esenciales, vitaminas y ciertos atributos 
sensoriales (color, flavor). Además, algunos productos de oxidación son potencialmente tóxicos (Esterbauer, 1993; Dobarganes y Márquez-Ruiz, 2003).

El aceite de chía posee un elevado contenido de ácidos grasos poliinsaturados ( $>80 \%$ ), por lo que constituye un sustrato particularmente susceptible a los procesos de deterioro oxidativo. A fin de disminuir la incidencia de los mismos, una alternativa es la adición de antioxidantes. Dichos compuestos han sido descriptos como sustancias que, cuando están presentes en bajas concentraciones comparadas con las de un sustrato oxidable, retardan significativamente la oxidación del mismo (Aruoma y col., 1992). La adición de antioxidantes, en su mayor parte sintéticos, es un procedimiento tecnológico habitual en la industria alimentaria ya que mejora la estabilidad de los lípidos y prolonga la vida útil de los alimentos que los contienen. Sin embargo, cada vez es mayor la preocupación de los consumidores por la seguridad alimentaria y los potenciales efectos de los aditivos sintéticos sobre la salud. El "antioxidante ideal" debe reunir varias condiciones para ser utilizado en alimentos. Así, debe (i) ser seguro; (ii) no conferir color, olor ni sabor; (iii) ser efectivo a bajas concentraciones; (iv) permanecer luego del procesamiento; (v) ser estable en el producto final; (vi) ser soluble en la fase lipídica; (vii) tener bajo costo (Frankel, 2005).

No obstante la mayor eficiencia, el bajo costo y la alta estabilidad de los antioxidantes sintéticos en los alimentos, estos compuestos pueden actuar como promotores carcinogénicos lo que ha llevado a una disminución en su aplicación (Namiki, 1990). Desde hace algunos años, existe una tendencia hacia la utilización de antioxidantes naturales en la industria alimentaria en virtud de los requerimientos por parte de los consumidores. Los alimentos contienen ciertas sustancias preservadoras naturales, otras pueden ser adicionadas al producto o surgir como resultado del procesamiento. Recientes investigaciones se han focalizado en el aislamiento e identificación de antioxidantes de origen natural con efectiva actividad (Reische y col., 2008).

Los mecanismos por los cuales estas sustancias ejercen su actividad son diversos y la eficacia de su acción puede verse influenciada notablemente por las características del sustrato (Decker y col., 2005; Frankel, 2005). A continuación, se describirán los mecanismos de acción más importantes asociados a los antioxidantes estudiados en el presente trabajo de Tesis. 


\section{Tocoferoles}

Los tocoferoles pueden actuar como antioxidantes naturales interfiriendo en la etapa de propagación en cadena de radicales libres, actuando como donores de hidrógeno ("chain breaking" donor, CB-D) o como aceptores de radicales libres ("chain breaking" acceptor, CB-A). Este segundo mecanismo incluye el "quenching" del oxígeno singulete (Frankel, 2005).

En el mecanismo CB-D, los tocoferoles compiten efectivamente con los ácidos grasos insaturados $(\mathrm{LH})$ por el radical peroxilo ( $\left.\mathrm{LOO}^{\circ}\right)$ transfiriendo un átomo de hidrógeno al LOO` para producir LOOH el cual es más estable (Frankel, 1991). Este hecho reduce la formación de radicales lipídicos $\left(\mathrm{L}^{\circ}\right)$ que ocurren cuando el $\mathrm{LH}$ reacciona con el $\mathrm{LOO}^{\circ}$; esta competencia enlentece la etapa de propagación de la autooxidación. En el caso de los tocoferoles, cuando ocurre la transferencia de un hidrógeno resulta en la formación de una semiquinona intermedia la cual se convierte en tocoferil quinona como producto final estable.

La tocoferil quinona y posiblemente las semiquinonas pueden reaccionar con el $L^{\bullet}$ para producir LH y así, hacer más lenta la etapa de propagación en cadena. Este tipo de mecanismo es definido como CB-A y en el mismo, la tocoferil quinona compite con el oxígeno triplete por el $L^{\bullet}$ (Frankel, 1991).

Los tocoferoles también pueden actuar sobre el oxígeno singulete $\left({ }^{1} \mathrm{O}_{2}\right)$ como medio de control de la oxidación. La capacidad de los tocoferoles de atrapar al ${ }^{1} \mathrm{O}_{2}$ ocurre a través de dos mecanismos primarios: (i) mediante el "quenching" del ${ }^{1} \mathrm{O}_{2} \mathrm{y}$ (ii) reaccionando en forma irreversible con el ${ }^{1} \mathrm{O}_{2}$ para formar una variedad de productos, principalmente hidroperoxidienona (Clough y col., 1979).

Por otra parte, los tocoferoles por sí mismos son rápidamente degradados en presencia del oxígeno molecular y de radicales libres en los alimentos, perdiendo su actividad antioxidante o convirtiéndose en sustancias prooxidantes (Jung y Min, 1990). La concentración de tocoferoles influye sobre la actividad antioxidante, siendo generalmente mayor a bajas concentraciones y menor o pro-oxidante en tenores elevados (Jung y Min, 1990). En general "in vtro" se ha observado el siguiente orden de actividad antioxidante decreciente: $\delta->\gamma_{-}>\beta->\alpha$ - (Lambelet y col., 2000) Sin embargo, la potencia antioxidante de los tocoferoles puede verse afectada por diferentes factores tales como la concentración, la temperatura, la polaridad, la viscosidad y el $\mathrm{pH}$ del medio en el que se encuentran. La actividad antioxidante en 
orden inverso al enunciado anteriormente ha sido observada a bajas temperaturas (White y Xing, 1997). Los tocoferoles pueden actuar como agentes antioxidantes o prooxidantes dependiendo de las concentraciones y del sustrato en cuestión. En aceite de soja, el a-tocoferol en altas concentraciones actúa como un agente prooxidante durante la oxidación lipídica produciendo un incremento de los niveles de hidroperóxidos y de dienos conjugados (Jung y Min, 1990), aunque incrementa su habilidad para inhibir la formación de hexanal (Frankel, 2005). Kamal-Eldin y Appelqvist (1996) han determinado que los tocoferoles no son prooxidantes "per se", sino que pueden actuar de manera sinérgica cuando están presentes en altas concentraciones con compuestos prooxidantes conocidos, tales como iones de metales de transición, peróxidos lipídicos y otros agentes antioxidantes. Podría asumirse que a mayores concentraciones de tocoferoles en los lípidos también son más elevadas las cantidades de radicales intermediarios formados a partir de la oxidación de los tocoferoles durante su almacenamiento. Estos compuestos intermediarios tales como los radicales alquilo, alcoxilo y peroxilo pueden iniciar el proceso de oxidación lipídica.

\section{Extracto de romero (Rosmarinus officinalis L.)}

El extracto de romero es obtenido a partir de las hojas de Rosmarinus officinalis L. Los antioxidantes presentes en el mismo (ácido carnósico, carnosol, rosmanol, epirosmanol e isorosmanol) han sido utilizados durante décadas en el procesamiento de alimentos. Actualmente, se encuentran en el mercado extractos concentrados desodorizados, los que no imparten sabor o color a los alimentos. Estos antioxidantes son más costosos que los de origen sintético y en general pueden requerir niveles de uso mayores, pero no registran cuestionamientos desde el punto de vista toxicológico, a las dosis recomendadas.

Cabe señalar que si bien el ácido carnósico y el carnosol son los responsables de más del $90 \%$ de la actividad antioxidante del romero (Aruoma y col., 1992), es necesario tener en cuenta que el primero de dichos compuestos es relativamente inestable. Schwarz y Ternes (1992) han estudiado la estabilidad del mismo habiendo detectado su rápida conversión a carnosol, el que se transforma subsecuentemente en rosmanol, 7-metilepirosmanol y epirosmanol, lo cual está facilitado por la exposición al oxígeno en presencia de luz y por el calentamiento del ácido carnósico en presencia de metanol. Debido a que muchos procesos 
comerciales para producir extractos de romero involucran tratamientos térmicos en presencia de solventes, podría esperarse una significativa conversión del ácido carnósico a carnosol. De esta manera, si bien pueden ser deseables mayores niveles de carnosol debido a su mayor establilidad, es necesario considerar paralelamente su menor actividad.

\section{Extracto de té verde (Camellia sinensis L.)}

El té es una bebida obtenida a partir de la especie Camellia sinensis L. Los compuestos activos del té son los flavonoides, un tipo de compuestos polifenólicos que poseen propiedades antioxidantes entre los que se encuentran las catequinas, teaflavinas y tearubiginas. Las catequinas son los principales constituyentes de las hojas del té verde, aunque también están presenten en el té Oolong y el té negro, mientras que las tearubiginas y las teaflavinas se encuentran sólo en estos últimos (Frankel, 2005).

El polifenol más abundante en el té verde es el (-)- galato de epigalocatequina (EGCG), aunque también se han identificado otras catequinas tales como la (-)epicatequina (EC), (-)-galato de epicatequina (ECG) y (-)-epigalocatequina (EGC) (Figura 5.1).<smiles>Oc1cc(O)c2c(c1)O[C@H](c1ccc(O)c(O)c1)[C@H](O)C2</smiles>

(-)- epicatequina (EC)<smiles>Oc1cc(O)c2c(c1)O[C@H](c1cc(O)c(O)c(O)c1)[C@H](O)C2</smiles>

(-) - epigalocatequina (EGC)<smiles>O=C(O[C@H]1Cc2c(O)cc(O)cc2O[C@H]1c1ccc(O)c(O)c1)c1cc(O)c(O)c(O)c1</smiles>

(-) - galato de epicatequina (ECG)<smiles>O=C(O[C@H]1Cc2c(O)cc(O)cc2O[C@H]1c1cc(O)c(O)c(O)c1)c1cc(O)c(O)c(O)c1</smiles>

(-) - galato de epigalocatequina (EGCG)

Figura 5.1. Estructura de las catequinas presentes en el té verde (Valenzuela 2004) 
Las catequinas con grupos hidroxilos libres pueden actuar como secuestrantes de radicales libres y podrían también retrasar su formación. Las catequinas que poseen múltiples grupos hidroxilos en su estructura química, cuando los mismos se encuentran en configuración orto, pueden también participar en la quelación de iones metálicos, además de sus efectos como secuestrantes de radicales libres (Ho y col., 1997).

\section{Palmitato de ascorbilo}

El palmitato de ascorbilo es un derivado sintético del ácido ascórbico (Figura 5.2). El mismo ha sido utilizado en sistemas que contienen grasas ya que su solubilidad en medios hidrofóbicos es superior a la que presenta el ácido ascórbico y sus sales, siendo frecuentemente empleado en combinación con tocoferoles. El palmitato de ascorbilo es considerado GRAS (generally recognized as safe) y en Estados Unidos, no se han fijado aún restricciones sobre sus niveles de uso. Este antioxidante es hidrolizado en el sistema digestivo para proveer ácidos ascórbico y palmítico, nutricionalmente disponibles (Johnson, 1995).<smiles>O=C1OC(C(O)CO)C(O)=C1O</smiles>

Acido ascórbico

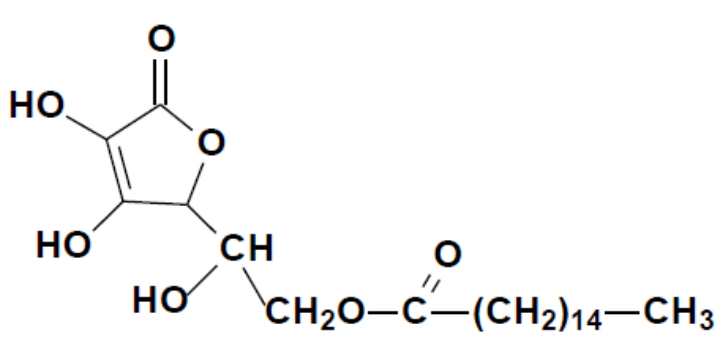

Palmitato de ascorbilo

Figura 5.2. Estructura del ácido ascórbico y del palmitato de ascorbilo

El ácido ascórbico puede funcionar como dador de átomos de hidrógeno, siendo capaz de atrapar radicales libres convirtiendo directamente los hidroperóxidos en productos estables. En alimentos, el ácido ascórbico tiene múltiples funciones: puede interceptar el oxígeno singulete, desplazar el potencial redox de los sistemas alimentarios al rango reductor, actuar en forma sinérgica con agentes quelantes y regenerar antioxidantes primarios tales como el tocoferol (Reische y col., 2008). Los radicales tocoferilos son reducidos a tocoferol mediante el ácido ascórbico (Figura 5.3). Se ha sugerido que dicho compuesto no debe ser sometido a elevadas temperaturas ni a la exposición de la luz (Frankel, 2005). 


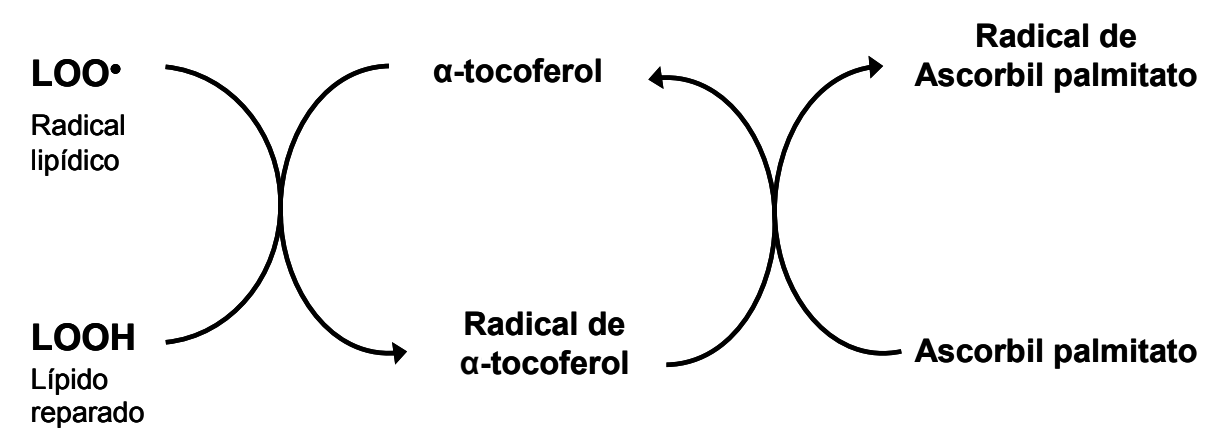

Figura 5.3. Desaparición del a-tocoferol y del ácido ascórbico durante la oxidación del linoleato de metilo (Niki, 1987)

A partir de numerosas evidencias científicas como las reseñadas anteriormente, la valoración del efecto antioxidante de las diversas sustancias ensayadas a tal fin, constituye un aspecto de la investigación de índole empírica. Por otra parte, es escasa la información disponible con respecto a la evaluación de distintas alternativas relacionadas con la conservación del aceite de chía.

En este capítulo se propone evaluar la acción de ciertos antioxidantes naturales (extractos de romero y de té verde, tocoferoles) y sintéticos (palmitato de ascorbilo) y de diferentes combinaciones de los mismos, sobre el deterioro oxidativo del aceite de chía. Asimismo, se estudiará la conservación del aceite con y sin la adición de los antioxidantes previamente mencionados, mediante su almacenamiento a distintas condiciones de temperatura. 


\section{MATERIALES Y MÉTODOS}

\section{Aceite y antioxidantes utilizados}

El aceite de chía objeto de este estudio fue provisto por Nutracéutica Sturla S.R.L. (Argentina), el cual fue obtenido por primera prensada en frío. A tal fin, se determinó la composición de ácidos grasos y el contenido de tocoferoles, según lo descripto en el Capítulo 3.

La mezcla de tocoferoles fue provista por DSM Nutritional Products Ltd. presentando una composición de aproximadamente $97 \%$ de tocoferoles $(\gamma-64 \%, \delta$ $24 \%, \alpha-8 \%$ y $1 \%$ de $\beta$-tocoferol) y $3 \%$ de otros compuestos.

Los extractos de romero (Guardian ${ }^{\mathrm{TM}} 08$ ) y de té verde (Guardian ${ }^{\mathrm{TM}}$ 20S/20M) así como el palmitato de ascorbilo (Grindox ${ }^{\mathrm{TM}} 562$ ) fueron suministrados por Danisco. El extracto de romero utilizado (oleosoluble) está compuesto por $4 \%(p / p)$ de diterpenos fenólicos y un vehículo constituido por mono- y diacilgliceroles; ésteres de ácido acético de mono y diacilgliceroles y propilenglicol. El extracto de té verde empleado ha sido obtenido y purificado a partir de hojas de $C$. sinensis y está compuesto por aproximadamente $20 \%$ de catequinas, con maltodextrina y sal como vehículo. Grindox ${ }^{\mathrm{TM}} 562$ es un antioxidante soluble en grasas y aceites constituido por una mezcla de $10 \%$ de palmitato de ascorbilo y $90 \%$ de un "carrier" compuesto por propilen glicol y monoleato de sorbitán como agente emulsificante.

\section{Ensayo de estabilidad oxidativa acelerada mediante Rancimat}

Preparación de las muestras

Los extractos de romero y de té verde, los tocoferoles y las mezclas de extracto de romero: tocoferoles (1:1), extracto de romero: extracto de té verde (1:1), extracto de té verde: tocoferoles (1:1) así como el palmitato de ascorbilo fueron adicionados al aceite de chía en las siguientes concentraciones del producto comercial: $250,500,1000,1500,2500$ y 5000 ppm.

Se prepararon las correspondientes soluciones madre de tocoferoles, extracto de romero y palmitato de ascorbilo en una relación antioxidante: aceite de chía 1:10.

Debido a la baja solubilidad del extracto de té verde en el aceite de chía, la solución madre fue obtenida mediante la preparación de una emulsión constituida por una fase acuosa (extracto de té verde) dispersa en el aceite de chía mediante monooleato de sorbitán como agente emulsificante en una concentración de 0,2\% $(\mathrm{p} / \mathrm{p})$ respecto a la masa del aceite $(\mathrm{g})$. 
Las concentraciones previamente mencionadas fueron alcanzadas mediante el agregado de la cantidad correspondiente de solución madre al aceite de chía de manera de lograr una masa final de $20 \mathrm{~g}$. Después de una adecuada agitación, todas las muestras fueron almacenadas en frascos color ámbar en atmósfera de nitrógeno a $4 \pm 1^{\circ} \mathrm{C}$ hasta su uso, al igual que las muestras control (aceite sin agregado de antioxidantes).

\section{Ensayo acelerado de estabilidad oxidativa}

Las distintas muestras fueron sometidas a un ensayo acelerado de oxidación en un equipo Rancimat (679 Metrohm, Suiza) (AOCS Cd 12b-92, 1998), tal como fue descripto en el Capítulo 3. Las condiciones empleadas fueron las siguientes: $5 \mathrm{~g}$ de aceite, $98^{\circ} \mathrm{C}$, flujo de aire $(20 \mathrm{~L} / \mathrm{h})$. Las determinaciones fueron realizadas por triplicado. Se calculó el factor de protección (FP) empleando la siguiente ecuación:

$\mathrm{FP}=\frac{\text { tiempo de induccion del aceite con antioxidante }(\mathrm{h})\left(\mathrm{t}_{\mathrm{ia}}\right)}{\text { tiempo de induccion del aceite } \sin \text { antioxidante }(\mathrm{h})\left(\mathrm{t}_{\mathrm{ic}}\right)}$

Ec. 5.10

\section{Estudio de la oxidación de aceite de chía mediante calorimetría diferencial de barrido (DSC)}

Debido a que la autooxidación lipídica es un proceso exotérmico, los métodos de análisis térmico son una herramienta valiosa para estudiar la termoestabilidad, termooxidación y autooxidación (Litwinienko y col., 1999). Estudios no isotérmicos de DSC pueden brindar una interesante información debido a que es un método simple, rápido y sensible que requiere pequeñas cantidades de muestra (2-10 mg).

El estudio de DSC se llevó a cabo en un calorímetro diferencial de barrido Q 100 (TA Instruments) sobre diversos sistemas: aceite control (aceite de chía sin adición de antioxidantes), aceite de chía con 2500 ppm de extracto comercial de romero, 2500 ppm de extracto de té verde, 1500 ppm de tocoferoles y 2500 ppm de de palmitato de ascorbilo.

Se pesaron aproximadamente $5 \mathrm{mg}$ de las distinas muestras, las cuales fueron colocadas en una cápsula de aluminio y sometidas a un tratamiento térmico a distintas velocidades $\left(\beta=5,10,15\right.$ y $20^{\circ} \mathrm{C} / \mathrm{min}$ ) realizando un barrido desde 10 a $350^{\circ} \mathrm{C}$, bajo un flujo de oxígeno de $100 \mathrm{~mL} / \mathrm{min}$. Simon y col. (2000) han informado que las velocidades de calentamiento no deberían exceder $20-25^{\circ} \mathrm{C} / \mathrm{min}$ ya que por 
encima de dicho valor la temperatura de la muestra sería distinta a la temperatura del horno, lo cual constituye un requisito para aplicar posteriormente los modelos que permiten calcular los parámetros cinéticos.

Las temperaturas extrapoladas correspondientes al inicio de la oxidación ( $\left.T_{e}\right)$ así como las temperaturas máximas de los picos $\left(T_{p 1}\right.$ y $\left.T_{p 2}\right)$ fueron determinadas -en cada caso- utilizando el programa TA Universal Analysis 2000 (versión 4.2E).

\section{Ensayo de almacenamiento}

Preparación de las muestras

A fin de evaluar la estabilidad del aceite de chía frente a la oxidación, se llevó a cabo un ensayo de almacenamiento a dos niveles de temperatura habitualmente empleados por parte del consumidor, temperatura ambiente $\left(T=20 \pm 2^{\circ} \mathrm{C}\right)$ y refrigeración $\left(T=4 \pm 1^{\circ} \mathrm{C}\right)$, con el agregado de distintos antioxidantes naturales (extractos de romero y de té verde) y un antioxidante sintético (palmitato de ascorbilo). Dichos sistemas fueron seleccionados en base al estudio acelerado de estabilidad oxidativa previamente comentado teniendo en cuenta las normativas vigentes (Código Alimentario Argentino (CAA) y Codex Alimentarius). Las concentraciones ensayadas de los productos comerciales correspondientes a los antioxidantes naturales fueron 500 y 2500 ppm y 2500 ppm de palmitato de ascorbilo. Debido a que el almacenamiento de los aceites vegetales en envases de vidrio sin la incidencia directa de la luz (color ámbar) es más adecuado frente a procesos de oxidación lipídica, en el presente trabajo de Tesis el estudio del efecto del almacenamiento de aceite de chía fue llevado a cabo en envases con dichas características. En la Tabla 5.1. se resumen los tratamientos utilizados.

Para ello, se prepararon las respectivas soluciones madre del aceite con cada antioxidante, según lo descripto en la sección 2.2 del presente Capítulo.

Seguidamente, $2,5 \mathrm{~kg}$ de aceite de chía fueron adicionados con el respectivo antioxidante con agitación mientras se realizó el fraccionamiento en los frascos de vidrio color ámbar de $30 \mathrm{~mL}$ de capacidad, con ausencia de una cámara de aire. Posteriormente, la mitad de los envases del lote fueron almacenados a $4 \pm 1^{\circ} \mathrm{C}$, mientras que los restantes se colocaron en un cuarto de temperatura controlada a $20 \pm 2^{\circ} \mathrm{C}$ durante un periodo de alrededor de 7 meses, realizándose periódicamente 
las respectivas tomas de muestra (c/ 15 días) por duplicado para su posterior análisis.

Tabla 5.1. Diseño experimental correspondiente al estudio del efecto de las condiciones de almacenamiento y la aplicación de antioxidantes en la conservación del aceite de chía

\begin{tabular}{|c|c|c|c|}
\hline $\mathrm{T}\left({ }^{\circ} \mathrm{C}\right)$ & Sistema & $\begin{array}{c}t \\
\text { (días) }\end{array}$ & Código \\
\hline \multirow{6}{*}{4} & Control & $0-225$ & CF \\
\hline & $\begin{array}{l}\text { Aceite de chía + Extracto de romero } \\
\qquad(500 \mathrm{ppm})\end{array}$ & $0-225$ & R500F \\
\hline & $\begin{array}{l}\text { Aceite de chía + Extracto de romero } \\
\qquad(2500 \mathrm{ppm})\end{array}$ & $0-225$ & R2500F \\
\hline & $\begin{array}{l}\text { Aceite de chía + Extracto de té } \\
\text { verde }(500 \text { ppm })\end{array}$ & $0-225$ & T500F \\
\hline & $\begin{array}{c}\text { Aceite de chía + Extracto de té } \\
\text { verde }(2500 \text { ppm })\end{array}$ & $0-225$ & T2500F \\
\hline & $\begin{array}{l}\text { Aceite de chía + Palmitato de } \\
\text { ascorbilo (2500 ppm) }\end{array}$ & $0-225$ & P2500F \\
\hline \multirow{6}{*}{20} & Control & $0-225$ & CA \\
\hline & $\begin{array}{l}\text { Aceite de chía + Extracto de romero } \\
\qquad(500 \text { ppm })\end{array}$ & $0-225$ & R500A \\
\hline & $\begin{array}{l}\text { Aceite de chía + Extracto de romero } \\
\qquad(2500 \mathrm{ppm})\end{array}$ & $0-225$ & R2500A \\
\hline & $\begin{array}{c}\text { Aceite de chía + Extracto de té } \\
\text { verde }(500 \mathrm{ppm})\end{array}$ & $0-225$ & T500A \\
\hline & $\begin{array}{c}\text { Aceite de chía + Extracto de té } \\
\text { verde }(2500 \mathrm{ppm})\end{array}$ & $0-225$ & T2500A \\
\hline & $\begin{array}{l}\text { Aceite de chía + Palmitato de } \\
\text { ascorbilo ( } 2500 \text { ppm) }\end{array}$ & $0-225$ & P2500A \\
\hline
\end{tabular}

\section{Análisis de las muestras}

A fin de realizar el seguimiento del proceso de oxidación lipídica, cabe señalar la importancia de la determinación de los compuestos representativos de los cambios primarios (hidroperóxidos) y secundarios (aldehídos, cetonas, etc) relacionados con el posible desarrollo del proceso comentado. En este sentido, se determinaron periódicamente el índice de peróxido (ver Capítulo 1) y el valor de $p$ anisidina durante el almacenamiento en las condiciones previamente comentadas. 
El índice de peróxido permite evaluar los cambios primarios de la oxidación lipídica mientras que el valor de $p$-anisidina está asociado a los productos secundarios originados por la descomposición de los productos primarios presentes en cada sistema.

El valor de $p$-anisidina ( $p$-AV) se define por convención como 100 veces la densidad óptica medida a $\lambda=350 \mathrm{~nm}$ en una cubeta de $1,0 \mathrm{~cm}$ de solución conteniendo $1,0 \mathrm{~g}$ de aceite en $100 \mathrm{~mL}$ de mezcla de solvente y reactivo, de acuerdo al método Cd 18-90 AOCS (1998). Este método determina la cantidad de aldehídos (principalmente 2-alquenal y 2,4-alcadienales) presentes en grasas animales y aceites vegetales mediante la reacción de los compuestos aldehídicos presentes en el aceite y la $p$-anisidina en una solución de ácido acético, midiendo posteriormente la absorbancia a $350 \mathrm{~nm}$. List y col. (1974) han informado una correlación altamente significativa entre el valor de $p$-anisidina y los resultados asociados a la aceptabilidad del sabor de aceites de soja para ensaladas. Dicho valor se calcula según la Ec. 5.11.

$p-A V=\frac{25 \times(1,2 A s-A b)}{m}$

donde:

As: absorbancia de la fase lipídica después de la reacción con la $p$-anisidina Ab: absorbancia de la fase lipídica antes de la reacción con la $p$-anisidina M: masa de la muestra (g)

Luego se calculó el valor total de oxidación (Totox), el cual se define como:

Totox $=2 \mathrm{PV}+\mathrm{p}-\mathrm{AV}$

Este valor tiene la ventaja de combinar evidencia sobre la historia pasada de un aceite (reflejado a través del valor de $p$-anisidina) con su estado presente (evidenciado mediante el PV). Así, la determinación del valor Totox ha sido llevada a cabo extensivamente para estimar el deterioro oxidativo de diversos alimentos grasos (Rossell, 1983).

Además, se determinó el contenido de ácidos grasos libres según la técnica de la AOCS, descripta en el Capítulo 3. 


\section{Análisis estadístico}

En el ensayo de estabilidad oxidativa acelerada mediante Rancimat, se realizaron dos ANOVA unifactoriales con el fin de analizar: i) el efecto de la concentración para un determinado antioxidante o mezcla de los mismos (factor de variación= concentración); ii) el efecto del tipo de antioxidante y/o mezcla de los mismos para una concentración dada (factor de variación= antioxidante). En aquellos casos donde se observaron diferencias estadísticamente significativas ( $p \leq$ 0,05), se utilizó a posteriori un test de comparaciones múltiples (Tukey).

Para el ensayo de almacenamiento del aceite de chía, los resultados obtenidos a $4 \pm 1^{\circ} \mathrm{C}$ y $25 \pm 2^{\circ} \mathrm{C}$ fueron analizados en forma independiente. En cada caso, se realizaron las comparaciones de medias entre los distintos sistemas estudiados mediante un ANOVA unifactorial (factor de variación= sistema). Además, se realizó un ANOVA unifactorial a fin de realizar la comparación de medias para cada sistema a lo largo del tiempo (factor de variación=tiempo).

\section{RESULTADOS Y DISCUSIÓN}

Diferentes autores han estudiado la estabilidad oxidativa de los lípidos presentes en alimentos a través de una variedad de metodologías, en un amplio rango de condiciones experimentales. Para ello, es necesario la aplicación de diversos métodos complementarios a fin de determinar la contribución de los productos de la oxidación formados en distintas etapas del proceso de deterioro de los alimentos (Frankel, 2005; Kamal-Eldin y Pokorný, 2005).

La efectividad de los antioxidantes para proteger a los alimentos frente a los procesos oxidativos depende de una serie de fenómenos complejos relacionados con el estado físico de los sustratos lipídicos, las condiciones de oxidación y los métodos utilizados para realizar el seguimiento de la misma. Por tal motivo, una correcta interpretación de la acción de los antioxidantes debe contemplar su evaluación bajo distintas condiciones, así como realizar la determinación de los diversos productos de la oxidación en el alimento (Frankel, 2005). 


\section{Ensayo de estabilidad oxidativa acelerada mediante RANCIMAT}

El análisis del efecto de antioxidantes sobre la estabilidad oxidativa del aceite de chía fue realizado evaluando los respectivos tiempos de inducción ( $\left.\mathrm{t}_{\mathrm{i}}\right)$, los cuales fueron determinados mediante un equipo Rancimat. Esta metodología ha sido desarrollada como una variante automatizada del método AOM (Active Oxygen Method) para la determinación del tiempo de inducción de grasas y aceites. El método Rancimat está avalado por diferentes normativas nacionales e internacionales (AOCS Cd 12b-92 e ISO 6886) (Metrohm Ionenanalytik, 2001), siendo utilizado frecuentemente para evaluar la eficiencia de antioxidantes sintéticos o naturales en la estabilización de aceites vegetales y grasas mediante un ensayo acelerado de oxidación (Verleyen y col., 2005).

Las principales características del aceite de chía comercial utilizado en el ensayo de oxidación acelerada mediante Rancimat se presentan en la Tabla 5.2.

Tabla 5.2. Características químicas del aceite de chía Sturla ${ }^{\circledR}$ utilizado en el ensayo de oxidación acelerada mediante Rancimat

\begin{tabular}{lc}
\hline Ácido graso (\%) & \\
Palmítico & 6,9 \\
Esteárico & 2,7 \\
Oleico & 6,4 \\
Linoleico & 20,3 \\
a-linolénico & 63,6 \\
Tocoferoles totales ( $\mu$ g/g aceite) & 416 \\
$\mathbf{t}_{\mathbf{i}}$ (Rancimat, $\left.\mathbf{h}\right)$ & 2,6 \\
\hline
\end{tabular}

En la Figura 5.4 se muestra el efecto de las distintas concentraciones de cada uno de los antioxidantes estudiados sobre la estabilidad oxidativa del aceite de chía. Los resultados obtenidos $\left(\mathrm{t}_{\mathrm{i} a} / \mathrm{t}_{\mathrm{ic}}\right)$ permitieron observar que el agregado de antioxidantes naturales aumentaron el $t_{i}$ del aceite de chía en todos los casos, dependiendo su extensión del tipo y concentración del antioxidante utilizado. El agregado de concentraciones crecientes de tocoferoles produjo un aumento significativo $(p \leq 0,05)$ del factor de protección hasta una concentración de 1500 ppm, en la cual se alcanzó un tia dos veces mayor al valor correspondiente al sistema control. Concentraciones superiores (2500 y 5000 ppm) también registraron 
incrementos significativos en el $t_{i}$, aunque de menor magnitud, los cuales fueron de 34 y $32 \%$, respectivamente. Las concentraciones de 250, 500 y 1000 ppm aumentaron el $t_{i}$ en 18,45 y $78 \%$, respectivamente.

Por otra parte, la adición de extracto de romero al aceite de chía evidenció aumentos crecientes en el tia hasta la máxima concentración estudiada (5000 ppm), en este caso 3,38 veces mayor que el $t_{i a}$ correspondiente al aceite control. Concentraciones entre 250 y 2500 ppm también presentaron diferencias significativas $(p \leq 0,05)$ con respecto al aceite control, si bien no se registraron diferencias significativas $(p>0,05)$ entre ellas, con aumentos del $t_{i}$ de alrededor de 39 y $53 \%$, respectivamente.

Paralelamente, mediante el agregado de extracto de té verde, el máximo $t_{i}$ fue alcanzado a la mayor concentración ensayada (5000 ppm), el cual fue 2,6 veces el $t_{i}$ del control, presentando diferencias significativas $(p \leq 0,05)$ con respecto al resto de las concentraciones estudiadas. La menor concentración ensayada (250 ppm) no mostró diferencias significativas $(p>0,05)$ mientras que niveles de 500 ppm evidenciaron aumentos significativos $(p \leq 0,05)$ de 1,45 veces con respecto al $t_{i c}$ del control.

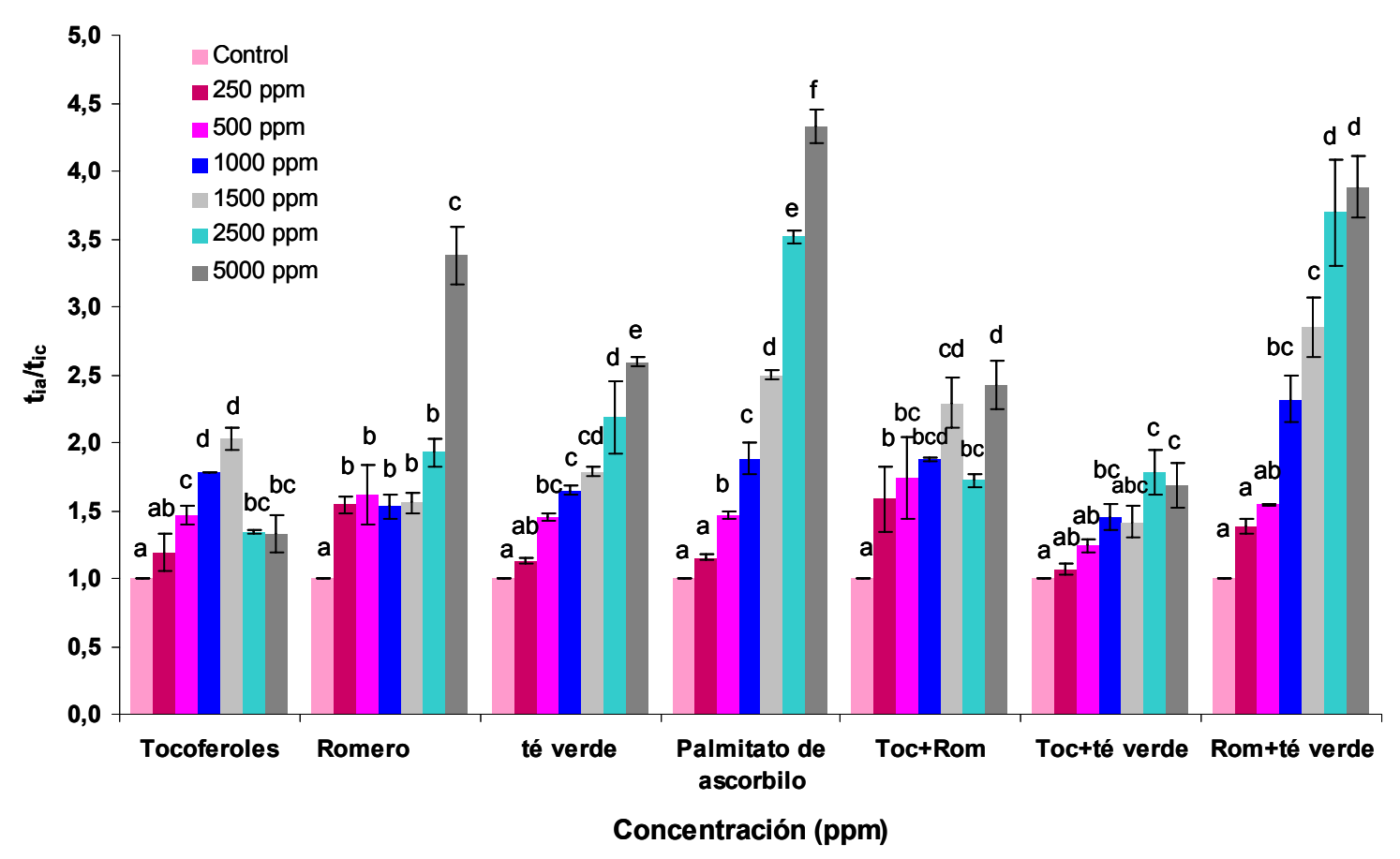

Figura 5.4. Efecto de la concentración de antioxidantes sobre la estabilidad oxidativa del aceite de chía. Las barras verticales indican la desviación estándar. Letras distintas indican diferencias significativas $(p \leq 0,05)$ entre concentraciones para un mismo antioxidante o mezcla de los mismos 
El palmitato de ascorbilo presentó diferencias significativas $(p \leq 0,05)$ con respecto al control a partir de $500 \mathrm{ppm}$, observándose incrementos significativos ( $\mathrm{p} \leq$ $0,05)$ en la estabilidad oxidativa del aceite de chía en función del aumento de la concentración, por ejemplo, $t_{i a} / t_{i c}=4,33$ a 5000 ppm. Estos resultados podrían atribuirse a la interacción del palmitato de ascorbilo con los tocoferoles naturales presentes en el aceite de chía. En este sentido, Reische y col. (2008) informaron que el ácido ascórbico tiene la capacidad de regenerar ciertos antioxidantes primarios como el tocoferol, además de tener otras múltiples funciones como antioxidante, tales como interceptar el oxígeno singulete, desplazar el potencial redox de los sistemas alimentarios al rango reductor y actuar sinérgicamente con agentes quelantes.

Con respecto a las mezclas de antioxidantes, la combinación de tocoferoles y extracto de romero (1:1), alcanzó los mayores $t_{i a}$ a 1500 y 5000 ppm, los cuales fueron 2,29 y 2,42 veces el $t_{i c}$ del control. El resto de las concentraciones $(250,500$, 1000 y 2500 ppm) no presentaron diferencias estadísticamente significativas entre ellas ( $p>0,05)$, produciendo incrementos del $t_{i}$, entre 1,6 a 1,7 veces el del control.

La combinación de tocoferoles y extracto de té verde, sólo mostró diferencias significativas $(p \leq 0,05)$ respecto del control a 1000,2500 y 5000 ppm con un factor de protección de 1,$45 ; 1,78$ y 1,69, respectivamente.

Con respecto a la mezcla de extractos de romero y de té verde, se obtuvieron incrementos significativos de $t_{i}$ con respecto al control a partir de una concentración de 1000 ppm, sin registrar diferencias significativas $(p>0,05)$ con respecto a 1500 ppm. Cabe destacar que los máximos niveles de $t_{\text {ia }}$ alcanzados mediante el agregado de esta combinación de antioxidantes fueron de alrededor 3,8 veces la relación $t_{i a} / t_{i c}$ a 2500 y 5000 ppm.

En la Figura 5.5 pueden observarse los efectos de los distintos antioxidantes y sus mezclas para cada una de las concentraciones estudiadas. La mezcla de tocoferoles y extracto de romero a $250 \mathrm{ppm}$, mostró una actividad antioxidante significativamente mayor $(p \leq 0,05)$ que la correspondiente al extracto de té verde y la combinación tocoferoles/extracto de té verde. A su vez, niveles de 500 ppm no permitieron detectar diferencias significativas $(p>0,05)$ entre los distintos antioxidantes ni sus mezclas, mientras que a 1000 ppm, la combinación de extractos naturales de romero/té verde presentó una mejor actividad antioxidante que los 
demás, seguida del palmitato de ascorbilo y la mezcla tocoferoles/romero, las cuales se diferenciaron significativamente $(p \leq 0,05)$ de la mezcla tocoferoles/té verde. El comportamiento de los antioxidantes estudiados a 1500 ppm fue similar que el registrado a $1000 \mathrm{ppm}$. Con respecto a las concentraciones más elevadas (2500 y 5000 ppm) el palmitato de ascorbilo y la mezcla romero/té verde presentaron la mayor actividad antioxidante; además, a 5000 ppm el extracto de romero también presentó una elevada actividad.

En general, los tocoferoles tuvieron asociada una menor actividad antioxidante que los demás aditivos estudiados. Este hecho puede explicarse mediante la "polar paradox" basada en las propiedades interfaciales de los diferentes antioxidantes (Frankel y col., 1994). De esta manera, dado que la mezcla de tocoferoles está constituida por antioxidantes de naturaleza lipofílica, estos compuestos permanecerían en solución en la fase oleosa, mientras que los de naturaleza hidrofílica (compuestos fenólicos) se orientarían hacia la interfase aire aceite, brindando así una mayor protección al aceite. Por otra parte, no se encontró sinergismo entre las combinaciones de los diversos antioxidantes ensayados.

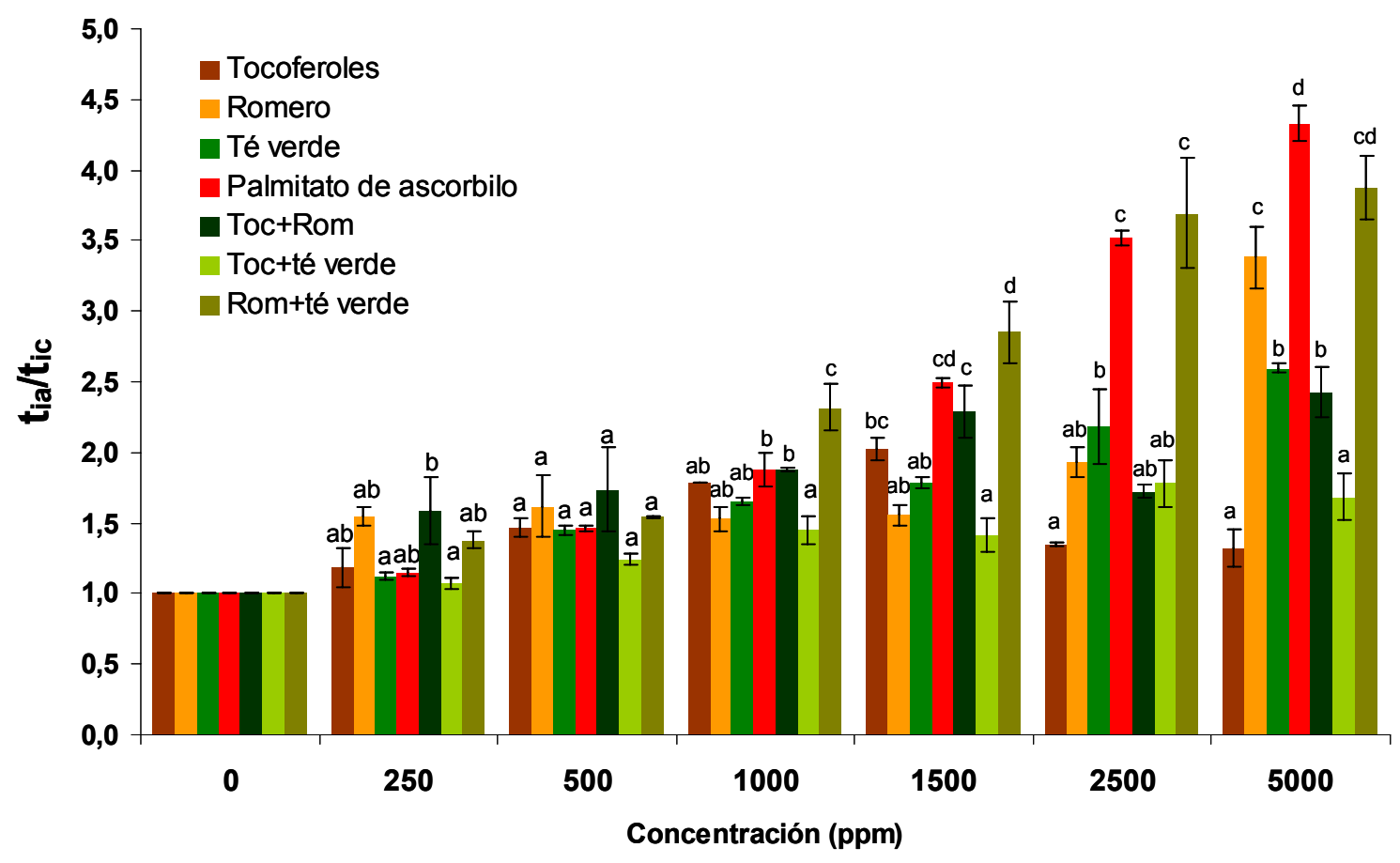

Figura 5.5. Efecto de los distintos antioxidantes y/o sus mezclas a cada concentración sobre la estabilidad oxidativa del aceite de chía. Las barras verticales indican la desviación estándar. Letras distintas indican diferencias significativas $(p \leq 0,05)$ entre antioxidantes o mezcla de los mismos para una misma concentración 


\section{Estudio de la oxidación de aceite de chía mediante calorimetría diferencial de barrido (DSC).}

Varios autores han informado que la determinación de la temperatura correspondiente al inicio del proceso de oxidación es una herramienta útil para evaluar el proceso oxidativo así como la eficiencia de diversos compuestos antioxidantes (Litwinienko y col., 1999). En virtud de ello, se llevó a cabo un estudio de la oxidación del aceite de chía comercial mediante la aplicación de calorimetría diferencial de barrido (DSC). Las curvas de DSC obtenidas a diversas velocidades de calentamiento del aceite de chía en presencia de oxígeno (100 $\mathrm{mL} / \mathrm{min})$ se muestran en la Figura 5.6. En dichas curvas pueden observarse dos picos relacionados con la ocurrencia de dos procesos principales. Así, el primer pico observado en las curvas de oxidación no isotérmicas de DSC se debe a la formación de peróxidos, mientras que el segundo resulta de la descomposición de dichos compuestos lábiles e inestables en otros productos. Estos resultados se basan en los estudios llevados a cabo por Litwinienko y Kasprzycka-Guttman (1998) en aceite de mostaza, quienes han examinado diversos tipos de reacciones complejas que podrían tener lugar en el proceso oxidativo, llegando a la conclusión que las mismas serían de tipo secuencial con inicio autocatalítico, lo cual puede representarse mediante el esquema presentado en la Ec. 5.13:

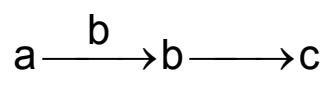

donde el primer paso, $a \rightarrow b$, es el proceso catalizado por $b$. Estos autores han encontrado un muy buen ajuste entre las temperaturas características $\left(T_{e}, T_{p 1}\right.$ y $\left.T_{p 2}\right)$ calculadas y las determinadas experimentalmente para este mecanismo de reacción. Dicha interpretación fue confirmada experimentalmente por otros estudios, incluyendo la oxidación de aceites parcialmente oxidados (Litwinienko, 2001). No obstante, la evaluación de la estabilidad de los aceites comestibles a través de los parámetros cinéticos debería considerar las temperaturas del inicio del proceso $\left(T_{e}\right)$ y la del primer pico $\left(T_{p 1}\right)$, ya que estas dos temperaturas características estarían relacionadas directamente con el proceso de autooxidación. 


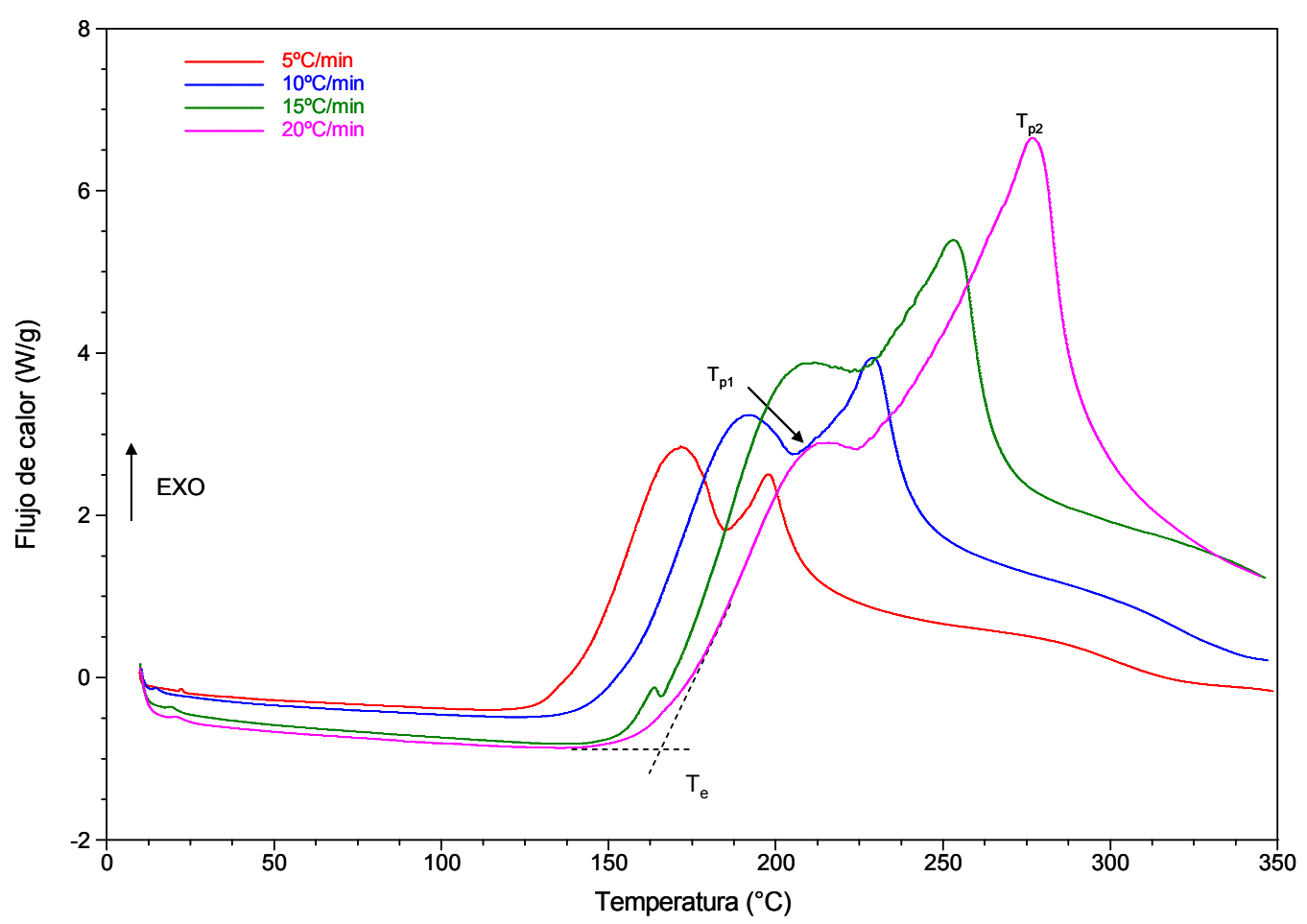

Figura 5.6. Curvas de DSC del aceite de chía obtenidas a diversas velocidades de calentamiento $\left(\beta=5,10,15,20^{\circ} \mathrm{C} / \mathrm{min}\right)$

Cabe señalar que las curvas de DSC obtenidas para el aceite de chía presentaron un perfil análogo a las correspondientes al aceite de lino, el cual se caracteriza por exhibir un contenido de ácido $\alpha$-linolénico similar (Litwinienko, 2001).

Los valores de la temperatura extrapolada de inicio de la oxidación $\left(T_{e}\right)$ así como los correspondientes a las temperaturas máximas de pico $\left(\begin{array}{lll}T_{p 1} & \text { y } & T_{p 2}\end{array}\right)$ se presentan en la Tabla 5.3.

Tabla 5.3. Temperatura extrapolada del inicio $\left(T_{e}\right)$ y temperaturas máximas del primer y segundo pico $\left(T_{p 1}, T_{p 2}\right)$ obtenidas a partir de las curvas de DSC a diferentes velocidades de calentamiento $(\beta)$ del aceite de chía

\begin{tabular}{cccc}
\hline $\boldsymbol{\beta}\left({ }^{\circ} \mathbf{C} / \mathbf{m i n}\right)$ & $\mathbf{T}_{\mathbf{e}}\left({ }^{\circ} \mathbf{C}\right)$ & $\mathbf{T}_{\mathbf{p} 1}\left({ }^{\circ} \mathbf{C}\right)$ & $\mathbf{T}_{\mathbf{p} 2}\left({ }^{\circ} \mathbf{C}\right)$ \\
\hline $\mathbf{5}$ & 139,5 & 173,4 & 199,8 \\
$\mathbf{1 0}$ & 155,3 & 192,9 & 227,9 \\
$\mathbf{1 5}$ & 163,2 & 208,7 & 248,1 \\
$\mathbf{2 0}$ & 168,2 & 212,6 & 265,1 \\
\hline
\end{tabular}


Como puede observarse, un aumento en la velocidad de calentamiento produjo un desplazamiento en los valores de la temperatura extrapolada del inicio $\left(T_{e}\right)$ y de las temperaturas máximas de pico $\left(T_{p 1}\right.$ y $\left.T_{p 2}\right)$ asociadas a los procesos exotérmicos observados. Estos valores fueron utilizados para la determinación de las energías de activación $\left(E_{a}\right)$ y los factores preexponenciales $(A)$ en el estudio de la termooxidación del aceite de chía a través del método de Ozawa-Flynn-Wall (OFW) (Ozawa, 1965, 1970; Flynn and Wall, 1966). La ventaja de la aplicación del método OFW radica en que la energía de activación puede ser determinada independientemente del modelo cinético de la reacción (Flyn y Wall, 1966, Ozawa, 1970).

$\log \beta=\mathrm{aT}_{\mathrm{p}}^{-1}+\mathrm{b}$

De acuerdo a dicho método, cuando se grafica $\log \beta$ versus $\mathrm{T}^{-1}$, se puede obtener una línea recta con pendiente $a=-0,4567 \mathrm{E}_{\mathrm{a}} / \mathrm{R}$ y ordenada al origen $b=-2,315+\log \left(A E_{a} / R\right)$. Así, es posible calcular la energía de activación $E_{a}$ a partir de la siguiente ecuación:

$$
E_{a}=-2,19 R \frac{d \log \beta}{d T^{-1}}
$$

donde:

$E_{a}$ : energía de activación de Arrhenius $(\mathrm{kJ} / \mathrm{mol})$

$R$ : constante de los gases $\left(\mathrm{kJ} / \mathrm{mol}{ }^{\circ} \mathrm{K}\right)$

$\mathrm{T}$ : temperatura absoluta $\left({ }^{\circ} \mathrm{K}\right)$

Así, las energías de activación de Arrhenius calculadas a partir de $T_{e}$ y $T_{p 1}$ pueden ser útiles para estudiar la susceptibilidad de los aceites a la oxidación así como para la determinación de los efectos de diversos aditivos, tales como los compuestos antioxidantes. Ulkowski y col. (2005) indicaron que el mejor punto para calcular los parámetros cinéticos de la autooxidación corresponden al inicio de la misma (temperatura extrapolada del comienzo del proceso, $T_{e}$ ) ya que frecuentemente el primer y segundo pico exotérmico pueden superponerse. 
Los valores de $E_{a}$ calculados a partir de $T_{e}$ y $T_{p 1}$ del aceite de chía control fueron 67,9 y $57,8 \mathrm{~kJ} / \mathrm{mol}$, respectivamente, los cuales resultaron mayores que la energía de activación calculada a partir del segundo pico ( $\left.T_{p 2}\right)$ (Tabla 5.4). Por otra parte, la $E_{a}$ correspondiente a $T_{e}$ del aceite de chía fue similar a la informada para el ácido a-linolénico puro $(62-70 \mathrm{~kJ} / \mathrm{mol}$ ) (Litwinienko, 2001), principal ácido graso presente en dicho aceite e inferior a la del aceite de maíz (104,3 kJ/mol) (Litwinienko y col., 1995).

Tabla 5.4. Parámetros estadísticos y cinéticos calculados a partir de $T_{e}, T_{p 1}$ y $T_{p 2}$ para aceite de chía control mediante del método Ozawa-Flynn-Wall

\begin{tabular}{lccc}
\hline & $\mathbf{T}_{\mathbf{e}}$ & $\mathbf{T}_{\mathbf{p} 1}$ & $\mathbf{T}_{\mathbf{p} 2}$ \\
\hline Pendiente (a) & $-3,729$ & $-3,177$ & $-2,441$ \\
Error estándar del estimador a & 0,371 & 0,491 & 0,643 \\
Constante (b) & 9,732 & 8,195 & 5,865 \\
Error estándar del estimador $\mathbf{b}$ & 0,888 & 0,506 & 0,615 \\
$\mathbf{R}^{2}$ & 0,9787 & 0,9839 & 0,9956 \\
$\mathbf{E}_{\mathbf{a}}(\mathbf{k J} / \mathbf{m o l})$ & 67,9 & 57,8 & 44,4 \\
$\mathbf{A}\left(\mathbf{s}^{-1}\right)$ & $2,88 \times 10^{11}$ & $5,93 \times 10^{9}$ & $1,04 \times 10^{8}$ \\
\hline
\end{tabular}

Las curvas de DSC correspondientes a los aceites de chía con el agregado de diversos antioxidantes así como las temperaturas del inicio $\left(T_{e}\right)$ y del primer pico $\left(T_{p 1}\right)$ a las distintas velocidades de calentamiento $\left(\beta=5,10,15,20^{\circ} \mathrm{C} / \mathrm{min}\right)$ se muestran en la Figura 5.7 y Tabla 5.5. Como puede observarse, los termogramas obtenidos para los diferentes tratamientos presentan similares transiciones aunque los valores de $T_{e}, T_{p 1}$ y $T_{p 2}$ se desplazan hacia mayores temperaturas en función del aumento de la velocidad de calentamiento $(\beta)$. 

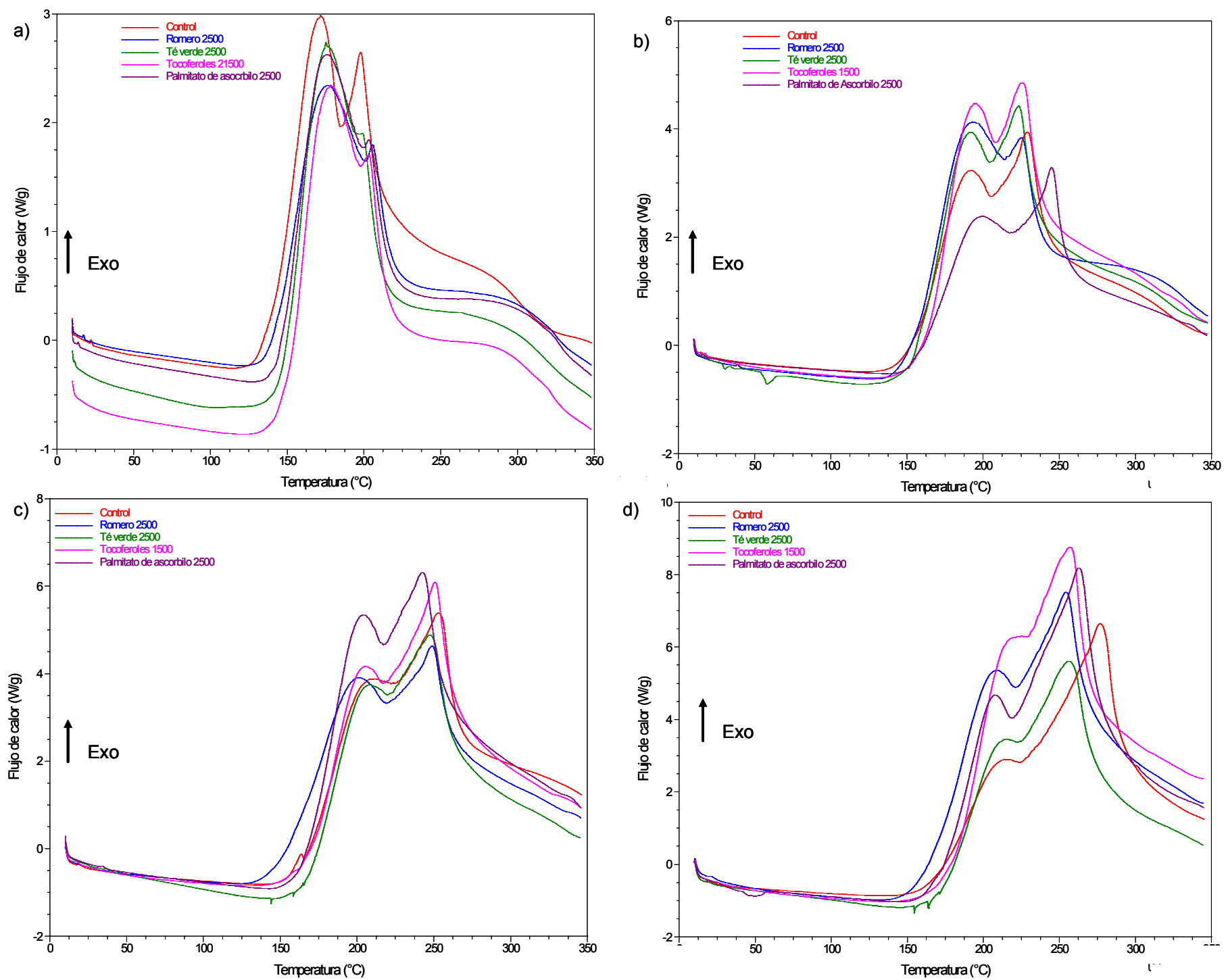

Figura 5.7. Curvas de DSC del aceite de chía sin y con el agregado de antioxidantes obtenidas a distintas velocidades de calentamiento $\beta\left({ }^{\circ} \mathrm{C} / \mathrm{min}\right.$ ): (a) 5; (b) 10; (c) 15; (d) 20 
Tabla 5.5. Temperatura extrapolada del inicio $\left(T_{e}\right)$ y del primer y segundo pico $\left(T_{p 1}, T_{p 2}\right)$ obtenidas a partir de las curvas de DSC a diferentes velocidades de calentamiento $(\beta)$ del aceite de chía con el agregado de diversos antioxidantes

\begin{tabular}{|c|c|c|c|c|c|c|c|}
\hline$\beta\left({ }^{\circ} \mathrm{C} / \mathrm{min}\right)$ & $\mathrm{T}_{\mathrm{e}}\left({ }^{\circ} \mathrm{C}\right)$ & $\mathrm{T}_{\mathrm{p} 1}\left({ }^{\circ} \mathrm{C}\right)$ & $\mathrm{T}_{\mathrm{p} 2}\left({ }^{\circ} \mathrm{C}\right)$ & $\beta\left({ }^{\circ} \mathrm{C} / \mathrm{min}\right)$ & $\mathrm{T}_{\mathrm{e}}\left({ }^{\circ} \mathrm{C}\right)$ & $\mathrm{T}_{\mathrm{p} 1}\left({ }^{\circ} \mathrm{C}\right)$ & $\mathrm{T}_{\mathrm{p} 2}\left({ }^{\circ} \mathrm{C}\right)$ \\
\hline 5 & 142,9 & 177,8 & 206,8 & 5 & 143,7 & 178,0 & 207,9 \\
\hline 10 & 151,8 & 193,0 & 229,2 & 10 & 161,2 & 195,1 & 233,9 \\
\hline 15 & 157,5 & 204,0 & 247,1 & 15 & 166,2 & 204,7 & 248,0 \\
\hline 20 & 163,1 & 208,4 & 250,8 & 20 & 176,5 & 220,0 & 266,4 \\
\hline 5 & 144,0 & 176,7 & 210,1 & 5 & 140,6 & 176,4 & 206,7 \\
\hline 10 & 154,8 & 193,3 & 226,4 & 10 & 156,2 & 197,1 & 236,4 \\
\hline 15 & 167,4 & 206,7 & 244,1 & 15 & 161,0 & 203,1 & 255,0 \\
\hline 20 & 169,5 & 210,3 & 252,3 & 20 & 168,7 & 206,6 & 263,1 \\
\hline
\end{tabular}


Las pendientes calculadas de los gráficos $\log \beta$ versus $\mathrm{T}^{-1}$ de los aceites de chía con el agregado de antioxidantes así como las respectivas $E_{a} y$ otros parámetros estadísticos y cinéticos se presentan en la Tabla 5.6. Los aceites de chía con el agregado de los extractos de romero y de té verde así como con palmitato de ascorbilo presentaron valores de $E_{a}$ y $A$-calculados a partir de $T_{e^{-}}$ mayores que los del control, lo cual puede asociarse con la capacidad de dichos antioxidantes de retrasar el proceso de autooxidación. Entre dichos compuestos, el extracto de romero mostró la mejor actividad antioxidante, con una $E_{a} 30 \%$ mayor con respecto al aceite control, mientras que el extracto de té verde y el palmitato de ascorbilo produjeron aumentos del 9 y $5 \%$, respectivamente. Si bien el palmitato de ascorbilo mostró una escasa actividad antioxidante, es necesario considerar que algunos autores sugieren que mediante la utilización de DSC, dicho compuesto podría registrar una menor actividad debido a la elevada presión parcial de oxígeno utilizada y a la temperatura empleada durante los ensayos mediante la aplicación de esta metodología. En estas condiciones, el palmitato de ascorbilo es oxidado rápida y reversiblemente a palmitato de dihidroascorbilo, el cual es posteriormente convertido a ácido 2,3-diceto-gulónico, perdiendo así su actividad antioxidante (Giuffrida y col., 2007).

Con respecto al aceite de chía con la adición de tocoferoles, los parámetros cinéticos previamente mencionados fueron inferiores a los correspondientes al aceite control, mostrando así su menor eficiencia en retardar el proceso de oxidación lipídica en relación a los otros antioxidantes estudiados, lo cual está asociado con la "polar paradox" (Frankel y col., 1994), tal como fue mencionado previamente. 
Tabla 5.6. Parámetros estadísticos y cinéticos correspondientes al aceite de chía con el agregado de antioxidantes calculados a partir de $T_{e}, T_{p 1}$ y $T_{p 2}$ mediante el método Ozawa-Flynn-Wall

\begin{tabular}{|c|c|c|c|c|c|c|c|}
\hline & $\mathbf{T}_{\mathrm{e}}$ & $\mathbf{T}_{\mathrm{p} 1}$ & $\mathbf{T}_{\mathrm{p} 2}$ & & $\mathbf{T}_{\mathbf{e}}$ & $\mathbf{T}_{\mathbf{p} 1}$ & $\mathbf{T}_{\mathrm{p} 2}$ \\
\hline Pendiente (a) & $-4,936$ & $-4,026$ & $-3,352$ & Pendiente (a) & $-3,452$ & $-3,341$ & $-2,645$ \\
\hline Error estándar del estimador a & 0,102 & 0,048 & 0,195 & Error estándar del estimador a & 0,650 & 0,118 & 0,087 \\
\hline Constante (b) & 12,612 & 9,627 & 7,669 & Constante (b) & 8,985 & 8,127 & 6,192 \\
\hline Error estándar del estimador b & 0,194 & 0,119 & 0,385 & Error estándar del estimador b & 1,464 & 0,255 & 0,216 \\
\hline$E_{a}(k J / m o l)$ & 89,88 & 73,93 & 58,52 & $E_{a}(k J / m o l)$ & 62,86 & 59,31 & 49,30 \\
\hline$A\left(s^{-1}\right)$ & $8,18 \times 10^{13}$ & $1,28 \times 10^{11}$ & $1,30 \times 10^{9}$ & $A\left(s^{-1}\right)$ & $1,28 \times 10^{11}$ & $3,38 \times 10^{9}$ & $9,46 \times 10^{7}$ \\
\hline \multicolumn{4}{|c|}{ Aceite de chía +2500 ppm de extracto de té verde } & \multicolumn{4}{|c|}{ Aceite de chía +2500 ppm de palmitato de ascorbilo } \\
\hline Pendiente (a) & $-4,072$ & $-3,613$ & $-3,004$ & Pendiente (a) & $-3,902$ & $-4,057$ & $-2,548$ \\
\hline $\mathbf{R}^{2}$ & 0,9509 & 0,9627 & 0,8937 & $\mathbf{R}^{2}$ & 0,9541 & 0,9541 & 0,9495 \\
\hline$E_{a}(k J / m o l)$ & 74,14 & 65,65 & 59,59 & $E_{a}(k J / m o l)$ & 71,06 & 73,87 & 46,40 \\
\hline$A\left(s^{-1}\right)$ & $1,26 \times 10^{13}$ & $1,40 \times 10^{10}$ & $4,42 \times 10^{9}$ & $A\left(s^{-1}\right)$ & $2,16 \times 10^{12}$ & $1,64 \times 10^{11}$ & $4,04 \times 10^{7}$ \\
\hline
\end{tabular}




\section{Almacenamiento del aceite de chía}

Con fines prácticos, las predicciones de la estabilidad oxidativa en los alimentos y aceites basadas en la determinación del periodo de inducción podrían relacionarse con la vida útil del producto. En este sentido, es importante señalar que las condiciones de ensayo utilizadas deben ser lo más cercanas posibles a aquéllas bajo las cuales el producto será almacenado (Frankel, 2005).

El aceite de chía utilizado para este ensayo presentó las características que se detallan en la Tabla 5.7.

Tabla 5.7. Características del aceite de chía Sturla ${ }^{\circledR}$ utilizado en el ensayo de almacenamiento

$\begin{array}{ll}\text { Tocoferoles totales ( } \boldsymbol{\mu} \mathbf{g} / \mathbf{g} \text { aceite) } & 542 \\ \mathbf{t}_{\mathbf{i}} \text { (Rancimat, } \boldsymbol{h} \text { ) } & 2,3 \\ \text { Ácidos grasos libres (\% oleico) } & 1,2 \\ \text { Índice de peróxido (meq peróxido/kg muestra) } & 1,0 \\ \text { Valor de } \boldsymbol{p} \text {-anisidina } & 0,3\end{array}$

En las Figuras $\mathbf{5 . 8}$ a $\mathbf{5 . 1 3}$ se muestra la evolución de los parámetros estudiados en el seguimiento de la oxidación lipídica durante el periodo de almacenamiento correspondiente a los distintos tratamientos estudiados. El análisis comparativo de las mismas permitió evidenciar que la temperatura de almacenamiento es un factor de gran relevancia en la evolución del proceso oxidativo. Así, al cabo de 225 días de almacenamiento a $4 \pm 1^{\circ} \mathrm{C}$ el aceite control registró un $\mathrm{PV}=9,9$ meq peróxido/kg aceite; $p-\mathrm{AV}=1,7$ y valor Totox $=21,5$, valores menores que los correspondientes a dicho sistema almacenado a $20 \pm 2^{\circ} \mathrm{C}(P V=16,9$ meq peróxido $/ \mathrm{kg}$ aceite; $p-A \bigvee=4,7$ y valor Totox $=38,5)$.

Además, pudo observarse que a lo largo del periodo de almacenamiento a $4 \pm 1^{\circ} \mathrm{C}$ tanto el aceite de chía control como aquéllos con la adición de antioxidantes presentaron valores de peróxidos $<10,0$ meq peróxido/kg aceite. Dicho valor es el nivel establecido por el Código Alimentario Argentino para diversos aceites refinados como el límite máximo apto para el consumo humano (Código Alimentario Argentino, 2008) y además, es considerado como el límite de aceptabilidad de aceites vegetales que contienen ácido linoleico como principal ácido graso (Frankel, 2005). 
Sin embargo, cabe señalar que en los aceites vegetales con un alto contenido de ácido a-linolénico, tales como el aceite de chía, el punto final de su aceptabilidad podría registrarse aún a menores niveles de oxidación. Así, los aceites ricos en ácido a-linolénico pueden desarrollar deterioros en el flavor mucho más rápidamente y en estadios más tempranos de oxidación que los correspondientes a aquéllos que contienen principalmente ácido linoleico (Frankel, 2005). El aceite de chía con el agregado de palmitato de ascorbilo presentó los valores más bajos de índice de peróxido, los cuales resultaron significativamente menores $(p \leq 0,05)$ a los correspondientes al aceite control a partir de los 30 días de almacenamiento a este nivel de temperatura. Pudo observarse además, un aumento en la velocidad de la oxidación primaria del aceite de chía sin el agregado de antioxidantes a partir de los 150 días de almacenamiento, registrándose diferencias significativas $(p \leq 0,05)$ con respecto a los aceites con la incorporación de antioxidantes desde los 165 días (Figura 5.8).

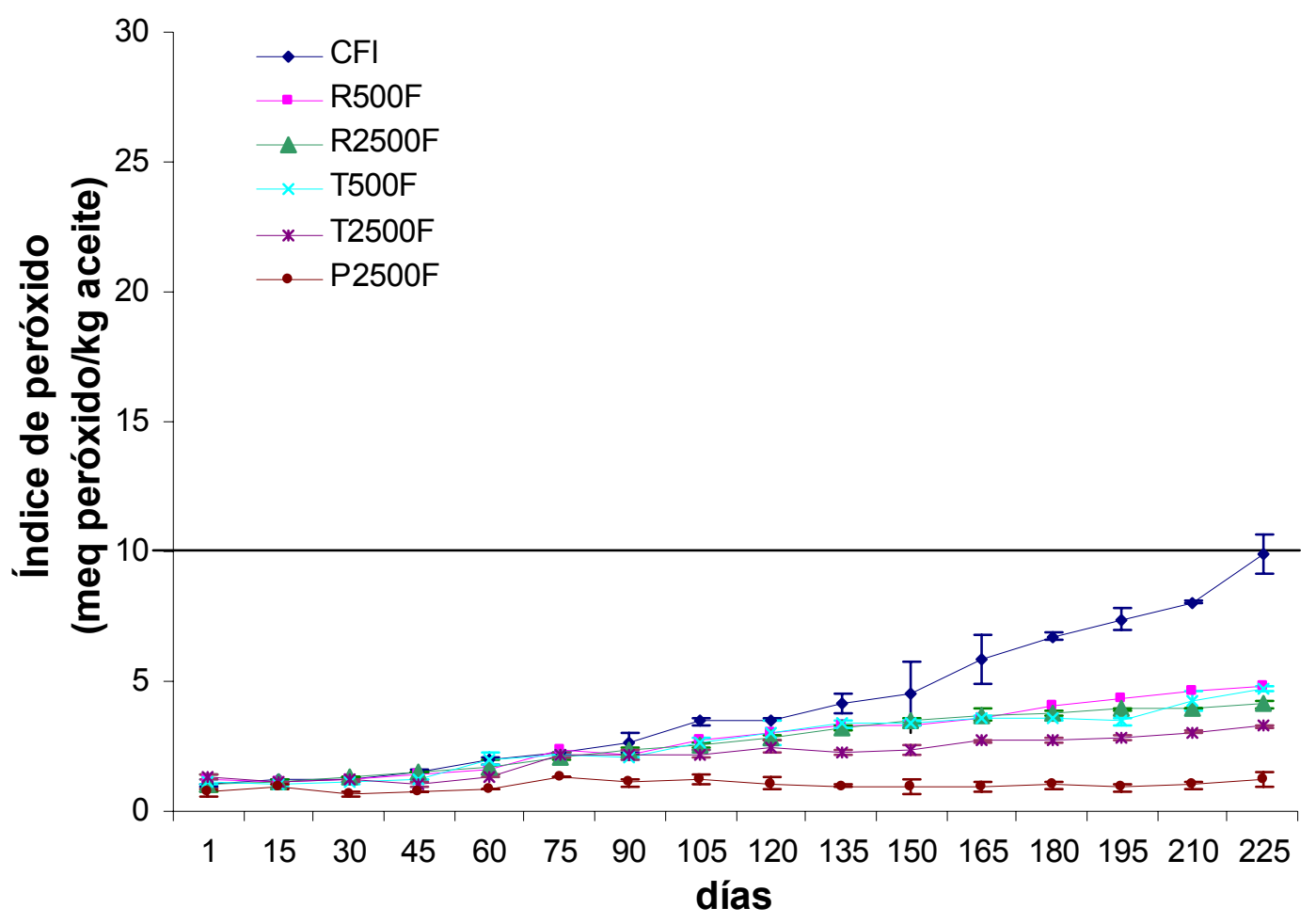

Figura 5.8. Evolución del índice de peróxido durante el almacenamiento de aceite de chía a $\mathrm{T}=4 \pm 1^{\circ} \mathrm{C}$. Las barras verticales indican la desviación estándar. 
Con respecto a la evolución de los valores de $p$-anisidina, los mismos se mantuvieron en niveles bajos (Figura 5.9). Si bien se detectaron algunas diferencias significativas entre muestras para diferentes tiempos de almacenamiento según el tipo de antioxidante, al final del periodo ( $t=225 \mathrm{~d}$ ) no se registraron diferencias significativas $(p>0,05)$ entre los diversos aceites estudiados.

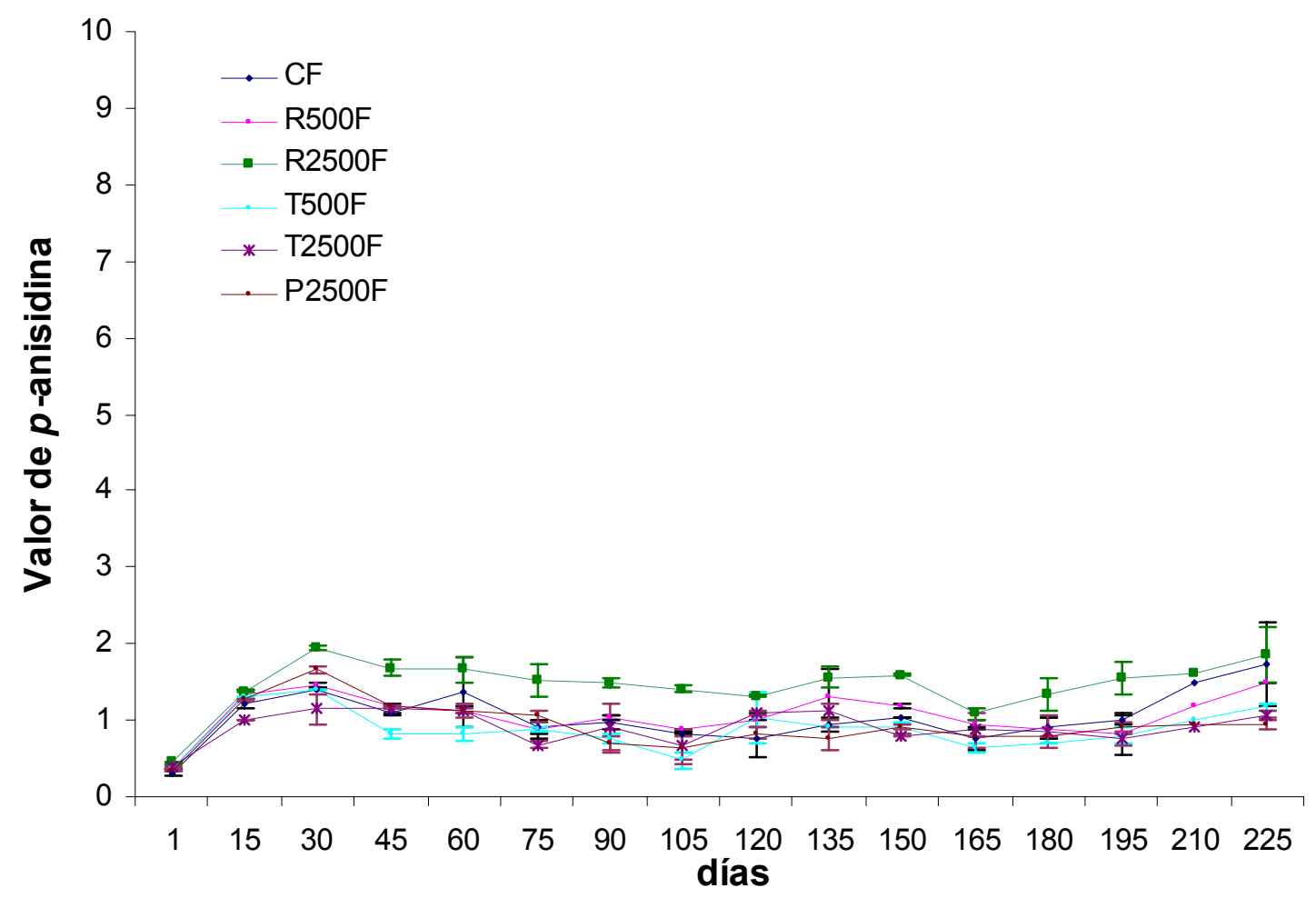

Figura 5.9. Evolución del valor de $p$-anisidina durante el almacenamiento de aceite de chía a $T=4 \pm 1^{\circ} \mathrm{C}$. Las barras verticales indican la desviación estándar.

La evolución del valor Totox brinda una información útil con respecto al progreso de la formación de los productos primarios y secundarios de la oxidación. Este parámetro mostró una tendencia similar a la observada para el PV, habiéndose registrado los máximos valores al final del periodo de almacenamiento (Figura 5.10), al cabo del cual el aceite de chía control presentó un valor Totox significativamente superior $(p \leq 0,05)$ al correspondiente a los aceites tratados con antioxidantes. Esta diferencia estaría asociada principalmente con la formación de productos primarios de oxidación (hidroperóxidos) determinada a través del PV, ya que tal como se mencionó previamente, no se registraron diferencias en la formación de los productos secundarios de la oxidación (valor de p-anisidina). Así, el aceite de chía 
control se encontraría en los primeros estadíos del proceso de oxidación a los 225 días de almacenamiento a $4 \pm 1^{\circ} \mathrm{C}$.

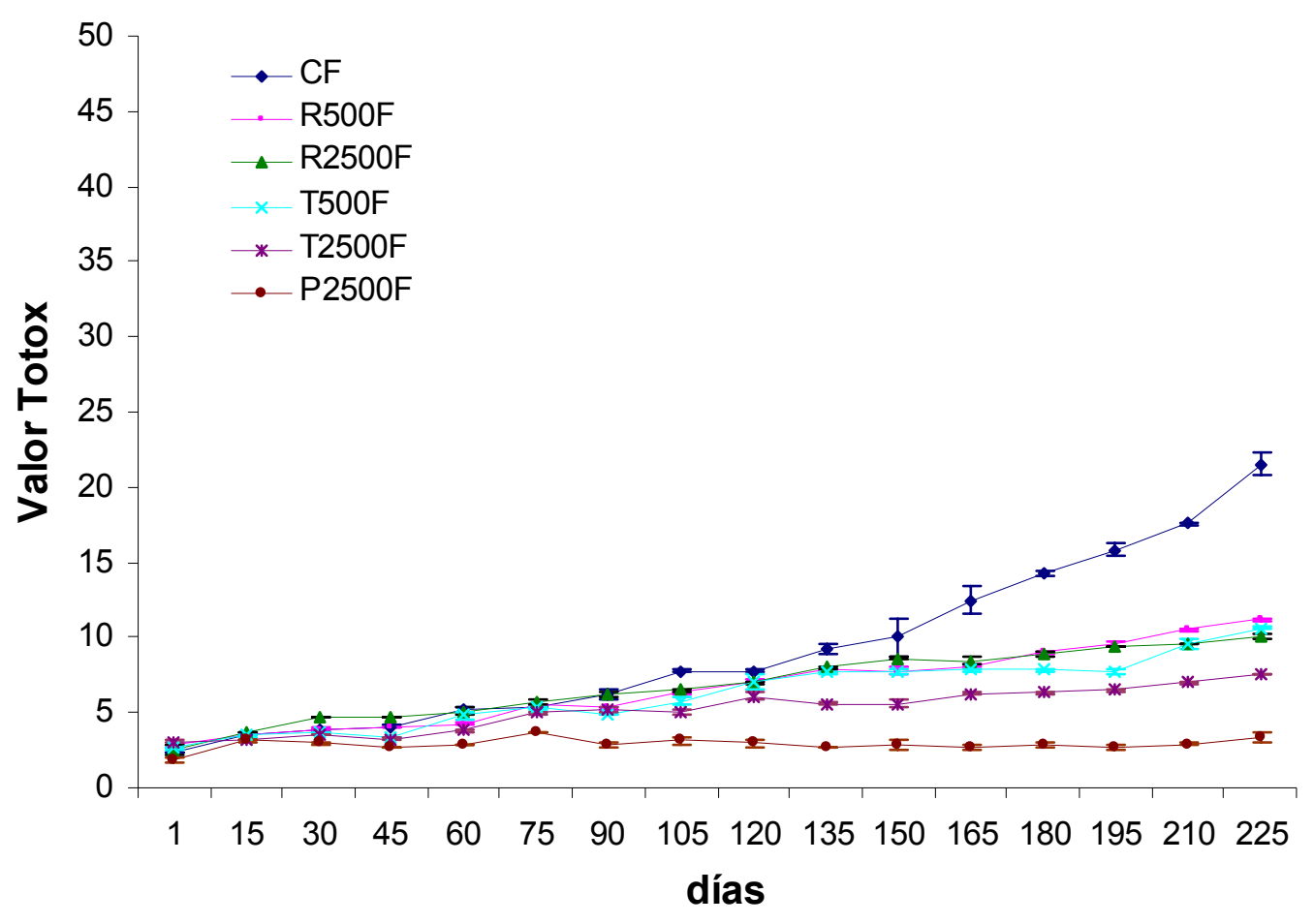

Figura 5.10. Evolución del valor Totox durante el almacenamiento de aceite de chía a $\mathrm{T}=4 \pm 1^{\circ} \mathrm{C}$. Las barras verticales indican la desviación estándar.

En lo que respecta al almacenamiento a $T=20 \pm 2^{\circ} \mathrm{C}$, todos los tratamientos evidenciaron un nivel de PV de 10 meq peróxido/kg de aceite entre los 60 - 120 días de almacenamiento, a excepción del aceite con adición de palmitato de ascorbilo (Figura 5.11). El PV correspondiente al sistema control registró un aumento de 0,9 a 16,9 meq peróxido/kg al cabo de 225 días de almacenamiento, presentando un valor máximo de aproximadamente 20,0 meq peróxido/kg a los 195 días. El límite máximo legislado (10 meq peróxido/kg) fue alcanzado al cabo de 60 días de almacenamiento a $20 \pm 2^{\circ} \mathrm{C}$, tiempo en el cual no se registraron diferencias significativas $(p>0,05)$ con respecto a los aceites tratados con los extractos de romero y de té verde a la menor concentración (500 ppm). Sin embargo, niveles de 2500 ppm de extractos de té verde y de romero lograron diferir el proceso de oxidación en el periodo inicial de almacenamiento, habiéndose alcanzado valores de 10,0 meq peróxido/kg al cabo de 
90 y 110 días, respectivamente. El PV correspondiente al aceite con palmitato de ascorbilo no varió significativamente $(p>0,05)$ a lo largo del periodo estudiado $(0,6-$ $1,5$ meq peróxido $/ \mathrm{kg})$, habiéndose registrado diferencias significativas $(p \leq 0,05)$ con respecto a los demás tratamientos a partir de los 45 días de almacenamiento en las condiciones mencionadas.

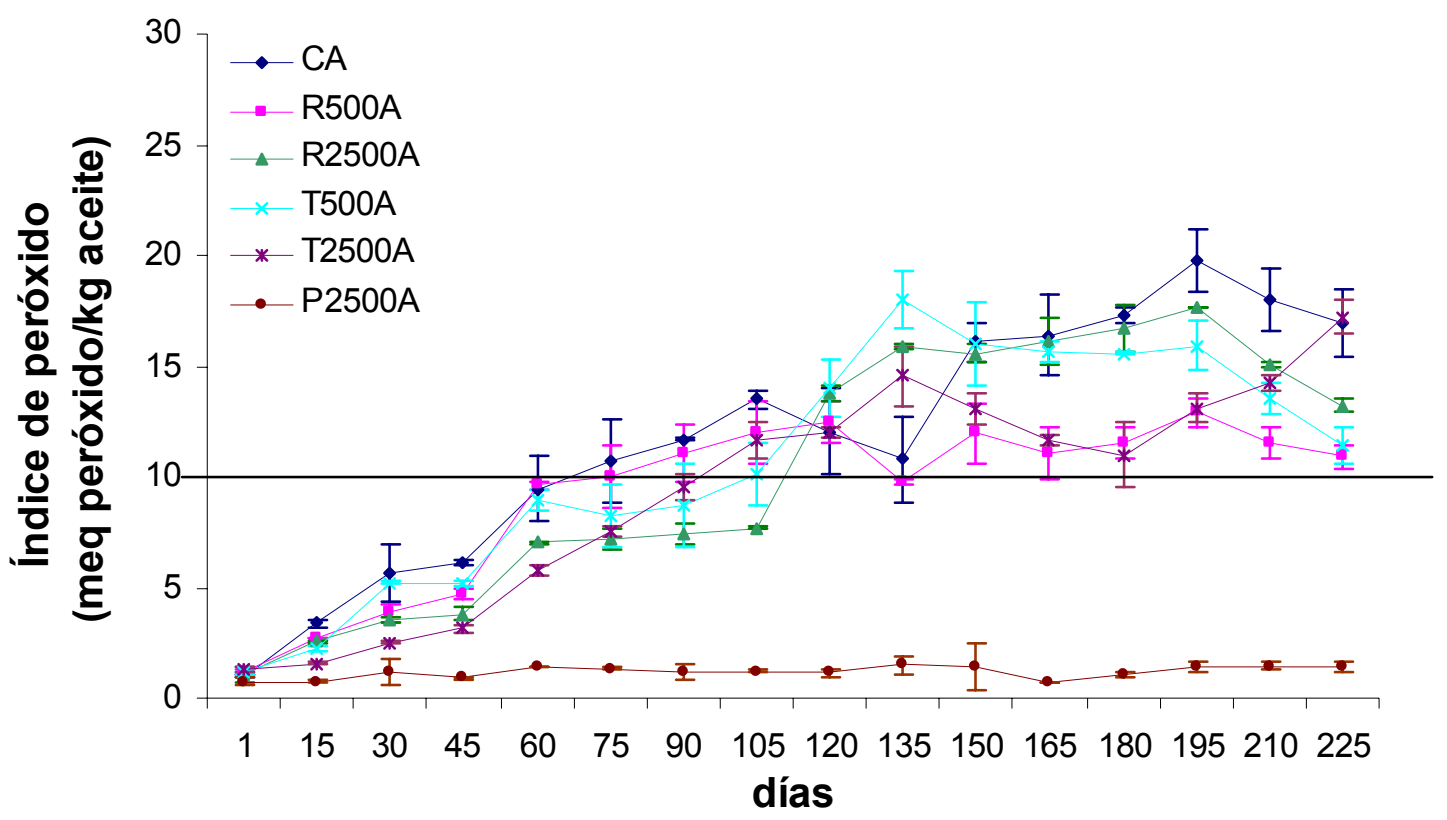

Figura 5.11. Evolución del índice de peróxido durante el almacenamiento de aceite de chía a $\mathrm{T}=20 \pm 2^{\circ} \mathrm{C}$. Las barras verticales indican la desviación estándar.

Con respecto al valor de $p$-anisidina, si bien a $20 \pm 2^{\circ} \mathrm{C}$ sus niveles registraron un rango de mayor amplitud que los correspondientes a los aceites almacenados a $4 \pm 1^{\circ} \mathrm{C}$, los mismos fueron inferiores a los informados en aceite de soja almacenado en oscuridad a temperatura ambiente durante un periodo similar ( $p$ - $A V=36,1 \pm 1,4$ ) (Anwar y col., 2007). Luego de 60 días de almacenamiento a $T=20 \pm 2^{\circ} \mathrm{C}$, el aceite de chía con la incorporación de palmitato de ascorbilo presentó un valor de p-AV significativamente menor $(p \leq 0,05)$ que los demás aceites de chía estudiados. 


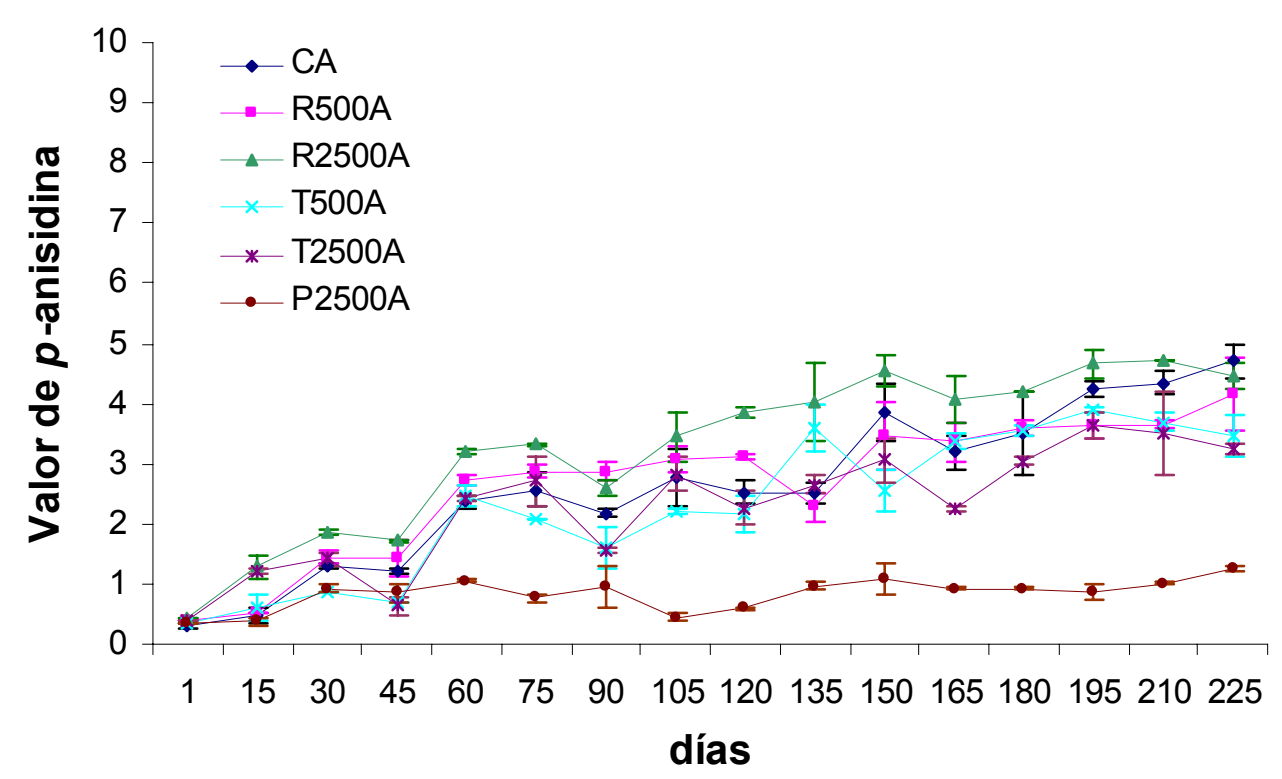

Figura 5.12. Evolución del valor de p-anisidina durante el almacenamiento de aceite de chía a $\mathrm{T}=20 \pm 2^{\circ} \mathrm{C}$. Las barras verticales indican la desviación estándar.

El valor Totox también exhibió una tendencia similar de evolución a la del índice de peróxido, pudiéndose observar que a temperatura ambiente $\left(20 \pm 2^{\circ} \mathrm{C}\right)$ el palmitato de ascorbilo resultó ser más efectivo que el resto de los antioxidantes ensayados en cuanto al desarrollo de la oxidación lipídica del aceite de chía.

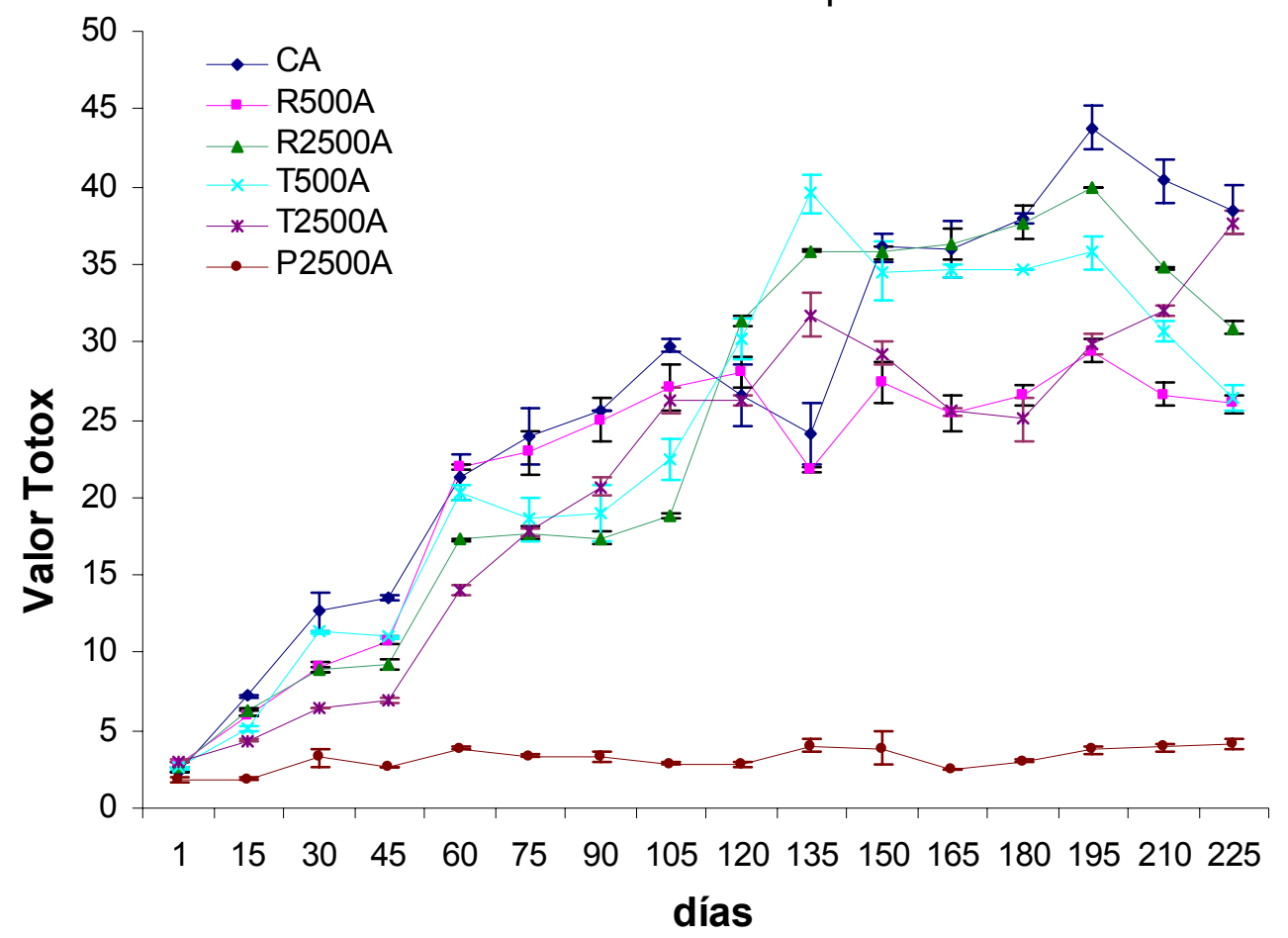

Figura 5.13. Evolución del valor Totox durante el almacenamiento de aceite de chía a $\mathrm{T}=20 \pm 2^{\circ} \mathrm{C}$. Las barras verticales indican la desviación estándar. 
En relación a la evaluación de los aceites estudiados al inicio $(t=0 \mathrm{~d})$, a un tiempo intermedio ( $\mathrm{t}=165 \mathrm{~d}$ ) y al final del periodo de almacenamiento ( $\mathrm{t}=225 \mathrm{~d}$ ) mediante Rancimat, aquéllos almacenados a $20 \pm 2^{\circ} \mathrm{C}$ mostraron una reducción significativa $(p \leq 0,05)$ en el $t_{i}$ al cabo de 225 días de almacenamiento con respecto a los valores del $t_{i}$ inicial (Figura 5.14). Como puede observarse, el $t_{i}$ correspondiente al inicio del periodo de almacenamiento fue variable según el tipo de antioxidante agregado. Así, si bien el palmitato de ascorbilo mostró un tia inicial elevado, al cabo de 165 de almacenamiento se registró una disminución significativa $(p \leq 0,05)$ en dicho parámetro, para los aceites almacenados a ambas temperaturas. Con respecto al extracto de romero, niveles de adición de 500 ppm registraron una disminución en el $t_{i a}$ independientemente de la temperatura de almacenamiento, mientras que a $2500 \mathrm{ppm}$, el almacenamiento a $4 \pm 1^{\circ} \mathrm{C}$ no mostró diferencias significativas con respecto al tia inicial. En relación al extracto de té verde, se observó un comportamiento similar al del extracto de romero a la menor concentración ensayada mientras que a tenores mayores, el $\mathrm{t}_{\mathrm{i} a}$ a 165 días no presentó diferencias significativas $(p>0,05)$ con respecto al $t_{\text {ia }}$ correspondiente estadío inicial de almacenamiento, aunque sí se observaron diferencias significativas $(p \leq 0,05)$ al finalizar el mismo $(\mathrm{t}=225 \mathrm{~d})$.

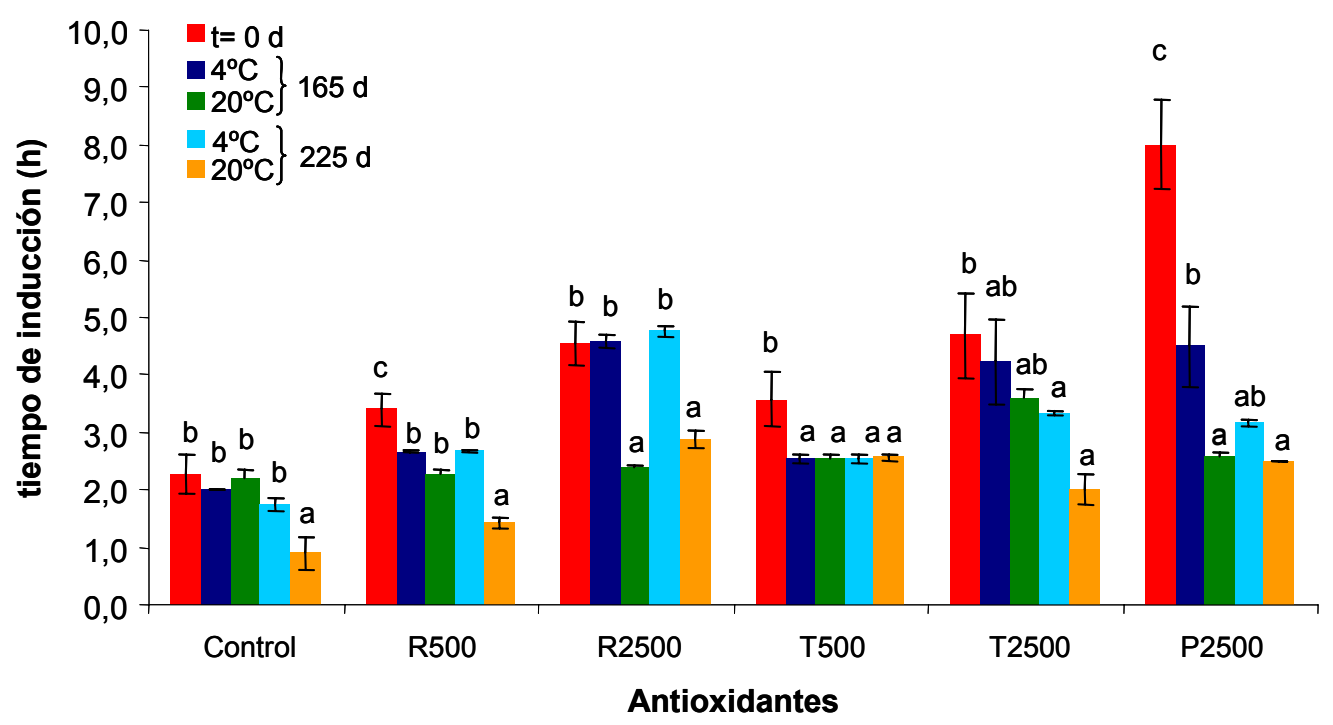

Figura 5.14. Estabilidad oxidativa (tiempo de inducción, Rancimat) del aceite de chía correspondiente a los distintos tratamientos a $\mathrm{t}=0,165$ y 225 días de almacenamiento. Las barras verticales indican la desviación estándar. Letras distintas indican que existen diferencias significativas $(p \leq 0,05)$ entre condiciones de almacenamiento para un mismo sistema 
Por otra parte, la evolución del contenido de ácidos grasos libres no presentó diferencias significativas $(p>0,05)$ entre el estadío inicial, 100 y 225 días para los ensayos de almacenamiento llevados a cabo a $4 \pm 1^{\circ} \mathrm{C}$ y $20 \pm 2^{\circ} \mathrm{C}$ (Figura 5.15). Estos resultados indican que el aceite de chía fue estable frente a la degradación hidrolítica de los triacilgliceroles, aún en condiciones de almacenamiento a temperatura ambiente.

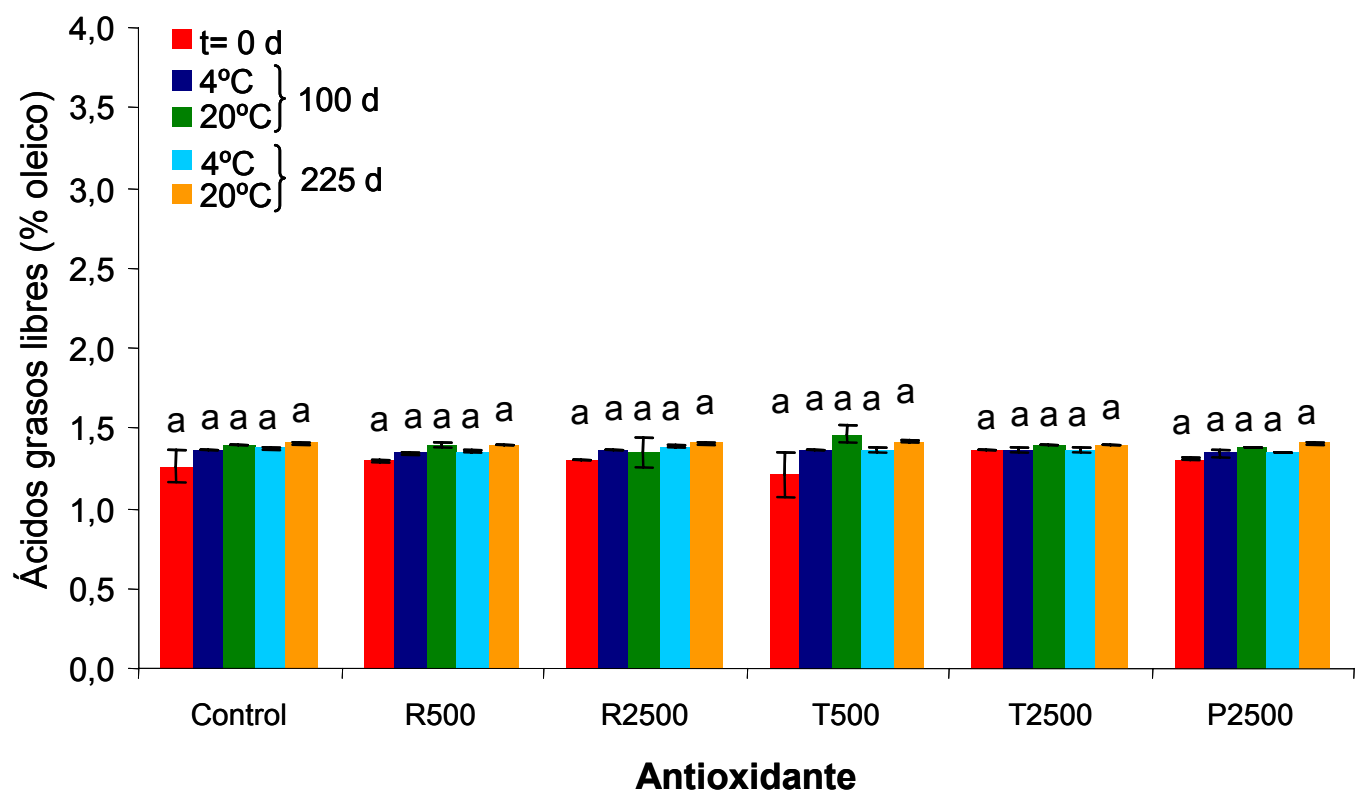

Figura 5.15. Evolución del contenido de ácidos grasos libres (\% oleico) correspondiente a los distintos tratamientos a $\mathrm{t}=0,100$ y 225 días de almacenamiento. Las barras verticales indican la desviación estándar. Las barras verticales indican la desviación estándar. Letras iguales indican que no existen diferencias significativas $(p>0,05)$ entre condiciones de almacenamiento para un mismo sistema 
Por otra parte, la composición de ácidos grasos registró escasas diferencias entre los distintos tratamientos, permaneciendo estable en las diferentes condiciones utilizadas durante el ensayo de almacenamiento (Figura 5.16).

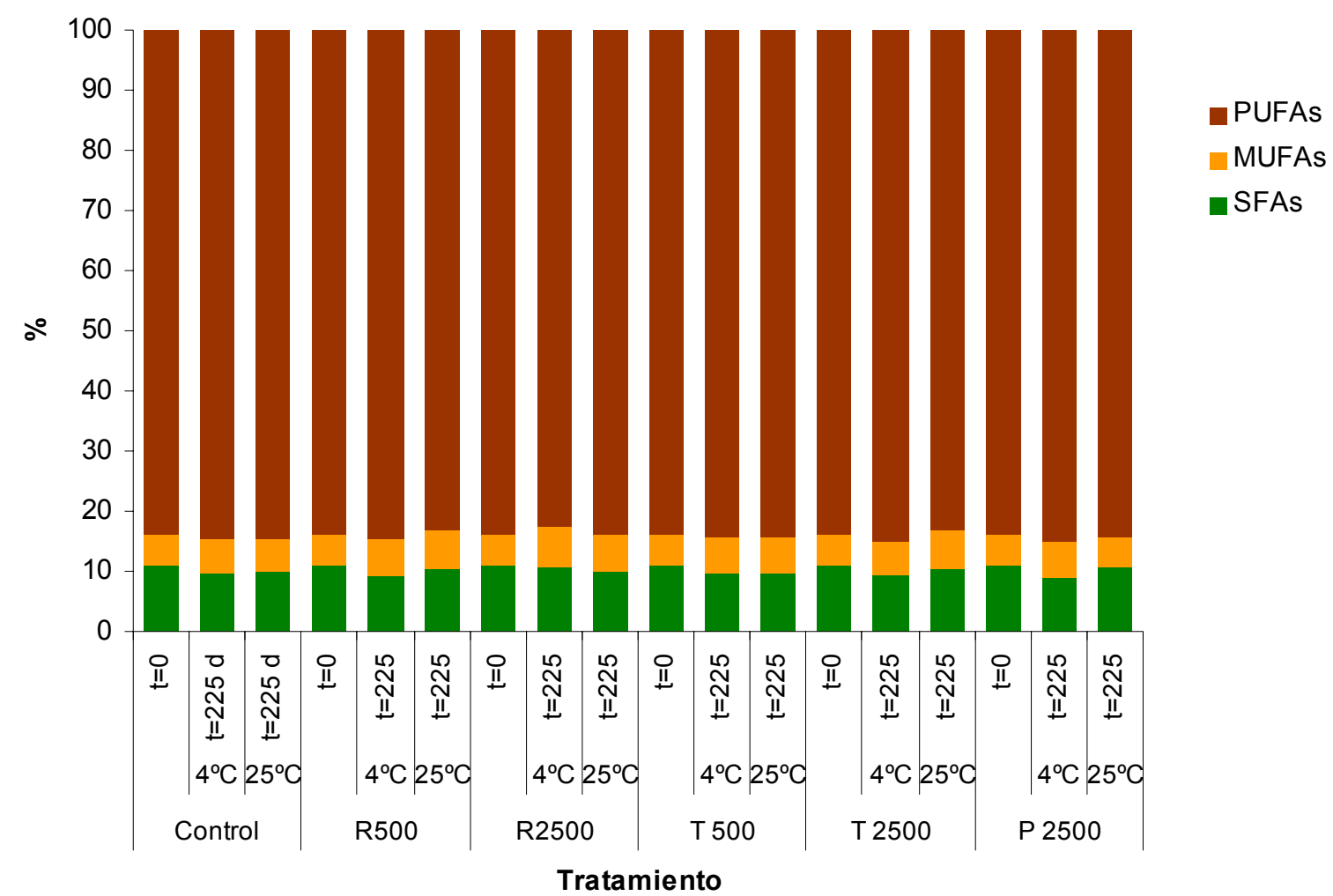

Figura 5.16. Evolución de la composición acídica (\% respecto del total de ácidos grasos) correspondiente a los distintos tratamientos a $\mathrm{t}=0$ y 225 días de almacenamiento

Con respecto al tenor de tocoferoles, se evidenció una disminución de aproximadamente $15 \%$ entre el inicio y el final del almacenamiento para las distintas condiciones y tratamientos realizados con los antioxidantes estudiados. 


\section{CONCLUSIONES PARCIALES}

- Los resultados del ensayo acelerado de estabilidad oxidativa sugieren que la adición de los extractos de romero y de té verde así como sus mezclas presentaron los mejores efectos antioxidantes a las mayores concentraciones estudiadas (5000 y 2500 ppm), no habiéndose registrado sinergismo entre los distintos antioxidantes estudiados Los resultados obtenidos pueden ser explicados teniendo en cuenta las propiedades interfaciales asociadas a los diferentes antioxidantes ("polar paradox").

- El estudio realizado mediante DSC permitió obtener los termogramas de oxidación correspondientes al aceite de chía, los cuales mostraron la existencia de dos picos relacionados con la formación de los hidroperóxidos (productos primarios del proceso oxidativo) y su posterior descomposición en otros productos (productos secundarios de oxidación).

- Los termogramas de DSC llevados a cabo a diferentes velocidades de calentamiento permitieron determinar los parámetros cinéticos de la oxidación del aceite de chía. Los valores de $E_{a}$ calculados a partir de $T_{e}$ y $T_{p 1}$ fueron de 67,9 y $57,8 \mathrm{~kJ} / \mathrm{mol}$, respectivamente. El agregado de $2500 \mathrm{ppm}$ de extracto de romero al aceite de chía produjo un incremento del $30 \%$ en la $E_{a}$.

- La evaluación de los distintos tratamientos reveló el papel preponderante de la temperatura de almacenamiento sobre la velocidad de oxidación del aceite de chía. Así, a $\mathrm{T}=4 \pm 1^{\circ} \mathrm{C}$ tanto el aceite de chía control como aquéllos con la adición de antioxidantes presentaron valores de peróxido $<10,0$ meq peróxido/kg aceite y de $p$-anisidina $<2,0$ al cabo de los 225 d de almacenamiento, si bien el aceite control comenzó a registrar un aumento significativo del $\mathrm{PV}$ a partir de $165 \mathrm{~d}$. En cambio, a $\mathrm{T}=20 \pm 2^{\circ} \mathrm{C}$ todos los sistemas alcanzaron un nivel de PV de 10,0 meq peróxido/kg de aceite entre los 60-120 d, a excepción del aceite con adición de palmitato de ascorbilo, en el cual dicho índice se mantuvo relativamente constante durante la duración del ensayo. La evolución del valor Totox presentó características diferentes de acuerdo a la temperatura de almacenamiento ensayada, con un mayor rango de valores registrado a $20 \pm 2^{\circ} \mathrm{C}$ debido a una mayor contribución de los productos secundarios de oxidación. 
- La composición acídica así como el contenido de ácidos grasos libres no presentaron modificaciones al cabo del periodo de almacenamiento estudiado, mientras que el tenor de tocoferoles evidenció una disminución del 15\% entre el inicio y el final del almacenamiento realizado en distintas condiciones de temperatura.

En virtud de lo expuesto previamente, se acepta la hipótesis IV: "La temperatura y el tiempo de almacenamiento del aceite de chía así como la adición de antioxidantes influyen sobre la estabilidad oxidativa y por consiguiente sobre su conservación". 


\section{DIFUSIÓN DE RESULTADOS}

\section{Publicaciones Cientificas en Revistas}

- Efecto de la adición de antioxidantes naturales (extracto de romero y tocoferoles) en la estabilidad oxidativa del aceite de chía. Vanesa Y. Ixtaina, Susana M. Nolasco, Mabel C. Tomás. A \&G Aceites y Grasas 80 (2010): 486-488.

Presentaciones en Congresos con trabajo extendido

- Efecto de la adición de antioxidantes naturales (extracto de romero y tocoferoles) en la estabilidad oxidativa del aceite de chía. Vanesa Y. Ixtaina, Susana M. Nolasco; Mabel C. Tomás. Proceedings XIII Congreso Latinoamericano de Grasas y Aceites. Rosario, Argentina, 4 al 6 de noviembre de 2009.

\section{Presentaciones en Congresos}

- Effect of natural antioxidants on the oxidative stability of chia seed oil. Vanesa Y. Ixtaina, Susana M. Nolasco, Mabel C. Tomás. $101^{\text {st }}$ AOCS Annual Meeting \& Expo, Phoenix (USA), 16-19 mayo de 2010. 
Conclusiones generales 
El presente trabajo de Tesis permitió realizar la caracterización fisicoquímica de las semillas y del aceite de chía (Salvia hispanica L.) obtenido mediante distintos procesos así como la implementación de alternativas tecnológicas para su conservación, todo lo cual representa un aporte significativo tendiente a la revalorización y adecuada aplicación de este cultivo ancestral en la industria alimentaria, mediante el desarrollo de alimentos funcionales, con beneficios potenciales para el consumidor.

En virtud de ello, pueden expresarse las siguientes conclusiones generales:

\section{Semillas}

Se realizó la caracterización integral de las semillas de chía (núculas) provenientes de dos orígenes diferentes (Argentina y Guatemala), determinando sus propiedades físicas (de tamaño y forma, gravimétricas y friccionales), microestructura y características fisicoquímicas.

- Las mezclas comerciales estudiadas estuvieron constituidas por una elevada proporción de semillas oscuras (92-98\%) siendo escasa la presencia de semillas blancas. Las semillas de chía se caracterizaron por presentar una forma elipsoidal con tres semiejes desiguales y pequeño tamaño $(L=1,60$ $2,73 \mathrm{~mm} ; \quad W=1,22-1,50 \mathrm{~mm} ; \quad T=0,65-0,85 \mathrm{~mm})$, habiéndose observado la existencia de variabilidad tanto dentro de las mezclas comerciales estudiadas (semillas oscuras y blancas) como entre las mismas.

La densidad aparente, la densidad real, la porosidad y el peso de mil semillas variaron entre $0,667-0,722 \mathrm{~g} / \mathrm{cm}^{3} ; 0,980-1,009 \mathrm{~g} / \mathrm{cm}^{3} ; 27,9-33,1 \%$, y $1,150-$ $1,323 \mathrm{~g}$, respectivamente, mientras que la esfericidad registró valores entre $63,0-64,5 \%$.

Con respecto a las propiedades friccionales, las semillas de chía mostraron bajos valores de ángulo de reposo de $16-18^{\circ}$ y coeficiente de fricción de 0,28 y 0,31 en chapa galvanizada y acero inoxidable, respectivamente.

La información obtenida a partir de la caracterización de las propiedades físicas de las semillas de chía es de utilidad para mejorar eficientemente el diseño y la construcción de los equipos y estructuras para el manejo, 
recolección, transporte, limpieza, clasificación y procesamiento agroindustrial de las mismas.

- Se obtuvo información acerca de la microestructura de las semillas (núculas) de chía mediante microscopía electrónica de barrido (SEM). Las micrografías permitieron visualizar que las mismas están constituidas por el pericarpio el cual rodea a la semilla verdadera. La organización interna del pericarpio de las núculas de chía -de ambos orígenes- estudiadas correspondió a la estructura típica característica del género Salvia, al cual pertenecen. Desde el exterior hacia el interior del pericarpio pudo observarse el epicarpio -de importancia en la exudación de mucílago cuando las semillas de chía son humedecidas-, el mesocarpio y una capa de células de esclereidas, la cual le confiere rigidez a la semilla.

- La caracterización fisicoquímica de las semillas de chía mediante su composición centesimal (b.s.) reveló un contenido de proteínas de 19-29\%, lípidos $25-32 \%$ y fibra $27-29 \%$, con un tenor cenizas entre $4-5 \%$. Estos valores coinciden con los informados en la literatura para semillas de chía de otras procedencias.

- El estudio de compuestos antioxidantes evidenció la presencia de tocoferoles, cuyo contenido total varió de 95-110 ppm, representado en su mayor parte por $\mathrm{y}$-tocoferol y en menores proporciones, por $\delta$-tocoferol. Asimismo se detectaron compuestos polifenólicos, los cuales estuvieron constituidos principalmente por miricetina, ácidos clorogénico y cafeico así como trazas de kaempferol y quercetina.

\section{Aceite}

Se obtuvo el aceite de chía mediante diversos procesos de extracción, los cuales incluyeron tanto aquéllos utilizados tradicionalmente por la industria aceitera (extracción con solventes y prensado), así como a través de nuevas alternativas tecnológicas de extracción mediante el empleo de $\mathrm{CO}_{2}$ supercrítico. Posteriormente, se llevó a cabo la respectiva caracterización fisicoquímica de los aceites obtenidos, la cual puede contribuir con información de interés a fin de complementar la 
definición de estándares de calidad, debido a la escasa disponibilidad de especificaciones relacionada con este aceite no tradicional.

\section{Extracción mediante procesos convencionales}

- El rendimiento de aceite alcanzado mediante el proceso de prensado fue de alrededor del 30\% menor al extraído con hexano.

- Los aceites obtenidos mediante los procesos de prensado y de extracción con solvente presentaron un perfil de ácidos grasos similar, destacándose el contenido de ácidos $\alpha$-linolénico ( 65\%) y linoleico ( 20\%) así como el bajo tenor de ácidos grasos saturados ( 9\%). Se determinó la composición triacilglicerídica identificándose 12 especies diferentes de triacilgliceroles, la mayoría de los cuales presentó al menos un resto de ácido a-linolénico esterificado al glicerol, siendo la trilinolenina el principal compuesto.

Además, se registró la presencia de un moderado tenor de compuestos bioactivos, tales como tocoferoles, polifenoles, carotenoides y fosfolípidos, cuya composición cuantitativa fue influenciada por el proceso de extracción.

\section{Extracción por fluidos supercríticos (EFSC)}

- Se realizó la extracción de aceite de chía mediante la utilización de $\mathrm{CO}_{2}$ supercrítico $\left(\mathrm{SC}-\mathrm{CO}_{2}\right)$ a partir de semillas provenientes de Argentina y de México, evaluando el efecto de las principales condiciones operativas del proceso. Se evidenció una gran relevancia de la presión y del tiempo sobre el rendimiento de extracción, el cual aumentó al incrementarse los valores de estas dos variables. Por otra parte, la temperatura de extracción tuvo una baja incidencia sobre dicho parámetro.

- A través de una correcta selección de las condiciones operativas (presión, temperatura y tiempo) del proceso de extracción con $\mathrm{SC}-\mathrm{CO}_{2}$, fue posible alcanzar un rendimiento similar al obtenido mediante la extracción con hexano. Dichas condiciones fueron 450 bar, $138 \mathrm{~min}, 60^{\circ} \mathrm{C}$ a un caudal constante de $8 \mathrm{~kg} \mathrm{CO}_{2} / \mathrm{h}$ para el aceite obtenido a partir de las semillas de Salta (Argentina) y de 450 bar, $300 \mathrm{~min}, 80^{\circ} \mathrm{C}$ a $1,82 \mathrm{~kg} \mathrm{CO} / \mathrm{h}$ para las de 
Jalisco (México), lográndose un rendimiento de aceite de $97 \%$ y $93 \%$, respectivamente.

- Se obtuvo un modelo polinomial cuadrático mediante la utilización de la Metodología de Superficies de Respuesta (MSR), a fin de predecir el rendimiento de aceite de chía a partir de una determinada masa de semillas a un caudal constante de $\mathrm{CO}_{2}(1,8 \mathrm{~kg} \mathrm{CO} / \mathrm{h})$. Dicha información es de utilidad a fin de contribuir a un futuro reescalado a nivel industrial.

- Se realizó un estudio de la cinética del proceso de extracción por $\mathrm{SC}-\mathrm{CO}_{2}$, el cual puede ser dividido en dos periodos, rápido y lento, obteniéndose en el primero la mayor parte del aceite. Así, si bien es necesaria una evaluación económica de costo-beneficio, la extracción de aceite de chía mediante el empleo de dicho proceso sería factible principalmente durante el periodo rápido de extracción.

- La composición acídica del aceite de chía extraído utilizando las condiciones operativas óptimas de EFSC fue similar a la obtenida mediante extracción con Soxhlet. No obstante, el tiempo de extracción tuvo influencia sobre la composición de ácidos grasos de los aceites obtenidos mediante $\mathrm{SC}-\mathrm{CO}_{2}$.

- Con respecto a los parámetros de calidad de los aceites obtenidos en las condiciones óptimas de EFSC, el contenido de ácidos grasos libres así como el índice de peróxido fueron inferiores a los correspondientes al aceite extraído con hexano. Sin embargo, la estabilidad oxidativa de los aceites obtenidos mediante $\mathrm{SC}-\mathrm{CO}_{2}$ fue menor, lo cual podría relacionarse -entre otros factores- con el menor contenido de tocoferoles y la posible presencia de oxígeno en el solvente de extracción.

En virtud de lo expuesto, el aceite de chía podría ser utilizado para mejorar la relación de ácidos grasos $\omega-6: \omega-3$ cuyo desbalance caracteriza actualmente a las dietas occidentales, aportando además otros compuestos de interés nutricional.

Es necesario tener en cuenta, que si bien la composición acídica y triacilglicerídica así como el contenido de otros compuestos minoritarios le confieren al aceite de chía cualidades benéficas desde el punto de vista nutricional, su alto tenor de PUFAs se traduce en la baja estabilidad oxidativa de los aceites obtenidos, 
por lo cual es muy importante el desarrollo de estrategias que contribuyan a lograr su adecuada conservación.

\section{Conservación del aceite de chía}

Teniendo en cuenta las consideraciones previamente realizadas, se evaluó la influencia de diferentes parámetros sobre la conservación del aceite de chía (temperatura y tiempo de almacenamiento, adición de antioxidantes).

- La adición de diversos antioxidantes produjo un aumento de la estabilidad oxidativa del aceite de chía, la cual fue determinada mediante un ensayo acelerado de oxidación. Dicho incremento se relacionó con el tipo y concentración del antioxidante/mezclas de antioxidantes utilizados. Los mejores efectos se registraron con extracto de romero (5000 ppm) y sus mezclas con extracto de té verde $(2500,5000$ ppm) así como con palmitato de ascorbilo a partir de 2500 ppm.

- La oxidación del aceite de chía fue estudiada mediante calorimetría diferencial de barrido (DSC), habiéndose obtenido los respectivos termogramas que evidenciaron las transiciones correspondientes a la formación de los hidroperóxidos y su posterior descomposición en otros productos. Se determinaron los parámetros cinéticos de la oxidación del aceite de chía, calculándose los valores de $E_{a}$ a partir de las $T_{e} y T_{p 1}$, los cuales fueron de 67,9 y $57,8 \mathrm{~kJ} / \mathrm{mol}$, respectivamente, habiendo registrado este parámetro un incremento del 30\% con la adición de 2500 ppm de extracto de romero.

- El almacenamiento del aceite de chía permitió evaluar la influencia de los distintos tratamientos ensayados a fin de lograr una adecuada conservación del mismo. Pudo observarse un efecto muy relevante de la temperatura sobre la velocidad de oxidación del aceite de chía. Los aceites almacenados a $\mathrm{T}=4 \pm 1^{\circ} \mathrm{C}$ con o sin la incorporación de antioxidantes presentaron valores de peróxido (PV) inferiores al límite de aceptabilidad aplicable a aceites vegetales con alto tenor de PUFAs, si bien el aceite control comenzó a registrar un aumento significativo a partir de 165 días. En contraste, a 
$\mathrm{T}=20 \pm 2^{\circ} \mathrm{C}$ todos los aceites alcanzaron un nivel de PV de 10,0 meq peróxido/kg de aceite entre los 60-120 días de almacenamiento, excepto en el caso de la adición de palmitato de ascorbilo, en el cual dicho índice se mantuvo relativamente constante durante la duración del ensayo.

Cabe señalar además que la composición acídica no registró modificaciones significativas respecto de la inicial, no evidenciándose tampoco indicios de rancidez hidrolítica durante el almacenamiento estudiado. 
Perspectivas futuras 
En función de los resultados obtenidos, se propone continuar con el estudio de diversas alternativas de almacenamiento del aceite de chía a fin de prolongar su vida útil, a través de la adición de mezclas de palmitato de ascorbilo con los extractos de romero, de té verde así como con la mezcla de tocoferoles o la utilización de otros antioxidantes naturales.

Teniendo en cuenta las características de calidad y estabilidad del aceite de chía, se proseguirá la investigación estudiando la incorporación del mismo en aceites mezcla. Para ello, se prevé la realización de mezclas que contengan distintas proporciones de aceite de chía/aceite de girasol -principal aceite vegetal consumido en nuestro país- y/o girasol de alto oleico, a fin de lograr un producto rico en $\omega-3$, con un adecuado balance de ácidos grasos y de estabilidad, caracterizándolo en lo que respecta a su composición acídica, tocoferoles, fosfolípidos, estabilidad oxidativa, índice de acidez.

En este sentido, se han realizado ensayos preliminares de evaluación sensorial de mezclas de aceite de chía/aceite refinado de girasol. En primer lugar, se ha llevado a cabo un ensayo de discriminación (prueba del triángulo) a fin de determinar el máximo porcentaje de reemplazo de aceite de girasol por aceite de chía, por debajo del cual no se detectan diferencias sensoriales con respecto al aceite refinado de girasol. Los resultados de dicho ensayo mostraron que a partir de una sustitución del $1 \% \mathrm{v} / \mathrm{v}$, se evidenciaron diferencias sensoriales con respecto al aceite puro de girasol. Dicho nivel de sustitución, si bien mejora la relación $\omega-6: \omega-3$ del aceite puro de girasol ( $\omega-6: \omega-3=189: 1)$ a 63:1, es aún insuficiente para alcanzar los valores óptimos recomendados por la FAO-OMS de 5:1 a 10:1. Por tal motivo, se implementó un segundo ensayo de evaluación sensorial, determinando la aceptabilidad de un aceite mezcla con mayores beneficios nutricionales. Para ello se consideró una relación óptima $\omega-6 / \omega-3=6: 1$, lo que se logró reemplazando $15 \%(\mathrm{v} / \mathrm{v})$ de aceite de girasol por aceite de chía. Los resultados obtenidos mostraron que la aceptabilidad del aceite mezcla chía/girasol (15:85) no presentó diferencias significativas $(p>0,05)$ con respecto a la del aceite de girasol puro.

Seguidamente, se propone continuar las actividades de investigación con el estudio de la incorporación del aceite de chía en alimentos funcionales. En este sentido se formularán emulsiones funcionales $\mathrm{O} / \mathrm{W}$ con aceite de chía (fase oleosa). Así, se estudiarán los factores que determinan su formación y estabilización mediante el empleo de agentes emulsificantes proteicos (caseinato de sodio) y 
presencia de lactosa (fase acuosa), evaluando diversas alternativas que permitan mejorar su estabilidad física y deterioro oxidativo (adición de antioxidantes naturales, almacenamiento refrigerado) a fin de resguardar los atributos de calidad y aceptabilidad por parte del consumidor.

Por otra parte, cabe señalar que la microencapsulación es una técnica que permite proteger y aislar diversos compuestos sensibles (aromas, aceites esenciales, compuestos lipídicos) de la influencia adversa proveniente del entorno químico $(\mathrm{pH}$, temperatura, sales, oxígeno, etc.). Así, se estudiará la microencapsulación del aceite de chía a partir de la liofilización y/o secado spray de dichas emulsiones $\mathrm{O} / \mathrm{W}$, investigando la influencia de las condiciones operativas sobre la eficiencia del proceso, la calidad del material encapsulado (aceite de chía) y su potencial incorporación en diversos alimentos.

Paralelamente, en el grupo de investigación se está abordando el estudio de las características fisicoquímicas y funcionales de la harina residual de extracción del aceite de chía y de sus componentes (fibra dietética soluble -mucílago-, proteínas). En este sentido, se están investigando el efecto del método de obtención y la influencia de las condiciones operativas (temperatura, tiempo de proceso, $\mathrm{pH}$, fuerza iónica) sobre la composición y características estructurales, para evaluar la aplicación potencial de los productos derivados de la semilla de chía (fibra/mucílago, proteínas) como agentes espesantes/emulsificantes en la industria alimentaria. En virtud de ello, también se investigará la capacidad del mucílago (fibra soluble) como material con propiedades encapsulantes -simulando una estructura análoga a la de la semilla- que permita ocluir al aceite de chía.

Por otra parte, otros aspectos que deberían considerarse son el análisis de los efectos que ejercen los factores genéticos y ambientales sobre la calidad de las semillas de chía y los subproductos derivados de ella así como su impacto sobre los procesos tecnológicos. Este hecho puede ser aún complejo debido a los requerimientos agroclimáticos propios de dicho cultivo -cuya zona de producción se circunscribe a la región noroeste- y al incipiente desarrollo de cultivares comerciales de semillas de chía.

En virtud de lo expuesto, las investigaciones planteadas pretenden realizar un aporte al abordaje integral del aprovechamiento de los subproductos derivados del cultivo de la chía, el cual constituye no sólo una alternativa interesante desde el 
punto de vista de su aplicación en la industria alimentaria, sino también desde una perspectiva socioeconómica en la diversificación de la producción agropecuaria, principalmente de la región noroeste de nuestro país. 
Bibliografía 
Abalone R, Cassinera A, Gastón A, Lara MA (2004). Some physical properties of Amaranth seeds. Biosyst Eng 89: 109-117.

American Heart Association (1999). Functional foods: position of ADA. J Am Diet Assoc 99: 1278-1285.

American Journal of Pharmacy (1885). Material medical of the new Mexican pharmacopoeia, part I. Am J Pharm 57: 5-7.

American Soybean Association (2009). Soy Stats. A reference guide to important soybean facts and figures. Acceso en julio de 2010. SoyStats Home http://www.soystats.com/default.htm

Anwar F, Shahid Chatha SA, ljaz Hussain A (2007). Assessment of oxidative deterioration of soybean oil at ambient and sunlight storage. Grasas Aceites 58: 390395.

AOAC (1990). Official methods of analysis, $15^{\text {th }}$ edn. AOAC International, Gaithersburg, USA, 1067 p.

AOCS (1998). Official methods and recommended practices of the American Oil Chemists' Society. AOCS Press, Champaign, USA.

Arranz S, Cert R, Pérez-Jiménez J, Cert A, Saura-Calixto F (2008). Comparison between radical scavenging capacity and oxidative stability of nut oils. Food Chem 110: 985-990.

Aruoma OI, Halliwell B, Aeschbach R, Löliger J (1992). Antioxidant and pro-oxidant properties of active rosemary constituents: carnosol and carnosic acid. Xenob 22:257-268.

Autino H (2009a) Prólogo. En Temas selectos en aceites y grasas. Eds. JM Block y D Barrera Arellano, Editorial Blücher, San Pablo, Brasil, pp. ix-x.

Autino H (2009b). Capítulo 2. Preparación de semillas oleaginosas. En Temas Selectos en aceites y grasas. Eds. JM Block y D Barrera Arellano, Editorial Blücher, San Pablo, Brasil, pp. 31-95. 
Aviara NA, Haque MA (2000). Moisture dependence of density, coefficient of friction and angle of repose of guna seed and kernel. J Eng Applications 2: 44-53.

Awika J, Rooney L, Wu X, Prior R, Cisneros-Zevallos L. (2003). Screening methods to measure antioxidant activity of sorghum (Sorghum bicolor) and sorghum products. J Agr Food Chem 51: 6657-6662.

Ayerza R (Jr) (1995). Oil Content and Fatty Acid Composition of Chia (Salvia hispanica L.) from Five Northwestern Locations in Argentina. J Am Oil Chem Soc 72: 1079-1081.

Ayerza R (Jr), Coates W (1996). Nuevos cultivos industriales: Proyecto Regional del Noroeste de Argentina. En Progreso en nuevos cultivos. Ed. J. Janick, ASHS Press, Alexandria, USA, pp. 45-51.

Ayerza R (Jr), Coates W (1997). Selection and development of chia cultivars: initial results. Proceedings of the Annual Meeting of the Association for the Advancement of Industrial Crops, Saltillo, México.

Ayerza R (Jr), Coates W (2004). Protein and oil content, peroxide index and fatty acid composition of chia (Salvia hispanica L.) grown in six tropical and subtropical ecosystems of South Amercia. Trop Sci 44:131-135.

Ayerza R, Coates W (2005). Chia. Rediscovering a Forgotten Crop of the Aztecs ( $1^{\text {st }}$ ed.). The University of Arizona Press, Tucson, USA, 197 p.

Bailey, E (1950). Melting and solidification of fats. Intersciencie Publisers, Inc Eds., New York, USA.

Bas D, Boyaci IH (2007). Modeling and optimization I: Usability of response surface methodology. J Food Eng 78:836-845.

Baümler E, Cuniberti A, Nolasco SM, Riccobene IC (2006). Moisture dependent physical and compression properties of safflower seed. J Food Eng 72: 134-140.

Belitz HD, Grosch W (1999). Food Chemistry (2nd ed). Springer-Verlag, Berlin, Germany. 
Beltrán-Orozco MC, Romero MR (2003). Chía, alimento milenario. Rev. Ind. Alim. septiembre/octubre: 20-29.

Berg J M, Tymoczko J L, Stryer L (2002). Biochemistry. Ed. W.H. Freeman and Company, New York, USA.

Bockisch M (1998). Extraction of vegetable oils. En Fats and oils handbook. AOCS Press, Champaign, USA.

Boekenoogen HA (1941). Olien Vetten Oliezadan 26, 143, from Hilgitch TP and Williams PN (1964). The chemical constitution of Natural Fats, Champman \& Hall, London, UK.

Bostyn S, Duval-Onen F, Porte C, Coïc JP, Fauduet H (2008). Kinetic modeling of the degradation of the a-tocopherol in biodiesel-rape methyl ester. Biores Technol 99: 6439-6445.

Bourre J (2003) Relations of omega-3, omega-9 fatty acids and brain structure and functions. A review on recent data. Food financial cost of omega-3. OCL 10: 165174.

Boutin O, Badens E (2009). Extraction from oleaginous seeds using supercritical CO2: Experimental design and products quality. J Food Eng 92: 396-402.

Bowen RAR, Clandinin MT (2005). Maternal dietary 22:6n_3 is more effective than 18:3n_3 in increasing content in phospholipids of glial cells from neonatal rat brain. Brit J Nutr 93: 601-611.

Bozan B, Temelli $\mathrm{F}$ (2002). Supercritical $\mathrm{CO}_{2}$ extraction of flaxseed. J Am Oil Chem Soc 79: $231-235$.

Brennan JG, Butters JR, Cowell ND, Lilley AEV (1998). Las operaciones de la ingeniería de los alimentos ( $3^{\text {ra }}$ ed.) Ed. Acribia, S.A, Zaragoza, España.

Brevedan MV, Carelli AA, Crapiste GH (2000). Changes in composition and quality of sunflower oils during extraction and degumming. Grasas Aceites 51: 417-423. 
Brown J (2003). Chia seed and meal data. International Flora Technologies, Inc., Gilbert, Ariz, I p.

Brunner G (2005). Supercritical fluids: technology and application to food processing. J Food Eng 67: 21-33.

Budantsev AL, Lobova TA (1997). Fruit morphology, anatomy and taxonomy of Tribe Nepeteae (Labiatae). Edinburgh J Bot 54: 183-216.

Burkart A (1979). Flora llustrada de Entre Ríos (Argentina). Vol. 5. Colección Científica INTA, Buenos Aires, Argentina, 606 p.

Bushway AA, Belyea PR, Bushway RJ (1981). Chia seed as a source of oil, polysaccharide and protein. J Food Sci 46: 1349-1350.

Cahill JP (2004). Genetic diversity among varieties of chia (Salvia hispanica L.) Gen Res Crop Evol 51: 773.

Cahill JP (2005). Human selection and domestication of chia (Salvia hispanica L.). Gen Res Crop Evol 51: 773-781.

Cahill JP, Provance MC (2002). Genetics of qualitative traits in domesticated chia (Salvia hispanica L.). The $\mathrm{J}$ of Heredity 93: 52-55.

Çahşir S, Marakoğlu T, Öğüt H, Öztürk Ö (2005). Physical properties of rapeseed (Brassica napus oleifera L.). J Food Eng 69: 61-66.

Calvo L, Cocero MJ, Diez JM (1994). Oxidative stability of sunflower oil extracted with supercritical carbon dioxide. J Am Oil Chem Soc 71: 1251-1254.

Carelli AA, Frizzera LL, Forbito PR, Crapiste GH (2002). Wax composition of sunflower seed oils. J Am Oil Chem Soc 79: 763-768.

Catchpole OJ, Grey JB, Smalifield BM (1996). Near-Critical Extraction of Sage, Celery, adn Coriander Seed. J Supercr Fluids 9: 273-279.

Catchpole OJ, Tallon SJ, Eltringham WE, Grey JB, Fenton KA, Vagi EM, Vyssotski MV, Mackenzie AN, Ryan J, Zhu Y (2009). The extraction and fractionation of specialty lipids using near-critical fluids. J. Sup Fluids 47: 591-597. 
Chan HWS (1977). Photo-sensitized oxidation of unsaturated fatty acid methyl esters. The identification of different pathways- J Am Oil Chem Soc 54: 100-104.

Chapkin RS (1992) Reappraisal of the essential fatty acids. En Fatty Acids in Foods and their Health Implications. Ed. CK Chow, Dekker, New York, USA, pp. 429436.

Chapman, GW (1980). A conversion factor to determined phospholipid content in soybean and sunflower crude oils. J Am Oil Chem Soc 57: 299-302.

Che Man YB, Haryati T, Ghazali HM, Asbi BA (1999). Composition and thermal profile of cure palm oil and its products. J Am Oil Chem Soc 76: 237-242.

Chibnall AC, Piper SH, Williams EF (1953). Further observations on phrenosinic acid. Biochem J 55: 707-711.

Choe E, Min DB (2006). Mechanism and Factors for Edible Oil Oxidation. Compr Rev Food Sci Food Saf 5:169-186.

Chrastill J (1982). Solubility of solids and liquids in supercritical gases. J Phys Chem 86: 3016-3021.

Christie WW (2003). Lipid analysis: Isolation, separation, identification, and structural analysis of lipids $\left(3^{\text {rd }}\right.$ ed). Oily Press, Bridgwater, UK.

Clifford T. (1999). Fundamentals of supercritical fluids. Oxford University Press., New York, USA, $51 \mathrm{pp}$.

Clough RL, Yee BG, Foote CS (1979). Chemistry of singlet oxygen. 30. The unstable primary product of tocopherol photooxidation J Am Chem Soc 101: 683-686.

Coates W, Ayerza R (Jr) (1996). Production Potential of Chia in Northwestern Argentina. Ind Crops Prod 5: 229 - 233.

Coates W, Ayerza R (Jr) (1997). New crop trials in the Patagonian region of Argentina. Abstracts of an International Conference of the Association for the Advancement of Industrial Crops, 23, Saltillo, México. 
Coates W, Ayerza R (Jr) (1998). Commercial production of chia in Northwestern Argentina. J Am Oil Chem Soc 75: 1417 - 1420.

Codex Alimentarius Commission: Codex Stan (1999). Codex standard for edible fats and oils not covered by individual standards. Codex Stan 19-1981, Rev 2-1999

Codex Mendoza (1542). Ed. Francisco del Paso y Troncoso (1925). Museo Nacional de Arqueología, Historia y Etnografía, México DF, México.

Código Alimentario Argentino (2008). Secretaría de Políticas, Regulación e Institutos y Secretaría de Agricultura, Ganadería, Pesca y Alimentos. www.anmat.gov.ar/codigoa/Capitulo_XI.pdf (acceso 20/07/2010).

Comisión de las Comunidades Europeas (2009). Diario Oficial de la Unión Europea L $294 / 14$.

Concha J, Soto C, Chamy R, Zúñiga ME (2006). Effect of Rosehip Extraction Process on Oil and Defatted Meal Physicochemical Properties. J. Am.Oil Chem. Soc. 83: $771-775$.

Cordain L (1999). Cereal grains: humanity's double edged sword. World Rev. Nutr. Diet. 84: 19-73.

Cortéz y Lárraz P (1958). Descripción geográfico moral de la diócesis de Goathemala. Vol. 20. Guatemala City: Sociedad de Geografía e Historia de Guatemala.

Coşkuner Y, Karababa E, (2007a). Some physical properties of flaxseed (Linum usitatissimum L.). J Food Eng 78: 1067 - 1073.

Coşkuner Y, Karababa E (2007b). Physical properties of coriander seeds (Coriandrum sativum L.). J Food Eng 80: 408 - 416.

Cuppett S, Schnepf M, Hall III C (1997). Using Natural Antioxidants in Foods (Chap. 2). En Natural Antioxidants. Chemistry, Health Effects, and Applications. Ed. F. Shahidi, AOCS Press, Champaign, USA, pp. 12-24. 
Darr JA, Poliakoff M (1999). New Directions in Inorganic and Metal-Organic Coordination Chemistry in Supercritical Fluids. Chem Rev 99:495.

Davidovich L A, Sulé C L, Lupín H M (1980). Kinetics of fish meal oxidation. J Am Oil Chem Soc 57:43-47.

de Rijke YB, Bredie SJ, Demacker PN, Vogelaar JM, Hak-Lemmers HL, Stalenhoef A $F$ (1997). The redox status of coenzyme Q10 in total LDL as an indicator of in vivo oxidative modification. Studies on subjects with familial combined hyperlipidemia. Arterioscl, Thromb Vasc Biol 17: 127-133.

de Rijke E, Out P, Niessen WMA, Ariese F, Gooijer C, Brinkman UAT (2006). Analytical separation and detection methods for flavonoids, J Chrom A 1112 : 3163.

Decker EA (1998). Strategies for manipulating the prooxidative/ antioxidative balance of foods to maximize oxidative stability. Trends Food Sci Technol 9: $241-248$.

Decker EA, Warner K, Richards MP, Shahidi F (2005). Measuring antioxidant effectiveness in food. J Agr Food Chem 53: 4303-4310.

del Valle JM, Aguilera JM (1988). An improved equation for predicting the solubility of vegetable oils in supercritical $\mathrm{CO}_{2}$. Ind Eng Chem Res 27: 1551-1553.

Demarco A (2009). Capítulo III: Extracción por solvente. En Temas Selectos en Aceites y Grasas. Eds. JM Block y D Barrera Arellano, Editorial Blücher, San Pablo, Brasil, pp. 67-95.

Deshpande SD, Bal S, Ojha TP (1993). Physical properties of soybean. J Agr Eng Res 56: 89- 98.

Devlin TM (2004). Bioquímica: Libro de texto con aplicaciones clínicas. Ed. Reverte, Barcelona, España.

Diario Oficial de la Unión Europea (2009). Autorización de la comercialización de semillas de chía (Salvia hispanica) como nuevo ingrediente alimentario con arreglo al Reglamento (CE) N²58/97 del Parlamento Europeo y del Consejo. 
Diehl BW (2008). NMR Spectroscopy of natural susbstances. Chapter 3 En: NMR Spectroscopy in Pharmaceutical Analysis. Eds. Holzgrabe U, Wawer I \& Diehl, B.W., Elsevier, Amsterdam, The Netherlands.

Dobarganes C, Márquez-Ruiz G (2003). Oxidized fats in foods. Curr Opin Clin Nutr Metab Care 6: 157-163.

Dunford NT, Teel JA, King JW (2003). A continuous counter current supercritical fluid deacidification process for phytosterol ester fortification in rice bran oil. Food Res Int 36: 175-181.

Dutta SK, Nema VK, Bhardwaj RK (1988). Physical properties of grain. J Agr Eng Res 39: 259-268.

Dyszel SM, Pettit BC (1990). Determination of the country origin of Pistachio Nuts by DSC and HPLC. J Am Oil Chem Soc 67: 947-951.

Eaton SB, Eaton III SB, Sinclair J, Cordain L, Man NJ (1998). Dietary intake of longchain polyunsaturated fatty acids during the Paleolithic. World Rev Nutr Diet 83: 12-23.

Eggers, R. (1996). Supercritical fluid extraction (SFE) of oilseed/lipids in natural products. En Supercritical fluid technology in oil and lipid chemistry. Eds. King JW, List GR, AOCS Press, Champaign, USA, pp. 35.

Eggers R, Ambrogi A, von Schnitzler J (2000). Special features of SCF solid extraction of natural products: deoiling of wheat gluten and extraction of rosehip oil. Braz J Chem Eng 17: 329-334.

Elliot JG (1999). Application of antioxidant vitamins in foods and beverages. Food Techn 53: 46-48.

Engel FA (1987). De las begonias al maíz: vida y producción en el Perú antiguo. Centro de Investigaciones de Zonas Áridas. Universidad Nacional Agraria La Molina, Lima, Perú.

Espinosa B (2001). Procesamiento supercrítico de productos naturales. Modelado, Análisis y Optimización. Tesis Doctoral. Universidad Nacional del Sur. 
Esterbauer H (1993). Cytotoxicity and genotoxicity of lipid oxidation products. Am J Clin Nutr 56: 7796-7865.

FAO/WHO Food Agricultural Organization/World Health Organization of the United Nations (1993). Joint FAO/WHO Food Standards Programme: Codex Alimentarius Commission: Fats, oils and related prodcuts, Codex standard for named vegetable oils, Codex-STAN 210 , vol $8,2^{\text {nd }}$ ed , Rome, Italy.

Flynn JH, Wall LA (1966). A quick direct method for determination of activation energy from thermogravimetric data. J Polym Sci B Polym Lett 4: 323-328.

Follegatti-Romero L, Piantino C, Grimaldi R, Cabral F (2009). Supercritical CO2 extraction of omega-3 rich oil from Sacha Inchi (Plukenetia volubilis L.) seeds. $J$ Sup Fluids 49: 323-329.

Food and Drug Administration (FDA) (2009). Listing of Food Additive. www.fda.gov/Food/FoodIngredientsPackaging/FoodAdditives/ucm191033.htm

Frankel, EN (1991). Recent advances in lipid oxidation. J Sci Food Agric 54: 495511.

Frankel EN (2005). Lipid Oxidation. The Oily Press, Bridgewater, UK.

Frankel EN, Huang S-W, Kanner J, German JB (1994). Interfacial phenomena in the evaluation of antioxidants: bulk oils versus emulsions. J Agr Food Chem 42: 10541059.

Freese R, Mutanen M. (1997). $\alpha$-Linolenic acid and marine long-chain n-3 fatty acids differ only slighty in their effects on hemostatic factors in healthy subjects. Am $J$ Clin Nutr 66:591-598.

Friedrich JP, Pryde EH (1984). Supercritical $\mathrm{CO}_{2}$ Extraction of Lipid-Bearing Materials and Characterization of the Products. J Am Oil Chem Soc 61: 223-228.

Galli C, Marangoni F (2006) $n-3$ fatty acids in the mediterranean diet. Prostag. Leukotr. Ess. Fatty Acids 75: 129-133. 
Garti N, Aronhime JS, Saring S (1989). The role of chain length and an emulsifier on the polymorfism of mixture of triglycerides. J Am Oil Chem Soc 8:1085-1089.

Giuffrida F, Destaillats D, Herrero Egart M, Hug B, Golay P, Skibsted LH, Dionisi F (2007). Activity and thermal stability of antioxidants by differential scanning calorimetry and electron spin resonance spectroscopy. Food Chem 101: 11081114.

Gómez AM, López CP, Martínez de la Ossa E (1996). Recovery of grape seed oil by liquid and supercritical carbon dioxide extraction: a comparison with conventional solvent extraction. Chem Eng J Bioch Eng J 61: 227-231.

Gordon MH, Rahman IA (1991). Effect of processing on the composition and oxidative stability of coconut oil. J Am Oil Chem Soc 68: 574-576.

Granstrom E, KumLin M (1987). Metabolism of prostaglandins and lipoxygenase products: Relevance for eicosanoid assay. En Prostaglandins and Related Substances. Eds. C. Benedetto, RG McDonald-Gibson, S Nigram, TF Slater. IRL Press, Oxford, UK, pp. 5-27.

Guan X, Yao, H (2008). Optimization of viscozyme L-assisted extraction of oat bran protein using response surface methodology. Food Chem 106: 345 - 351.

Guiragossian VY, Van Scoyoc SW, Auxtell JD (1977). Chemical and Biological Methods for Grain and Forage Sorghum. Departament of Agronomy International Programs in Agricutlure, Purdue University, West Lafayette, Indiana, USA.

Gunstone FD (2002). Vegetable oils in food technology: composition, properties and uses. Ed. Blackwell Publishing, CRC Press, Oxford, UK.

Gunstone FD (2006). Minor Specialty Oils. Nutraceutical and Specialty Lipids and their Co-Products (vol. 5). En Nutraceutical Science and Technology Series, Ed. F. Shahidi, Taylor and Francis Ed., Boca Ratón, USA, pp. 91-125.

Guo DA, Venkatramesh M, Nes WD (1995). Development regulation of sterol biosynthesis in Zea mays. Lipids 30:203-219. 
Gupta RK, Das SK (1997). Physical properties of Sunflower seeds. J Agr Eng Res 66: 1-8.

Gupta SK, Jaworski RJ (1991). An evaluation of the efficacy of antioxidants in soap by Differential Scanning Calorimetry (DSC). J Am Oil Chem Soc 68: 278-279.

Haque MS, Ghoshal KK (1981) Floral biology and breeding system in the genus Salvia L. Proc Indian Nat Sci Acad B47:716-724.

Hassan MN, Rahman NN, Ibrahim MH, Omar AK (2000). Simple fractionation through the supercritical carbon dioxide extraction of palm kernel oil. Sep Purif Technol 19: 113-120.

Hedge IC (1970). Observations on the mucilage of Salvia fruits. Notes Roy Bot Gard Edinburgh 30:79-95.

Hernández M, Chávez A, Bourges H (1977). Valor nutritivo de los alimentos mexicanos. Tablas de uso práctico. Instituto Nacional de la Nutrición. México. L 12.

Hernández-Gómez JA, Miranda-Colín S,.Peña-Lomelí A (2008). Cruzamiento natural de chía (Salvia hispanica L.). Revista Chapingo. Serie hortic 14: 331-337.

Herrero M, Cifuentes A, Ibañez E (2006). Sub and supercritical fluid extraction of functional ingredients from different natural sources: plants, food-by-products, algae and microalgae: A review. Food Chem 98: 136-148.

Hicks S (1966). Desert plants and people. Naylor Company, San Antonio, USA.

Hirschmann $H$ (1960). The nature of substrate asymmetry in stereoselective reactions. J Biol Chem 235: 2762-2767.

Ho CT, Chen CW, Wanasundara UN, Shahidi F (1997). Natural Antioxidants from Tea (Chap. 12). En Natural Antioxidants. Chemistry, Health Effects, and Applications. Ed. F. Shahidi, AOCS Press, Champaign, USA, pp. 213-223.

Howell RW, Collins FI (1957). Factors affecting linolenic and linoleic acid content of soybean. Agron J 49: 593-597. 
Huang D, Ou B, Prior R (2005). The chemistry behind antioxidant capacity assays. J Agr Food Chem 53: 1841-1856.

Ikeda I, Tanake K, Sugano M, Vahouny G, Gallo L (1988). Inhibition of cholesterol absorption in rats by plant sterols. J. Lipid Res 29:1573-1582.

Instituto Argentino de Racionalización de Materiales (IRAM) (1970). Norma 5597/70. Aceites vegetales. Micrométodo de determinación de fósforo. Ed. IRAM Buenos Aires, Argentina.

Insituto Nacional de Alimentos (2003). Análisis fisicoquímico de semillas de chía. Buenos Aires, pp. 1.

Iqbal S, Bhanger M, Anwar F (2005). Antioxidant properties and components of some commercially available varieties of rice bran in Pakistan. Food Chem 93: 265272.

IUPAC (1979). Nomenclature of Organic Chemistry, Sections A, B, C, D, E, F, and H. Pergamon Press, London, UK, pp.182.

IUPAC (1992). Standard Methods for the Analysis of oils, Fats and Derivates. $\left(7^{\text {th }}\right.$ ed.) Eds. Paquot C, Hautffenne A. International Union of Pure and Applied Chemistry, Blackwell Scientific Publications Inc., Oxford, UK.

Jachmanián I, Margenat L, Torres A, Grompone MA (2006). Estabilidad oxidativa y contenido de tocoferoles en el aceite de canola extraído con $\mathrm{CO}_{2}$ supercrítico. Grasas Aceites 57: 155 - 159.

Jain RK, Bal S (1997). Physical properties of Pearl millet. J Agr Eng Res 66: 85-91.

Jiao S, Li D, Huang Z, Zhang Z, Bhandari B, Chen X, Mao Z (2008). Optimization of supercritical carbon dioxide extraction of flaxseed oil using response surface methodology. Int J Food Eng 4: 1-17.

Jiménez Márquez A, Beltrán Maza G, Aguiera Herrera MP, Uceda Ojeda M (2007). Calorimetría diferencial de barrido. Influencia de la composición del aceite de oliva virgen en su perfil térmico. Grasas Aceites 58: 122-129. 
Johnson LE (1995). Food technology of the antioxidant nutrients. Crit Rev Food Sci Nutr 35: 149.

Jung MY, Min DB (1990). Effects of oxidized $\alpha-.,-, y \delta$ tocopherols on the oxidative stability of purified soybean oil. J Food Sci 55: 1464.

Kachru RP, Gupta RK, Alam A (1994). Physico-chemical Constituents and Engineering Properties. Scientific Publishers, Jodhpur, India.

Kamal-Eldin A., Appelqvist L-Å (1995). The Effects of Extraction Methods on Sesame Oil Stability. J Am Oil Chem Soc 72: 967-969.

Kamal-Eldin A, Appelqvist L-A (1996). The chemistry and antioxidant properties of tocopherols and tocotrienols. Lipids 31: 671-701.

Kamal-Eldin A, Pokorný J (2005). Analysis of Lipid Oxidation. Eds. Kamal-Eldin A, Pokorný, AOCS Press, Champaign, Illinois, USA.

Karnofsky G (1949). The theory of solvent extraction, J Am Oil Chem Soc 26: 564569.

Karnofsky G (1986). Design of oil seed extractors I. Oil extraction. J Am Oil Chem Soc 63: 1011-1014.

Karnofsky G (1987). Design of oil seed extractors I. Oil extraction (Supplement). J Am Oil Chem Soc 64: 1533-1536.

King ChO, Katz DL, Brier JC (1944). The solvent extraction of soybean flakes. American Institute of Chemical Engineers, University of Michigan, Ann Arbor, Michigan, USA, pp.533-556.

King JW (1993) Analysis of fats and oils by SFE and SFC. Inform 4: 1089-1098.

Labuza TP, Mc Nayli L, Gallagher D, Hawekes J, Hurtado F (1972). Stability of intermediate moisture foods. 1. Lipid Oxidation. J Food Sci 37:154-159.

Lambelet P, Saucy F, Loliger J (2000). Mecanismos de acción de los antioxidantes. Aceites Grasas 39: 217-220. 
Leo L, Rescio L, Ciurlia L, Zacheo G (2005). Supercritical carbon dioxide extraction of oil and a-tocopherol from almond seeds. J Sci Food Agr 85: 2167-2174.

León J (1987). Botánica de los cultivos tropicales ( $2^{\mathrm{a}}$ ed.). IICA, Ed. Agroamérica, San José, Costa Rica, 525 p.

Lin KY, Daniel JD, Whistler RL (1994). Structure of chia seed polysaccharide exudate. Carbohydr Polym 23: 13-18.

Ling WH, Jones PJ (1995). Dietary Phytosterols: A review of metabolism, benefits and side effects. Life Sci 57:195-206.

List GR, Evans CD, Kwolek K, Warner K, Bound BK (1974). Oxidation and quality of soybean oil: A preliminary study of the anisidine test. J Am Oil Chem Soc 51: 1721.

List GR, Evans CD, Black LT, Mounts TL (1978). Removal of phosphorus and iron by commercial degumming of soybean oil. J Am Oil Chem Soc 55: 275-276.

Litwinienko G (2001). Autoxidation of unsaturated fatty acids and their esters. J Therm Anal Calorim 165: 639-646.

Litwinienko G, Kasprzycka-Guttman T, Jarosz-Jarszewska (1995). Dynamic and isothermal DSC investigation of the kinetics of thermooxidative decomposition of some edible oils. $J$ Therm Anal 45: 741-750.

Litwinienko G, Kasprzycka-Guttman T (1998). A DSC study on thermoxidation kinetics of mustard oil. Thermochim Acta 319: 185-191.

Litwinienko G, Kasprzycka-Guttman T, Jamaneck D (1999). DSC study of antioxidant properties of dihydroxyphenols. Thermochim Acta 331: 79-86.

Machmudah S, Kawahito Y, Sasaki M, Goto M (2007). Supercritical $\mathrm{CO}_{2}$ extraction of rosehip oils: Fatty acids composition and process optimization. $J$ Sup Fluid 41: 421-428.

Maduako JN, Faborode MO (1990). Some physical properties of cocoa pods in relation to primary processing. Ife J Technol 2: 1-7. 
Mann P (1959). Systematics of flowering plants. Methuen and Co. Ltd. London, UK, pp. 254-255.

Mannina L, Luchinat C, Emanuele MC, Segre A (1999). Acyl positional distribution of glycerol tri-esters in vegetable oils: a ${ }^{13} \mathrm{C}$ NMR study. Chem Phys Lipids 103: 4755.

Mariani C, Venturini S (1996). Sull'aumento delle cere durante la conservazione degli oli di olive. Riv Ital Sos. Grass 73: 489-498.

Marikkar JMN, Lai OM, Ghazali HM, Che Man YB (2002). Compositional and thermal analysis of RBD palm oil adulterated with lipase-catalyzed interesterified lard. Food Chem 76: 249-28.

Martin Mosquero MA, Pastor J, Juan R (2004). Estudio de las núculas de Calamintha Mill. y Clinopodium L. (Lamiaceae) en el suroeste de España. Lazaroa 25: 135141.

Martínez M (1959). Plantas Útiles de la Flora Mexicana. Ediciones de Botas, DF, México, pp. 198-202.

Martínez M (2010) Extracción y caracterización de aceite de nuez (Juglans regia L.): influencia del cultivar y de factores tecnológicos sobre su composición y estabilidad oxidativa. Tesis doctoral. Universidad Nacional de Córdoba.

Martínez ML, Mattea MA, Maestri DM (2008). Pressing and supercritical dioxide extraction of walnut oil. J Food Eng 88: 399 - 404.

Mason RL, Gunst RF, Hess JL (2003). Statistical Design and Analysis of Experiments. Wiley, NewYork, USA.

Matt B (2008). Chia: The Ord Valley's new super crop. ABC Rural. http://www.abc.net.au/rural/content/2008/s2367335.htm. Acceso en Julio de 2010.

Mattea MA (1999). Fundamentos sobre el prensado de semillas oleaginosas. Aceites Grasas: $427-431$. 
Mattson FH (1963). The specific distribution of unsaturated fatty acids in triglycerides of plants. J Lipid Res 4:392.

McCabe WL, Smith JC, Harriot P (1986). Unit Operations of Chemical Engineering. McGraw- Hill, New York, USA.

Mead JF, Alfin-Slater RB, Howton DR, Popjat G (1986). Lipids: Chemistry, Biochemistry and Nutrition. Plenum Press, New York, USA, 486 pp.

Meléndez - Martínez A, Britton J, Vicario I, Heredia F (2006). Relationship between the colour and the chemical structure of carotenoid pigments. Food Chem 101: 1145-1150.

Messina V, Biolatto A, Descalzo AM, Sancho A, Baby R, Walsoe de Reca N (2009). Effect of pan-frying in extra-virgin olive oil on odour profile, volatile compounds and vitamins. Int J Food Sci Techn 44: 552-559.

Metrohm Ionenanalytik (2001). 743 Rancimat - Instrucciones para el Uso. Harisau, Suiza.

Minguez-Mosquera MI, Rejano L, Gandul B, Sanchez AH, Garrido J (1991). Colorpigment correlation in virgin olive oil. J Am Oil Chem Soc 68: 332-336.

Miranda F (1978). La vegetación de Chiapas. Primera parte. Ediciones del Gobierno del estado. Sección autográfica. Departamento de Prensa y Turismo. Tuxtla Gutiérrez, México, pp. 311-312.

Mohsenin NN (1986). Physical properties of plant and animal materials. Gordon Breach Science Publishers ( $2^{\text {nd }}$ ed. $)$, New York, USA.

Molero Gómez A, Martínez de la Ossa E (2002). Quality of borage seed oil extracted by liquid and supercritical carbon dioxide. Chem Eng J 88: 103-109.

Moreau RA, Kamal-Eldin A (2009). Gourmet and Health-Promoting Specialty Oils. Eds. Moreau RA, Kamal-Eldin A, AOCS Press, 587 p. 
Multon JL (1982). Conservation et stockage des grains et graines et produits derivés. Collection sciences et techniques agro-alimentaires, Technique et documentation (Lavoisier).

Myers NW (1977). Solvent extraction in the soybean industry. J Am Oil Chem Soc 54: 491-493.

Namiki M (1990). Antioxidants/antimutagens in food. Crit Rev Food Sci Nutr 29:273.

Nassu RT, Gonçalves LAG (1999). Determination of meeting point of vegetable oils and fats by differential scanning calorimeter (DSC) technique. Grasas Aceites 50: 16-21.

National Research Council (1989) Lost crops of the Incas: little-known plants of the Andes with promise for worldwide cultivation. National Academic Press, Washington DC, USA.

Nawar W W (1996). Lipids. En Food Chemistry, Cap. 15. Ed. Fennema O., Marcel Dekker Inc., New York, USA.

Nielsen SS (1998). Food analysis. En Crude fats analysis. Purdue University, West Lafayette, USA, pp. 203-214.

Nik WBW, Ani FN, Masjuki HH, Giap SGE (2005). Rheology of bio-edible oils according to several rheological models and its potential as hydraulic fluid. Ind Crops Prod 22: 249-255.

Nilsson WB (1996). Supercritical Fluid Extraction and Fractionation of Fish Oils. En Supercritical Fluid Technology in Oil and Lipid Chemistry, edited by JW King and GR List, AOCS Press, Champaign, USA, pp. 180-212.

Nilsson WB, Hudson JK (1993). Solubility of simple and mixed triacylglycerols in supercritical $\mathrm{CO}_{2}$. J Am Oil Chem Soc 70:749-754.

Norulaini NAN, Setianto WB, Zaidul ISM, Nawi AH, Azizi CYM, Mohd Omar AK (2009). Effects of supercritical carbon dioxide extraction parameters on virgin coconut oil yield and medium-chain triglyceride content. Food Chem 116: 193197. 
Oje K, Ugbor EC (1991). Some physical properties of oil bean seed. J Agr Eng Res 50: 305-313.

Olajide JO, Ade-Omowaye BIO (1999). Some physical properties of Locust bean seed. J Agr Eng Res 74: 213-215.

Oliveira R, Rodríguez MF, Bernardo-Gil MA (2002). Characterization and supercritical carbon dioxide extraction of walnut oil. J Am Oil Chem Soc 79: 225230.

Oomah BD, Kenasehuk EO (1995). Cultivars and agronomic aspects. En Flaxseed in Human Nutrition. Eds. SC Cunnane and LU Thompson. AOCS Press, Champaign, USA, pp. 43-45.

Oyelade OJ, Odugbenro PO, Abioye AO, Raji NL (2005). Some physical properties of African star apple (Chrysophyllum alibidum) seeds. J Food Eng 67: 435-440.

Özarslan C (2002). Physical properties of cotton seed. Biosyst Eng 83: 169-174.

Ozawa T (1965). A new method of analyzing thermogravimetric data. Bull Chem Cos Jpn 38: 1881-1885.

Ozawa T (1970). Kinetic analysis of derivative curves in thermal analysis. $J$ Therm Anal 2: 301-324.

Özkal SG (2009). Response surface analysis and modeling of flaxseed oil yield in supercritical carbon dioxide. J Am Oil Chem Soc 86: 1129 - 1135.

Özkal SG, Salgin U, Yener ME (2005a) Supercritical carbon dioxide extraction of hazelnut oil. J Food Eng 69: 217 - 223

Özkal SG, Yener ME, Bayindırli L (2005b) Mass transfer modeling of apricot kernel oil extraction with supercritical carbon dioxide. J Supercr Fluid 35: 119-127.

Panfili G, Cinquanta L, Fratianni A, Cubadda R (2003). Extraction of Wheat Germ Oil by Supercritical $\mathrm{CO}_{2}$ : Oil and Defatted Cake Characterization. J Am Oil Chem Soc 80: 157-160. 
Parker TD, Adams DA, Zhou K, Harris M, Yu L (2003). Fatty acid composition and oxidative stability of cold-pressed edible seed oils. J. Food Sci. 68: 1240-1243.

Patricelli A, Assogna A, Emmi E, Sodini G (1979). Fattori che influenzano lèstrazione del lipidi da semi decorticati di girasole. Riv Ital Sost Grasse 61: 136-142.

Pericin D, Radulovic L, Trivic S, Dimic E (2008). Evaluation of solubility of pumpkin seed globulins by response surface method. J Food Eng 84: 591-594.

Pérez EE, Carelli AA, Crapiste GH (2004). Chemical characterization of oils and meals from wild sunflower (Helianthus petiolaris nutt). J Am Oil Chem Soc 81: 245-249.

Pérez-Camino MC, Moreda W, Mateos R, Cert A (2003). Simultaneous determination of long-chain aliphatic aldehydes and waxes in olive oils. J Chrom A 983: 283288.

Pinto F, Vicente A, Marsico G, Vonghia G, Montemurro O (1992). In vivo digestibility and Nutritive Characteristics of Diets Containing Almond Hulls Supplemented with Undercorticated Sunflower Oilseed Meal. Proceedings of the $13^{\text {th }}$ International Sunflower Conference, Int. Sunflower Conference, Int Sunflower Assoc., Paris, France, Vol II: 1632-1637.

Plants for a Future (2002). Acceso en Julio de 2010. http://www.pfaf.org/database/

Prámparo M, Mattea M, Gregory S (2003). Influencia del tipo de contacto sólido líquido en la extracción de aceites vegetales. Aceites Grasas 53: 592-597.

Ramamoorthy TP (1985). Salvia L. En Flora Fanerógama del Valle de México. Volumen II (Dicotiledóneas). Eds. J Rzedowski, GC De Rzedowski, Instituto Politécnico Nacional de México, DF, México, pp. 298-310.

Ramamoorthy TP y Elliot M (1993). Mexican Lamiaceae: diversity, distribution, endemism and origin. En Biological Diversity of Mexico. Origin and Distribution. Eds. TP Ramamoorthy, R Bye, A Lot, J Fa, Oxford University Press, New York, USA, pp. 513-42. 
Ramírez MC, Quiles JL (2005). Vitamina C, vitamina E y otros antioxidantes. En Tratado de Nutrición. Tomo I: Bases Fisiológicas y Bioquímicas de la Nutrición Eds. F. Sánchez, A. Medina Gil, Acción Médica, Madrid, España.

Ravenet J (1992). Silos. Editorial Barcelona Ravenet, Barcelona, España, 191 p.

Rawls HR, Van Santen PJ (1968). Singlet oxygen and the initiation of fatty acid autooxidation. Tetrahedron Lett 14: 1675-1678.

Reische DW, Lillard DA, Eitenmiller RR (2008). Antioxidants (Cap. 15). En: Food Lipids. Chemistry, Nutrition and Biotechnology. Eds. Casimir Akoh y David Min, CRC Press, Boca Ratón, USA, pp. 409-433.

Robinson D (1991). Bioquímica y valor nutritivo de los alimentos. Ed. Arancibia S.A., Zaragoza, España

Rodríguez Vallejo J (1992). Historia de la agricultura y de la fitopatología, con referencia especial a México. Colegio de Post-graduados en Ciencias Agrícolas, Ciudad de México, México.

Rossell JB (1983). Measurements of rancidity. En Rancidity in Foods. Eds. JC Allen and J Hamilton, Applied Science Publisher, London, UK, pp. 21-45.

Rubio-Rodríguez N, de Diego SM, Beltrán S, Jaime I, Sanz MT, Rovira J (2008). Supercritical fluid extraction of the omega-3 rich oil contained in hake (Merluccius capensis-Merluccius paradoxus) by-products: study of the influence of process parameters on the extraction yield and oil quality. J Sup Fluids 47: 215-226.

Ruetsch L, Daghero J, Mattea M (2003). Supercritical extraction of solid matrices. Model formulation and experiments. Lat Am Appl Res 33: 103-107.

Rulfo JM (1937). La chia. Agricultura I: 28 - 37.

Ryding $O$ (1992). Pericarp structure and phylogeny within Lamiaceae subfamily Nepetoideae tribe Ocimeae. Nord J Bot 12: 273-298.

Sahagún, B (1579). Historia general de las cosas de Nueva España (Codex Florentino). Eds. A.M. Garibay, 1989. Editorial Porrua, DF, México. 
Salgin U, Döker O, Çalimli A (2006) Extraction of sunflower oil with supercritical $\mathrm{CO}_{2}$ : Experiments and modeling. J Supercr Fluids 38:326-331

Salgin S, Salgin U (2006). Supercritical fluid extraction of walnut kernel oil. Eur J Lipid Sci Tech 108: 577-582.

Saura-Calixto F, Goñi I (2006). Antioxidant capacity of the Spanish Mediterranean diet. Food Chem 94: 442-447.

Schwarz K, Ternes W (1992). Antioxidative constituents of Rosmarinus officinalis and Salvia officinalis. Zeitschrift für Lebensmitteluntersuchung und -Forschung A 195: 99-103.

Shahidi F (1997). Natural antioxidants: an overview. En Natural Antioxidants, Chap. 1. Ed. Shahidi F., AOCS Press, Illinois, USA.

Shahidi F, Wanasundara PKJPD (1992). Phenolic antioxidants. Crit Rev Food Sci Nutr 32: 67-103.

Simon JA, Pong J, Bernert J, Browner W (1995) Serum fatty acids and the risk of stroke. Stroke 26: 778-782.

Simon P, Kolman L, Niklová I, Schmidt S (2000). Analysis of the period of oxidation of edible oils by Differential Scanning Calorimetry (DSC). J Am Oil Chem Soc 77: 639-642.

Simopoulos AP (1998). Overview of evolutionary aspects of omega-3 fatty acids in the diet. En The return of $\omega-3$ fatty acids into the food supply. I. Land-based animal food products and their health effects. Ed. A.P Simopoulos, World Rev Nutr Diet vol. 83, Karger, Basel, Suiza, pp. 1-11.

Simopoulos AP (2004). Omega-6/omega-3 essential fatty acid ratio and chronic diseases. Food Rev Int 20: 77-90.

Singh J, Bargale PC (1990). Mechanical expression of oil from linseed. J Oilseeds Res 7: 106-110. 
Singh J, Bargale PC (2000). Development of a small capacity double stage compression screw press for oil expression. J Food Eng 43: 75-82.

Singh KK, Goswami TK (1996). Physical properties of Cumin seed. J Agr Eng Res 64: 93-98.

Singh KK, Wiesenborn DP, Tostenson K, Kangas N (2002). Influence of moisture content and cooking on screw pressing of crambe seed. J Am Oil Chem Soc 79: 165-170.

Slater TF, McDonald-Gibson RG (1987). Introduction to the eicosanoids. En Prostaglandins and Related Substances. Eds. C. Benedetto, RG McDonaldGibson, S Nigram and TF Slater, IRL Press, Oxford, UK, pp. 1-4.

Song JH, Fujimoto K, Miyazawa T (2000). Polyunsaturated (n-3) fatty acids suceptible to peroxidation are increased in plasma and tissue lipids of rats fed docosahexaenoic acid-containing oils. J Nutr 130: 3028-3033.

Soustelle J (1955). La vie quotidienne des aztèques à la veille de la conquête espagnole. Ed. Hachette, París, Francia.

Stahl E, Schutz E, Mangold HK (1980). Extraction of Seed Oils with Liquid and Supercritical $\mathrm{CO}_{2}$. J Agr Food Chem 28: 1153-1157.

Statgraphics Plus Version 4.0. (1999). Statistical Graphic Corporation. Manugistics Inc., Rockville, USA.

Studio Balance (2010). http://www.chiasund.dk/plant.htmL. Acceso 25/07/2010.

Sugihara N, Tsuruta Y, Date Y, Furuno K, Kohashi K (1994). High peroxidative susceptibility of fish oil polyunsaturated fatty acid in cultured rat hepatocytes. Tox Appl Pharm 126:124-128.

Szydlowska-Czerniak A, Karlovits G, Dianoczki C, Recseg K, Szlyk E (2008). Comparison of two analytical methods for assessing antioxidant capacity of rapeseed and olive oils. J Am Oil Chem Soc 85: 141-149. 
Taga MS, Miller EE, Pratt DE (1984). Chia seeds as a source of natural lipid antioxidants. J Am Oil Chem Soc 61, 928-931.

Tan CP, Che Man YB (2000). Differential Scanning Calorimetry Analysis of edible oils: comparison of thermal properties and chemical composition. J Am Oil Chem Soc $77: 143-155$.

Tan CP, Che Man YB (2002). Differential Scanning Calorimetry of palm oil: effects of scanning rate variation. Food Chem 76: 89 - 102.

Tecante A (2010). Comunicación personal.

Thompson RA, Isaacs GW (1967). Porosity determination of grains and seeds with air comparison pycnometer. Trans ASAE 10: 693-696.

Ting IP, Brown JH, Naqvi J, Kumamoto J, matsumura M (1990). Chia: a potential oil crop for arid zones. Proceedings of the First International Conference on New Industrial Crops and Products. Eds. HH Naqvi, A Estilai and IP Ting. Association for the Advancement of Industrial Crops, Riverside, USA, pp. 197-202.

Tironi VA (2005). Rancidez oxidativa en salmón de mar (Pseudopercis semifasciata). Interacción lípidos oxidados - proteínas. Tesis Doctoral. Centro de Investigación y Desarrollo en Criotecnología de Alimentos (CIDCA). Facultad de Ciencias Exactas, Universidad Nacional de La Plata (FCE-UNLP)

Trimachi G, Secchiari P, Feruzzi G, Pistola A, Casarosa L (1992). Sunflower seed meal characterization for animal feeding. Proceedings of the $13^{\text {th }}$ International Sunflower Conference Vol II, Int. Sunflower Assoc., Paris, Francia, pp. 16381643.

Tuberoso C, Kowalczyk A, Sarritzu E, Cabras P (2007). Determination of antioxidant compounds and antioxidant activity in commercial oilseeds for food use. Food Chem 103: 1494 - 1501.

Tunde-Akintunde TY, Akintunde BO (2004). Some physical properties of Sesame seed. Biosyst Eng 88: 127-129. 
Ulkowski M, Musialik M, Litwinienko G (2005). Use of differential scanning calorimetry to study lipid oxidation. 1. Oxidative stability of lecithin and linolenic acid. J Agr Food Chem 53: 9073-9077.

United States Department of Agriculture - USDA (2002). Nutrient Database for Standard Reference. Release 15, Nutrient. Data Laboratory, Beltsville Research Center, US Departament of Agriculture, Pennsylvania, USA.

United States Department of Agriculture - USDA (2010). World Agricultural Supply and Demand Estimates. Wasde 486. US Departament of Agriculture, Pennsylvania, USA.

Valavanidis A, Nisiotou C, Papageorgiu Y, KremLi I, Satravelas N, Zineris N, Zygalaki H (2004). Comparison of the radical scavenging potencial of polar and lipidic fractions for olive oil and other vegetable oils under normal conditions and after thermal treatment. J Agric Food Chem 52: 2358-2365.

Valenzuela A (2004). El consumo de té y la salud: características y propiedades benéficas de esta bebida milenaria. Rev Chil Nutr 31: 72-82.

Vázquez-Ovando A, Rosado-Rubio G, Chel-Guerrero L, Betancur-Ancona D (2009). Physicochemical properties of a fibrous fraction from chia (Salvia hispanica L.). LWT - Food Sci Techn 42: 168 - 173.

Vázquez Yanes C, Orozco A, Rojas M, Sánchez ME, Cervantes V (1997). La reproducción de las plantas: semillas y meristemas. Fondo de Cultura Económica, DF, México.

Velasco Vargas I, Tecante A, Valdivia López MA, Aburto Juárez ML (2004). Extracción y caracterización del aceite de semilla de chía (Salvia hispanica L.): estudio para su valoración y aprovechamiento. En: Proceedings of the IV Encuentro Nacional de Biotecnología IPN, Santa Cruz, Tlaxcala, México.

Verleyen T, Van Dick S, Adams C A (2005). Accelerated Stability Test. En Analysis of Lipid Oxidation, Chapter 9. Eds. Kamal-Eldin A., Pokorný J., AOCS Press, Champaign, USA, pp. 221-228. 
Vilche C, Gely M, Santalla E (2003). Physical properties of quinoa seeds. Biosyst Eng 86: 59-65.

Ward JA (1976). Processing high oil content seeds in continuous press. J Am Oil Chem Soc 53: 261-264.

Watson G (1938). Nahuatl word in American English. American Speech 13: 108-121.

Westerman D, Santos R, Bosley J, Rogers J, Al Duri B (2006). Extraction of amaranth seed oil by supercritical carbon dioxide. J Sup Fluids 37: 38-52.

Wheeler DH, Riemenschneidre RW, Sando EW (1940). Preparation, properties and thiocyanogen absorption of triolein and trilinolenin. J Biol Chem 132: 687-699.

White PJ, Xing Y (1997). Antioxidants from cereals and legumes. En Natural Antioxidants: Chemistry, Health Effects and Applications. Ed. F Shahidi, AOAC Press, Champaign, Illinois, USA, pp 25-63.

Wiesenborn D, Doddapaneni R, Tostenson K, Kangas N. (2001). Cooking indices to predict screw-press performance for crambe seed. J Am Oil Chem Soc 78: 467471.

Wingard MR, Phillips RC (1949). The determination of the rate extraction of crude lipids from oilseeds with solvents. J Am Oil Chem Soc 26: 422-426.

Xu X, Gao Y, Liu G, Wang Q, Zhao J (2008). Optimization of supercritical carbon dioxide extraction of sea buckthorn (Hippophaë thamnoides L.) oil using response surface methodology. LWT - Food Sci Techn 41: 1223-1231.

Zaidul ISM, Nik Norulaini NA, Mohd Omar AK, Smith RL Jr (2006). Supercritical carbon dioxide $\left(\mathrm{SC}-\mathrm{CO}_{2}\right)$ extraction and fractionation of palm kernel oil from palm kernel as cocoa butter replacers blend. J Food Eng 73: 210-216.

Zhao H, Tuominen EKJ, Kinnunen PKJ (2004). Formation of amyloid fibers triggered by phosphatidylserine-containing membranes. Biochem 43: 10302-10307.

Zheng Y, Wiesenborn DP, Tostenson K, Kangas N (2003). Screw pressing of whole and dehulled flaxseed for organic oil. J Am Oil Chem Soc 80: 1039-1045. 
“Es justamente la posibilidad de realizar un sueño lo que hace que la vida sea interesante" De "El Alquimista", Paulo Coehlo 